\title{
Waste Isolation Pilot Plant \\ CY 2000 \\ Site Environmental Report
}

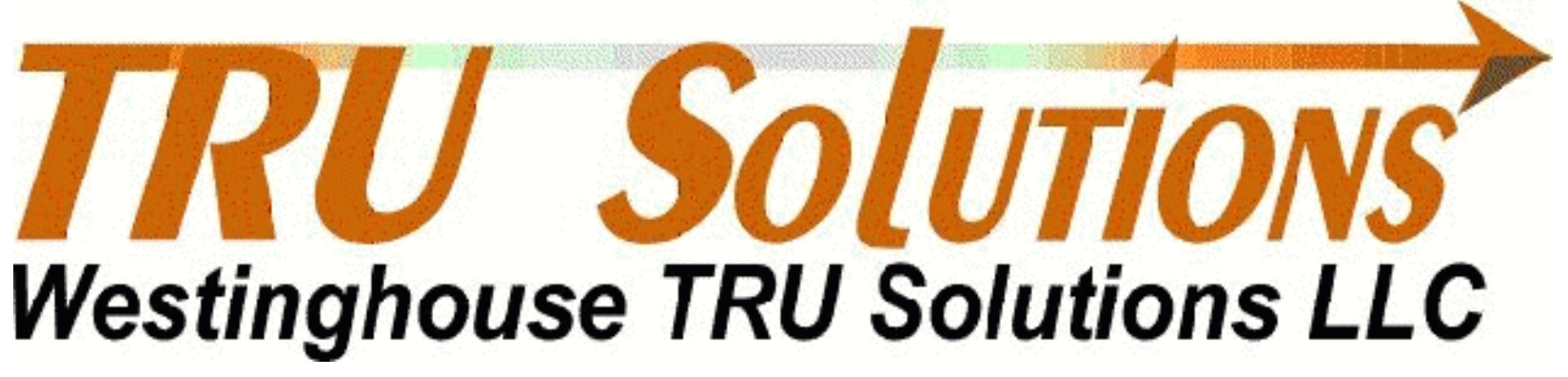

Prepared for

Westinghouse TRU Solutions, LLC

by

Environmental Science and Research Foundation, Inc.

101 S. Park Avenue, Suite 5

Idaho Falls, ID 83402

http://www.esrf.org 
This document has been reproduced directly from the best possible copy. It is available to DOE and DOE contractors from the following address:

Office of Scientific and Technical Information

P.O. Box 62

Oak Ridge, TN 37831

Prices available from (615) 576-8401

Available to the public from the National Technical Information Services

U.S. Department of Commerce

5285 Port Royal Road Springfield, Virginia 22161

Processing and final preparation of this report was performed by the Environmental Science and Research Foundation, Inc. for Waste Isolation Pilot Plant Management and Operating Contractor for the U.S. Department of Energy under Contract No. DE-AC04-01AL66444. 


\section{Acknowledgments}

The authors appreciate the reviews by Harold Johnson of the U.S. Department of Energy Carlsbad Field Office, Alex Puglisi and Bill Bartlett of CTAC, and Candice Jierree, Andy Stanley, Joe Harvill, Marsha Beekman, Jeff Knox, Wesley Nance, and Stewart Jones of Westinghouse TRU Solutions, LLC (WTS).

Stewart Jones and Wesley Nance served as the liaison between the WTS and the Environmental Science and Research Foundation, Inc. and provided overall coordination between the two companies. Jim W. Kenney and Don Gray of the Environmental Evaluation Group provided radiological data for scientific comparisons in advance of releasing the data in their own report. Irene Quintana provided assistance with radiological data and was quick to respond to all queries.

Clerical and formatting work was done by Patty Isaeff and Janet Cook of the Environmental Science and Research Foundation, Inc. Roy Evans, Washington State Department of Health, provided thorough reviews. Randy Morris coordinated the writing of this report. Greg Morgan of The Chartwell Group provided advice and assistance with the color figures and designed the cover.

Many WTS groups contributed to this report, which would not have been complete and accurate without their assistance. WIPP laboratory personnel provided the gross alpha and gross beta results for the ambient air filters.

The WTS Environmental Compliance Group was very helpful throughout the writing of this report: Koreen S. Guillermo, Jim R. Hollen, Carl S. Ortiz, Dan C. Robertson, Linda Frank-Supka, and Cindy L. Woodin.

The WTS Environmental Monitoring Group implements U.S. DOE Order 5400.1, "General Environmental Protection Program," by providing the technical assistance to collect samples, analyze data, perform verification and validation, protect fauna and flora, implement land management activities, monitor ground water, and provide data for this report.

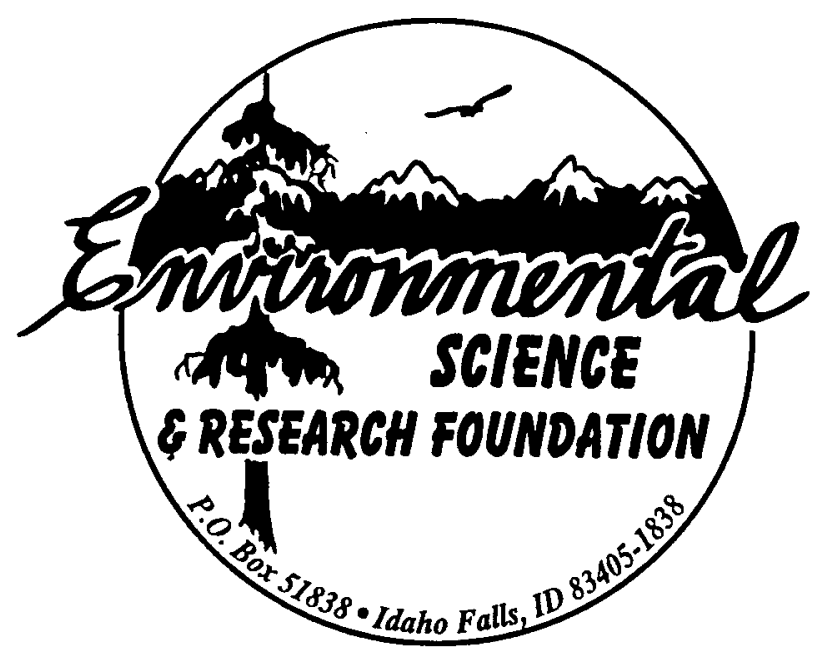


This page intentionally left blank. 


\section{Executive Summary}

The U.S. Department of Energy's (DOE) Carlsbad Field Office and Westinghouse TRU Solutions, LLC (WTS) are dedicated to maintaining high quality management of Waste Isolation Pilot Plant (WIPP) environmental resources. DOE Order 5400.1, General Environmental Protection Program, and DOE Order 231.1, Environmental, Safety, and Health Reporting, require that the environment at and near DOE facilities be monitored to ensure the safety and health of the public and the environment. This Waste Isolation Pilot Plant 2000 Site Environmental Report summarizes environmental data from calendar year (CY) 2000 that characterize environmental management performance and demonstrate compliance with federal and state regulations.

This report was prepared in accordance with DOE Order 5400.1, DOE Order 231.1, the Environmental Regulatory Guide for Radiological Effluent Monitoring and Environmental Surveillance (DOE/EH- 0173T), and the Waste Isolation Pilot Plant Environmental Protection Implementation Plan (DOE/WIPP 96-2199). The above orders and guidance documents require that DOE facilities submit an Annual Site Environmental Report to DOE Headquarters, Office of the Assistant Secretary for Environment, Safety, and Health. The purpose of this report is to provide a comprehensive description of operational environmental monitoring activities, to provide an abstract of environmental activities conducted to characterize site environmental management performance to confirm compliance with environmental standards and requirements, and to highlight significant programs and efforts of environmental merit at WIPP during CY 2000. The format of this report follows guidance offered in a June 1, 2001 memo from DOE's Office of Policy and Guidance with the subject "Guidance for the preparation of Department of Energy (DOE)
Annual Site Environmental Reports (ASERs) for Calendar Year 2000.”

WIPP received its first shipment of waste on March 26, 1999. In 2000, no evidence was found of any adverse effects from WIPP on the surrounding environment.

\section{Introduction}

Located in southeastern New Mexico, WIPP is the world's first underground repository permitted to safely and permanently dispose of transuranic (TRU) radioactive and mixed waste generated through the research and production of nuclear weapons and other activities related to the national defense of the United States. TRU mixed waste is TRU waste mixed with hazardous waste regulated under the Resource Conservation and Recovery Act (RCRA). Transuranic waste consists of material contaminated with more than $3.7 \times 10^{3} \mathrm{~Bq} / \mathrm{g}(100$ $\mathrm{nCi} / \mathrm{g}$ ) of alpha-emitting elements having atomic numbers greater than uranium, the heaviest natural element. Most TRU waste is contaminated industrial trash, such as rags, old tools, sludges from solidified liquids, and glass, metal, and other materials from dismantled buildings.

WIPP's legislative mandate is to demonstrate the safe disposal of TRU wastes from national defense activities and programs. To fulfill this mandate, WIPP has been designed to safely handle, store, and dispose of TRU waste in a fully-operational disposal facility. When waste arrives at WIPP, it is placed in excavated storage rooms, carved from rock salt, $655 \mathrm{~m}(2,150 \mathrm{ft})$ below the earth's surface. The nature of the salt is such that after a storage room has been filled, the salt will slowly fill the remaining spaces, thus isolating the waste for thousands of years. 


\section{Environmental Program Information}

It is DOE's policy to conduct its operations at WIPP in compliance with all applicable environmental laws and regulations, and to safeguard the integrity of the southeastern New Mexico environment. This is accomplished through radiological and nonradiological environmental monitoring, environmental compliance, and land management programs, which include wildlife monitoring and the WIPP Raptor Program. The purpose of these programs is to obtain land use permits, implement selected compliance functions such as NEPA compliance, collect data needed to detect and quantify possible impacts WIPP may have on the surrounding environment and to provide technical support to DOE's Carlsbad Field Office in the fields of environmental science and land management.

Environmental activities at WIPP generally fall into four categories: collecting environmental samples and analyzing them for a variety of contaminants, preparing and publishing documents showing compliance with federal and state regulations, evaluating whether WIPP activities cause any environmental impacts, and taking corrective action when an adverse effect on the environment is identified.

WIPP's Environmental Monitoring Plan outlines the programs that monitor the environment on, and immediately surrounding, the WIPP site. It discusses major environmental monitoring and surveillance activities at WIPP and WIPP's quality assurance/quality control program as it relates to environmental monitoring.

WIPP's effluent monitoring and environmental surveillance programs are designed to determine adequate protection of the public and the environment during DOE operations, and to ensure that operations comply with DOE and other applicable federal and state radiation standards and requirements. The Environmental Monitoring Program monitors the pathways that radionuclides and other contaminants could take to reach the environment surrounding WIPP. Pathways monitored include air, groundwater, surface water, soils, sediments, vegetation, and game animals. Groundwater quality and wildlife populations are also monitored. The goal of the program is to determine if the local ecosystem has been impacted during the predisposal and disposal phases of WIPP, and, if so, to evaluate the severity, geographic extent, and environmental significance of those impacts. The Environmental Monitoring Program is conducted in compliance with DOE Orders 5400.1 and 5400.5.

Southeastern New Mexico is home to an abundant array of wildlife. Wildlife species are monitored on the WIPP site to document any population changes that may occur as a result of WIPP activities. Species of special concern, including federally-listed threatened and endangered species, receive special consideration when planning WIPP activities that may impact wildlife habitat.

WIPP's Land Management Plan was created in accordance with the WIPP Land Withdrawal Act of 1992. This plan identifies resource values, promotes multiple-use management, and identifies long-term goals for the management of WIPP lands. In accordance with its Land Management Plan, WIPP follows a land reclamation program and a long-range reclamation plan. In 2000, reclamation efforts on the Site Preliminary Design and Validation salt pile were culminated. WIPP also conducts oil and gas surveillance in the region surrounding the WIPP site to identify new activities associated with oil and gas exploration and production. During CY 2000, EOG Resources initiated drilling of a second directional well under Section 31 of the WIPP Land Withdrawal Area. This well on James Ranch Unit \#27, is an active, producing well. Also, in 2000, WIPP surveillance teams conducted 24 scheduled surveillances with 223 cursory field inspections.

In 2000, the National Academy of Sciences issued Improving Operations and Long-term Safety of the Waste Isolation Pilot Plant: 
Interim Report (NAS 2000). In this report, the Academy made several recommendations regarding radiological monitoring, waste characterization and packaging, gas generation, and transportation communication, notification, and emergency response. These issues are currently under consideration to determine program implementation in future years.

\section{Environmental Compliance}

WIPP is required to comply with applicable federal and state laws and DOE orders. In 2000, WIPP maintained compliance with these laws and DOE orders.

\section{Comprehensive Environmental Response, Compensation, and Liability Act}

The Comprehensive Environmental Response, Compensation, and Liability Act (CERCLA) establishes a comprehensive federal strategy for responding to, and establishing liability for, releases of hazardous substances from a facility to the environment. Through July 2001, no release sites have been identified at WIPP that would require cleanup under provisions of CERCLA.

\section{Federal Acquisition, Recycling, and Pollution Prevention}

In 1995, WIPP adopted a systematic and cost-effective affirmative procurement plan for the promotion and procurement of products containing recovered materials. Affirmative procurement is designed to "close the loop" in the waste minimization recycling process by supporting the market for materials collected through recycling and salvage operations. In 2000, WTS purchased 99.99 percent of Environmental Protection Agency (EPA)required items through its affirmative procurement program. WTS also purchased numerous items which were not required by the EPA program but, nevertheless, contained recovered materials.

WIPP continued its recycling program in 2000. In addition, a Pollution Prevention
Opportunity Assessment (PPOA) was performed to evaluate the extent of the use of similar, but different, chemicals for the same purposes. The concern was twofold: whether some chemicals were superfluous and could be eliminated, and whether the additional required Material Safety Data Sheets, and consequent costs, were excessive. The report on this PPOA is in progress.

Other noteworthy pollution prevention (P2) activities during 2000 included:

- Leaded Brine Reduction.

- Implementation of PPOA 98-02, Cafeteria Waste.

- Medical Waste Reduction.

- Improvements in the Recycling Center.

\section{Resource Conservation and Recovery Act}

The Resource Conservation and Recovery Act (RCRA) ensures that hazardous wastes are managed and disposed of in ways that protect human health and the environment. WIPP is subject to generator requirements under RCRA and the New Mexico Hazardous Waste Act. Non-mixed TRU radioactive waste shipments to WIPP were postponed after November 22, 1999, to address requirements of the Waste Isolation Pilot Plant New Mexico Hazardous Waste Facility Permit (HWFP), which was issued on October 27, 1999, and went into effect on November 26, 1999.

WIPP prepared, and in May, 2000, submitted to NMED, a WIPP Sampling and Analysis Plan for Solid Waste Management Units and Areas of Concern to comply with the corrective action requirements contained in Module VII of the WIPP HWFP. The objectives of the Sampling and Analysis Plan are to define the extent of concentrations of hazardous constituents that exceed background metal concentrations in soil at specific Solid Waste Management Units, and to perform a release assessment at specific Areas of Concern 
to determine if hazardous constituents are present above background concentrations. Comments from NMED were received in December, 2000. A response to the NMED comments concerning the sampling plan was sent to NMED on January 3, 2001. No further comments have been received to date.

As required, a notice was sent on December 8, 1999, to inform individuals on the WIPP mailing list that DOE had established three repositories for information associated with corrective action activities at WIPP. These are located at the New Mexico State Library in Santa Fe, at the University of New Mexico Library in Albuquerque, and at the SkeenWhitlock Building in Carlsbad.

\section{National Environmental Policy Act}

The National Environmental Policy Act (NEPA) requires the federal government to use all practicable means to consider potential environmental impacts of proposed federal projects as part of the decision-making process. NEPA dictates the public shall be allowed to review and comment on proposed projects that have the potential to significantly affect the environment. NEPA also directs the federal government to use all practicable means to improve and coordinate federal plans, functions, programs, and resources relating to human health and the environment.

Title 10 CFR $\S 1021.331$ requires, following completion of each Environmental Impact Statement and its associated Record of Decision (ROD), that DOE prepare a mitigation action plan addressing mitigation commitments expressed in the ROD. DOE Order 451.1B requires DOE facilities to track and annually report progress in implementing a commitment for environmental impact mitigation. To fulfill this DOE Order requirement, WTS issued the 2000 Annual Mitigation Report for the Waste Isolation Pilot Plant on June 20, 2000.

\section{Clean Air Act}

The Clean Air Act provides for the preservation, protection, and enhancement of air quality. Under section 109 of the Clean Air Act, the EPA established the National Ambient Air Quality Standards for six “criteria” pollutants. The initial WIPP emissions inventory was developed as a baseline document to calculate maximum potential hourly and annual emissions of both hazardous and criteria pollutants. The air emissions inventory is conducted biennially and compared to baseline data to identify trends and potential emissions problems. The biennial inventory scheduled for CY 1998 was postponed because conditions at the site were unchanged from the previous inventory. The air emissions inventory for CY 1999 was conducted in 2000. Based on the 1999 air emissions inventory, WIPP operations do not exceed the 10-ton-per-year emission limit for any individual pollutant or the 25-ton-per-year limit for any combination of pollutants.

Based on emission estimates generated in the air emissions inventory, the WIPP site is not required to obtain federal Clean Air Act permits. The next air emissions inventory will be conducted in 2002 for CY 2001.

WIPP was required to obtain a New Mexico Air Quality Construction Permit for two primary backup diesel generators. During 2000, the generators were operated for approximately 34 of the 480 hours allowed by the permit. There were no malfunctions or abnormal conditions of operations that would cause a violation of the permit.

\section{Clean Water Act}

Section 402 of the Clean Water Act established provisions for the issuance of permits for discharges into waters of the United States. WIPP has no pollutant discharges from point sources and is currently exempt from obtaining a National Pollutant Discharge Elimination System permit. 
A permit for Storm Water Discharge Associated with Industrial Activity was issued in 1998. No sampling is required to demonstrate compliance with this permit unless a release occurs. Operational permit compliance activities are limited to quarterly inspections of retention basins, spill containment devices, reclamations sites, and site housekeeping practices. Quarterly discharge monitoring reports are submitted to the New Mexico Environment Department to demonstrate compliance with inspection, monitoring, and reporting requirements as identified in the WIPP Sewage System Discharge Plan.

\section{Safe Drinking Water Act}

The Safe Drinking Water Act provides the regulatory strategy for protecting public water supply systems and sources of drinking water. The WIPP water supply is categorized as a nontransient, noncommunity system for reporting and testing requirements. The water supply is sampled 10 times every three years for various chemical constituents. Samples were collected in July 2000 and the results were submitted to the New Mexico Environmental Department. All samples were below action levels as specified by New Mexico monitoring requirements for lead and copper in tap water. The next lead and copper sampling period will be July 2002. Bacterial samples were collected and reported monthly throughout 2000. All results were below Safe Drinking Water Act regulatory limits.

\section{National Historic Preservation Act}

The National Historic Preservation Act was enacted to protect the nation's cultural resources and establish the National Register of Historic Places. Federal agencies are required to ensure that historic and cultural properties are given proper consideration in the preparation of NEPA-related documents. No new archeological sites were discovered in 2000. One archaeological investigation was conducted for a new monitoring well. No artifacts were encountered.

\section{Hazardous Materials Transportation Act}

The Hazardous Materials Transportation Act is one of the major transportation-related statutes that affects WIPP operations. It provides for the safe transportation of hazardous materials, including radioactive materials. DOE orders establish packaging and transportation criteria and require DOE field offices to conduct their operations in accordance with all applicable international, federal, state, local, and tribal laws, rules, and regulations governing materials transportation. These DOE orders also require the development of a transportation plan and use of the DOE TRANSCOM (transportation and tracking communications) system to monitor shipments.

\section{Packaging and Transporting Radioactive Materials}

The WIPP Land Withdrawal Act requires TRU waste containers destined for WIPP to be shipped using specification packagings certified by the Nuclear Regulatory Commission (NRC). Certified shipping containers tor TRU waste satisfy NRC quality assurance requirements. Contact-handled TRU waste will be shipped in TRUPACT-II and HalfPACT containers. Containers for remote-handled waste are currently in the certification process.

\section{Environmental Compliance Assessment Program}

The Environmental Compliance Assessment Program plays a major role in the overall program for environmental protection activities at WIPP. The program was developed to determine if facility activities protect human health and the environment and if these activities are in compliance with applicable federal, state, and local requirements; with permit conditions and requirements; and with best management practices. During 2000, WTS environmental compliance assessments identified and implemented a number of improvements. 


\section{ISO 14000}

IS0 14001 is the specific section of the ISO 14000 standard devoted to Environment Management Systems. The WTS Environmental Management System (EMS) received third-party registration on August 5, 1997. Two third-party registration surveillance audits were conducted in 2000 . No nonconformance or findings were identified during either of the 2000 registered surveillance audits. The WTS registrar for Advanced Waste Management recommended continued registration of the WTS EMS.

\section{Pollution Prevention Committee}

WIPP's Pollution Prevention Committee was formed in 1993. The primary purpose of this committee is to foster recycling activities at WIPP. The committee sponsored activities to raise employee awareness of waste minimization on Earth Day, National America Recycles day, and during Energy month (October).

\section{Environmental Training}

Environmental training was provided to personnel associated with environmental operations at WIPP.

\section{Environmental Radiological Program Information}

Radionuclides present in the environment, whether naturally-occurring or from human-made sources, contribute to radiation doses to humans. Therefore, environmental monitoring around nuclear facilities is imperative for characterizing radiological conditions, and for detecting releases and determining their effects, should they occur. The WIPP Environmental Monitoring Program monitors air, surface and groundwater, soils, and biota to characterize the radiation environment and to detect potential releases from WIPP activities. Plutonium-238, ${ }^{239+240} \mathrm{Pu}$, and ${ }^{241} \mathrm{Am}$, are monitored because they are components of TRU waste. Cobalt-60, ${ }^{90} \mathrm{Sr},{ }^{137} \mathrm{Cs},{ }^{234} \mathrm{U},{ }^{235} \mathrm{U}$, and ${ }^{238} \mathrm{U}$ are monitored in order to establish a baseline for these radionuclides, and to ensure WIPP's technical ability to detect them in the extremely unlikely event they should be enhanced by WIPP activities. Potassium-40, is monitored because of possible enhancement in southeastern New Mexico due to potash mining.

Samples were not determined to contain measurable radionuclide concentrations (or activities) unless the measured results exceeded Minimum Detectable Concentrations (MDC) (or activities, MDA). However, if measured radionuclide concentrations were less than twice the value of the Total Propagated Uncertainty $(2 \times \mathrm{TPU})$, they were also considered non-detects. In almost every case, Analysis of Variance (ANOVA) was used to analysis differences in radionuclide concentrations between sampling stations and years in order to identify patterns related to WIPP activities.

\section{Effluent Monitoring}

If radionuclides are released into the environment from WIPP, they would first be detected in airborne effluents. Therefore, WIPP monitors airborne effluents from the facility at three locations. Station A samples unfiltered underground exhaust air, Station B samples unfiltered underground exhaust air in maintenance mode and high efficiency particulate air (HEPA) filtered exhaust air in filtration mode, and Station C samples HEPA filtered air from the Waste Handling Building. Samples were composited monthly or quarterly, in accordance with the Periodic Confirmatory Measurement Protocol for the Waste Isolation Pilot Plant, and analyzed for ${ }^{241} \mathrm{Am},{ }^{238} \mathrm{Pu}$, and ${ }^{239+240} \mathrm{Pu}$.

Concentrations were less than the MDA at all stations in all time periods, except for ${ }^{239+240} \mathrm{Pu}$ on Station A during May and ${ }^{239+240} \mathrm{Pu}$ on Station B during the second quarter. In both of these cases, measured values were less than $2 \times$ TPU, indicating the samples did not likely contain detectable ${ }^{239+240} \mathrm{Pu}$. 
There was no significant difference in the concentration of any radionuclide at Stations B and $\mathrm{C}$ between the years 1999 and 2000.

Because of the different composition periods, it was not possible to compare results from Station A across years.

\section{Airborne Gross Alpha/Beta}

Gross alpha and beta measurements in airborne particulates are used as screening techniques to provide timely information on levels of radioactivity in the environment around the WIPP site. Airborne particulate samples were collected from seven locations around WIPP on a weekly basis. Analysis of Variance (ANOVA) indicated no statistically significant differences between sampling stations.

The annual mean gross alpha activity concentrations at each location in 2000 were compared with 1998 and 1999 data to determine whether gross alpha in air particulates had increased since waste has been stored at WIPP. The concentrations were not found to be significantly different at any location.

In 2000, environmental conditions (such as weather) caused the weekly gross beta concentrations to vary by an order of magnitude at each location. The annual concentrations of gross beta activities found at all locations were similar. The annual mean gross beta activity concentrations found at each location in 2000 were compared with those from 1998 and 1999. No significant differences were found between years at any of the locations.

One duplicate sample was collected at a different location every quarter by rotating a portable sampler from one location to another. The samples were collected by two samplers in identical conditions at all four locations. Relative Error Ratios (RER) were less than one in all of the weekly gross alpha and in 96 percent of the weekly gross beta measurements, thus indicating a good agreement between duplicates.

\section{Airborne Particulates}

Inhalation of dust particles is the major pathway for the intake of plutonium.

Accordingly, plutonium and other radionuclides of interest were determined in air particulate samples around WIPP.

There were no statistically significant differences between sampling stations for the concentration of any radionuclide in composite air filters.

As expected, uranium radionuclides were consistently detected in airborne particulate samples. Uranium-234 was detected in every sample. Uranium-234 concentrations were not significantly different between quarters or between 2000 results and those from 1998 and 1999. Uranium-235 was detected in approximately 18 percent of the samples, but there were no significant differences between quarters or years. Uranium-238 was detected in each of the composite air filters. There were significant quarterly differences, with the second quarter having the highest concentration and the fourth quarter the lowest. There was also a significant difference between years, with 1999 having higher concentrations than 2000. Uranium-234, ${ }^{235} \mathrm{U}$, and ${ }^{238} \mathrm{U}$ are all found naturally in the environment and the concentrations and patterns of variation observed were consistent with those expected from natural uranium varying due to changes in weather or other environmental conditions..

Neither ${ }^{238} \mathrm{Pu}$ nor ${ }^{239+240} \mathrm{Pu}$ were detected in any quarterly composited air filter. The concentration of ${ }^{241} \mathrm{Am}$ was greater than the MDC in two of the quarterly composites but, because these results were less than twice the Total Propagated Uncertainty $(2 \times \mathrm{TPU}),{ }^{241} \mathrm{Am}$ was not likely present in detectable amounts in these samples. Potassium-40 was detected in 86 percent of the quarterly composites. Cobalt- 60 was detected in four and ${ }^{137} \mathrm{Cs}$ in two of the quarterly composites, while ${ }^{90} \mathrm{Sr}$ was not detected at all. All of these radionuclides are expected to occur in airborne particulates, and 
there is no evidence these detections are related to WIPP activity.

Duplicate samples were analyzed to check for reproducibility of the data. RERs were calculated to determine if the results from the duplicate samplers agreed with those from the regular samplers. For all results except two, the RERs were less than one, indicating a good agreement between regular and duplicate samples.

\section{Groundwater}

Groundwater samples, collected twice in 2000 from seven wells around WIPP, were analyzed for gamma-emitting radionuclides, ${ }^{90} \mathrm{Sr}$, and isotopes of uranium, plutonium, and americium. Isotopes of naturally-occurring uranium were detected in every well. The results for the concentrations of uranium isotopes in water samples collected in 2000 were compared with the results from 1998 and 1999. There was no significant difference in concentrations of any uranium isotope between groundwater samples collected in those years.

Plutonium-238, ${ }^{239+240} \mathrm{Pu}$, and ${ }^{241} \mathrm{Am}$ were also analyzed. The concentration of ${ }^{239+240} \mathrm{Pu}$ was greater than the MDC in one sample from one well. However, the result was less than $2 \times$ TPU and not considered a detection. There was no statistical difference among ${ }^{239+240} \mathrm{Pu}$ concentrations between wells or years. Plutonium-238 and ${ }^{241} \mathrm{Am}$ were nondetectable in all samples.

Radium-226 progeny have the same energy as ${ }^{241} \mathrm{Am}$ and ${ }^{238} \mathrm{Pu}$. Data are being gathered in an attempt to identify a pattern to the ${ }^{226} \mathrm{Ra}$ concentration and to determine if the ${ }^{226} \mathrm{Ra}$ progeny are causing false positive concentrations in the same region of interest as the ${ }^{241} \mathrm{Am}$ and ${ }^{238} \mathrm{Pu}$. In 2000, groundwater samples were analyzed for ${ }^{226} \mathrm{Ra}$ and ${ }^{228} \mathrm{Ra}$, in an attempt to account for their influence on apparent detections of ${ }^{241} \mathrm{Am}$ (DOE/WIPP $00-2225$ ). Radium-226 was detected in 73 percent of the samples and ${ }^{228} \mathrm{Ra}$ was detected in 67 percent of the samples. Both radionuclides were detected in at least one sample from each of the five wells sampled and the mean concentrations were all above the mean detection limits.

The annual mean concentration of ${ }^{137} \mathrm{Cs}$ exceeded the annual mean MDC in only two wells and ${ }^{60} \mathrm{Co}$ exceeded the annual mean MDC in only one. Strontium-90 was not detectable in any well, and ${ }^{40} \mathrm{~K}$ was detected in all wells. These radionuclides are expected to be present in small concentrations in groundwater samples.

\section{Surface Water}

Surface water samples were collected once from each of 14 locations around WIPP in 2000. As expected, ${ }^{238} \mathrm{U}$ was detected in surface water at every sampling location and ${ }^{235} \mathrm{U}$ was detected in samples from 28 percent of the sampling locations. Uranium-234 was detected in all but one of the samples. There were no significant differences in concentration of uranium isotopes between years. Differences among sampling locations were detected for each uranium isotope with river locations being higher than tank locations. Large spatial variations in uranium concentrations in surface water are expected because of the different characteristics of the water bodies and the underlying sediments.

Samples were also analyzed for ${ }^{238} \mathrm{Pu}$, ${ }^{239+240} \mathrm{Pu}$, and ${ }^{241} \mathrm{Am}$. Measured concentrations for the $\mathrm{Pu}$ isotopes were below the MDC. While one location had measured concentrations of ${ }^{241} \mathrm{Am}$ above the MDC, this result was also less than $2 \times$ TPU, indicating no statistical significance.

As expected, ${ }^{40} \mathrm{~K}$ was detected in 70 percent of the surface water samples. Cobalt-60 and ${ }^{137} \mathrm{Cs}$ were each detected in 17 percent of the samples, although at different sampling locations. Strontium-90 was not detected in any surface water sample. A duplicate sample was collected at one sampling location. The RER values for ${ }^{241} \mathrm{Am}$ and the plutonium isotopes in these samples were all less than one, indicating no difference between duplicate samples. For 
the uranium isotopes, only about half of the RER values were less than one, indicating much less reproducibility in uranium measurements due to the nonhomogeneous distribution of the naturally occurring nuclides.

\section{Soil Samples}

Soil samples were collected from six locations surrounding WIPP. Samples from each location were collected at three different depths. Measurements of radionuclides in depth profiles provide information about their vertical movements in soil systems.

Uranium-238 was detected in every soil sample in 2000 and ${ }^{234} U$ was detected in all but one. Uranium-235 was detected in two of the 18 samples. No uranium isotope varied significantly with location or depth. However, both ${ }^{234} \mathrm{U}$ and ${ }^{238} \mathrm{U}$ did vary significantly with year. In both cases, samples collected in 1998 showed significantly higher concentrations than those collected in later years. However, all measured concentrations fell within the range of natural concentrations of uranium found in soils throughout the world. All of these results suggest a natural variability consistent with the existence of natural uranium.

Soil samples were also analyzed for ${ }^{238} \mathrm{Pu}$, ${ }^{239+240} \mathrm{Pu}$, and ${ }^{241} \mathrm{Am}$. Neither plutonium isotope was detected in any sample. Although ${ }^{241} \mathrm{Am}$ was greater than the MDC in two of the 18 soil samples, both these results were less than their respective uncertainty values.

Potassium-40 was detected in every sample. This naturally-occurring radionuclide is ubiquitous in soils. The concentration of ${ }^{40} \mathrm{~K}$ was not significantly different between depths or between years, as expected. However, it was significantly different between sampling locations, due to natural variability. The range of concentrations observed are consistent with average natural ${ }^{40} \mathrm{~K}$ concentrations around the world.

Cesium-137 was detected in 10 of the 18 soil samples. There was no significant difference in ${ }^{137} \mathrm{Cs}$ concentration between locations or soil depths. Although ${ }^{137} \mathrm{Cs}$ is a fission product, it is ubiquitous in soils because of global fallout from atmospheric nuclear weapons testing. There was no statistically significant difference between concentrations measured in 1998, 1999, and 2000.

Strontium-90 was not detected in any soil sample in 2000 . However, ${ }^{60} \mathrm{Co}$, a ubiquitous radionuclide in soils, was detected in two samples. There was no significant difference in ${ }^{60} \mathrm{Co}$ concentrations between depths, locations, or years.

\section{Sediments}

Sediment samples were collected from 12 locations around the WIPP site, mostly from the same water bodies from which the surface water samples were collected. Uranium-234 and ${ }^{238} U$ were detected in every sediment sample. Uranium-235 was detected in 75 percent of the samples. Uranium-234 differed significantly between sampling locations, but no pattern related to WIPP was evident. Uranium-235 differed between years, with 2000 being higher than either 1998 or 1999.

Neither ${ }^{238} \mathrm{Pu}$ nor ${ }^{239+240} \mathrm{Pu}$ were detected in any sediment sample in 2000. Americium-241 was measured above the MDC in two samples, but in both cases the measured values were less than $2 \times$ TPU, indicating no detection.

As expected, ${ }^{137} \mathrm{Cs}$ was detected in half of the sediment samples, and ${ }^{60} \mathrm{Co}$ was detected in one sediment sample. Strontium-90 was not detected in any sediment sample. None of these radionuclides had sufficient detections to justify statistical comparisons between locations or years.

Potassium-40 was detected, as expected, in all sediment samples. It did not vary significantly between years, but it did vary significantly between locations. Overall, the concentrations measured in 2000 were similar to the average concentration of ${ }^{40} \mathrm{~K}$ found in soils throughout the United States. 
Duplicate analyses were performed for all the radionuclides in one sediment sample. The RER was less than one for ${ }^{241} \mathrm{Am}$ and all uranium isotopes, indicating acceptable correspondence between the original and the duplicate samples. For ${ }^{137} \mathrm{Cs}$ and ${ }^{40} \mathrm{~K}$, the RER was greater than one. However, a paired t-test indicated no significant difference between any of these duplicate measurements.

\section{Biota}

The concentration of radionuclides in plants is an important factor in estimating the intake of individual radionuclides by humans through ingestion. Therefore, rangeland vegetation samples were collected from the same six locations where soil samples were collected. Also collected were muscle tissues from two road-killed deer and one quail, both species commonly consumed by humans. Fish samples were taken from three different locations on the Pecos River. The whole fish and the muscle tissue from the deer and quail were analyzed for radionuclides.

Isotopes of natural uranium were detected in all vegetation samples. The concentration of ${ }^{234} \mathrm{U}$ and ${ }^{238} \mathrm{U}$ did not vary significantly between locations, but it did vary significantly between years, with the average concentration for 2000 being higher than those for both 1998 and 1999. This difference is likely due to variability in the suite of plant species collected.

Concentrations of ${ }^{238} \mathrm{Pu},{ }^{239+240} \mathrm{Pu}$, and ${ }^{241} \mathrm{Am}$ were less than the minimum detectable concentrations in every vegetation sample. On the other hand, ${ }^{40} \mathrm{~K}$ was detected in every vegetation sample. The concentration of ${ }^{40} \mathrm{~K}$ in vegetation was not significantly different between locations, but was significantly different between years. Cobalt- $60,{ }^{90} \mathrm{Sr}$, and ${ }^{137} \mathrm{Cs}$ were each detected in one vegetation sample. These detections are due to natural variability, and not related to WIPP activity.

A duplicate analysis of one vegetation sample was performed for all the radionuclides of interest. Concentrations of ${ }^{241} \mathrm{Am},{ }^{234} \mathrm{U},{ }^{238} \mathrm{U}$,
${ }^{40} \mathrm{~K}$, and ${ }^{60} \mathrm{Co}$ were above detection limits in the duplicate sample. All RER values were less than one, indicating good agreement between the duplicates.

Of the radionuclides of interest, only ${ }^{40} \mathrm{~K}$ was detected in deer tissue. Its mean concentration was similar to that found in other mammals throughout the world. Potassium-40 was also the only radionuclide detected in the single quail sample.

Uranium-234 was detected in one fish sample, ${ }^{238} \mathrm{U}$ was in another. Neither plutonium isotope was detected in fish. Americium-241 was above the MDC, but less than $2 \times \mathrm{TPU}$, in three of the four fish samples.

Cesium-137 and ${ }^{60} \mathrm{Co}$ were each detected in one fish sample, while ${ }^{90} \mathrm{Sr}$ was not detected in any fish sample. Potassium-40 was detected in all fish. There was no statistically significant difference between concentrations ${ }^{40} \mathrm{~K}$ in fish at any location. However, because of natural variability, there was a significant difference between years. Potassium-40 was lower in 1998 than in subsequent years.

\section{Environmental Nonradiological Pro- gram Information}

Nonradiological environmental surveillance programs at WIPP include land management programs (including reclamation of disturbed lands, oil and gas surveillance, and wildlife population monitoring) and meteorological monitoring. In addition to nonradiological environmental surveillance programs, volatile organic compounds (VOCs) were monitored to comply with provisions of WIPP's hazardous waste facility permit, and liquid effluent monitoring was conducted in accordance to WIPP Sewage System Discharge Plan criteria.

The principal functions of the WIPP nonradiological environmental surveillance program are to:

- Assess the impacts of WIPP activities on the surrounding ecosystem. 
- Monitor ecological conditions in the Los Medaños region.

- Investigate unusual or unexpected elements in the ecological databases.

- Comply with applicable commitments identified with existing agreements.

\section{WIPP Raptor Program}

The WIPP Raptor Program was established in the early 1990s to monitor and protect raptors on the WIPP site, and to educate site workers and the public about these birds. The program presently serves four functions: wildlife monitoring, scientific research, community outreach, and interagency cooperation. In 2000, research continued on long-term studies of productivity and population demographics of the raptor community in and around WIPP. The primary objective for the 2000 nesting season was to locate all raptor and raven nests within the $3000 \mathrm{~km}^{2}$ study area, centered on WIPP. Secondary objectives were to estimate raptor productivity in the area and to determine causes of raptor mortality.

\section{Meteorology}

The annual precipitation at WIPP for 2000 was $305 \mathrm{~mm}$ (12 in). The mean annual temperature was $17^{\circ} \mathrm{C}\left(63^{\circ} \mathrm{F}\right)$. Winds near WIPP blew predominantly from the southeast during 2000.

\section{Volatile Organic Compound Monitoring}

The volatile organic compound (VOC) monitoring program is designed to measure VOC concentrations attributable to hazardous waste disposal units (panels) which are either open and are in the process of being filled or which are full and have been closed. This Confirmatory VOC Monitoring Program was implemented as a requirement of the HWFP, Module IV, Section D and Attachment N, and is intended to demonstrate that regulated VOCs are not being emitted by the waste at concentrations in excess of concentrations of concern (see Table 5.7) as prescribed in the permit.

Nine target compounds, which contribute approximately 99 percent of the calculated human health risks from RCRA constituents, are monitored. Sampling for target compounds is done at two air monitoring stations. One station monitors air found in the mine before it has passed through the panels containing the waste, while the other station monitors air that has passed through the waste panels. Differences measured between the two stations represent VOC contributions from the waste panels.

In 2000, four of the nine target compounds were measured above the detection limit (1,1,1-trichloroethane, chlorobenzene, methylene chloride, and toluene). None of these compounds were found at an average concentration greater than 0.05 percent of the concentration of concern as listed in WIPP's hazardous waste facility permit, and were therefore at insignificant levels with respect to human health and the environment. For each compound, 104 sample pairs (the difference between the first and second sampler) were compared. Positive sample pair differences were found in 15 of the 104 sample pairs for methylene chloride, 36 of 104 sample pairs for toluene, one of 104 sample pairs for chlorobenzene, and 2 of 104 sample pairs for 1,1,1-trichloroethane, indicating there were differences in concentrations of these compounds between air samples collected before and after the waste panels.

\section{Seismic Activity}

Locations of 52 seismic events within 300 $\mathrm{km}$ (186 mi) of WIPP were recorded in 2000. The strongest recorded event (magnitude 2.5) was located about $80 \mathrm{~km}(50 \mathrm{mi})$ west-northwest ofWIPP. These seismic events had no effect on WIPP structures.

\section{Liquid Effluent Monitoring}

The WIPP sewage lagoon system is a zero-discharge facility. The entire facility is 
lined with 30-mil synthetic liners and is designed to dispose of domestic sewage as well as site-generated brine waters. The facility is operated under the WIPP Sewage System Discharge Plan and is managed in accordance with EPA sewage sludge regulations, New Mexico Water Quality Control Regulations, and applicable WIPP controlled procedures.

\section{Groundwater Monitoring}

Current groundwater monitoring activities at WIPP are outlined in the WIPP Groundwater Monitoring Program Plan. The objectives of the WIPP Groundwater Monitoring Program are to:

- Determine the physical and chemical characteristics of groundwater.

- Maintain Monitoring of groundwater levels surrounding the WIPP facility, both before and throughout the operational lifetime of the facility.

- Document and identify effects, if any, of WIPP operations on groundwater parameters.

- Fulfill the requirements of the RCRA Part B Permit Application and DOE Order 5400.1.

Data obtained by the WIPP Groundwater Monitoring Program supports two major programs at WIPP: (1) the RCRA Detection Monitoring Program, and (2) performance assessments supporting the Compliance Certification Application.

Groundwater monitoring activities during 2000 included groundwater quality sampling and groundwater level monitoring. Groundwater quality data were gathered from six wells in the Culebra member of the Rustler Formation and one well in the Dewey Lake Formation. Field analyses for Eh (Intensity Factor: an indicator of oxidation or reduction of chemical species), specific gravity, specific conductance, acidity or alkalinity, chloride, divalent cations, and total iron were performed on a periodic basis during serial sampling.

Groundwater surface elevations in the vicinity of WIPP may be influenced by site activities, such as pumping tests for site characterization, water quality sampling, or shaft sealing. In October 1988, WIPP was tasked with conducting a Groundwater Level Monitoring Program. Groundwater surface elevation data were gathered from 70 well bores, six of which were equipped with productioninflated packers to allow groundwater level monitoring of more than one producing zone through the same well bore. These well bores were used to monitor eight water-bearing zones in the WIPP region. The zone of primary interest was the Culebra member of the Rustler Formation. Groundwater elevation measurements in the Culebra member indicated the generalized directional flow of groundwater was north to south in the vicinity of WIPP.

Regional groundwater levels taken in Culebra observation wells with four or more data points for the year showed increasing trends in water levels in 37 wells and decreasing trends in 22 wells. Total fluctuations of more than $0.6 \mathrm{~m}$ $(2 \mathrm{ft})$ in groundwater levels occurred in 11 wells completed to the Culebra. The fluctuations in three of these wells may have been influenced by groundwater sampling activities. Seven wells experienced water-level fluctuations due to maintenance activities and one well showed increasing water levels due to the drilling of several nearby oil wells.

\section{Radiological Dose Assessment}

The potential radiation dose to members of the public from WIPP operations was calculated to demonstrate compliance with federal regulations and DOE's policies and objectives of keeping this dose as low as possible.

\section{Dose Limits}

For more than 50 years, extensive research has been conducted on the effects of radiation 
on humans and the environment. Much of this research used standard epidemiological and toxicological approaches to characterize the response of populations and individuals to high radiation doses. From this, a good understanding of the risks associated with high radiation doses was achieved. However, there is still uncertainty as to what risks are incurred from low radiation dose and dose rates, so models are used to predict these risks.

Environmental radiation protection standards for the management and disposal of TRU radioactive wastes set limits on the total annual radiation dose to members of the public at $0.25 \mathrm{mSv}(25 \mathrm{mrem})$ to the whole body and $0.75 \mathrm{mSv}$ (75 mrem) to any critical organ. National standards for emissions of radionuclides from DOE facilities state that the maximum annual dose to any member of the public from air emissions must be no greater than $0.1 \mathrm{mSv}(10 \mathrm{mrem})$. The Safe Drinking Water Act states that average annual concentrations of beta- and gamma-emitting humanmade radionuclides in drinking water shall not result in an annual dose greater than $0.04 \mathrm{mSv}$ (4 mrem). It is important to note that all of these dose limits are set for doses due to radionuclides released to the environment from DOE operations. They do not include, and are in addition to, doses from natural background radiation or from medical procedures.

\section{Background Radiation}

Radiation is a naturally-occurring phenomenon that has been in the environment since the beginning of time. There are several sources of natural radiation: cosmic and cosmogenic radiation (from outer space and the earth's atmosphere), terrestrial radiation (from the earth's crust), and internal radiation (naturally-occurring radiation in our bodies). In addition to natural radioactivity, small amounts of radioactivity from the 1986 Chernobyl nuclear accident and above-ground nuclear weapons tests that occurred from 1945 to 1980 are also present in the environment. Together, these sources of radiation are called "background" radiation. Every human is constantly exposed to background radiation. Exposure to radioactivity from weapons testing fallout is quite small compared to natural radioactivity and continually gets smaller as radionuclides decay. The average annual dose received by a member of the public from naturally-occurring radionuclides is about $3 \mathrm{mSv}$ (300 mrem).

\section{Dose from Air Emissions}

The National Emission Standards for Hazardous Air Pollutants issued by the EPA set limits for doses due to radionuclide emissions to air. To determine the potential radiation dose received by members of the public from WIPP, used the computer model CAP88-PC, version 2.0. CAP88 dose calculations are based on the assumption that exposed persons remain at home during the entire year and all vegetables, milk, and meat consumed are home produced. Thus, this dose calculation is a maximum potential dose which encompasses dose from inhalation, plume submersion, deposition, and ingestion of air emitted radionuclides.

For 2000, the CAP88 model predicted the highest dose to someone residing near WIPP to be at the Smith Ranch approximately $8 \mathrm{~km}$ ( $5 \mathrm{mi}$ ) northwest of WIPP. Results showed the whole body dose potentially received by someone residing at this location to be about $5.18 \times 10^{-8} \mathrm{mSv}\left(5.18 \times 10^{-6} \mathrm{mrem}\right)$ per year. The critical organ dose was less than $9.01 \times 10^{-7} \mathrm{mSv}$ $\left(9.01 \times 10^{-5} \mathrm{mrem}\right)$ per year.

\section{Total Potential Dose from WIPP Operations}

The potential dose to an individual from the ingestion of WIPP-related radionuclides transported in water is estimated to be nonexistent. Drinking water for communities near WIPP comes from groundwater sources which are too far away to be affected by potential WIPP contaminants. Groundwater and surface water samples collected around WIPP during 2000 did not contain radionuclide concentrations different from those in samples collected prior to WIPP receiving waste. 
Game animals sampled during 2000 were mule deer, quail, and fish. The only radionuclides detected, were not different from background levels measured prior to commencement of waste shipments to WIPP. Therefore, no dose from WIPP related radionuclides is estimated to have been received by any individual from this pathway during 2000.

The only pathway for which a dose could be estimated was that of air emissions. Air emissions from WIPP were not considered above background ambient air levels. Estimated concentrations of radionuclides in air emissions accounted for the calculable dose from WIPP operations during 2000.

The total dose from the air pathway (see "Dose from Air Emissions," above), was $5.18 \times 10^{-5}$ percent of the whole body dose limits of $0.1 \mathrm{mSv}(10 \mathrm{mrem})$ per year specified in 40 CFR $\S 61.92$. The dose to a hypothetical person residing year-round at the WIPP fence line was estimated to be $9.35 \times 10^{-7} \mathrm{mSv}$ $\left(9.35 \times 10^{-5} \mathrm{mrem}\right)$ per year whole body and $1.63 \times 10^{-5} \mathrm{mSv}\left(1.63 \times 10^{-3} \mathrm{mrem}\right)$ per year to the critical organ. This is $3.7 \times 10^{-4}$ percent of the whole body dose limits of $0.25 \mathrm{mSv}$ ( $25 \mathrm{mrem})$ per year whole body dose and $2.2 \times 10^{-3}$ percent of the dose limit of $0.75 \mathrm{mSv}$ (75 mrem) per year specified in 40 CFR $\S 191.03(b)$.

\section{Dose to non-human Biota}

DOE Order 5400.5 lists the environmental radiation protection requirements that WIPP must meet to protect aquatic animals. In addition, dose limits below which no deleterious effects on populations of aquatic and terrestrial organisms have been observed have been discussed by the National Council on Radiation Protection and Measurements and the International Atomic Energy Agency. Those absorbed dose limits are:

- Aquatic Animals $10 \mathrm{mGy} / \mathrm{d}(1 \mathrm{rad} / \mathrm{d})$.

- Terrestrial Plants $10 \mathrm{mGy} / \mathrm{d}(1 \mathrm{rad} / \mathrm{d})$.

- Terrestrial Animals $1 \mathrm{mGy} / \mathrm{d}(0.1 \mathrm{rad} / \mathrm{d})$.
DOE requires discussion of radiation doses to non-human biota in the Annual Site Environmental Report using the Interim Technical Standard, DOE-STD-XXXX-00, $A$ Graded Approach for Evaluating Radiation Doses to Aquatic and Terrestrial Biota. The Interim Technical Standard uses a multi-phase approach, including an initial screening phase with conservative assumptions.

In the initial screen, maximum concentrations of radionuclides detected in soil, sediment, and water during environmental monitoring are divided by Biota Concentration Guides (BCG), concentrations of radioactivity in the sampled media which would provide a radiation dose equal to the appropriate limits. These fractions are summed for each organism and, if the sum of fractions is less than 1 , the site is deemed to have passed the screen and no further action is required. This screening evaluation is intended to provide a very conservative evaluation of whether the site is in compliance with the recommended limits.

This guidance was used to screen radionuclide concentrations observed around WIPP during 2000. The sum of fractions was less than one for all media, demonstrating compliance with the proposed rule. Radiation in the environment surrounding WIPP does not have a deleterious effect on populations of plants and animals.

\section{Quality Assurance}

The fundamental objective of a quality assurance (QA) program is to ensure high-quality measurements are produced and reported from the analytical laboratory. The defensibility of data generated by laboratories must be based on sound scientific principles, method evaluations, and data verification and validation. Wastren, of Grand Junction, CO; Air Toxics, Ltd. of Folsom, CA; and Trace Analysis, of Lubbock, TX, were the contract laboratories that performed the radiological and nonradiological analyses for WIPP environmental samples. The WIPP laboratory 
performed the gross alpha and gross beta analyses on weekly air dust samples.

WTS performed assessments and audits to ensure the quality of the systems, processes, and deliverables was maintained or improved in 2000. Along with these regulatory requirements, the Environmental Monitoring Section also implements DOE Order 414.1A, Quality Assurance. The parameters for performance evaluations are completeness, reproducibility, accuracy, comparability, and representativeness.

\section{Completeness}

The completeness parameter was calculated as the ratio of the number of valid results to the total number of samples collected and analyzed. The Environmental Monitoring Program's overall data quality objective of 98 percent completeness for environmental samples was achieved during 2000.

\section{Reproducibility}

The reproducibility of the measurements was validated through analysis of duplicate samples. A low-volume air sampler was rotated in each quarter from location to location and sampled along with routine samples. The duplicate samples for other matrices were collected at the same time, same place, and under similar conditions as routine samples. These samples were analyzed in the same analytical batch and/or sample delivery group using similar methods for radiochemical separations and counting as original samples. The RER of the duplicate air samples was calculated. Of the 104 RER values calculated for duplicate air samplers, 102 values were less than one, which is considered to demonstrate reproducibility.

\section{Accuracy and Comparability}

The accuracy of the analyses were assured/controlled by using National Institute of Standards and Technology-traceable standards for instrument calibration. Internal quality control was performed by using spiked laboratory control samples. Intercomparisons were performed with the DOE Environmental Measurements Laboratory to ensure the reliability of radiochemical separation methods and counting instruments. Accuracy was expressed in terms of percent bias (Appendix C).

The percent bias for data from the contract laboratory, Wastren, was acceptable for all radionuclides and all media except for ${ }^{40} \mathrm{~K}$ in soil and vegetation during the December inter-comparison. These values had biases of 56.10 percent and 66.67 percent, respectively. Percent biases of less than $50 \%$ are considered acceptable.

Environmental Resource Associates provided an interlaboratory assessment of the analysis for volatile organics. Air Toxics participated in this assessment and received a score of 100 percent and an overall assessment of "excellent." Environmental Resource Associates also provided an interlaboratory assessment of the analysis for water pollutants. Trace Analysis participated in this assessment and received scores ranging from 35 percent ("Needs improvement") to 97 percent ("Excellent"). In most cases where the Overall Assessment was less than Excellent, Trace Analysis, Inc., was able to review procedures, check calibrations, identify changes in lab personnel, and otherwise determine why failures occurred and provide corrective actions to improve future performance.

\section{Representativeness}

The quality objective of representativeness was based on potential radiation exposure of the population through inhalation and ingestion. Samples of ambient air, surface water, sediment, groundwater, and biota were collected from areas representative of potential pathways for intake.

The samples were collected using DOE and EPA accepted methodologies for environmental sampling and approved procedures, ensuring they were representative of the media sampled. 
These samples were analyzed for natural radioactivity, fallout radioactivity from nuclear weapons tests, and other anthropogenic radionuclides. The reported concentrations at various locations were representative of the baseline information for radionuclides of interest at the WIPP facility. 


\section{Table of Contents}

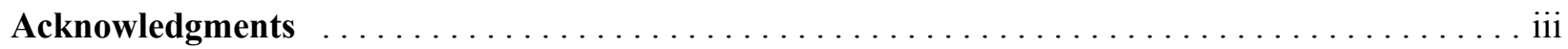

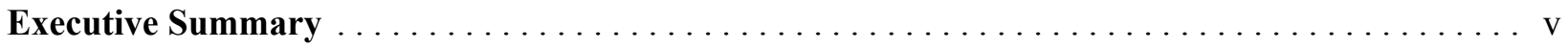

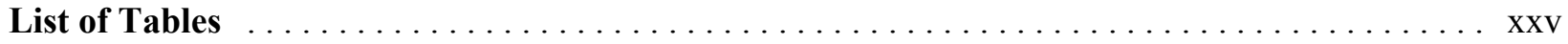

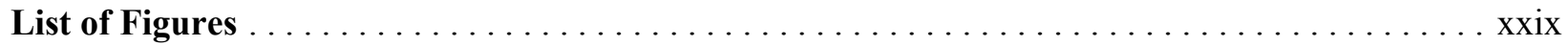

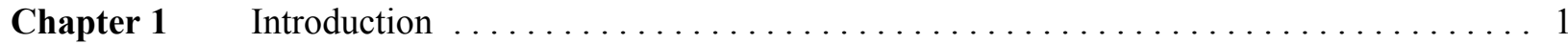

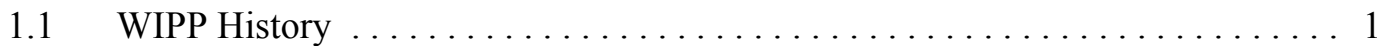

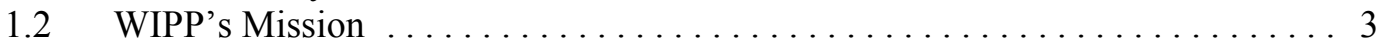

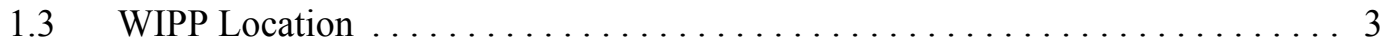

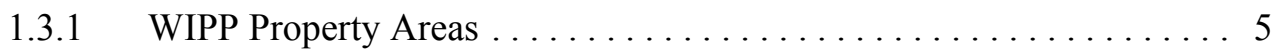

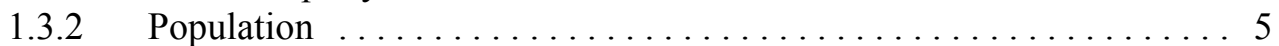

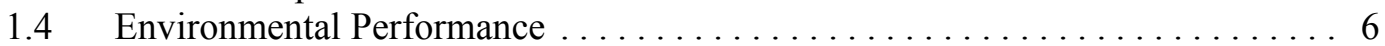

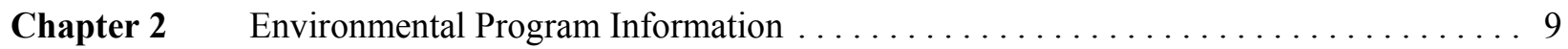

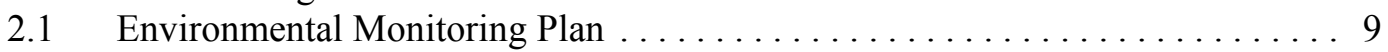

2.2 WIPP Environmental Monitoring Program $\ldots \ldots \ldots \ldots \ldots \ldots \ldots \ldots \ldots \ldots$

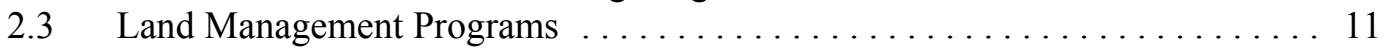

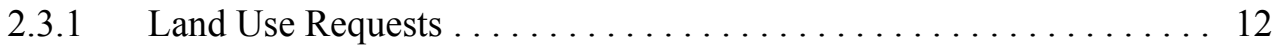

2.3.2 Wildlife Population Monitoring ................. 12

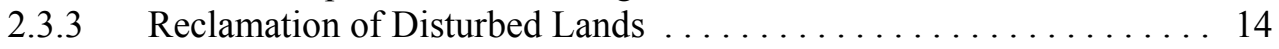

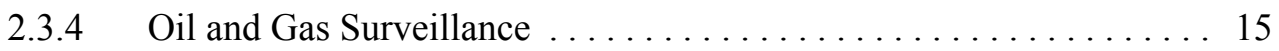

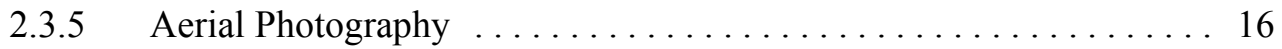

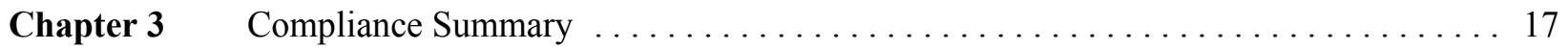

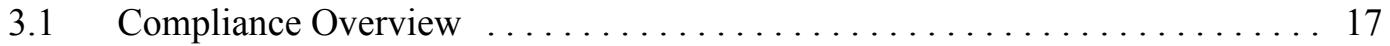

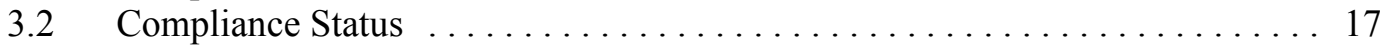

3.2.1 Comprehensive Environmental Response, Compensation, and

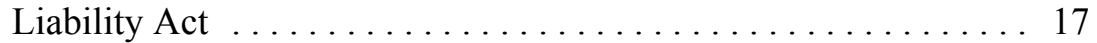

3.2.2 Federal Acquisition, Recycling, and Pollution Prevention . . . . . . 18

3.2.3 Resource Conservation and Recovery Act ................ 19

3.2 .4 National Environmental Policy Act . . . . . . . . . . . . . 21

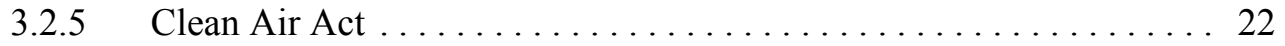

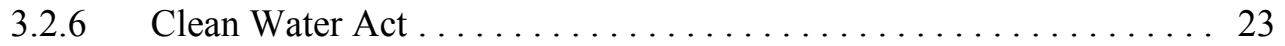

3.2 .7 Safe Drinking Water Act ...................... 25

3.2.8 National Historic Preservation Act . . . . . . . . . . . . . . . . . 25

3.2.9 Hazardous Materials Transportation Act . . . . . . . . . . . . . . . 25

3.2.10 Packaging and Transporting Radioactive Materials . . . . . . . . 26

3.3 Other Significant Accomplishments and Ongoing Compliance

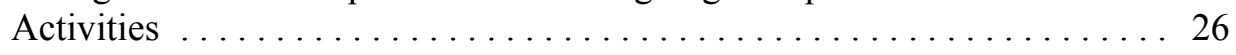

3.3.1 Environmental Compliance Assessment Program . . . . . . . . . 26 
3.3.2 ISO 14000 - Standards for Environmental Management . . . . . . . 27

3.3.3 Pollution Prevention Committee . . . . . . . . . . . . . . . . . . 27

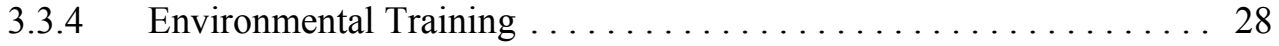

Chapter $4 \quad$ Environmental Radiological Program Information $\ldots \ldots \ldots \ldots \ldots \ldots \ldots \ldots \ldots$

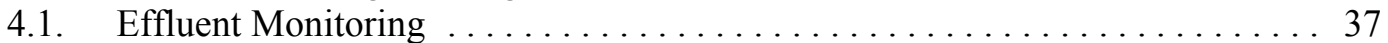

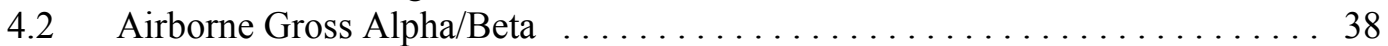

4.3 Airborne Particulates . . . . . . . . . . . . . . . . . . . . . . . 42

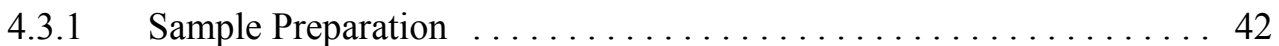

4.3.2 Determination of Individual Radionuclides . . . . . . . . . . . . . 43

4.3.3 Results and Discussions . . . . . . . . . . . . . . . . . . . . 43

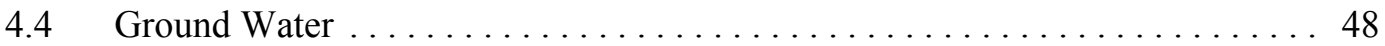

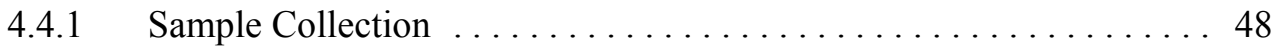

4.4.2 Determination of Individual Radionuclides . . . . . . . . . . . . 48

4.4.3 Results and Discussions . . . . . . . . . . . . . . . . . . . 48

$4.5 \quad$ Surface Water . . . . . . . . . . . . . . . . . . . . . . . . . 51

4.5.1 Sample Collection ....................... 51

4.5.2 Determination of Individual Radionuclides ............. 51

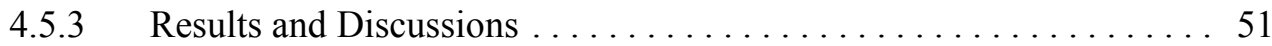

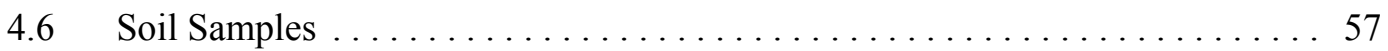

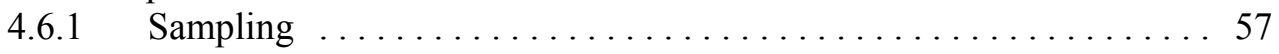

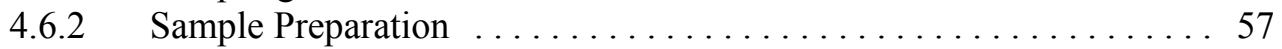

4.6.3 Determination of Individual Radionuclides . . . . . . . . . . 57

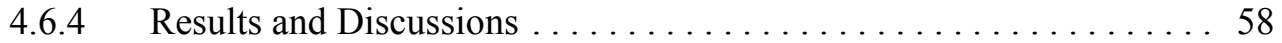

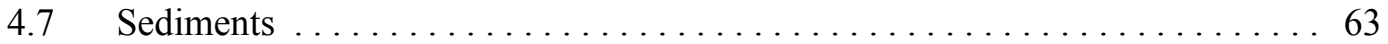

4.7.1 Sample Collection . . . . . . . . . . . . . . . . . 63

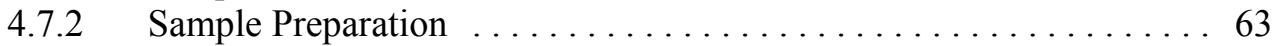

4.7.3 Determination of Individual Radionuclides . . . . . . . . . . . . 63

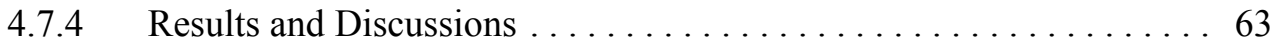

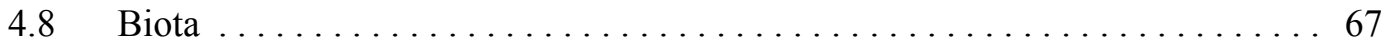

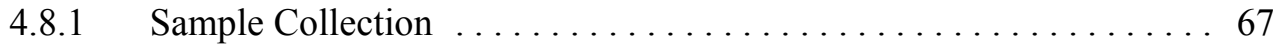

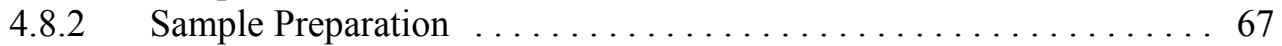

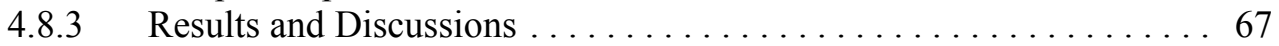

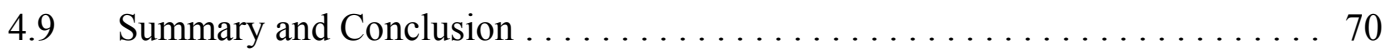

Chapter $5 \quad$ Environmental Nonradiological Program Information $\ldots \ldots \ldots \ldots \ldots \ldots \ldots \ldots 71$

$5.1 \quad$ Principal Functions of Nonradiological Sampling $\ldots \ldots \ldots \ldots \ldots \ldots \ldots 7$

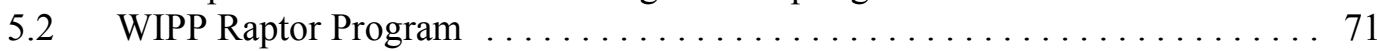

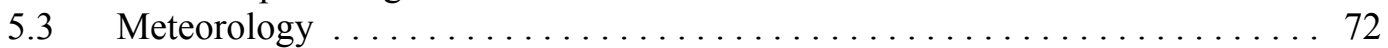

5.3.1 Climatic Data ........................... 72

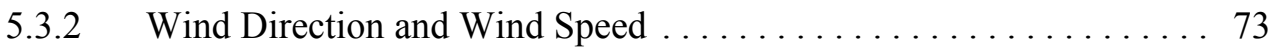

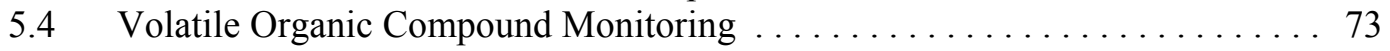

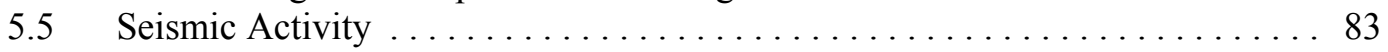

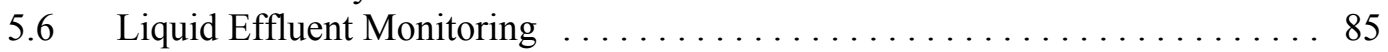

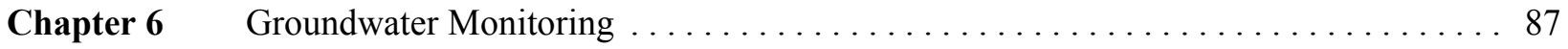

6.1 Groundwater Quality Sampling $\ldots \ldots \ldots \ldots \ldots \ldots \ldots \ldots \ldots \ldots$

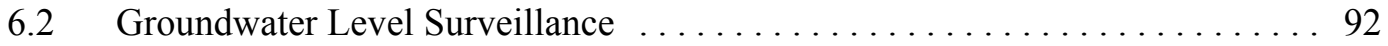

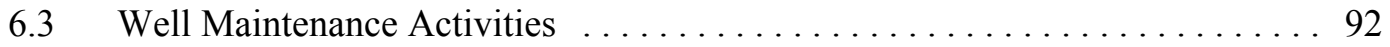


Chapter $7 \quad$ Radiological Dose Assessment $\ldots \ldots \ldots \ldots \ldots \ldots \ldots \ldots \ldots \ldots \ldots \ldots \ldots \ldots \ldots$

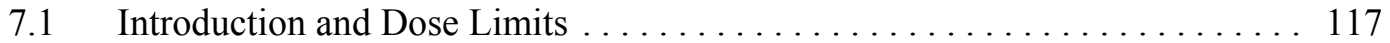

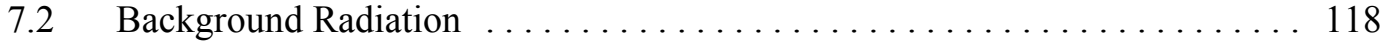

7.3 Dose from Air Emissions . . . . . . . . . . . . . . . . . . . . . . . . . . . 119

7.3.1 Maximally Exposed Individual from Air Emission Pathway . . . . 119

7.4 Total Potential Dose from WIPP Operations . . . . . . . . . . . . . . 120

7.4.1 Potential Dose from Water Ingestion Pathway . . . . . . . . . . . 120

7.4.2 Potential Dose from Wild Game Ingestion . . . . . . . . . . . . . . . 120

7.4.3 Total Potential Dose from All Pathways . . . . . . . . . . . . . . . . 120

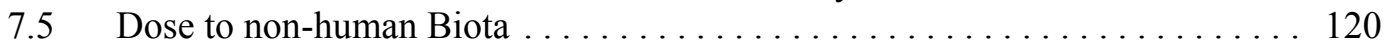

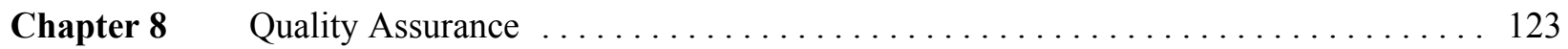

$8.1 \quad$ Completeness. . . . . . . . . . . . . . . . . . . . . . 123

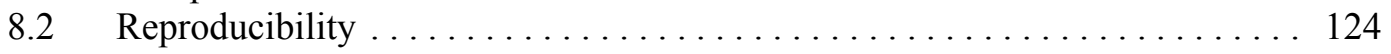

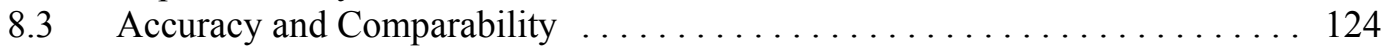

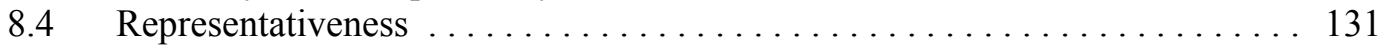

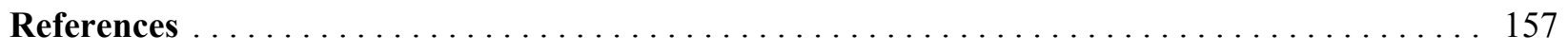

Appendix A $\quad$ Acronyms, Abbreviations, and Symbols $\ldots \ldots \ldots \ldots \ldots \ldots \ldots \ldots$ A-1

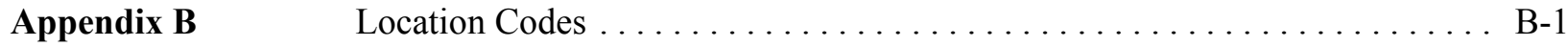

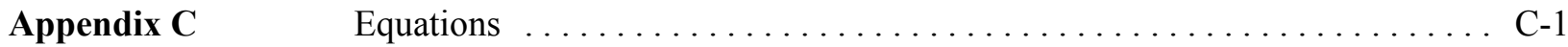

Appendix D Concentrations of Alpha and Beta Activities in Air Particulates . . . . . . . D D-1

Appendix E $\quad$ Air Sampling Data: Mass and Volume of Composite Air Samples . . . . . . . E-1

Appendix F $\quad$ Time Trend Plots for Detectable Constituents $\ldots \ldots \ldots \ldots \ldots \ldots \ldots \ldots$ F-1

Appendix G $\quad$ Air Sampling Data: Concentrations of Radionuclides $\ldots \ldots \ldots \ldots \ldots$ G-1

Appendix $\mathbf{H} \quad$ Authors and Contributors $\ldots \ldots \ldots \ldots \ldots \ldots \ldots \ldots \ldots \ldots \ldots \ldots \ldots \ldots$ 
This page intentionally left blank.

-xxiv- 


\section{List of Tables}

Table 2.1 The Environmental Monitoring Plan outlines the sampling schedule for

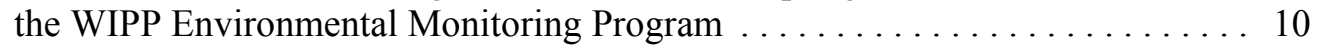

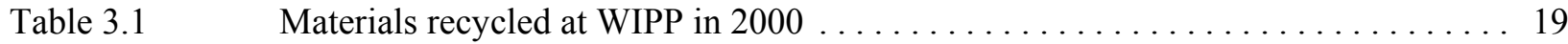

Table $3.2 \quad$ WIPP's key RCRA permit deliverables and due dates $\ldots \ldots \ldots \ldots \ldots \ldots \ldots 22$

Table $3.3 \quad$ Activities associated with major environmental regulations applicable to the WIPP project . . . . . . . . . . . . . . . . . . . . . . . . 29

Table $3.4 \quad$ Primary DOE orders affecting the WIPP environmental program $\ldots \ldots \ldots \ldots 31$

Table 3.5 Active environmental permits for the WIPP (does not include RCRA

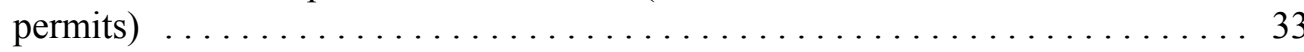

Table 4.1 Activity $(\mathrm{Bq})$ of quarterly composite air samples from effluent monitoring

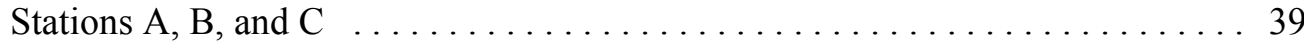

Table 4.2 Annual mean gross alpha and gross beta activity concentrations $\left(\mathrm{Bq} / \mathrm{m}^{3}\right)$ found in weekly air particulate samples . . . . . . . . . . . . . . 42

Table 4.3 Minimum, maximum and average radionuclide concentrations $\left(\mathrm{Bq} / \mathrm{m}^{3}\right)$ in air filter composites from stations surrounding the WIPP site $\ldots \ldots \ldots \ldots 45$

Table $4.4 \quad$ Results of duplicate composite air filter sampling $\ldots \ldots \ldots \ldots \ldots \ldots \ldots \ldots$

Table 4.5 Preliminary quarterly average radionuclide concentrations $\left(\mathrm{Bq} / \mathrm{m}^{3}\right)$ measured in air particulate samples by the Environmental Evaluation Group

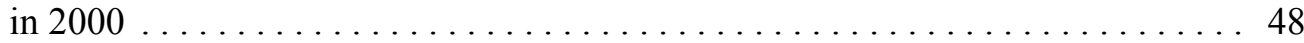

Table 4.6 Average annual radionuclide concentrations $(\mathrm{Bq} / \mathrm{L})$ in groundwater from wells

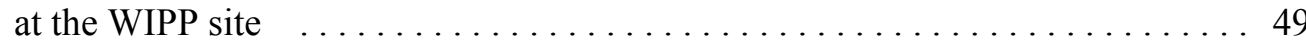

Table 4.7 Preliminary radionuclide concentrations $(\mathrm{Bq} / \mathrm{L})$ measured by EEG in

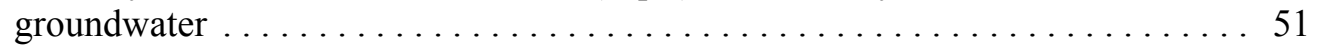

Table $4.8 \quad$ Uranium concentrations $(\mathrm{Bq} / \mathrm{L})$ in surface water near the WIPP site $\ldots \ldots \ldots \ldots 3$

Table 4.9 Americium and plutonium concentrations $(\mathrm{Bq} / \mathrm{L})$ in surface water near

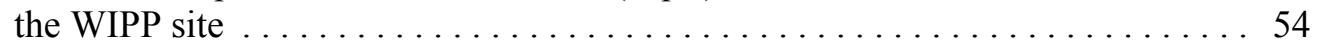

Table $4.10 \quad$ Selected radionuclide concentrations $(\mathrm{Bq} / \mathrm{L})$ in surface water near the

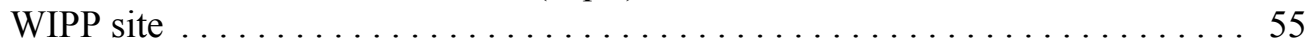

Table $4.11 \quad$ Results of duplicate surface water sample analysis $\ldots \ldots \ldots \ldots \ldots \ldots \ldots \ldots$ 
Table 4.12 Preliminary concentration $(\mathrm{Bq} / \mathrm{L})$ of radionuclides measured by EEG in

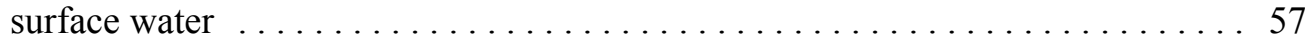

Table $4.13 \quad$ Uranium concentrations $(\mathrm{Bq} / \mathrm{g})$ in soil near the WIPP site $\ldots \ldots \ldots \ldots \ldots \ldots$

Table $4.14 \quad$ Americium and plutonium concentrations $(\mathrm{Bq} / \mathrm{g})$ in soil near the WIPP site $\ldots \ldots 60$

Table 4.15 Selected radionuclide concentrations $(\mathrm{Bq} / \mathrm{g})$ in soil near the WIPP site $\ldots \ldots \ldots 61$

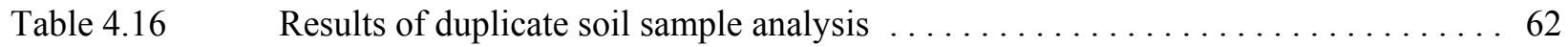

Table $4.17 \quad$ Uranium concentrations $(\mathrm{Bq} / \mathrm{g})$ in sediment near the WIPP site $\ldots \ldots \ldots \ldots 6$

Table 4.18 Americium and plutonium concentrations $(\mathrm{Bq} / \mathrm{g})$ in sediment near the

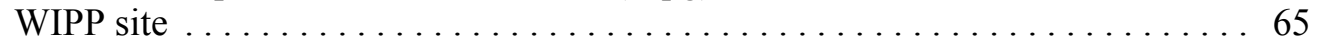

Table 4.19 Selected radionuclide concentrations $(\mathrm{Bq} / \mathrm{g})$ in sediment near the

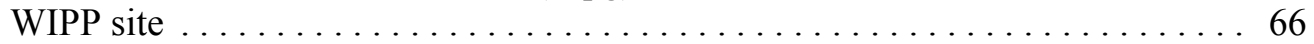

Table $4.20 \quad$ Results of duplicate sediment sample analysis $\ldots \ldots \ldots \ldots \ldots \ldots \ldots \ldots \ldots 6$

Table 4.21 Radionuclide concentrations (Bq/g wet mass) in vegetation near the

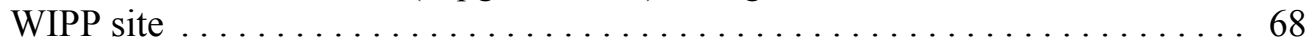

Table $4.22 \quad$ Results of duplicate vegetation sample analysis $\ldots \ldots \ldots \ldots \ldots \ldots \ldots \ldots \ldots$

Table 4.23 Radionuclide concentrations (Bq/g wet mass) in deer and quail near the WIPP site . . . . . . . . . . . . . . . . . . . . . . . 69

Table 4.24 Radionuclide concentrations (Bq/g wet mass) in fish near the WIPP site. . . . . . 70

Table $5.1 \quad$ A summary of 2000 temperature observations at 2 -meter height $\ldots \ldots \ldots \ldots$

Table 5.2 A summary of 2000 temperature observations at 10 -meter height $\ldots \ldots \ldots \ldots$

Table $5.3 \quad$ A summary of 2000 temperature observations at 50 -meter height $\ldots \ldots \ldots \ldots 77$

Table $5.4 \quad 2000$ wind frequencies at 2-meter height, stratified by direction and speed

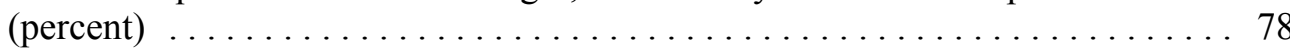

Table $5.5 \quad 2000$ wind frequencies at 10-meter height, stratified by direction and speed

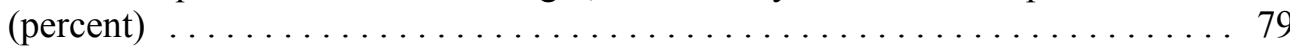

Table 5.6 2000 wind frequencies at 50-meter height, stratified by direction and speed

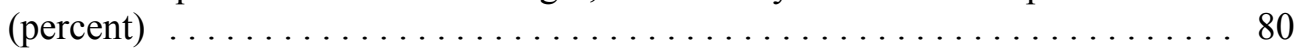

Table 5.7 Concentrations of concern for volatile organic compounds, from attachment $\mathrm{N}$ of the Hazardous Waste Facility permit (No. NM489019088) 
Table 5.8 Volatile organic compound sample pair differences measured at WIPP

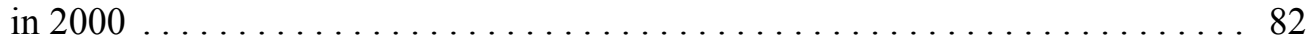

Table $6.1 \quad$ Analytical parameters for which groundwater was analyzed $\ldots \ldots \ldots \ldots \ldots$. $\ldots 1$

Table 6.2 Analytical results for groundwater sampled from well WQSP-1 $\ldots \ldots \ldots \ldots$

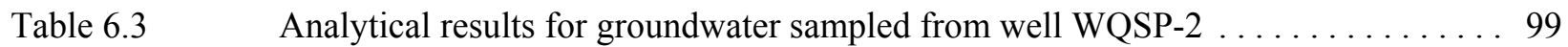

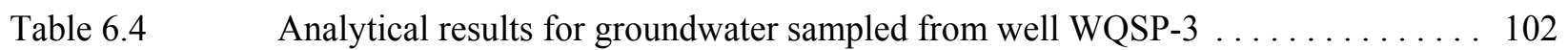

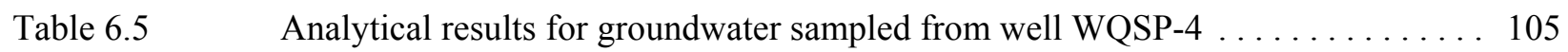

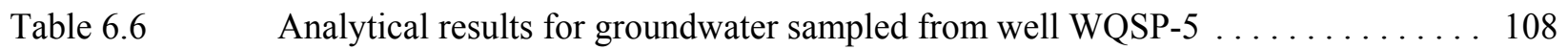

Table $6.7 \quad$ Analytical results for groundwater sampled from well WQSP- $6 \ldots \ldots \ldots \ldots 11$

Table $6.8 \quad$ Analytical results for groundwater sampled from well WQSP-6A $\ldots \ldots \ldots \ldots 114$

Table 7.1 Annual estimated average radiation dose received by a member of the population of the United States from naturally-occurring radiation sources (adapted from NCRP-1987) . . . . . . . . . . . . . . . . . . . . . 119

Table 7.2 General screening results for potential radiation dose to non-human biota $\ldots \ldots 122$

Table 8.1 Comparison of duplicate air monitoring results (first quarter of 2000) from WIPP Environmental Monitoring Laboratory data from Smith Ranch

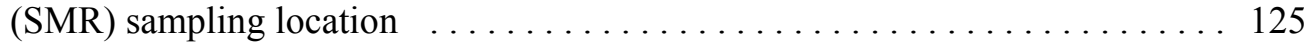

Table 8.2 Comparison of duplicate air monitoring results (second quarter of 2000) WIPP Environmental Monitoring Laboratory data from Carlsbad

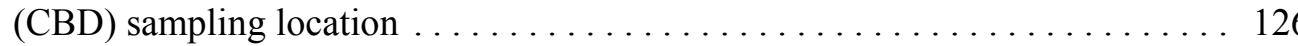

Table 8.3 Comparison of duplicate air monitoring results (third quarter of 2000) from WIPP Environmental Monitoring Laboratory data from South East Control (SEC) sampling location . . . . . . . . . . . . . . . . . . . . . . 127

Table 8.4 Comparison of duplicate air monitoring results (fourth quarter of 2000) from WIPP Environmental Monitoring Laboratory data from WIPP Far Field

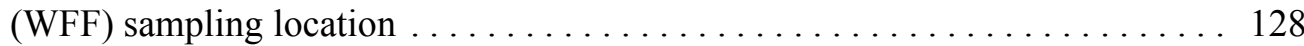

Table 8.5 Environmental Measurement Laboratory assessments for Wastren 2000 (air filter) . . . . . . . . . . . . . . . . . . . . . . . . . 129

Table 8.6 Environmental Measurement Laboratory assessments for Wastren 2000

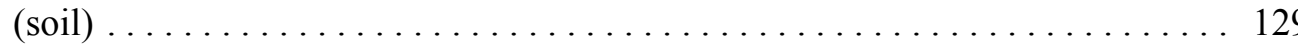

Table 8.7 Environmental Measurement Laboratory assessments for Wastren 2000 (vegetation) .................................. 130 
Table 8.8 Environmental Measurement Laboratory assessments for Wastren 2000

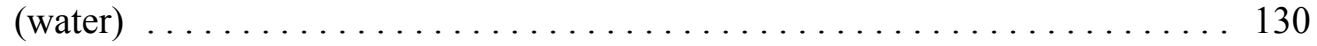

Table 8.9 Performance evaluation of Air Toxics, Inc., for volatile organic compounds

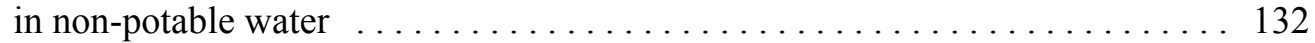

Table 8.10 Environmental Resource Associates performance evaluation of Air Toxics, Inc., for volatile organic compounds in non-potable water . . . . . . . . . . 133

Table 8.11 Environmental Resource Associates performance evaluation (Potable WatR ${ }^{\mathrm{TM}}$ ) of Trace Analysis, Inc., for metals in potable water . . . . . . 134

Table 8.12 Environmental Resource Associates assessment of Trace Analysis, Inc.,

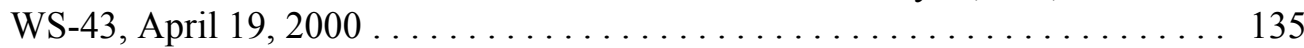

Table 8.13 Environmental Resource Associates assessment of Trace Analysis, Inc.,

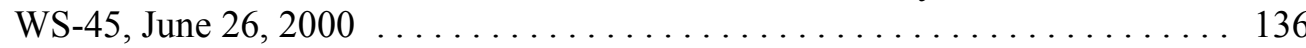

Table 8.14 Environmental Resource Associates assessment of Trace Analysis, Inc., WS-51, December 20, $2000 \ldots \ldots \ldots \ldots \ldots \ldots \ldots \ldots \ldots \ldots \ldots \ldots$

Table 8.15 Environmental Resource Associates assessment of Trace Analysis, Inc.,

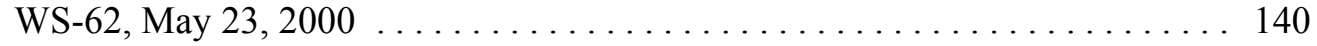

Table 8.16 Environmental Resource Associates assessment of Trace Analysis, Inc.,

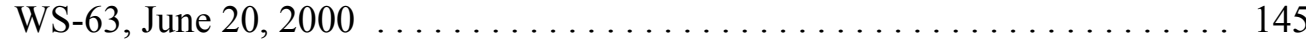

Table 8.17 Environmental Resource Associates assessment of Trace Analysis, Inc.,

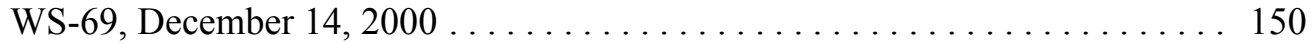




\section{List of Figures}

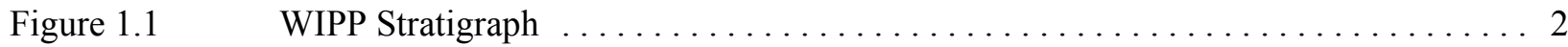

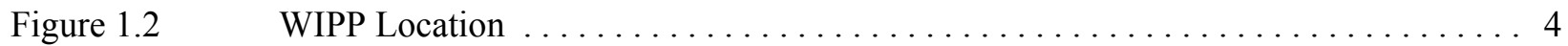

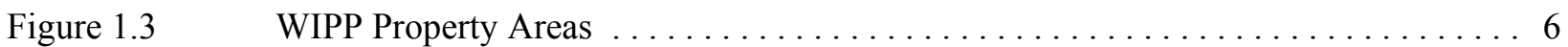

Figure $4.1 \quad$ Air Sampling Locations on and near the WIPP Facility . . . . . . . . . . . 40

Figure 4.2 Gross Alpha Activity Concentration Measured in Air Particulates Each Week in 2000 . . . . . . . . . . . . . . . . . . . . . . . . . . . 41

Figure 4.3 Gross Beta Activity Concentration Measured in Air Particles Each Week in 2000 .................................. 43

Figure 4.4 Average Gross Alpha and Beta Activity Concentrations Measured in Air Particles in Three Consecutive Years $\ldots \ldots \ldots \ldots \ldots \ldots \ldots \ldots . \ldots . \ldots 4$

Figure $4.5 \quad$ Surface Water Sampling Locations in $2000 \ldots \ldots \ldots \ldots \ldots \ldots \ldots \ldots \ldots \ldots \ldots \ldots \ldots$

Figure $4.6 \quad$ Soil and Vegetation Sampling Areas in $2000 \ldots \ldots \ldots \ldots \ldots \ldots \ldots$

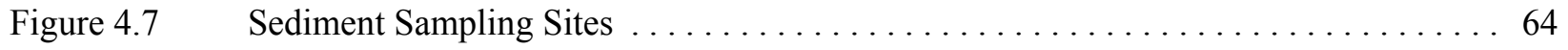

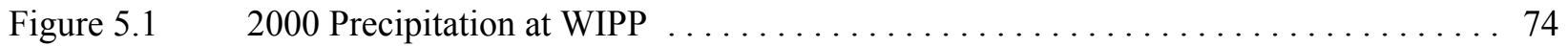

Figure $5.2 \quad 2000$ WIPP Site Temperature at 2-meter Height $\ldots \ldots \ldots \ldots \ldots \ldots \ldots \ldots \ldots$

Figure $5.3 \quad 2000$ WIPP Site Temperature at 10 -meter Height $\ldots \ldots \ldots \ldots \ldots \ldots \ldots \ldots$

Figure $5.4 \quad 2000$ WIPP Site Temperature at 50-meter Height . . . . . . . . . . . . . . . . . . . 77

Figure $5.5 \quad 2000$ WIPP Site Wind Rose at 2-meter Height $\ldots \ldots \ldots \ldots \ldots \ldots \ldots \ldots \ldots \ldots$

Figure $5.6 \quad 2000$ WIPP Site Wind Rose at $10-$ meter Height $\ldots \ldots \ldots \ldots \ldots \ldots \ldots \ldots$

Figure $5.7 \quad 2000$ WIPP Site Wind Rose at 50 -meter Height $\ldots \ldots \ldots \ldots \ldots \ldots \ldots \ldots \ldots$

Figure $5.8 \quad$ WIPP Seismograph Station Locations $\ldots \ldots \ldots \ldots \ldots \ldots \ldots \ldots \ldots \ldots \ldots \ldots$

Figure $6.1 \quad$ Water Quality Sampling Program Sample Wells $\ldots \ldots \ldots \ldots \ldots \ldots \ldots \ldots$

Figure $6.2 \quad$ Ground water Level Surveillance Wells $\ldots \ldots \ldots \ldots \ldots \ldots \ldots \ldots \ldots$

Figure 6.3 Potentiometric Surface, Adjusted to Equivalent Freshwater Head, of the Culebra Dolomite Member of the Rustler Formation near the WIPP Site . . . . . . 94 
Figure 6.4 Flow Rate and Direction of Groundwater Flowing Across the WIPP Site,

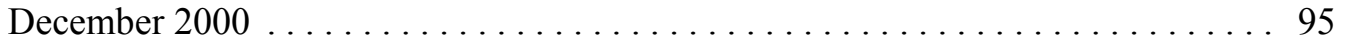

Figure $7.1 \quad$ Three General Models Used to Predict Risk from Radiation Dose $\ldots \ldots \ldots \ldots \ldots 118$ 


\section{Chapter 1 Introduction}

The Waste Isolation Pilot Plant (WIPP) is the world's first underground repository with the necessary permits and certifications for safe and permanent disposal of transuranic (TRU) radioactive and mixed waste generated by defense-related activities. A TRU waste is eligible for disposal at WIPP if it has been generated in whole or in part by one or more of the activities listed in section 10101(3) of the Nuclear Waste Policy Act of 1982, including: naval reactors development, weapons activities, verification and control technology, defense nuclear materials production, defense nuclear waste and materials by-products management, defense nuclear materials security and safeguards and security investigations, and defense research and development.

TRU waste is defined in the WIPP Land Withdrawal Act of 1992 (PL 102-579) as radioactive waste containing more than 100 nanocuries $(3,700 \mathrm{~Bq})$ of alpha-emitting TRU isotopes per gram of waste, with half-lives greater than 20 years. A TRU isotope is an isotope of an element with an atomic number greater than uranium (92). There are certain exceptions to the WIPP Land Withdrawal Act definition, including: high-level radioactive waste; waste that the Secretary of Energy has determined, with the concurrence of the Administrator of the Environmental Protection Agency, does not need the degree of isolation required by 40 CFR $\S 191$ disposal regulations; or waste that the Nuclear Regulatory Commission has approved for disposal on a case-by-case basis in accordance with 10 CFR $\S$ 61. Most TRU waste is contaminated industrial trash, including used protective clothing, rags, tools and equipment, sludges from solidified liquids, and glass, metal, and other materials from dismantled buildings.

The WIPP Project is authorized by the U.S. Department of Energy (DOE) National Security and Military Applications of Nuclear Energy Authorization Act of 1980 (PL 96-164).
WIPP's legislative mandate is to demonstrate the safe disposal of TRU wastes from national defense activities and programs. To fulfill this mandate, WIPP has been designed to safely handle, store, and dispose of TRU waste in a fully-operational disposal facility. After more than 20 years of scientific study, public input, and regulatory struggles, WIPP received its first shipment of waste on March 26, 1999.

When TRU waste arrives at WIPP, it is transported into the Waste Handling Building. The waste containers are removed from the shipping containers, placed on the waste hoist, and lowered to the repository level of $655 \mathrm{~m}$ $(2,150 \mathrm{ft}$; approximately $0.5 \mathrm{mi})$ below the surface. During the disposal phase, the containers of waste are removed from the hoist and placed in excavated storage rooms in the Salado Formation, a thick sequence of salt beds deposited approximately 250 million years ago (Figure 1.1). Once a disposal area has been filled with waste, specially designed closures will be placed in the excavated disposal rooms, and seals will be placed in the shafts. Salt under pressure is relatively plastic, and mine openings will be allowed to creep closed for final disposal, encapsulating and isolating the waste.

\subsection{WIPP History}

Government officials and scientists initiated the WIPP site selection process in the 1950s. At that time, the National Academy of Sciences conducted a nationwide search for stable geological formations to contain wastes for thousands of years. In 1955, after extensive study, salt deposits were recommended as a promising medium for the disposal of radioactive waste.

Salt was chosen as the material for the planned disposal of nuclear waste for several reasons. Most deposits of salt are found in stable geological areas with very little earthquake activity, assuring the stability of a 


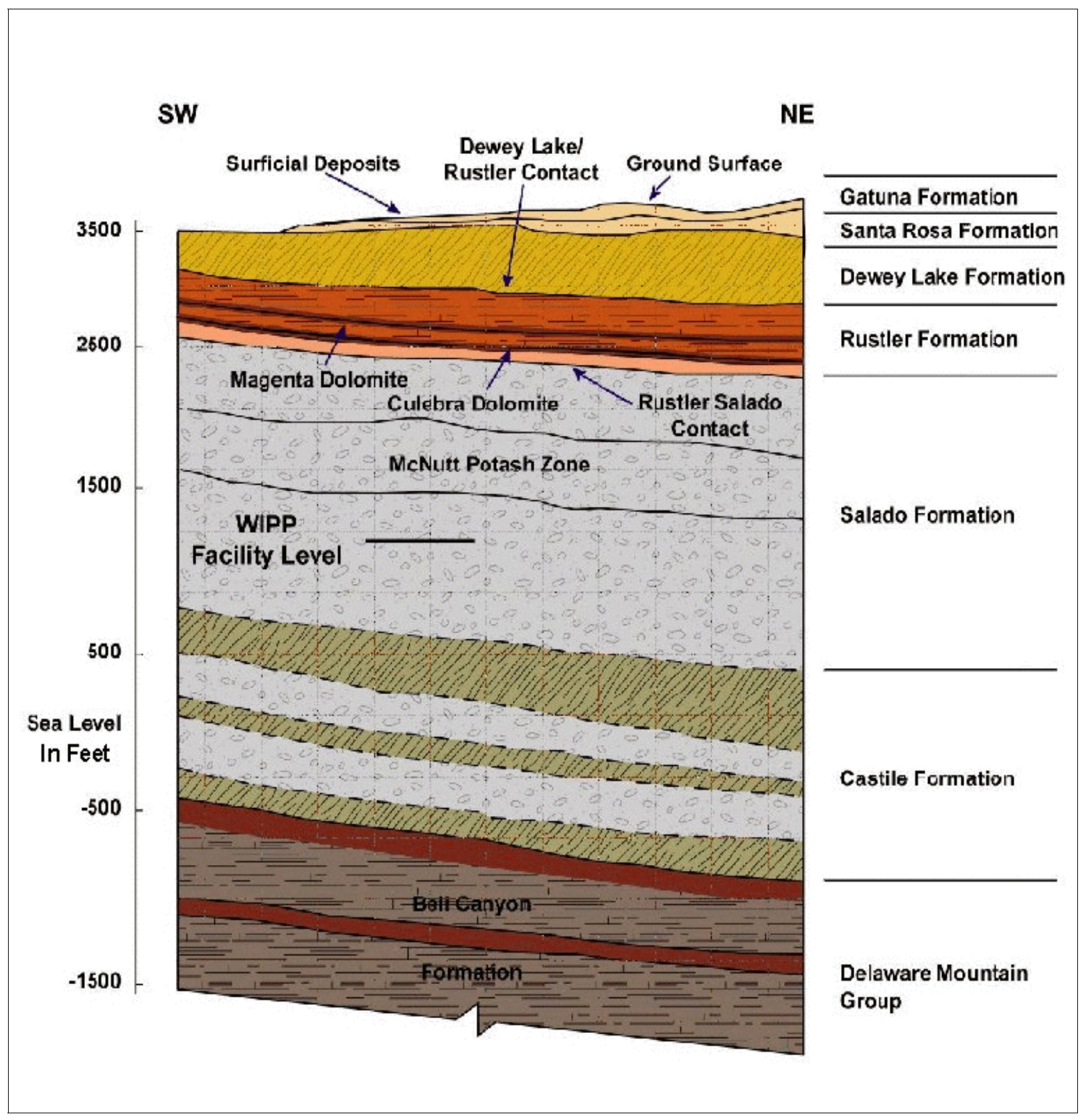

Figure 1.1 WIPP Stratigraph

waste repository. Salt deposits also demonstrate the absence of flowing fresh water that could move waste to the surface. Water, if it had been or were present, would have dissolved the salt beds. In addition, salt is relatively easy to mine. Finally, rock salt heals its own fractures because it is relatively plastic. This means salt formations will slowly and progressively move in to fill mined areas and will safely seal radioactive waste from the environment.

Government scientists searched for an appropriate site for the disposal of radioactive waste throughout the 1960 s, and finally tested the area of south-eastern New Mexico in the early 1970s. Salt formations at WIPP were deposited in thick beds during the evaporation 
of an ancient ocean, the Permian Sea. These geologic formations consist mainly of sodium chloride, the same substance as table salt.

However, at WIPP, the salt is not granular, but is in the form of solid rock. The main salt formation at WIPP is about $610 \mathrm{~m}(2,000 \mathrm{ft})$

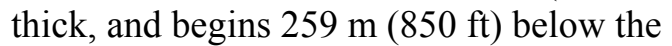
earth's surface. Formed about 225 million years ago during the Permian Age, the large expanses of uninterrupted salt beds provide a repository that has been stable and free from the disturbances of large earthquakes for more than 200 million years. This proven stability over such a long time span offers the predictability that the salt will remain stable for the comparatively short 10,000-year period that WIPP is mandated to isolate the waste from the human environment.

In 1979, Congress authorized the construction of WIPP, and DOE constructed the facility during the 1980s. In late 1993, DOE created the Carlsbad Field Office (CBFO) to lead the TRU waste disposal efforts. The Carlsbad Field Office coordinates the TRU program at waste-generating sites and national laboratories.

In 1999, WIPP received its first waste shipments. On March 25, the first waste bound for WIPP departed Los Alamos National Laboratory in New Mexico; it arrived at WIPP the following morning, and the first wastes were placed underground later that day. On April 17, WIPP celebrated its official grand opening. Ten days later, on April 27, the first out-of-state shipment arrived at WIPP, from the Idaho National Engineering and Environmental Laboratory. Later in the year, on October 27, the Secretary of the New Mexico Environment Department issued a WIPP Hazardous Waste Facility Permit, which allows WIPP to manage, store, and dispose of contact-handled TRU mixed waste. Mixed waste is waste contaminated by both hazardous and radioactive substances. "Contact-handled mixed waste" is TRU mixed waste with a surface dose rate less than 200 millirem per hour.

\subsection{WIPP's Mission}

Current temporary radioactive waste storage facilities at 23 locations across the United States were never intended to provide permanent disposal. WIPP is the nation's first operating underground repository for defense-generated TRU waste and is a critical step toward solving the nation's nuclear waste disposal problem. Its mission is to provide for the safe, permanent, and environmentally-sound disposal of TRU radioactive waste left from research, development, and production of nuclear weapons. Over the next 35 years, WIPP is expected to receive about 37,000 shipments of waste from locations across the U.S.

The mission of the CBFO Is to protect human health and the environment by opening and operating WIPP for safe disposal of TRU waste and by establishing an effective system for management of TRU waste from generation to disposal.

\subsection{WIPP Location}

Located in Eddy County in the remote Chihuahuan Desert of southeastern New Mexico (Figure 1.2), the WIPP site encompasses approximately $41.1 \mathrm{~km}^{2}$, or $16 \mathrm{mi}^{2}$. The site is $42 \mathrm{~km}$ (26 mi) east of Carlsbad in a region known as Los Medaños. This part of New Mexico is relatively flat and is sparsely inhabited, with little surface water. The WIPP site boundary extends a minimum of $1.6 \mathrm{~km}$ ( 1 mi) beyond any of the WIPP underground developments. The WIPP Land Withdrawal Act was signed into law on October 30, 1992, transferring the land from the Department of the Interior to DOE. With the exception of facilities within the boundaries of the posted 5.7 $\mathrm{km}^{2}\left(2.2 \mathrm{mi}^{2}\right)$ Off-Limits Area, the surface land uses remain largely unchanged from pre-1992 uses, and are managed in accordance with accepted practices for multiple land use. However, mining and drilling for purposes other than those which support WIPP are prohibited within the WIPP site. 


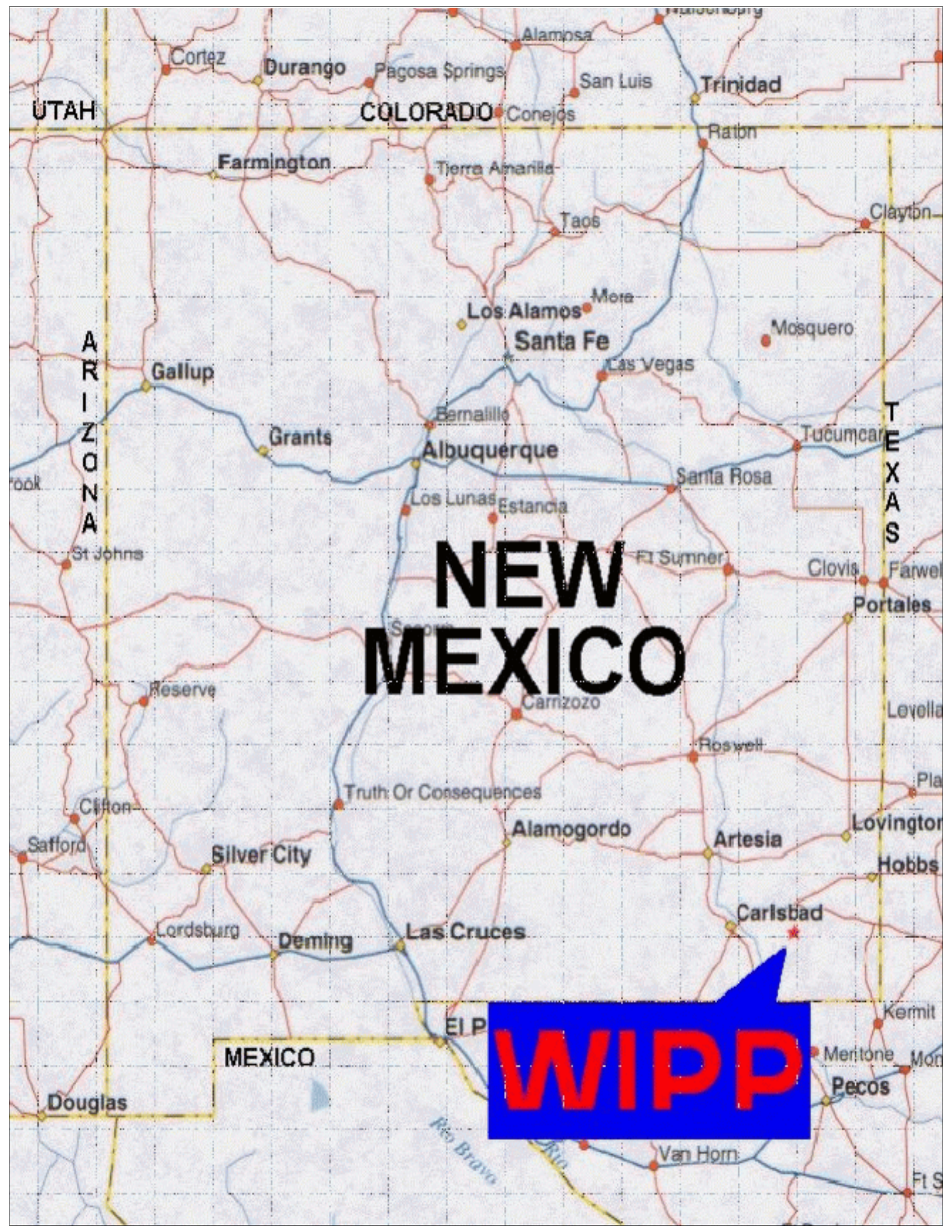

Figure 1.2 WIPP Location 
The majority of the lands in the immediate vicinity of WIPP are managed by the Department of the Interior's Bureau of Land Management (BLM). Land uses in the surrounding area include livestock grazing; potash mining; oil and gas exploration and production; and recreational activities such as hunting, camping, hiking, and bird watching. The region is home to diverse populations of animals and plants.

\subsubsection{WIPP Property Areas}

There are five types of property areas within WIPP's boundary (Figure 1.3).

\section{Property Protection Area}

The interior core of the facility encompasses approximately $0.129 \mathrm{~km}^{2}\left(0.05 \mathrm{mi}^{2}\right)$ surrounded by a chain link fence. This area is under tight security and uniformed security personnel are on duty 24 hours a day.

\section{$\underline{\text { Exclusive Use Area }}$}

The Exclusive Use Area comprises $1.12 \mathrm{~km}^{2}$ $\left(0.432 \mathrm{mi}^{2}\right)$. It is surrounded by a five-strand barbed wire fence and is restricted exclusively for the use of the DOE and its contractors and subcontractors in support of the project. In addition, this area is defined as the point of closest public access for the purpose of analyzing accident consequences to the general public in the WIPP Safety Analysis Report (DOE/WIPP 95-2065). This area is marked by DOE "no trespassing" signs and is patrolled by WIPP security personnel to prevent unauthorized activities or uses.

\section{$\underline{\text { Off-Limits Area }}$}

Managed as an area where unauthorized entry and introduction of weapons and/or dangerous materials is prohibited, the Off-Limits Area includes $5.7 \mathrm{~km}^{2}\left(2.2 \mathrm{mi}^{2}\right)$. Pertinent prohibitions are posted at consistent intervals along the perimeter. Grazing and public thoroughfare will continue in this area until such time that these activities present a threat to the security, safety, or environmental quality of WIPP. This sector is patrolled by WIPP security personnel to prevent unauthorized activity or use.

\section{WIPP Land Withdrawal Area}

The WIPP site boundary delineates the perimeter of the $41.4 \mathrm{~km}^{2}\left(16 \mathrm{mi}^{2}\right)$ WIPP Land Withdrawal Area. This tract includes properties outlying the Property Protection Area, the Exclusive Use Area, and the Off-Limits Area. This sector is designated as a Multiple Land Use Area, and is managed accordingly.

\section{$\underline{\text { Special Management Areas }}$}

Certain properties used in the operation of WIPP (e.g., reclamation sites, well pads, roads) are, or may be, identified as Special Management Areas (SMA). A SMA designation is made due to values, resources, and/or circumstances that meet criteria for protection and management under special management designations. Unique resources of value that are in danger of being lost or damaged, areas where ongoing construction is occurring, fragile plant and/or animal communities, sites of archaeological significance, locations containing safety hazards, or sectors that may receive an unanticipated elevated security status would be suitable for designation as a SMA. Accordingly, the subject sector would receive special management emphasis under this stipulation. Special Management Areas will be posted against trespass and will be safeguarded commensurate with applicable laws governing property protection. WIPP security personnel will patrol these areas to prevent unauthorized access or use.

\subsubsection{Population}

Approximately 26 residents live within 16 $\mathrm{km}(10 \mathrm{mi})$ of the WIPP site. The majority of the local population within $80.5 \mathrm{~km}(50 \mathrm{mi})$ of WIPP is concentrated in and around the communities of Carlsbad, Hobbs, Eunice, Loving, Jal, and Artesia, New Mexico. The 


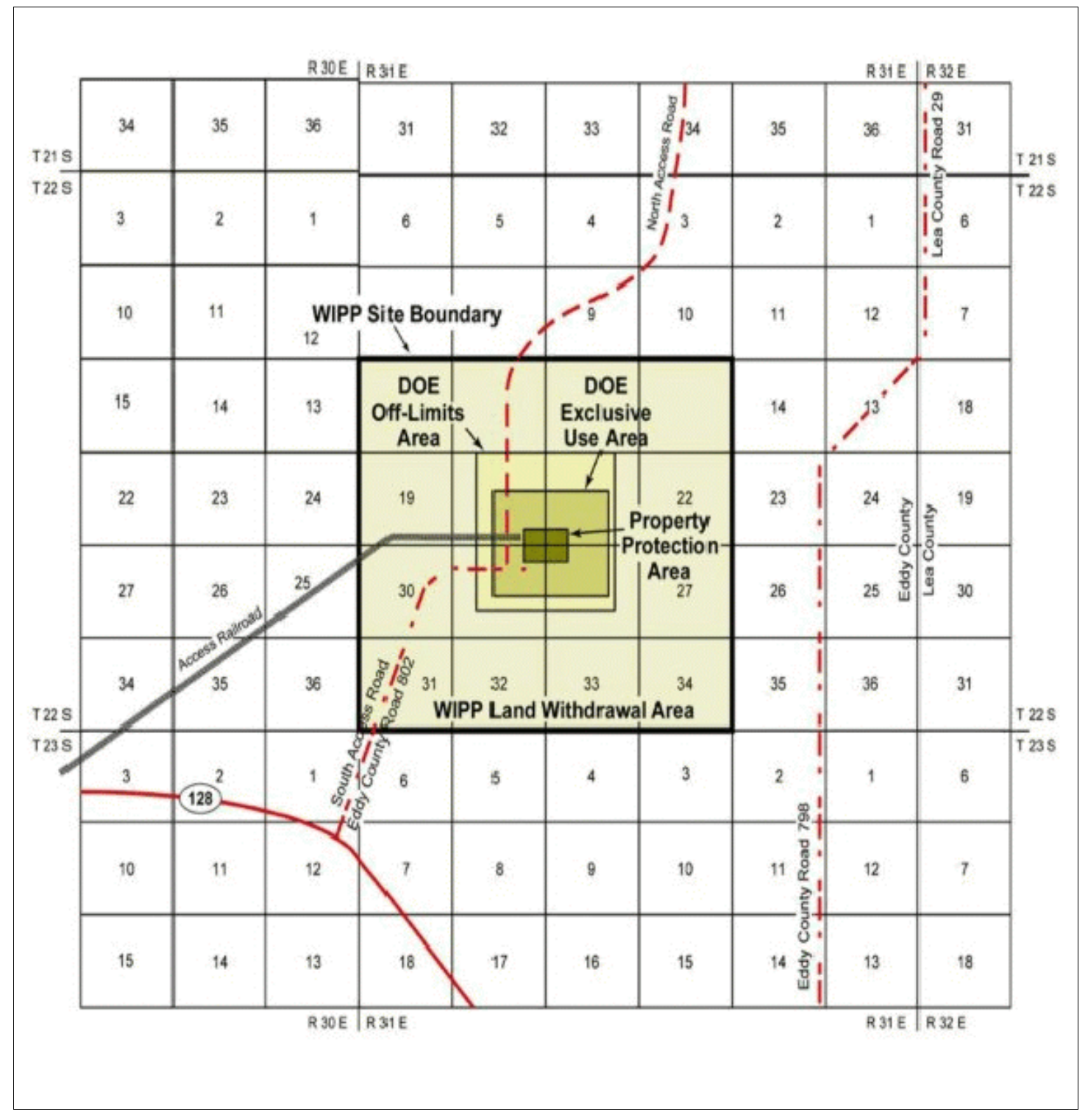

Figure 1.3 WIPP Property Areas

nearest community is the village of Loving (current estimated population 1,326), $29 \mathrm{~km}$ (18 mi) west-southwest of WIPP. The nearest major populated area is Carlsbad, $42 \mathrm{~km}(26 \mathrm{mi})$ west of WIPP. The current estimated population of Carlsbad is approximately 25,625. The population within $16 \mathrm{~km}(10 \mathrm{mi})$ of WIPP is associated with ranching, oil and gas exploration/production, and potash mining. There are two nearby ranch residences (Smith Ranch and Mills Ranch) which are continuously monitored as part of the Environmental Monitoring Plan (DOE/WIPP 99-2194).

\subsection{Environmental Performance}

The Department of Energy's Environmental Policy Statement describes DOE's commitment to environmental protection and pledges to conduct operations "in an environmentally safe and sound manner. . . in compliance with the letter and spirit of applicable environmental statutes, regulations, and standards" (DOE 1986). The Statement also affirms DOE's commitment to "good environmental management in all of its programs and at all of its facilities in order to correct existing 
environmental problems and to anticipate and address potential environmental problems before they pose a threat to the quality of the environment or public welfare."

Additionally, it states, "It is DOE's policy that efforts to meet environmental obligations be carried out consistently across all operations and among all field organizations and programs. .." (DOE 1986).

DOE used laboratory tests, field tests, and computer models to demonstrate WIPP's expected 10,00 year performance as a permanent disposal site. The Environmental Protection Agency (EPA) certified in May 1998, WIPP's ability to protect the environment and human health, while assuring continued compliance through periodic recertification.

Westinghouse TRU Solutions, LLC (WTS) conducted the Environmental Monitoring Program at WIPP in calendar year (CY) 2000 to monitor for any potential radiological effects of WIPP on people and the environment. Other organizations oversee the WIPP program, including the EPA, which is responsible for certifying whether radioactive material disposal requirements are met; the state of New Mexico, which regulates the handling of the hazardous components of mixed wastes; and the Environmental Evaluation Group, an independent technical oversight group that participates in and comments on various WIPP issues and activities. The Carlsbad Environmental Monitoring and Research Center conducts a supplementary environment monitoring program around WIPP. Several other agencies, committees, and panels monitor progress at WIPP and contribute to the project's development through regulation, review, and comment at the state and federal levels.

This Waste Isolation Pilot Plant 2000 Site Environmental Report was prepared by the Environmental Science and Research Foundation, Inc. for Westinghouse TRU Solutions, LLC in accordance with DOE Order 231.1. This report documents WIPP's radiological, nonradiological, and groundwater monitoring programs and their results for $\mathrm{CY}$ 2000. 
This page intentionally left blank. 


\section{Chapter 2 \\ Environmental Program Information}

DOE's policy for the management of WIPP is to conduct its operations in a manner commensurate with applicable environmental laws and regulations, and to safeguard the integrity of the southeastern New Mexico environment. This is accomplished through radiological and nonradiological environmental monitoring, environmental compliance, and land management programs, which include monitoring wildlife populations, the WIPP Raptor Program, and reclamation of disturbed lands. The purpose of these programs is to obtain land use permits, implement selected compliance functions such as NEPA compliance, collect data needed to detect and quantify possible impacts WIPP may have on the surrounding ecosystem and, when necessary, provide technical support in the disciplines of environmental science and land management to DOE's Carlsbad Field Office.

Environmental monitoring activities at WIPP generally fall into four categories: collecting environmental samples from various matrices and analyzing them for specific radionuclides; preparing and publishing documents showing compliance with federal, state, and local regulations; evaluating whether WIPP activities cause any environmental impacts; and taking corrective action when an adverse effect on the environment is identified.

\subsection{Environmental Monitoring Plan}

WIPP's Environmental Monitoring Plan (EMP) outlines the programs that monitor the environment on, and immediately surrounding, the WIPP site (DOE/WIPP 99-2194). It discusses major environmental monitoring and surveillance activities at WIPP and reflects the importance of monitoring as a critical element of an effective environmental protection program. The EMP also discusses the WIPP quality assurance/quality control (QA/QC) program as it relates to environmental monitoring. The purpose of the EMP is to outline the programs that evaluate WIPP's effect on the local ecosystem. Effluent and environmental monitoring also provide the data necessary to demonstrate compliance with applicable environmental protection regulations. The EMP sampling schedule is provided in Table 2.1.

The EMP describes the monitoring of naturally-occurring and specific anthropogenic (human-made) radionuclides. This surveillance includes monitoring worldwide fallout from historic nuclear weapons tests. The geographic scope of radiological sampling is based on projections of potential release pathways from the waste stored at WIPP. Airborne radioactivity is also monitored at Carlsbad, NM and local ranches.

The EMP also describes monitoring of volatile organic compounds (VOCs), wildlife populations, meteorology, groundwater chemistry, and other nonradiological environmental parameters. In general nonradiological monitoring is conducted within or near the WIPP boundary.

Results and discussions pertaining to the monitoring programs prescribed by the EMP are provided in Chapter 4, "Environmental Radiological Program Information," and Chapter 5, "Environmental Nonradiological Program Information." DOE Order 5400.1 requires the EMP to be reviewed internally every year and updated every three years. The most recent EMP update was in September 1999. 
Table 2.1 The Environmental Monitoring Plan outlines the sampling schedule for the WIPP Environmental Monitoring Program.

\begin{tabular}{lcc}
\hline \multicolumn{1}{c}{ Type of Sample } & Number of Sampling Locations & Sampling Frequency \\
\hline Liquid effluent & 1 & Semiannual (oversight) \\
Liquid effluent & 1 & Quarterly (DP 831 permit ${ }^{\mathrm{a}}$ ) \\
Airborne effluent & 3 & Periodic/Confirmatory \\
Meteorology & 2 & Continuous \\
Atmospheric particulate & 7 & Weekly \\
Vegetation & 6 & Annual \\
Beef/Deer/Game Birds/Rabbits & 3 & Annual \\
Soil & 6 & Annual \\
Surface water & 14 & Annual \\
Groundwater & 7 & Semiannual \\
Fish & 3 & Annual \\
Sediment & 12 & Annual \\
Aerial photography & Sitewide & Annual \\
Volatile organic compounds (VOCs) & 2 & Semiweekly \\
\hline
\end{tabular}

${ }^{a}$ Monitoring compliance with the Sewage System Discharge Plan, DP-831.

\subsection{WIPP Environmental Monitoring Program}

It is the policy of DOE to conduct effluent monitoring and environmental surveillance programs that are appropriate for determining adequate protection of the public and the environment during WIPP operations, and to ensure operations comply with DOE and other applicable federal or state radiation standards and requirements. It is DOE's objective that all DOE operations properly and accurately measure radionuclides in effluent streams and in the ambient environmental media. The goal of the WIPP Environmental Monitoring Program is to determine if the local ecosystem has been impacted during the predisposal and disposal phases of WIPP, and, if so, to evaluate the severity, geographic extent, and environmental significance of those impacts. The program fulfills DOE Orders 5400.1 (General

Environmental Protection Program) and 5400.5

(Radiation Protection of the Public and the Environment).

The Environmental Monitoring Program monitors pathways by which WIPP-related radionuclides and other contaminants could reach the environment surrounding the WIPP site. The pathways measured include air, surface water, groundwater, sediments, soils, and biota (e.g., vegetation, game birds, and fish). In addition, the program monitors groundwater quality and the overall health of the local environment. Nonradiological portions of the program focus on the area immediately surrounding the site while radiological surveillance generally covers a broader geographical area. 
In addition to monitoring for radionuclides contained in WIPP wastes, background radiation (naturally-occurring radioactivity and radioactivity associated with worldwide fallout from historic weapons testing) is also monitored. The geographic scope of radiological sampling is based on projections of potential release pathways for the types of radionuclides in WIPP wastes. Also, Carlsbad, NM and local ranches are monitored, even though release scenarios involving radiation doses to residents of these population centers are improbable.

The atmospheric pathway, which can lead to the inhalation of radionuclides, has been determined to be the most likely exposure pathway to the public from WIPP. Therefore, airborne particulate sampling for alpha-emitting radionuclides is emphasized. Air sampling results are used to trend environmental radiological levels and determine if there has been a deviation from established baseline concentrations.

Nonradiological environmental monitoring activities at WIPP consist of a comprehensive set of sampling programs designed to detect and quantify impacts of construction and operational activities. The ecological monitoring program focuses on nonradiological effects of WIPP, such as habitat disturbance.

WIPP has collected preoperational radiological and nonradiological environmental data. The environmental monitoring data collected prior to March 1999 are being compiled to broaden the radiological baseline in the WIPP vicinity and could be used as a confirmatory tool to quantify unplanned radiological occurrences. Baseline conditions were initially characterized by the Radiological Baseline Program. When the first shipment of waste arrived at WIPP, this program became an operational monitoring program.

Preoperational studies must be considered during environmental evaluations. These assessments have contributed to baseline data gathered during the construction phase and provided much of the foundation for long-term monitoring programs. Below are listed examples of such investigations.

- The WIPP Site Characterization Program was instituted in 1976 by Sandia National Laboratories to monitor air quality, background radiation levels, and groundwater quality.

- The WIPP Biology Program began in 1975 with site characterization studies of climate, soils, vegetation, arthropods, and vertebrates.

- Investigations of site geohydrology were conducted by the U.S. Geological Survey (USGS) at the request of the DOE. In addition, the Nuclear Regulatory Commission issued a contract to Columbia University to perform a study of radionuclide mobility in the highly saline groundwaters of the Delaware Basin.

- Radiological monitoring of air, water, and biological media was conducted by the U.S. Atomic Energy Commission before and after the Project Gnome nuclear detonation in 1961.

\subsection{Land Management Programs}

On October 30, 1992, the WIPP Land Withdrawal Act (Public Law 109-579) became law. This act transferred the responsibility for the management of the WIPP Land Withdrawal Area from the Secretary of the Interior to the Secretary of Energy. In accordance with Sections 3(a)(1) and (3) of the act, these lands:

“... are withdrawn from all forms of entry, appropriation, and disposal under the public land laws ... and are reserved for the use of the Secretary of Energy ... for the construction, experimentation, operation, repair and maintenance, disposal, shutdown, monitoring, decommissioning, and other activities associated with the purposes of WIPP as set forth in Section 213 of the DOE National Security and 
Military Application of the Nuclear Energy Act of 1980 (Public Law) 96-164; 93 Stat. 1259, 1265) and this Act."

DOE developed the Land Management Plan (DOE/WIPP 93-004) (LMP) as required by Section 4 of the Land Withdrawal Act. The LMP was developed to identify resource values, promote multiple-use management, and identify long-term goals for the management of WIPP lands until the culmination of the decommissioning phase. This plan was developed in consultation and cooperation with the BLM and the state of New Mexico. Changes or amendments to the plan require the involvement of the BLM, the state of New Mexico, and affected stakeholders, as appropriate.

Guidelines in the LMP provide for the management and oversight of WIPP lands under the jurisdiction of DOE. Lands outside the WIPP boundary used in the operation of WIPP (e.g., groundwater surveillance well pads outside the withdrawal area) are also included in the plan. Furthermore, the plan provides for multiagency involvement in the administration of DOE land management actions. For example, the BLM is responsible for administering grazing leases through a Memorandum of Understanding (MOU). The LMP is available to anyone desiring to conduct activities on lands under the jurisdiction of WIPP in addition to those involved in developing or amending existing land management actions.

The LMP encourages direct communication among stakeholders, including federal and state agencies, involved in managing the resources within, or activities impacting the areas adjacent to, the WIPP Land Withdrawal Area. It sets forth cooperative arrangements and protocols for addressing WIPP-related land management actions. Commitments contained in current permits, agreements, or concurrent MOUs with other agencies will be respected when addressing and evaluating land use management activities and future amendments that affect the management of WIPP lands.
The LMP was reviewed in 1999. It is reviewed on a biennial basis to assess the adequacy and effectiveness of the document, or as may be necessary to address emerging issues potentially affecting WIPP lands. Affected agencies, groups, and individuals may be involved in the review process. Components of the LMP emphasize management protocols for the following issues: administration of the plan, environmental compliance, wildlife, cultural resources, grazing, recreation, energy and mineral resources, lands/realty, reclamation, security, industrial safety, emergency management, maintenance, and work control.

\subsubsection{Land Use Requests}

Parties who wish to conduct activities that may impact lands under the jurisdiction of WIPP, but outside the secured fence area of the facility designated as the Property Protection Area, are required by the LMP to prepare a Land Use Request (LUR). A LUR consists of a narrative description of the project, a completed environmental review, and a map depicting the location of the proposed activity. The LUR, and associated NEPA checklists, are used to determine if applicable regulatory requirements have been met prior to the approval of a proposed project. A LUR may be submitted to the land use coordinator by any WIPP organization or outside entity wishing to complete any construction, right-of-way, pipeline easement, or similar action within the WIPP boundary or on lands used in the operation of WIPP, under the jurisdiction of the DOE. During 2000, 19 LURs were submitted for review and approval; all met applicable criteria and were approved.

\subsubsection{Wildlife Population Monitoring}

Southeastern New Mexico is home to diverse populations of plants and wildlife. Shrubs and grasses are the most prominent components of the local flora. Dominant trees include shinnery oak (Quercus havardii), honey mesquite (Prosopis glandulosa), and western soapberry (Sapindus drummondii). Much of the 
area is composed of combined dune and grassland habitats that include perennial grasses and shrubs.

According to the BLM's Resource Management Plan, 15 percent of the wildlife species identified in the area use the shinnery oak habitat, while 30 percent occupy areas consisting primarily of grasses. The juxtaposition of shinnery oak/dune habitat with grassland habitat has resulted in a diverse wildlife population.

This portion of New Mexico supports an abundant and diverse population of mammals, including black-tailed jackrabbits (Lepus californicus), desert cottontails (Sylvilagus audoboni), desert mule deer (Odocoileus hemionus), coyotes (Canis latrans), gray foxes (Urocyon cinereoargenteus), badgers (Taxidea taxis), and striped skunks (Mephitis mephitis).

The habitat heterogeneity of the Los Medaños region also accounts for a wide assortment of bird species. Scaled quail (Callipepla squamata), mourning doves (Zenaida macroura), loggerhead shrikes (Lanius ludovicianus), black-throated sparrows (Amphispiza bilineata), Chihuahuan ravens (Corvus cryptoleucus), and a unique desert subspecies of the northern bobwhite (Colinus virginianus) are but a few examples of the array of avian inhabitants. Due to a scarcity of surface waters in the immediate vicinity of WIPP, migrating or breeding waterfowl are not common.

In addition, this area supports a particularly abundant and diverse population of raptors, or birds of prey. Harris' hawks (Parabuteo unicinctus), Swainson's hawks (Buteo swainsoni), and great horned owls (Bubo virginianus) are species commonly found nesting in the area. Northern harriers (Cicus cyaneus), burrowing owls (Athene cunicularia), barn owls (Tyto alba), and American kestrels (Falco sparverius) are also found at the site.

Reptiles and amphibians are also found in great numbers in southeastern New Mexico.
Representative of the no fewer than 10 native amphibians are the tiger salamander (Ambystoma tigrinum), green toad (Bufo debilis), plain's spadefoot toad (Spea bombifrons), red-spotted toad (Bufo punctatus), and New Mexico spadefoot toad (Spea muliplicata). Their significance is seldom recognized until spring or summer rains, at which time they appear in extraordinary numbers.

Reptiles are more conspicuous due to their diurnal nature. Characteristic reptiles in the region include the ornate box turtles (Terrapene ornata), side-blotched lizards (Uta stansburiana), western whiptails (Cnemidophorus tigris), bullsnakes (Pituophis melanoleucus), prairie rattlesnakes (Crotalus viridis), and Texas horned lizards (Phrynosoma cornutum), a federal notice-of-review species listed under the Endangered Species Act.

Birds and mammals compose the upper levels of the food chain in the natural ecosystem around WIPP. These organisms may be affected by noise and human presence as well as by changes in habitat structure due to salt impacts. Population densities are monitored annually to define normal cycles of abundance and to detect major changes in populations or communities which may be due to activities at WIPP.

Beginning in 1985 , population density measurements of birds and small nocturnal mammals were performed annually to assess the effects of WIPP surface activities (e.g., construction, salt piles) on wildlife populations. Customary protocol involved comparative data analyses between two outlying or "control" plots and two experimental plots near WIPP operations. No consistent differences were found between the control and experimental plots. A Hantavirus investigation during 1994 prompted the temporary postponement of small nocturnal mammal surveys. Previous years' investigations revealed no detectable detrimental impacts from salt encroachment on the peripheral environment; therefore, annual appraisals of small mammal populations were discontinued indefinitely. 
WTS personnel manage several wildlife research projects and conduct a number of general wildlife management activities. Specific wildlife populations are monitored and researched in accordance with applicable laws, agreements, and regulations. Each activity is mandated and/or supported by state and federal guidelines or by way of commitments created through interagency agreements and MOUs. Wildlife within the WIPP Land Withdrawal Area are given consideration by way of the WIPP LUR process during planning stages of projects that may disturb or encroach on wildlife habitat.

In 1979, DOE consulted with the United States Fish and Wildlife Service (USF\&WS) and was informed of the presence of threatened or endangered species at or near the WIPP site. However, no critical habitats for endangered species were identified at WIPP. In 1989, DOE again consulted with the USF\&WS and was advised of no status changes since 1979.

During 1989, DOE consulted with the New Mexico Department of Game and Fish (NMDG\&F) regarding state-listed endangered species in the vicinity of WIPP. NMDG\&F Regulation 657, dated January 9, 1988, listed seven birds and one reptile in one of two endangerment categories that may be present at the site.

In 1995, the USF \&WS provided an updated list of threatened and endangered species for Eddy and Lea Counties, New Mexico. Included were 18 species that may be present on WIPP lands. A comprehensive evaluation in support of the second Supplemental Environmental Impact Statement (SEIS-II) was conducted in 1996 to determine the presence or absence of threatened or endangered species in the vicinity of WIPP and WIPP's effect on these species. Results indicated that activities associated with the operation of WIPP had no impact on any threatened or endangered species. The protection of threatened and endangered species is taken into consideration when planning and administering projects on WIPP lands.
WIPP, and the region surrounding it, is widely recognized for its concentration and diversity of raptors. The area is home to several raptor species of special concern, including Harris' hawks, Swainson's hawks, burrowing owls, and barn owls, as well as other species.

DOE, the BLM, and other government agencies are keenly aware of the value and importance of protecting and monitoring raptor populations. To assist in this effort at WIPP, the BLM and DOE established the WIPP Raptor Program (WRP) in the early 1990s to monitor, protect, and educate about raptors on the WIPP site. The WRP is administered by the WIPP Environmental Monitoring Program with input from the BLM and others. Scientific consultation, research direction, and field operations are conducted by scientists from Rocky Mountain College in Billings, Montana.

In CY 2000, research continued on long term studies of productivity and population demographics of the raptor community in and around WIPP. These studies are described in greater detail in Chapter 5.

\subsubsection{Reclamation of Disturbed Lands}

DOE recognizes its responsibility pursuant to federal, state, and local environmental regulations to enhance and restore areas affected by WIPP activities, including disturbed lands accepted as part of the land transfer from the BLM.

During CY 2000, reclamation efforts on the Site Preliminary Design and Validation (SPDV) salt pile were culminated. After the pile was recontoured, a geotextile liner was rolled across the surface and covered with approximately three feet of rooting medium. One-half inch crushed rock was blended with the upper six inches of rooting medium as an erosion deterrent. The pile was then planted with five species of native grasses and two species of wild flowers.

Also in 2000, a surface area of approximately 0.2 ha ( 0.5 acres) with an access 
road of approximately $0.40 \mathrm{~km}$ ( 0.25 miles), was disked and seeded as the final reclamation efforts for the plugged well bore P-14.

WIPP reclamation activities are conducted in accordance with DOE Order 5400.1; the DOE Organization Act (42 U.S.C. § 7112); the Federal Land Policy and Management Act of 1976 (43 U.S.C. § 1751); the WIPP Disposal Phase Final Supplemental Environmental Impact Statement (SEIS-II), the Supplemental Environmental Impact Statement (SEIS-I); the Final Environmental Impact Statement (FEIS); and all applicable reclamation requirements by federal laws and regulations, executive orders, MOUs, DOE orders, and state and local laws.

Without an active reclamation program for disturbed areas, the establishment of stable ecological conditions in arid environments may require decades or centuries to achieve, depending on the disturbances and environmental conditions present. Reclamation activities are intended to reduce soil erosion, increase the rate of plant colonization and succession, and provide habitat for wildlife in disturbed areas. Reclamation ultimately serves to mitigate the effects of WIPP-related activities on affected plant and animal communities. The objective of the reclamation program is to reclaim lands used in the operation of WIPP that are no longer commissioned for WIPP operations. DOE will also establish reclamation guidelines for land use requesters on a case-bycase basis.

In accordance with the LMP, WIPP follows a reclamation program and a long-range reclamation plan. As locations are identified for reclamation, WIPP personnel reclaim these areas by using the best acceptable reclamation practices. Seed mixes used reflect those species indigenous to the area with priority given to those plant species which are conducive to soil stabilization, wildlife, and livestock needs.

\subsubsection{Oil and Gas Surveillance}

The oil and gas industry is well established in southeastern New Mexico. Nearly all phases of oil and gas activities have occurred in the vicinity of WIPP, including seismic exploration, exploratory drilling, field development (comprised of production and injection wells), and other activities associated with hydrocarbon extraction.

The Los Medaños region, where WIPP is located, is part of the Delaware Basin. Although the Delaware Basin accounts for approximately 32 percent of lands in Eddy County, approximately 20 percent of the oil and gas wells are located within its boundaries. During 1995, oil and gas reserves in the immediate vicinity of the WIPP Land Withdrawal Area were evaluated by the New Mexico Bureau of Mines and Mineral Resources. Results from this evaluation were compiled in a report, Evaluation of Mineral Resources at the Waste Isolation Pilot Plant Site, March 31, 1996.

One aspect of the WIPP land withdrawal, unique to most DOE facilities, was the intent to maintain a multiple land use concept in the management of the property. However, an exception to a global multiple use strategy was required to reduce likelihood of inadvertent intrusion on the repository and to safeguard the surface infrastructure. Accordingly, all drilling and mining on the WIPP site has been prohibited. Oil and gas activities within $1.6 \mathrm{~km}$ (1 mi) of the WIPP boundary are monitored twice monthly to identify new activities associated with oil and gas exploration and production, including:

- drilling,

- survey staking,

- geophysical exploration,

- pipeline construction,

- work-overs,

- changes in well status, and

- anomalous occurrences (e.g., leaks, spills, accidents, etc.).

During CY 2000, WIPP surveillance teams conducted 24 scheduled surveillances with 223 cursory field inspections. 
One exception to the prohibition of mining and drilling on the WIPP site involved two mineral leases. Under a provision contained in the Land Withdrawal Act (Public Law 102-579), these two mineral leases, consisting of 129 ha $(320 \mathrm{ac})$ each, were not appropriated in the proceedings. Both tracts, located in T.22 S., R. 31 E., Section 31, prohibit drilling within the first $1,830 \mathrm{~m}(6,000 \mathrm{ft})$ of the surface. In accordance with the WIPP Land Withdrawal Act, existing rights under these leases were not affected unless the Administrator of EPA determined, after consultation with the Secretary of Energy, that the area in question should have been purchased.

This determination was made because of the presence of an existing gas well that had been drilled directionally from the adjacent Section 6 of Township 23 South, Range 31 East. During deliberations, it was determined the DOE would condemn (withdraw from public use) the upper $1,830 \mathrm{~m}(6,000 \mathrm{ft})$ of Section 31. This action would require operators interested in accessing minerals under the section to stage drilling operations outside the WIPP boundary and directionally drill under Section 31 . The condemnation of the upper $1,830 \mathrm{~m}(6,000 \mathrm{ft})$ would provide an adequate protective zone for DOE operations while still allowing the legal owner of the minerals to access the reserves. Section 4(b)(5) of the Land Withdrawal Act describes this action as follows:

\section{(5) Mining:}

(A) In general. Except as provided in subparagraph (B), no surface or subsurface mining, or oil or gas production, including slant drilling from outside the boundaries of the Withdrawal, shall be permitted at any time (including after decommissioning) on lands on or under the Withdrawal.

(B) Exception. Existing rights under Federal Oil and Gas Leases No. NMNM 02953 and No. NMNM 02953 shall not be affected unless the Administrator determines, after consultation with the Secretary and the Secretary of the Interior, that the acquisition of such leases by the Secretary is required to comply with the final disposal regulations.

During CY 2000, EOG Resources Inc, initiated drilling on the second well drilled directionally under Section 31 of the WIPP Land Withdrawal Area. This well was entitled James Ranch Unit \#27. Total depth for the well is approximately $3,505.2 \mathrm{~m}$ (11,500 feet) with the bottom hole location approximately $228.6 \mathrm{~m}$ (750 feet) inside the WIPP boundary. This well was drilled vertically to a depth of $1,676.4 \mathrm{~m}$ (5,500 feet) as the kick-off point (KOP). Once the KOP had been reached, a down hole motor with a 1.5 degree slant was deployed. Drilling progressed on the angular deviation to a depth of $2,700.2 \mathrm{~m}(8,859$ feet $)$. Vertical drilling resumed to the total depth of the well. James Ranch Unit \#27 is an active, producing oil well.

\subsubsection{Aerial Photography}

Aerial photographs of the WIPP site are taken periodically to record impacts of WIPP activities on the local environment. The extent of habitat displacement, caused by the construction of roads, parking lots, buildings, and salt storage piles is documented in the aerial photographs. 


\section{Chapter 3 \\ Compliance Summary}

WIPP is required to comply with applicable federal and state laws and DOE orders. Documentation of requisite federal and state permits, notifications, and applications for approval is maintained by the WTS Environment, Safety, and Health Department. Regulatory requirements are incorporated in facility plans and implementing procedures.

\subsection{Compliance Overview}

In 2000, WIPP maintained compliance with applicable federal and state environmental regulations. Section 3.2 contains a listing of environmental statutes/regulations applicable to WIPP. Section 3.3 describes significant accomplishments and ongoing compliance activities relative to the regulations most pertinent to WIPP's development and eventual opening of the facility. A detailed breakdown of WIPP's compliance with environmental regulations is available in the WIPP Biennial Environmental Compliance Report (DOE/WIPP 99-2171).

\subsection{Compliance Status}

A summary of WIPP's compliance with major environmental regulations is presented in Table 3.3. Applicable DOE Orders are found in Table 3.4, and a list of WIPP permits appears in Table 3.5.

\subsubsection{Comprehensive Environmental Response, Compensation, and Liability Act}

No release sites have been identified at WIPP that would require cleanup under the provisions of the Comprehensive Environmental Response, Compensation, and Liability Act (CERCLA). CERCLA establishes a comprehensive federal strategy for responding to, and establishing liability for, releases of hazardous substances from a facility to the environment. Any spills of hazardous substances that exceed a reportable quantity must be reported to the National Response Center under the provisions of section 103 of CERCLA and 40 CFR $\S 302$. Hazardous substance cleanup procedures are specified in the National Oil and Hazardous Substances Pollution Contingency Plan (40 CFR § 300).

Superfund Amendments and Reauthorization Act of 1986

WIPP is required by Sections 311 and 312 of the Superfund Amendments and Reauthorization Act (SARA) Title III (also known as the Emergency Planning and Community Right-to-Know Act) to submit (1) a list of chemicals for which a material safety data sheet is required, and (2) an Emergency and Hazardous Chemical Inventory Form (Tier II Form) to the State Emergency Response Commission, the Local Emergency Planning Committee, and the fire departments with jurisdiction over the facility.

The list of chemicals provides external emergency responders with information they may need when responding to a hazardous chemical emergency at WIPP. The Tier II Form, due on March 1 of each year, provides information to the public about hazardous chemicals that a facility has on site at any time during the year above threshold planning quantities. WIPP submits the list of chemicals and the Tier II Form to each fire department with which the DOE Carlsbad Field Office (CBFO) maintains an MOU. 
Accidental Releases of Reportable Quantities of Hazardous Substances

During 2000, no releases of hazardous substances exceeded the reportable quantity limits.

\subsubsection{Federal Acquisition, Recycling, and Pollution Prevention}

In July 1995, WIPP adopted a systematic and cost-effective affirmative procurement plan for the promotion and procurement of products containing recovered materials. Affirmative procurement is designed to "close a loop" in the waste minimization recycling process by supporting the market for materials collected through recycling and salvage operations.

Affirmative procurement programs are mandated by Resource Conservation and Recovery Act (RCRA) section 6002(I), which requires federal agencies and their procuring agencies to establish material preference programs targeted to purchase recycled materials. Executive Order 13101 and the EPA guidelines in 40 CFR $\S \S 248$ through 250 and 252 through 253 provide additional guidance for implementing affirmative procurement programs at federal facilities.

Affirmative procurement programs must include four elements: (1) a preference program, (2) a promotion program, (3) an estimation, certification, and verification procedure, and (4) procedures for annual review and monitoring procedures. The purchase and use of recycled products at WIPP will help foster markets for recovered materials and reduce the amount of solid waste requiring disposal.

WIPP's Affirmative Procurement Program Plan is WP 02-EC.07. In 2000, WTS purchased 99.99 percent of the items identified in the EPA guidelines through this program. WTS also purchased numerous items which were not required by the EPA program but, nevertheless, contained recovered materials. $\underline{\text { Pollution Prevention Programs }}$

Noteworthy pollution prevention (P2) activities during 2000 included the following activities:

- Leaded Brine Reduction.--Leaded brine was identified as a RCRA waste stream at WIPP in 1995. Natural waters present in mining operations accumulate salt from the formation and exhaust shaft walls. The resulting brine leaches traces of lead from the galvanized chain link fence material used for ground control in the shaft. In 2000 WIPP continued the implementation of process changes and consequently met the Fiscal Year (FY) 2000 hazardous waste reduction goal established in EMS ISO 14001 targets and objectives.

- Implementation of the second phase of Pollution Prevention Opportunity Assessment (PPOA) 98-02, Cafeteria Waste.-A reusable cup program was started at the town and site cafeterias to reduce the use of Styrofoam cups. Employees were given reusable cups, manufactured from recycled plastic, for use in the cafeterias. Two immediate benefits were realized: Because fewer Styrofoam cups were purchased, cafeteria costs were less. This cost savings was passed along to the customer and the price of soft drinks was reduced nearly 35 percent. Also, for items off the grill, the cafeterias also began substituting paper boats for Styrofoam plates and containers.

- Medical Waste Reduction.-This was identified as an area which needed review. Because of influenza vaccinations and increased cholesterol level testing, the waste stream had doubled and included a greater variety of waste items. Awareness training was provided to the nursing staff. 
- Sanitary Waste Transfer Station. -Improvements in 2000 for the recycling center included issuing a contract for pickup and removal of recycled material, bailing of cardboard and plastics, and accurate tracking of recyclables.

- Pollution Prevention Opportunity Assessment (PPOA).-An assessment was performed to evaluate (1) concerns of using similar chemicals for the same tasks, (2) benefits of implementing and expanding an online, electronic Material Safety Data Sheet system at WIPP, (3) developing an approved chemicals list, and (4) increasing product substitution. This report is currently in progress.
- Flourescent bulbs.-A letter was submitted to the New Mexico Environment Department requesting the immediate implementation of universal waste regulations for the management of flourescent bulbs and debris waste in an effort to reduce costs associated with universal waste management by eliminating waste manifests and reducing the number of waste shipments.

- Recycling-WIPP continued its mandatory recycling program. (Table 3.1).

Table 3.1 Materials recycled at WIPP in 2000.

\begin{tabular}{lcc}
\hline & \multicolumn{2}{c}{ Mass } \\
\cline { 2 - 3 } \multicolumn{1}{c}{ Material } & Metric Tons & Pounds \\
\hline Office and mixed paper & 53.62 & 118,210 \\
Aluminum cans & 4.77 & 10,516 \\
Cardboard & 16.31 & 35,957 \\
Batteries & 2.45 & 5,401 \\
Oil & 1.90 & 4,189 \\
Scrap metal & 34.86 & 76,852 \\
Plastic & 0.07 & 154 \\
Toner Cartridges & 0.31 & 683 \\
Ethylene glycol & 3.96 & 8,730 \\
Computer Equipment & 10.92 & 24,074 \\
Flourescent bulbs and debris & 1.12 & 2,469 \\
\hline
\end{tabular}

\subsubsection{Resource Conservation and Recovery Act}

Resource Conservation and Recovery Act (42 United States Code [U.S.C.] § 3251 et seq.) was enacted in 1976. Implementing regulations were promulgated in May 1980. This body of regulations ensures that hazardous wastes are managed and disposed in a way that protects human health and the environment. The Hazardous and Solid Waste Amendments of 1984 prohibit land disposal of hazardous wastes 
unless treatment standards are met. The amendments also place increased emphasis on waste minimization activities and serve as a mechanism to enforce RCRA cleanup requirements.

The WIPP facility is subject to the permitting requirements under RCRA and the New Mexico Hazardous Waste Act. Title 40 CFR § 264 outlines the technical standards for treatment, storage, and disposal facilities. Title 40 CFR $\S 270$ outlines the requirements of the RCRA permitting program with respect to general format and content for applications and the administrative aspects of the permitting and modification processes.

Non-mixed, TRU radioactive waste shipments began on March 26, 1999. Shipments continued until November 22, 1999, when they were postponed in order to address requirements of the Waste Isolation Pilot Plant Hazardous Waste Facility Permit NM4890139088-TSDF. On October 27, 1999, WIPP received the final permit which became effective on November 26, 1999.

$\underline{\text { Hazardous Waste Generator Compliance }}$

Nonradioactive hazardous waste is currently generated through normal facility operations, and is managed in Satellite Accumulation Areas and "less-than-90-day" storage areas. In addition, hazardous waste generated at WIPP is characterized, packaged, labeled, and manifested prior to shipment to an off-site treatment, storage, and disposal facility in accordance with the requirements codified in 40 CFR $\S 262$.

WIPP Solid Waste Management Units and Areas of Concerns

The New Mexico Environment Department (NMED) on October 27, 1999 issued the WIPP Hazardous Waste Facility Permit. Module VII of the permit contains the requirements for corrective action for the WIPP Solid Waste Management Units (SWMUs) and Areas of Concern (AOCs). The permit identified 15
SWMUs requiring a RCRA Facility Investigation (RFI), three SWMUs not requiring a RFI (the Hazardous Waste Management Units), and eight AOCs in the 4,146 ha (16 $\left.\mathrm{mi}^{2}\right)$ WIPP Land Withdrawal Area.

\section{$\underline{\text { Solid Waste Management Units }}$}

The 15 SWMUs included in the permit that require a RFI are listed below:

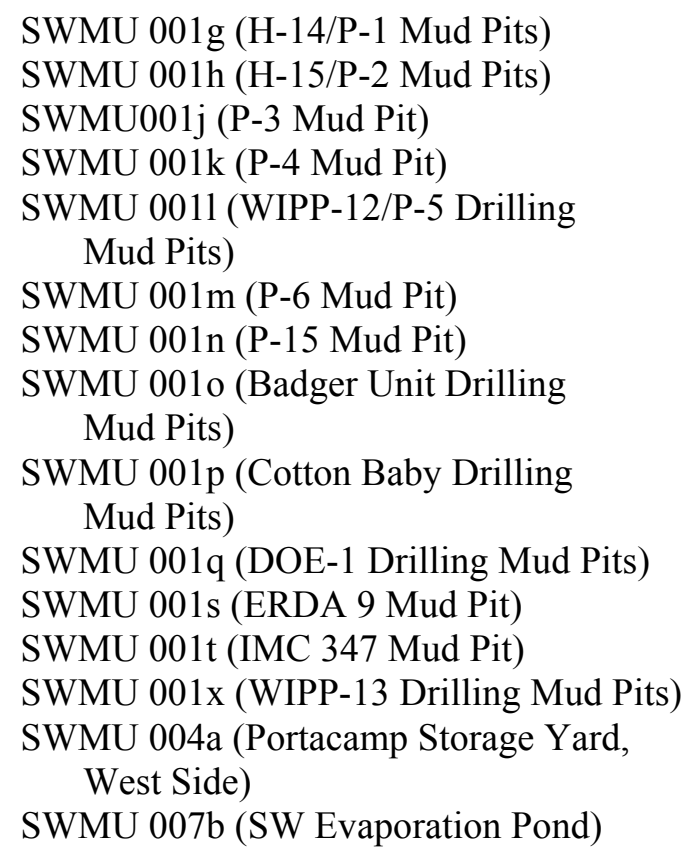

\section{$\underline{\text { Areas of Concern }}$}

Following are the eight AOCs included in the permit.

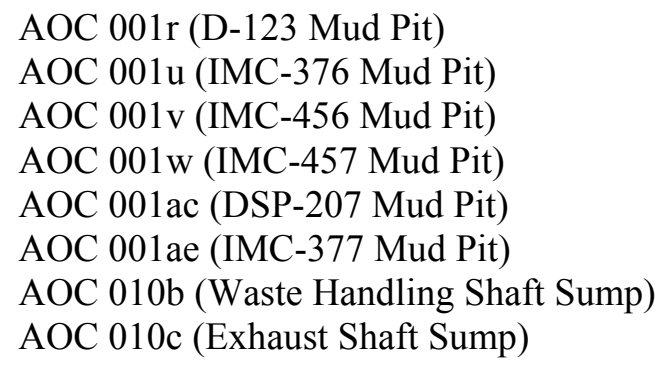

Some of the SWMUs and AOCs were identified in the original RCRA Part B Permit Application for the facility (Revision 0 , DOE/WIPP 91-005), and were included in a RCRA Facility Assessment (RFA) performed by 
NMED (NMED/DOE/AIP 94/1 1994). The 15 SWMUs and eight AOCs identified in the permit are associated with: natural resource exploration activities prior to the development of the WIPP, early WIPP mineral assessment and geological studies to support the development of the facility, or facility construction.

The SWMU program at WIPP began in 1994 under EPA regulatory authority. NMED subsequently received regulatory authority from EPA. A Phase 1 RFI was completed at WIPP during 1996 as part of a Voluntary Release Assessment.

Samples were collected at some of the SWMUs as part of an RFA performed by WTS Environmental Compliance (NMED/DOE/AIP 94/1 1994). WIPP conducted two rounds of soil sampling at selected SWMUs in 1995 and 1996. In the summer of 1995, soil samples were collected for initial characterization by the toxicity characteristic leaching procedure (TCLP). A second round of sampling at the same SWMUs was conducted in the summer of 1996 and involved collecting soil samples for total constituent analyses.

The total constituent analysis data were collected based on a request from NMED to support the TCLP data collected in the initial sampling round. NMED reviewed the sampling conducted by WIPP at the SWMUs and defined a list of SWMUs with constituents of concern and AOCs to be included in the permit. These SWMUs/AOCs and constituents of concern for the SWMUs were described in the Technical Support Document, Exclusion/Inclusion of Solid Waste Management Units and Areas of Concern, Permit Module VII Correction Action for Solid Waste Management Units (NMED 1999).

\section{Program Deliverables and Schedule}

As required by Module VII, Table 1 $\mathrm{RFI} / \mathrm{CMS}$ Schedule of Compliance, WIPP is in compliance with the Permit reporting requirements. The key Permit deliverables and their dates of submittal as contained in Module VII, Table 1 include: (1) A Notice to inform the individuals on the WIPP mailing list, maintained by the Secretary of NMED, that the U.S.

Department of Energy had established three repositories for information associated with corrective action activities at WIPP (December 1999), and (2) Submittal of a Facility Work Plan on February 24, 2000. Annual reviews and updates to the Facility Work Plan will be completed. The third Permit date is for the Sampling and Analysis Plan (SAP), in lieu of an RFI Work Plan, which was submitted to NMED on May 24, 2000 (Table 3.2).

The SAP addresses the current permit requirements for an RFI of SWMUs and AOCs. It uses the results of previous investigations performed at WIPP and expands the investigations as required by the permit. As an alternative to the RFI specified in Module VII of the permit, current NMED guidance identifies an Accelerated Corrective Action Approach (ACAA) that may be used for any SWMU or AOC (NMED 1998). This ACAA is used to replace the standard RFI Work Plan and Report sequence with a more flexible decision-making approach. The ACAA process allows a facility to proceed on an accelerated time line. The ACAA process can be entered either before or after a RFI Work Plan. According to NMED's guidance, a facility can prepare an RFI Work Plan or ACAA for any SWMU or AOC (NMED 1998).

The SAP has two primary objectives: to define the extent of concentrations of hazardous constituents that exceed background concentrations in soil at specific SWMUs, and to perform a release assessment at specific AOCs to determine if hazardous constituents are present above background concentrations. The scope of this investigation is limited to the SWMUs and AOCs identified in the permit.

\subsubsection{National Environmental Policy Act}

The National Environmental Policy Act (NEPA) requires the federal government to use all practicable means to consider potential 
environmental impacts of proposed projects as part of the decision-making process. NEPA dictates the public shall be allowed to review and comment on proposed projects that have the potential to significantly affect the environment. NEPA also directs the federal government to use all practicable means to improve and coordinate federal plans, functions, programs, and resources relating to human health and the environment.

NEPA procedural objectives and public involvement requirements are detailed in the Council on Environmental Quality regulations implementing NEPA in 40 CFR $\S \S 1500-1508$. DOE codified its requirements for implementing the council's regulations in $10 \mathrm{CFR} \S 1021$. Further procedural NEPA compliance guidance is provided in DOE Order 451.1B. Title 10 CFR $\S 1021.331$ requires that, following completion of each Environmental Impact Statement (EIS) and its associated Record of Decision (ROD), DOE shall prepare a mitigation action plan that addresses mitigation commitments expressed in the ROD.
Further, DOE Order 451.1B requires DOE facilities to track and annually report progress in implementing a commitment for environmental impact mitigation that is essential to render the impacts of a proposed action not significant or that is made in a ROD. The 2000Annual Mitigation Report for the Waste Isolation Pilot Plant (NEPA ID\# WIP:00:001), reporting progress on commitments made during WIPP's EIS process, was issued June 20, 2000.

On December 19, 2000, DOE released two NEPA documents in support of their decision to conduct waste confirmation activities at WIPP. These were the Supplement Analysis and Determination for the Proposed Characterization for Disposal of Contacthandled Transuranic Waste at the Waste Isolation Pilot Plant (DOE/EIS-0200-SA01) and the Revision to the Record of Decision for the Department of Energy's Waste Management Program: Treatment and Storage of Transuranic Waste (65 FR 82985).

Table 3.2 WIPP's key RCRA ${ }^{a}$ permit deliverables and due dates.

\section{Due Date}

Deliverable(s)
December 8, 1999

February 24, 2000

May 24, 2000
A notice to inform individuals on the WIPP mailing list maintained by the Secretary of the New Mexico Environmental Department that the U.S. Department of Energy has established three repositories for information associated with corrective action activities at WIPP. Completed.

Facility Work Plan. Annual reviews and updates to the Facility Work Plan will be completed as necessary.

RCRA Facility Investigation Work Plan or Accelerated Corrective Action Approach for SWMU's.

${ }^{a}$ Resource Conservation and Recovery Act

\subsubsection{Clean Air Act}

The Clean Air Act (42 U.S.C. $§ 7401$ et seq.) provides for the preservation, protection, and enhancement of air quality, particularly at locations of special interest such as areas of natural, recreational, scenic, or historic value.
Under section 109 of the Clean Air Act, the EPA established the National Ambient Air Quality Standards for six "criteria" pollutants: sulfur dioxide, total suspended particulates, carbon monoxide, ozone, nitrogen oxides, and lead. These standards establish primary and secondary criteria for ambient air quality that the 
EPA considers necessary to protect public health and welfare.

The initial WIPP air emissions inventory was developed as a baseline document to calculate maximum potential hourly and annual emissions of both hazardous and criteria pollutants. An air emissions inventory is conducted biennially and compared to the baseline data to identify trends and potential emissions problems. The biennial inventory scheduled for CY 1998 was postponed because conditions at the site were unchanged from the previous inventory. The next inventory, for CY 1999, was conducted in 2000. Emission estimates are used to determine if WIPP is required to obtain an air permit as specified in the following regulations:

- Clean Air Act, § 112, National Emissions Standards for Hazardous Air Pollutants (NESHAP)

- Clean Air Act, Part C Prevention of Significant Deterioration-Criteria Pollutants

- New Mexico Administrative Code Title 20, Chapter 2, Air Quality

Based on the current air emissions inventory, WIPP operations do not exceed the 10-ton-per-year emission limit for any individual Hazardous Air Pollutant (HAP) or the 25-ton-per-year limit for any combination of HAPs emissions established in Subpart A of NESHAP.

Based on the air emissions inventory, the WIPP site is not required to obtain federal Clean Air Act permits. WIPP, in consultation with the NMED Air Quality Bureau, working in concert with data provided in the first air emissions inventory, was required to obtain a New Mexico Air Quality Control Regulation 702, Operating Permit (recodified in 1997 as Title 20, Chapter 2, Part 72, Construction Permits) for two primary backup diesel generators at the site. The only emission points where the WIPP site exceeds state threshold criteria are the backup diesel generators. WIPP completed all necessary requirements for emissions monitoring and sampling required by New Mexico Air Quality Permit 310-M-2. During 2000, the backup diesel generators were operated for approximately 34 of the 480 hours allowed by the permit. There were no malfunctions or abnormal conditions of operation that would cause a violation of the permit.

WIPP's normal operations do not involve or entail any planned or expected releases of airborne radioactive materials to the workplace or the environment. Waste containers accepted for disposal at WIPP are required to meet the 10 CFR $\S 835$ external contamination limits. To ensure compliance, the containers are surveyed both prior to release from the generator sites and as the Transuranic Package Transporter Model (TRUPACT-II) containers are opened at WIPP.

Since radioactive material remains in the waste containers, there are no emissions of radionuclides to the ambient air from DOE facilities during normal WIPP waste handling, and the public is not subjected to radioactivity from the WIPP facility. Since no radioactivity above background was released from the WIPP facility during 2000, it may be concluded that WIPP was operated in compliance with the release standards of 40 CFR $\S 191$, Subpart A, and 40 CFR $\S 61$, Subpart H.

The 1995 Safety Analysis Report (DOE/WIPP 95-2065) originally established the adequacy of the WIPP safety bases regarding plant response to conditions considered to be "extremely unlikely." External doses to workers from the handling of contact-handled waste containers were estimated to be well within DOE's "as low as reasonably achievable" goals and well below regulatory limits. Similarly, consequences to the public and workers as a result of the release of VOCs during disposal phase normal operations were shown to be many orders of magnitude below health-based limits. The Safety Analysis Report is updated each year with no change to these conclusions. 


\subsubsection{Clean Water Act}

Section 402 of the Clean Water Act (33 U.S.C. §§ 1251-1376) establishes provisions for the issuance of permits for discharges into waters of the United States. Regulations promulgated to define this permitting process are contained in 40 CFR $\S 122$, subpart A, Section (b)(1), and state that ". . . National Pollutant Discharge Elimination System (NPDES) program requires permits for the discharge of 'pollutants' from any 'point source' into waters of the United States."

In August 1997, WIPP submitted to the EPA a Notice of Intent (NOI) for Storm Water Discharges Associated with Industrial Activity under a NPDES Multi-Sector General Permit. Permit NMR00A021 was issued February 23, 1998. This permit expired on October 30, 2000, and a NOI will be submitted to EPA on or before January 29, 2001, for coverage under NPDES Storm Water Multi-Sector General Permit for Industrial Activities that was reissued on October 30, 2000.

As a condition of the multi-sector general permit, a pollution prevention plan has been developed and implemented. The plan describes how the Best Management Practices and other requirements of the NPDES storm water regulations are being implemented at WIPP.

No sampling is required to demonstrate compliance with the WIPP Storm Water Permit unless a release occurs. Operational permit compliance activities are limited to quarterly inspections of retention basins, spill containment devices, reclamation sites, and site housekeeping practices.

The NPDES sewage sludge regulations promulgated in 40 CFR $\S 122.21$ require all facilities that generate or dispose of sewage sludge to submit an information package describing sewage sludge management and disposal practices. This information is reviewed by the EPA to determine if a NPDES permit will be required for the disposal of sewage sludge at a facility.
On February 14, 1994, DOE submitted an information package to the EPA Water Management Division and requested a written determination of whether a NPDES permit would be required for sewage sludge generated at WIPP. On March 31, 1994, the EPA Region VI Permits Issuance Section notified DOE that they had received the information package. The agency determined that the information package was complete and, at a future date, would notify DOE if a full and complete sewage sludge permit application would be required. To date this notification has not been made, indicating an application is not yet required.

On January 16, 1992, NMED issued the Sewage System Discharge Plan (DP-831) for the WIPP sewage facility. In addition to sewage effluent, DP-831 allows for the disposal of a maximum of 5,680 L (1,500 gal) per day of nonhazardous brines from pumping of observation wells at the site. Observation well brine waters are collected in portable tanks and transported to the north sewage system evaporation basin. Characterization samples were collected to appropriately disposition brines. On August 28, 1995, WTS submitted a request to NMED Ground Water Protection and Remediation Bureau requesting a minor amendment to DP-831, increasing the amount of nonhazardous brine for disposal to 7,570 L (2,000 gal) per day. On October 4, 1995, NMED approved the amendment to DP-831.

In December 1996, an application for renewal of DP-831 was submitted to NMED. The application requested the renewal of the existing permit conditions and the addition of the H-19 evaporation pond. This pond was constructed by Sandia National Laboratories for use during the Culebra Transport Test Program. The discharge plan renewal and modification was approved by NMED on July 3, 1997. The permit approved the discharge of up to $30,300 \mathrm{~L}$ $(8,000 \mathrm{gal})$ per day to the $\mathrm{H}-19$ evaporation pond. DOE submits quarterly discharge monitoring reports to NMED to demonstrate compliance with the inspection, monitoring, and reporting requirements identified in the plan. 
Water quality analysis as specified by DP-831 was modified with the issuance of the July 3, 1997, permit. The permit requires quarterly sampling and analysis of the sewage system influent for nitrate, total Kjeldahl nitrogen, total dissolved solids (TDS), ${ }^{238} \mathrm{Pu}$, ${ }^{239+240} \mathrm{Pu},{ }^{241} \mathrm{Am},{ }^{234} \mathrm{U},{ }^{235} \mathrm{U},{ }^{238} \mathrm{U}$, and ${ }^{90} \mathrm{Sr}$. On January 24, 2000, NMED approved a request for the discharge to the sewage system of up to 100 gallons of neutralized laboratory acid waste.

\subsubsection{Safe Drinking Water Act}

The Safe Drinking Water Act (SDWA) (42 U.S.C. $\S 300 f$, et seq.) of 1974 provides the regulatory strategy for protecting public water supply systems and underground sources of drinking water. NMED notified WIPP in a September 9, 1992, letter that the WIPP public water supply was categorized as a nontransient, noncommunity system for reporting and testing requirements.

New Mexico water supply regulations mandate that when a public water supply system supplements other systems, that water system is treated as a single system for compliance sampling purposes. The Carlsbad municipal water supply system is contracted to provide raw water to WIPP from city-owned wells $50 \mathrm{~km}$ (31 mi) north of the site. Because of this contractual agreement, the city of Carlsbad completes the source, or point-of-entry, samples for the various chemical constituents at each well field source.

In a letter dated August 28, 1996, NMED set the frequency for sampling lead and copper in the drinking water supply at ten samples every three years. The required samples were collected in July 1999 and the results were submitted to NMED. All samples were below action levels as specified by New Mexico monitoring requirements for lead and copper in tap water. The next lead and copper sampling period will be in July, 2002.

Bacterial samples were collected and reported monthly throughout 2000 . All bacteriological/analytical results were below the SDWA regulatory limits.

\subsubsection{National Historic Preservation Act}

The National Historic Preservation Act (NHPA) (16 U.S.C. $\S 470$ et seq.) was enacted to protect the nation's cultural resources and establish the National Register of Historic Places. Federal agencies are required to coordinate NEPA compliance with the responsibilities of the NHPA to ensure that historic and cultural properties are given proper consideration in the preparation of NEPA documentation. Agency obligations under the NHPA, however, are independent from NEPA and must be complied with even when no additional NEPA documentation is required (i.e., for proposed projects not classified as major federal actions with significant environmental impacts, DOE must still consider impacts to historic properties and sites). Where both NEPA and the NHPA are applicable, environmental assessments (EAs) and EISs must integrate NHPA considerations along with other environmental impact analyses and studies (see 40 CFR $\S 1502.25$ ).

During 2000, one archaeological investigation was conducted to assess cultural resources in an area proposed for a new monitoring well. No artifacts were encountered.

\subsubsection{Hazardous Materials Transportation Act}

The Hazardous Materials Transportation Act (49 App. U.S.C. § 1801 et seq.; 49 CFR $\S \S 106-179)$ is one of the major transportation-related statutes that affects DOE at WIPP. It provides for safe transportation of hazardous materials, including radioactive materials. DOE complies with applicable U.S. Department of Transportation (DOT) regulations and corresponding Nuclear Regulatory Commission (NRC) regulations. DOE orders reference these regulations. DOE Orders also require the development of a transportation plan and use of DOE TRANSCOM (transportation tracking and 
communications) system to monitor shipments. Additional requirements are included for shipment inspections, notifications, dates, and special instructions.

The primary federal transportation regulations applicable to WIPP include:

- Title 10 CFR $\S 71$, NRC requirements for packaging, preparing, and transporting licensed material, and

- Title 49 CFR $\S 397$, Subpart D, requirements for routing of radioactive materials.

The WTS Shipping Coordination Section implements applicable DOT and EPA regulations and DOE orders for the transport of hazardous waste and hazardous materials from WIPP. Shipping sites implement applicable DOT and EPA regulations and DOE orders for the transport of TRU waste to WIPP.

\subsubsection{Packaging and Transporting Radioactive Materials}

Regulations for transportation of radioactive materials, under the authority of the DOT, are found in 49 CFR $\S \S 171$ through 178. If the quantity of radioactive material exceeds certain limits, as determined by 49 CFR $\S 173.431$, a Type B shipping container (packaging) must be used. The specific requirements for the shipment of radioactive materials and requirements applicable to the Type B packages to be used to transport waste to the WIPP facility are detailed in 49 CFR 172-173, 40 CFR 262, and the NRC Certificate of Compliance for the package. Regulations for Type B packaging, under the authority of the NRC, are found in 10 CFR $\S 71$, Packaging and Transportation of Radioactive Materials. The WIPP Land Withdrawal Act requires that TRU waste containers shipped to WIPP shall be transported using packages which have had the design certified by the NRC and which have been determined by the NRC to satisfy its QA requirements.
Additional transportation requirements for the mixed waste shipments (i.e., TRU mixed wastes) are detailed in 40 CFR $\S 262$. The appendix to $\S 262$ provides an example of a uniform hazardous waste manifest and instructions to waste generators and shippers of hazardous wastes.

Contact-handled TRU waste is shipped in the TRUPACT-II and the HalfPACT. The HalfPACT is a shorter version of the TRUPACT-II; it was designed to transport heavier contact-handled TRU waste containers. The NRC certified the TRUPACT-II container on August 30, 1989. Since 1989, expansion of the TRUPACT-II payload envelope has been accomplished through applications to the NRC for revisions of the TRUPACT-II Safety Analysis Report for Packaging (SARP) and the Certificate of Compliance (C of C), when applicable. The NRC certified the HalfPACT container on November 2, 2000. The current revision of the TRUPACT-II C of C, No. 11, expires June 30, 2004. The current revision of he HalfPACT C of C, No. 9279, expires October 31, 2005. Containers for remotehandled waste are currently in the certification process.

\subsection{Other Significant Accomplishments and Ongoing Compliance Activities}

\subsubsection{Environmental Compliance Assessment Program}

The Environmental Compliance Assessment Program plays a major role in the overall program for environmental protection activities at WIPP. The program was developed to determine if impactive or potentially impactive facility activities protect human health and the environment and if these activities are in compliance with applicable federal, state, and local requirements; with permit conditions and requirements; and with best management practices.

During 2000, WTS conducted environmental compliance assessments in the following subject areas: Volatile Organic 
Compound Monitoring Program, Groundwater and Detection Monitoring Programs, Radiation Laboratory Requirements, Waste Characterization and Waste Minimization Programs, and Department of Energy Laboratory Accreditation Program Requirements. Improvements in these areas were identified and implemented.

\subsubsection{ISO 14000 - Standards for Environmental Management}

ISO 14001 is the specific section of the ISO 14000 standard devoted to Environment Management Systems (EMS). Integration of WIPP's ISO 14001 program with other Westinghouse and DOE programs, such as the Voluntary Protection Program (VPP) and Integrated Safety Management System (ISMS), are underway. The WTS continues to support the ISO 14001 lessons learned programs and shares EMS implementation documentation with both the DOE complex and the private sector.

The WTS Environmental Management System (EMS) received third-party registration on August 5, 1997. Two third-party registration surveillance audits were conducted in 2000 . No nonconformance or findings were identified during either of the 2000 registration surveillance audits. The WTS registrar for Advanced Waste Management recommended continued registration of the WTS EMS.

The EMS Implementation Document (WP 02-EC.0) was developed to define the roles of WTS departments and subcontractors to implement the EMS and update the WTS Environmental Management Policy. WP- 02-EC.0 applies to all WTS operations and designated WTS subcontractors at the WIPP site.

The WTS Environmental Aspects and Impacts table in WP 02-EC.0 identifies activities at WIPP that have the potential to have a significant impact on the environment. The Environmental Objectives and Targets table identifies environmental objectives and targets designed to mitigate potential environmental impacts and identifies the dates and organization responsible for implementing each of the significant objectives.

The goals for this activity are to ensure a system of continuous environmental improvements to more clearly define each organization's roles and responsibilities for implementing the EMS, and to promote pollution prevention at WIPP. Additionally, EMS training has been provided to the entire WTS and WTS subcontractor workforce and EMS training modules have now been integrated into sitewide training programs.

Several actions have been taken to more effectively implement the ISO 14001 Standards at the site. WTS formed an ISO 14001 Integration Team that includes members from a majority of WTS and subcontractor organizations. Each member is tasked with providing their department's environmental objectives and targets leading to overall improvement under WIPP's EMS.

Articles on ISO 14001 requirements are published periodically in the WIPP Today and TRU News. The Environmental Compliance Section of the WTS Environment, Safety, and Health Department is responsible for coordinating the annual sitewide review of the EMS Implementation Document, the Environmental Policy, and the Aspects and Impacts and Objectives and Targets tables to ensure that the EMS remains effective.

\subsubsection{Pollution Prevention Committee}

The Pollution Prevention (P2) Committee was formed in 1993 with a representative from each department. The primary purpose of this committee is to foster recycling activities at WIPP. The committee prepared a waste minimization charter, which outlines the committee's responsibilities.

On Earth Day, 2000, the committee conducted activities to heighten employee awareness of the dangers of household chemicals. Information was also provided to 
WIPP employees on non-hazardous substitutions for hazardous household cleaning products.

Activities for the 2000 America Recycles day celebration included a clothing drive to support the Welfare-To-Work clothing drive. Five-hundred thirty-five pieces of clothing, 65 pairs of shoes and 30 miscellaneous items (purses, hats, belts, and ties) were collected. The P2 committee also handed out pledge cards in support of the state of New Mexico and National America Recycles day celebration. WIPP collected the second largest amount of pledge cards within the state.
During October 2000, Energy Month was celebrated with posters being hung around site emphasizing the importance of saving energy.

\subsubsection{Environmental Training}

Environmental training was provided to personnel associated with environmental operations at WIPP. Training courses included technical topics (e.g., RCRA sampling), EMS, basic environmental safety and health training, and general sitewide training such as the required General Employee Training module. These courses were conducted both on-site by WIPP personnel and off-site by various contractors. 
Table 3.3 Activities associated with major environmental regulations applicable to the WIPP project.

\section{Statute/Regulation}

Atomic Energy Act of 1954 and 40 CFR 191, Subpart A.

\section{Clean Air Act}

Clean Water Act

Comprehensive Environmental Response, Compensation, and Liability Act/SARA

Endangered Species Act of 1973

Federal Land Policy and Management Act

Federal Insecticide, Fungicide, and Rodenticide Act

Hazardous Materials Transportation Act

National Environmental Policy Act (as supplemented by DOE Order 451.1B, and 10 CFR § 1021)

\section{Related Activity}

WIPP was authorized by DOE and EPA to open. Monitoring/reporting began upon first receipt of waste, March 26, 1999.

Monitoring/reporting began upon first receipt of waste, March 26, 1999.

Quarterly inspections of best management practices to comply with (storm water retention basins) NPDES storm water general permit (NMR00A021).

No Land Disposal Units exist at the site. No CERCLA site cleanup required. Reports filed as required under SARA for hazardous substances are maintained on site.

In November 1996, WIPP completed the 1996 Threatened and Endangered Species Survey. The survey is part of the analysis required for the SEIS-II. There were no threatened or endangered species located on WIPP land. Individual permits to collect biological samples and to band nonendangered species of raptors are maintained. Consultation with federal and state agencies is not required.

An MOU between DOE and the BLM was issued in July 1994. This MOU outlines the responsibilities the BLM and DOE have with regard to land use management for the withdrawal area.

All pesticides must be approved by Industrial Safety and Hygiene.

Appropriate shipping papers accompany hazardous materials and hazardous wastes shipped off-site to ensure compliance with the act.

The 2000 Annual Mitigation Report for the Waste Isolation Pilot Plant (NEPA ID\# WIP:00:001) was issued June 20, 2000, in accordance with the requirement of DOE Order 451.1B, National Environmental Policy Act Compliance Program. This order requires DOE facilities to track and annually report progress in implementing a commitment for environmental impact mitigation that is essential to render the impacts of a proposed action nonsignificant or that is made in the ROD. 
Table 3.3, cont

\section{Statute/Regulation}

National Historic Preservation Act

New Mexico Air Quality Control Act

New Mexico Water Quality Act

New Mexico Wildlife Conservation Act

Resource Conservation and Recovery Act

Toxic Substances Control Act

Safe Drinking Water Act

\section{Status}

The Supplement Analysis and Determination for the Proposed Characterization for Disposal of Contact-handled Transuranic Waste at the Waste Isolation Pilot Plant (DOE/EIS-0200-SA01) was issued on December 19, 2000 to support DOE's decision to conduct waste confirmation activities at WIPP.

The Revision to the Record of Decision for the Department of Energy's Waste Management Program: Treatment and Storage of Transuranic Waste (65 FR 82985) was issued on December 19, 2000 to support DOE's decision to conduct waste confirmation activities at WIPP.

Activities requiring excavation in previously undisturbed areas are surveyed by licensed, permitted archaeologists. Required reports are submitted to the New Mexico State Historic Preservation Officer.

During 2000, the backup diesel generators were operated for approximately 34 of the 480 hours allowed by the permit. There were no malfunctions or abnormal conditions of operation that would cause a violation of the permit.

NMED has issued a ground water discharge plan (DP-831) to WIPP for the disposal of site generated wastewater. DOE submits quarterly discharge monitoring reports to the NMED Groundwater Quality Bureau to comply with the requirements of DP-831.

See "Endangered Species Act."

Hazardous-waste generator compliance: All site generated hazardous wastes were transported offsite within the 90-day accumulation period. Permit compliance: NMED granted RCRA permit NM4890139088 effective November 26, 1999. Underground Storage Tanks: Annual registration fee paid.

Procurement of asbestos-/PCB-containing materials not allowed. Other portions of the Toxic Substances Control Act are not applicable.

The WIPP public water system is characterized as a nontransient, noncommunity system (NMED, September 9, 1992). Drinking water is piped from the Carlsbad, NM, municipal system and the city of Carlsbad is responsible for compliance. 
Table 3.4 Primary DOE orders affecting the WIPP environmental program.

\section{Order No.}

DOE 5400.1 Paragraphs 2B, 4B, and $4 \mathrm{C}$ of Chapter II, and $2 \mathrm{D}$ and $3 \mathrm{~B}$ of Chapter III were canceled and replaced by DOE O 231.1

DOE 5400.5 Paragraph 1A(3)(A) of Chapter II is canceled by DOE O 231.1

DOE O 231.1, Change 2

DOE 0 225.1A, cancels DOE O 225.1

DOE O 414.1A

DOE O 435.1

DOE O 451.1A

DOE O 460.1A

\section{Title}

General Environmental

Protection Program

Radiation Protection of the Public and the Environment

Environmental, Safety, and Health Reporting

Accident Investigation

Quality Assurance

Radioactive Waste Management

National Environmental Policy Act Compliance Program

Packaging and Transportation Safety

\section{Annotation}

Establishes environmental protection program requirements, authorities, and responsibilities for DOE operations for ensuring compliance with federal and state environmental protection laws and regulations, federal executive orders, and internal department policies.

Establishes standards and requirements for operations of DOE and DOE contractors with respect to protection of the public and the environment against undue risk from radiation.

Ensures collecting and reporting on environment, safety, and health information.

Prescribes requirements for conducting investigations of accidents and preventing recurrence of such accidents.

Promotes effective management through performance requirements and technical standards.

Promotes radioactive waste management in a manner that is protective of workers, public health and safety, and the environment.

Establishes DOE policy for implementation of the National Environmental Policy Act of 1969 (P.L. 91-190)

Establishes safety requirements for the proper packaging and transporting of DOE offsite shipments and onsite transfers of hazardous materials and for model transportation. 
Table 3.4, cont.

\begin{tabular}{lll}
\hline \multicolumn{1}{c}{ Order No. } & \multicolumn{1}{c}{ Title } & \multicolumn{1}{c}{ Annotation } \\
\hline DOE 5480.23 & $\begin{array}{l}\text { Nuclear Safety Analysis } \\
\text { Reports }\end{array}$ & $\begin{array}{l}\text { Establishes uniform requirements for the preparation and review of safety analyses of } \\
\text { DOE operations that include the following: identification of hazards, their elimination or } \\
\text { control, assessment of risk, and documented management authorization of their operation. }\end{array}$ \\
DOE O 151.1 & $\begin{array}{l}\text { Comprehensive Emergency } \\
\text { Management System }\end{array}$ & $\begin{array}{l}\text { Establishes requirements for comprehensive planning, preparedness, response, and } \\
\text { recovery activities of emergency management programs for DOE and for programs } \\
\text { requiring DOE assistance. }\end{array}$ \\
DOE O 430.1A & $\begin{array}{l}\text { Establishes procedures to plan, acquire, operate, maintain, and dispose of physical assets } \\
\text { as valuable national resources. }\end{array}$ \\
\hline
\end{tabular}


Table 3.5 Active environmental permits for the WIPP (does not include RCRA a permits).

\begin{tabular}{|c|c|c|c|c|c|c|c|c|}
\hline Granting Agency Age & Type of Permit & $\begin{array}{l}\text { Permit } \\
\text { Number }\end{array}$ & $\begin{array}{c}\text { Granted/ } \\
\text { Submitted }\end{array}$ & Expiration & $\begin{array}{c}\text { Current Permit } \\
\text { Status }\end{array}$ & WTS $^{\text {b }}$ Owner & $\begin{array}{l}\text { Signed By } \\
\text { Title/Date }\end{array}$ & $\begin{array}{l}\text { Signed } \\
\text { For }\end{array}$ \\
\hline $\begin{array}{l}\text { Department of the } \\
\text { Interior, Bureau of } \\
\text { Land Management }\end{array}$ & $\begin{array}{l}\text { Right-of-way for } \\
\text { water pipeline }\end{array}$ & NM53809 & $08 / 17 / 83$ & None & $\begin{array}{c}\text { Active } \\
\text { (in perpetuity) }\end{array}$ & Engineering & $\begin{array}{l}\text { Issued by } \text { BLM }^{c} \text { - } \\
\text { WIPP signature not } \\
\text { required } 08 / 17 / 83\end{array}$ & DOE-CBFO $^{\mathrm{d}}$ \\
\hline $\begin{array}{l}\text { Department of the } \\
\text { Interior, Bureau of } \\
\text { Land Management }\end{array}$ & $\begin{array}{l}\text { Right-of-way for the } \\
\text { north access road }\end{array}$ & NM55676 & $08 / 24 / 83$ & None & $\begin{array}{c}\text { Active } \\
\text { (in perpetuity) }\end{array}$ & $\begin{array}{l}\text { Facility } \\
\text { Operations }\end{array}$ & $\begin{array}{l}\text { Issued by BLM - } \\
\text { WIPP signature not } \\
\text { required } 08 / 24 / 83\end{array}$ & DOE-CBFO \\
\hline $\begin{array}{l}\text { Department of the } \\
\text { Interior, Bureau of } \\
\text { Land Management }\end{array}$ & $\begin{array}{l}\text { Right-of-way for } \\
\text { railroad }\end{array}$ & NM55699 & $09 / 27 / 83$ & None & $\begin{array}{c}\text { Active } \\
\text { (in perpetuity) }\end{array}$ & $\begin{array}{l}\text { Facility } \\
\text { Operations }\end{array}$ & $\begin{array}{l}\text { Issued by BLM - } \\
\text { WIPP signature not } \\
\text { required } 09 / 27 / 83\end{array}$ & DOE-CBFO \\
\hline $\begin{array}{l}\text { Department of the } \\
\text { Interior, Bureau of } \\
\text { Land Management }\end{array}$ & $\begin{array}{l}\text { Right-of-way for } \\
\text { dosimetry and aerosol } \\
\text { sampling sites }\end{array}$ & NM63136 & $07 / 31 / 86$ & $07 / 31 / 2011$ & Active & $\begin{array}{l}\text { Environmental } \\
\text { Monitoring }\end{array}$ & $\begin{array}{l}\text { Issued by BLM - } \\
\text { WIPP signature not } \\
\text { required } 07 / 31 / 86\end{array}$ & DOE-CBFO \\
\hline $\begin{array}{l}\text { Department of the } \\
\text { Interior, Bureau of } \\
\text { Land Management }\end{array}$ & $\begin{array}{l}\text { Right-of-way for } \\
\text { seven subsidence } \\
\text { monuments }\end{array}$ & NM65801 & $11 / 07 / 86$ & None & Active & $\begin{array}{l}\text { Mine } \\
\text { Engineering }\end{array}$ & $\begin{array}{l}\text { Issued by BLM - } \\
\text { WIPP signature not } \\
\text { required } 11 / 07 / 86\end{array}$ & DOE-CBFO \\
\hline $\begin{array}{l}\text { Department of the } \\
\text { Interior, Bureau of } \\
\text { Land Management }\end{array}$ & $\begin{array}{l}\text { Right-of-way for } \\
\text { aerosol sampling site }\end{array}$ & NM77921 & 08/18/89 & $08 / 18 / 2019$ & Active & $\begin{array}{l}\text { Environmental } \\
\text { Monitoring }\end{array}$ & $\begin{array}{l}\text { Issued by BLM - } \\
\text { WIPP signature not } \\
\text { required } 09 / 18 / 89\end{array}$ & DOE-CBFO \\
\hline
\end{tabular}


Table 3.5, cont

\begin{tabular}{|c|c|c|c|c|c|c|c|c|}
\hline Granting Agency & Type of Permit & $\begin{array}{l}\text { Permit } \\
\text { Number }\end{array}$ & $\begin{array}{l}\text { Granted/ } \\
\text { Submitted }\end{array}$ & Expiration & $\begin{array}{c}\text { Current Permit } \\
\text { Status }\end{array}$ & WTS Owner & $\begin{array}{l}\text { Signed By } \\
\text { Title/Date }\end{array}$ & $\begin{array}{l}\text { Signed } \\
\text { For }\end{array}$ \\
\hline $\begin{array}{l}\text { Department of the } \\
\text { Interior, Bureau of } \\
\text { Land Management }\end{array}$ & $\begin{array}{l}\text { Right-of-way for ten } \\
\text { raptor nesting } \\
\text { platforms }\end{array}$ & NM82212 & 09/12/89 & $12 / 13 / 2019$ & Active & $\begin{array}{l}\text { Environmental } \\
\text { Monitoring }\end{array}$ & $\begin{array}{l}\text { N/A } / A^{e} \text { Right- of- } \\
\text { way not germane. } \\
\text { Platforms within } \\
\text { WIPP boundary }\end{array}$ & DOE-CBFO \\
\hline $\begin{array}{l}\text { New Mexico } \\
\text { Commissioner of } \\
\text { Public Lands }\end{array}$ & $\begin{array}{l}\text { Right-of-way for high } \\
\text { volume air sampler }\end{array}$ & RW-22789 & $10 / 03 / 85$ & $10 / 03 / 2020$ & Active & $\begin{array}{l}\text { Environmental } \\
\text { Monitoring }\end{array}$ & $\begin{array}{l}\text { Permit - for use by } \\
\text { individual \& WIPP }\end{array}$ & $\begin{array}{l}\text { Personal } \\
\text { Permit }\end{array}$ \\
\hline $\begin{array}{l}\text { Department of the } \\
\text { Interior, Bureau of } \\
\text { Land Management }\end{array}$ & $\begin{array}{l}\text { Right-of-way for } \\
\text { survey monument } \\
\text { installation }\end{array}$ & NM82245 & $12 / 13 / 89$ & $12 / 13 / 2019$ & Active & $\begin{array}{l}\text { Mine } \\
\text { Engineering }\end{array}$ & $\begin{array}{l}\text { Issued by BLM - } \\
\text { WIPP signature not } \\
\text { required } 12 / 13 / 89\end{array}$ & DOE-CBFO \\
\hline $\begin{array}{l}\text { New Mexico } \\
\text { Environment } \\
\text { Department } \\
\text { Groundwater Bureau }\end{array}$ & Discharge permit & DP-831 & 07/03/97 & 07/03/2002 & Active & $\begin{array}{l}\text { EC\&S }{ }^{\mathrm{f}} \text { and } \\
\text { Facility } \\
\text { Operations }\end{array}$ & $\begin{array}{l}\text { G. E. Dials, } \\
\text { Manager } \\
12 / 16 / 1996\end{array}$ & DOE-CBFO \\
\hline $\begin{array}{l}\text { New Mexico } \\
\text { Environment } \\
\text { Department }\end{array}$ & $\begin{array}{l}\text { Operating permit for } \\
\text { two backup diesel } \\
\text { generators }\end{array}$ & $310-\mathrm{M}-2$ & $12 / 07 / 93$ & None & Active & $\begin{array}{l}\text { EC\&S and } \\
\text { Facility } \\
\text { Operations }\end{array}$ & $\begin{array}{l}\text { A. E. Hunt Project } \\
\text { Manager } \\
06 / 18 / 1993\end{array}$ & DOE-CBFO \\
\hline $\begin{array}{l}\text { New Mexico State } \\
\text { Engineer Office }\end{array}$ & $\begin{array}{l}\mathrm{H}-14 \text { and } \mathrm{H}-15 \text { test } \\
\text { wells }\end{array}$ & $\begin{array}{c}\text { NM1469 \& } \\
\text { NM1470 }\end{array}$ & $10 / 18 / 86$ & None & Active & $\begin{array}{l}\text { Environmental } \\
\text { Monitoring } \\
\left(\mathrm{SNL}^{\mathrm{g}} / \mathrm{DOE}\right)\end{array}$ & $\begin{array}{l}\text { J. W. Mercer, } \\
\text { SNL Engineering } \\
\text { Products Div. } 7133 \\
\sim 10 / 12 / 86^{\mathrm{h}}\end{array}$ & DOE-CBFO \\
\hline
\end{tabular}


Table 3.5, cont

\begin{tabular}{|c|c|c|c|c|c|c|c|c|}
\hline Granting Agency & Type of Permit & $\begin{array}{l}\text { Permit } \\
\text { Number }\end{array}$ & $\begin{array}{l}\text { Granted/ } \\
\text { Submitted }\end{array}$ & Expiration & $\begin{array}{c}\text { Current Permit } \\
\text { Status }\end{array}$ & WTS Owner & $\begin{array}{l}\text { Signed By } \\
\text { Title/Date }\end{array}$ & $\begin{array}{l}\text { Signed } \\
\text { For }\end{array}$ \\
\hline $\begin{array}{l}\text { New Mexico } \\
\text { Department of Game } \\
\text { and Fish }\end{array}$ & $\begin{array}{l}\text { Concurrence that } \\
\text { WIPP construction } \\
\text { activities will have no } \\
\text { significant impact on } \\
\text { state-listed threatened } \\
\text { or endangered species }\end{array}$ & $\begin{array}{c}\text { None } \\
07 / 25 / 83\end{array}$ & $05 / 26 / 89$ & None & Active & $\begin{array}{l}\text { Environmental } \\
\text { Monitoring }\end{array}$ & N/A & $\mathrm{N} / \mathrm{A}$ \\
\hline $\begin{array}{l}\text { Department of the } \\
\text { Interior, Fish and } \\
\text { Wildlife Service }\end{array}$ & $\begin{array}{l}\text { Concurrence that } \\
\text { WIPP construction } \\
\text { activities will have no } \\
\text { significant impact on } \\
\text { federally-listed } \\
\text { threatened or } \\
\text { endangered species }\end{array}$ & None & $05 / 29 / 80$ & None & Active & $\begin{array}{l}\text { Environmental } \\
\text { Monitoring }\end{array}$ & N/A & N/A \\
\hline $\begin{array}{l}\text { New Mexico State } \\
\text { Engineer Office }\end{array}$ & $\begin{array}{l}\text { Appropriation: } \\
\text { exhaust shaft } \\
\text { exploratory borehole }\end{array}$ & $\begin{array}{l}\text { C-2505 } \\
\text { C-2506 } \\
\text { C-2507 }\end{array}$ & $12 / 06 / 96$ & $12 / 31 / 2000^{i}$ & Active & $\begin{array}{l}\text { EC\&S and } \\
\text { Geotechnical } \\
\text { Engineering }\end{array}$ & $\begin{array}{l}\text { E. K. Hunter, Asst. } \\
\text { Manager ONTWO } \\
09 / 10 / 1997\end{array}$ & DOE-CBFO \\
\hline $\begin{array}{l}\text { New Mexico State } \\
\text { Engineer Office }\end{array}$ & $\begin{array}{l}\text { Appropriation: } \\
\text { WQSP-1 through 6a }\end{array}$ & $\begin{array}{l}\text { C-2413 } \\
\text { through } \\
\text { C-2419 }\end{array}$ & $10 / 21 / 96$ & None & Active & $\begin{array}{l}\text { EC\&S and } \\
\text { Environmental } \\
\text { Monitoring }\end{array}$ & $\begin{array}{l}\text { E. K. Hunter, Asst. } \\
\text { Manager ONTWO } \\
07 / 03 / 1996\end{array}$ & DOE-CBFO \\
\hline $\begin{array}{l}\text { New Mexico State } \\
\text { Engineer Office }\end{array}$ & $\begin{array}{l}\text { Declaration of owner } \\
\text { of underground water } \\
\text { rights }\end{array}$ & $\begin{array}{l}\mathrm{C}-2636 \\
\text { through } \\
\mathrm{C}-2639\end{array}$ & $01 / 12 / 99$ & None $\mathrm{e}^{\mathrm{j}}$ & Active & $\begin{array}{l}\text { EC\&S and } \\
\text { Environmental } \\
\text { Monitoring }\end{array}$ & G. T. Basabilvaso & DOE-CBFO \\
\hline $\begin{array}{l}\text { New Mexico } \\
\text { Environment } \\
\text { Department-UST } \\
\text { Bureau }\end{array}$ & $\begin{array}{l}\text { Registration of two } \\
\text { underground storage } \\
\text { tanks }\end{array}$ & $\begin{array}{l}\text { NM } 1198 \\
\text { (Number } \\
\text { changes } \\
\text { annually) }\end{array}$ & $07 / 01 / 00$ & $06 / 30 / 2001$ & Active & $\begin{array}{l}\text { EC\&S and } \\
\text { Facility } \\
\text { Operations }\end{array}$ & $\begin{array}{l}\text { V. Daub, Deputy } \\
\text { Project Site } \\
\text { Manager } \\
06 / 18 / 1992\end{array}$ & DOE-CBFO \\
\hline
\end{tabular}


Table 3.5, cont

\begin{tabular}{|c|c|c|c|c|c|c|c|c|}
\hline Granting Agency & Type of Permit & $\begin{array}{l}\text { Permit } \\
\text { Number }\end{array}$ & $\begin{array}{l}\text { Granted/ } \\
\text { Submitted }\end{array}$ & Expiration & $\begin{array}{c}\text { Current Permit } \\
\text { Status }\end{array}$ & WTS Owner & $\begin{array}{l}\text { Signed By } \\
\text { Title/Date }\end{array}$ & $\begin{array}{l}\text { Signed } \\
\text { For }\end{array}$ \\
\hline $\begin{array}{l}\text { New Mexico } \\
\text { Environment } \\
\text { Department, Solid } \\
\text { Waste Bureau }\end{array}$ & $\begin{array}{l}\text { Solid waste hauler } \\
\text { registration }\end{array}$ & 006655 & $12 / 01 / 99$ & None & Active & $\begin{array}{l}\text { N/A-Issued to } \\
\text { Cast Trucking }\end{array}$ & N/A & $\mathrm{N} / \mathrm{A}$ \\
\hline $\begin{array}{l}\text { U.S. Environmental } \\
\text { Protection Agency }\end{array}$ & $\begin{array}{l}\text { NPDES Storm water } \\
\text { multi-sector general } \\
\text { permit for use in the } \\
\text { state of New Mexico }\end{array}$ & NMR05A225 & $02 / 23 / 98$ & $\begin{array}{l}10 / 31 / 00 \\
\text { NOI for new } \\
\text { permit by } \\
01 / 29 / 2001\end{array}$ & Active & $\mathrm{EC} \& S$ & $\begin{array}{l}\text { G. E. Dials, } \\
\text { Manager, } \\
\text { DOE-CBFO }\end{array}$ & DOE-CBFO \\
\hline $\begin{array}{l}{ }^{\mathrm{a}} \mathrm{RCRA} \text { - Resource Con } \\
{ }^{\mathrm{b}} \mathrm{WTS} \text { - Westinghouse } \\
{ }^{\mathrm{c}} \mathrm{BLM} \text { - Bureau of Land } \\
{ }^{\mathrm{d} D O E} \text { - CBFO - U.S. D } \\
{ }^{\mathrm{e}} \mathrm{N} / \mathrm{A} \text { - Not Applicable }\end{array}$ & $\begin{array}{l}\text { ation and Recovery Act } \\
\text { Solutions, LLC } \\
\text { hagement } \\
\text { ment of Energy, Carlsbad }\end{array}$ & ield Office & \multicolumn{6}{|c|}{ 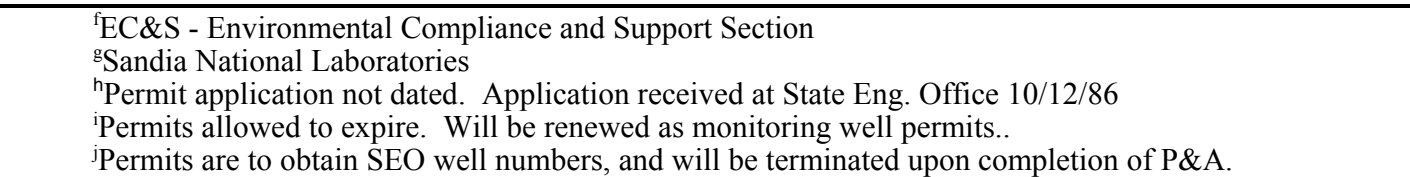 } \\
\hline
\end{tabular}




\section{Chapter 4 \\ Environmental Radiological Program Information}

Radionuclides present in the environment, whether naturally-occurring or human-made, contribute to radiation doses to humans. Therefore, environmental monitoring around nuclear facilities is imperative to characterize radiological conditions, detect releases, and determine their effects, should they occur. Because of this, DOE requires an environmental monitoring program for nuclear facilities (DOE Order 5400.1).

The WIPP Environmental Monitoring Program monitors air, surface and groundwater, soils, and biota to characterize the radiation environment and to detect potential releases from WIPP activities. This program is carried in accordance with the Waste Isolation Pilot Plant Environmental Monitoring Plan (DOE/WIPP 99-2194). This chapter summarizes the results of radiological monitoring during CY 2000.

The radiological environment near WIPP includes natural radioactivity, global fallout, and, potentially, radioactive contamination from the GNOME shot, a 1961 underground nuclear explosion about $20 \mathrm{~km}$ (13 mi) southwest of the WIPP site which accidentally vented to the atmosphere. Therefore, most environmental samples are expected to contain small amounts of natural radioactivity and fission products.

Throughout this chapter, radionuclides were considered "detected" in a sample if the measured concentration or activity exceeded the minimum detectable concentration (MDC) or activity (MDA). The MDC was determined by the different analytical laboratories based on the natural background radiation, the analytical technique, and inherent characteristics of the analytical equipment. The MDC represents the minimum concentration of a radionuclide detectable in a given sample using the given equipment and techniques.
Total propagated uncertainty (TPU) is an estimate of the uncertainty in the measurement due to all sources, including counting error, measurement error, chemical recovery error, detector efficiency, and any other sources of uncertainty. If measured radionuclide concentrations were less than twice the value of the TPU $(2 \times$ TPU $)$, they were also considered non-detects.

Comparisons of radionuclide concentrations were made between years and locations using the statistical procedure, Analysis of Variance (ANOVA). When this, or another statistical test, was used, the value of $p$, the probability of obtaining the value of the test statistic by chance alone, was reported. In many cases, scientists have accepted a value of $p<0.05$ as indicative of a difference between samples. However, interpretation of $p$ requires some judgement on the part of the reader; individual readers may choose to defend higher or lower values of $p$ as their cutoff value. For this report, $\mathrm{p}<0.05$ was used.

\subsection{Effluent Monitoring}

If radionuclides are released into the environment from WIPP, they would first be detected in airborne effluents. Thus, WIPP monitors airborne effluents from the underground at three locations, effluent monitoring Stations A, B, and C. Station A samples the unfiltered underground exhaust air. Station B samples the underground exhaust air after HEPA filtration and, sometimes, non-filtered air during maintenance. Station C samples the air from the Waste Handling Building after HEPA filtration. Each station is a fixed air sampler, collecting particulates from the effluent air stream on a Versapore filter.

During 2000, 354 samples were collected from Station A for a total air volume sampled of $16,930 \mathrm{~m}^{3}\left(597,806 \mathrm{ft}^{3}\right)$. Because only a small 
fraction of the air released through Station A is sampled, the activity on the filter is normalized to the total air flow through Station A using an EPA approved methodology. Forty-five samples were collected from Station B for a total air volume sampled of $25,185 \mathrm{~m}^{3}\left(889,311 \mathrm{ft}^{3}\right)$, and 50 samples were collected from Station $\mathrm{C}$ for a total air volume sampled of $8,903 \mathrm{~m}^{3}$ $\left(314,376 \mathrm{ft}^{3}\right)$. Samples were composited each quarter, in most cases. Because of the large number of samples from Station A during the second and third quarters, these samples were composited monthly. Samples were analyzed radiochemically for ${ }^{241} \mathrm{Am},{ }^{238} \mathrm{Pu}$, and ${ }^{239+240} \mathrm{Pu}$, the components of the contact handled waste at WIPP expected to produce 98 percent of the potential dose to humans.

Concentrations were less than the MDA at all stations in all time periods, except for ${ }^{239+240} \mathrm{Pu}$ on Station A during May and ${ }^{239+240} \mathrm{Pu}$ on Station B during the second quarter (Table 4.1). In both of these cases, measured values were less than $2 \times \mathrm{TPU}$, indicating the samples did not likely contain detectable ${ }^{239+240} \mathrm{Pu}$.

There was no significant difference in the concentration of any radionuclide at Stations B and C between the years 1999 and 2000. Because of the different composition periods, it was not possible to compare results from Station A across years.

Results from Stations A, B, and C were used as input for the dose assessment presented in Chapter 7.

Additional sampling was routinely performed in the underground using fixed air samplers and continuous air monitors. Evaluation of the samples from both indicate there were no detectable releases above background activity from the WIPP facility.

\subsection{Airborne Gross Alpha/Beta}

Gross alpha and beta measurements in airborne particulates are used as a screening technique to provide timely information on levels of radioactivity in the environment around the WIPP site. Airborne particulate samples were collected from seven different locations around WIPP: Southeast Control (SEC), Carlsbad (CBD), J.C. Mills Ranch (MLR), Smith Ranch (SMR), WIPP East (WEE), WIPP South (WSS), and WIPP Far Field (WFF) (Figure 4.1). Because SEC is approximately 20 miles upwind (see Chapter 5) of the WIPP site, it is not considered to have been contaminated by WIPP activities.

Each week at each station, approximately $600 \mathrm{~m}^{3}\left(21,200 \mathrm{ft}^{3}\right)$ of air was filtered through a 4.7-cm (1.85-in) diameter glass microfiber filter using a low-volume continuous air sampler. The samples were collected at a height of $1.5-2 \mathrm{~m}$ (5-6.5 ft) to closely match the height at which air is inhaled by humans. Filters were counted for gross alpha and beta only after being stored for five to seven days in the laboratory to make sure the short-lived radon progeny had decayed.

Blank filters were also counted for gross alpha and beta activities so that background corrections (activities present in the blank filters) could be made in the gross alpha and beta measurements of the air samples. Blanks were counted weekly along with the samples. The gross alpha and beta activities per cubic meter of air were then determined by dividing the total activity of gross alpha and beta found in each weekly sample by the amount of air pulled through each sample. The results are given in Appendix D. The mass and volume of air collected each week are reported in Appendix E.

As expected, weekly gross alpha activity concentrations measured in 2000 varied by an order of magnitude throughout the year at each location (Figure 4.2). Measured concentrations ranged from a minimum of $7.75 \times 10^{-6} \pm$ $1.07 \times 10^{-5} \mathrm{~Bq} / \mathrm{m}^{3}\left(2.09 \times 10^{-4} \pm 2.89 \times 10^{-4} \mathrm{pCi} / \mathrm{m}^{3}\right)$ to a maximum of $2.24 \times 10^{-4} \pm 5.52 \times 10^{-5} \mathrm{~Bq} / \mathrm{m}^{3}$ $\left(6.05 \times 10^{-3} \pm 1.49 \times 10^{-3} \mathrm{pCi} / \mathrm{m}^{3}\right)$ (Table 4.2). However, the annual mean concentrations of gross alpha activities found at all locations were similar, ranging from $8.69 \times 10^{-5} \pm 8.40 \times 10^{-5}$ to $9.50 \times 10^{-5} \pm 8.85 \times 10^{-5} \mathrm{~Bq} / \mathrm{m}^{3}\left(2.35 \times 10^{-3} \pm\right.$ $2.27 \times 10^{-3}$ to $\left.2.57 \times 10^{-3} \pm 2.39 \times 10^{-3} \mathrm{pCi} / \mathrm{m}^{3}\right)$. Analysis of Variance (ANOVA) indicated no 
Table 4.1 Activity (Bq) of quarterly composite air samples from effluent monitoring Stations A, B, and $\mathrm{C}$.

\begin{tabular}{|c|c|c|c|c|c|c|c|c|c|}
\hline Nuclide & ctivity & $2 \times \mathrm{TPU}^{\mathrm{a}}$ & $\mathbf{M D A}^{\mathbf{b}}$ & Activity & $2 \times \mathrm{TPU}$ & MDA & Activity & $2 \times \mathrm{TPU}$ & MDA \\
\hline & \multicolumn{3}{|c|}{ Station A } & \multicolumn{3}{|c|}{ Station B } & \multicolumn{3}{|c|}{ Station C } \\
\hline \multicolumn{10}{|c|}{$1^{\text {st }}$ Quarter } \\
\hline${ }^{241} \mathrm{Am}$ & $1.06 \times 10^{-4}$ & $3.12 \times 10^{-4}$ & $5.70 \times 10^{-4}$ & $1.25 \times 10^{-4}$ & $1.79 \times 10^{-4}$ & $1.70 \times 10^{-4}$ & $-6.48 \times 10^{-5}$ & $2.36 \times 10^{-4}$ & $6.44 \times 10^{-4}$ \\
\hline${ }^{238} \mathrm{Pu}$ & $1.83 \times 10^{-4}$ & $2.64 \times 10^{-4}$ & $2.50 \times 10^{-4}$ & $7.11 \times 10^{-5}$ & $2.33 \times 10^{-4}$ & $4.96 \times 10^{-4}$ & $0.00 \times 10^{0}$ & $0.00 \times 10^{0}$ & $1.51 \times 10^{-4}$ \\
\hline${ }^{239+240} \mathrm{Pu}$ & $9.59 \times 10^{-5}$ & $3.16 \times 10^{-4}$ & $6.70 \times 10^{-4}$ & $0.00 \times 10^{0}$ & $0.00 \times 10^{0}$ & $1.85 \times 10^{-4}$ & $0.00 \times 10^{0}$ & $0.00 \times 10^{0}$ & $1.51 \times 10^{-4}$ \\
\hline \multicolumn{10}{|c|}{$2^{\text {nd }}$ Quarter } \\
\hline${ }^{241} \mathrm{Am}$ & & & & $7.93 \times 10^{-5}$ & $2.74 \times 10^{-4}$ & $5.81 \times 10^{-4}$ & $1.63 \times 10^{-4}$ & $7.29 \times 10^{-4}$ & $1.51 \times 10^{-3}$ \\
\hline${ }^{238} \mathrm{Pu}$ & & See below ${ }^{\mathrm{c}}$ & & $1.34 \times 10^{-4}$ & $2.68 \times 10^{-4}$ & $4.93 \times 10^{-4}$ & $0.00 \times 10^{0}$ & $0.00 \times 10^{-4}$ & $5.37 \times 10^{-4}$ \\
\hline${ }^{239+240} \mathrm{Pu}$ & & & & $2.00 \times 10^{-4}$ & $2.33 \times 10^{-4}$ & $1.80 \times 10^{-4}$ & $0.00 \times 10^{0}$ & $0.00 \times 10^{-4}$ & $1.98 \times 10^{-4}$ \\
\hline \multicolumn{10}{|c|}{$3^{\text {rd }}$ Quarter } \\
\hline$\overline{{ }^{241} \mathrm{Am}}$ & & & & $4.22 \times 10^{-5}$ & $9.92 \times 10^{-3}$ & $9.63 \times 10^{-4}$ & $1.23 \times 10^{-4}$ & $7.60 \times 10^{-4}$ & $3.35 \times 10^{-4}$ \\
\hline${ }^{238} \mathrm{Pu}$ & & See below ${ }^{\mathrm{c}}$ & & $-4.37 \times 10^{-4}$ & $5.04 \times 10^{-5}$ & $1.54 \times 10^{-3}$ & $-1.53 \times 10^{-4}$ & $5.22 \times 10^{-4}$ & $1.18 \times 10^{-3}$ \\
\hline${ }^{239+240} \mathrm{Pu}$ & & & & $3.62 \times 10^{-4}$ & $6.07 \times 10^{-4}$ & $1.44 \times 10^{-3}$ & $-1.53 \times 10^{-4}$ & $3.03 \times 10^{-4}$ & $8.15 \times 10^{-4}$ \\
\hline \multicolumn{10}{|c|}{$4^{\text {th }}$ Quarter } \\
\hline$\overline{{ }^{241} \mathrm{Am}}$ & $2.97 \times 10^{4}$ & $6.41 \times 10^{-4}$ & $1.53 \times 10^{-3}$ & $3.11 \times 10^{-4}$ & $9.41 \times 10^{-4}$ & $1.77 \times 10^{-3}$ & $-1.20 \times 10^{-3}$ & $4.67 \times 10^{-4}$ & $1.20 \times 10^{-3}$ \\
\hline${ }^{238} \mathrm{Pu}$ & $1.19 \times 10^{-4}$ & $2.33 \times 10^{-4}$ & $3.22 \times 10^{-4}$ & $1.34 \times 10^{-4}$ & $2.65 \times 10^{-4}$ & $3.65 \times 10^{-4}$ & $-2.64 \times 10^{-4}$ & $6.41 \times 10^{-4}$ & $1.51 \times 10^{-3}$ \\
\hline${ }^{239+240} \mathrm{Pu}$ & $2.37 \times 10^{-4}$ & $3.30 \times 10^{-4}$ & $3.21 \times 10^{-4}$ & $1.34 \times 10^{-4}$ & $2.66 \times 10^{-4}$ & $3.67 \times 10^{-3}$ & $2.64 \times 10^{-4}$ & $5.22 \times 10^{-3}$ & $1.11 \times 10^{-3}$ \\
\hline
\end{tabular}

\begin{tabular}{|c|c|c|c|c|c|c|c|c|c|}
\hline \multirow{5}{*}{$\begin{array}{l}{ }^{241} \mathrm{Am} \\
{ }^{238} \mathrm{Pu} \\
{ }^{239+240} \mathrm{Pu}\end{array}$} & \multicolumn{3}{|c|}{ Station A } & \multicolumn{2}{|c|}{$2^{\text {nd }}$ Quarter } & \multirow[t]{2}{*}{ Monthly } & \multirow{2}{*}{\multicolumn{3}{|c|}{ June }} \\
\hline & \multicolumn{3}{|c|}{ April } & \multicolumn{2}{|c|}{ May } & & & & \\
\hline & $-6.44 \times 10^{-5}$ & $1.29 \times 10^{-4}$ & $4.74 \times 10^{-4}$ & $1.29 \times 10^{-4}$ & $1.36 \times 10^{-4}$ & $4.74 \times 10^{-4}$ & $7.48 \times 10^{-5}$ & $2.59 \times 10^{-4}$ & $5.48 \times 10^{-4}$ \\
\hline & $7.41 \times 10^{-5}$ & $3.32 \times 10^{-4}$ & $7.00 \times 10^{-4}$ & $1.53 \times 10^{-4}$ & $1.51 \times 10^{-4}$ & $2.07 \times 10^{-4}$ & $0.00 \times 10^{-4}$ & $1.84 \times 10^{-4}$ & $1.75 \times 10^{-4}$ \\
\hline & $4.44 \times 10^{-4}$ & $4.26 \times 10^{-4}$ & $5.44 \times 10^{-4}$ & $3.06 \times 10^{-4}$ & $3.10 \times 10^{-4}$ & $2.07 \times 10^{-4}$ & $0.00 \times 10^{-4}$ & $3.19 \times 10^{-4}$ & $4.77 \times 10^{-4}$ \\
\hline & \multicolumn{3}{|c|}{ Station A } & \multicolumn{2}{|c|}{$3^{\text {rd }}$ Quarter } & \multirow[t]{2}{*}{ Monthly } & & & \\
\hline & \multicolumn{3}{|c|}{ July } & \multicolumn{2}{|r|}{ August } & & \multicolumn{3}{|c|}{ September } \\
\hline${ }^{241} \mathrm{Am}$ & $-7.30 \times 10^{-6}$ & $7.89 \times 10^{-3}$ & $7.33 \times 10^{-4}$ & $-2.88 \times 10^{-4}$ & $1.36 \times 10^{-2}$ & $1.10 \times 10^{-3}$ & $-3.78 \times 10^{-4}$ & $8.15 \times 10^{-3}$ & $1.08 \times 10^{-3}$ \\
\hline${ }^{238} \mathrm{Pu}$ & $1.23 \times 10^{-4}$ & $5.41 \times 10^{-4}$ & $1.37 \times 10^{-3}$ & $-9.48 \times 10^{-10}$ & $1.51 \times 10^{-6}$ & $5.78 \times 10^{-4}$ & $-2.33 \times 10^{-4}$ & $3.34 \times 10^{-4}$ & $9.66 \times 10^{-4}$ \\
\hline${ }^{239+240} \mathrm{Pu}$ & $-1.73 \times 10^{-4}$ & $3.41 \times 10^{-4}$ & $1.27 \times 10^{-3}$ & $-9.48 \times 10^{-5}$ & $4.78 \times 10^{-4}$ & $1.64 \times 10^{-3}$ & $-1.18 \times 10^{-4}$ & $4.00 \times 10^{-4}$ & $1.08 \times 10^{-3}$ \\
\hline
\end{tabular}

a Total propagated uncertainty.

${ }^{\mathrm{b}}$ Minimum detectable activity.

${ }^{\mathrm{c}}$ The $2^{\text {nd }}$ and $3^{\text {rd }}$ quarter filters for Station A were composited monthly due to the large number of samples.

statistically significant difference between sampling stations $(\mathrm{p}=0.933)$.

In 2000, the weekly gross beta concentrations also varied throughout the year at each station (Figure 4.3). Stations tended to vary together, showing a strong annual pattern.

gross beta activities found at all locations were similar, ranging from $9.15 \times 10^{-4} \pm 5.74 \times 10^{-4}$ to $9.53 \times 10^{-4} \pm 6.43 \times 10^{-4} \mathrm{~Bq} / \mathrm{m}^{3}\left(2.47 \times 10^{-2} \pm\right.$ $1.55 \times 10^{-2}$ to $2.58 \times 10^{-2} \pm 1.74 \times 10^{-2} \mathrm{pCi} / \mathrm{m}^{3}$ ). There was no significant difference between sampling stations (ANOVA, $\mathrm{p}=0.471$ ).
Concentrations ranged over almost an order of magnitude, from a minimum of $3.45 \times 10^{-4} \pm$ $6.44 \times 10^{-5} \mathrm{~Bq} / \mathrm{m}^{3}\left(9.32 \times 10^{-3} \pm 1.74 \times 10^{-3} \mathrm{pCi} / \mathrm{m}^{3}\right)$ to a maximum of $2.09 \times 10^{-3} \pm 2.47 \times 10^{-4} \mathrm{~Bq} / \mathrm{m}^{3}$ $\left(5.65 \times 10^{-2} \pm 6.68 \times 10^{-3} \mathrm{pCi} / \mathrm{m}^{3}\right)$ (Table 4.2). However, the annual mean concentrations of

Gross alpha and gross beta activity concentrations in 1998, 1999, and 2000 were compared using ANOVA to determine whether they had increased since waste began to be received at WIPP (Figure 4.4). There was no significant difference in measured gross alpha $(p=0.066)$ or gross beta $(p=0.601)$ activity concentration between years. 


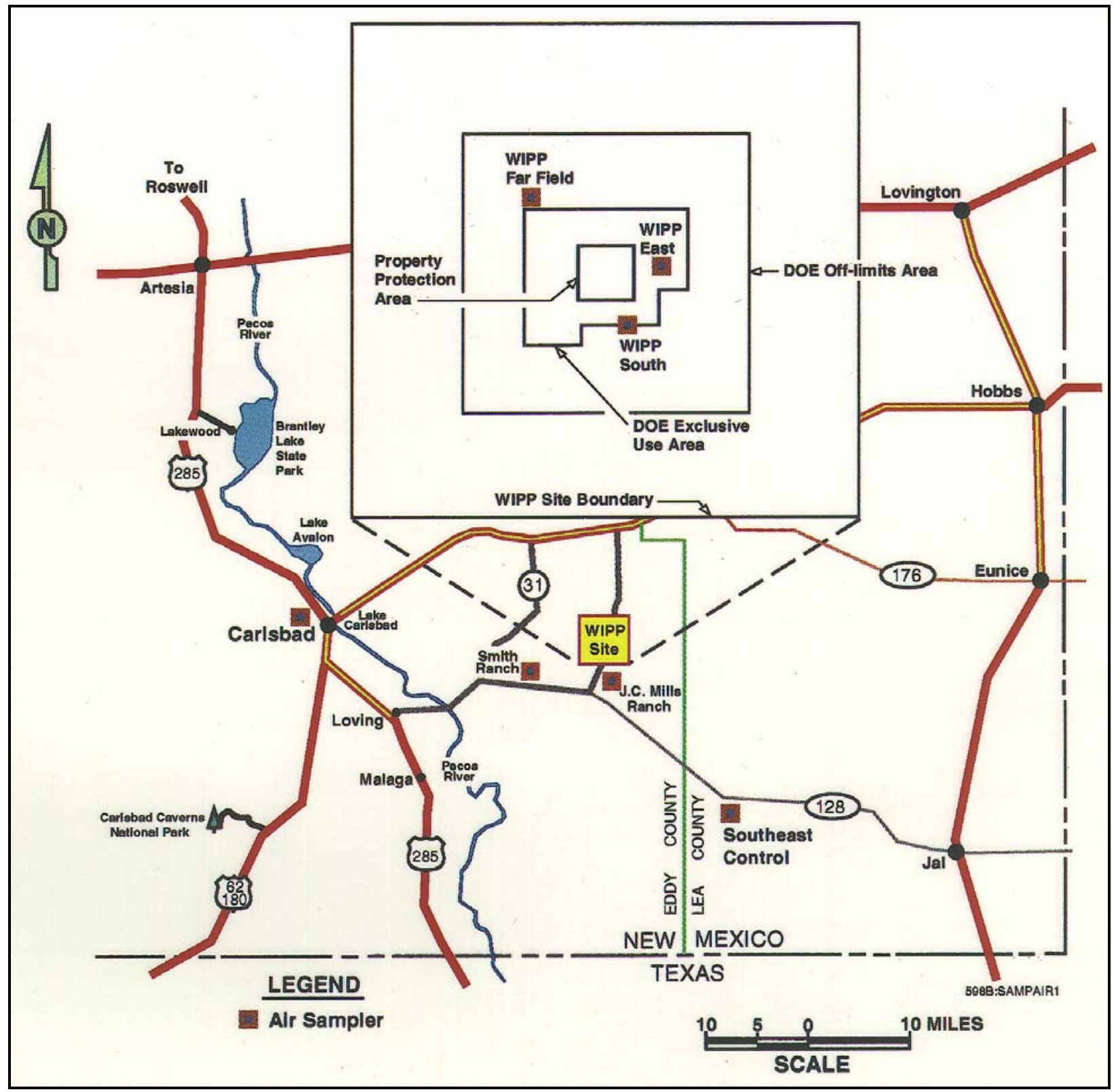

Figure 4.1 Air Sampling Locations on and near the WIPP Facility.

One duplicate sample was collected every quarter by rotating the portable sampler from one location to another: SMR in the first quarter, $\mathrm{CBD}$ in the second quarter, SEC in the third quarter, and WFF in the fourth quarter. The samples were collected by both samplers in identical conditions at all four locations.

Duplicate samples were collected and analyzed for the quality control of (1) air sampling technique, (2) determination of gross alpha and beta activities, and (3) analysis of the individual radionuclides in airborne particulate. Relative Error Ratios (RER; see Appendix C) were less than one in all of the weekly gross alpha and 96 percent of the weekly gross beta measurements. An RER less than one indicates good agreement between duplicates. A paired t-test indicated that while most duplicate measurements were not different, gross beta measurements in the 


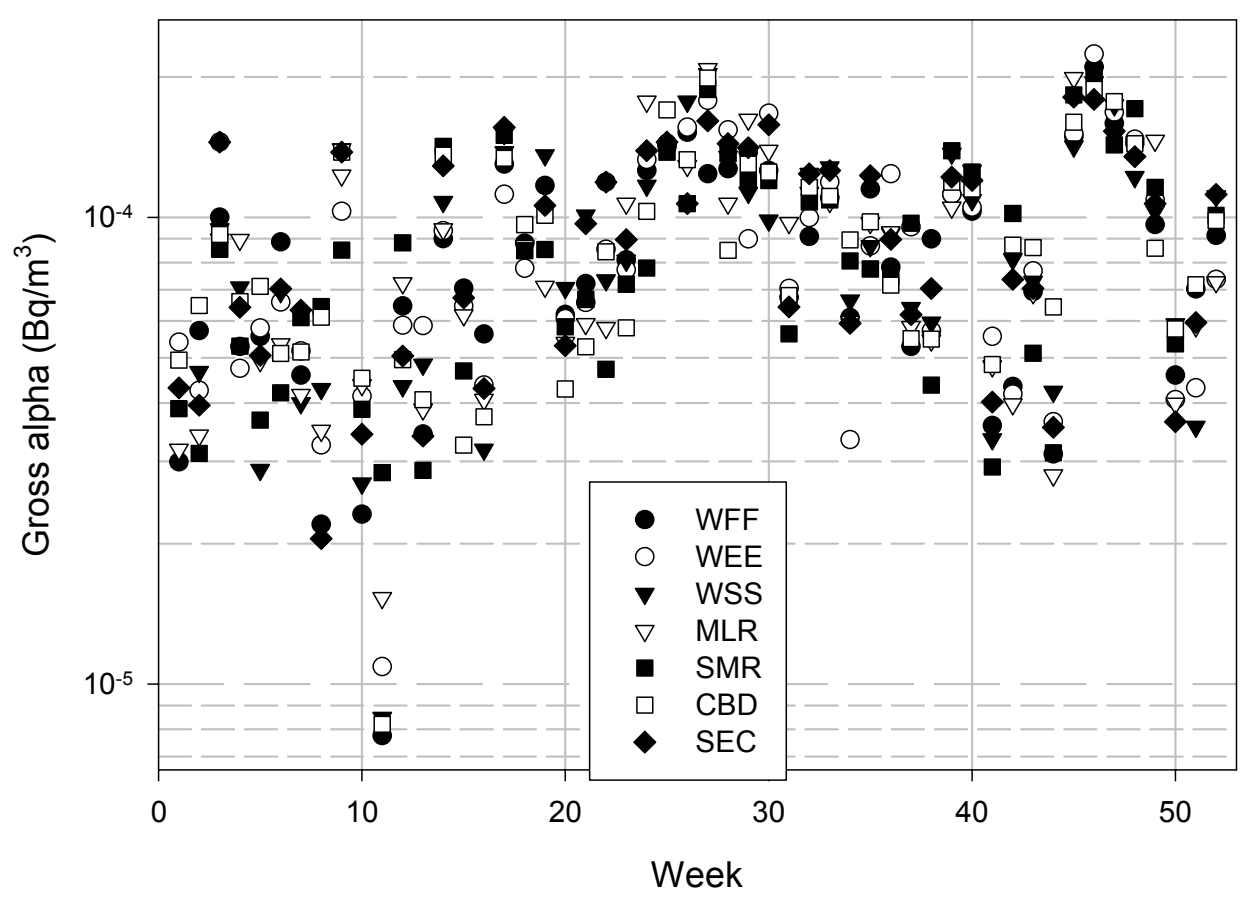

Figure 4.2 Gross alpha activity concentration measured in air particulates each week in 2000. See text for sampling station location.

third quarter were different between duplicates $(p=0.004)$. Examination of the logbooks

showed some mechanical difficulties with the samplers during this period and the problem has been corrected. The duplicate data are provided in Appendix D.

One duplicate sample was collected every quarter by rotating the portable sampler from one location to another: SMR in the first quarter, $\mathrm{CBD}$ in the second quarter, SEC in the third quarter, and WFF in the fourth quarter. The samples were collected by both samplers in identical conditions at all four locations. Duplicate samples were collected and analyzed for the quality control of (1) air sampling technique, (2) determination of gross alpha and beta activities, and (3) analysis of the individual radionuclides in airborne particulate. Relative Error Ratios (RER; see Appendix C) were less than one in all of the weekly gross alpha and 96 percent of the weekly gross beta measurements. An RER less than one indicates good agreement between duplicates. A paired t-test indicated that while most duplicate measurements were not different, gross beta measurements in the third quarter were different between duplicates $(p=0.004)$. Examination of the logbooks showed some mechanical difficulties with the samplers during this period and the problem has been corrected. The duplicate data are provided in Appendix D. 
Table 4.2 Annual mean gross alpha and gross beta activity concentrations $\left(\mathrm{Bq} / \mathrm{m}^{3}\right)$ found in weekly air particulate samples. See Appendix B for sample locations.

\begin{tabular}{ccccccc}
\hline Location & Minimum & $\mathbf{2} \times \mathbf{T P U}^{\mathbf{a}}$ & Maximum & $\mathbf{2} \times \mathbf{T P U}$ & Mean & $\mathbf{2}^{\mathbf{c}} \mathbf{S D}^{\mathbf{b}}$ \\
\hline & & & Gross alpha & & \\
\hline CBD & $8.20 \times 10^{-6}$ & $1.15 \times 10^{-5}$ & $1.99 \times 10^{-4}$ & $5.01 \times 10^{-5}$ & $8.99 \times 10^{-5}$ & $8.55 \times 10^{-5}$ \\
MLR & $1.53 \times 10^{-5}$ & $1.38 \times 10^{-5}$ & $2.08 \times 10^{-4}$ & $4.89 \times 10^{-5}$ & $8.86 \times 10^{-5}$ & $9.64 \times 10^{-5}$ \\
SEC & $2.05 \times 10^{-5}$ & $1.53 \times 10^{-5}$ & $1.81 \times 10^{-4}$ & $4.65 \times 10^{-5}$ & $9.50 \times 10^{-5}$ & $8.85 \times 10^{-5}$ \\
SMR & $2.84 \times 10^{-5}$ & $1.92 \times 10^{-5}$ & $2.03 \times 10^{-4}$ & $5.28 \times 10^{-5}$ & $8.84 \times 10^{-5}$ & $9.04 \times 10^{-5}$ \\
WEE & $1.09 \times 10^{-5}$ & $1.28 \times 10^{-5}$ & $2.24 \times 10^{-4}$ & $5.52 \times 10^{-5}$ & $8.90 \times 10^{-5}$ & $9.18 \times 10^{-5}$ \\
WFF & $7.75 \times 10^{-6}$ & $1.07 \times 10^{-5}$ & $2.10 \times 10^{-4}$ & $5.40 \times 10^{-5}$ & $8.69 \times 10^{-5}$ & $8.40 \times 10^{-5}$ \\
WSS & $8.47 \times 10^{-6}$ & $1.20 \times 10^{-5}$ & $2.05 \times 10^{-4}$ & $5.23 \times 10^{-5}$ & $9.17 \times 10^{-5}$ & $9.20 \times 10^{-5}$ \\
\hline & & & Gross beta & & \\
\hline CBD & $4.47 \times 10^{-4}$ & $7.69 \times 10^{-5}$ & $1.75 \times 10^{-3}$ & $2.03 \times 10^{-4}$ & $9.29 \times 10^{-4}$ & $5.81 \times 10^{-4}$ \\
MLR & $4.78 \times 10^{-4}$ & $7.71 \times 10^{-5}$ & $1.79 \times 10^{-3}$ & $2.16 \times 10^{-4}$ & $9.15 \times 10^{-4}$ & $5.74 \times 10^{-4}$ \\
SEC & $5.50 \times 10^{-4}$ & $8.54 \times 10^{-5}$ & $1.81 \times 10^{-3}$ & $2.08 \times 10^{-4}$ & $9.43 \times 10^{-4}$ & $6.08 \times 10^{-4}$ \\
SMR & $4.86 \times 10^{-4}$ & $8.85 \times 10^{-5}$ & $1.66 \times 10^{-3}$ & $1.96 \times 10^{-4}$ & $9.17 \times 10^{-4}$ & $5.44 \times 10^{-4}$ \\
WEE & $3.45 \times 10^{-4}$ & $6.44 \times 10^{-5}$ & $1.83 \times 10^{-3}$ & $2.20 \times 10^{-4}$ & $9.53 \times 10^{-4}$ & $6.43 \times 10^{-4}$ \\
WFF & $5.06 \times 10^{-4}$ & $8.36 \times 10^{-5}$ & $2.09 \times 10^{-3}$ & $2.47 \times 10^{-4}$ & $9.39 \times 10^{-4}$ & $6.19 \times 10^{-4}$ \\
WSS & $5.24 \times 10^{-4}$ & $8.51 \times 10^{-5}$ & $1.83 \times 10^{-3}$ & $2.19 \times 10^{-4}$ & $9.36 \times 10^{-4}$ & $5.85 \times 10^{-4}$ \\
\hline
\end{tabular}

a Total propagated uncertainty

${ }^{\mathrm{b}}$ Standard deviation of the mean

\subsection{Airborne Particulates}

The major pathways for the intake of radioactive materials into the human body are from the inhalation of dust particles and the ingestion of food and drinking water. The uptake of insoluble materials (classified as class $\mathrm{Y}$ compounds in earlier metabolic models or "S" type materials in recent models) through ingestion is very poor; therefore, inhalation becomes the major pathway for the intake of such radioactive materials. Plutonium, the major constituent of the TRU wastes to be disposed at the WIPP site, is mostly in insoluble form (class Y or S); therefore, the inhalation pathway would contribute most of the radiation dose. Accordingly, plutonium and other radionuclides of interest were determined in air particulate samples around the WIPP site.

Isotopes of plutonium and americium were analyzed because they are the most significant alpha-emitting radionuclides among the constituents of TRU wastes received at the WIPP site. Uranium isotopes were analyzed because they are prominent alpha-emitting radionuclides in the natural environment.
WIPP analyzed samples for ${ }^{90} \mathrm{Sr},{ }^{60} \mathrm{Co}$, and ${ }^{137} \mathrm{Cs}$ in order to demonstrate the ability to quantify these beta and gamma-emitting contaminants should they appear in the TRU waste stream. These radionuclides have been the subject of background studies at WIPP prior to 1999 and continue to be monitored.

Potassium-40, a natural gamma-emitting radionuclide which is ubiquitous in the earth's crust, was also monitored because of its possible enhancement in southeastern New Mexico due to potash mining.

\subsubsection{Sample Preparation}

Weekly air particulate samples were collected as described in Section 4.2 and composited for each quarter. The composites were transferred into a Pyrex beaker, spiked with appropriate tracers, and heated in a Muffle furnace at $250^{\circ} \mathrm{C}\left(482^{\circ} \mathrm{F}\right)$ for two hours, followed by two hours at $375^{\circ} \mathrm{C}\left(707^{\circ} \mathrm{F}\right)$ and six hours at $525^{\circ} \mathrm{C}\left(977^{\circ} \mathrm{F}\right)$. The ash was cooled, transferred quantitatively into a Teflon beaker by rinsing with concentrated nitric acid, and heated with concentrated hydrofluoric acid until completely dissolved. Hydrofluoric acid was removed by evaporating to dryness. 


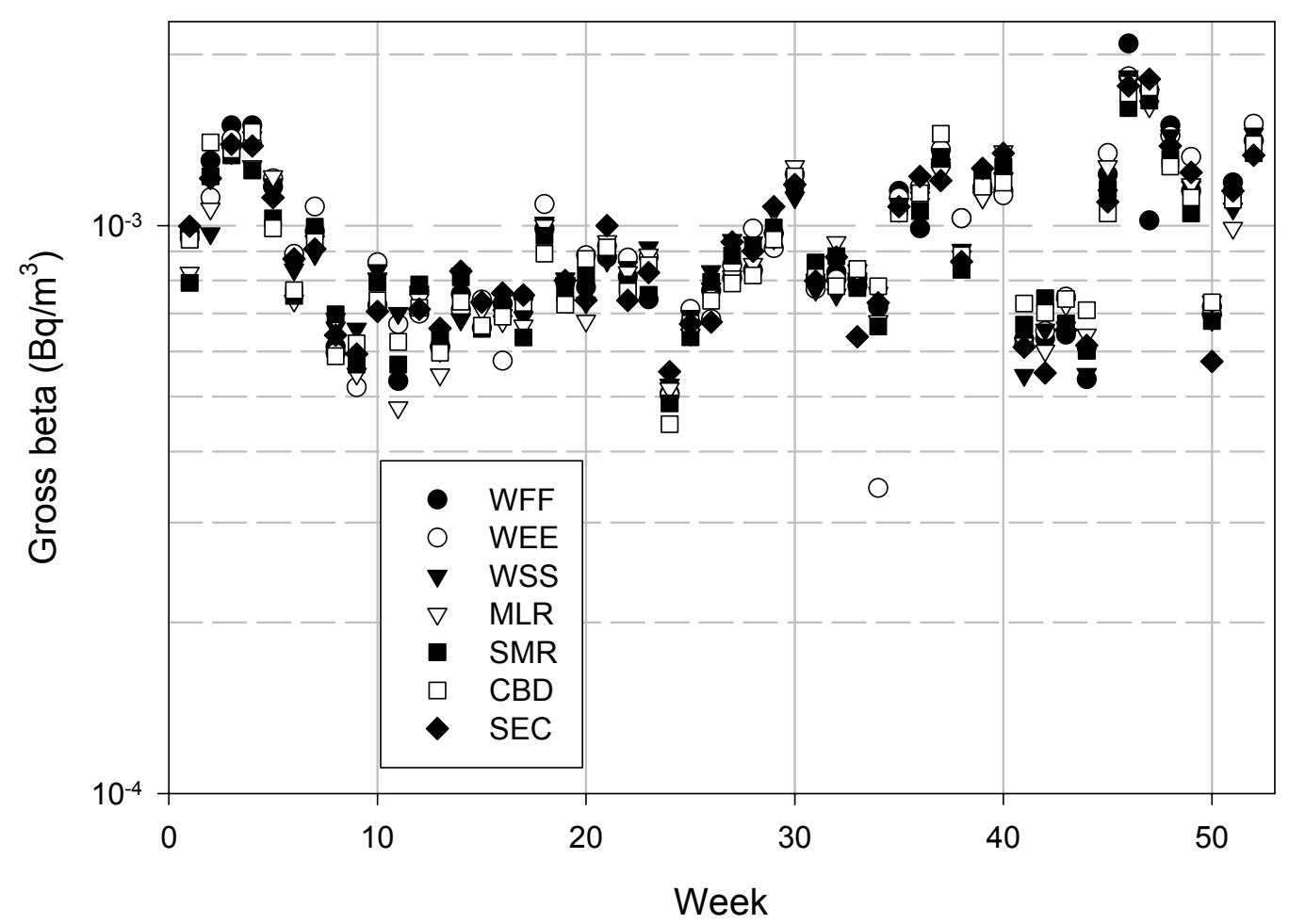

Figure 4.3 Gross beta activity concentration measured in air particulates each week in 2000 . See text for sampling station locations.

Approximately $25 \mathrm{ml}(0.845 \mathrm{oz})$ of concentrated nitric acid and one gram $(0.0353 \mathrm{oz})$ of boric acid were added, heated, and finally evaporated to dryness. The residue was dissolved in $8 \mathrm{M}$ (molar) nitric acid for gamma spectrometry and determinations of ${ }^{90} \mathrm{Sr}$ and alpha-emitting radionuclides.

\subsubsection{Determination of Individual Radionuclides}

Gamma-emitting radionuclides were measured in the air filters by gamma spectrometry. Strontium-90 and alpha-emitting radionuclides were determined by sequential separation and counting. Determination of actinides involved co-precipitation, ion exchange separation, and alpha spectrometry.

\subsubsection{Results and Discussions}

There was no significant difference in the concentration of any radionuclide between sampling stations (ANOVA, $\mathrm{p}>0.174$ ).

Therefore, the minima, maxima, and means for all stations combined are reported in Table 4.3. Detailed data for each station are reported in Appendix G (Table G.1).

Natural uranium isotopes were detected in every composite sample. Concentrations of ${ }^{234} \mathrm{U}$ ranged from $1.41 \times 10^{-6} \pm 2.54 \times 10^{-7} \mathrm{~Bq} / \mathrm{m}^{3}$ 

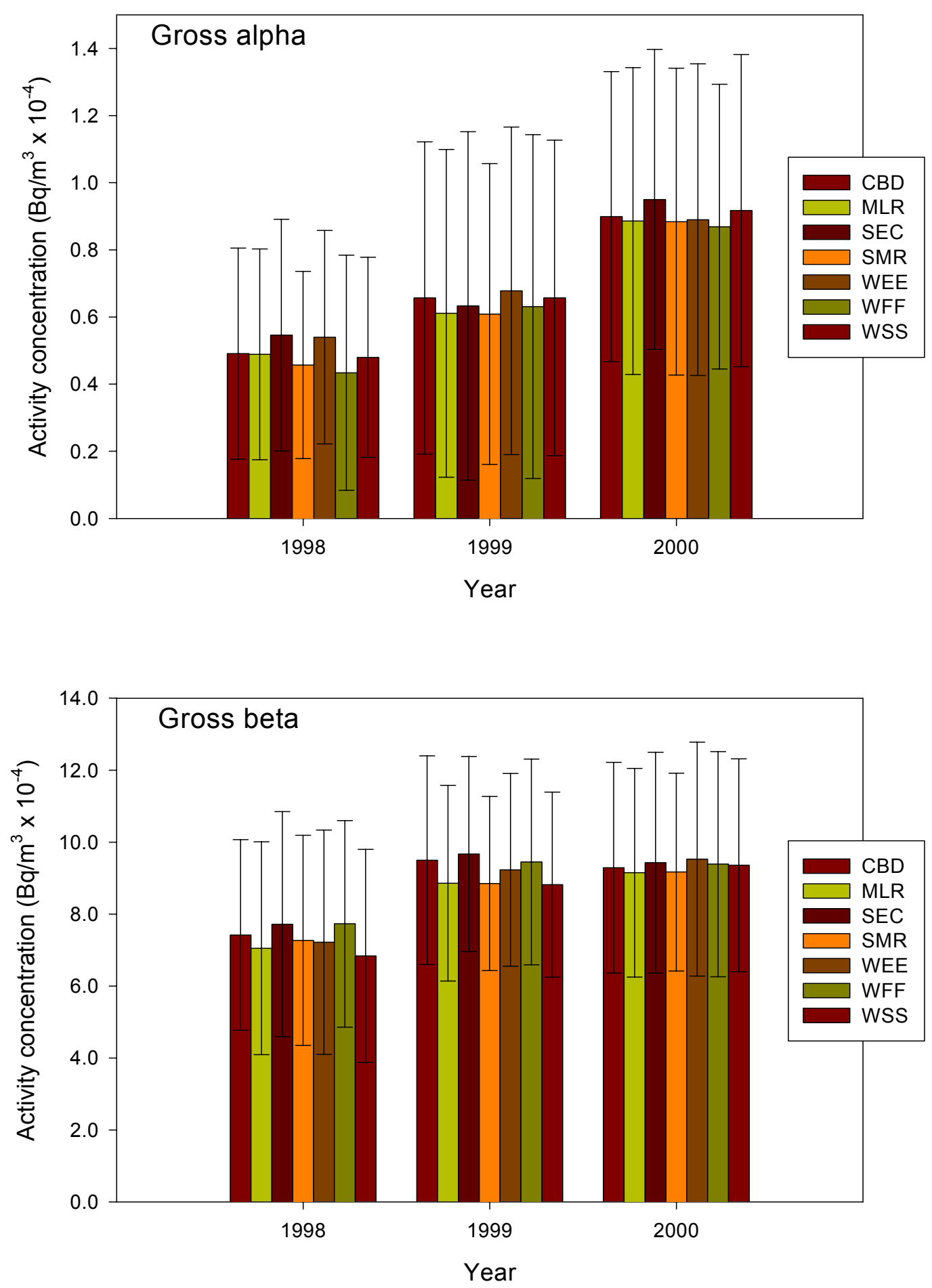

Figure 4.4 Average gross alpha and beta activity concentrations measured in air particulates in three consecutive years. The year 1999 was the first year in which radioactivity was stored in WIPP. See text for sampling station locations. 
Table 4.3 Minimum, maximum and average radionuclide concentrations $\left(\mathrm{Bq} / \mathrm{m}^{3}\right)$ in air filter composites from stations surrounding the WIPP site. See Appendix B for locations. See Appendix G for supporting data.

\begin{tabular}{|c|c|c|c|c|}
\hline \multicolumn{2}{|c|}{ Radionuclide } & {$[\mathbf{R N}]^{\mathbf{a}}$} & $2 \times T_{P} U^{b}$ & MDC $^{\mathrm{c}}$ \\
\hline \multirow[t]{3}{*}{${ }^{241} \mathrm{Am}$} & Minimum & $-6.96 \times 10^{-9}$ & $7.63 \times 10^{-8}$ & $2.24 \times 10^{-8}$ \\
\hline & Maximum & $9.77 \times 10^{-8}$ & $1.18 \times 10^{-7}$ & $1.84 \times 10^{-7}$ \\
\hline & Average & $3.65 \times 10^{-8}$ & $1.37 \times 10^{-8}$ & $9.37 \times 10^{-8}$ \\
\hline \multirow[t]{3}{*}{${ }^{238} \mathrm{Pu}$} & Minimum & $-2.28 \times 10^{-8}$ & $2.65 \times 10^{-8}$ & $2.16 \times 10^{-8}$ \\
\hline & Maximum & $2.31 \times 10^{-8}$ & $4.63 \times 10^{-8}$ & $1.50 \times 10^{-7}$ \\
\hline & Average & $1.25 \times 10^{-9}$ & $6.28 \times 10^{-9}$ & $9.48 \times 10^{-8}$ \\
\hline \multirow[t]{3}{*}{${ }^{239+240} \mathrm{Pu}$} & Minimum & $-1.09 \times 10^{-8}$ & $4.80 \times 10^{-8}$ & $6.45 \times 10^{-8}$ \\
\hline & Maximum & $8.46 \times 10^{-8}$ & $8.38 \times 10^{-8}$ & $2.12 \times 10^{-7}$ \\
\hline & Average & $2.36 \times 10^{-8}$ & $1.18 \times 10^{-8}$ & $1.29 \times 10^{-7}$ \\
\hline \multirow[t]{3}{*}{${ }^{234} \mathrm{U}$} & Minimum & $1.41 \times 10^{-6}$ & $2.54 \times 10^{-7}$ & $5.82 \times 10^{-8}$ \\
\hline & Maximum & $3.01 \times 10^{-6}$ & $3.78 \times 10^{-7}$ & $3.99 \times 10^{-7}$ \\
\hline & Average & $2.24 \times 10^{-6}$ & $7.32 \times 10^{-8}$ & $1.70 \times 10^{-7}$ \\
\hline \multirow[t]{3}{*}{${ }^{235} \mathrm{U}$} & Minimum & $-3.32 \times 10^{-8}$ & $1.99 \times 10^{-7}$ & $6.87 \times 10^{-8}$ \\
\hline & Maximum & $2.07 \times 10^{-7}$ & $1.30 \times 10^{-7}$ & $4.61 \times 10^{-7}$ \\
\hline & Average & $1.03 \times 10^{-7}$ & $2.23 \times 10^{-8}$ & $1.84 \times 10^{-7}$ \\
\hline \multirow[t]{3}{*}{${ }^{238} \mathrm{U}$} & Minimum & $1.36 \times 10^{-6}$ & $2.38 \times 10^{-7}$ & $6.64 \times 10^{-8}$ \\
\hline & Maximum & $2.95 \times 10^{-6}$ & $3.65 \times 10^{-7}$ & $2.93 \times 10^{-7}$ \\
\hline & Average & $2.18 \times 10^{-6}$ & $7.13 \times 10^{-8}$ & $1.49 \times 10^{-7}$ \\
\hline \multirow[t]{3}{*}{${ }^{40} \mathrm{~K}$} & Minimum & $1.82 \times 10^{-4}$ & $9.82 \times 10^{-5}$ & $1.57 \times 10^{-4}$ \\
\hline & Maximum & $5.47 \times 10^{-3}$ & $3.07 \times 10^{-3}$ & $1.06 \times 10^{-3}$ \\
\hline & Average & $1.71 \times 10^{-3}$ & $1.86 \times 10^{-4}$ & $3.73 \times 10^{-4}$ \\
\hline \multirow[t]{3}{*}{${ }^{60} \mathrm{Co}$} & Minimum & $-4.31 \times 10^{-5}$ & $4.32 \times 10^{-5}$ & $1.16 \times 10^{-5}$ \\
\hline & Maximum & $4.97 \times 10^{-5}$ & $4.11 \times 10^{-5}$ & $2.70 \times 10^{-5}$ \\
\hline & Average & $5.08 \times 10^{-7}$ & $4.36 \times 10^{-6}$ & $1.72 \times 10^{-5}$ \\
\hline \multirow[t]{3}{*}{${ }^{90} \mathrm{Sr}$} & Minimum & $-2.96 \times 10^{-6}$ & $2.59 \times 10^{-6}$ & $2.59 \times 10^{-6}$ \\
\hline & Maximum & $5.11 \times 10^{-6}$ & $5.29 \times 10^{-6}$ & $9.92 \times 10^{-6}$ \\
\hline & Average & $1.54 \times 10^{-6}$ & $8.09 \times 10^{-7}$ & $7.16 \times 10^{-6}$ \\
\hline \multirow[t]{3}{*}{${ }^{137} \mathrm{Cs}$} & Minimum & $-3.22 \times 10^{-5}$ & $1.29 \times 10^{-5}$ & $1.13 \times 10^{-5}$ \\
\hline & Maximum & $1.89 \times 10^{-5}$ & $1.05 \times 10^{-5}$ & $1.35 \times 10^{-5}$ \\
\hline & Average & $1.37 \times 10^{-6}$ & $2.18 \times 10^{-6}$ & $1.24 \times 10^{-5}$ \\
\hline
\end{tabular}

${ }^{\mathrm{a}}[\mathrm{RN}]=$ Radionuclide concentration

$\mathrm{b}$ Total Propagated Uncertainty (Standard Deviation, in the case of the mean)

${ }^{\mathrm{c}}$ Minimum Detectable Concentration

$\left(3.81 \times 10^{-5} \pm 6.86 \times 10^{-6} \mathrm{pCi} / \mathrm{m}^{3}\right)$ at MLR in the fourth quarter to $3.01 \times 10^{-6} \pm 3.78 \times 10^{-7} \mathrm{~Bq} / \mathrm{m}^{3}$ $\left(8.14 \times 10^{-5} \pm 1.02 \times 10^{-5} \mathrm{pCi} / \mathrm{m}^{3}\right)$ at WEE in the first quarter (Appendix F, Table F.1). There was no significant difference between concentrations measured in 1999 and 2000 (ANOVA, $p=$ 0.268 ), or between quarters (ANOVA, $\mathrm{p}=$ 0.143 ).

The activity concentration of ${ }^{235} \mathrm{U}$ in the natural environment is very low compared to the concentrations of ${ }^{234} \mathrm{U}$ and ${ }^{238} \mathrm{U}$ (1 $\mu \mathrm{g}$ of natural uranium contains $12.2 \mathrm{mBq}[0.33 \mathrm{pCi}]$ of ${ }^{238} \mathrm{U}$, $0.56 \mathrm{mBq}[0.01 \mathrm{pCi}]$ of ${ }^{235} \mathrm{U}$, and $12.8 \mathrm{mBq}$ $[0.35 \mathrm{pCi}]$ of $\left.{ }^{234} \mathrm{U}\right)$; therefore, the amount of ${ }^{235} \mathrm{U}$ in air particulate samples is expected to be very low. Uranium-235 was detected in approximately 18 percent of the quarterly composite samples. The lowest concentration $\left(-3.32 \times 10^{-8} \pm 1.99 \times 10^{-7} \mathrm{~Bq} / \mathrm{m}^{3}\left[-8.97 \times 10^{-7} \pm\right.\right.$ $\left.\left.5.38 \times 10^{-6} \mathrm{pCi} / \mathrm{m}^{3}\right]\right)$ was measured at MLR in the second quarter and the highest concentration $\left(2.07 \times 10^{-7} \pm 1.30 \times 10^{-7} \mathrm{~Bq} / \mathrm{m}^{3}\left[5.59 \times 10^{-6} \pm\right.\right.$ 
$\left.\left.3.51 \times 10^{-6} \mathrm{pCi} / \mathrm{m}^{3}\right]\right)$ was found at $\mathrm{CBD}$ in the third quarter (Table G.1). Like ${ }^{234} \mathrm{U}$, there was no significant difference between years (ANOVA, $\mathrm{p}=0.205$ ) or quarters (ANOVA, $\mathrm{p}=$ $0.388)$.

Uranium-238 was also, as expected, detected in 100 percent of the composite air filters. Concentrations ranged from $1.36 \times 10^{-6} \pm$ $2.38 \times 10^{-7} \mathrm{~Bq} / \mathrm{m}^{3}\left(3.68 \times 10^{-5} \pm 6.43 \times 10^{-6} \mathrm{pCi} / \mathrm{m}^{3}\right)$ at MLR in the fourth quarter to $2.95 \times 10^{-6} \pm$ $3.65 \times 10^{-7} \mathrm{~Bq} / \mathrm{m}^{3}\left(7.97 \times 10^{-5} \pm 9.86 \times 10^{-6} \mathrm{pCi} / \mathrm{m}^{3}\right)$ at CBD in the first quarter (Table G.1). There were significant quarterly differences (ANOVA, $\mathrm{p}=0.005)$, with the second quarter having the highest concentration and the fourth quarter the lowest. There was also a significant difference between years (ANOVA, $\mathrm{p}=0.005$ ), with 1999 having higher concentrations than 2000 .

Neither ${ }^{238} \mathrm{Pu}$ nor ${ }^{239+240} \mathrm{Pu}$ were detected in any sample in 2000. The concentration of ${ }^{241} \mathrm{Am}$ was greater than the MDC in two of the quarterly composites; SMR in the second quarter $\left(6.66 \times 10^{-8} \pm 9.19 \times 10^{-8} \mathrm{~Bq} / \mathrm{m}^{3}\left[1.80 \times 10^{-6} \pm\right.\right.$ $\left.\left.2.48 \times 10^{-6} \mathrm{pCi} / \mathrm{m}^{3}\right]\right)$ and WEE in the second quarter $\left(6.11 \times 10^{-8} \pm 8.70 \times 10^{-8} \mathrm{~Bq} / \mathrm{m}^{3}\left[1.65 \times 10^{-6}\right.\right.$ $\left.\left.\pm 2.35 \times 10^{-6} \mathrm{pCi} / \mathrm{m}^{3}\right]\right)$ (Table G.1). In both cases the results were less than $2 \times \mathrm{TPU}$ and, therefore, ${ }^{241} \mathrm{Am}$ was not likely present in detectable amounts in these samples.

Concentrations of ${ }^{40} \mathrm{~K}$ (Table G.1) were detected in approximately 86 percent of the samples. The minimum $\left(1.82 \times 10^{-4} \pm 9.82 \times 10^{-5}\right.$ $\left.\mathrm{Bq} / \mathrm{m}^{3}\left[4.92 \times 10^{-3} \pm 2.65 \times 10^{-3} \mathrm{pCi} / \mathrm{m}^{3}\right]\right)$ was found at SMR in the third quarter, while the maximum $\left(5.47 \times 10^{-3} \pm 3.07 \times 10^{-3} \mathrm{~Bq} / \mathrm{m}^{3}\right.$ $\left.\left[1.48 \times 10^{-1} \pm 8.30 \times 10^{-2} \mathrm{pCi} / \mathrm{m}^{3}\right]\right)$ was found at
WSS in the first quarter. While insufficient data were available in 1999 to make an annual comparison, there was no significant difference between quarters in 2000 (ANOVA, $p=0.189$ ).

As expected, ${ }^{137} \mathrm{Cs}$ was detected in two of the quarterly composite samples and ${ }^{60} \mathrm{Co}$ was detected in four. Strontium-90 was never detected in a quarterly composite air filter in 2000 .

Duplicate air particulate samples were collected by rotating the portable sampler from one location to another every quarter: SMR in the first quarter, $\mathrm{CBD}$ in the second quarter, SEC in the third quarter, and WFF in the fourth quarter. The samples were collected by both samplers in identical conditions at all four locations. The duplicate samples were analyzed to check the reproducibility of the data. The results are given in Table 4.4. The original and duplicate results for ${ }^{234} \mathrm{U},{ }^{238} \mathrm{U}$, and ${ }^{40} \mathrm{~K}$ were compared using the RER. The results for all other radionuclides were excluded because of insufficient detections for a meaningful test. Relative Error Ratios were less than one for all results except ${ }^{234} \mathrm{U}$ at $\mathrm{SEC}$, and ${ }^{40} \mathrm{~K}$ at CBD and SEC. This suggests overall good agreement between duplicates.

The results obtained for the concentrations of ${ }^{238} \mathrm{Pu},{ }^{239+240} \mathrm{Pu},{ }^{241} \mathrm{Am},{ }^{90} \mathrm{Sr}$, and ${ }^{137} \mathrm{Cs}$ in air particulates compared favorably with those measured by the Environmental Evaluation Group (EEG) (Table 4.5). The annual mean concentrations of these radionuclides were very low, and most samples collected by either WIPP or EEG did not contain detectable concentrations. 
Table 4.4 Results of duplicate composite air filter sampling. Units are $\mathrm{Bq} / \mathrm{m}^{3}$. See Appendix B for sampling stations.

\begin{tabular}{|c|c|c|c|c|c|}
\hline & & {$[\mathbf{R N}]^{\mathrm{a}}$} & $2 \times T_{P U}^{b}$ & MDC $^{\mathrm{c}}$ & RER $^{\text {d }}$ \\
\hline Location & Quarter & \multicolumn{4}{|c|}{${ }^{40} \mathrm{~K}$} \\
\hline$\overline{\text { SMR }}$ & 1 & $5.40 \times 10^{-4}$ & $4.16 \times 10^{-4}$ & $9.49 \times 10^{-4}$ & 0.814 \\
\hline SMR Dup. & 1 & $1.24 \times 10^{-3}$ & $7.46 \times 10^{-4}$ & $9.50 \times 10^{-4}$ & \\
\hline CBD & 2 & $1.43 \times 10^{-3}$ & $1.03 \times 10^{-4}$ & $1.57 \times 10^{-4}$ & 1.237 \\
\hline CBD Dup. & 2 & $1.24 \times 10^{-3}$ & $1.13 \times 10^{-4}$ & $1.60 \times 10^{-4}$ & \\
\hline SEC & 3 & $1.37 \times 10^{-3}$ & $1.65 \times 10^{-4}$ & $1.97 \times 10^{-4}$ & 1.981 \\
\hline SEC Dup. & 3 & $1.84 \times 10^{-3}$ & $1.74 \times 10^{-4}$ & $2.41 \times 10^{-4}$ & \\
\hline WFF & 4 & $1.70 \times 10^{-3}$ & $4.96 \times 10^{-4}$ & $2.66 \times 10^{-4}$ & 0.297 \\
\hline \multirow[t]{2}{*}{ WFF Dup. } & 4 & $1.50 \times 10^{-3}$ & $4.55 \times 10^{-4}$ & $2.70 \times 10^{-4}$ & \\
\hline & & \multicolumn{4}{|c|}{${ }^{234} \mathbf{U}$} \\
\hline SMR & 1 & $2.48 \times 10^{-6}$ & $3.58 \times 10^{-7}$ & $2.54 \times 10^{-7}$ & 0.716 \\
\hline SMR Dup. & 1 & $2.85 \times 10^{-6}$ & $3.64 \times 10^{-7}$ & $1.18 \times 10^{-7}$ & \\
\hline CBD & 2 & $2.76 \times 10^{-6}$ & $4.96 \times 10^{-7}$ & $1.96 \times 10^{-7}$ & 0.349 \\
\hline CBD Dup. & 2 & $2.53 \times 10^{-6}$ & $4.65 \times 10^{-7}$ & $1.90 \times 10^{-7}$ & \\
\hline SEC & 3 & $2.36 \times 10^{-6}$ & $4.48 \times 10^{-7}$ & $1.90 \times 10^{-7}$ & 1.150 \\
\hline SEC Dup. & 3 & $1.70 \times 10^{-6}$ & $3.66 \times 10^{-7}$ & $1.81 \times 10^{-7}$ & \\
\hline WFF & 4 & $1.72 \times 10^{-6}$ & $2.50 \times 10^{-7}$ & $1.06 \times 10^{-7}$ & 0.961 \\
\hline \multirow[t]{2}{*}{ WFF Dup. } & 4 & $1.40 \times 10^{-6}$ & $2.20 \times 10^{-7}$ & $5.99 \times 10^{-8}$ & \\
\hline & & \multicolumn{4}{|c|}{${ }^{238} \mathrm{U}$} \\
\hline SMR & 1 & $2.88 \times 10^{-6}$ & $3.73 \times 10^{-7}$ & $1.67 \times 10^{-7}$ & 0.223 \\
\hline SMR Dup. & 1 & $2.77 \times 10^{-6}$ & $3.56 \times 10^{-7}$ & $1.00 \times 10^{-7}$ & \\
\hline CBD & 2 & $2.55 \times 10^{-6}$ & $4.77 \times 10^{-7}$ & $2.40 \times 10^{-7}$ & 0.088 \\
\hline CBD Dup. & 2 & $2.49 \times 10^{-6}$ & $4.58 \times 10^{-7}$ & $1.41 \times 10^{-7}$ & \\
\hline SEC & 3 & $2.17 \times 10^{-6}$ & $4.32 \times 10^{-7}$ & $2.33 \times 10^{-7}$ & 0.187 \\
\hline SEC Dup. & 3 & $2.06 \times 10^{-6}$ & $4.02 \times 10^{-7}$ & $1.34 \times 10^{-7}$ & \\
\hline WFF & 4 & $1.75 \times 10^{-6}$ & $2.53 \times 10^{-7}$ & $1.14 \times 10^{-7}$ & 0.377 \\
\hline WFF Dup. & 4 & $1.62 \times 10^{-6}$ & $2.39 \times 10^{-7}$ & $8.02 \times 10^{-8}$ & \\
\hline
\end{tabular}

${ }^{\mathrm{a}}[\mathrm{RN}]=$ Radionuclide concentration

${ }^{\mathrm{b}}$ Total propagated uncertainty

${ }^{\mathrm{c}}$ Minimum detectable concentration

${ }^{\mathrm{d}}$ Relative Error Ratio 
Table 4.5 Preliminary quarterly average radionuclide concentrations $\left(\mathrm{Bq} / \mathrm{m}^{3}\right)$ measured in air particulate samples by the Environmental Evaluation Group in 2000.

\begin{tabular}{|c|c|c|c|c|}
\hline & \multicolumn{4}{|c|}{ Quarter } \\
\hline & 1 & 2 & 3 & 4 \\
\hline & \multicolumn{4}{|c|}{${ }^{241} \mathrm{Am}$} \\
\hline Concentration & $-2.57 \times 10^{-8}$ & $-3.33 \times 10^{-9}$ & $\mathrm{NR}^{\mathrm{b}}$ & NR \\
\hline \multirow[t]{2}{*}{$2 \times \mathrm{SD}^{\mathrm{a}}$} & $1.57 \times 10^{-8}$ & $1.19 \times 10^{-8}$ & NR & NR \\
\hline & \multicolumn{4}{|c|}{${ }^{238} \mathbf{P u}$} \\
\hline Concentration & $-1.11 \times 10^{-8}$ & $6.37 \times 10^{-9}$ & NR & NR \\
\hline \multirow{2}{*}{$2 \times \mathrm{SD}$} & $2.18 \times 10^{-8}$ & $2.42 \times 10^{-8}$ & NR & NR \\
\hline & \multicolumn{4}{|c|}{${ }^{239+240} \mathrm{Pu}$} \\
\hline Concentration & $8.37 \times 10^{-9}$ & $1.09 \times 10^{-8}$ & NR & NR \\
\hline \multirow[t]{2}{*}{$2 \times \mathrm{SD}$} & $1.24 \times 10^{-8}$ & $1.37 \times 10^{-8}$ & NR & NR \\
\hline & \multicolumn{4}{|c|}{${ }^{137} \mathrm{Cs}$} \\
\hline Concentration & $-9.12 \times 10^{-8}$ & $1.63 \times 10^{-6}$ & NR & NR \\
\hline \multirow[t]{2}{*}{$2 \times \mathrm{SD}$} & $8.46 \times 10^{-7}$ & $1.21 \times 10^{-6}$ & NR & NR \\
\hline & \multicolumn{4}{|c|}{${ }^{90} \mathrm{Sr}$} \\
\hline Concentration & $2.02 \times 10^{-6}$ & $8.71 \times 10^{-7}$ & NR & NR \\
\hline $2 \times \mathrm{SD}$ & $6.04 \times 10^{-7}$ & $8.55 \times 10^{-7}$ & NR & NR \\
\hline
\end{tabular}

${ }^{a}$ Standard Deviation.

${ }^{\mathrm{b}}$ Not reported

\subsection{Groundwater}

\subsubsection{Sample Collection}

Groundwater samples were collected from seven different wells around the WIPP site as shown in Figure 6.1. Approximately three bore volumes (approximately $3,800 \mathrm{~L}$ [1,000 gal]) of water were pumped out of these wells before collecting approximately $38 \mathrm{~L}$ (10 gal) of water samples. The water samples were collected from depths ranging from 180-270 $\mathrm{m}$ (600-900 $\mathrm{ft}$ ) from six wells (WQSP-1 to WQSP-6), and from a depth of $69 \mathrm{~m}(225 \mathrm{ft})$ from WQSP-6A. Samples were collected twice in 2000.

Approximately $8 \mathrm{~L}$ (2 gal) of water were sent to the contract laboratory for the determination of radionuclides of interest. The rest of the samples were used to analyze for nonradiological parameters or were put into storage. The samples were acidified to $\mathrm{pH} \leq 2$ by adding concentrated nitric acid drop by drop.

\subsubsection{Determination of Individual Radionuclides}

The acidified water samples were used for the determination of gamma-emitting radionuclides, such as ${ }^{40} \mathrm{~K},{ }^{60} \mathrm{Co}$, and ${ }^{137} \mathrm{Cs}$, by gamma- spectrometry. An aliquot of approximately $1 \mathrm{~L}(34 \mathrm{oz})$ was used for the determination of ${ }^{90} \mathrm{Sr}$. Another aliquot was used for the sequential determinations of the uranium isotopes, the plutonium isotopes, and ${ }^{241} \mathrm{Am}$ by alpha spectrometry, which involved the co-precipitation of actinides with iron carrier, ion exchange chromatographic separation of individual radionuclides, source preparation by electrodeposition or micro-precipitating, and alpha spectrometry.

\subsubsection{Results and Discussions}

Isotopes of naturally-occurring uranium were detected in every well in 2000 (Table 4.6). The mean concentrations of ${ }^{234} \mathrm{U}$ ranged from $1.41 \times 10^{-1} \pm 2.47 \times 10^{-3} \mathrm{~Bq} / \mathrm{L}\left(3.81 \times 10^{0} \pm\right.$ $\left.6.68 \times 10^{-2} \mathrm{pCi} / \mathrm{L}\right)$ in WQSP-3 to $7.79 \times 10^{-1} \pm$ $1.10 \times 10^{-2} \mathrm{~Bq} / \mathrm{L}\left(2.11 \times 10^{1} \pm 2.97 \times 10^{-1} \mathrm{pCi} / \mathrm{L}\right)$ in WQSP-1. Uranium-235 ranged from $1.24 \times 10^{-3}$ $\pm 2.34 \times 10^{-4} \mathrm{~Bq} / \mathrm{L}\left(3.35 \times 10^{-2} \pm 6.32 \times 10^{-3} \mathrm{pCi} / \mathrm{L}\right)$ in WQSP-3 to $6.79 \times 10^{-3} \pm 4.40 \times 10^{-4} \mathrm{~Bq} / \mathrm{L}$ $\left(1.84 \times 10^{-1} \pm 1.19 \times 10^{-2} \mathrm{pCi} / \mathrm{L}\right)$ in WQSP-1. The mean concentration of ${ }^{238} \mathrm{U}$ ranged from $1.93 \times 10^{-2} \pm 6.81 \times 10^{-4} \mathrm{~Bq} / \mathrm{L}\left(5.22 \times 10^{-1} \pm\right.$ $\left.1.84 \times 10^{-2} \mathrm{pCi} / \mathrm{L}\right)$ in WQSP-3 to $1.31 \times 10^{-1} \pm$ $2.37 \times 10^{-3} \mathrm{~Bq} / \mathrm{L}\left(3.54 \times 10^{0} \pm 6.41 \times 10^{-2} \mathrm{pCi} / \mathrm{L}\right)$ in WQSP-1. Because of natural variability, the concentration of ${ }^{238} \mathrm{U}$ was significantly different 
Table 4.6 Average annual radionuclide concentrations $(\mathrm{Bq} / \mathrm{L})$ in groundwater from wells at the WIPP site. See Chapter 6 for the sampling locations.

\begin{tabular}{|c|c|c|c|c|c|c|c|c|c|}
\hline \multirow[b]{2}{*}{ Location } & Mean & $\mathbf{2} \times \mathbf{S D}^{\mathrm{a}}$ & $\mathrm{MDC}^{\mathrm{b}}$ & Mean & $2 \times \mathrm{SD}$ & MDC & Mean & $2 \times \mathrm{SD}$ & MDC \\
\hline & \multicolumn{3}{|c|}{${ }^{241} \mathrm{Am}$} & \multicolumn{3}{|c|}{${ }^{238} \mathrm{Pu}$} & \multicolumn{3}{|c|}{${ }^{239+240} \mathrm{Pu}$} \\
\hline WQSP-1 & $1.33 \times 10^{-4}$ & $1.49 \times 10^{-4}$ & $7.21 \times 10^{-4}$ & $1.38 \times 10^{-4}$ & $7.64 \times 10^{-5}$ & $6.66 \times 10^{-4}$ & $.35 \times 10^{-4}$ & $8.69 \times 10^{-5}$ & $9.65 \times 10^{-4}$ \\
\hline WQSP-2 & $2.59 \times 10^{-4}$ & $1.52 \times 10^{-4}$ & $6.22 \times 10^{-4}$ & $5.14 \times 10^{-5}$ & $4.42 \times 10^{-5}$ & $7.71 \times 10^{-4}$ & $2.44 \times 10^{-5}$ & $5.11 \times 10^{-5}$ & $9.07 \times 10^{-4}$ \\
\hline WQSP-3 & $2.00 \times 10^{-4}$ & $1.53 \times 10^{-4}$ & $7.13 \times 10^{-4}$ & $1.12 \times 10^{-4}$ & $9.06 \times 10^{-5}$ & $8.34 \times 10^{-4}$ & $5.00 \times 10^{-5}$ & $1.23 \times 10^{-4}$ & $1.19 \times 10^{-3}$ \\
\hline WQSP-4 & $1.78 \times 10^{-4}$ & $1.41 \times 10^{-4}$ & $7.03 \times 10^{-4}$ & $3.37 \times 10^{-5}$ & $6.67 \times 10^{-5}$ & $7.34 \times 10^{-4}$ & $7.80 \times 10^{-5}$ & $7.74 \times 10^{-5}$ & $7.95 \times 10^{-4}$ \\
\hline WQSP-5 & $3.03 \times 10^{-4}$ & $1.66 \times 10^{-4}$ & $8.08 \times 10^{-4}$ & $-1.69 \times 10^{-4}$ & $7.87 \times 10^{-5}$ & $1.01 \times 10^{-3}$ & $.67 \times 10^{-4}$ & $1.13 \times 10^{-4}$ & $9.96 \times 10^{-4}$ \\
\hline WQS & $-3.70 \times 10^{-5}$ & $3.07 \times 10^{-4}$ & $7.36 \times 10^{-4}$ & $-5.45 \times 10^{-5}$ & $1.45 \times 10^{-4}$ & $1.05 \times 10^{-3}$ & $4.55 \times 10^{-4}$ & $2.32 \times 10^{-4}$ & $1.08 \times 10^{-3}$ \\
\hline \multirow[t]{2}{*}{ WQSP-6A } & $97 \times 10^{-4}$ & $2.77 \times 10^{-4}$ & $1.20 \times 10^{-3}$ & $4.86 \times 10^{-5}$ & $7.63 \times 10^{-5}$ & $5.20 \times 10^{-4}$ & $2.49 \times 10^{-5}$ & $1.86 \times 10^{-4}$ & $1.35 \times 10^{-3}$ \\
\hline & \multicolumn{3}{|c|}{${ }^{234} \mathbf{U}$} & \multicolumn{3}{|c|}{${ }^{235} \mathbf{U}$} & \multicolumn{3}{|c|}{${ }^{238} \mathbf{U}$} \\
\hline WQS & $7.79 \times 10^{-1}$ & $1.10 \times 10^{-2}$ & $1.42 \times 10^{-3}$ & $6.79 \times 10^{-3}$ & $4.40 \times 10^{-4}$ & $1.66 \times 10^{-3}$ & & $2.37 \times 10^{-3}$ & $1.41 \times 10^{-3}$ \\
\hline WQSP-2 & $4.82 \times 10^{-1}$ & $5.27 \times 10^{-3}$ & $1.63 \times 10^{-3}$ & $3.66 \times 10^{-3}$ & $2.10 \times 10^{-4}$ & $1.51 \times 10^{-3}$ & $7.35 \times 10^{-2}$ & $1.10 \times 10^{-3}$ & $1.40 \times 10^{-3}$ \\
\hline WQS & $1.41 \times 10^{-1}$ & $2.47 \times 10^{-3}$ & $1.78 \times 10^{-3}$ & $1.24 \times 10^{-3}$ & $2.34 \times 10^{-4}$ & $1.55 \times 10^{-3}$ & $1.93 \times 10^{-2}$ & $6.81 \times 10^{-4}$ & $1.29 \times 10^{-3}$ \\
\hline WQS & $3.24 \times 10^{-1}$ & $4.99 \times 10^{-3}$ & $1.33 \times 10^{-3}$ & $3.33 \times 10^{-3}$ & $3.27 \times 10^{-4}$ & $1.61 \times 10^{-3}$ & $5.42 \times 10^{-2}$ & $1.28 \times 10^{-3}$ & $1.44 \times 10^{-3}$ \\
\hline WQSP-5 & $3.31 \times 10^{-1}$ & $2.84 \times 10^{0}$ & $1.30 \times 10^{-3}$ & $2.91 \times 10^{-3}$ & $3.02 \times 10^{-4}$ & $1.47 \times 10^{-3}$ & $5.00 \times 10^{-2}$ & $1.20 \times 10^{-3}$ & $1.24 \times 10^{-3}$ \\
\hline WQSP-6 & $2.64 \times 10^{-1}$ & $7.26 \times 10^{-3}$ & $1.34 \times 10^{-3}$ & $2.32 \times 10^{-3}$ & $4.67 \times 10^{-4}$ & $1.60 \times 10^{-3}$ & $3.79 \times 10^{-2}$ & $1.71 \times 10^{-3}$ & $1.36 \times 10^{-3}$ \\
\hline \multirow[t]{2}{*}{ WQSP-6A } & $44 \times 10^{-1}$ & $3.33 \times 10^{-3}$ & $1.84 \times 10^{-3}$ & $3.80 \times 10^{-3}$ & $5.41 \times 10^{-4}$ & $2.03 \times 10^{-3}$ & $7.59 \times 10^{-2}$ & $2.12 \times 10^{-3}$ & $1.68 \times 10^{-3}$ \\
\hline & \multicolumn{3}{|c|}{${ }^{137} \mathrm{Cs}$} & \multicolumn{3}{|c|}{${ }^{60} \mathrm{Co}$} & \multicolumn{3}{|c|}{${ }^{40} \mathrm{~K}$} \\
\hline WQSP-1 & $4.71 \times 10^{-1}$ & $9.45 \times 10^{-2}$ & $4.66 \times 10^{-1}$ & $5.27 \times 10^{-2}$ & $9.90 \times 10^{-2}$ & $4.71 \times 10^{-1}$ & $1.35 \times 10^{2}$ & $4.66 \times 10^{0}$ & $1.10 \times 10^{1}$ \\
\hline WQs & $5.51 \times 10^{-1}$ & $5.26 \times 10^{-2}$ & $4.75 \times 10^{-1}$ & $5.30 \times 10^{-2}$ & $5.72 \times 10^{-2}$ & $4.63 \times 10^{-1}$ & $1.18 \times 10^{2}$ & $2.61 \times 10^{0}$ & $1.17 \times 10^{1}$ \\
\hline WQSP-3 & $4.03 \times 10^{-1}$ & $9.55 \times 10^{-2}$ & $4.68 \times 10^{-1}$ & $-2.79 \times 10^{-1}$ & $1.18 \times 10^{-1}$ & $4.73 \times 10^{-1}$ & $1.43 \times 10^{2}$ & $4.65 \times 10^{0}$ & $1.14 \times 10^{1}$ \\
\hline WQSP-4 & $6.53 \times 10^{-1}$ & $9.55 \times 10^{-2}$ & $4.71 \times 10^{-1}$ & $9.16 \times 10^{-2}$ & $1.04 \times 10^{-1}$ & $4.73 \times 10^{-1}$ & $1.35 \times 10^{2}$ & $4.44 \times 10^{0}$ & $1.14 \times 10^{1}$ \\
\hline WQS & $7.14 \times 10^{-2}$ & $9.67 \times 10^{-2}$ & $4.70 \times 10^{-1}$ & $-4.88 \times 10^{-2}$ & $1.03 \times 10^{-1}$ & $4.68 \times 10^{-1}$ & $1.28 \times 10^{2}$ & $4.21 \times 10^{0}$ & $1.17 \times 10^{1}$ \\
\hline QSP-6 & $2.02 \times 10^{-1}$ & $1.44 \times 10^{-1}$ & $4.38 \times 10^{-1}$ & $5.22 \times 10^{-1}$ & $1.73 \times 10^{-1}$ & $4.91 \times 10^{-1}$ & $2.75 \times 10^{2}$ & $1.05 \times 10^{1}$ & $9.83 \times 10^{0}$ \\
\hline \multirow[t]{2}{*}{ WQSP-6A } & $30 \times 10^{-1}$ & $1.17 \times 10^{-1}$ & $4.37 \times 10^{-1}$ & $-4.05 \times 10^{-3}$ & $1.44 \times 10^{-1}$ & $4.87 \times 10^{-1}$ & $2.73 \times 10^{2}$ & $8.52 \times 10^{0}$ & $1.03 \times 10^{1}$ \\
\hline & \multicolumn{3}{|c|}{${ }^{90} \mathrm{Sr}$} & \multicolumn{3}{|c|}{${ }^{226} \mathbf{R a}^{\mathbf{c}}$} & \multicolumn{3}{|c|}{${ }^{228} \mathbf{R a}^{\mathrm{c}}$} \\
\hline WQS & $-3.47 \times 10^{-19}$ & $4.95 \times 10^{-3}$ & $3.89 \times 10^{-2}$ & $3.69 \times 10^{0}$ & $8.05 \times 10^{-2}$ & $3.28 \times 10^{-2}$ & $6.55 \times 10^{-1}$ & $2.17 \times 10^{-2}$ & $9.89 \times 10^{-2}$ \\
\hline WQSP-2 & $1.19 \times 10^{-3}$ & $2.72 \times 10^{-3}$ & $3.98 \times 10^{-2}$ & $4.62 \times 10^{0}$ & $2.38 \times 10^{-2}$ & $3.56 \times 10^{-2}$ & $6.00 \times 10^{-1}$ & $7.72 \times 10^{-3}$ & $1.25 \times 10^{-1}$ \\
\hline WQSP-3 & $-2.59 \times 10^{-3}$ & $4.88 \times 10^{-3}$ & $3.81 \times 10^{-2}$ & $5.24 \times 10^{0}$ & $1.09 \times 10^{-1}$ & $4.43 \times 10^{-2}$ & $7.24 \times 10^{-1}$ & $3.39 \times 10^{-2}$ & $1.62 \times 10^{-1}$ \\
\hline WQSP-4 & $-6.66 \times 10^{-4}$ & $5.02 \times 10^{-3}$ & $3.93 \times 10^{-2}$ & $6.04 \times 10^{0}$ & $1.29 \times 10^{-1}$ & $3.31 \times 10^{-2}$ & $7.82 \times 10^{-1}$ & $2.32 \times 10^{-2}$ & $1.02 \times 10^{-1}$ \\
\hline WQSP-5 & $6.44 \times 10^{-3}$ & $4.93 \times 10^{-3}$ & $3.78 \times 10^{-2}$ & $1.82 \times 10^{0}$ & $4.15 \times 10^{-2}$ & $2.27 \times 10^{-2}$ & $2.42 \times 10^{-1}$ & $1.72 \times 10^{-2}$ & $9.20 \times 10^{-2}$ \\
\hline WQSP-6 & $-1.48 \times 10^{-3}$ & $7.49 \times 10^{-3}$ & $3.74 \times 10^{-2}$ & $\mathrm{~N} / \mathrm{A}^{\mathrm{d}}$ & N/A & N/A & N/A & N/A & N/A \\
\hline WOSP-6A & $-6.78 \times 10^{-3}$ & $5.79 \times 10^{-3}$ & $3.58 \times 10^{-2}$ & $\mathrm{~N} / \mathrm{A}$ & $\mathrm{N} / \mathrm{A}$ & $\mathrm{N} / \mathrm{A}$ & $\mathrm{N} / \mathrm{A}$ & $\mathrm{N} / \mathrm{A}$ & $\mathrm{N} / \mathrm{A}$ \\
\hline
\end{tabular}

${ }^{a}$ Standard deviation of the mean (Total Propagated Uncertainty for ${ }^{226+228}$ Ra; see Footnote ${ }^{c}$ )

${ }^{\mathrm{b}}$ Minimum detectable concentration

${ }^{c}$ Analyzed in only the Fall 2000 samples.

${ }^{\mathrm{d}}$ Not analyzed - Fall 2000 samples from Wells WQSP-6 and -6A were not submitted for analysis February 2001.

between wells (ANOVA, $\mathrm{p}=0.001$ ), with WQSP-1 standing out as higher in concentration than the other wells. However, no pattern related to WIPP activities could be determined. Uranium-234 $(\mathrm{p}=0.063)$ and ${ }^{235} \mathrm{U}(\mathrm{p}=0.490)$ did not differ between wells.
The concentrations of uranium isotopes in water samples collected from these wells were compared between the years 1998, 1999, and 2000. There was no significant difference in the concentration of any uranium isotope (ANOVA, $\mathrm{p}>0.075)$. 
Plutonium-238, ${ }^{239+240} \mathrm{Pu}$, and ${ }^{241} \mathrm{Am}$ were also analyzed in these groundwater samples (Table 4.6). Neither ${ }^{238} \mathrm{Pu}$ nor ${ }^{241} \mathrm{Am}$ were detected in any sample. The concentration of ${ }^{239+240} \mathrm{Pu}$ was greater than the MDC in one sample from well WQSP-4 during the spring sampling $\left(3.62 \times 10^{-4}\right.$ $\pm 4.18 \times 10^{-4} \mathrm{~Bq} / \mathrm{L} ; \mathrm{MDC}=3.27 \times 10^{-4} \mathrm{~Bq} / \mathrm{L}$ $\left[9.78 \times 10^{-3} \pm 1.13 \times 10^{-2} \mathrm{pCi} / \mathrm{L} ; \mathrm{MDC}=8.84 \times 10^{-3}\right.$ $\mathrm{pCi} / \mathrm{L}])$. However, this result was very close to the MDC and less than $2 \times$ TPU. Therefore, ${ }^{239+240} \mathrm{Pu}$ was not likely present in detectable amounts in this sample. The annual mean from WQSP-4, as well as all other individual sample results and means were below the detection limit for ${ }^{239+240} \mathrm{Pu}$. Analysis of variance did not show differences in ${ }^{238} \mathrm{Pu},{ }^{239+240} \mathrm{Pu}$, or ${ }^{241} \mathrm{Am}$ between wells $(p>0.177)$, or between years $1998-2000$ for all wells $(p>0.075)$.

As discussed in last year's Annual Site Environmental Report (DOE/WIPP 00-2225), groundwater results from wells WQSP-1, WQSP-3, and WQSP-4 have exhibited a pattern of activity above the MDC for ${ }^{238} \mathrm{Pu}$ and ${ }^{241} \mathrm{Am}$. In order to help explain these apparently above background concentrations, WIPP began analyzing groundwater for ${ }^{226} \mathrm{Ra}$ and ${ }^{228} \mathrm{Ra}$ during the fall sampling of 2000. Radium-226 was detected in 73 percent of the samples and ${ }^{228} \mathrm{Ra}$ was detected in 67 percent of the samples. Both radionuclides were detected in at least one sample from each of the five wells sampled and the mean concentrations were all above the mean detection limits (Table 4.6). However, the concentrations of ${ }^{226} \mathrm{Ra}$ in water from wells WQSP-1, WQSP-3, and WQSP-4 were all lower than those reported in the 1995 Annual Site Environmental Report $(6.0 \pm 0.06 \mathrm{~Bq} / \mathrm{L}, 7.8 \pm$ $0.06 \mathrm{~Bq} / \mathrm{L}$, and $9.1 \pm 0.07 \mathrm{~Bq} / \mathrm{L}$, respectively).
These results are important because one decay product of ${ }^{226} \mathrm{Ra},{ }^{222} \mathrm{Rn}$, emits alpha particles with an energy of $5.489 \mathrm{MeV}$, very close to the most abundant alpha energy of ${ }^{241} \mathrm{Am}(5.486 \mathrm{MeV})$ and ${ }^{238} \mathrm{Pu}(5.499 \mathrm{MeV})$. Because these energies are close, the region of interest in the alpha spectrum from the groundwater samples likely contained counts originating from ${ }^{222} \mathrm{Rn}$ that were identified as ${ }^{238} \mathrm{Pu}$ or ${ }^{241} \mathrm{Am}$. Additional ${ }^{226} \mathrm{Ra}$ progeny were also likely present. The solubility of the components can vary causing the ${ }^{222} \mathrm{Rn}$ activity and associated ${ }^{226} \mathrm{Ra}$ progeny to appear in some analyses, but not all. This phenomenon may explain the trend of seemingly high concentrations of ${ }^{238} \mathrm{Pu}$ and ${ }^{241} \mathrm{Am}$ observed in some groundwater samples over time. These patterns will become more apparent as more samples are analyzed for ${ }^{226} \mathrm{Ra}$.

Cesium-137 was detected in at least one sample from every well except WQSP-6. However, the annual mean concentration exceeded the annual mean MDC only in wells WQSP-1, WQSP-2 and WQSP-4 (Table 4.6). Cobalt-60 was detected only in wells WQSP-2 and WQSP-6, with the annual mean concentration exceeding the annual mean MDC only in well WQSP-6 (Table 4.6). Strontium-90 was not detectable in any well, and ${ }^{40} \mathrm{~K}$ was detected in all wells.

EEG also measured groundwater for ${ }^{241} \mathrm{Am}$, ${ }^{238} \mathrm{Pu},{ }^{239+240} \mathrm{Pu},{ }^{90} \mathrm{Sr}$, and ${ }^{137} \mathrm{Cs}$ (Table 4.7).

There was a statistically significant difference between the mean concentrations of ${ }^{137} \mathrm{Cs}$ (paired t-test, $\mathrm{p}=0.003$ ) measured by WIPP and EEG, with the mean concentration measured by WIPP being higher. Mean concentrations of ${ }^{90} \mathrm{Sr}$ measured by the two groups was not significantly different (paired t-test, $\mathrm{p}=0.346$ ). No other radionuclides were detected by EEG in any sample. 
Table 4.7 Preliminary radionuclide concentrations $(\mathrm{Bq} / \mathrm{L})$ measured by $\mathrm{EEG}^{\mathrm{a}}$ in groundwater. See Appendix B for locations.

\begin{tabular}{|c|c|c|c|c|c|c|}
\hline \multirow[b]{2}{*}{ Well } & {$[\mathbf{R N}]^{\mathrm{b}}$} & $2 \times \mathrm{TPU}^{\mathrm{c}}$ & {$[\mathbf{R N}]$} & $2 \times$ TPU & {$[\mathbf{R N}]$} & $2 \times \mathrm{TPU}$ \\
\hline & \multicolumn{2}{|c|}{${ }^{241} \mathrm{Am}$} & \multicolumn{2}{|c|}{${ }^{238} \mathrm{Pu}$} & \multicolumn{2}{|c|}{${ }^{239+240} \mathrm{Pu}$} \\
\hline$\overline{\text { WQSP-1 }}$ & $1.22 \times 10^{-3}$ & $9.90 \times 10^{-4}$ & $-2.50 \times 10^{-4}$ & $5.80 \times 10^{-4}$ & $-2.60 \times 10^{-4}$ & $6.00 \times 10^{-4}$ \\
\hline WQSP-2 & $8.70 \times 10^{-4}$ & $1.18 \times 10^{-3}$ & $2.00 \times 10^{-5}$ & $6.70 \times 10^{-4}$ & $-6.00 \times 10^{-5}$ & $6.50 \times 10^{-4}$ \\
\hline WQSP-3 & $6.00 \times 10^{-4}$ & $3.78 \times 10^{-3}$ & $-5.20 \times 10^{-4}$ & $1.23 \times 10^{-3}$ & $1.15 \times 10^{-3}$ & $1.49 \times 10^{-3}$ \\
\hline WQSP-4 & $3.30 \times 10^{-4}$ & $6.40 \times 10^{-4}$ & $1.10 \times 10^{-3}$ & $1.16 \times 10^{-3}$ & $8.70 \times 10^{-4}$ & $1.05 \times 10^{-3}$ \\
\hline WQSP-5 & $\mathrm{NR}^{\mathrm{d}}$ & NR & $1.50 \times 10^{-4}$ & $6.40 \times 10^{-4}$ & $-2.20 \times 10^{-4}$ & $5.90 \times 10^{-4}$ \\
\hline WQSP-6 & $1.70 \times 10^{-4}$ & $7.40 \times 10^{-4}$ & $-3.20 \times 10^{-4}$ & $7.60 \times 10^{-4}$ & $-1.70 \times 10^{-4}$ & $7.20 \times 10^{-4}$ \\
\hline \multirow[t]{2}{*}{ WQSP-6A } & $6.00 \times 10^{-5}$ & $5.80 \times 10^{-4}$ & $-2.10 \times 10^{-4}$ & $5.70 \times 10^{-4}$ & $-3.90 \times 10^{-4}$ & $6.50 \times 10^{-4}$ \\
\hline & \multicolumn{2}{|c|}{${ }^{90} \mathrm{Sr}$} & \multicolumn{2}{|c|}{${ }^{137} \mathrm{Cs}$} & & \\
\hline WQSP-1 & $-4.56 \times 10^{-3}$ & $2.05 \times 10^{-2}$ & $-3.18 \times 10^{-2}$ & $8.11 \times 10^{-2}$ & & \\
\hline WQSP-2 & $2.23 \times 10^{-2}$ & $4.73 \times 10^{-2}$ & $8.11 \times 10^{-2}$ & $8.58 \times 10^{-2}$ & & \\
\hline WQSP-3 & $1.42 \times 10^{-1}$ & $1.02 \times 10^{-1}$ & $1.18 \times 10^{-1}$ & $9.89 \times 10^{-2}$ & & \\
\hline WQSP-4 & $1.68 \times 10^{-3}$ & $7.64 \times 10^{-2}$ & $-3.53 \times 10^{-3}$ & $7.37 \times 10^{-2}$ & & \\
\hline WQSP-5 & $-3.32 \times 10^{-3}$ & $4.67 \times 10^{-2}$ & $1.94 \times 10^{-2}$ & $6.62 \times 10^{-2}$ & & \\
\hline WQSP-6 & $-4.65 \times 10^{-3}$ & $4.11 \times 10^{-2}$ & $-1.41 \times 10^{-2}$ & $5.49 \times 10^{-2}$ & & \\
\hline WQSP-6A & $-4.41 \times 10^{-3}$ & $3.42 \times 10^{-2}$ & $0.00 \times 10^{0}$ & $5.21 \times 10^{-2}$ & & \\
\hline
\end{tabular}

${ }^{\mathrm{a}}$ Environmental Evaluation Group

${ }^{\mathrm{b}}[\mathrm{RN}]=$ Radionuclide concentration

${ }^{\mathrm{c}}$ Total propagated uncertainty

${ }^{\mathrm{d}}$ Not Reported

\subsection{Surface Water}

\subsubsection{Sample Collection}

Fourteen different locations around the WIPP site, as shown in Figure 4.5, were identified for collecting the surface water samples (see Appendix B for location codes). Samples were collected once in 2000. If the surface water collection location was dry, sediment was collected. Sediment results are described in Section 4.7. This year, surface water was collected from all sites, including the FWT, RCP1-4, and SWL.

Water from the sampling location was used to rinse 3.78 -L (1-gal) polyethylene containers several times. Approximately 3.78 L (1-gal) of water was collected from each location. The samples were acidified immediately after collection with concentrated nitric acid to $\mathrm{pH} \leq 2$. Later, the samples were shipped to the contract laboratory for analysis. Chain of custody was maintained throughout the process.

\subsubsection{Determination of Individual Radionuclides}

Gamma-spectrometry was used for the determination of ${ }^{40} \mathrm{~K},{ }^{60} \mathrm{Co}$, and ${ }^{137} \mathrm{Cs}$.

Strontium-90, a beta-emitting radionuclide, was determined by separating it from the sample and beta counting. Uranium, plutonium, and americium were determined by alpha spectrometry. These alpha-emitting radionuclides were separated from the bulk of water samples by co-precipitation with an iron carrier. Ion-exchange chromatography was used for the separation of individual radionuclides. Finally, the samples were counted by alpha spectrometry.

\subsubsection{Results and Discussions}

Isotopes of natural uranium were detected in surface water at every sampling location (Table 4.8). Uranium-238 was lowest at RCP-4 $\left(1.78 \times 10^{-3} \pm 9.11 \times 10^{-4} \mathrm{~Bq} / \mathrm{L}\left[4.81 \times 10^{-2} \pm\right.\right.$ $\left.\left.2.46 \times 10^{-2} \mathrm{pCi} / \mathrm{L}\right]\right)$ and highest at $\mathrm{PCN}$ 


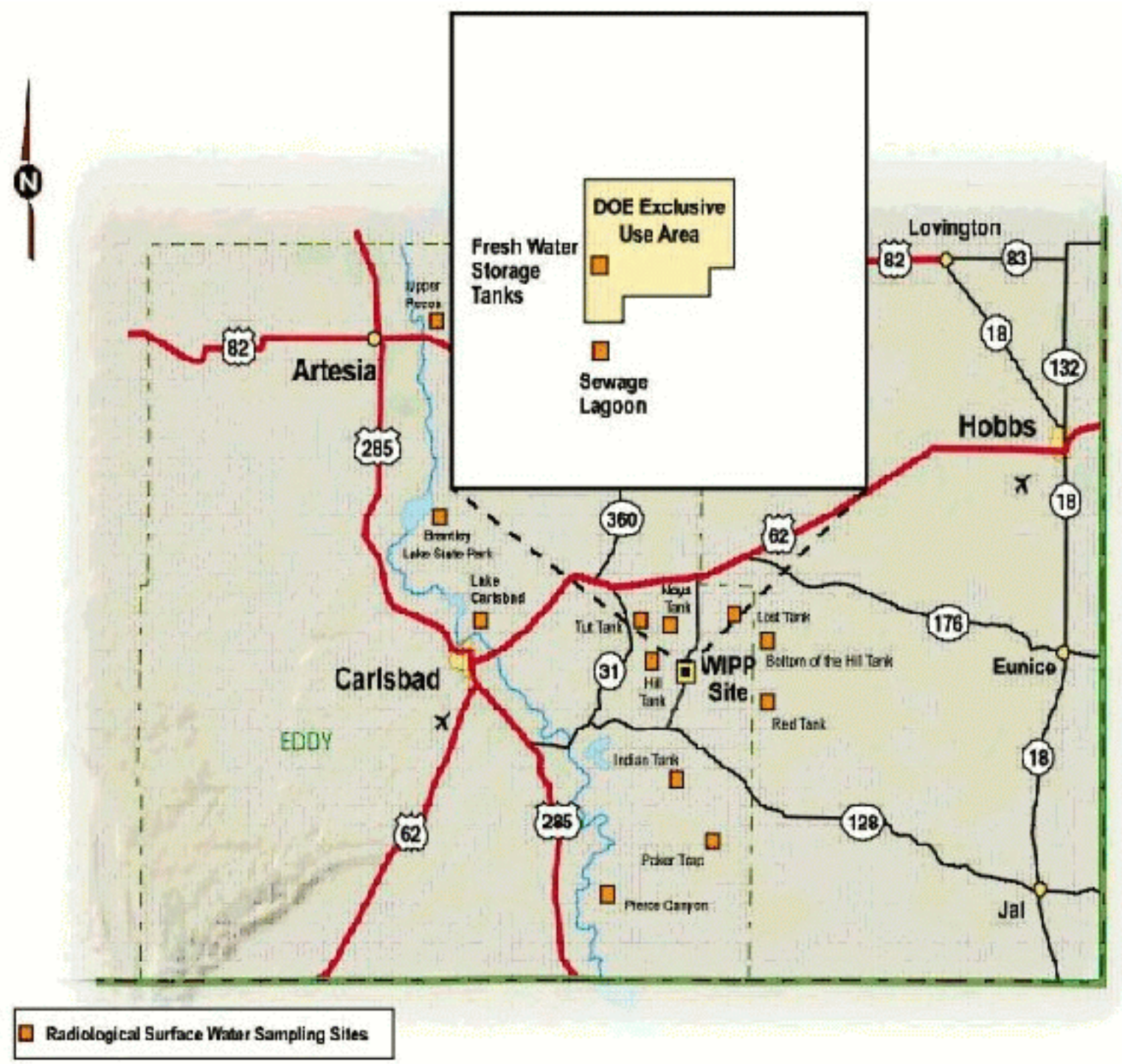

Figure 4.5 Surface water sampling locations in 2000.

$\left(8.72 \times 10^{-2} \pm 7.16 \times 10^{-3} \mathrm{~Bq} / \mathrm{L}\left[2.36 \times 10^{0} \pm\right.\right.$ $\left.\left.1.94 \times 10^{-1} \mathrm{pCi} / \mathrm{L}\right]\right)$. Uranium-235 was detected in 28 percent of the samples. Concentrations ranged from $1.14 \times 10^{-4} \pm 6.02 \times 10^{-4} \mathrm{~Bq} / \mathrm{L}$ $\left(3.08 \times 10^{-3} \pm 1.63 \times 10^{-2} \mathrm{pCi} / \mathrm{L}\right)$ at $\mathrm{RCP}-2$ to $6.09 \times 10^{-3} \pm 1.83 \times 10^{-3} \mathrm{~Bq} / \mathrm{L}\left(1.65 \times 10^{-1} \pm\right.$ $4.95 \times 10^{-2} \mathrm{pCi} / \mathrm{L}$ ) at $\mathrm{PCN}$. Concentrations of ${ }^{234} \mathrm{U}$ ranged from $3.07 \times 10^{-4} \pm 6.83 \times 10^{-4} \mathrm{~Bq} / \mathrm{L}$ $\left(8.30 \times 10^{-3} \pm 1.85 \times 10^{-2} \mathrm{pCi} / \mathrm{L}\right)$ at RCP-4 to $1.90 \times 10^{-1} \pm 1.26 \times 10^{-2} \mathrm{~Bq} / \mathrm{L}\left(5.14 \times 10^{0} \pm\right.$ $\left.3.41 \times 10^{-1} \mathrm{pCi} / \mathrm{L}\right)$ at $\mathrm{PCN}$. It was detected in all but one of the samples.

Results for uranium concentrations in 2000 samples were compared with the uranium concentrations in 1998 and 1999 samples. There was no significant difference in the concentration of any uranium isotope between years (ANOVA, ${ }^{234} \mathrm{U} p=0.544,{ }^{235} \mathrm{U} \mathrm{p}=0.401$, $\left.{ }^{238} \mathrm{U} \mathrm{p}=0.573\right)$. 
Table 4.8 Uranium concentrations $(\mathrm{Bq} / \mathrm{L})$ in surface water near the WIPP site. See Appendix B for the sampling locations.

\begin{tabular}{|c|c|c|c|c|c|c|c|c|c|}
\hline \multirow[b]{2}{*}{ Location } & {$[\mathbf{R N}]^{\mathrm{a}}$} & $2 \times \mathrm{TPU}^{\mathrm{b}}$ & MDC $^{\mathrm{c}}$ & [RN] & $2 \times \mathrm{TPU}$ & MDC & {$[\mathrm{RN}]$} & $2 \times \mathrm{TPU}$ & MDC \\
\hline & & ${ }^{234} \mathbf{U}$ & & \multicolumn{3}{|c|}{${ }^{235} \mathrm{U}$} & \multicolumn{3}{|c|}{${ }^{238} \mathbf{U}$} \\
\hline BHT & $1.86 \times 10^{-2}$ & $3.13 \times 10^{-3}$ & $1.32 \times 10^{-3}$ & $9.28 \times 10^{-4}$ & $1.04 \times 10^{-3}$ & $1.80 \times 10^{-3}$ & $2.13 \times 10^{-2}$ & $3.37 \times 10^{-3}$ & $1.45 \times 10^{-3}$ \\
\hline BRA & $9.93 \times 10^{-2}$ & $8.00 \times 10^{-3}$ & $1.73 \times 10^{-3}$ & $3.01 \times 10^{-3}$ & $1.54 \times 10^{-3}$ & $2.09 \times 10^{-3}$ & $5.15 \times 10^{-2}$ & $5.22 \times 10^{-3}$ & $1.44 \times 10^{-3}$ \\
\hline CBD & $1.51 \times 10^{-1}$ & $1.08 \times 10^{-2}$ & $1.01 \times 10^{-3}$ & $4.41 \times 10^{-3}$ & $1.60 \times 10^{-3}$ & $1.42 \times 10^{-3}$ & $7.07 \times 10^{-2}$ & $6.38 \times 10^{-3}$ & $9.31 \times 10^{-4}$ \\
\hline FWT & $5.89 \times 10^{-2}$ & $5.62 \times 10^{-3}$ & $1.11 \times 10^{-3}$ & $1.14 \times 10^{-3}$ & $9.25 \times 10^{-4}$ & $1.37 \times 10^{-3}$ & $2.14 \times 10^{-2}$ & $3.10 \times 10^{-3}$ & $1.11 \times 10^{-3}$ \\
\hline HIL & $1.99 \times 10^{-2}$ & $3.14 \times 10^{-3}$ & $2.21 \times 10^{-3}$ & $1.09 \times 10^{-3}$ & $1.52 \times 10^{-3}$ & $2.86 \times 10^{-3}$ & $1.82 \times 10^{-2}$ & $2.89 \times 10^{-3}$ & $1.47 \times 10^{-3}$ \\
\hline IDN & $8.28 \times 10^{-3}$ & $1.89 \times 10^{-3}$ & $1.05 \times 10^{-3}$ & $1.08 \times 10^{-3}$ & $8.35 \times 10^{-4}$ & $1.12 \times 10^{-3}$ & $8.64 \times 10^{-3}$ & $1.91 \times 10^{-3}$ & $9.01 \times 10^{-4}$ \\
\hline LST & $1.98 \times 10^{-2}$ & $3.00 \times 10^{-3}$ & $1.13 \times 10^{-3}$ & $1.71 \times 10^{-3}$ & $1.05 \times 10^{-3}$ & $1.31 \times 10^{-3}$ & $2.24 \times 10^{-2}$ & $3.23 \times 10^{-3}$ & $1.43 \times 10^{-3}$ \\
\hline NOY & $1.45 \times 10^{-2}$ & $2.66 \times 10^{-3}$ & $1.30 \times 10^{-3}$ & $1.87 \times 10^{-3}$ & $1.15 \times 10^{-3}$ & $1.44 \times 10^{-3}$ & $2.04 \times 10^{-2}$ & $3.17 \times 10^{-3}$ & $1.16 \times 10^{-3}$ \\
\hline $\mathrm{PCN}$ & $1.90 \times 10^{-1}$ & $1.26 \times 10^{-2}$ & $1.55 \times 10^{-3}$ & $6.09 \times 10^{-3}$ & $1.83 \times 10^{-3}$ & $1.54 \times 10^{-3}$ & $8.72 \times 10^{-2}$ & $7.16 \times 10^{-3}$ & $1.14 \times 10^{-3}$ \\
\hline PKT & $3.95 \times 10^{-2}$ & $4.94 \times 10^{-3}$ & $2.42 \times 10^{-3}$ & $3.34 \times 10^{-3}$ & $2.24 \times 10^{-3}$ & $3.68 \times 10^{-3}$ & $4.06 \times 10^{-2}$ & $4.92 \times 10^{-3}$ & $1.51 \times 10^{-3}$ \\
\hline RCP1 & $8.47 \times 10^{-3}$ & $1.95 \times 10^{-3}$ & $1.03 \times 10^{-3}$ & $5.07 \times 10^{-4}$ & $7.39 \times 10^{-4}$ & $1.36 \times 10^{-3}$ & $7.21 \times 10^{-3}$ & $1.83 \times 10^{-3}$ & $1.29 \times 10^{-3}$ \\
\hline $\mathrm{RCP} 2$ & $3.28 \times 10^{-3}$ & $1.21 \times 10^{-3}$ & $1.16 \times 10^{-3}$ & $1.14 \times 10^{-4}$ & $6.02 \times 10^{-4}$ & $1.37 \times 10^{-3}$ & $3.54 \times 10^{-3}$ & $1.25 \times 10^{-3}$ & $1.16 \times 10^{-3}$ \\
\hline RCP3 & $1.36 \times 10^{-2}$ & $2.48 \times 10^{-3}$ & $1.26 \times 10^{-3}$ & $6.16 \times 10^{-4}$ & $1.14 \times 10^{-3}$ & $2.23 \times 10^{-3}$ & $8.89 \times 10^{-3}$ & $2.07 \times 10^{-3}$ & $1.69 \times 10^{-3}$ \\
\hline $\mathrm{RCP} 4$ & $3.07 \times 10^{-4}$ & $6.83 \times 10^{-4}$ & $1.40 \times 10^{-3}$ & $3.07 \times 10^{-4}$ & $6.83 \times 10^{-4}$ & $1.40 \times 10^{-3}$ & $1.78 \times 10^{-3}$ & $9.11 \times 10^{-4}$ & $9.19 \times 10^{-4}$ \\
\hline RED & $1.60 \times 10^{-2}$ & $2.72 \times 10^{-3}$ & $9.63 \times 10^{-4}$ & $9.60 \times 10^{-4}$ & $8.60 \times 10^{-4}$ & $1.29 \times 10^{-3}$ & $1.65 \times 10^{-2}$ & $2.75 \times 10^{-3}$ & $7.60 \times 10^{-4}$ \\
\hline TUT & $1.62 \times 10^{-2}$ & $2.76 \times 10^{-3}$ & $1.06 \times 10^{-3}$ & $9.74 \times 10^{-4}$ & $8.72 \times 10^{-4}$ & $1.31 \times 10^{-3}$ & $1.89 \times 10^{-2}$ & $2.99 \times 10^{-3}$ & $9.73 \times 10^{-4}$ \\
\hline SWL & $1.29 \times 10^{-2}$ & $2.62 \times 10^{-3}$ & $1.41 \times 10^{-3}$ & $2.17 \times 10^{-4}$ & $7.53 \times 10^{-4}$ & $1.65 \times 10^{-3}$ & $7.71 \times 10^{-3}$ & $2.00 \times 10^{-3}$ & $1.26 \times 10^{-3}$ \\
\hline TUT & $9.25 \times 10^{-3}$ & $2.03 \times 10^{-3}$ & $1.14 \times 10^{-3}$ & $6.79 \times 10^{-4}$ & $8.10 \times 10^{-4}$ & $1.41 \times 10^{-3}$ & $8.61 \times 10^{-3}$ & $1.95 \times 10^{-3}$ & $1.14 \times 10^{-3}$ \\
\hline UPR & $1.48 \times 10^{-1}$ & $1.10 \times 10^{-2}$ & $2.45 \times 10^{-3}$ & $2.29 \times 10^{-3}$ & $1.85 \times 10^{-3}$ & $3.17 \times 10^{-3}$ & $6.98 \times 10^{-2}$ & $6.58 \times 10^{-3}$ & $1.63 \times 10^{-3}$ \\
\hline
\end{tabular}

Analysis of variance was also used to test for differences in uranium concentration between sampling locations. Differences were detected for each uranium isotope $(\mathrm{p}<0.001)$. Pierce Canyon (PCN) had the highest concentrations, with other locations along the Pecos River (BRA, CBD, and UPR) in another homogeneous subset of the data. All of the surface tanks were in another homogeneous subset having the lowest concentrations. Large spatial variations in uranium concentration in surface water are expected because of the different characteristics of the water bodies and the underlying sediments. For example, the PCN site drains a large surface area and leaches uranium from the sediments. The TUT tank is mostly rainwater and has relatively little contact with sediments.
In 1998, significant differences in uranium concentrations were observed between sampling locations along the Pecos River. These were explained as resulting from different concentrations of suspended sediments due to different water speeds. Uranium concentrations in surface water from the four river locations (BRA, CBD, PCN, and UPR) were compared across the years 1998-2000 to test this hypothesis. Significant differences in concentration were found for ${ }^{234} \mathrm{U}$ and ${ }^{238} \mathrm{U}$, but no significant difference was found for ${ }^{235} \mathrm{U}$. For the two nuclides exhibiting significant differences, PCN had the highest concentration with the other locations making up a homogeneous subset. These results make the hypothesis seem unlikely and the observed differences are likely due to normal annual variability. 
These water samples were also analyzed for ${ }^{238} \mathrm{Pu},{ }^{239+240} \mathrm{Pu}$, and ${ }^{241} \mathrm{Am}$ (Table 4.9).

Concentrations of ${ }^{238} \mathrm{Pu}$ and ${ }^{239+240} \mathrm{Pu}$ were below the MDC in every sample. Americium-241 was greater than the minimum detectable concentration in the sample from BHT (Table 4.9) but its value was less than $2 \times$ TPU. There was no statistically significant difference in concentration between sampling locations (ANOVA, $p>0.591$ ) for any of these radionuclides. On the other hand, there was a significant difference between years.

Americium-241 $(\mathrm{p}=0.003),{ }^{238} \mathrm{Pu}(\mathrm{p}<0.001)$, and ${ }^{239+240} \mathrm{Pu}(\mathrm{p}<0.001)$ were all significantly lower in 1999 than in either 1998 or 2000 , which were not different from one another. While this result is interesting, it does not provide evidence of contamination of surface water due to WIPP activities because waste was not stored at WIPP prior to 1999.

Potassium- $40,{ }^{60} \mathrm{Co},{ }^{90} \mathrm{Sr}$, and ${ }^{137} \mathrm{Cs}$ are ubiquitous in soils and might reasonably be expected in surface water samples due to leaching from sediments. As expected, ${ }^{40} \mathrm{~K}$ was detected in 70 percent of the surface water samples (Table 4.10). It's concentration ranged from $7.81 \times 10^{0} \pm 8.35 \times 10^{0} \mathrm{~Bq} / \mathrm{L}\left(2.11 \times 10^{2} \pm\right.$ $\left.2.26 \times 10^{2} \mathrm{pCi} / \mathrm{L}\right)$ at IDN to $2.89 \times 10^{2} \pm 1.57 \times 10^{1}$ $\mathrm{Bq} / \mathrm{L}\left(7.81 \times 10^{3} \pm 4.24 \times 10^{2} \mathrm{pCi} / \mathrm{L}\right)$ at $\mathrm{RCP}-2$. Cobalt-60 and ${ }^{137} \mathrm{Cs}$ were each detected in 17 percent of the samples, although at different sampling locations. Cobalt-60 ranged from $-5.10 \times 10^{-1} \pm 3.95 \times 10^{-1} \mathrm{~Bq} / \mathrm{L}\left(-1.38 \times 10^{1} \pm\right.$ $\left.1.07 \times 10^{1} \mathrm{pCi} / \mathrm{L}\right)$ at $\mathrm{BHT}$ to $6.75 \times 10^{-1} \pm$ $3.63 \times 10^{-1} \mathrm{~Bq} / \mathrm{L}\left(1.82 \times 10^{1} \pm 9.81 \times 10^{0} \mathrm{pCi} / \mathrm{L}\right)$ at SWL. Strontium-90 was not detected in any surface water sample.

Table 4.9 Americium and plutonium concentrations $(\mathrm{Bq} / \mathrm{L})$ in surface water near the WIPP site. See Appendix B for the sampling locations.

\begin{tabular}{|c|c|c|c|c|c|c|c|c|c|}
\hline \multirow[b]{2}{*}{ Location } & {$[\mathbf{R N}]^{\mathrm{a}}$} & $2 \times$ TPU $^{b}$ & MDC $^{\mathrm{c}}$ & {$[\mathrm{RN}]$} & $2 \times \mathrm{TPU}$ & MDC & [RN] & $2 \times \mathrm{TPU}$ & MDC \\
\hline & \multicolumn{3}{|c|}{${ }^{241} \mathrm{Am}$} & \multicolumn{3}{|c|}{${ }^{238} \mathrm{Pu}$} & \multicolumn{3}{|c|}{${ }^{239+240} \mathrm{Pu}$} \\
\hline HT & $4.92 \times 10^{-4}$ & $.76 \times 10^{-4}$ & $13 \times 10$ & $-3.17 \times 10^{-5}$ & $3.85 \times 10^{-4}$ & $23 \times 10^{-3}$ & $-3.16 \times 10^{-4}$ & $6.00 \times 10^{-4}$ & $1.90 \times 10^{-3}$ \\
\hline BRA & $2.57 \times 10^{-4}$ & $6.70 \times 10^{-4}$ & $26 \times 10^{-4}$ & $2.85 \times 10^{-4}$ & $.23 \times 10^{-4}$ & $.00 \times 10^{-3}$ & $1.77 \times 10^{-4}$ & $6.92 \times 10^{-4}$ & $1.65 \times 10^{-3}$ \\
\hline $\mathrm{BD}$ & $3.32 \times 10^{-4}$ & $6.58 \times 10^{-4}$ & $8.17 \times 10^{-4}$ & $1.04 \times 10^{-4}$ & $3.74 \times 10^{-4}$ & $9.80 \times 10^{-4}$ & $-4.51 \times 10^{-4}$ & $5.43 \times 10^{-4}$ & $2.00 \times 10^{-3}$ \\
\hline FWT & $2.27 \times 10^{-6}$ & $5.56 \times 10^{-4}$ & $05 \times 10^{-3}$ & $.56 \times 10^{-4}$ & $3.12 \times 10^{-4}$ & $4.22 \times 10^{-4}$ & $1.25 \times 10^{-4}$ & $4.90 \times 10^{-4}$ & $.21 \times 10^{-3}$ \\
\hline HIL & $1.32 \times 10^{-4}$ & $5.28 \times 10^{-4}$ & $7.30 \times 10^{-4}$ & $2.15 \times 10^{-4}$ & $5.45 \times 10^{-4}$ & $1.23 \times 10^{-3}$ & $-3.57 \times 10^{-5}$ & $4.34 \times 10^{-4}$ & $1.39 \times 10^{-3}$ \\
\hline IDN & $1.84 \times 10^{-4}$ & $6.72 \times 10^{-4}$ & $1.11 \times 10^{-3}$ & $1.18 \times 10^{-4}$ & $4.63 \times 10^{-4}$ & $1.14 \times 10^{-3}$ & $2.05 \times 10^{-4}$ & $5.60 \times 10^{-4}$ & $1.26 \times 10^{-3}$ \\
\hline LST & $8.10 \times 10^{-5}$ & $5.79 \times 10^{-4}$ & $1.05 \times 10^{-3}$ & $3.27 \times 10^{-5}$ & $3.76 \times 10^{-4}$ & $.12 \times 10^{-3}$ & $2.28 \times 10^{-4}$ & $6.22 \times 10^{-4}$ & $1.40 \times 10^{-3}$ \\
\hline NOY & $3.78 \times 10^{-4}$ & $7.03 \times 10^{-4}$ & $8.73 \times 10^{-4}$ & $-2.17 \times 10^{-5}$ & $2.65 \times 10^{-4}$ & $8.47 \times 10^{-4}$ & $3.69 \times 10^{-4}$ & $5.16 \times 10^{-4}$ & $9.32 \times 10^{-4}$ \\
\hline $\mathrm{CN}$ & $1.65 \times 10^{-4}$ & $8.26 \times 10^{-4}$ & $1.56 \times 10^{-3}$ & $2.54 \times 10^{-4}$ & $4.67 \times 10^{-4}$ & $8.95 \times 10^{-4}$ & $-3.17 \times 10^{-5}$ & $3.86 \times$ & $1.24 \times 10^{-3}$ \\
\hline PKT & $4.49 \times 10^{-4}$ & $6.36 \times 10^{-4}$ & $6.70 \times 10^{-4}$ & $2.31 \times 10^{-4}$ & $4.24 \times 10^{-4}$ & $8.13 \times 10^{-4}$ & $6.05 \times 10^{-4}$ & $6.65 \times 10^{-4}$ & $9.89 \times 10^{-4}$ \\
\hline $\mathrm{RCP} 1$ & $1.45 \times 10^{-4}$ & $7.69 \times 10^{-4}$ & $1.48 \times 10^{-3}$ & $1.92 \times 10^{-4}$ & $3.53 \times 10^{-4}$ & $6.77 \times 10^{-4}$ & $1.68 \times 10^{-4}$ & $4.57 \times 10^{-4}$ & $1.03 \times 10^{-3}$ \\
\hline $\mathrm{CP} 2$ & $1.75 \times 10^{-4}$ & $5.77 \times 10^{-4}$ & & & $3.57 \times 10^{-4}$ & $1.70 \times 10^{-3}$ & & $5.75 \times 10^{-4}$ & $1.37 \times 10^{-3}$ \\
\hline $\mathrm{RCP} 3$ & $1.78 \times 10^{-4}$ & $5.81 \times 10^{-4}$ & $8.03 \times 10^{-4}$ & $8.90 \times 10^{-5}$ & $3.20 \times 10^{-4}$ & $8.36 \times 10^{-4}$ & $-1.48 \times 10^{-4}$ & $6.35 \times 10^{-4}$ & $1.78 \times 10^{-3}$ \\
\hline $\mathrm{RCP} 4$ & $2.72 \times 10^{-4}$ & $5.98 \times 10^{-4}$ & $7.43 \times 10^{-4}$ & $8.31 \times 10^{-5}$ & $2.98 \times 10^{-4}$ & $7.80 \times 10^{-4}$ & $6.90 \times 10^{-4}$ & $7.73 \times 10^{-4}$ & $1.28 \times 10^{-3}$ \\
\hline RED & $1.43 \times 10^{-4}$ & $6.19 \times 10^{-4}$ & $1.02 \times 10^{-3}$ & $3.69 \times 10^{-4}$ & $5.23 \times 10^{-4}$ & $4.99 \times 10^{-4}$ & $5.15 \times 10^{-4}$ & $7.80 \times 10^{-4}$ & $1.44 \times 10^{-3}$ \\
\hline TUT & $1.10 \times 10^{-5}$ & $5.71 \times 10^{-4}$ & $1.08 \times 10^{-3}$ & $2.02 \times 10^{-4}$ & $5.12 \times 10^{-4}$ & $1.15 \times 10^{-3}$ & $3.02 \times 10^{-4}$ & $6.26 \times 10^{-4}$ & $1.31 \times 10^{-3}$ \\
\hline SWL & $2.73 \times 10^{-4}$ & $5.87 \times 10^{-4}$ & $8.00 \times 10^{-4}$ & $-1.70 \times 10^{-4}$ & $1.97 \times 10^{-4}$ & $1.10 \times 10^{-3}$ & $5.66 \times 10^{-5}$ & $4.60 \times 10^{-4}$ & $1.22 \times 10^{-3}$ \\
\hline TUT & $-2.13 \times 10^{-4}$ & $4.73 \times 10^{-4}$ & $1.17 \times 10^{-3}$ & $3.23 \times 10^{-5}$ & $3.71 \times 10^{-4}$ & $1.11 \times 10^{-3}$ & $6.44 \times 10^{-5}$ & $5.24 \times 10^{-4}$ & $1.38 \times 10^{-3}$ \\
\hline UPR & $3.01 \times 10^{-4}$ & $7.20 \times 10^{-4}$ & $9.95 \times 10^{-4}$ & $-2.75 \times 10^{-5}$ & $3.35 \times 10^{-4}$ & $1.07 \times 10^{-3}$ & $5.49 \times 10^{-5}$ & $4.46 \times 10^{-4}$ & $1.18 \times 10^{-3}$ \\
\hline
\end{tabular}

${ }^{\mathrm{a}}[\mathrm{RN}]=$ Radionuclide concentration

$\mathrm{b}$ Total propagated uncertainty

${ }^{\mathrm{c}}$ Minimum detectable concentration 
Table 4.10 Selected radionuclide concentrations $(\mathrm{Bq} / \mathrm{L})$ in surface water near the WIPP site. See Appendix B for the sampling locations.

\begin{tabular}{|c|c|c|c|c|c|c|}
\hline & {$[\mathbf{R N}]^{\mathrm{a}}$} & $2 \times \mathrm{TPU}^{\mathrm{b}}$ & $\mathrm{MDC}^{\mathrm{c}}$ & [RN] & $2 \times \mathrm{TPU}$ & MDC \\
\hline Location & \multicolumn{3}{|c|}{${ }^{137} \mathrm{Cs}$} & \multicolumn{3}{|c|}{${ }^{60} \mathrm{Co}$} \\
\hline $\mathrm{BHT}$ & $-1.19 \times 10^{-1}$ & $3.81 \times 10^{-1}$ & $4.46 \times 10^{-1}$ & $-5.10 \times 10^{-1}$ & $3.95 \times 10^{-1}$ & $4.23 \times 10^{-1}$ \\
\hline BRA & $-1.05 \times 10^{-1}$ & $3.84 \times 10^{-3}$ & $4.50 \times 10^{-1}$ & $-4.60 \times 10^{-2}$ & $3.83 \times 10^{-1}$ & $4.24 \times 10^{-1}$ \\
\hline CBD & $2.57 \times 10^{-1}$ & $3.73 \times 10^{-1}$ & $4.42 \times 10^{-1}$ & $2.87 \times 10^{-1}$ & $3.66 \times 10^{-1}$ & $4.16 \times 10^{-1}$ \\
\hline FWT & $4.23 \times 10^{-1}$ & $3.73 \times 10^{-1}$ & $4.45 \times 10^{-1}$ & $1.35 \times 10^{-1}$ & $3.75 \times 10^{-1}$ & $4.21 \times 10^{-1}$ \\
\hline HIL & $1.29 \times 10^{-1}$ & $3.80 \times 10^{-1}$ & $4.48 \times 10^{-1}$ & $5.90 \times 10^{-1}$ & $3.72 \times 10^{-1}$ & $4.30 \times 10^{-1}$ \\
\hline IDN & $7.60 \times 10^{-1}$ & $3.74 \times 10^{-1}$ & $4.50 \times 10^{-1}$ & $3.77 \times 10^{-1}$ & $3.76 \times 10^{-1}$ & $4.28 \times 10^{-1}$ \\
\hline LST & $8.69 \times 10^{-1}$ & $3.64 \times 10^{-1}$ & $4.39 \times 10^{-1}$ & $-2.41 \times 10^{-1}$ & $3.80 \times 10^{-1}$ & $4.14 \times 10^{-1}$ \\
\hline NOY & $-1.47 \times 10^{-1}$ & $3.79 \times 10^{-1}$ & $4.42 \times 10^{-1}$ & $-2.46 \times 10^{-1}$ & $3.80 \times 10^{-1}$ & $4.14 \times 10^{-1}$ \\
\hline $\mathrm{PCN}$ & $2.32 \times 10^{-1}$ & $3.72 \times 10^{-1}$ & $4.41 \times 10^{-1}$ & $-8.31 \times 10^{-2}$ & $3.76 \times 10^{-1}$ & $4.15 \times 10^{-1}$ \\
\hline PKT & $3.14 \times 10^{-1}$ & $3.76 \times 10^{-1}$ & $4.47 \times 10^{-1}$ & $-1.90 \times 10^{-1}$ & $3.88 \times 10^{-1}$ & $4.24 \times 10^{-1}$ \\
\hline RCP1 & $-2.52 \times 10^{-1}$ & $3.81 \times 10^{-1}$ & $4.43 \times 10^{-1}$ & $-4.23 \times 10^{-1}$ & $3.89 \times 10^{-1}$ & $4.19 \times 10^{-1}$ \\
\hline RCP2 & $3.05 \times 10^{-1}$ & $3.80 \times 10^{-1}$ & $4.51 \times 10^{-1}$ & $5.04 \times 10^{-1}$ & $3.70 \times 10^{-1}$ & $4.26 \times 10^{-1}$ \\
\hline $\mathrm{RCP} 3$ & $4.36 \times 10^{-1}$ & $3.74 \times 10^{-1}$ & $4.46 \times 10^{-1}$ & $-3.63 \times 10^{-1}$ & $3.89 \times 10^{-1}$ & $4.20 \times 10^{-1}$ \\
\hline RCP4 & $8.94 \times 10^{-1}$ & $3.61 \times 10^{-1}$ & $4.36 \times 10^{-2}$ & $-3.70 \times 10^{-1}$ & $3.85 \times 10^{-1}$ & $4.16 \times 10^{-1}$ \\
\hline RED & $-2.05 \times 10^{-1}$ & $3.73 \times 10^{-1}$ & $4.14 \times 10^{-1}$ & $-1.34 \times 10^{-1}$ & $3.76 \times 10^{-1}$ & $4.14 \times 10^{-1}$ \\
\hline TUT & $2.81 \times 10^{-1}$ & $3.74 \times 10^{-1}$ & $4.44 \times 10^{-1}$ & $-4.07 \times 10^{-1}$ & $3.87 \times 10^{-1}$ & $4.17 \times 10^{-1}$ \\
\hline SWL & $3.60 \times 10^{-1}$ & $3.74 \times 10^{-1}$ & $4.44 \times 10^{-1}$ & $6.75 \times 10^{-1}$ & $3.63 \times 10^{-1}$ & $4.23 \times 10^{-1}$ \\
\hline TUT & $-2.62 \times 10^{-1}$ & $3.81 \times 10^{-1}$ & $4.43 \times 10^{-1}$ & $3.54 \times 10^{-1}$ & $3.67 \times 10^{-1}$ & $4.18 \times 10^{-1}$ \\
\hline \multirow[t]{2}{*}{ UPR } & $-8.63 \times 10^{-1}$ & $3.98 \times 10^{-1}$ & $4.47 \times 10^{-1}$ & $9.61 \times 10^{-2}$ & $3.57 \times 10^{-1}$ & $4.03 \times 10^{-1}$ \\
\hline & \multicolumn{3}{|c|}{${ }^{90} \mathrm{Sr}$} & \multicolumn{3}{|c|}{${ }^{40} \mathrm{~K}$} \\
\hline BHT & $-2.59 \times 10^{-3}$ & $1.74 \times 10^{-2}$ & $3.15 \times 10^{-2}$ & $1.33 \times 10^{1}$ & $3.68 \times 10^{0}$ & $1.18 \times 10^{1}$ \\
\hline BRA & $5.92 \times 10^{-3}$ & $2.15 \times 10^{-2}$ & $3.74 \times 10^{-2}$ & $8.71 \times 10^{0}$ & $3.74 \times 10^{0}$ & $1.22 \times 10^{1}$ \\
\hline CBD & $1.63 \times 10^{-2}$ & $2.18 \times 10^{-2}$ & $3.70 \times 10^{-2}$ & $2.73 \times 10^{2}$ & $1.48 \times 10^{1}$ & $9.14 \times 10^{0}$ \\
\hline FWT & $1.33 \times 10^{-2}$ & $1.92 \times 10^{-2}$ & $3.22 \times 10^{-2}$ & $2.79 \times 10^{2}$ & $1.52 \times 10^{1}$ & $9.22 \times 10^{0}$ \\
\hline HIL & $5.92 \times 10^{-3}$ & $1.96 \times 10^{-2}$ & $3.44 \times 10^{-2}$ & $1.04 \times 10^{1}$ & $3.81 \times 10^{0}$ & $1.24 \times 10^{1}$ \\
\hline IDN & $5.55 \times 10^{-3}$ & $1.81 \times 10^{-2}$ & $3.18 \times 10^{-2}$ & $7.81 \times 10^{0}$ & $3.85 \times 10^{0}$ & $1.26 \times 10^{1}$ \\
\hline LST & $7.40 \times 10^{-3}$ & $1.89 \times 10^{-2}$ & $3.26 \times 10^{-2}$ & $2.74 \times 10^{2}$ & $1.49 \times 10^{1}$ & $9.11 \times 10^{0}$ \\
\hline NOY & $1.15 \times 10^{-2}$ & $1.96 \times 10^{-2}$ & $3.33 \times 10^{-2}$ & $2.86 \times 10^{2}$ & $1.55 \times 10^{1}$ & $9.23 \times 10^{0}$ \\
\hline $\mathrm{PCN}$ & $8.88 \times 10^{-3}$ & $2.37 \times 10^{-2}$ & $4.11 \times 10^{-2}$ & $2.78 \times 10^{2}$ & $1.51 \times 10^{1}$ & $9.21 \times 10^{0}$ \\
\hline PKT & $2.11 \times 10^{-2}$ & $1.96 \times 10^{-2}$ & $3.18 \times 10^{-2}$ & $2.85 \times 10^{2}$ & $1.55 \times 10^{1}$ & $9.31 \times 10^{0}$ \\
\hline RCP1 & $1.11 \times 10^{-3}$ & $1.70 \times 10^{-2}$ & $3.03 \times 10^{-2}$ & $9.10 \times 10^{0}$ & $3.64 \times 10^{0}$ & $1.18 \times 10^{1}$ \\
\hline $\mathrm{RCP} 2$ & $1.07 \times 10^{-2}$ & $1.74 \times 10^{-2}$ & $3.00 \times 10^{-2}$ & $2.89 \times 10^{2}$ & $1.57 \times 10^{1}$ & $9.41 \times 10^{0}$ \\
\hline $\mathrm{RCP} 3$ & $3.70 \times 10^{-4}$ & $1.89 \times 10^{-2}$ & $3.37 \times 10^{-2}$ & $9.04 \times 10^{0}$ & $3.77 \times 10^{0}$ & $1.23 \times 10^{1}$ \\
\hline RCP4 & $-1.26 \times 10^{-2}$ & $1.59 \times 10^{-2}$ & $3.07 \times 10^{-2}$ & $2.66 \times 10^{2}$ & $1.45 \times 10^{1}$ & $8.99 \times 10^{0}$ \\
\hline RED & $1.85 \times 10^{-3}$ & $1.78 \times 10^{-2}$ & $3.18 \times 10^{-2}$ & $2.64 \times 10^{2}$ & $1.44 \times 10^{1}$ & $8.98 \times 10^{0}$ \\
\hline TUT & $1.85 \times 10^{-3}$ & $1.74 \times 10^{-2}$ & $3.07 \times 10^{-2}$ & $2.74 \times 10^{2}$ & $1.49 \times 10^{1}$ & $9.16 \times 10^{0}$ \\
\hline SWL & $-3.70 \times 10^{-3}$ & $1.89 \times 10^{-2}$ & $3.40 \times 10^{-2}$ & $2.86 \times 10^{2}$ & $1.55 \times 10^{1}$ & $9.32 \times 10^{0}$ \\
\hline TUT & $1.15 \times 10^{-2}$ & $2.00 \times 10^{-2}$ & $3.37 \times 10^{-2}$ & $2.85 \times 10^{2}$ & $1.54 \times 10^{1}$ & $9.17 \times 10^{0}$ \\
\hline UPR & $8.51 \times 10^{-3}$ & $2.07 \times 10^{-2}$ & $3.55 \times 10^{-2}$ & $2.80 \times 10^{2}$ & $1.54 \times 10^{1}$ & $9.17 \times 10^{0}$ \\
\hline
\end{tabular}

${ }^{\mathrm{a}}[\mathrm{RN}]=$ Radionuclide concentration

$\mathrm{b}$ Total propagated uncertainty

${ }^{\mathrm{c}}$ Minimum detectable concentration 
Duplicate samples were collected from three locations (BHT, PCN, and RCP-1) to check the reproducibility of the sampling and the measurement techniques (Table 4.11). The RER values for ${ }^{241} \mathrm{Am}$ and the plutonium uranium isotopes in these samples were all less than one, indicating no difference between duplicate samples. For the uranium isotopes, only about half of the RER values were less than one, indicating much less reproducibility in uranium measurements. However, across all three uranium isotopes, a paired-sample t-test, using duplicate samples as the pairs, found no significant differences between pairs $(p>0.153)$.

EEG also analyzed for ${ }^{238} \mathrm{Pu},{ }^{239+240} \mathrm{Pu}$, ${ }^{241} \mathrm{Am},{ }^{137} \mathrm{Cs}$, and ${ }^{90} \mathrm{Sr}$ in surface water samples collected from around the WIPP site (Table 4.12). EEG reported a possible detection of ${ }^{90} \mathrm{Sr}$ at PCN where WIPP did not detect any ${ }^{90} \mathrm{Sr}$. Neither organization detected any of the target radionuclides at any other common sampling location.

Table 4.11 Results of duplicate surface water sample analysis. Units are Bq/L. See Appendix B for the sampling locations.

\begin{tabular}{|c|c|c|c|c|c|c|c|c|}
\hline \multirow[b]{2}{*}{ Location } & {$[\mathrm{RN}]^{\mathrm{a}}$} & $2 \times \mathrm{TPU}^{\mathrm{b}}$ & MDC $^{c}$ & RER $^{\mathrm{d}}$ & {$[\mathbf{R N}]$} & $2 \times$ TPU & MDC & RER \\
\hline & \multicolumn{4}{|c|}{${ }^{241} \mathrm{Am}$} & \multicolumn{4}{|c|}{${ }^{238} \mathbf{P u}$} \\
\hline$\overline{\mathrm{BHT}}$ & $4.92 \times 10^{-4}$ & $6.76 \times 10^{-4}$ & $3.73 \times 10^{-4}$ & $\overline{0.361}$ & $-3.17 \times 10^{-5}$ & $3.85 \times 10^{-4}$ & $1.23 \times 10^{-3}$ & 0.229 \\
\hline BHT Dup. & $1.51 \times 10^{-4}$ & $6.62 \times 10^{-4}$ & $1.05 \times 10^{-3}$ & & $7.70 \times 10^{-5}$ & $2.76 \times 10^{-4}$ & $7.23 \times 10^{-4}$ & \\
\hline PCN & $1.65 \times 10^{-4}$ & $8.26 \times 10^{-4}$ & $1.56 \times 10^{-3}$ & 0.237 & $2.54 \times 10^{-4}$ & $4.67 \times 10^{-4}$ & $8.95 \times 10^{-4}$ & 0.896 \\
\hline PCN Dup. & $4.32 \times 10^{-4}$ & $7.67 \times 10^{-4}$ & $5.18 \times 10^{-4}$ & & $-2.25 \times 10^{-4}$ & $2.60 \times 10^{-4}$ & $1.46 \times 10^{-3}$ & \\
\hline RCP-1 & $1.45 \times 10^{-4}$ & $7.69 \times 10^{-4}$ & $1.48 \times 10^{-3}$ & 0.220 & $1.92 \times 10^{-4}$ & $3.53 \times 10^{-4}$ & $6.77 \times 10^{-4}$ & 0.646 \\
\hline \multirow[t]{2}{*}{ RCP-1 Dup. } & $3.72 \times 10^{-4}$ & $6.83 \times 10^{-4}$ & $9.32 \times 10^{-4}$ & & $-1.37 \times 10^{-4}$ & $3.67 \times 10^{-4}$ & $1.27 \times 10^{-3}$ & \\
\hline & \multicolumn{4}{|c|}{${ }^{239+240} \mathrm{Pu}$} & \multicolumn{4}{|c|}{${ }^{234} \mathbf{U}$} \\
\hline BHT & $-3.16 \times 10^{-4}$ & $6.00 \times 10^{-4}$ & $1.90 \times 10^{-3}$ & 0.963 & $1.86 \times 10^{-2}$ & $3.13 \times 10^{-3}$ & $1.32 \times 10^{-3}$ & 6.847 \\
\hline BHT Dup. & $5.89 \times 10^{-4}$ & $7.24 \times 10^{-4}$ & $1.27 \times 10^{-3}$ & & $6.62 \times 10^{-2}$ & $6.21 \times 10^{-3}$ & $1.24 \times 10^{-3}$ & \\
\hline $\mathrm{PCN}$ & $-3.17 \times 10^{-5}$ & $3.86 \times 10^{-4}$ & $1.24 \times 10^{-3}$ & 0.362 & $1.90 \times 10^{-1}$ & $1.26 \times 10^{-2}$ & $1.55 \times 10^{-3}$ & 0.917 \\
\hline PCN Dup. & $2.62 \times 10^{-4}$ & $7.14 \times 10^{-4}$ & $1.61 \times 10^{-3}$ & & $2.07 \times 10^{-1}$ & $1.35 \times 10^{-2}$ & $1.04 \times 10^{-3}$ & \\
\hline RCP-1 & $1.68 \times 10^{-4}$ & $4.57 \times 10^{-4}$ & $1.03 \times 10^{-3}$ & 0.446 & $8.47 \times 10^{-3}$ & $1.95 \times 10^{-3}$ & $1.03 \times 10^{-3}$ & 1.575 \\
\hline \multirow[t]{2}{*}{ RCP-1 Dup. } & $5.19 \times 10^{-4}$ & $6.40 \times 10^{-4}$ & $1.07 \times 10^{-3}$ & & $4.70 \times 10^{-3}$ & $1.39 \times 10^{-3}$ & $9.35 \times 10^{-4}$ & \\
\hline & \multicolumn{4}{|c|}{${ }^{235} \mathrm{U}$} & \multicolumn{4}{|c|}{${ }^{238} \mathrm{U}$} \\
\hline BHT & $9.28>$ & $1.04 \times 10^{-3}$ & $1.80 \times 10^{-3}$ & 1.946 & $2.13 \times 10^{-2}$ & $3.37 \times 10^{-3}$ & $<10^{-3}$ & 6.860 \\
\hline BHT Dup. & $4.78 \times 10^{-3}$ & $1.69 \times 10^{-3}$ & $1.46 \times 10^{-3}$ & & $7.16 \times 10^{-2}$ & $6.52 \times 10^{-3}$ & $<10^{-3}$ & \\
\hline $\mathrm{PCN}$ & $6.09 \times 10^{-3}$ & $1.83 \times 10^{-3}$ & $1.54 \times 10^{-3}$ & 0.150 & $8.72 \times 10^{-2}$ & $7.16 \times 10^{-3}$ & $1.14 \times 10^{-3}$ & 0.681 \\
\hline PCN Dup. & $5.72 \times 10^{-3}$ & $1.72 \times 10^{-3}$ & $1.11 \times 10^{-3}$ & & $9.43 \times 10^{-2}$ & $7.59 \times 10^{-3}$ & $8.93 \times 10^{-4}$ & \\
\hline RCP-1 & $5.07 \times 10^{-4}$ & $7.39 \times 10^{-4}$ & $1.36 \times 10^{-3}$ & 0.512 & $7.21 \times 10^{-3}$ & $1.83 \times 10^{-3}$ & $1.29 \times 10^{-3}$ & 0.825 \\
\hline RCP-1 Dup. & $5.74 \times 10^{-5}$ & $4.73 \times 10^{-4}$ & $1.15 \times 10^{-3}$ & & $5.28 \times 10^{-3}$ & $1.46 \times 10^{-3}$ & $8.60 \times 10^{-4}$ & \\
\hline
\end{tabular}

${ }^{\mathrm{a}}[\mathrm{RN}]=$ Radionuclide concentration

${ }^{\mathrm{b}}$ Total propagated uncertainty

${ }^{\mathrm{c}}$ Minimum detectable concentration

${ }^{\mathrm{d}}$ Relative Error Ratio 
Table 4.12 Preliminary concentration $(\mathrm{Bq} / \mathrm{L})$ of radionuclides measured by $\mathrm{EEG}^{\mathrm{a}}$ in surface water. See Appendix B for locations.

\begin{tabular}{|c|c|c|c|c|c|c|}
\hline \multirow[b]{2}{*}{ Location } & {$[\mathbf{R N}]^{\mathbf{b}}$} & $2 \times T_{P} U^{c}$ & {$[\mathbf{R N}]$} & $2 \times$ TPU & [RN] & $2 \times$ TPU \\
\hline & \multicolumn{2}{|c|}{${ }^{241} \mathrm{Am}$} & \multicolumn{2}{|c|}{${ }^{239+240} \mathrm{Pu}$} & \multicolumn{2}{|c|}{${ }^{238} \mathbf{P u}$} \\
\hline$\overline{\mathrm{CBD}}$ & $9.10 \times 10^{-4}$ & $1.78 \times 10^{-3}$ & $-1.20 \times 10^{-4}$ & $6.80 \times 10^{-4}$ & $-1.50 \times 10^{-4}$ & $5.50 \times 10^{-4}$ \\
\hline LAG & $\mathrm{NR}^{\mathrm{d}}$ & NR & NR & NR & NR & NR \\
\hline $\mathrm{PCN}$ & $1.08 \times 10^{-3}$ & $1.50 \times 10^{-3}$ & $-3.90 \times 10^{-4}$ & $5.70 \times 10^{-4}$ & $-5.20 \times 10^{-4}$ & $6.60 \times 10^{-4}$ \\
\hline \multirow[t]{2}{*}{$\mathrm{RCP}$} & $-4.30 \times 10^{-4}$ & $8.40 \times 10^{-4}$ & $-2.10 \times 10^{-4}$ & $6.20 \times 10^{-4}$ & $-2.50 \times 10^{-4}$ & $6.20 \times 10^{-4}$ \\
\hline & \multicolumn{2}{|c|}{${ }^{137} \mathrm{Cs}$} & \multicolumn{2}{|c|}{${ }^{90} \mathrm{Sr}$} & & \\
\hline $\mathrm{CBD}$ & $1.94 \times 10^{-2}$ & $4.89 \times 10^{-2}$ & $1.29 \times 10^{-2}$ & $2.31 \times 10^{-2}$ & & \\
\hline LAG & $1.08 \times 10^{-1}$ & $2.05 \times 10^{-1}$ & NR & NR & & \\
\hline PCN & $-5.64 \times 10^{-2}$ & $4.84 \times 10^{-2}$ & $3.30 \times 10^{-2}$ & $2.39 \times 10^{-2}$ & & \\
\hline $\mathrm{RCP}$ & $1.59 \times 10^{-2}$ & $4.10 \times 10^{-2}$ & $-1.48 \times 10^{-2}$ & $5.04 \times 10^{-2}$ & & \\
\hline
\end{tabular}

${ }^{a}$ Environmental Evaluation Group

${ }^{\mathrm{b}}[\mathrm{RN}]=$ Radionuclide concentration

${ }^{\mathrm{c}}$ Total propagated uncertainty

${ }^{\mathrm{d}}$ Not Reported

\subsection{Soil Samples}

\subsubsection{Sampling}

Soil samples were collected from near the low-volume air samplers at six different locations around the WIPP site; MLR, SEC, SMR, WEE, WFF, and WSS (Figure 4.6; Appendix B). Samples were collected from each location in three incremental profiles: surface soil (SS, 0-2 cm [0-0.8 in]), intermediate soil (SI, 2-5 cm [0.8-2 in]), and deep soil (SD, $5-10 \mathrm{~cm}$ [2-4 in ] ). Measurements of radionuclides in depth profiles provide information about their vertical movements in the soil systems.

\subsubsection{Sample Preparation}

Soil samples were dried at $110^{\circ} \mathrm{C}\left(230^{\circ} \mathrm{F}\right)$ for several hours and homogenized by grinding to small particle sizes. One gram $(0.04 \mathrm{oz})$ of soil was dissolved by heating it with a mixture of nitric, hydrochloric, and hydrofluoric acids. Finally, it was heated with nitric and boric acids, and the residue was dissolved in hydrochloric acid for the determination of individual radionuclides.

\subsubsection{Determination of Individual Radionuclides}

Gamma-emitting radionuclides $\left({ }^{40} \mathrm{~K},{ }^{60} \mathrm{Co}\right.$, and ${ }^{137} \mathrm{Cs}$ ) were determined by counting an aliquot of well-homogenized ground soil samples by gamma-spectrometry. Strontium- 90 was analyzed from an aliquot of the sample solution by separating it from other stable and radioactive elements using radiochemical techniques and beta counting. Another aliquot of the sample solution was used for the sequential determinations of alpha-emitting radionuclides, such as ${ }^{234} \mathrm{U},{ }^{235} \mathrm{U}$, and ${ }^{238} \mathrm{U} ;{ }^{238} \mathrm{Pu}$ and ${ }^{239+240} \mathrm{Pu}$; and ${ }^{241} \mathrm{Am}$. These radionuclides were separated from the bulk of the inorganic materials present in the soil samples and from one another by radiochemical separations including co-precipitation and ion-exchange chromatography. Finally, the samples were micro-precipitated, filtered onto micro-filters, and counted alpha spectrometrically. 


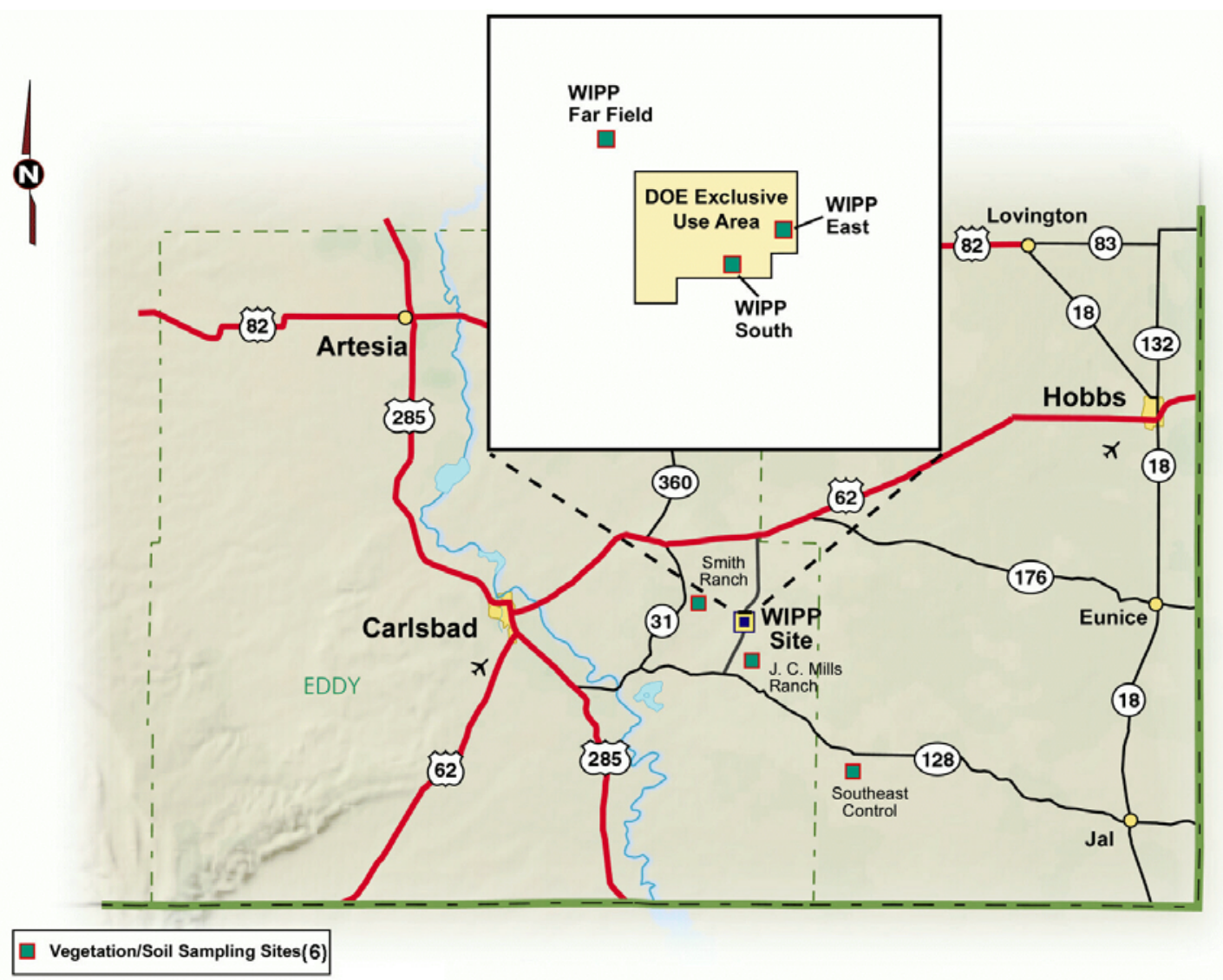

Figure 4.6 Soil and vegetation sampling areas in 2000 .

\subsubsection{Results and Discussions}

Uranium-238 was detected in every soil sample in 2000 and ${ }^{234} U$ was detected in all but one. Uranium-235 was detected in two of the 18 samples. Concentrations of ${ }^{234} \mathrm{U}$ in surface soils $(0-2 \mathrm{~cm})$ ranged from a minimum of $6.59 \times 10^{-3} \pm$ $1.74 \times 10^{-3} \mathrm{~Bq} / \mathrm{g}\left(1.78 \times 10^{-1} \pm 4.70 \times 10^{-2} \mathrm{pCi} / \mathrm{g}\right)$ at WEE to a maximum of $2.01 \times 10^{-2} \pm 3.29 \times 10^{-3}$ $\mathrm{Bq} / \mathrm{g}\left(5.43 \times 10^{-1} \pm 8.89 \times 10^{-2} \mathrm{pCi} / \mathrm{g}\right)$ at SMR (Table 4.13). Concentrations of ${ }^{238} \mathrm{U}$ in the same samples ranged from $7.33 \times 10^{-3} \pm 2.00 \times 10^{-3} \mathrm{~Bq} / \mathrm{g}$ $\left(1.98 \times 10^{-1} \pm 5.41 \times 10^{-2} \mathrm{pCi} / \mathrm{g}\right)$ at WFF to $2.35 \times 10^{-2} \pm 3.48 \times 10^{-3} \mathrm{~Bq} / \mathrm{g}\left(6.35 \times 10^{-1} \pm\right.$ $9.41 \times 10^{-2} \mathrm{pCi} / \mathrm{g}$ ) at SMR. The concentration of ${ }^{235} \mathrm{U}$ in surface soils ranged from $-1.85 \times 10^{-4} \pm$ $1.11 \times 10^{-3} \mathrm{~Bq} / \mathrm{g}\left(-5.00 \times 10^{-3} \pm 3.00 \times 10^{-2} \mathrm{pCi} / \mathrm{g}\right)$ at SMR to $6.66 \times 10^{-4} \pm 7.77 \times 10^{-4} \mathrm{~Bq} / \mathrm{g}\left(1.80 \times 10^{-2} \pm\right.$ $\left.2.10 \times 10^{-2} \mathrm{pCi} / \mathrm{g}\right)$ at WFF. Because of the very low activity of ${ }^{235} \mathrm{U}$ in soil, most of the results were non-detects and associated with large analytical uncertainties.

The results for uranium in intermediate depth $(2-5 \mathrm{~cm})$ soil samples are also given in Table 4.13. The concentration of ${ }^{234} \mathrm{U}$ ranged from $8.33 \times 10^{-3} \pm 1.90 \times 10^{-3} \mathrm{~Bq} / \mathrm{g}\left(2.25 \times 10^{-1} \pm\right.$ $\left.5.14 \times 10^{-2} \mathrm{pCi} / \mathrm{g}\right)$ at WFF to $1.96 \times 10^{-2}$ $\pm 3.03 \times 10^{-3} \mathrm{~Bq} / \mathrm{g}\left(5.30 \times 10^{-1} \pm 8.19 \times 10^{-2} \mathrm{pCi} / \mathrm{g}\right)$ at SMR. Uranium-238 in these soils was lowest at WFF $\left(7.88 \times 10^{-3} \pm 1.85 \times 10^{-3} \mathrm{~Bq} / \mathrm{g}\left[2.13 \times 10^{-1}\right.\right.$ $\left.\left.\pm 5.00 \times 10^{-2} \mathrm{pCi} / \mathrm{g}\right]\right)$ and highest at SMR $\left(1.90 \times 10^{-2} \pm 2.97 \times 10^{-3} \mathrm{~Bq} / \mathrm{g}\left[5.14 \times 10^{-1} \pm\right.\right.$ $\left.\left.8.03 \times 10^{-2} \mathrm{pCi} / \mathrm{g}\right]\right)$. The only two detections of ${ }^{235} \mathrm{U}$ in soils occurred in intermediate depth soils at MLR and SMR. Concentrations ranged from $2.11 \times 10^{-5} \pm 5.55 \times 10^{-4} \mathrm{~Bq} / \mathrm{g}\left(5.70 \times 10^{-4} \pm\right.$ $\left.1.50 \times 10^{-2} \mathrm{pCi} / \mathrm{g}\right)$ at WFF to $1.77 \times 10^{-3} \pm$ $1.08 \times 10^{-3} \mathrm{~Bq} / \mathrm{g}\left(4.78 \times 10^{-2} \pm 2.92 \times 10^{-2} \mathrm{pCi} / \mathrm{g}\right)$ at MLR. 
Table 4.13 Uranium concentrations $(\mathrm{Bq} / \mathrm{g})$ in soil near the WIPP site. See Appendix B for the sampling locations.

\begin{tabular}{|c|c|c|c|c|c|c|c|c|c|c|}
\hline \multirow[b]{2}{*}{ Location } & \multirow{2}{*}{$\begin{array}{c}\text { Depth } \\
(\mathrm{cm})\end{array}$} & {$[\mathbf{R N}]^{a}$} & $2 \times \mathrm{TPU}^{\mathrm{b}}$ & MDC $^{\mathrm{c}}$ & [RN] & $2 \times$ TPU & MDC & [RN] & $2 \times \mathrm{TPU}$ & MDC \\
\hline & & \multicolumn{3}{|c|}{${ }^{234} \mathbf{U}$} & \multicolumn{3}{|c|}{${ }^{235} \mathbf{U}$} & \multicolumn{3}{|c|}{${ }^{238} \mathbf{U}$} \\
\hline MLR & $0-2$ & $1.45 \times 10^{-2}$ & $2.55 \times 10^{-3}$ & $9.25 \times 10^{-4}$ & $4.44 \times 10^{-4}$ & $6.29 \times 10^{-4}$ & $1.11 \times 10^{-3}$ & $1.62 \times 10^{-2}$ & $2.74 \times 10^{-3}$ & $1.30 \times 10^{-3}$ \\
\hline MLR & $2-5$ & $1.45 \times 10^{-2}$ & $2.65 \times 10^{-3}$ & $1.35 \times 10^{-3}$ & $1.77 \times 10^{-3}$ & $1.08 \times 10^{-3}$ & $1.49 \times 10^{-3}$ & $1.69 \times 10^{-2}$ & $2.87 \times 10^{-3}$ & $1.38 \times 10^{-3}$ \\
\hline MLR & $5-10$ & $1.59 \times 10^{-2}$ & $2.67 \times 10^{-3}$ & $1.31 \times 10^{-3}$ & $1.18 \times 10^{-3}$ & $8.74 \times 10^{-4}$ & $1.33 \times 10^{-3}$ & $1.70 \times 10^{-2}$ & $2.78 \times 10^{-3}$ & $1.56 \times 10^{-3}$ \\
\hline SEC & $0-2$ & $1.10 \times 10^{-2}$ & $2.25 \times 10^{-3}$ & $1.08 \times 10^{-3}$ & $4.87 \times 10^{-4}$ & $5.71 \times 10^{-4}$ & $9.51 \times 10^{-4}$ & $1.27 \times 10^{-2}$ & $2.41 \times 10^{-3}$ & $8.03 \times 10^{-4}$ \\
\hline SEC & $2-5$ & $1.15 \times 10^{-2}$ & $2.30 \times 10^{-3}$ & $1.30 \times 10^{-3}$ & $6.47 \times 10^{-4}$ & $8.20 \times 10^{-4}$ & $1.52 \times 10^{-3}$ & $1.15 \times 10^{-2}$ & $2.29 \times 10^{-3}$ & $1.16 \times 10^{-3}$ \\
\hline SEC & $5-10$ & $1.41 \times 10^{-2}$ & $2.65 \times 10^{-3}$ & $1.93 \times 10^{-3}$ & $4.97 \times 10^{-4}$ & $1.08 \times 10^{-3}$ & $2.20 \times 10^{-3}$ & $1.43 \times 10^{-2}$ & $2.60 \times 10^{-3}$ & $1.53 \times 10^{-3}$ \\
\hline SMR & $0-2$ & $2.01 \times 10^{-2}$ & $3.29 \times 10^{-3}$ & $2.18 \times 10^{-3}$ & $-1.85 \times 10^{-4}$ & $1.11 \times 10^{-3}$ & $2.55 \times 10^{-3}$ & $2.35 \times 10^{-2}$ & $3.48 \times 10^{-3}$ & $1.63 \times 10^{-3}$ \\
\hline SMR & $2-5$ & $1.96 \times 10^{-2}$ & $3.03 \times 10^{-3}$ & $2.20 \times 10^{-2}$ & $9.91 \times 10^{-4}$ & $7.03 \times 10^{-4}$ & $7.40 \times 10^{-4}$ & $1.90 \times 10^{-2}$ & $2.97 \times 10^{-3}$ & $9.30 \times 10^{-4}$ \\
\hline SMR & $5-10$ & $1.70 \times 10^{-2}$ & $2.90 \times 10^{-3}$ & $1.13 \times 10^{-3}$ & $2.53 \times 10^{-4}$ & $5.69 \times 10^{-4}$ & $1.22 \times 10^{-3}$ & $1.79 \times 10^{-2}$ & $2.99 \times 10^{-3}$ & $1.37 \times 10^{-3}$ \\
\hline WEE & $0-2$ & $6.59 \times 10^{-3}$ & $1.74 \times 10^{-3}$ & $1.36 \times 10^{-3}$ & $2.12 \times 10^{-5}$ & $2.58 \times 10^{-4}$ & $8.27 \times 10^{-4}$ & $8.21 \times 10^{-3}$ & $1.85 \times 10^{-3}$ & $6.66 \times 10^{-4}$ \\
\hline WEE & $2-5$ & $8.92 \times 10^{-3}$ & $2.03 \times 10^{-3}$ & $9.08 \times 10^{-4}$ & $8.15 \times 10^{-4}$ & $7.56 \times 10^{-4}$ & $1.19 \times 10^{-3}$ & $1.00 \times 10^{-2}$ & $2.15 \times 10^{-3}$ & $9.04 \times 10^{-4}$ \\
\hline WEE & $5-10$ & $9.18 \times 10^{-3}$ & $2.00 \times 10^{-3}$ & $9.25 \times 10^{-4}$ & $6.82 \times 10^{-4}$ & $6.29 \times 10^{-4}$ & $9.16 \times 10^{-4}$ & $1.01 \times 10^{-2}$ & $2.10 \times 10^{-3}$ & $9.21 \times 10^{-4}$ \\
\hline WFF & $0-2$ & $6.96 \times 10^{-3}$ & $1.89 \times 10^{-3}$ & $1.11 \times 10^{-3}$ & $6.66 \times 10^{-4}$ & $7.77 \times 10^{-4}$ & $1.33 \times 10^{-3}$ & $7.33 \times 10^{-3}$ & $2.00 \times 10^{-3}$ & $1.52 \times 10^{-3}$ \\
\hline WFF & $2-5$ & $8.33 \times 10^{-3}$ & $1.90 \times 10^{-3}$ & $9.74 \times 10^{-4}$ & $2.11 \times 10^{-5}$ & $5.55 \times 10^{-4}$ & $1.36 \times 10^{-3}$ & $7.88 \times 10^{-3}$ & $1.85 \times 10^{-3}$ & $9.70 \times 10^{-4}$ \\
\hline WFF & $5-10$ & $9.77 \times 10^{-3}$ & $2.24 \times 10^{-3}$ & $1.44 \times 10^{-3}$ & $1.30 \times 10^{-3}$ & $1.02 \times 10^{-3}$ & $1.60 \times 10^{-3}$ & $9.25 \times 10^{-3}$ & $2.18 \times 10^{-3}$ & $1.48 \times 10^{-3}$ \\
\hline WSS & $0-2$ & $8.77 \times 10^{-3}$ & $1.98 \times 10^{-3}$ & $1.06 \times 10^{-3}$ & $5.82 \times 10^{-4}$ & $5.96 \times 10^{-4}$ & $9.25 \times 10^{-4}$ & $8.51 \times 10^{-3}$ & $1.92 \times 10^{-3}$ & $7.81 \times 10^{-4}$ \\
\hline WSS & $2-5$ & $9.25 \times 10^{-3}$ & $2.07 \times 10^{-3}$ & $1.30 \times 10^{-3}$ & $5.44 \times 10^{-4}$ & $7.97 \times 10^{-4}$ & $1.53 \times 10^{-3}$ & $1.01 \times 10^{-2}$ & $2.15 \times 10^{-3}$ & $8.03 \times 10^{-4}$ \\
\hline WSS & $5-10$ & $8.21 \times 10^{-3}$ & $2.05 \times 10^{-3}$ & $1.92 \times 10^{-3}$ & $7.10 \times 10^{-4}$ & $1.11 \times 10^{-3}$ & $2.19 \times 10^{-3}$ & $9.10 \times 10^{-3}$ & $2.07 \times 10^{-3}$ & $1.52 \times 10^{-3}$ \\
\hline
\end{tabular}

Concentrations of ${ }^{234} \mathrm{U},{ }^{235} \mathrm{U}$, and ${ }^{238} \mathrm{U}$ were also measured in deep soils $(5-10 \mathrm{~cm})$ (Table 4.13). Concentrations of ${ }^{234} U$ varied from $8.21 \times 10^{-3} \pm 2.05 \times 10^{-3} \mathrm{~Bq} / \mathrm{g}\left(2.22 \times 10^{-1} \pm\right.$ $\left.5.54 \times 10^{-2} \mathrm{pCi} / \mathrm{g}\right)$ at WSS to $1.70 \times 10^{-2} \pm$ $2.90 \times 10^{-3} \mathrm{~Bq} / \mathrm{g}\left(4.59 \times 10^{-1} \pm 7.84 \times 10^{-2} \mathrm{pCi} / \mathrm{g}\right)$ at SMR. The lowest concentration of ${ }^{238} \mathrm{U}$ in deep soils was found at WSS $\left(9.10 \times 10^{-3} \pm 2.07 \times 10^{-3}\right.$ $\left.\mathrm{Bq} / \mathrm{g}\left[2.46 \times 10^{-1} \pm 5.59 \times 10^{-2} \mathrm{pCi} / \mathrm{g}\right]\right)$ and the highest concentration was found at SMR $\left(1.79 \times 10^{-2} \pm 2.99 \times 10^{-3} \mathrm{~Bq} / \mathrm{g}\left[4.84 \times 10^{-1} \pm\right.\right.$ $\left.\left.8.08 \times 10^{-2} \mathrm{pCi} / \mathrm{g}\right]\right)$. Uranium-235 was not detected in deep soil.

No uranium isotope varied significantly with location (ANOVA, $\mathrm{p}>0.124$ ) or depth (ANOVA, $p>0.611$ ). However, both ${ }^{234} U$ and ${ }^{238} \mathrm{U}$ did vary significantly with year $(\mathrm{p}<0.001$ for both). In both cases, samples collected in 1998 showed significantly higher concentrations than those collected in later years. Nevertheless, all maximum measured concentrations fell within the range of natural concentrations of uranium found in soils throughout the world (Pais and Jones 1997). All these results suggest a pattern of natural variability consistent with the existence of natural uranium, without amendment from artificial sources.

Plutonium-238, ${ }^{239+240} \mathrm{Pu}$, and ${ }^{241} \mathrm{Am}$ were also analyzed in these soil samples (Table 4.14). Neither plutonium isotope was detected in any sample. The measured concentration of ${ }^{241} \mathrm{Am}$ was greater than the MDC in two of the 18 soil samples; MLR, 2-5 cm, and WSS, 5-10 cm. However, ${ }^{241} \mathrm{Am}$ both these results were less than their $2 \times \mathrm{TPU}$, indicating ${ }^{241} \mathrm{Am}$ was not likely present in the samples. 
Table 4.14 Americium and plutonium concentrations $(\mathrm{Bq} / \mathrm{g})$ in soil near the WIPP site. See Appendix B for the sampling locations.

\begin{tabular}{|c|c|c|c|c|c|c|c|c|c|c|}
\hline & D & {$[\mathrm{RN}]^{\mathrm{a}}$} & $2 \times \mathrm{TPU}^{\mathrm{b}}$ & MDC $^{\mathrm{c}}$ & [RN] & $2 \times$ TPU & $\overline{\text { MDC }}$ & [RN] & $2 \times$ TPU & MDC \\
\hline Location & (cm) & & ${ }^{241} \mathrm{Am}$ & & & ${ }^{238} \mathbf{P u}$ & & & ${ }^{239+240} \mathrm{Pu}$ & \\
\hline$\overline{\text { MLR }}$ & $0-2$ & $7.40 \times 10^{-5}$ & $4.04 \times 10^{-4}$ & $6.40 \times 10^{-4}$ & $8.53 \times 10^{-5}$ & $1.71 \times 10^{-4}$ & $2.30 \times 10^{-4}$ & $2.04 \times 10^{-4}$ & $3.67 \times 10^{-4}$ & $7.31 \times 10^{-4}$ \\
\hline MLR & $2-5$ & $3.70 \times 10^{-4}$ & $5.29 \times 10^{-4}$ & $3.20 \times 10^{-4}$ & $-1.51 \times 10^{-4}$ & $1.51 \times 10^{-4}$ & $8.07 \times 10^{-4}$ & $2.44 \times 10^{-4}$ & $3.34 \times 10^{-4}$ & $5.31 \times 10^{-4}$ \\
\hline MLR & $5-10$ & $1.48 \times 10^{-4}$ & $4.26 \times 10^{-4}$ & $3.33 \times 10^{-4}$ & $-6.79 \times 10^{-5}$ & $9.62 \times 10^{-5}$ & $5.81 \times 10^{-4}$ & $2.54 \times 10^{-4}$ & $4.08 \times 10^{-4}$ & $7.86 \times 10^{-4}$ \\
\hline SEC & $0-2$ & $1.48 \times 10^{-4}$ & $3.52 \times 10^{-4}$ & $2.38 \times 10^{-4}$ & $1.00 \times 10^{-4}$ & $2.54 \times 10^{-4}$ & $5.71 \times 10^{-4}$ & $2.82 \times 10^{-4}$ & $3.95 \times 10^{-4}$ & $7.14 \times 10^{-4}$ \\
\hline SEC & $2-5$ & $1.85 \times 10^{-4}$ & $4.84 \times 10^{-4}$ & $8.05 \times 10^{-4}$ & $-4.11 \times 10^{-5}$ & $8.22 \times 10^{-5}$ & $5.79 \times 10^{-4}$ & $-1.43 \times 10^{-4}$ & $2.87 \times 10^{-4}$ & $1.02 \times 10^{-3}$ \\
\hline SEC & $5-10$ & $-3.70 \times 10^{-5}$ & $3.34 \times 10^{-4}$ & $6.42 \times 10^{-4}$ & $6.63 \times 10^{-5}$ & $2.61 \times 10^{-4}$ & $6.45 \times 10^{-4}$ & $2.81 \times 10^{-4}$ & $3.93 \times 10^{-4}$ & $7.10 \times 10^{-4}$ \\
\hline SMR & $0-2$ & $2.59 \times 10^{-4}$ & $4.53 \times 10^{-4}$ & $6.18 \times 10^{-4}$ & $4.70 \times 10^{-5}$ & $1.69 \times 10^{-4}$ & $7.07 \times 10^{-4}$ & $3.12 \times 10^{-5}$ & $2.53 \times 10^{-4}$ & $6.70 \times 10^{-4}$ \\
\hline SMR & $2-5$ & $1.85 \times 10^{-4}$ & $3.98 \times 10^{-4}$ & $2.69 \times 10^{-4}$ & $5.22 \times 10^{-5}$ & $1.88 \times 10^{-4}$ & $4.90 \times 10^{-4}$ & $2.26 \times 10^{-4}$ & $3.09 \times 10^{-4}$ & $4.90 \times 10^{-4}$ \\
\hline SMR & $5-10$ & $5.92 \times 10^{-4}$ & $6.32 \times 10^{-4}$ & $7.98 \times 10^{-4}$ & $-8.16 \times 10^{-5}$ & $1.16 \times 10^{-4}$ & $6.99 \times 10^{-4}$ & $3.46 \times 10^{-4}$ & $4.84 \times 10^{-4}$ & $8.74 \times 10^{-4}$ \\
\hline WEE & $0-2$ & $2.59 \times 10^{-4}$ & $4.41 \times 10^{-4}$ & $2.66 \times 10^{-4}$ & $-2.04 \times 10^{-4}$ & $1.55 \times 10^{-4}$ & $7.61 \times 10^{-4}$ & $1.60 \times 10^{-4}$ & $4.34 \times 10^{-4}$ & $9.36 \times 10^{-4}$ \\
\hline WEE & $2-5$ & $-1.11 \times 10^{-4}$ & $2.96 \times 10^{-4}$ & $6.67 \times 10^{-4}$ & $-7.17 \times 10^{-5}$ & $1.02 \times 10^{-4}$ & $6.14 \times 10^{-4}$ & $6.26 \times 10^{-4}$ & $5.61 \times 10^{-4}$ & $8.30 \times 10^{-4}$ \\
\hline WEE & $5-10$ & $7.40 \times 10^{-5}$ & $3.27 \times 10^{-4}$ & $2.55 \times 10^{-4}$ & $-1.20 \times 10^{-4}$ & $1.39 \times 10^{-4}$ & $7.81 \times 10^{-4}$ & $4.80 \times 10^{-4}$ & $5.11 \times 10^{-4}$ & $7.81 \times 10^{-4}$ \\
\hline WFF & $0-2$ & $2.59 \times 10^{-4}$ & $4.65 \times 10^{-4}$ & $3.15 \times 10^{-4}$ & $-1.66 \times 10^{-4}$ & $1.67 \times 10^{-4}$ & $8.91 \times 10^{-4}$ & $1.66 \times 10^{-4}$ & $3.05 \times 10^{-4}$ & $5.86 \times 10^{-4}$ \\
\hline WFF & $2-5$ & $2.22 \times 10^{-4}$ & $4.58 \times 10^{-4}$ & $7.58 \times 10^{-4}$ & $-8.77 \times 10^{-5}$ & $1.24 \times 10^{-4}$ & $7.51 \times 10^{-4}$ & $3.28 \times 10^{-4}$ & $5.27 \times 10^{-4}$ & $1.02 \times 10^{-3}$ \\
\hline WFF & $5-10$ & $1.11 \times 10^{-4}$ & $4.49 \times 10^{-4}$ & $7.41 \times 10^{-4}$ & $-4.43 \times 10^{-5}$ & $8.87 \times 10^{-5}$ & $6.24 \times 10^{-4}$ & $2.43 \times 10^{-4}$ & $4.03 \times 10^{-4}$ & $7.58 \times 10^{-4}$ \\
\hline WSS & $0-2$ & $-3.70 \times 10^{-5}$ & $3.30 \times 10^{-4}$ & $6.22 \times 10^{-4}$ & $8.72 \times 10^{-5}$ & $1.74 \times 10^{-4}$ & $2.35 \times 10^{-4}$ & $-8.69 \times 10^{-5}$ & $2.33 \times 10^{-4}$ & $8.07 \times 10^{-4}$ \\
\hline WSS & $2-5$ & $3.70 \times 10^{-5}$ & $3.64 \times 10^{-4}$ & $5.78 \times 10^{-4}$ & $-2.08 \times 10^{-5}$ & $2.53 \times 10^{-4}$ & $8.10 \times 10^{-4}$ & $-1.20 \times 10^{-8}$ & $3.47 \times 10^{-4}$ & $9.64 \times 10^{-4}$ \\
\hline WSS & $5-10$ & $3.70 \times 10^{-4}$ & $4.94 \times 10^{-4}$ & $2.73 \times 10^{-4}$ & $-4.16 \times 10^{-5}$ & $8.33 \times 10^{-5}$ & $5.86 \times 10^{-4}$ & $-1.24 \times 10^{-4}$ & $1.44 \times 10^{-4}$ & $8.10 \times 10^{-4}$ \\
\hline
\end{tabular}

Potassium-40, as expected, was detected in every sample (Table 4.15). This naturally-occurring gamma-emitting radionuclide is ubiquitous in soils. Concentrations in surface soils ranged from $1.79 \times 10^{-1} \pm 2.35 \times 10^{-2} \mathrm{~Bq} / \mathrm{g}\left(4.84 \times 10^{0} \pm\right.$ $\left.6.35 \times 10^{-1} \mathrm{pCi} / \mathrm{g}\right)$ at WEE to $8.05 \times 10^{-1} \pm$ $4.88 \times 10^{-2} \mathrm{~Bq} / \mathrm{g}\left(2.18 \times 10^{1} \pm 1.32 \times 10^{0} \mathrm{pCi} / \mathrm{g}\right)$ at SMR. In intermediate depth soils, concentrations of ${ }^{40} \mathrm{~K}$ varied from $2.06 \times 10^{-1} \pm$ $2.20 \times 10^{-2} \mathrm{~Bq} / \mathrm{g}\left(5.57 \times 10^{0} \pm 5.95 \times 10^{-1} \mathrm{pCi} / \mathrm{g}\right)$ at WEE to $6.48 \times 10^{-1} \pm 4.41 \times 10^{-2} \mathrm{~Bq} / \mathrm{g}\left(1.75 \times 10^{1} \pm\right.$ $1.19 \times 10^{0} \mathrm{pCi} / \mathrm{g}$ ) at SMR. Potassium-40 concentrations in deep soils were lowest at WFF $\left(2.01 \times 10^{-1} \pm 2.09 \times 10^{-2} \mathrm{~Bq} / \mathrm{g}\left(4.30 \times 10^{0} \pm\right.\right.$ $\left.1.30 \times 10^{0} \mathrm{pCi} / \mathrm{g}\right)$ and highest at SMR $\left(5.46 \times 10^{-1}\right.$ $\pm 3.78 \times 10^{-2} \mathrm{~Bq} / \mathrm{g}\left(1.48 \times 10^{1} \pm 1.02 \times 10^{0} \mathrm{pCi} / \mathrm{g}\right)$.

The concentration of ${ }^{40} \mathrm{~K}$ was not significantly different between depths or between years. However, it was significantly different between sampling locations. It was highest at SMR and MLR and lowest at WFF and WSS (Table 4.15). The range of concentrations observed is consistent with the average natural ${ }^{40} \mathrm{~K}$ concentration in soils around the world $\left(4.00 \times 10^{-1} \mathrm{~Bq} / \mathrm{g}\left[1.08 \times 10^{1} \mathrm{pCi} / \mathrm{g}\right]\right.$; NCRP 1994).

Cesium-137 was detected in 10 of the 18 soil samples (Table 4.15). In surface soils, concentrations ranged from $1.35 \times 10^{-3} \pm$ $3.15 \times 10^{-3} \mathrm{~Bq} / \mathrm{g}\left(3.65 \times 10^{-2} \pm 8.51 \times 10^{-2} \mathrm{pCi} / \mathrm{g}\right)$ at WFF to $1.37 \times 10^{-2} \pm 2.17 \times 10^{-3} \mathrm{~Bq} / \mathrm{g}\left(3.70 \times 10^{-1} \pm\right.$ $5.86 \times 10^{-2} \mathrm{pCi} / \mathrm{g}$ ) at MLR. The concentration in intermediate depth soils ranged from $-2.75 \times 10^{-3}$ $\pm 3.78 \times 10^{-3} \mathrm{~Bq} / \mathrm{g}\left(-7.43 \times 10^{-2} \pm 1.02 \times 10^{-1} \mathrm{pCi} / \mathrm{g}\right)$ at SEC to $1.08 \times 10^{-2} \pm 2.34 \times 10^{-3} \mathrm{~Bq} / \mathrm{g}\left(2.92 \times 10^{-1}\right.$ $\left.\pm 6.32 \times 10^{-2} \mathrm{pCi} / \mathrm{g}\right)$ at SMR. In deep soils, the lowest concentrations of ${ }^{137} \mathrm{Cs}$ were found at SEC $\left(2.36 \times 10^{-3} \pm 3.25 \times 10^{-3} \mathrm{~Bq} / \mathrm{g}\left[6.38 \times 10^{-2} \pm\right.\right.$ $\left.\left.8.78 \times 10^{-2} \mathrm{pCi} / \mathrm{g}\right]\right)$ and the highest concentrations were found at SMR $\left(1.03 \times 10^{-2} \pm 2.29 \times 10^{-3} \mathrm{~Bq} / \mathrm{g}\right.$ $\left.\left[2.78 \times 10^{-1} \pm 6.19 \times 10^{-2} \mathrm{pCi} / \mathrm{g}\right]\right)$. There was no significant difference in ${ }^{137} \mathrm{Cs}$ concentration between locations (ANOVA, $\mathrm{p}=0.151$ ), or soil depths $(\mathrm{p}=0.396)$. 
Table 4.15 Selected radionuclide concentrations $(\mathrm{Bq} / \mathrm{g})$ in soil near the WIPP site. See Appendix B for the sampling locations.

\begin{tabular}{|c|c|c|c|c|c|c|c|}
\hline \multirow[b]{2}{*}{ Location } & \multirow{2}{*}{$\begin{array}{l}\text { Depth } \\
\text { (cm) }\end{array}$} & {$[\mathbf{R N}]^{\mathrm{a}}$} & $2 \times T_{P U^{b}}^{b}$ & MDC $^{\mathrm{c}}$ & $\overline{\text { [RN] }}$ & $2 \times \mathrm{TPU}$ & MDC \\
\hline & & \multicolumn{3}{|c|}{${ }^{137} \mathrm{Cs}$} & \multicolumn{3}{|c|}{${ }^{60} \mathrm{Co}$} \\
\hline MLR & $0-2$ & $1.37 \times 10^{-2}$ & $2.17 \times 10^{-3}$ & $4.37 \times 10^{-3}$ & $-1.51 \times 10^{-3}$ & $3.76 \times 10^{-3}$ & $4.37 \times 10^{-3}$ \\
\hline MLR & $2-5$ & $2.07 \times 10^{-3}$ & $3.86 \times 10^{-3}$ & $4.43 \times 10^{-3}$ & $9.69 \times 10^{-4}$ & $3.84 \times 10^{-3}$ & $4.18 \times 10^{-3}$ \\
\hline MLR & $5-10$ & $4.38 \times 10^{-3}$ & $1.10 \times 10^{-3}$ & $3.38 \times 10^{-3}$ & $-2.34 \times 10^{-3}$ & $4.04 \times 10^{-3}$ & $4.20 \times 10^{-3}$ \\
\hline SEC & $0-2$ & $2.13 \times 10^{-3}$ & $8.87 \times 10^{-4}$ & $2.76 \times 10^{-3}$ & $-2.66 \times 10^{-3}$ & $3.60 \times 10^{-3}$ & $3.57 \times 10^{-3}$ \\
\hline SEC & $2-5$ & $-2.75 \times 10^{-3}$ & $3.78 \times 10^{-3}$ & $4.05 \times 10^{-3}$ & $3.40 \times 10^{-3}$ & $3.07 \times 10^{-3}$ & $3.66 \times 10^{-3}$ \\
\hline SEC & $5-10$ & $2.36 \times 10^{-3}$ & $3.25 \times 10^{-3}$ & $3.77 \times 10^{-3}$ & $1.79 \times 10^{-3}$ & $3.15 \times 10^{-3}$ & $3.54 \times 10^{-3}$ \\
\hline SMR & $0-2$ & $7.16 \times 10^{-3}$ & $1.65 \times 10^{-3}$ & $4.50 \times 10^{-3}$ & $5.55 \times 10^{-3}$ & $3.52 \times 10^{-3}$ & $4.31 \times 10^{-3}$ \\
\hline SMR & $2-5$ & $1.08 \times 10^{-2}$ & $2.34 \times 10^{-3}$ & $6.27 \times 10^{-3}$ & $1.18 \times 10^{-3}$ & $4.28 \times 10^{-3}$ & $4.67 \times 10^{-3}$ \\
\hline SMR & $5-10$ & $1.03 \times 10^{-2}$ & $2.29 \times 10^{-3}$ & $6.19 \times 10^{-3}$ & $5.36 \times 10^{-3}$ & $3.71 \times 10^{-3}$ & $4.50 \times 10^{-3}$ \\
\hline WEE & $0-2$ & $3.47 \times 10^{-3}$ & $1.20 \times 10^{-3}$ & $3.64 \times 10^{-3}$ & $3.23 \times 10^{-3}$ & $3.72 \times 10^{-3}$ & $4.33 \times 10^{-3}$ \\
\hline WEE & $2-5$ & $8.45 \times 10^{-3}$ & $3.43 \times 10^{-3}$ & $4.24 \times 10^{-3}$ & $1.96 \times 10^{-3}$ & $3.59 \times 10^{-3}$ & $4.03 \times 10^{-3}$ \\
\hline WEE & $5-10$ & $7.19 \times 10^{-3}$ & $2.91 \times 10^{-3}$ & $3.58 \times 10^{-3}$ & $-3.55 \times 10^{-3}$ & $3.41 \times 10^{-3}$ & $3.26 \times 10^{-3}$ \\
\hline WFF & $0-2$ & $1.35 \times 10^{-3}$ & $3.15 \times 10^{-3}$ & $2.70 \times 10^{-3}$ & $-1.60 \times 10^{-3}$ & $3.36 \times 10^{-3}$ & $3.41 \times 10^{-3}$ \\
\hline WFF & $2-5$ & $-1.07 \times 10^{-4}$ & $3.74 \times 10^{-3}$ & $4.18 \times 10^{-3}$ & $8.37 \times 10^{-4}$ & $3.51 \times 10^{-3}$ & $3.84 \times 10^{-3}$ \\
\hline WFF & $5-10$ & $4.09 \times 10^{-3}$ & $3.23 \times 10^{-3}$ & $3.84 \times 10^{-3}$ & $3.15 \times 10^{-3}$ & $3.09 \times 10^{-3}$ & $3.64 \times 10^{-3}$ \\
\hline WSS & $0-2$ & $4.87 \times 10^{-3}$ & $3.07 \times 10^{-3}$ & $3.69 \times 10^{-3}$ & $-1.22 \times 10^{-3}$ & $3.32 \times 10^{-3}$ & $3.40 \times 10^{-3}$ \\
\hline WSS & $2-5$ & $-3.89 \times 10^{-4}$ & $3.79 \times 10^{-3}$ & $4.22 \times 10^{-3}$ & $4.15 \times 10^{-3}$ & $3.27 \times 10^{-3}$ & $3.93 \times 10^{-3}$ \\
\hline \multirow[t]{2}{*}{ WSS } & $5-10$ & $3.53 \times 10^{-3}$ & $9.59 \times 10^{-4}$ & $2.74 \times 10^{-3}$ & $3.18 \times 10^{-3}$ & $2.84 \times 10^{-3}$ & $3.37 \times 10^{-3}$ \\
\hline & & \multicolumn{3}{|c|}{${ }^{90} \mathrm{Sr}$} & \multicolumn{3}{|c|}{${ }^{40} K$} \\
\hline MLR & $0-2$ & $1.44 \times 10^{-2}$ & $1.85 \times 10^{-2}$ & $3.11 \times 10^{-2}$ & $4.95 \times 10^{-1}$ & $3.37 \times 10^{-2}$ & $5.86 \times 10^{-2}$ \\
\hline MLR & $2-5$ & $5.55 \times 10^{-3}$ & $1.96 \times 10^{-2}$ & $3.37 \times 10^{-2}$ & $4.71 \times 10^{-1}$ & $3.30 \times 10^{-2}$ & $5.97 \times 10^{-2}$ \\
\hline MLR & $5-10$ & $2.29 \times 10^{-2}$ & $2.26 \times 10^{-2}$ & $3.74 \times 10^{-2}$ & $2.39 \times 10^{-1}$ & $2.81 \times 10^{-2}$ & $7.74 \times 10^{-2}$ \\
\hline SEC & $0-2$ & $1.63 \times 10^{-2}$ & $1.78 \times 10^{-2}$ & $2.96 \times 10^{-2}$ & $2.24 \times 10^{-1}$ & $2.13 \times 10^{-2}$ & $5.22 \times 10^{-2}$ \\
\hline SEC & $2-5$ & $5.92 \times 10^{-3}$ & $1.70 \times 10^{-2}$ & $2.96 \times 10^{-2}$ & $2.42 \times 10^{-1}$ & $2.24 \times 10^{-2}$ & $5.41 \times 10^{-2}$ \\
\hline SEC & $5-10$ & $3.33 \times 10^{-3}$ & $1.70 \times 10^{-2}$ & $3.00 \times 10^{-2}$ & $2.19 \times 10^{-1}$ & $2.28 \times 10^{-2}$ & $5.96 \times 10^{-2}$ \\
\hline SMR & $0-2$ & $9.62 \times 10^{-3}$ & $2.74 \times 10^{-2}$ & $4.77 \times 10^{-2}$ & $8.05 \times 10^{-1}$ & $4.88 \times 10^{-2}$ & $6.18 \times 10^{-2}$ \\
\hline SMR & $2-5$ & $-1.18 \times 10^{-2}$ & $2.52 \times 10^{-2}$ & $4.70 \times 10^{-2}$ & $6.48 \times 10^{-1}$ & $4.41 \times 10^{-2}$ & $7.84 \times 10^{-2}$ \\
\hline SMR & $5-10$ & $1.15 \times 10^{-2}$ & $2.66 \times 10^{-2}$ & $4.59 \times 10^{-2}$ & $5.46 \times 10^{-1}$ & $3.78 \times 10^{-2}$ & $6.75 \times 10^{-2}$ \\
\hline WEE & $0-2$ & $1.22 \times 10^{-2}$ & $2.63 \times 10^{-2}$ & $4.51 \times 10^{-2}$ & $1.79 \times 10^{-1}$ & $2.35 \times 10^{-2}$ & $6.61 \times 10^{-2}$ \\
\hline WEE & $2-5$ & $2.37 \times 10^{-2}$ & $2.89 \times 10^{-2}$ & $4.85 \times 10^{-2}$ & $2.06 \times 10^{-1}$ & $2.20 \times 10^{-2}$ & $5.72 \times 10^{-2}$ \\
\hline WEE & $5-10$ & $2.92 \times 10^{-2}$ & $2.63 \times 10^{-2}$ & $4.33 \times 10^{-2}$ & $2.17 \times 10^{-1}$ & $1.97 \times 10^{-2}$ & $4.67 \times 10^{-2}$ \\
\hline WFF & $0-2$ & $1.70 \times 10^{-2}$ & $3.11 \times 10^{-2}$ & $5.29 \times 10^{-2}$ & $2.02 \times 10^{-1}$ & $2.00 \times 10^{-2}$ & $5.04 \times 10^{-2}$ \\
\hline WFF & $2-5$ & $3.70 \times 10^{-4}$ & $2.74 \times 10^{-2}$ & $4.88 \times 10^{-2}$ & $2.37 \times 10^{-1}$ & $2.60 \times 10^{-2}$ & $6.98 \times 10^{-2}$ \\
\hline WFF & $5-10$ & $2.00 \times 10^{-2}$ & $3.00 \times 10^{-2}$ & $5.07 \times 10^{-2}$ & $2.01 \times 10^{-1}$ & $2.09 \times 10^{-2}$ & $5.38 \times 10^{-2}$ \\
\hline WSS & $0-2$ & $1.44 \times 10^{-2}$ & $2.81 \times 10^{-2}$ & $4.85 \times 10^{-2}$ & $2.45 \times 10^{-1}$ & $2.20 \times 10^{-2}$ & $5.23 \times 10^{-2}$ \\
\hline WSS & $2-5$ & $1.30 \times 10^{-2}$ & $2.74 \times 10^{-2}$ & $4.74 \times 10^{-2}$ & $2.20 \times 10^{-1}$ & $2.40 \times 10^{-2}$ & $6.38 \times 10^{-2}$ \\
\hline WSS & $5-10$ & $2.96 \times 10^{-3}$ & $2.74 \times 10^{-2}$ & $4.85 \times 10^{-2}$ & $2.36 \times 10^{-1}$ & $2.04 \times 10^{-2}$ & $4.66 \times 10^{-2}$ \\
\hline
\end{tabular}

${ }^{\mathrm{a}}[\mathrm{RN}]=$ Radionuclide concentration

${ }^{\mathrm{b}}$ Total propagated uncertainty

${ }^{\mathrm{c}}$ Minimum detectable concentration 
Although ${ }^{137} \mathrm{Cs}$ is a fission product, it is ubiquitous in soils because of global fallout from atmospheric nuclear weapons testing. In 1998, prior to WIPP accepting any waste, the average concentration of ${ }^{137} \mathrm{Cs}$ in soils around WIPP was $4.3 \times 10^{-3} \mathrm{~Bq} / \mathrm{g}\left(1.16 \times 10^{-1} \mathrm{pCi} / \mathrm{g}\right)$. There was no statistically significant difference between concentrations measured in 1998, 1999, and 2000 (ANOVA, $\mathrm{p}=0.535$ ).

Strontium-90 was not detected in any soil sample in 2000 (Table 4.15). However, ${ }^{60} \mathrm{Co}$ was detected in two samples from SMR. There was no significant difference in ${ }^{60} \mathrm{Co}$ concentrations between depths $(p=0.714)$, locations $(\mathrm{p}=0.675)$, or years $(\mathrm{p}=0.356)$.

Soil samples collected from one location (WFF) were divided into two parts and analyzed separately (Table 4.16). Uranium-234, ${ }^{238} \mathrm{U}$, ${ }^{40} \mathrm{~K}$, and ${ }^{137} \mathrm{Cs}$ were compared between the duplicates. Other radionuclides of interest had insufficient detections to allow a reasonable comparison. The RER was less than one for ${ }^{234} \mathrm{U}$ in all samples. However, it was greater than one in one out of three ${ }^{238} \mathrm{U}$ analyses, two out of three ${ }^{40} \mathrm{~K}$ analyses, and one out of three ${ }^{137} \mathrm{Cs}$ analyses. A paired t-test indicated a significant difference between ${ }^{234} \mathrm{U}$ duplicates $(\mathrm{p}=0.019)$ and between ${ }^{40} \mathrm{~K}$ duplicates $(p=0.043)$. This circumstance indicates a lack of precision in these analyses, primarily due to the non-homogeneous distribution of radionuclides in soils. Because of small-scale differences in topography, soil type and structure, soil moisture, and other microenvironmental conditions, radionuclides are rarely homogeneously distributed in soils, and good agreement between duplicate samples is difficult to achieve. However, all the measurements were low, within the range of natural concentrations, and did not differ in time or space in such a way as to suggest WIPP related contamination of the environment.

Table 4.16 Results of duplicate soil sample analysis. Units are $\mathrm{Bq} / \mathrm{g}$. See Appendix B for the sampling locations.

\begin{tabular}{|c|c|c|c|c|c|c|c|c|c|}
\hline \multirow[b]{2}{*}{ Location } & \multirow{2}{*}{$\begin{array}{c}\text { Depth } \\
\text { (cm) }\end{array}$} & {$[\mathrm{RN}]^{\mathrm{a}}$} & $2 \times \mathrm{TPU}^{\mathrm{b}}$ & MDC $^{\mathrm{c}}$ & RER $^{d}$ & [RN] & $2 \times \mathrm{TPU}^{\mathrm{a}}$ & $\mathrm{MDC}^{\mathrm{b}}$ & RER $^{\mathrm{c}}$ \\
\hline & & \multicolumn{4}{|c|}{${ }^{234} \mathbf{U}$} & \multicolumn{4}{|c|}{${ }^{238} \mathbf{U}$} \\
\hline WFF & $0-2$ & $6.96 \times 10^{-3}$ & $1.89 \times 10^{-3}$ & $1.11 \times 10^{-3}$ & 0.63 & $7.33 \times 10^{-3}$ & $2.00 \times 10^{-3}$ & $1.52 \times 10^{-3}$ & 1.11 \\
\hline $\mathrm{WFF}^{\mathrm{e}}$ & $0-2$ & $5.40 \times 10^{-3}$ & $1.59 \times 10^{-3}$ & $1.44 \times 10^{-3}$ & & $4.44 \times 10^{-3}$ & $1.67 \times 10^{-3}$ & $2.22 \times 10^{-3}$ & \\
\hline WFF & $2-5$ & $8.33 \times 10^{-3}$ & $1.90 \times 10^{-3}$ & $9.74 \times 10^{-4}$ & 0.76 & $7.88 \times 10^{-3}$ & $1.85 \times 10^{-3}$ & $9.70 \times 10^{-4}$ & 0.46 \\
\hline WFF D & $2-5$ & $6.40 \times 10^{-3}$ & $1.67 \times 10^{-3}$ & $1.07 \times 10^{-3}$ & & $6.73 \times 10^{-3}$ & $1.70 \times 10^{-3}$ & $1.07 \times 10^{-3}$ & \\
\hline WFF & $5-10$ & $9.77 \times 10^{-3}$ & $2.24 \times 10^{-3}$ & $1.44 \times 10^{-3}$ & 0.87 & $9.25 \times 10^{-3}$ & $2.18 \times 10^{-3}$ & $1.48 \times 10^{-3}$ & 0.64 \\
\hline \multirow[t]{2}{*}{ WFF D ${ }^{\mathrm{e}}$} & $5-10$ & $7.25 \times 10^{-3}$ & $1.81 \times 10^{-3}$ & $1.01 \times 10^{-3}$ & & $7.44 \times 10^{-3}$ & $1.82 \times 10^{-3}$ & $1.00 \times 10^{-3}$ & \\
\hline & & \multicolumn{4}{|c|}{${ }^{40} \mathrm{~K}$} & \multicolumn{4}{|c|}{${ }^{137} \mathrm{Cs}$} \\
\hline WFF & $0-2$ & $2.02 \times 10^{-1}$ & $2.00 \times 10^{-2}$ & $5.04 \times 10^{-2}$ & 2.42 & $1.35 \times 10^{-3}$ & $3.15 \times 10^{-3}$ & $2.70 \times 10^{-3}$ & 1.45 \\
\hline WFF D $^{\mathrm{e}}$ & $0-2$ & $2.79 \times 10^{-1}$ & $2.47 \times 10^{-2}$ & $5.89 \times 10^{-2}$ & & $7.71 \times 10^{-3}$ & $3.05 \times 10^{-3}$ & $3.73 \times 10^{-3}$ & \\
\hline WFF & $2-5$ & $2.37 \times 10^{-1}$ & $2.60 \times 10^{-2}$ & $6.98 \times 10^{-2}$ & 0.95 & $-1.07 \times 10^{-4}$ & $3.74 \times 10^{-3}$ & $4.18 \times 10^{-3}$ & 0.78 \\
\hline WFF D ${ }^{\mathrm{e}}$ & $2-5$ & $2.72 \times 10^{-1}$ & $2.48 \times 10^{-2}$ & $5.99 \times 10^{-2}$ & & $3.00 \times 10^{-3}$ & $1.40 \times 10^{-3}$ & $4.44 \times 10^{-3}$ & \\
\hline WFF & $5-10$ & $2.01 \times 10^{-1}$ & $2.09 \times 10^{-2}$ & $5.38 \times 10^{-2}$ & 1.86 & $4.09 \times 10^{-3}$ & $3.23 \times 10^{-3}$ & $3.84 \times 10^{-3}$ & 0.92 \\
\hline WFF D & $5-10$ & $2.59 \times 10^{-1}$ & $2.33 \times 10^{-2}$ & $5.61 \times 10^{-2}$ & & $-1.20 \times 10^{-4}$ & $3.27 \times 10^{-3}$ & $3.65 \times 10^{-3}$ & \\
\hline $\begin{array}{l}{ }^{\mathrm{a}}[\mathrm{RN}]=\mathrm{R} \\
{ }^{\mathrm{b}} \text { Total pro } \\
{ }^{\mathrm{c}} \text { Minimum } \\
{ }^{\mathrm{d}} \text { Relative } \\
{ }^{\mathrm{d}} \text { Diation }\end{array}$ & dionucli & $\begin{array}{l}\text { de concentra } \\
\text { ncertainty }\end{array}$ & & & & & & & \\
\hline
\end{tabular}




\subsection{Sediments}

\subsubsection{Sample Collection}

Sediment samples were collected from 12 locations around the WIPP site, mostly from the same water bodies from which the surface water samples were collected (Figure 4.7, see Appendix B for location codes). The samples were collected in $1 \mathrm{~L}$ plastic containers from the top $15 \mathrm{~cm}$ (6 in) of the sediments of the water bodies and shipped to the commercial laboratory for the determination of individual radionuclides.

\subsubsection{Sample Preparation}

Sediment samples were dried at $110^{\circ} \mathrm{C}$ $\left(230^{\circ} \mathrm{F}\right)$ for several hours and homogenized by grinding to smaller particle sizes. A $0.75-\mathrm{g}$ (0.04-oz) aliquot was dissolved by heating it with a mixture of nitric, hydrochloric, and hydrofluoric acids. The residue was heated with nitric and boric acids to remove hydrofluoric acid quantitatively. Finally, the residue was dissolved in hydrochloric acid for the determination of individual radionuclides.

\subsubsection{Determination of Individual Radionuclides}

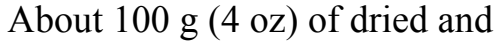
homogenized sediment samples were counted by gamma-spectrometry for the determinations of ${ }^{40} \mathrm{~K},{ }^{60} \mathrm{Co}$, and ${ }^{137} \mathrm{Cs}$. Strontium-90 was determined from an aliquot of dissolved sediment samples by chemical separation and beta counting. Uranium, plutonium, and americium were determined by alpha spectrometry after chemical separations, micro-precipitating, and filtering onto micro filter papers.

\subsubsection{Results and Discussions}

Uranium-234 and ${ }^{238} U$ were detected in every sediment sample in (Table 4.17).
Uranium-235 was detected in 75 percent of the samples. The concentration of ${ }^{234} \mathrm{U}$ ranged from $8.02 \times 10^{-3} \pm 1.85 \times 10^{-3} \mathrm{~Bq} / \mathrm{g}\left(2.17 \times 10^{-1} \pm\right.$ $\left.5.00 \times 10^{-2} \mathrm{pCi} / \mathrm{g}\right)$ at RED to $4.75 \times 10^{-2} \pm$ $4.71 \times 10^{-3} \mathrm{~Bq} / \mathrm{g}\left(1.28 \times 10^{0} \pm 1.27 \times 10^{-1} \mathrm{pCi} / \mathrm{g}\right)$ at CBD. The concentration of ${ }^{238} \mathrm{U}$ ranged from $2.42 \times 10^{-3} \pm 3.23 \times 10^{-3} \mathrm{~Bq} / \mathrm{g}\left(6.54 \times 10^{-2} \pm\right.$ $\left.8.73 \times 10^{-2} \mathrm{pCi} / \mathrm{g}\right)$ at IDN to $3.38 \times 10^{-2} \pm 4.02 \times 10^{-3}$ $\mathrm{Bq} / \mathrm{g}\left(9.14 \times 10^{-1} \pm 1.09 \times 10^{-1} \mathrm{pCi} / \mathrm{g}\right)$ at BRA. The concentration of ${ }^{235} \mathrm{U}$ was lowest at RED $\left(8.97 \times 10^{-4} \pm 8.29 \times 10^{-4} \mathrm{~Bq} / \mathrm{g}\left[2.42 \times 10^{-2} \pm\right.\right.$ $\left.\left.2.24 \times 10^{-2} \mathrm{pCi} / \mathrm{g}\right]\right)$ and highest at IDN $\left(5.68 \times 10^{-3}\right.$ $\left.\pm 1.67 \times 10^{-3} \mathrm{~Bq} / \mathrm{g}\left[1.54 \times 10^{-1} \pm 4.51 \times 10^{-2} \mathrm{pCi} / \mathrm{g}\right]\right)$. As expected, the ${ }^{235} \mathrm{U}$ concentration was much lower than the concentrations of ${ }^{234} \mathrm{U}$ and ${ }^{238} \mathrm{U}$. Uranium-234 differed significantly between sampling locations (ANOVA, $p=0.010$ ), but no pattern related to WIPP was evident. Because of natural variability, ${ }^{235} \mathrm{U}$ differed between years (ANOVA, $p=0.011$ ), with 2000 being higher than either 1998 or 1999.

Neither ${ }^{238} \mathrm{Pu}$ nor ${ }^{239+240} \mathrm{Pu}$ were detected in any sediment sample in 2000 (Table 4.18). Americium-241 was measured above the MDC at BHT and PKT. However, in both cases the measured values were less than $2 \times \mathrm{TPU}$, indicating ${ }^{241} \mathrm{Am}$ was not likely present.

Cesium-137 was detected in half of the sediment samples, ranging from $-2.70 \times 10^{-3} \pm$ $3.93 \times 10^{-3} \mathrm{~Bq} / \mathrm{g}\left(-7.30 \times 10^{-2} \pm 1.06 \times 10^{-1} \mathrm{pCi} / \mathrm{g}\right)$ at BRA to $1.86 \times 10^{-2} \pm 2.27 \times 10^{-3} \mathrm{~Bq} / \mathrm{g}\left(5.03 \times 10^{-1} \pm\right.$ $6.14 \times 10^{-2} \mathrm{pCi} / \mathrm{g}$ ) at IDN (Table 4.19).

Strontium-90 was not detected in any sediment sample and Cobalt-60 was detected in one sediment sample $(\mathrm{PCN})$. None of these radionuclides had sufficient detections to justify statistical comparisons between locations or years.

Potassium-40 was detected, as expected, in all sediment samples (Table 4.19). Its lowest concentration was found at RED $\left(1.62 \times 10^{-1} \pm\right.$ $\left.2.83 \times 10^{-2} \mathrm{~Bq} / \mathrm{g}\left[4.38 \times 10^{0} \pm 7.65 \times 10^{-1} \mathrm{pCi} / \mathrm{g}\right]\right)$ and its highest concentration was found at HIL 


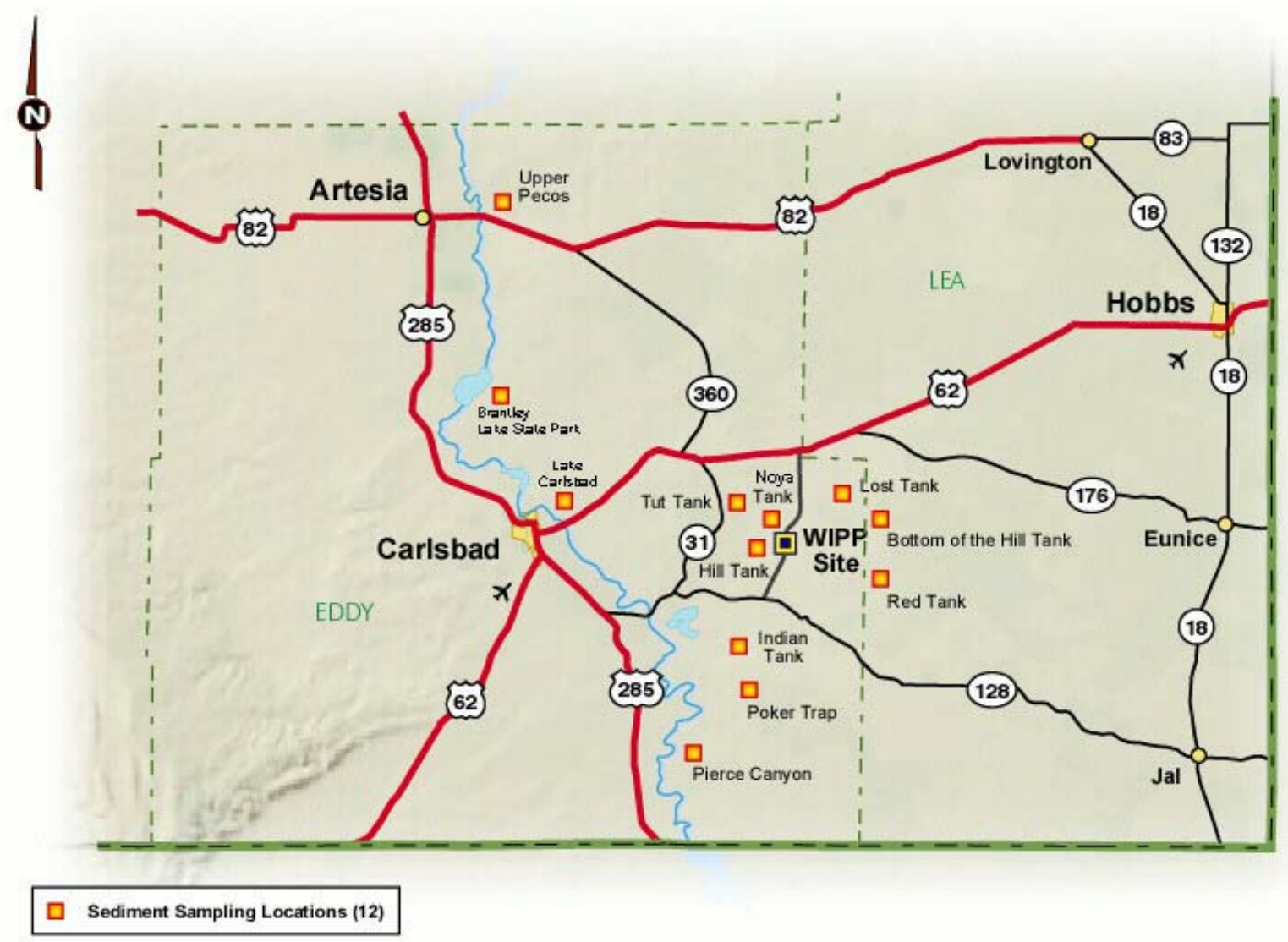

Figure 4.7. Sediment Sampling Sites

$\left(1.09 \times 10^{0} \pm 8.82 \times 10^{-2} \mathrm{~Bq} / \mathrm{g}\left[2.95 \times 10^{1} \pm\right.\right.$ $\left.\left.2.38 \times 10^{0} \mathrm{pCi} / \mathrm{g}\right]\right)$. Potassium-40 did not vary significantly between years (ANOVA, $\mathrm{p}=0.757$ ) but it did vary significantly between locations $(\mathrm{p}<0.001)$ with HIL, TUT, and PKT significantly higher than RED and the river locations. Overall, the concentrations measured in 2000 were similar to the average concentration of ${ }^{40} \mathrm{~K}$ found in soils throughout the United States $\left(4.00 \times 10^{-1} \mathrm{~Bq} / \mathrm{g}\left[1.08 \times 10^{1}\right.\right.$ pCi/g]; NCRP 1994).
Duplicate analyses were performed for all the radionuclides in sediment samples from BHT (Table 4.20). The RER was less than one for ${ }^{241} \mathrm{Am}$ and all uranium isotopes, indicating acceptable correspondence between the original and the duplicate samples. For ${ }^{137} \mathrm{Cs}$ and ${ }^{40} \mathrm{~K}$, it was greater than one. However, a t-test indicated no significant difference between any of these duplicate measurements $(p>0.139)$. 
Table 4.17 Uranium concentrations $(\mathrm{Bq} / \mathrm{g})$ in sediment near the WIPP site. See Appendix B for the sampling locations.

\begin{tabular}{|c|c|c|c|c|c|c|c|c|c|}
\hline \multirow[b]{2}{*}{ Location } & {$[\mathbf{R N}]^{\mathbf{a}}$} & $2 \times \mathrm{TPU}^{\mathrm{b}}$ & $\mathrm{MDC}^{\mathrm{c}}$ & [RN] & $2 \times \mathrm{TPU}$ & MDC & [RN] & $2 \times \mathrm{TPU}$ & MDC \\
\hline & \multicolumn{3}{|c|}{${ }^{234} \mathbf{U}$} & \multicolumn{3}{|c|}{${ }^{235} \mathbf{U}$} & \multicolumn{3}{|c|}{${ }^{238} \mathbf{U}$} \\
\hline BHT & 2.45 & $3.24 \times 10^{-3}$ & I.J. & -3 & $8.62 \times 10^{-4}$ & & 2.73 & $3.45 \times 10^{-3}$ & $10^{-3}$ \\
\hline BRA & $3.24 \times 10^{-2}$ & $3.94 \times 10^{-3}$ & $1.48 \times 10^{-3}$ & $2.00 \times 10^{-3}$ & $1.22 \times 10^{-3}$ & $1.79 \times 10^{-3}$ & $3.38 \times 10^{-2}$ & $4.02 \times 10^{-3}$ & $1.24 \times 10^{-3}$ \\
\hline CBD & $4.75 \times 10^{-2}$ & $4.71 \times 10^{-3}$ & $7.81 \times 10^{-4}$ & $89 \times 10^{-3}$ & $9.81 \times 10^{-4}$ & $1.09 \times 10^{-3}$ & $2.99 \times 10^{-2}$ & $3.54 \times 10^{-3}$ & $7.20 \times 10^{-4}$ \\
\hline HIL & $1.99 \times 10^{-2}$ & $2.90 \times 10^{-3}$ & $9.89 \times 10^{-4}$ & $.01 \times 10^{-3}$ & $1.05 \times 10^{-3}$ & $1.16 \times 10^{-3}$ & $2.00 \times 10^{-2}$ & $2.89 \times 10^{-3}$ & $8.86 \times 10^{-4}$ \\
\hline IDN & $2.19 \times 10^{-2}$ & $3.06 \times 10^{-3}$ & $9.43 \times 10^{-4}$ & $68 \times 10^{-3}$ & $1.67 \times 10^{-3}$ & $1.16 \times 10^{-3}$ & $2.42 \times 10^{-3}$ & $3.23 \times 10^{-3}$ & $9.39 \times 10^{-4}$ \\
\hline LST & $1.87 \times 10^{-2}$ & $2.78 \times 10^{-3}$ & $1.09 \times 10^{-3}$ & $1.17 \times 10^{-3}$ & $7.22 \times 10^{-4}$ & $8.08 \times 10^{-4}$ & $1.94 \times 10^{-2}$ & $2.81 \times 10^{-3}$ & $6.82 \times 10^{-4}$ \\
\hline NOY & $1.14 \times 10^{-2}$ & $2.16 \times 10^{-3}$ & $9.08 \times 10^{-4}$ & $9.49 \times 10^{-4}$ & $7.39 \times 10^{-4}$ & $9.71 \times 10^{-4}$ & $1.02 \times 10^{-2}$ & $2.02 \times 10^{-3}$ & $7.84 \times 10^{-4}$ \\
\hline PCN & $2.24 \times 10^{-2}$ & $3.09 \times 10^{-3}$ & $9.34 \times 10^{-4}$ & $2.04 \times 10^{-3}$ & $1.03 \times 10^{-3}$ & $1.09 \times 10^{-3}$ & $2.16 \times 10^{-2}$ & $3.03 \times 10^{-3}$ & $1.18 \times 10^{-3}$ \\
\hline PKT & $2.90 \times 10^{-2}$ & $3.61 \times 10^{-3}$ & $9.98 \times 10^{-4}$ & $1.52 \times 10^{-3}$ & $9.22 \times 10^{-4}$ & $1.11 \times 10^{-3}$ & $2.50 \times 10^{-2}$ & $3.30 \times 10^{-3}$ & $8.93 \times 10^{-4}$ \\
\hline RED & $8.02 \times 10^{-3}$ & $1.85 \times 10^{-3}$ & $1.35 \times 10^{-3}$ & $8.97 \times 10^{-4}$ & $8.29 \times 10^{-4}$ & $1.35 \times 10^{-3}$ & $7.04 \times 10^{-3}$ & $1.68 \times 10^{-3}$ & $9.98 \times 10^{-4}$ \\
\hline TUT & $2.73 \times 10^{-2}$ & $3.52 \times 10^{-3}$ & $1.64 \times 10^{-3}$ & $3.32 \times 10^{-4}$ & $1.18 \times 10^{-3}$ & $2.49 \times 10^{-3}$ & $2.92 \times 10^{-2}$ & $3.61 \times 10^{-3}$ & $1.03 \times 10^{-3}$ \\
\hline TUT & $1.99 \times 10^{-2}$ & $2.97 \times 10^{-3}$ & $8.78 \times 10^{-4}$ & $1.59 \times 10^{-3}$ & $9.64 \times 10^{-4}$ & $1.16 \times 10^{-3}$ & $2.23 \times 10^{-2}$ & $3.17 \times 10^{-3}$ & $1.09 \times 10^{-3}$ \\
\hline UPR & $2.27 \times 10^{-2}$ & $3.15 \times 10^{-3}$ & $1.05 \times 10^{-3}$ & $2.23 \times 10^{-3}$ & $1.12 \times 10^{-3}$ & $1.24 \times 10^{-3}$ & $2.43 \times 10^{-2}$ & $3.27 \times 10^{-3}$ & $1.05 \times 10^{-3}$ \\
\hline
\end{tabular}

${ }^{\mathrm{a}}[\mathrm{RN}]=$ Radionuclide concentration

b Total propagated uncertainty

${ }^{\mathrm{c}}$ Minimum detectable concentration

Table 4.18 Americium and plutonium concentrations $(\mathrm{Bq} / \mathrm{g})$ in sediment near the WIPP site. See Appendix B for the sampling locations.

\begin{tabular}{|c|c|c|c|c|c|c|c|c|c|}
\hline \multirow[b]{2}{*}{ Location } & {$[\mathrm{RN}]^{\mathrm{a}}$} & $2 \times \mathrm{TPU}^{\mathrm{b}}$ & $\mathrm{MDC}^{\mathrm{c}}$ & [RN] & $2 \times \mathrm{TPU}$ & MDC & [RN] & $2 \times \mathrm{TPU}$ & MDC \\
\hline & \multicolumn{3}{|c|}{${ }^{241} \mathrm{Am}$} & \multicolumn{3}{|c|}{${ }^{238} \mathrm{Pu}$} & \multicolumn{3}{|c|}{${ }^{239+240} \mathrm{Pu}$} \\
\hline HT & $2.96 \times 10^{-4}$ & $4.48 \times 10^{-4}$ & $2.71 \times 10^{-4}$ & $5.28 \times 10^{-5}$ & $1.90 \times 10^{-4}$ & $4.97 \times 10^{-4}$ & $5.45 \times 10^{-4}$ & $5.60 \times 10^{-4}$ & $9.22 \times 10^{-4}$ \\
\hline BRA & $4.07 \times 10^{-4}$ & $5.07 \times 10^{-4}$ & $5.34 \times 10^{-4}$ & $7.03 \times 10^{-4}$ & $5.48 \times 10^{-4}$ & $7.17 \times 10^{-4}$ & $4.68 \times 10^{-4}$ & $4.16 \times 10^{-4}$ & $4.72 \times 10^{-4}$ \\
\hline CBD & $-1.48 \times 10^{-4}$ & $2.10 \times 10^{-4}$ & $5.50 \times 10^{-4}$ & $7.97 \times 10^{-5}$ & $1.59 \times 10^{-4}$ & $2.15 \times 10^{-4}$ & $4.93 \times 10^{-4}$ & $4.31 \times 10^{-4}$ & $5.46 \times 10^{-4}$ \\
\hline HIL & $2.96 \times 10^{-4}$ & $4.73 \times 10^{-4}$ & $5.38 \times 10^{-4}$ & $1.12 \times 10^{-4}$ & $2.85 \times 10^{-4}$ & $6.40 \times 10^{-4}$ & $5.59 \times 10^{-5}$ & $3.71 \times 10^{-4}$ & $9.24 \times 10^{-4}$ \\
\hline IDN & $3.70 \times 10^{-5}$ & $3.54 \times 10^{-4}$ & $5.62 \times 10^{-4}$ & $3.49 \times 10^{-4}$ & $3.96 \times 10^{-4}$ & $5.46 \times 10^{-4}$ & $6.00 \times 10^{-4}$ & $5.25 \times 10^{-4}$ & $6.65 \times 10^{-4}$ \\
\hline LST & $2.96 \times 10^{-4}$ & $6.35 \times 10^{-4}$ & $1.06 \times 10^{-3}$ & $6.53 \times 10^{-5}$ & $2.57 \times 10^{-4}$ & $6.36 \times 10^{-4}$ & $3.59 \times 10^{-4}$ & $4.20 \times 10^{-4}$ & $7.00 \times 10^{-4}$ \\
\hline NOY & $1.11 \times 10^{-4}$ & $4.45 \times 10^{-4}$ & $7.34 \times 10^{-4}$ & $5.38 \times 10^{-5}$ & $1.93 \times 10^{-4}$ & $5.05 \times 10^{-4}$ & $3.76 \times 10^{-4}$ & $4.13 \times 10^{-4}$ & $6.14 \times 10^{-4}$ \\
\hline PCN & $2.96 \times 10^{-4}$ & $4.08 \times 10^{-4}$ & $2.47 \times 10^{-3}$ & $-3.84 \times 10^{-5}$ & $7.68 \times 10^{-5}$ & $5.41 \times 10^{-4}$ & $2.11 \times 10^{-4}$ & $4.74 \times 10^{-4}$ & $1.00 \times 10^{-3}$ \\
\hline PKT & $3.70 \times 10^{-4}$ & $5.30 \times 10^{-4}$ & $3.20 \times 10^{-4}$ & $8.22 \times 10^{-5}$ & $3.24 \times 10^{-4}$ & $8.00 \times 10^{-4}$ & $1.03 \times 10^{-4}$ & $4.00 \times 10^{-4}$ & $9.52 \times 10^{-4}$ \\
\hline RED & $1.48 \times 10^{-4}$ & $3.94 \times 10^{-4}$ & $6.11 \times 10^{-4}$ & $-8.24 \times 10^{-5}$ & $1.17 \times 10^{-4}$ & $7.06 \times 10^{-4}$ & $2.05 \times 10^{-4}$ & $2.91 \times 10^{-4}$ & $2.78 \times 10^{-4}$ \\
\hline TUT & $1.85 \times 10^{-4}$ & $4.13 \times 10^{-4}$ & $5.12 \times 10^{-4}$ & $1.76 \times 10^{-4}$ & $2.49 \times 10^{-4}$ & $2.38 \times 10^{-4}$ & $5.45 \times 10^{-4}$ & $4.77 \times 10^{-4}$ & $6.03 \times 10^{-4}$ \\
\hline TUT & $4.44 \times 10^{-4}$ & $6.89 \times 10^{-4}$ & $1.07 \times 10^{-3}$ & $-9.37 \times 10^{-5}$ & $1.33 \times 10^{-4}$ & $8.03 \times 10^{-4}$ & $2.34 \times 10^{-4}$ & $5.12 \times 10^{-4}$ & $1.09 \times 10^{-3}$ \\
\hline UPR & $1.48 \times 10^{-4}$ & $3.34 \times 10^{-4}$ & $2.02 \times 10^{-4}$ & $-1.87 \times 10^{-4}$ & $2.25 \times 10^{-4}$ & $8.30 \times 10^{-4}$ & $2.73 \times 10^{-4}$ & $3.37 \times 10^{-4}$ & $5.61 \times 10^{-4}$ \\
\hline
\end{tabular}

${ }^{\mathrm{a}}[\mathrm{RN}]=$ Radionuclide concentration

${ }^{\mathrm{b}}$ Total propagated uncertainty

${ }^{\mathrm{c}}$ Minimum detectable concentration 
Table 4.19 Selected radionuclide concentrations $(\mathrm{Bq} / \mathrm{g})$ in sediment near the WIPP site. See Appendix B for the sampling locations.

\begin{tabular}{|c|c|c|c|c|c|c|}
\hline \multirow[b]{2}{*}{ Location } & {$[\mathrm{RN}]^{\mathrm{a}}$} & $2 \times$ TPU $^{b}$ & MDC $^{\mathrm{c}}$ & [RN] & $2 \times$ TPU & MDC \\
\hline & \multicolumn{3}{|c|}{${ }^{137} \mathrm{Cs}$} & \multicolumn{3}{|c|}{${ }^{60} \mathrm{Co}$} \\
\hline BHT & $1.03 \times 10^{-2}$ & $2.06 \times 10^{-3}$ & $6.30 \times 10^{-3}$ & $4.31 \times 10^{-3}$ & $5.12 \times 10^{-3}$ & $5.41 \times 10^{-3}$ \\
\hline BRA & $-2.70 \times 10^{-3}$ & $3.93 \times 10^{-3}$ & $3.98 \times 10^{-3}$ & $1.48 \times 10^{-3}$ & $4.16 \times 10^{-3}$ & $4.20 \times 10^{-3}$ \\
\hline CBD & $1.18 \times 10^{-2}$ & $4.14 \times 10^{-3}$ & $5.02 \times 10^{-3}$ & $-8.53 \times 10^{-4}$ & $5.41 \times 10^{-3}$ & $5.21 \times 10^{-3}$ \\
\hline HIL & $5.48 \times 10^{-3}$ & $4.30 \times 10^{-3}$ & $4.84 \times 10^{-3}$ & $-1.74 \times 10^{-3}$ & $5.74 \times 10^{-3}$ & $5.44 \times 10^{-3}$ \\
\hline IDN & $1.86 \times 10^{-2}$ & $2.27 \times 10^{-3}$ & $6.16 \times 10^{-3}$ & $-1.74 \times 10^{-3}$ & $5.81 \times 10^{-3}$ & $5.51 \times 10^{-3}$ \\
\hline LST & $4.60 \times 10^{-3}$ & $1.96 \times 10^{-3}$ & $6.36 \times 10^{-3}$ & $-5.93 \times 10^{-3}$ & $6.23 \times 10^{-3}$ & $5.51 \times 10^{-3}$ \\
\hline NOY & $7.87 \times 10^{-4}$ & $2.99 \times 10^{-3}$ & $3.20 \times 10^{-3}$ & $-6.17 \times 10^{-3}$ & $4.17 \times 10^{-3}$ & $3.47 \times 10^{-3}$ \\
\hline $\mathrm{PCN}$ & $1.80 \times 10^{-3}$ & $4.07 \times 10^{-3}$ & $4.38 \times 10^{-3}$ & $7.74 \times 10^{-3}$ & $4.03 \times 10^{-3}$ & $4.73 \times 10^{-3}$ \\
\hline PKT & $1.27 \times 10^{-2}$ & $2.16 \times 10^{-3}$ & $6.46 \times 10^{-3}$ & $-1.38 \times 10^{-2}$ & $6.80 \times 10^{-3}$ & $5.39 \times 10^{-3}$ \\
\hline RED & $-1.85 \times 10^{-3}$ & $3.48 \times 10^{-3}$ & $3.55 \times 10^{-3}$ & $2.53 \times 10^{-3}$ & $3.59 \times 10^{-3}$ & $3.79 \times 10^{-3}$ \\
\hline TUT & $9.35 \times 10^{-3}$ & $2.10 \times 10^{-3}$ & $6.53 \times 10^{-3}$ & $-2.46 \times 10^{-3}$ & $5.77 \times 10^{-3}$ & $5.40 \times 10^{-3}$ \\
\hline TUT & $3.18 \times 10^{-3}$ & $5.44 \times 10^{-3}$ & $5.91 \times 10^{-3}$ & $-4.07 \times 10^{-3}$ & $6.90 \times 10^{-3}$ & $6.35 \times 10^{-3}$ \\
\hline \multirow[t]{2}{*}{ UPR } & $6.28 \times 10^{-3}$ & $3.13 \times 10^{-3}$ & $3.66 \times 10^{-3}$ & $2.54 \times 10^{-3}$ & $3.76 \times 10^{-3}$ & $3.92 \times 10^{-3}$ \\
\hline & \multicolumn{3}{|c|}{${ }^{90} \mathrm{Sr}$} & \multicolumn{3}{|c|}{${ }^{40} \mathrm{~K}$} \\
\hline BHT & $4.81 \times 10^{-3}$ & $2.59 \times 10^{-2}$ & $4.55 \times 10^{-2}$ & $8.11 \times 10^{-1}$ & $7.03 \times 10^{-2}$ & $1.01 \times 10^{-1}$ \\
\hline BRA & $7.40 \times 10^{-4}$ & $2.55 \times 10^{-2}$ & $4.55 \times 10^{-2}$ & $5.25 \times 10^{-1}$ & $4.61 \times 10^{-2}$ & $6.67 \times 10^{-2}$ \\
\hline CBD & $7.40 \times 10^{-3}$ & $2.81 \times 10^{-2}$ & $4.92 \times 10^{-2}$ & $3.92 \times 10^{-1}$ & $4.07 \times 10^{-2}$ & $8.29 \times 10^{-2}$ \\
\hline HIL & $-3.70 \times 10^{-3}$ & $2.59 \times 10^{-2}$ & $4.74 \times 10^{-2}$ & $1.09 \times 10^{0}$ & $8.82 \times 10^{-2}$ & $8.90 \times 10^{-2}$ \\
\hline IDN & $1.92 \times 10^{-2}$ & $2.78 \times 10^{-2}$ & $4.74 \times 10^{-2}$ & $7.31 \times 10^{-1}$ & $6.45 \times 10^{-2}$ & $9.67 \times 10^{-2}$ \\
\hline LST & $-2.59 \times 10^{-3}$ & $2.55 \times 10^{-2}$ & $4.63 \times 10^{-2}$ & $7.60 \times 10^{-1}$ & $6.60 \times 10^{-2}$ & $9.27 \times 10^{-2}$ \\
\hline NOY & $8.14 \times 10^{-3}$ & $2.70 \times 10^{-2}$ & $4.74 \times 10^{-2}$ & $4.13 \times 10^{-1}$ & $3.81 \times 10^{-2}$ & $6.49 \times 10^{-2}$ \\
\hline $\mathrm{PCN}$ & $1.85 \times 10^{-3}$ & $2.74 \times 10^{-2}$ & $4.88 \times 10^{-2}$ & $5.03 \times 10^{-1}$ & $4.70 \times 10^{-2}$ & $8.11 \times 10^{-2}$ \\
\hline PKT & $-1.85 \times 10^{-3}$ & $2.74 \times 10^{-2}$ & $4.96 \times 10^{-2}$ & $8.13 \times 10^{-1}$ & $6.79 \times 10^{-2}$ & $7.94 \times 10^{-2}$ \\
\hline RED & $-3.70 \times 10^{-4}$ & $2.74 \times 10^{-2}$ & $4.92 \times 10^{-2}$ & $1.62 \times 10^{-1}$ & $2.83 \times 10^{-2}$ & $8.11 \times 10^{-2}$ \\
\hline TUT & $8.88 \times 10^{-3}$ & $2.89 \times 10^{-2}$ & $5.03 \times 10^{-2}$ & $7.61 \times 10^{-1}$ & $6.79 \times 10^{-2}$ & $1.07 \times 10^{-1}$ \\
\hline TUT & $9.99 \times 10^{-3}$ & $2.85 \times 10^{-2}$ & $4.96 \times 10^{-2}$ & $8.65 \times 10^{-1}$ & $7.72 \times 10^{-2}$ & $1.21 \times 10^{-1}$ \\
\hline UPR & $-1.85 \times 10^{-3}$ & $2.89 \times 10^{-2}$ & $5.18 \times 10^{-2}$ & $4.48 \times 10^{-1}$ & $4.25 \times 10^{-2}$ & $7.71 \times 10^{-2}$ \\
\hline
\end{tabular}

Table 4.20 Results of duplicate sediment sample analysis. Units are Bq/g. See Appendix B for the sampling locations.

\begin{tabular}{|c|c|c|c|c|c|c|c|c|}
\hline \multirow[b]{2}{*}{ Location } & {$[\mathbf{R N}]^{\mathrm{a}}$} & $2 \times T_{P} U^{b}$ & MDC $^{c}$ & RER $^{\text {d }}$ & {$[\mathbf{R N}]$} & $2 \times \mathrm{TPU}^{\mathrm{a}}$ & MDC $^{\mathbf{b}}$ & $\overline{\text { RER }^{\mathrm{c}}}$ \\
\hline & \multicolumn{4}{|c|}{${ }^{241} \mathrm{Am}$} & \multicolumn{4}{|c|}{${ }^{137} \mathrm{Cs}$} \\
\hline$\overline{\mathrm{BHT}}$ & $2.96 \times 10^{-4}$ & $4.48 \times 10^{-4}$ & $2.71 \times 10^{-4}$ & 0.690 & $1.03 \times 10^{-2}$ & $2.06 \times 10^{-3}$ & $6.30 \times 10^{-3}$ & 2.344 \\
\hline \multirow[t]{2}{*}{ BHT Dup. } & $-7.40 \times 10^{-5}$ & $2.94 \times 10^{-4}$ & $5.65 \times 10^{-4}$ & & $-4.95 \times 10^{-3}$ & $6.18 \times 10^{-3}$ & $6.22 \times 10^{-3}$ & \\
\hline & \multicolumn{4}{|c|}{${ }^{40} \mathbf{K}$} & \multicolumn{4}{|c|}{${ }^{234} \mathbf{U}$} \\
\hline BHT & $8.11 \times 10^{-1}$ & $7.03 \times 10^{-2}$ & $1.01 \times 10^{-1}$ & 1.658 & $2.45 \times 10^{-2}$ & $3.24 \times 10^{-3}$ & $9.31 \times 10^{-4}$ & 0.379 \\
\hline \multirow[t]{2}{*}{ BHT Dup. } & $9.92 \times 10^{-1}$ & $8.32 \times 10^{-2}$ & $9.96 \times 10^{-2}$ & & $2.28 \times 10^{-2}$ & $3.22 \times 10^{-3}$ & $8.89 \times 10^{-4}$ & \\
\hline & \multicolumn{4}{|c|}{${ }^{235} \mathbf{U}$} & \multicolumn{4}{|c|}{${ }^{238} \mathbf{U}$} \\
\hline BHT & $1.14 \times 10^{-3}$ & $8.62 \times 10^{-4}$ & $1.26 \times 10^{-3}$ & 0.396 & $2.73 \times 10^{-2}$ & $3.45 \times 10^{-3}$ & $1.02 \times 10^{-3}$ & 0.566 \\
\hline BHT Dup. & $1.65 \times 10^{-3}$ & $9.72 \times 10^{-4}$ & $1.10 \times 10^{-3}$ & & $2.45 \times 10^{-2}$ & $3.35 \times 10^{-3}$ & $8.19 \times 10^{-4}$ & \\
\hline
\end{tabular}




\subsection{Biota}

\subsubsection{Sample Collection}

The concentration of radionuclides in plants is an important factor in estimating the intake of individual radionuclides by humans through ingestion. Therefore, rangeland vegetation samples were collected from the same six locations from where the soil samples were collected (Figure 4.5). The vegetation samples were chopped into 2.5-5-cm (1-2-in)-pieces, mixed together well, air dried at room temperature, and sent to the contract laboratory for analysis. Also collected were muscle tissues from two road-killed deer and one quail, both species commonly consumed by humans. Fish is also consumed in large amounts; therefore, fish samples from PCN, PEC, and BRA (three different locations on the Pecos River) were collected. The muscle tissues from the deer, quail, and fish were sent to the contract laboratory for analysis.

\subsubsection{Sample Preparation}

Weighed aliquots were taken from the bulk of the chopped vegetation samples and animal tissue samples from each location. The aliquots were transferred into separate containers and dried at $100^{\circ} \mathrm{C}\left(212^{\circ} \mathrm{F}\right)$. Gamma spectrometric determinations of ${ }^{40} \mathrm{~K},{ }^{60} \mathrm{Co}$, and ${ }^{137} \mathrm{Cs}$ were performed directly from these aliquots. The samples were then dry-ashed, followed by wet-ashing and dissolution in $8 \mathrm{M}$ nitric acid. Aliquots from the dissolved samples were taken for the determinations of ${ }^{90} \mathrm{Sr},{ }^{233+234} \mathrm{U},{ }^{235} \mathrm{U},{ }^{238} \mathrm{U}$, ${ }^{238} \mathrm{Pu},{ }^{239+240} \mathrm{Pu}$, and ${ }^{241} \mathrm{Am}$.

\subsubsection{Results and Discussions}

\section{$\underline{\text { Vegetation }}$}

Uranium-234 and ${ }^{238} \mathrm{U}$ were detected in all vegetation samples; because of it's naturally low concentration, ${ }^{235} \mathrm{U}$ was not detected in any vegetation sample (Table 4.21). Concentrations of ${ }^{234} \mathrm{U}$ ranged from $7.07 \times 10^{-4} \pm 2.65 \times 10^{-4} \mathrm{~Bq} / \mathrm{g}$ $\left(1.91 \times 10^{-2} \pm 7.16 \times 10^{-3} \mathrm{pCi} / \mathrm{g}\right)$ at SMR to $2.42 \times 10^{-3} \pm 4.87 \times 10^{-4} \mathrm{~Bq} / \mathrm{g}\left(6.54 \times 10^{-2} \pm\right.$ $\left.1.32 \times 10^{-2} \mathrm{pCi} / \mathrm{g}\right)$ at SEC. Uranium-238 varied between $5.66 \times 10^{-4} \pm 2.23 \times 10^{-4} \mathrm{~Bq} / \mathrm{g}\left(1.53 \times 10^{-2}\right.$ $\left.\pm 6.03 \times 10^{-3} \mathrm{pCi} / \mathrm{g}\right)$ at WSS to $2.25 \times 10^{-3} \pm$ $3.77 \times 10^{-4} \mathrm{~Bq} / \mathrm{g}\left(6.08 \times 10^{-2} \pm 1.02 \times 10^{-2} \mathrm{pCi} / \mathrm{g}\right)$ at WFF. The concentration of ${ }^{234} \mathrm{U}$ and ${ }^{238} \mathrm{U}$ did not vary significantly between locations (ANOVA, ${ }^{234} \mathrm{U} p=0.879,{ }^{238} \mathrm{U} \mathrm{p}=0.907$ ), but it did vary significantly between years (ANOVA, ${ }^{234} \mathrm{U}$ and ${ }^{238} \mathrm{U}, \mathrm{p}=0.001$ ), with the average concentration for 2000 being higher than those for both 1998 and 1999. The primary source for uranium in plant tissues is the soil, so this difference from the uranium results for soils may seem counterintuitive. However, uptake of radionuclides and contamination by resuspension are highly species dependent. Because of small-scale differences in soil type, shading, water availability, and other microenvironmental conditions, plants of the same species collected adjacent to one another will often have very different radionuclide concentrations. Therefore, the observed difference from the soil results may reflect a difference in the species mix sampled between years, natural variability in uranium concentration in soils, and differences in environmental conditions between years.

Concentrations of ${ }^{238} \mathrm{Pu},{ }^{239+240} \mathrm{Pu}$, and ${ }^{241} \mathrm{Am}$ were less than the minimum detectable concentrations in every vegetation sample (Table 4.21).

Potassium-40 was detected in every vegetation sample (Table 4.21), ranging from $1.11 \times 10^{0} \pm 9.05 \times 10^{-2} \mathrm{~Bq} / \mathrm{g}\left(3.00 \times 10^{1} \pm 2.45 \times 10^{0}\right.$ $\mathrm{pCi} / \mathrm{g})$ at $\mathrm{SEC}$ to $1.90 \times 10^{0} \pm 1.26 \times 10^{-1} \mathrm{~Bq} / \mathrm{g}$ $\left(5.14 \times 10^{1} \pm 3.41 \times 10^{0} \mathrm{pCi} / \mathrm{g}\right)$ at SMR. The concentration of ${ }^{40} \mathrm{~K}$ in vegetation was not significantly different between locations (ANOVA, $\mathrm{p}=0.911$ ) but was significantly different between years (ANOVA, $\mathrm{p}<0.001$ ), with the 1999 mean being higher than both the 1998 and the 2000 means. Like uranium, the 
Table 4.21 Radionuclide concentrations (Bq/g wet mass) in vegetation near the WIPP site. See Appendix B for the sampling locations.

\begin{tabular}{|c|c|c|c|c|c|c|c|c|c|}
\hline \multirow[b]{2}{*}{ Location } & {$[\mathbf{R N}]^{\mathbf{a}}$} & $2 \times \mathrm{TPU}^{\mathrm{b}}$ & MDC $^{\mathrm{c}}$ & [RN] & $2 \times \mathrm{TPU}$ & MDC & {$[\mathrm{RN}]$} & $2 \times \mathrm{TPU}$ & MDC \\
\hline & \multicolumn{3}{|c|}{${ }^{241} \mathrm{Am}$} & \multicolumn{3}{|c|}{${ }^{238} \mathrm{Pu}$} & \multicolumn{3}{|c|}{${ }^{239} \mathrm{Pu}$} \\
\hline MLR & $1.87 \times 10^{-5}$ & $5.16 \times 10^{-5}$ & $6.40 \times 10^{-5}$ & $7.02 \times 10^{-6}$ & $2.52 \times 10^{-5}$ & $6.60 \times 10^{-5}$ & $1.40 \times 10^{-5}$ & $5.29 \times 10^{-5}$ & $1.23 \times 10^{-4}$ \\
\hline SEC & $1.74 \times 10^{-5}$ & $5.77 \times 10^{-5}$ & $7.98 \times 10^{-5}$ & $-5.17 \times 10^{-6}$ & $1.03 \times 10^{-5}$ & $7.29 \times 10^{-5}$ & $4.64 \times 10^{-5}$ & $5.27 \times 10^{-5}$ & $7.29 \times 10^{-5}$ \\
\hline SMR & $1.91 \times 10^{-5}$ & $5.96 \times 10^{-5}$ & $8.25 \times 10^{-5}$ & $-6.48 \times 10^{-6}$ & $1.30 \times 10^{-5}$ & $9.13 \times 10^{-5}$ & $-9.70 \times 10^{-6}$ & $6.81 \times 10^{-5}$ & $1.86 \times 10^{-4}$ \\
\hline WEE & $2.17 \times 10^{-5}$ & $6.81 \times 10^{-5}$ & $1.13 \times 10^{-4}$ & $-1.81 \times 10^{-5}$ & $2.10 \times 10^{-5}$ & $1.18 \times 10^{-4}$ & $6.04 \times 10^{-6}$ & $4.91 \times 10^{-5}$ & $1.30 \times 10^{-4}$ \\
\hline WFF & $2.86 \times 10^{-6}$ & $4.97 \times 10^{-5}$ & $7.89 \times 10^{-5}$ & $9.75 \times 10^{-6}$ & $3.50 \times 10^{-5}$ & $9.16 \times 10^{-5}$ & $1.30 \times 10^{-5}$ & $5.11 \times 10^{-5}$ & $1.27 \times 10^{-4}$ \\
\hline \multirow[t]{2}{*}{ WSS } & $2.28 \times 10^{-5}$ & $5.64 \times 10^{-5}$ & $3.81 \times 10^{-5}$ & $9.18 \times 10^{-6}$ & $3.30 \times 10^{-5}$ & $8.63 \times 10^{-5}$ & $7.64 \times 10^{-5}$ & $8.55 \times 10^{-5}$ & $1.42 \times 10^{-4}$ \\
\hline & \multicolumn{3}{|c|}{${ }^{234} \mathbf{U}$} & \multicolumn{3}{|c|}{${ }^{235} \mathbf{U}$} & \multicolumn{3}{|c|}{${ }^{238} \mathrm{U}$} \\
\hline MLR & $7.12 \times 10^{-4}$ & $2.18 \times 10^{-4}$ & $1.74 \times 10^{-4}$ & $3.42 \times 10^{-5}$ & $7.70 \times 10^{-5}$ & $1.63 \times 10^{-4}$ & $8.88 \times 10^{-4}$ & $2.36 \times 10^{-4}$ & $1.24 \times 10^{-4}$ \\
\hline SEC & $2.42 \times 10^{-3}$ & $4.87 \times 10^{-4}$ & $2.63 \times 10^{-4}$ & $9.94 \times 10^{-5}$ & $1.17 \times 10^{-4}$ & $1.94 \times 10^{-4}$ & $1.93 \times 10^{-3}$ & $4.23 \times 10^{-4}$ & $1.64 \times 10^{-4}$ \\
\hline SMR & $7.07 \times 10^{-4}$ & $2.65 \times 10^{-4}$ & $3.47 \times 10^{-4}$ & $5.41 \times 10^{-5}$ & $1.55 \times 10^{-4}$ & $3.27 \times 10^{-4}$ & $9.97 \times 10^{-4}$ & $2.66 \times 10^{-4}$ & $1.81 \times 10^{-4}$ \\
\hline WEE & $8.70 \times 10^{-4}$ & $2.56 \times 10^{-4}$ & $1.36 \times 10^{-4}$ & $8.98 \times 10^{-5}$ & $9.54 \times 10^{-5}$ & $1.46 \times 10^{-4}$ & $7.24 \times 10^{-4}$ & $2.44 \times 10^{-4}$ & $2.17 \times 10^{-4}$ \\
\hline WFF & $2.23 \times 10^{-3}$ & $3.74 \times 10^{-4}$ & $1.44 \times 10^{-4}$ & $7.04 \times 10^{-5}$ & $8.94 \times 10^{-5}$ & $1.62 \times 10^{-4}$ & $2.25 \times 10^{-3}$ & $3.77 \times 10^{-4}$ & $1.81 \times 10^{-4}$ \\
\hline \multirow[t]{2}{*}{ WSS } & $7.53 \times 10^{-4}$ & $2.62 \times 10^{-4}$ & $2.26 \times 10^{-4}$ & $-8.40 \times 10^{-6}$ & $7.22 \times 10^{-5}$ & $2.08 \times 10^{-4}$ & $5.66 \times 10^{-4}$ & $2.23 \times 10^{-4}$ & $1.81 \times 10^{-4}$ \\
\hline & \multicolumn{3}{|c|}{${ }^{137} \mathrm{Cs}$} & \multicolumn{3}{|c|}{${ }^{60} \mathrm{Co}$} & & & \\
\hline MLR & $2.13 \times 10^{-2}$ & $7.33 \times 10^{-3}$ & $9.43 \times 10^{-3}$ & $-2.10 \times 10^{-3}$ & $8.41 \times 10^{-3}$ & $9.21 \times 10^{-3}$ & & & \\
\hline SEC & $-1.04 \times 10^{-2}$ & $8.45 \times 10^{-3}$ & $9.28 \times 10^{-3}$ & $-8.19 \times 10^{-3}$ & $9.16 \times 10^{-3}$ & $9.55 \times 10^{-3}$ & & & \\
\hline SMR & $5.28 \times 10^{-3}$ & $7.37 \times 10^{-3}$ & $8.79 \times 10^{-3}$ & $1.83 \times 10^{-4}$ & $8.00 \times 10^{-3}$ & $8.92 \times 10^{-3}$ & & & \\
\hline WEE & $-1.35 \times 10^{-3}$ & $8.76 \times 10^{-3}$ & $1.01 \times 10^{-2}$ & $8.25 \times 10^{-3}$ & $8.27 \times 10^{-3}$ & $9.91 \times 10^{-3}$ & & & \\
\hline WFF & $6.48 \times 10^{-3}$ & $9.18 \times 10^{-3}$ & $1.10 \times 10^{-2}$ & $-6.40 \times 10^{-3}$ & $1.04 \times 10^{-2}$ & $1.10 \times 10^{-2}$ & & & \\
\hline \multirow[t]{2}{*}{ WSS } & $2.75 \times 10^{-3}$ & $8.30 \times 10^{-3}$ & $9.76 \times 10^{-3}$ & $1.22 \times 10^{-2}$ & $7.80 \times 10^{-3}$ & $9.73 \times 10^{-3}$ & & & \\
\hline & \multicolumn{3}{|c|}{${ }^{90} \mathrm{Sr}$} & \multicolumn{3}{|c|}{${ }^{40} K$} & & & \\
\hline MLR & $3.33 \times 10^{-3}$ & $5.18 \times 10^{-3}$ & $8.88 \times 10^{-3}$ & $1.18 \mathrm{E}+00$ & $9.63 \times 10^{-2}$ & $1.54 \times 10^{-1}$ & & & \\
\hline SEC & $6.66 \times 10^{-3}$ & $5.18 \times 10^{-3}$ & $8.14 \times 10^{-3}$ & $1.11 \mathrm{E}+00$ & $9.05 \times 10^{-2}$ & $1.49 \times 10^{-1}$ & & & \\
\hline SMR & $4.81 \times 10^{-3}$ & $5.18 \times 10^{-3}$ & $8.51 \times 10^{-3}$ & $1.90 \mathrm{E}+00$ & $1.26 \times 10^{-1}$ & $1.78 \times 10^{-1}$ & & & \\
\hline WEE & $1.30 \times 10^{-2}$ & $5.92 \times 10^{-3}$ & $8.88 \times 10^{-3}$ & $1.49 \mathrm{E}+00$ & $1.09 \times 10^{-1}$ & $1.74 \times 10^{-1}$ & & & \\
\hline WFF & $5.92 \times 10^{-3}$ & $5.18 \times 10^{-3}$ & $8.51 \times 10^{-3}$ & $1.23 \mathrm{E}+00$ & $9.94 \times 10^{-2}$ & $1.67 \times 10^{-1}$ & & & \\
\hline WSS & $-7.40 \times 10^{-4}$ & $4.81 \times 10^{-3}$ & $8.51 \times 10^{-3}$ & $1.12 \mathrm{E}+00$ & $1.04 \times 10^{-1}$ & $1.61 \times 10^{-1}$ & & & \\
\hline
\end{tabular}

${ }^{\mathrm{a}}[\mathrm{RN}]=$ Radionuclide concentration

b Total propagated uncertainty

${ }^{\mathrm{c}}$ Minimum detectable concentration

primary source for potassium in plant tissues is the soil, and this difference from the ${ }^{40} \mathrm{~K}$ results for soil is probably due to the same factors. Cobalt-60, ${ }^{90} \mathrm{Sr}$, and ${ }^{137} \mathrm{Cs}$ were each detected in one vegetation sample.

A duplicate analysis of the vegetation sample from WSS was performed for all the radionuclides of interest (Table 4.22). Concentrations of ${ }^{241} \mathrm{Am},{ }^{234} \mathrm{U},{ }^{238} \mathrm{U},{ }^{40} \mathrm{~K}$, and ${ }^{60} \mathrm{Co}$ were above detection limits in the duplicate sample. All RER values were less than one, indicating good agreement between the duplicates.

$\underline{\text { Animals }}$

Of the radionuclides of interest, only ${ }^{40} \mathrm{~K}$ was detected in deer tissue (Table 4.23). Its mean concentration was $1.49 \times 10^{-1} \pm 9.87 \times 10^{-3}$ $\mathrm{Bq} / \mathrm{g}\left(4.03 \times 10^{0} \pm 2.67 \times 10^{-1} \mathrm{pCi} / \mathrm{g}\right)$, similar to that found in other mammals throughout the world. Potassium-40 was also the only radionuclide detected in the single quail sample (Table 4.23). 
Table 4.22 Results of duplicate vegetation sample analysis. Units are Bq/g. See Appendix B for the sampling locations.

\begin{tabular}{|c|c|c|c|c|c|c|c|c|}
\hline \multirow[b]{2}{*}{ Location } & {$[\mathrm{RN}]^{\mathrm{a}}$} & $2 \times \mathrm{TPU}^{\mathrm{b}}$ & MDC $^{\mathrm{c}}$ & RER $^{\text {d }}$ & [RN] & $2 \times \mathrm{TPU}$ & MDC & RER \\
\hline & \multicolumn{4}{|c|}{${ }^{241} \mathrm{Am}$} & \multicolumn{4}{|c|}{${ }^{234} \mathbf{U}$} \\
\hline$\overline{\text { WSS }}$ & $2.28 \times 10^{-5}$ & $5.64 \times 10^{-5}$ & $3.81 \times 10^{-5}$ & 0.399 & $7.53 \times 10^{-4}$ & $2.62 \times 10^{-4}$ & $2.26 \times 10^{-4}$ & 0.677 \\
\hline \multirow{2}{*}{ WSS Dup. } & $5.86 \times 10^{-5}$ & $6.98 \times 10^{-5}$ & $3.56 \times 10^{-5}$ & & $4.67 \times 10^{-4}$ & $3.30 \times 10^{-4}$ & $5.18 \times 10^{-6}$ & \\
\hline & \multicolumn{4}{|c|}{${ }^{238} \mathbf{U}$} & \multicolumn{4}{|c|}{${ }^{40} \mathrm{~K}$} \\
\hline WSS & $5.66 \times 10^{-4}$ & $2.23 \times 10^{-4}$ & $1.81 \times 10^{-4}$ & 0.426 & $1.12 \times 10^{0}$ & $1.04 \times 10^{-1}$ & $1.61 \times 10^{-1}$ & 0.535 \\
\hline \multirow[t]{2}{*}{ WSS Dup. } & $7.46 \times 10^{-4}$ & $3.58 \times 10^{-4}$ & $4.37 \times 10^{-4}$ & & $1.04 \times 10^{0}$ & $9.41 \times 10^{-2}$ & $1.53 \times 10^{-1}$ & \\
\hline & \multicolumn{4}{|c|}{${ }^{60} \mathrm{Co}$} & & & & \\
\hline WSS & $1.22 \times 10^{-2}$ & $7.80 \times 10^{-3}$ & $9.73 \times 10^{-3}$ & 0.881 & & & & \\
\hline WSS Dup. & $1.99 \times 10^{-3}$ & $8.62 \times 10^{-3}$ & $9.79 \times 10^{-3}$ & & & & & \\
\hline
\end{tabular}

${ }^{\mathrm{a}}[\mathrm{RN}]=$ Radionuclide concentration

${ }^{\mathrm{b}}$ Total propagated uncertainty

${ }^{\mathrm{c}}$ Minimum detectable concentration

${ }^{\mathrm{d}}$ Relative Error Ratio

Table 4.23 Radionuclide concentrations (Bq/g wet mass) in deer and quail near the WIPP site.

\begin{tabular}{|c|c|c|c|c|c|c|c|c|c|}
\hline & {$[\mathbf{R N}]^{\mathrm{a}}$} & $2 \times$ TPU $^{b}$ & MDC $^{\mathrm{c}}$ & [RN] & $2 \times$ TPU & MDC & [RN] & $2 \times$ TPU & MDC \\
\hline $\begin{array}{l}\text { Sample } \\
\text { Type }\end{array}$ & \multicolumn{3}{|c|}{${ }^{241} \mathrm{Am}$} & \multicolumn{3}{|c|}{${ }^{238} \mathbf{P u}$} & \multicolumn{3}{|c|}{${ }^{239} \mathbf{P u}$} \\
\hline Deer $^{d}$ & $-7.45 \times 10^{-7}$ & $1.84 \times 10^{-5}$ & $4.72 \times 10^{-5}$ & $4.01 \times 10^{-6}$ & $1.12 \times 10^{-5}$ & $3.59 \times 10^{-5}$ & $-8.75 \times 10^{-6}$ & $1.40 \times 10^{-5}$ & $6.90 \times 10^{-5}$ \\
\hline \multirow[t]{2}{*}{ Quail $^{\mathrm{e}}$} & $3.70 \times 10^{-5}$ & $7.79 \times 10^{-5}$ & $1.16 \times 10^{-4}$ & $2.60 \times 10^{-5}$ & $5.39 \times 10^{-5}$ & $1.13 \times 10^{-4}$ & $1.15 \times 10^{-5}$ & $4.54 \times 10^{-5}$ & $1.13 \times 10^{-4}$ \\
\hline & \multicolumn{3}{|c|}{${ }^{234} \mathrm{U}$} & \multicolumn{3}{|c|}{${ }^{235} \mathrm{U}$} & \multicolumn{3}{|c|}{${ }^{238} \mathrm{U}$} \\
\hline Deer & $3.42 \times 10^{-5}$ & $2.60 \times 10^{-5}$ & $5.99 \times 10^{-5}$ & $2.79 \times 10^{-5}$ & $2.71 \times 10^{-5}$ & $6.88 \times 10^{-5}$ & $2.12 \times 10^{-5}$ & $2.25 \times 10^{-5}$ & $5.96 \times 10^{-5}$ \\
\hline \multirow[t]{2}{*}{ Quail } & $3.58 \times 10^{-4}$ & $2.39 \times 10^{-4}$ & $3.67 \times 10^{-4}$ & $3.70 \times 10^{-4}$ & $2.91 \times 10^{-4}$ & $4.74 \times 10^{-4}$ & $1.92 \times 10^{-4}$ & $1.98 \times 10^{-4}$ & $3.32 \times 10^{-4}$ \\
\hline & \multicolumn{3}{|c|}{${ }^{137} \mathrm{Cs}$} & \multicolumn{3}{|c|}{${ }^{60} \mathrm{Co}$} & & & \\
\hline Deer & $5.91 \times 10^{-4}$ & $1.15 \times 10^{-3}$ & $1.83 \times 10^{-3}$ & $5.95 \times 10^{-4}$ & $1.21 \times 10^{-3}$ & $1.85 \times 10^{-3}$ & & & \\
\hline \multirow[t]{2}{*}{ Quail } & $1.19 \times 10^{-3}$ & $2.72 \times 10^{-3}$ & $2.81 \times 10^{-3}$ & $-4.51 \times 10^{-3}$ & $3.31 \times 10^{-3}$ & $2.83 \times 10^{-3}$ & & & \\
\hline & \multicolumn{3}{|c|}{${ }^{90} \mathrm{Sr}$} & \multicolumn{3}{|c|}{${ }^{40} \mathbf{K}$} & & & \\
\hline Deer & $0.00 \times 10^{0}$ & $9.96 \times 10^{-4}$ & $2.46 \times 10^{-3}$ & $1.49 \times 10^{-1}$ & $9.87 \times 10^{-3}$ & $3.71 \times 10^{-2}$ & & & \\
\hline Quail & $5.55 \times 10^{-4}$ & $2.48 \times 10^{-3}$ & $4.26 \times 10^{-3}$ & $8.34 \times 10^{-2}$ & $1.82 \times 10^{-2}$ & $5.73 \times 10^{-2}$ & & & \\
\hline
\end{tabular}

${ }^{\mathrm{a}}[\mathrm{RN}]=$ Radionuclide concentration

b Total propagated uncertainty

${ }^{\mathrm{c}}$ Minimum detectable concentration

${ }^{\mathrm{d}}$ Mean of two samples collected near WIPP. TPU represents the standard deviation of the mean.

${ }^{\mathrm{E}}$ Single sample

Uranium-234 was detected in the fish sample from $\mathrm{PCN}$ and ${ }^{238} \mathrm{U}$ was in the sample from BRA (Table 4.24). Neither plutonium isotope was detected in fish. Americium-241 was above the MDC, but less than $2 \times$ TPU, in three of the four fish samples.
Cesium-137 and ${ }^{60} \mathrm{Co}$ were each detected in one fish sample (Table 4.24) while ${ }^{90} \mathrm{Sr}$ was not detected in any fish sample. Potassium-40 was detected in all fish (Table 4.24). It was lowest in the sample from BRA $\left(1.87 \times 10^{-1} \pm 2.34 \times 10^{-2}\right.$ $\left.\mathrm{Bq} / \mathrm{g}\left[5.05 \times 10^{0} \pm 6.32 \times 10^{-1} \mathrm{pCi} / \mathrm{g}\right]\right)$, and highest in the sample from PCN $\left(4.72 \times 10^{-1} \pm 4.61 \times 10^{-2}\right.$ $\left.\mathrm{Bq} / \mathrm{g}\left[1.28 \times 10^{1} \pm 1.25 \times 10^{0} \mathrm{pCi} / \mathrm{g}\right]\right)$. 
Table 4.24 Radionuclide concentrations (Bq/g wet mass) in fish near the WIPP site. See Appendix B for the sampling locations.

\begin{tabular}{|c|c|c|c|c|c|c|c|c|c|}
\hline & {$[\mathrm{RN}]^{\mathrm{a}}$} & $2 \times T_{P U}^{b}$ & MDC $^{\mathrm{c}}$ & {$[\mathrm{RN}]$} & $2 \times$ TPU & MDC & [RN] & $2 \times$ TPU & MDC \\
\hline Location & \multicolumn{3}{|c|}{${ }^{241} \mathrm{Am}$} & \multicolumn{3}{|c|}{${ }^{238} \mathbf{P u}$} & \multicolumn{3}{|c|}{${ }^{239} \mathrm{Pu}$} \\
\hline$\overline{\mathrm{BRA}}$ & $2.35 \times 10^{-5}$ & $3.62 \times 10^{-5}$ & $2.19 \times 10^{-5}$ & $-1.58 \times 10^{-6}$ & $1.92 \times 10^{-5}$ & $6.15 \times 10^{-5}$ & $3.62 \times 10^{-5}$ & $3.59 \times 10^{-5}$ & $4.45 \times 10^{-5}$ \\
\hline PCN & $3.16 \times 10^{-5}$ & $4.24 \times 10^{-5}$ & $5.37 \times 10^{-5}$ & $1.46 \times 10^{-6}$ & $1.67 \times 10^{-5}$ & $4.99 \times 10^{-5}$ & $-3.27 \times 10^{-10}$ & $2.43 \times 10^{-5}$ & $6.75 \times 10^{-5}$ \\
\hline PEC & $2.98 \times 10^{-5}$ & $3.86 \times 10^{-5}$ & $2.13 \times 10^{-5}$ & $-1.27 \times 10^{-6}$ & $1.54 \times 10^{-5}$ & $4.94 \times 10^{-5}$ & $2.53 \times 10^{-6}$ & $2.06 \times 10^{-5}$ & $5.44 \times 10^{-5}$ \\
\hline \multirow[t]{2}{*}{ PEC } & $3.34 \times 10^{-5}$ & $3.81 \times 10^{-5}$ & $1.94 \times 10^{-5}$ & $3.13 \times 10^{-6}$ & $1.12 \times 10^{-5}$ & $2.94 \times 10^{-5}$ & $1.25 \times 10^{-5}$ & $2.24 \times 10^{-5}$ & $4.47 \times 10^{-5}$ \\
\hline & \multicolumn{3}{|c|}{${ }^{234} \mathbf{U}$} & \multicolumn{3}{|c|}{${ }^{235} \mathbf{U}$} & \multicolumn{3}{|c|}{${ }^{238} \mathbf{U}$} \\
\hline BRA & $7.90 \times 10^{-5}$ & $6.09 \times 10^{-5}$ & $9.50 \times 10^{-5}$ & $5.93 \times 10^{-6}$ & $2.34 \times 10^{-5}$ & $5.79 \times 10^{-5}$ & $1.67 \times 10^{-4}$ & $7.00 \times 10^{-5}$ & $4.74 \times 10^{-5}$ \\
\hline PCN & $2.03 \times 10^{-4}$ & $8.51 \times 10^{-5}$ & $1.00 \times 10^{-4}$ & $1.27 \times 10^{-5}$ & $5.41 \times 10^{-5}$ & $1.19 \times 10^{-4}$ & $5.65 \times 10^{-5}$ & $5.51 \times 10^{-5}$ & $9.51 \times 10^{-5}$ \\
\hline PEC & $7.78 \times 10^{-5}$ & $6.42 \times 10^{-5}$ & $1.06 \times 10^{-4}$ & $-8.77 \times 10^{-6}$ & $6.42 \times 10^{-5}$ & $1.06 \times 10^{-4}$ & $6.66 \times 10^{-5}$ & $5.62 \times 10^{-5}$ & $9.04 \times 10^{-5}$ \\
\hline \multirow[t]{2}{*}{ PEC } & $7.57 \times 10^{-5}$ & $5.40 \times 10^{-5}$ & $7.66 \times 10^{-5}$ & $-1.14 \times 10^{-5}$ & $2.64 \times 10^{-5}$ & $8.20 \times 10^{-5}$ & $3.31 \times 10^{-5}$ & $3.70 \times 10^{-5}$ & $6.14 \times 10^{-5}$ \\
\hline & \multicolumn{3}{|c|}{${ }^{137} \mathrm{Cs}$} & \multicolumn{3}{|c|}{${ }^{60} \mathrm{Co}$} & & & \\
\hline BRA & $1.70 \times 10^{-4}$ & $1.56 \times 10^{-3}$ & $1.79 \times 10^{-3}$ & $2.54 \times 10^{-3}$ & $1.75 \times 10^{-3}$ & $1.99 \times 10^{-3}$ & & & \\
\hline PCN & $6.63 \times 10^{-3}$ & $1.93 \times 10^{-3}$ & $2.36 \times 10^{-3}$ & $-2.13 \times 10^{-4}$ & $2.43 \times 10^{-3}$ & $2.65 \times 10^{-3}$ & & & \\
\hline PEC & $5.56 \times 10^{-5}$ & $1.77 \times 10^{-3}$ & $2.02 \times 10^{-3}$ & $1.33 \times 10^{-3}$ & $1.97 \times 10^{-3}$ & $2.22 \times 10^{-3}$ & & & \\
\hline \multirow[t]{2}{*}{ PEC- } & $2.13 \times 10^{-3}$ & $2.37 \times 10^{-3}$ & & $2.36 \times 10^{-3}$ & $2.62 \times 10^{-3}$ & & & & \\
\hline & \multicolumn{3}{|c|}{${ }^{90} \mathrm{Sr}$} & \multicolumn{3}{|c|}{${ }^{40} \mathrm{~K}$} & & & \\
\hline BRA & $9.25 \times 10^{-4}$ & $1.55 \times 10^{-3}$ & $2.63 \times 10^{-3}$ & $1.87 \times 10^{-1}$ & $2.34 \times 10^{-2}$ & $2.62 \times 10^{-2}$ & & & \\
\hline PCN & $-5.55 \times 10^{-4}$ & $1.37 \times 10^{-3}$ & $2.48 \times 10^{-3}$ & $4.72 \times 10^{-1}$ & $4.61 \times 10^{-2}$ & $4.10 \times 10^{-2}$ & & & \\
\hline PEC & $9.99 \times 10^{-4}$ & $1.48 \times 10^{-3}$ & $2.48 \times 10^{-3}$ & $2.77 \times 10^{-1}$ & $3.11 \times 10^{-2}$ & $3.21 \times 10^{-2}$ & & & \\
\hline PEC & $5.55 \times 10^{-4}$ & $1.44 \times 10^{-3}$ & $2.44 \times 10^{-3}$ & $3.45 \times 10^{-1}$ & $3.67 \times 10^{-2}$ & $3.70 \times 10^{-2}$ & & & \\
\hline
\end{tabular}

${ }^{\mathrm{a}}[\mathrm{RN}]=$ Radionuclide concentration

b Total propagated uncertainty

${ }^{\mathrm{c}}$ Minimum detectable concentration

There was no statistically significant difference between concentrations of ${ }^{40} \mathrm{~K}$ in fish at any location (ANOVA, $\mathrm{p}=0.675)$. However, there was a significant difference between years $(\mathrm{p}=0.005)$. Potassium-40 was lower in 1998 than in either subsequent year.

\subsection{Summary and Conclusion}

The Environmental Monitoring Program collected samples of air particulates, soil, sediment, groundwater, surface water, and biota and analyzed them for radionuclides considered to be indicators of potential contamination from the WIPP facility, as well as other radionuclides of potential interest. Measured concentrations were examined for evidence of WIPP-related contamination, such as higher concentrations of TRU radionuclides after 1998, or higher concentrations in downwind or down gradient directions. Radionuclide concentrations observed were highly variable in space and time and between media. However, no time or space relationships related to WIPP were observed, and concentrations were consistent with background levels. In no case, could environmental concentrations be attributed to WIPP releases. 


\section{Chapter 5 \\ Environmental Nonradiological Program Information}

This chapter discusses nonradiological environmental surveillance data collected between January 1 and December 31, 2000. Nonradiological programs at WIPP include wildlife population monitoring, meteorological monitoring, and seismic monitoring. In addition, VOCs were monitored to comply with the provisions of WIPP's hazardous waste permit, and liquid effluent monitoring was conducted in accordance with WIPP's Sewage System Discharge Plan (DP-831).

\subsection{Principal Functions of Nonradio- logical Sampling}

The principal functions of the nonradiological environmental surveillance program are to:

- assess the impacts of WIPP operations on the surrounding ecosystem;

- monitor ecological conditions in the Los Medaños region;

- investigate unusual or unexpected elements in the ecological databases;

- provide environmental data which are important to the mission of the WIPP project, but which have not or will not be acquired by other programs; and

- comply with applicable commitments identified with existing agreements (e.g., BLM/DOE MOU, Interagency Agreements, Agreements in Principle, etc.).

\subsection{WIPP Raptor Program (WRP)}

WIPP, and the region surrounding it, is widely recognized for its concentration and diversity of raptors. The area is home to several raptor species of special concern, including Harris' hawks, Swainson's hawks, burrowing owls, and barn owls, as well as other species.

DOE, the BLM, and other government agencies are aware of the value and importance of protecting and monitoring raptor populations. To assist in this effort at WIPP, the BLM and DOE established the WRP in the early 1990s to monitor and protect raptors on the WIPP site, and to educate site workers and the public about these birds. The WRP is administrated by the WIPP Environmental Monitoring Program with input from the BLM and others. Scientific consultation, research direction, and field operations are conducted by scientists from the Department of Biology at Rocky Mountain College (Restani 2000).

Raptor research at WIPP began in 1981 when DOE initiated a study of the social behavior of Harris' hawks conducted by the University of New Mexico. Research results revealed the extent of the overall raptor population, and provided new information about raptor species in the area. In the late 1980s, the BLM designated the Los Medaños Raptor Area, which included the WIPP site, as a National Key Raptor Area. This designation served as a catalyst for the development of the WRP. Simultaneously, DOE reorganized its program to encompass expanded objectives.

The WRP presently serves four significant functions:

- Wildlife Monitoring. The WRP provides DOE, BLM, and other agencies with current information about the status of raptor populations in and around WIPP. 
- Scientific Research. WRP staff conduct research on topics that contribute to the understanding of raptors in the desert southwest.

- Community Outreach. The program offers a community service by providing educational programs to schools and organized groups.

- Interagency Cooperation. The WRP is funded by DOE, but works closely with several other federal and state agencies.

In 2000, long-term studies of productivity and population demographics of the raptor community in and around WIPP continued. The primary objective for the 2000 nesting season was to locate all raptor and raven nests within the $3000 \mathrm{~km}^{2}$ study area, centered on WIPP. Secondary objectives were to estimate raptor productivity in the area and to determine causes of raptor mortality.

Researcher ornithologists located 365 raptor and raven territories in 2000, of which 107 were Swainson's hawk territories and 119 were Chihuahuan raven territories. The number of nests far surpassed those found in previous years studies, reflecting a change in study objectives rather than a real population explosion.

Average Harris' hawk brood size in 2000 (1.71 nestlings) was higher than that reported in 1999 (1.2 nestlings) or 1998 (1.04), indicating a possible increase in productivity of Harris' hawks. For Swainson's hawks the results were more equivocal. Average brood size in 2000 (1.34 nestlings) was higher than 1998 (1.00 nestlings) but lower than 1999 (1.50 nestlings). These results are preliminary and should be interpreted with caution.

Electrocution by power poles continues to be an important cause of raptor mortality and is predicted to increase as oil and gas exploration increases in the area. In one case, however, a nest was deliberately destroyed by an unknown person or persons. For more information on the WIPP Raptor Program, see the Waste Isolation Pilot Plant WIPP Raptor Program 2000 Annual Report (Restani 2000).

\subsection{Meteorology}

The primary WIPP meteorological station is located $600 \mathrm{~m}(1,970 \mathrm{ft})$ northeast of the Waste Handling Building. The main function of the station is to provide data for atmospheric dispersion modeling. The station measures and records wind speed, wind direction, and temperature at elevations of 2,10 , and $50 \mathrm{~m}$ $(6.5,33$, and $165 \mathrm{ft})$. The station records ground-level measurements of barometric pressure, relative humidity, precipitation, and solar radiation.

In addition to the primary meteorological station, the WIPP Far Field Station is located $1,000 \mathrm{~m}(3,300 \mathrm{ft})$ northwest of the Waste Handling Building. At the WIPP Far Field Station, a secondary meteorological station measures and records temperature and atmospheric pressure at ground level and wind speed and wind direction at $10 \mathrm{~m}(33 \mathrm{ft})$.

\subsubsection{Climatic Data}

The annual precipitation at the WIPP site for 2000 was $305 \mathrm{~mm}$ (12 in), which was $105 \mathrm{~mm}$ (4.1 in) greater than the previous year's rainfall. Figure 5.1 displays the monthly precipitation at WIPP.

The mean annual temperature for the WIPP area in 2000 was $17^{\circ} \mathrm{C}\left(63^{\circ} \mathrm{F}\right)$. The mean monthly temperatures for the WIPP area ranged from $4^{\circ} \mathrm{C}\left(39^{\circ} \mathrm{F}\right)$ during December to $29^{\circ} \mathrm{C}$ $\left(84^{\circ} \mathrm{F}\right)$ in July. Generally, maximum temperatures occurred from May through September, while minimum temperatures occurred in January, November, and December, as illustrated in Figures 5.2, 5.3, and 5.4 and Tables 5.1, 5.2, and 5.3. The lowest recorded temperature was $-11^{\circ} \mathrm{C}\left(12^{\circ} \mathrm{F}\right)$ in January. The maximum recorded temperature was $41^{\circ} \mathrm{C}$ $\left(106^{\circ} \mathrm{F}\right)$ in May. 


\subsubsection{Wind Direction and Wind Speed}

Winds in the WIPP area in 2000 blew predominantly from the southeast $\left(135^{\circ}\right)$. Seasonal weather systems move through this area, briefly altering the predominant southeasterly winds and sometimes resulting in violent convectional storms. Wind speed measured at the $10-\mathrm{m}(33-\mathrm{ft})$ level were calm (less than 0.5 meters per second $[\mathrm{m} / \mathrm{s}])(1.1$ miles per hour [mph]) about 0.5 percent of the time. At the $10-\mathrm{m}$ level, winds of 3.7 through $6.3 \mathrm{~m} / \mathrm{s}$ ( 8.3 to $14.1 \mathrm{mph}$ ) were the most prevalent over 2000 , occurring 40 percent of the time. Figures 5.5, 5.6, and 5.7 and Tables 5.4, 5.5, and 5.6 display the annual wind data at WIPP for 2000.

\subsection{Volatile Organic Compound Monitoring}

Volatile organic compound monitoring was implemented on April 21, 1997, in accordance with WP12-VC.01, Confirmatory Volatile Organic Compound Monitoring Program. This program was implemented as a requirement of the HWFP, Module IV, Section D and Attachment $\mathrm{N}$, and is intended to demonstrate that regulated VOCs are not being emitted by the waste at concentrations in excess of concentrations of concern as prescribed in the permit.

Nine target compounds, which contribute approximately 99 percent of the calculated human health risks from RCRA constituents, were chosen for monitoring. These target compounds are 1,1-dichloroethylene, methylene chloride, chloroform, 1,1,1-trichloroethane, carbon tetrachloride, 1,2-dichloroethane, toluene, chlorobenzene, and 1,1,2,2-tetrachloroethane.

Sampling for target compounds is done at two air monitoring stations. The stations are identified as VOC-A, located downstream from hazardous waste disposal unit Panel 1 in Drift E300, and VOC-B, located upstream from Panel 1. In 2000, VOC-B was located in Drift S1950. As waste is placed in new panels, VOC-B will be relocated to ensure that it samples underground air before it passes the waste panels. The location of VOC-A is not anticipated to change. 


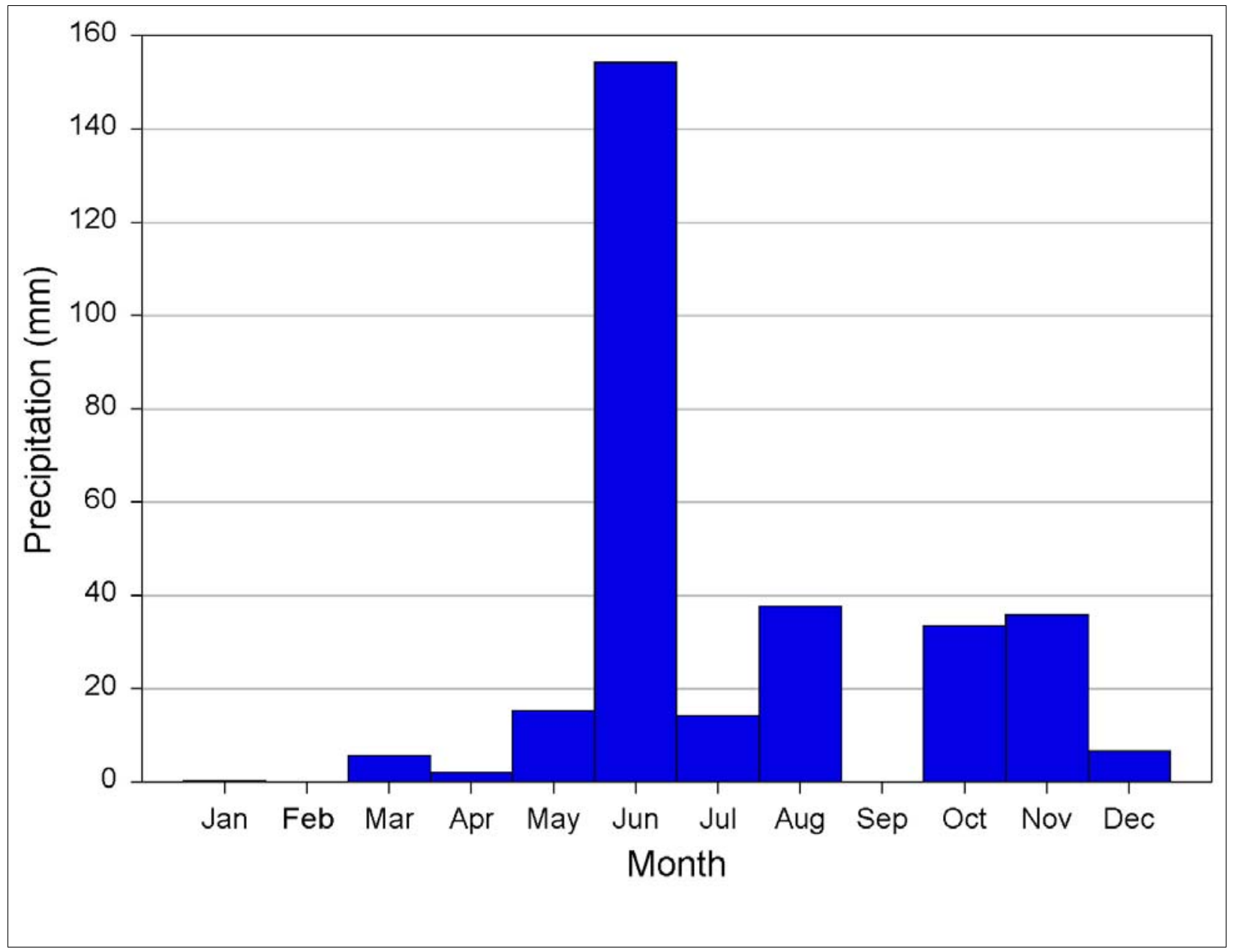

Figure 5.12000 Precipitation at WIPP 


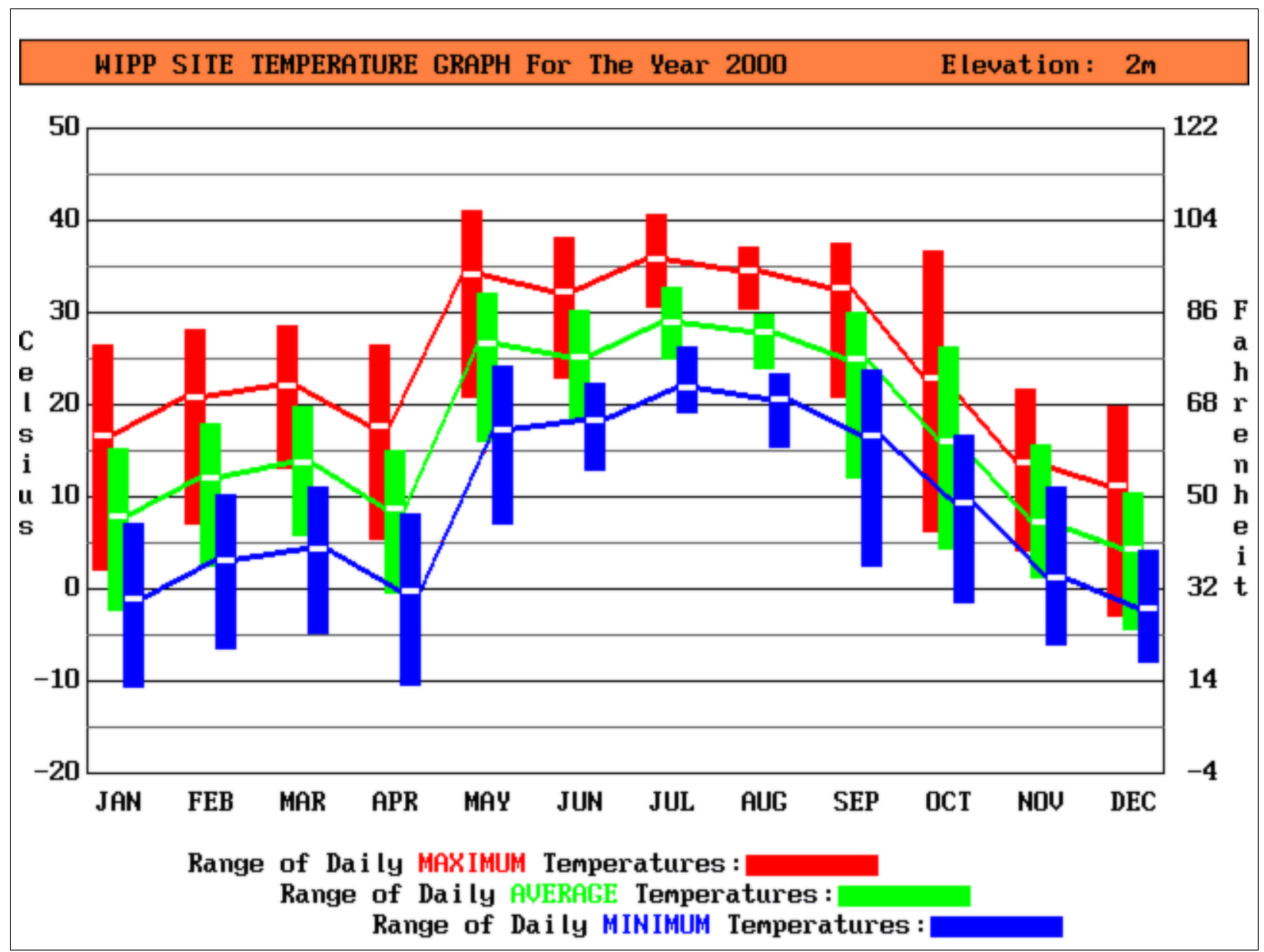

Figure 5.2 2000 WIPP Site Temperature at 2-Meter Height

Table 5.1 A summary of 2000 temperature observations at 2-meter height.

\begin{tabular}{|c|c|c|c|c|c|c|c|c|c|}
\hline Month & $\begin{array}{c}\text { Max of } \\
\text { Daily } \\
\text { Highs } \\
\left({ }^{\circ} \mathrm{C}\right)\end{array}$ & $\begin{array}{l}\text { Avg of } \\
\text { Daily } \\
\text { Highs } \\
\left({ }^{\circ} \mathrm{C}\right)\end{array}$ & $\begin{array}{c}\text { Min of } \\
\text { Daily } \\
\text { Highs } \\
\left({ }^{\circ} \mathrm{C}\right)\end{array}$ & $\begin{array}{c}\text { Max } \\
\text { of Daily } \\
\text { Averages } \\
\left({ }^{\circ} \mathrm{C}\right)\end{array}$ & $\begin{array}{c}\text { Avg of } \\
\text { Daily } \\
\text { Averages } \\
\left({ }^{\circ} \mathrm{C}\right)\end{array}$ & $\begin{array}{c}\text { Min of } \\
\text { Daily } \\
\text { Averages } \\
\left({ }^{\circ} \mathrm{C}\right)\end{array}$ & $\begin{array}{l}\text { Max of } \\
\text { Daily } \\
\text { Lows } \\
\left({ }^{\circ} \mathrm{C}\right)\end{array}$ & $\begin{array}{l}\text { Avg of } \\
\text { Daily } \\
\text { Lows } \\
\left({ }^{\circ} \mathrm{C}\right)\end{array}$ & $\begin{array}{l}\text { Min of } \\
\text { Daily } \\
\text { Lows } \\
\left({ }^{\circ} \mathrm{C}\right)\end{array}$ \\
\hline$\overline{\mathrm{Jan}}$ & 26.36 & 16.67 & 2.02 & 15.11 & 7.88 & -2.27 & 7.05 & -1.03 & -10.53 \\
\hline Feb & 28.20 & 20.79 & 7.01 & 17.93 & 12.16 & 2.48 & 10.29 & 3.17 & -6.47 \\
\hline Mar & 28.59 & 22.15 & 13.07 & 19.80 & 13.66 & 5.80 & 11.07 & 4.38 & -4.82 \\
\hline Apr & 26.36 & 17.69 & 5.33 & 15.09 & 8.77 & -0.51 & 8.05 & -0.31 & -10.37 \\
\hline May & 41.06 & 34.14 & 20.75 & 32.04 & 26.59 & 16.00 & 24.12 & 17.39 & 7.04 \\
\hline Jun & 38.04 & 32.19 & 22.87 & 30.29 & 25.27 & 18.29 & 22.35 & 18.38 & 12.82 \\
\hline Jul & 40.66 & 35.78 & 30.71 & 32.62 & 28.90 & 25.07 & 26.17 & 21.90 & 19.14 \\
\hline Aug & 37.03 & 34.49 & 30.44 & 29.84 & 27.92 & 23.96 & 23.42 & 20.57 & 15.50 \\
\hline Sep & 37.48 & 32.72 & 20.80 & 30.03 & 25.08 & 12.01 & 23.73 & 16.68 & 2.41 \\
\hline Oct & 36.60 & 23.00 & 6.28 & 26.24 & 16.01 & 4.36 & 16.58 & 9.31 & -1.43 \\
\hline Nov & 21.64 & 13.70 & 4.18 & 15.54 & 7.23 & 1.25 & 11.13 & 1.15 & -5.97 \\
\hline Dec & 19.87 & 11.22 & -3.02 & 10.45 & 4.29 & -4.33 & 4.11 & -2.11 & -8.01 \\
\hline Annual & 41.06 & 24.55 & -3.02 & 32.62 & 16.98 & -4.33 & 26.17 & 9.12 & -10.53 \\
\hline
\end{tabular}




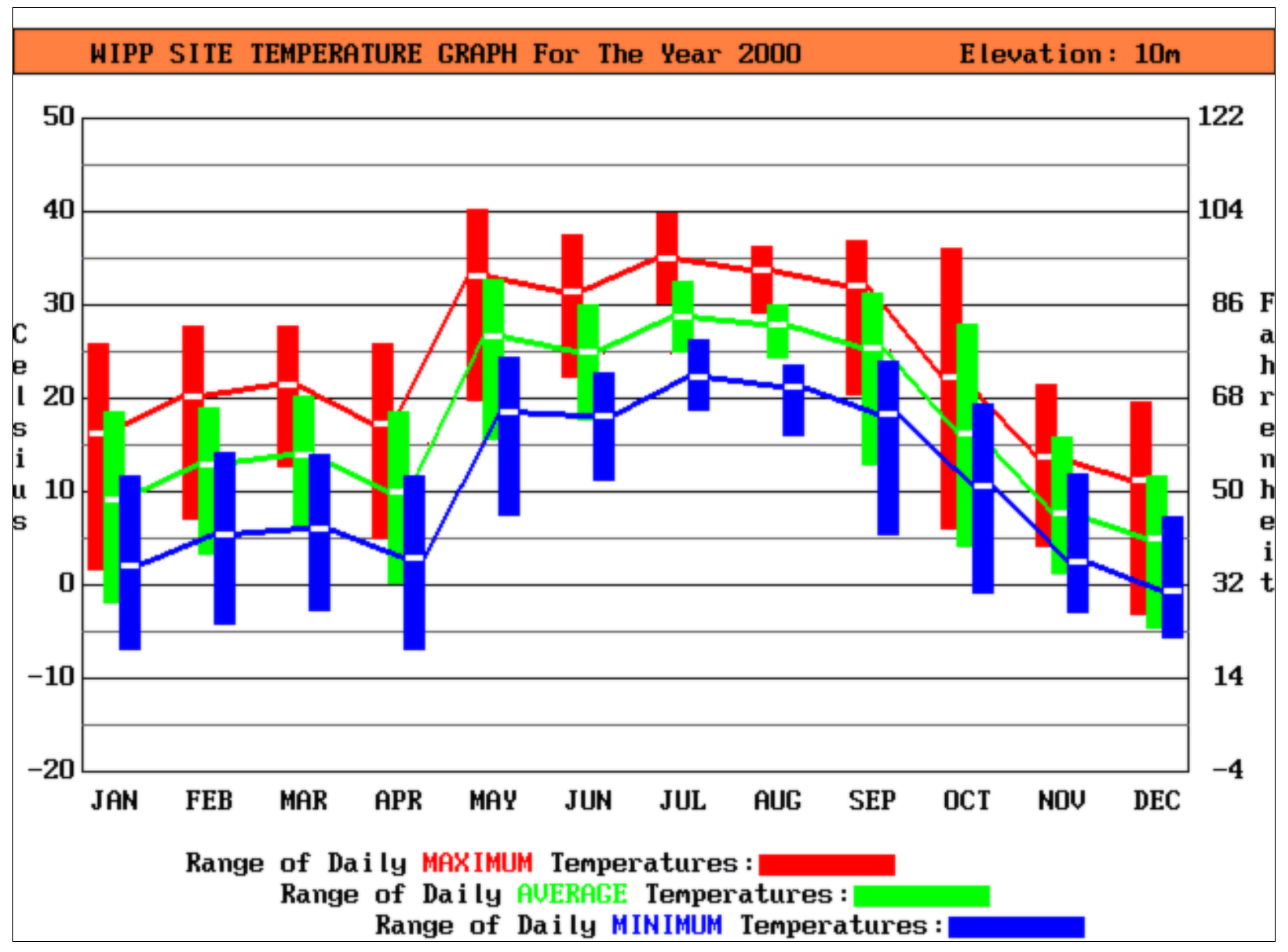

Figure 5.3 2000 WIPP Site Temperature at 10-Meter Height

Table 5.2 A summary of 2000 temperature observations at 10-meter height.

\begin{tabular}{lccccccccc}
\hline Month & $\begin{array}{c}\text { Max of } \\
\text { Daily Highs } \\
\left(\mathbf{(}^{\mathbf{}} \mathbf{C}\right)\end{array}$ & $\begin{array}{c}\text { Avg of } \\
\text { Daily } \\
\text { Highs } \\
\left({ }^{\circ} \mathbf{C}\right)\end{array}$ & $\begin{array}{c}\text { Min of } \\
\text { Daily } \\
\text { Highs } \\
\left({ }^{\circ} \mathbf{C}\right)\end{array}$ & $\begin{array}{c}\text { Max of } \\
\text { Daily } \\
\text { Averages } \\
\left({ }^{\circ} \mathbf{C}\right)\end{array}$ & $\begin{array}{c}\text { Avg of } \\
\text { Daily } \\
\text { Averages } \\
\left({ }^{\circ} \mathbf{C}\right)\end{array}$ & $\begin{array}{c}\text { Min of } \\
\text { Daily } \\
\text { Averages } \\
\left({ }^{\circ} \mathbf{C}\right)\end{array}$ & $\begin{array}{c}\text { Max of } \\
\text { Daily } \\
\text { Lows } \\
\left({ }^{\circ} \mathbf{C}\right)\end{array}$ & $\begin{array}{c}\text { Avg of } \\
\text { Daily } \\
\text { Lows } \\
\left({ }^{\mathbf{0}} \mathbf{C}\right)\end{array}$ & $\begin{array}{c}\text { Min of } \\
\text { Daily } \\
\text { Lows } \\
\left({ }^{\mathbf{0}} \mathbf{C}\right)\end{array}$ \\
\hline Jan & 25.81 & 16.28 & 1.77 & 18.55 & 9.07 & -1.97 & 11.70 & 2.08 & -6.84 \\
Feb & 27.71 & 20.12 & 6.99 & 18.91 & 12.89 & 3.28 & 14.26 & 5.45 & -4.14 \\
Mar & 27.77 & 21.46 & 12.75 & 20.13 & 14.05 & 6.04 & 14.05 & 6.11 & -2.70 \\
Apr & 25.81 & 17.32 & 5.06 & 18.60 & 10.07 & 0.11 & 11.70 & 2.98 & -6.84 \\
May & 40.24 & 33.16 & 19.74 & 32.68 & 26.57 & 15.66 & 24.28 & 18.46 & 7.58 \\
Jun & 37.43 & 31.41 & 22.36 & 30.06 & 24.92 & 17.72 & 22.62 & 18.11 & 11.24 \\
Jul & 39.75 & 35.02 & 30.12 & 32.47 & 28.74 & 24.96 & 26.33 & 22.31 & 18.82 \\
Aug & 36.25 & 33.65 & 29.26 & 29.95 & 27.85 & 24.37 & 23.58 & 21.28 & 16.11 \\
Sep & 36.78 & 32.02 & 20.32 & 31.22 & 25.45 & 12.88 & 24.05 & 18.28 & 5.34 \\
Oct & 35.98 & 22.29 & 5.99 & 27.88 & 16.25 & 4.13 & 19.28 & 10.62 & -0.75 \\
Nov & 21.37 & 13.73 & 4.13 & 15.88 & 7.80 & 1.33 & 11.97 & 2.44 & -2.89 \\
Dec & 19.49 & 11.32 & -3.18 & 11.72 & 5.01 & -4.50 & 7.24 & -0.67 & -5.70 \\
\hline Annual & 40.24 & 23.98 & -3.18 & 32.68 & 17.39 & -4.50 & 26.33 & 10.62 & -6.84 \\
\hline
\end{tabular}




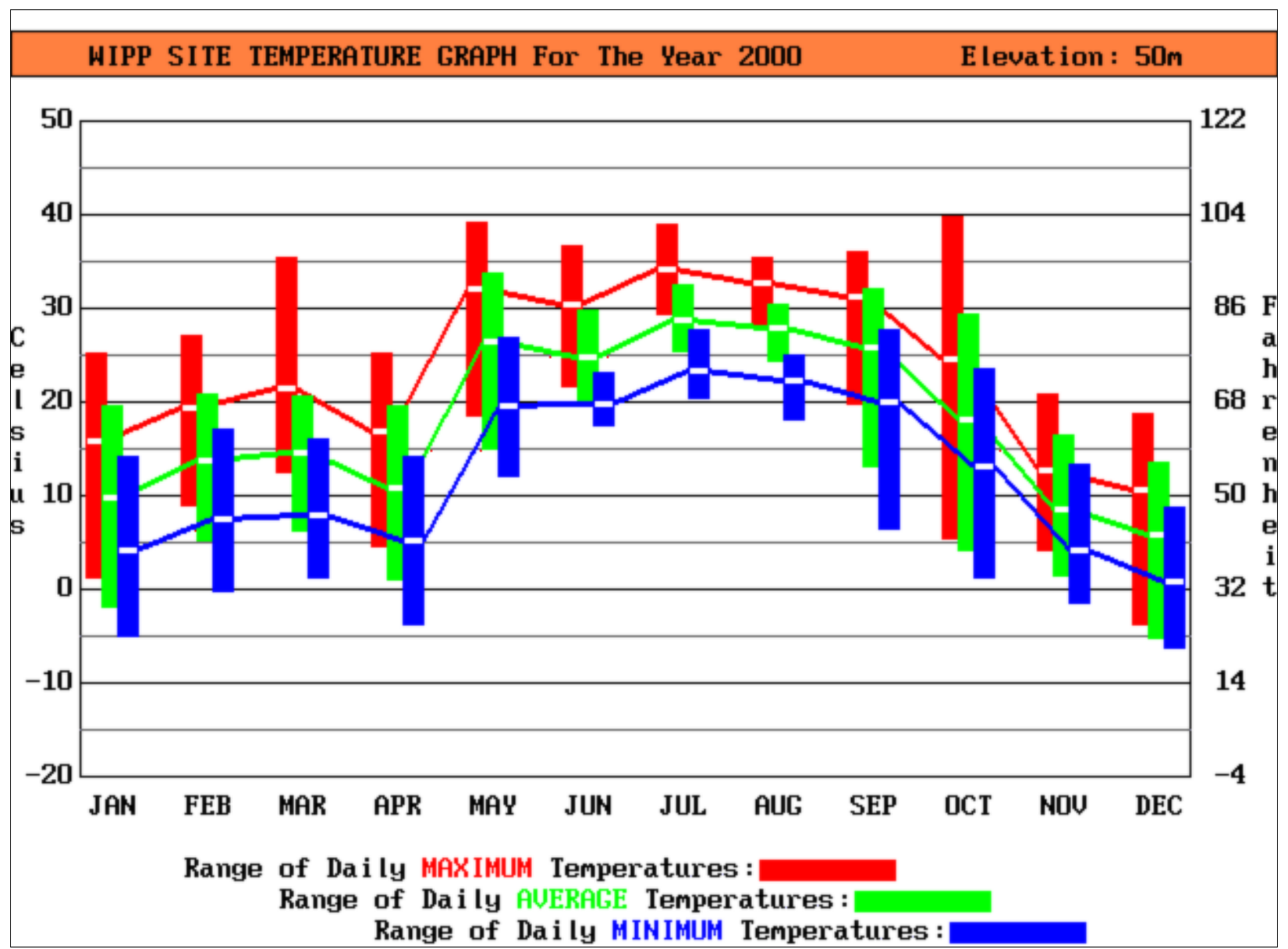

Figure 5.4 2000 WIPP Site Temperature at 50-Meter Height

Table 5.3 A summary of 2000 temperature observations at 50-meter height.

\begin{tabular}{|c|c|c|c|c|c|c|c|c|c|}
\hline Month & $\begin{array}{c}\text { Max of } \\
\text { Daily } \\
\text { Highs } \\
\left({ }^{\circ} \mathrm{C}\right) \\
\end{array}$ & $\begin{array}{c}\text { Avg of } \\
\text { Daily } \\
\text { Highs } \\
\left({ }^{\circ} \mathrm{C}\right) \\
\end{array}$ & $\begin{array}{l}\text { Min of } \\
\text { Daily } \\
\text { Highs } \\
\left({ }^{\circ} \mathrm{C}\right)\end{array}$ & $\begin{array}{c}\text { Max of } \\
\text { Daily } \\
\text { Averages } \\
\left({ }^{\circ} \mathrm{C}\right) \\
\end{array}$ & $\begin{array}{c}\text { Avg of } \\
\text { Daily } \\
\text { Averages } \\
\left({ }^{\circ} \mathrm{C}\right) \\
\end{array}$ & $\begin{array}{c}\text { Min of } \\
\text { Daily } \\
\text { Averages } \\
\left({ }^{\circ} \mathrm{C}\right) \\
\end{array}$ & $\begin{array}{c}\text { Max of } \\
\text { Daily } \\
\text { Lows } \\
\left({ }^{\circ} \mathrm{C}\right) \\
\end{array}$ & $\begin{array}{c}\text { Avg of } \\
\text { Daily } \\
\text { Lows } \\
\left({ }^{\circ} \mathrm{C}\right) \\
\end{array}$ & $\begin{array}{l}\text { Min of } \\
\text { Daily } \\
\text { Lows } \\
\left({ }^{\circ} \mathrm{C}\right) \\
\end{array}$ \\
\hline $\begin{array}{l}\text { Jan } \\
\end{array}$ & 25.17 & 15.78 & 1.23 & 19.49 & 9.88 & -1.96 & 14.09 & 4.07 & -4.94 \\
\hline Feb & 26.98 & 19.47 & 8.86 & 20.86 & 13.76 & 5.20 & 17.09 & 7.49 & -0.23 \\
\hline Mar & 35.50 & 21.36 & 12.46 & 20.56 & 14.64 & 6.27 & 16.06 & 7.99 & 1.25 \\
\hline Apr & 25.17 & 16.91 & 4.55 & 19.60 & 10.92 & 1.13 & 14.09 & 5.12 & -3.81 \\
\hline May & 39.20 & 32.16 & 18.57 & 33.73 & 26.56 & 15.10 & 26.84 & 19.63 & 12.15 \\
\hline Jun & 36.58 & 30.50 & 21.69 & 29.83 & 24.89 & 20.08 & 23.04 & 19.74 & 17.42 \\
\hline Jul & 39.01 & 34.13 & 29.33 & 32.51 & 28.69 & 25.46 & 27.62 & 23.24 & 20.51 \\
\hline Aug & 35.46 & 32.75 & 28.35 & 30.43 & 27.89 & 24.45 & 24.95 & 22.26 & 18.10 \\
\hline Sep & 36.10 & 31.19 & 19.71 & 32.18 & 25.84 & 13.18 & 27.71 & 19.97 & 6.54 \\
\hline Oct & 39.80 & 24.58 & 5.51 & 29.35 & 18.07 & 4.09 & 23.63 & 13.20 & 1.35 \\
\hline Nov & 20.88 & 12.77 & 4.10 & 16.50 & 8.51 & 1.39 & 13.26 & 4.07 & -1.44 \\
\hline Dec & 18.74 & 10.67 & -3.73 & 13.60 & 5.80 & -5.21 & 8.67 & 0.82 & -6.16 \\
\hline Annual & 39.80 & 23.52 & -3.73 & 33.73 & 17.95 & -5.21 & 27.71 & 12.30 & -6.16 \\
\hline
\end{tabular}




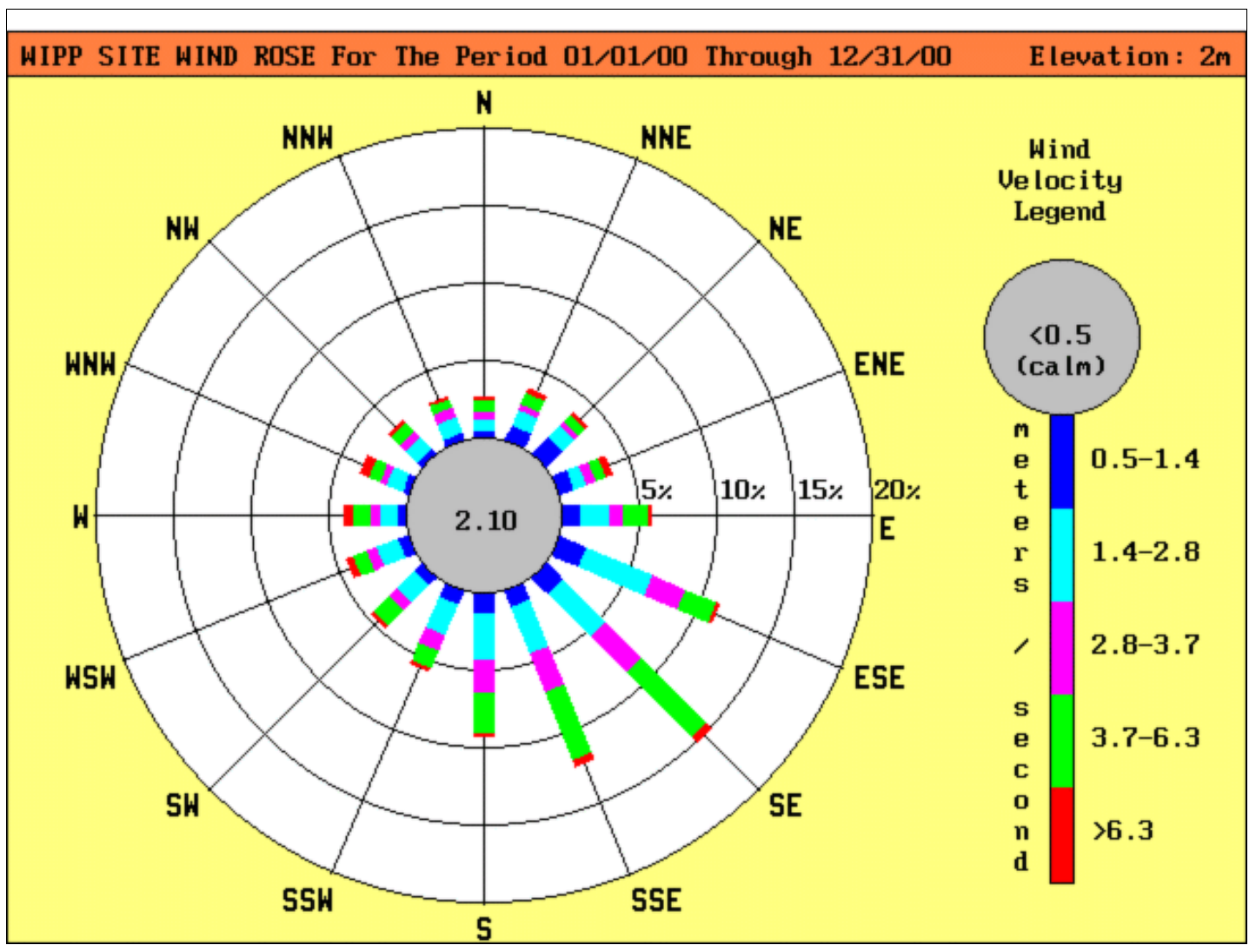

Figure 5.5 2000 WIPP Site Wind Rose at 2-Meter Height

Table 5.4 2000 wind frequencies at 2-meter height, stratified by direction and speed (percent).

\begin{tabular}{|c|c|c|c|c|c|c|c|}
\hline \multirow[b]{2}{*}{ Direction } & \multicolumn{6}{|c|}{ Wind Speed Range, meters/second } & \multirow[b]{2}{*}{ Totals } \\
\hline & $<0.5$ & $0.5-1.4$ & $1.4-2.8$ & $2.8-3.7$ & $3.7-6.3$ & $>6.3$ & \\
\hline $\mathrm{N}$ & $0.088^{\mathrm{a}}$ & 0.425 & 0.764 & 0.530 & 0.782 & 0.144 & 2.732 \\
\hline NNE & 0.123 & 1.031 & 1.148 & 0.445 & 0.843 & 0.313 & 3.904 \\
\hline NE & 0.114 & 1.532 & 1.010 & 0.372 & 0.750 & 0.146 & 3.924 \\
\hline ENE & 0.211 & 0.969 & 0.882 & 0.641 & 0.843 & 0.387 & 3.933 \\
\hline $\mathrm{E}$ & 0.240 & 1.157 & 1.889 & 0.969 & 1.649 & 0.234 & 6.139 \\
\hline ESE & 0.249 & 1.807 & 4.706 & 2.422 & 2.232 & 0.144 & 11.560 \\
\hline SE & 0.211 & 1.505 & 3.957 & 3.227 & 6.098 & 0.615 & 15.613 \\
\hline SSE & 0.155 & 1.248 & 3.263 & 2.724 & 4.841 & 0.375 & 12.605 \\
\hline $\mathrm{S}$ & 0.138 & 1.365 & 3.008 & 2.150 & 2.677 & 0.155 & 9.492 \\
\hline SSW & 0.105 & 0.940 & 2.238 & 1.204 & 1.312 & 0.182 & 5.980 \\
\hline SW & 0.094 & 0.679 & 1.737 & 0.855 & 1.391 & 0.243 & 4.999 \\
\hline WSW & 0.108 & 0.638 & 1.502 & 0.800 & 0.949 & 0.445 & 4.443 \\
\hline W & 0.064 & 0.530 & 1.248 & 0.720 & 1.239 & 0.565 & 4.367 \\
\hline WNW & 0.059 & 0.460 & 1.139 & 0.580 & 0.873 & 0.513 & 3.623 \\
\hline NW & 0.082 & 0.451 & 1.248 & 0.597 & 0.817 & 0.173 & 3.368 \\
\hline NNW & 0.059 & 0.431 & 1.180 & 0.691 & 0.738 & 0.220 & 3.318 \\
\hline Tot & 2.100 & 15.168 & 30.918 & 18.928 & 28.033 & 4.853 & 100.000 \\
\hline
\end{tabular}

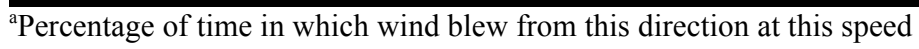




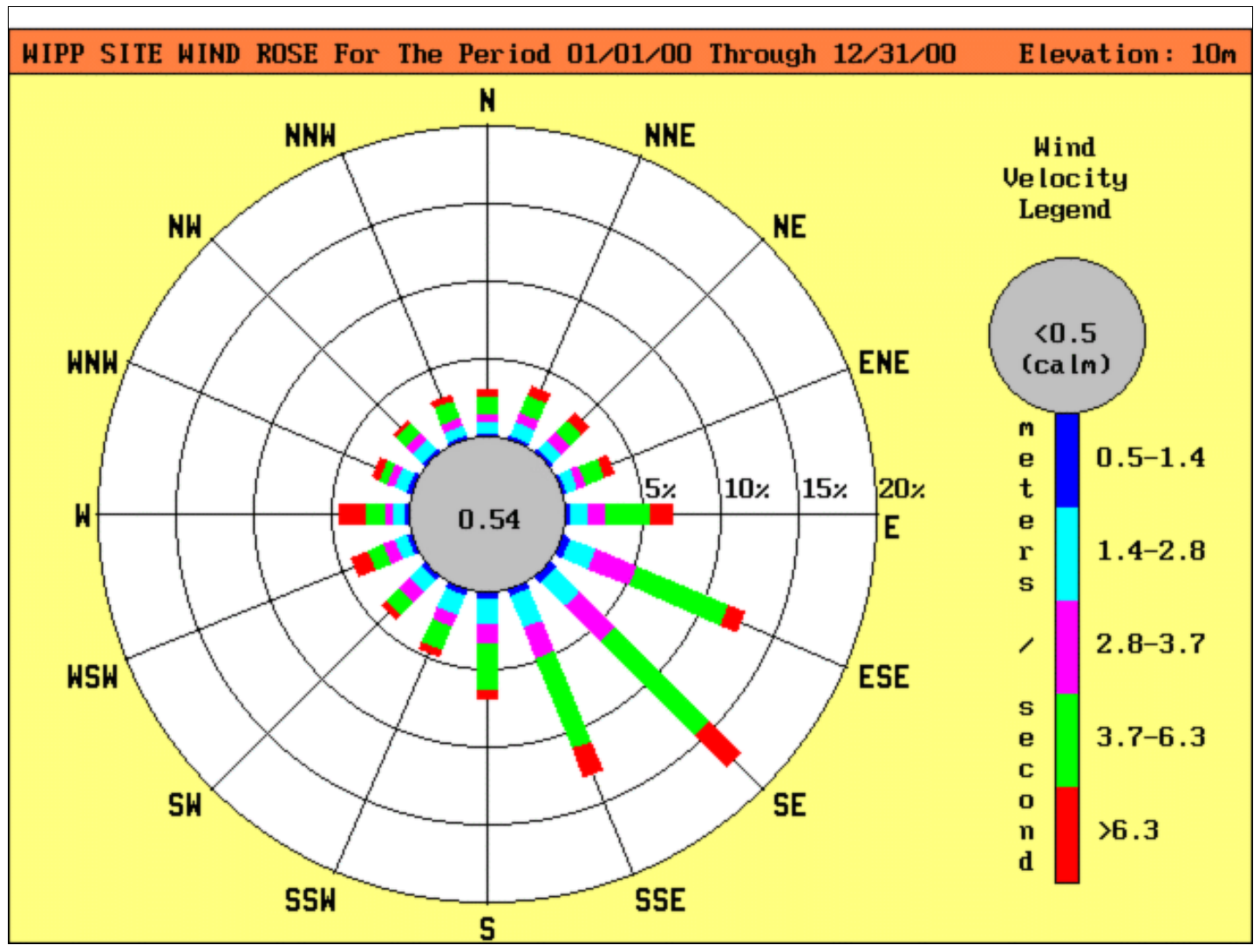

Figure 5.6 2000 WIPP Site Wind Rose at 10-Meter Height

Table 5.5 2000 wind frequencies at 10-meter height, stratified by direction and speed (percent).

\begin{tabular}{|c|c|c|c|c|c|c|c|}
\hline \multirow[b]{2}{*}{ Direction } & \multicolumn{6}{|c|}{ Wind Speed Range, meters/second } & \multirow[b]{2}{*}{ Totals } \\
\hline & $<0.5$ & $0.5-1.4$ & 1.4-2.8 & $2.8-3.7$ & $3.7-6.3$ & $>6.3$ & \\
\hline$\overline{\mathrm{N}}$ & 0.029 & 0.246 & 0.767 & 0.548 & 1.183 & 0.489 & 3.263 \\
\hline NNE & 0.038 & 0.223 & 1.051 & 0.715 & 1.286 & 0.633 & 3.945 \\
\hline $\mathrm{NE}$ & 0.021 & 0.226 & 0.984 & 0.750 & 1.025 & 0.715 & 3.719 \\
\hline ENE & 0.023 & 0.249 & 0.823 & 0.677 & 1.365 & 0.741 & 3.878 \\
\hline $\mathrm{E}$ & 0.038 & 0.331 & 1.177 & 1.215 & 2.882 & 1.494 & 7.137 \\
\hline ESE & 0.038 & 0.472 & 1.977 & 2.823 & 6.598 & 1.019 & 12.927 \\
\hline SE & 0.047 & 0.416 & 2.349 & 3.304 & 8.552 & 2.961 & 17.628 \\
\hline SSE & 0.059 & 0.392 & 2.267 & 2.170 & 6.346 & 1.883 & 13.118 \\
\hline $\mathrm{S}$ & 0.044 & 0.428 & 1.710 & 1.362 & 3.025 & 0.533 & 7.102 \\
\hline SSW & 0.029 & 0.360 & 1.403 & 0.958 & 1.704 & 0.401 & 4.856 \\
\hline SW & 0.038 & 0.316 & 1.183 & 0.884 & 1.169 & 0.589 & 4.179 \\
\hline WSW & 0.050 & 0.293 & 0.984 & 0.852 & 1.198 & 1.072 & 4.449 \\
\hline W & 0.018 & 0.322 & 0.867 & 0.577 & 1.300 & 1.661 & 4.744 \\
\hline WNW & 0.029 & 0.299 & 0.908 & 0.501 & 0.729 & 0.431 & 2.896 \\
\hline NW & 0.018 & 0.278 & 0.975 & 0.627 & 0.884 & 0.237 & 3.019 \\
\hline NNW & 0.018 & 0.199 & 0.747 & 0.650 & 1.142 & 0.384 & 3.140 \\
\hline Total & 0.536 & 5.049 & 20.173 & 18.612 & 40.390 & 15.241 & 100.000 \\
\hline
\end{tabular}

${ }^{\mathrm{a}}$ Percentage of time in which wind blew from this direction at this speed 


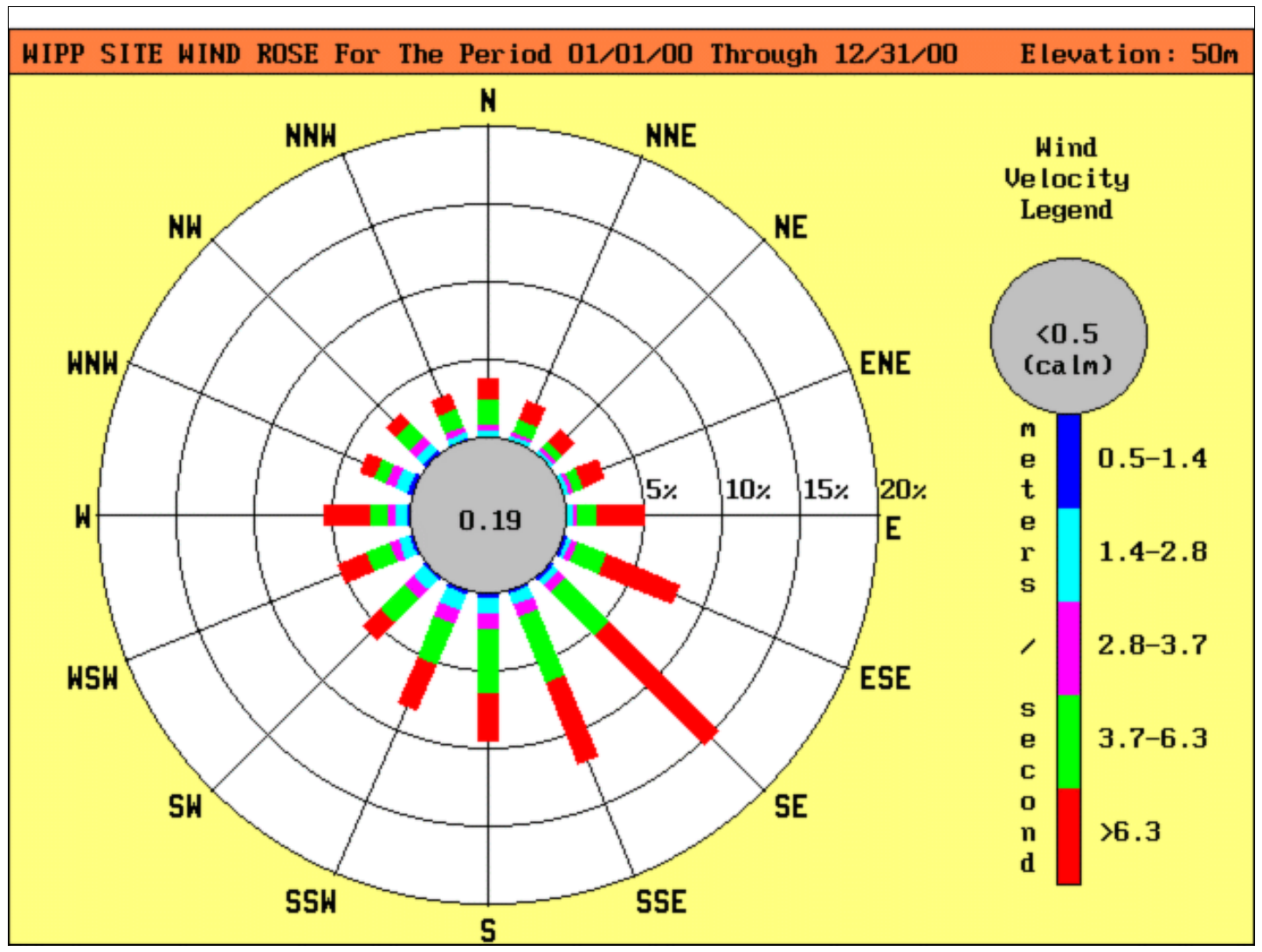

Figure 5.7 2000 WIPP Site Wind Rose at 50-Meter Height

Table 5.6 2000 wind frequencies at 50-meter height, stratified by direction and speed (percent).

\begin{tabular}{|c|c|c|c|c|c|c|c|}
\hline \multirow[b]{2}{*}{ Direction } & \multicolumn{6}{|c|}{ Wind Speed Range, meters/second } & \multirow[b]{2}{*}{ Totals } \\
\hline & $<0.5$ & $0.5-1.4$ & $1.4-2.8$ & $2.8-3.7$ & $3.7-6.3$ & $>6.3$ & \\
\hline $\mathrm{N}$ & 0.009 & 0.111 & 0.477 & 0.451 & 1.719 & 1.315 & 4.083 \\
\hline NNE & 0.009 & 0.085 & 0.366 & 0.346 & 0.890 & 1.335 & 3.031 \\
\hline $\mathrm{NE}$ & 0.009 & 0.103 & 0.325 & 0.237 & 0.720 & 1.069 & 2.463 \\
\hline ENE & 0.009 & 0.100 & 0.293 & 0.275 & 0.794 & 1.482 & 2.952 \\
\hline E & 0.003 & 0.123 & 0.392 & 0.351 & 1.318 & 3.031 & 5.219 \\
\hline ESE & 0.009 & 0.126 & 0.398 & 0.477 & 2.056 & 5.072 & 8.139 \\
\hline SE & 0.009 & 0.146 & 0.580 & 0.674 & 4.124 & 9.984 & 15.516 \\
\hline SSE & 0.012 & 0.185 & 0.846 & 0.990 & 4.648 & 5.550 & 12.230 \\
\hline $\mathrm{S}$ & 0.006 & 0.264 & 1.084 & 1.016 & 4.206 & 3.055 & 9.630 \\
\hline SSW & 0.012 & 0.249 & 1.160 & 1.028 & 2.844 & 3.248 & 8.540 \\
\hline SW & 0.029 & 0.243 & 1.043 & 0.852 & 2.182 & 1.710 & 6.059 \\
\hline WSW & 0.018 & 0.223 & 0.849 & 0.720 & 1.675 & 1.936 & 5.421 \\
\hline W & 0.009 & 0.231 & 0.794 & 0.548 & 1.169 & 2.967 & 5.717 \\
\hline WNW & 0.023 & 0.305 & 0.934 & 0.674 & 0.978 & 0.961 & 3.875 \\
\hline NW & 0.009 & 0.190 & 0.805 & 0.618 & 1.271 & 0.770 & 3.664 \\
\hline NNW & 0.018 & 0.088 & 0.489 & 0.445 & 1.341 & 1.081 & 3.462 \\
\hline Tot & 0.190 & 2.771 & 10.836 & 9.703 & 31.934 & 44.566 & 100.000 \\
\hline
\end{tabular}

a Percentage of time in which wind blew from this direction at this speed 
Target compounds found in VOC-B represent air found in the underground before the air passes through the panels containing waste. The VOC concentrations measured at this location are the sum of background concentrations entering the mine through the air intake shaft plus additional concentrations contributed by facility operations upstream of the waste panels.

Concentrations measured at VOC-A will be equal to those found at VOC-B plus any contributions from the waste panels. Differences measured between the two stations will then represent any VOC contributions from the waste panels. Any concentration differences between the two stations must be less than the concentrations of concern listed in Attachment $\mathrm{N}$ of the Hazardous Waste Facility Permit (Table 5.7).

Sample pair differences are calculated by subtracting the concentration of a compound of interest observed at VOC-B from that measured at VOC-A for the given sampling period (Table 5.8). Negative values indicate ambient air concentrations of a compound (VOC-B) were greater than concentrations in the air passing through the panel (VOC-A). Negative values could be caused by emissions from normal mining activities near VOC-B which quickly dispersed in the mine ventilation flow and were not detected at VOC-A. The annual averages shown in Table 5.8 were calculated by averaging all sample pair differences from January 1, 2000 to December 31, 2000. Samples in which a compound of interest was non-detectable (less than the 0.5 parts per billion by volume [ppbv] minimum detection limit [MDL]) were assigned a value of zero for the purposes of computing this average.
During 2000, four of the nine target compounds (1,1,1-trichloroethane, chlorobenzene, methylene chloride, and toluene) were measured above the $0.5 \mathrm{ppbv}$ MDL. For each of the detected target compounds, the annual average was less than 0.05 percent of the respective concentration of concern listed in Table 5.7 and were, therefore, at insignificant levels with respect to human health and the environment.

Positive sample pair differences for methylene chloride were found in 15 of 104 sample pairs. The 2000 annual average sample pair difference for methylene chloride was -0.15 ppbv, with a minimum difference value of -3.35 ppbv and a maximum value of 1.39 ppbv. Methylene chloride, a common laboratory contaminant, can also be found in paint remover, aerosol propellant, degreasing and metal cleaning agents, and adhesives.

Positive sample pair differences for toluene were found in 36 of the 104 sample pairs. The overall 2000 average for toluene sample pair differences was $0.09 \mathrm{ppbv}$, with a minimum difference value of -7.96 and a maximum difference value of $3.09 \mathrm{ppbv}$. Possible sources of toluene contamination could be products of incomplete combustion of diesel fuel, cleaning solvents, or paint. 
One positive and one negative sample pair difference for chlorobenzene were found out of 104 sample pairs in 2000 . The overall 2000 average for chlorobenzene sample differences was $0.00 \mathrm{ppbv}$, with a minimum difference of -0.9 and a maximum difference value of 0.66 ppbv. Chlorobenzene was detected in 1999 sampling as well. Chlorobenzene can be found as a tar and grease remover in cleaning and degreasing operations and is used in the manufacture of insecticides.

Two positive sample pair differences were observed for 1,1,1-trichloroethane in 2000. The overall 2000 average sample difference for this compound was $0.00 \mathrm{ppbv}$, with a minimum difference of $-1.59 \mathrm{ppbv}$, and a maximum difference of $1.42 \mathrm{ppbv}$. 1,1,1-Trichloroethane was not detected in 1999. This compound can be found in electronics and metals cleaning solvent solutions.

The routine laboratory reporting limit was $5.0 \mathrm{ppbv}$ for 1,1,1-trichloroethane, 1,1-dichloroethylene, methylene chloride, and toluene and 2.0 (ppbv) for

1,1,2,2-tetrachloroethane, 1,2-dichloroethane, carbon tetrachloride, chlorobenzene, and chloroform. For dilution factors greater than one, the $5.0 \mathrm{ppbv}$ and $2.0 \mathrm{ppbv}$ values are multiplied by the dilution factor to calculate the laboratory reporting limits for the diluted sample.

The minimum detection limit (MDL) is defined as the minimum concentration of a substance that can be measured and reported with a 99 percent confidence to be greater than zero. Values were estimated for constituents detected at concentrations less than the laboratory reporting limits but above the 0.5 ppbv MDL.

Volatile organic compound sampling reported in this section was performed using guidance included in Compendium Method TO-14A, Determination of Volatile Organic Compounds (Volatile organic compounds) in Ambient Air Using Specially Prepared Canisters with Subsequent Analysis By Gas

Chromatography (EPA 1997). The samples were analyzed using gas chromatography/mass spectrometry under an established QA/QC program. Laboratory analytical procedures were developed based on the concepts contained in both TO-14A and the draft EPA Contract Laboratory Program Volatile Organics Analysis of Ambient Air in Canisters (EPA 1994). The results of year 2000 VOC monitoring did not indicate an increase in volatile organic compounds in air downstream of Panel I. Thus, waste stored at WIPP did not release significant amounts of VOCs.

Table 5.8 Volatile organic compound sample pair differences measured at WIPP in 2000.

\begin{tabular}{lcccc}
\hline Compound & $\begin{array}{c}\text { Nos. of } \\
\text { Sample Pairs } \\
\text { (A and B) }\end{array}$ & $\begin{array}{c}\text { 2000 Annual } \\
\text { Average of } \\
\text { Sample Pair } \\
\text { Differences } \\
\left(\mathbf{p p b v}^{\mathbf{a}}\right)\end{array}$ & $\begin{array}{c}\text { Minimum of } \\
\text { Sample Pair } \\
\text { Differences } \\
\left(\mathbf{p p b v}^{\mathbf{a}}\right)\end{array}$ & $\begin{array}{c}\text { Maximum of } \\
\text { Sample Pair } \\
\text { Differences } \\
\left(\mathbf{p p b v}^{\mathbf{a}}\right)\end{array}$ \\
\hline 1,1,1-Trichloroethane & 104 & 0.00 & -1.59 & 1.42 \\
1,1,2,2-Tetrachloroethane & 104 & 0 & 0 & 0 \\
1,1-Dichloroethylene & 104 & 0 & 0 & 0 \\
1,2-Dichloroethane & 104 & 0 & 0 & 0 \\
Carbon Tetrachloride & 104 & 0 & 0 & 0 \\
Chlorobenzene & 104 & 0.00 & -0.9 & 0.66 \\
Chloroform & 104 & 0 & -3.35 & 0 \\
Methylene Chloride & 104 & -0.15 & -7.96 & 3.39 \\
Toluene & 104 & 0.09 & & 3.09 \\
\hline
\end{tabular}

${ }^{\mathrm{a}}$ Parts per billion by volume 


\subsection{Seismic Activity}

WIPP is located about 60 miles east of the western margin of the Permian Basin. The geologic structure and tectonic pattern of the Permian Basin are chiefly the result of large-scale subsidence and uplift during the Paleozoic era. The broad basin is divided into a series of sub-basins which passed through their last stage of significant subsidence during the Late Permian age. The Delaware sub-basin occupies the southwestern portion of the Permian Basin and hosts the WIPP site. It is bordered by the Roosevelt Uplift to the north, the Marathon Thrust Belt to the south, the Central (Permian) Basin Platform to the east, and the Sierra Diablo Platform and Guadalupe and Sacramento Mountains to the west. The Delaware Basin contains a thick sequence of evaporite layers.

All major tectonic elements of the Delaware Basin were essentially formed before deposition of the Permian evaporites, and the region has been relatively stable since then. Deep-seated faults are rare, except along the western and eastern basin margins, and there is no evidence of young, deep-seated faults inside the basin.

Researchers suspect that some low-magnitude earthquakes may result from secondary oil recovery (water flooding). Their foci are about as deep as the bottom of relatively shallow hydrocarbon wells.

Significant recent seismic events near WIPP on January 2, 1992, and April 14, 1995, had magnitudes of 5.0 and 5.3 respectively. The January 2, 1992, Rattlesnake Canyon earthquake had an epicenter $60 \mathrm{~km}$ (36 mi) east-southeast of the WIPP site, while an April 14, 1995, event's epicenter was located about $240 \mathrm{~km}$ (144 mi) southwest of WIPP, near Alpine, Texas. Neither earthquake had any effect on WIPP structures, as documented by post-event inspections by WIPP staff and the NMED. The magnitudes of both events were within the parameters used to develop the seismic risk assessment of the WIPP structures.

Seismic information for the WIPP region before 1962 was derived from chronicles of the effects of those tremors on people, structures, and surface features. Seismicity in New Mexico reported prior to 1962 was mostly limited to the corridor between Albuquerque and Socorro, part of a structure known as the Rio Grande Rift. Since 1962, most seismic information has been based on instrumental data recorded at various seismograph stations.

Currently, seismicity within $300 \mathrm{~km}$ (186 $\mathrm{mi}$ ) of the WIPP site is being monitored by the New Mexico Institute of Mining and Technology (NMIMT), in Socorro, New Mexico, using data from a seven-station network approximately centered on the site (Figure 5.8). Station signals are transmitted to the NMIMT Seismological Observatory in Socorro. When appropriate, readings from the WIPP network stations are combined with readings from an additional NMIMT network in the central Rio Grande Rift. Occasionally, data are also exchanged with the University of Texas at El Paso and Texas Tech University in Lubbock, both of which operate stations in west Texas.

The mean operational efficiency of the WIPP seismic monitoring stations during 2000 was approximately 96.8 percent. From January 1 through December 31, 2000, locations for 52 seismic events were recorded within $300 \mathrm{~km}$ (186 mi) of WIPP. These data included origin times, epicenter coordinates, and magnitudes. The strongest recorded event (magnitude 2.5) was located approximately $80 \mathrm{~km}(50 \mathrm{mi})$ westnorthwest of the site. This event was part of a swarm which appeared to be centered within the Cass Ranch gas field. The possibility therefore exists that the swarm events were induced by hydrocarbon extraction activities. These events had no effect on WIPP structures. 


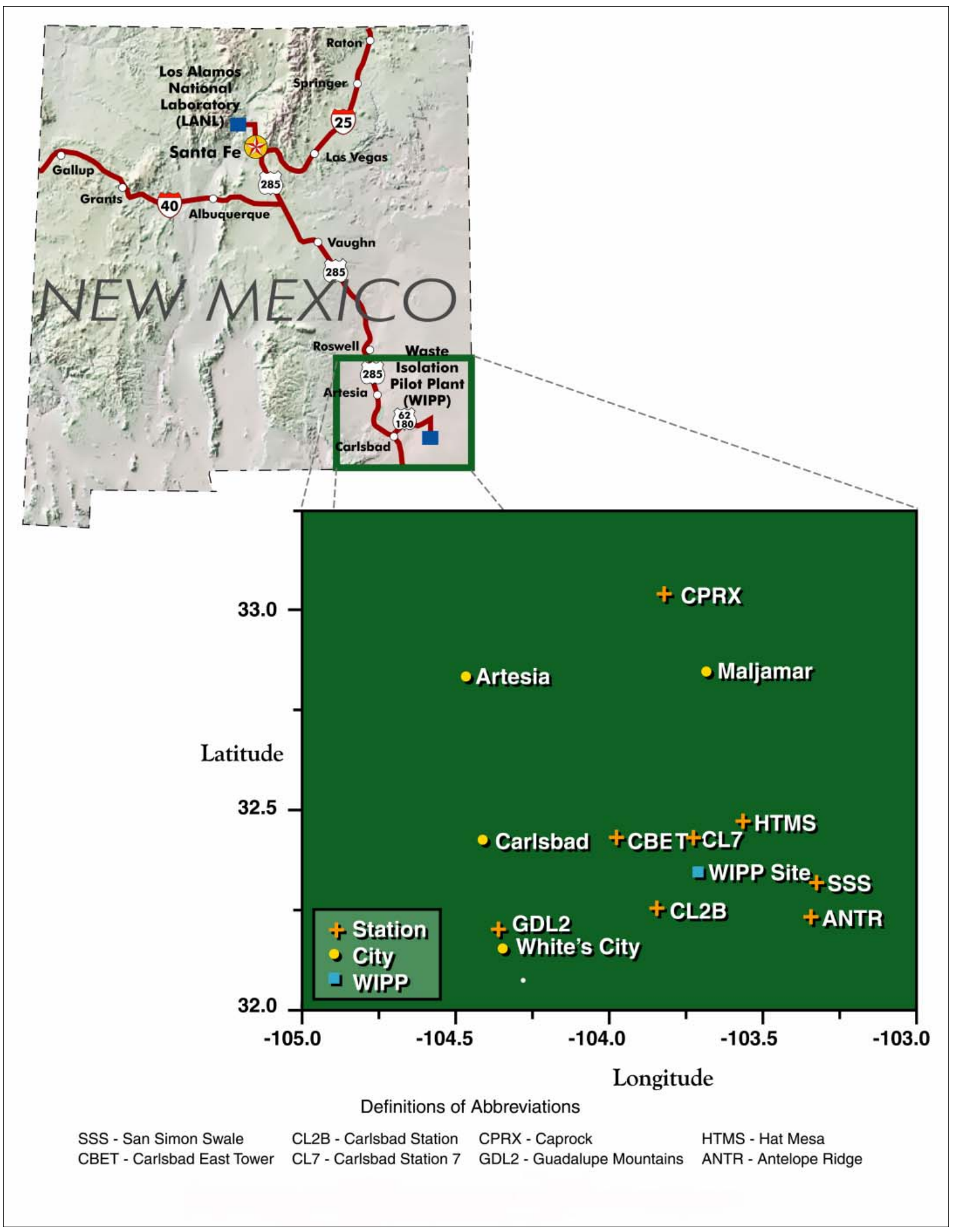

Figure 5.8 WIPP Seismograph Station Locations 


\subsection{Liquid Effluent Monitoring}

The WIPP sewage lagoon system is a zero-discharge facility consisting of two primary settling lagoons, two polishing lagoons, a chlorination system, and three evaporation basins. The entire facility is lined with 30-mil synthetic liners and is designed to dispose of domestic sewage as well as site-generated brine waters from observation well pumping and underground dewatering activities at the site.

The WIPP sewage facility is operated under Sewage System Discharge Permit No. 831 (DP-831), issued by the state of New Mexico in accordance with the Clean Water Act, and is managed in accordance with EPA sewage sludge regulations (40 CFR $\S 503$ ), New Mexico Water Quality Control Regulations (NMAC
20.6.2.3), and applicable WIPP controlled procedures. These requirements provide the framework for disposal of domestic sewage, site-generated brine waters, and non-hazardous waste waters.

DP-831 allows for the disposal of 7,570 L $(2,000 \mathrm{gal})$ per day of nonhazardous brines. DOE submits quarterly discharge monitoring reports to NMED to demonstrate compliance with the inspection, monitoring, and reporting requirements identified in the plan. Because effluent is not discharged from the facility, no effluent limits were established in DP-831. The NMED Groundwater Protection and Remediation Bureau established a list of analytes to be sampled on a quarterly basis as indicators of sewage system performance. 
This page intentionally left blank. 


\section{Chapter 6 \\ Groundwater Monitoring}

Current groundwater monitoring activities at WIPP are outlined in the WIPP Groundwater Monitoring Program Plan (WID WP 02-1, Revision 5). This is a QA document containing program plans for each activity performed by groundwater monitoring personnel. In addition, WIPP has detailed procedures for performing specific activities, such as pumping system installations, field parameter analyses and documentation, and QA records management. Groundwater monitoring activities are also defined in the Environmental Monitoring Plan (DOE/WIPP 92-2194).

The objectives of the Groundwater Monitoring Program are to:

- determine the physical and chemical characteristics of groundwater;

- maintain surveillance of groundwater levels surrounding the WIPP facility, both before and throughout the operational lifetime of the facility;

- document and identify effects, if any, of WIPP operations on groundwater parameters; and

- fulfill the requirements of the RCRA Operating Permit, the EPA Compliance Certification Application (CCA) and DOE Order 5400.1.

The data obtained by the WIPP Groundwater Monitoring Program (formerly designated the WIPP Groundwater Quality Surveillance Program [WQSP]) supported two major programs at WIPP: (1) the RCRA Detection Monitoring Program supporting the RCRA Part B Permit in compliance with 40 CFR $\S 264$ and 20 New Mexico Administrative Code (NMAC) 4.1, and (2) performance assessment supporting the Compliance Certification (DOE/CAO 96-2184) in compliance with 40 CFR $\S 191$ and 40 CFR $\S$ 194. Each of these programs requires a unique set of analyses and data. Particular sample needs are defined by each program.

Background data were collected from 1995 through 1997 and reported in the Waste Isolation Pilot Plant RCRA Background Groundwater Quality Baseline Report (DOE/WIPP 98-2285). The Background data were expanded in 2000 to include 10 rounds of sampling instead of five. The data were published in Addendum 1 Waste Isolation Pilot Plant RCRA Background Groundwater Quality Baseline Update Report. These background data will be compared to water quality data collected throughout the operational life of the facility.

Groundwater monitoring activities during 2000 included groundwater quality sampling and groundwater level surveillance. Groundwater quality data were gathered from six wells completed in the Culebra member of the Rustler Formation (wells WQSP-1 through WQSP-6) and one well completed in the Dewey Lake Formation (well WQSP-6A; Figure 6.1). Groundwater surface elevation data were gathered from 65 well bores, five of which were equipped with production-inflated packers to allow groundwater level surveillance of more than one producing zone through the same well bore (Figure 6.2).

\subsection{Groundwater Quality Sampling}

The RCRA Permit Module V requires groundwater quality sampling twice a year, from March through May (Round 10 for 2000) and, again, from September through November (Round 11 for 2000). Sampling for groundwater quality was performed at seven well sites during 2000 (Figure 6.1). Field analysis for Eh (Intensity Factor: an indicator of oxidation or reduction of chemical species), specific gravity, specific conductance, acidity or alkalinity, chloride, divalent cations, and total iron were performed periodically during the sampling. 


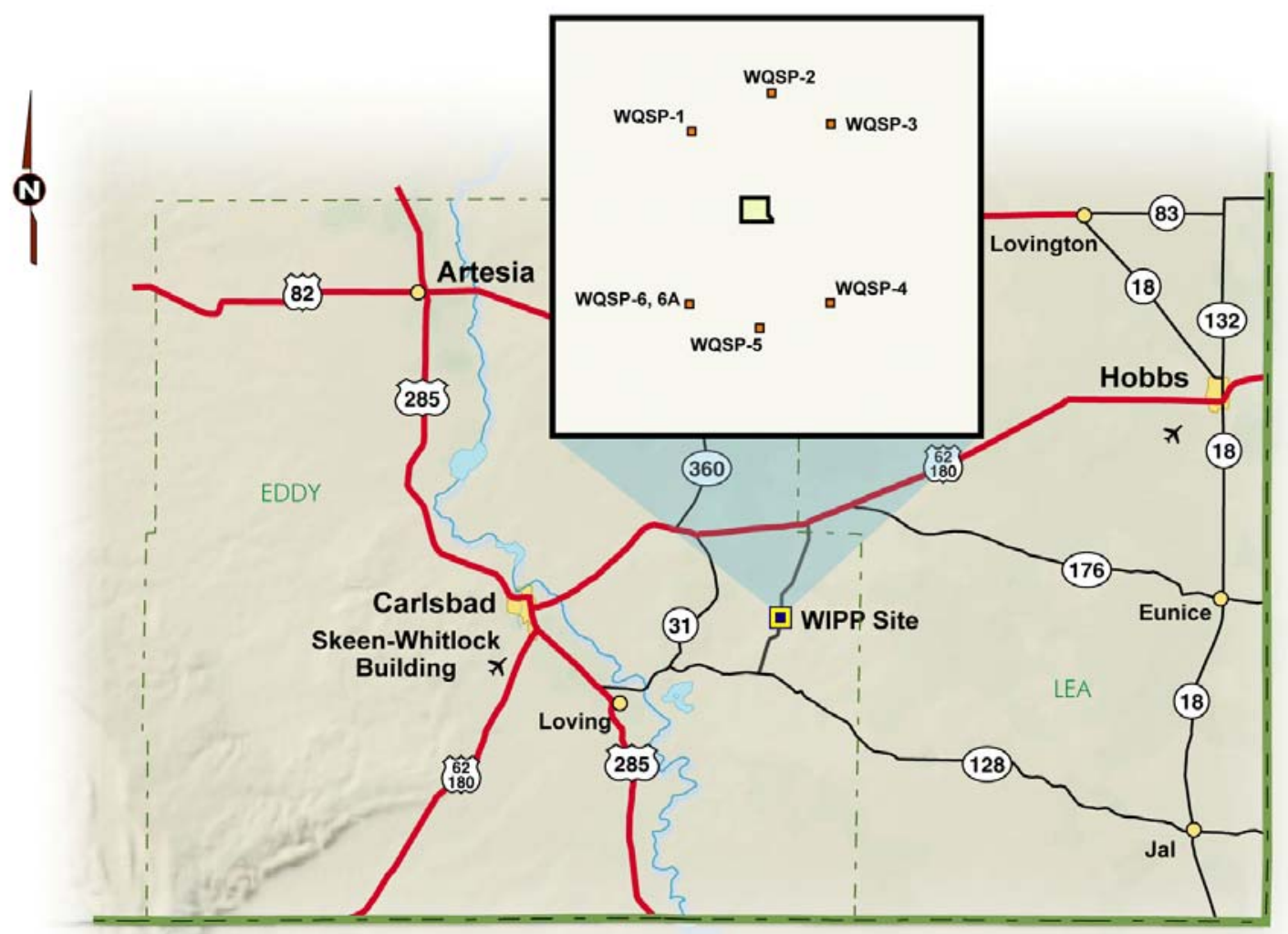

Figure 6.1 Water Quality Sampling Program Wells 


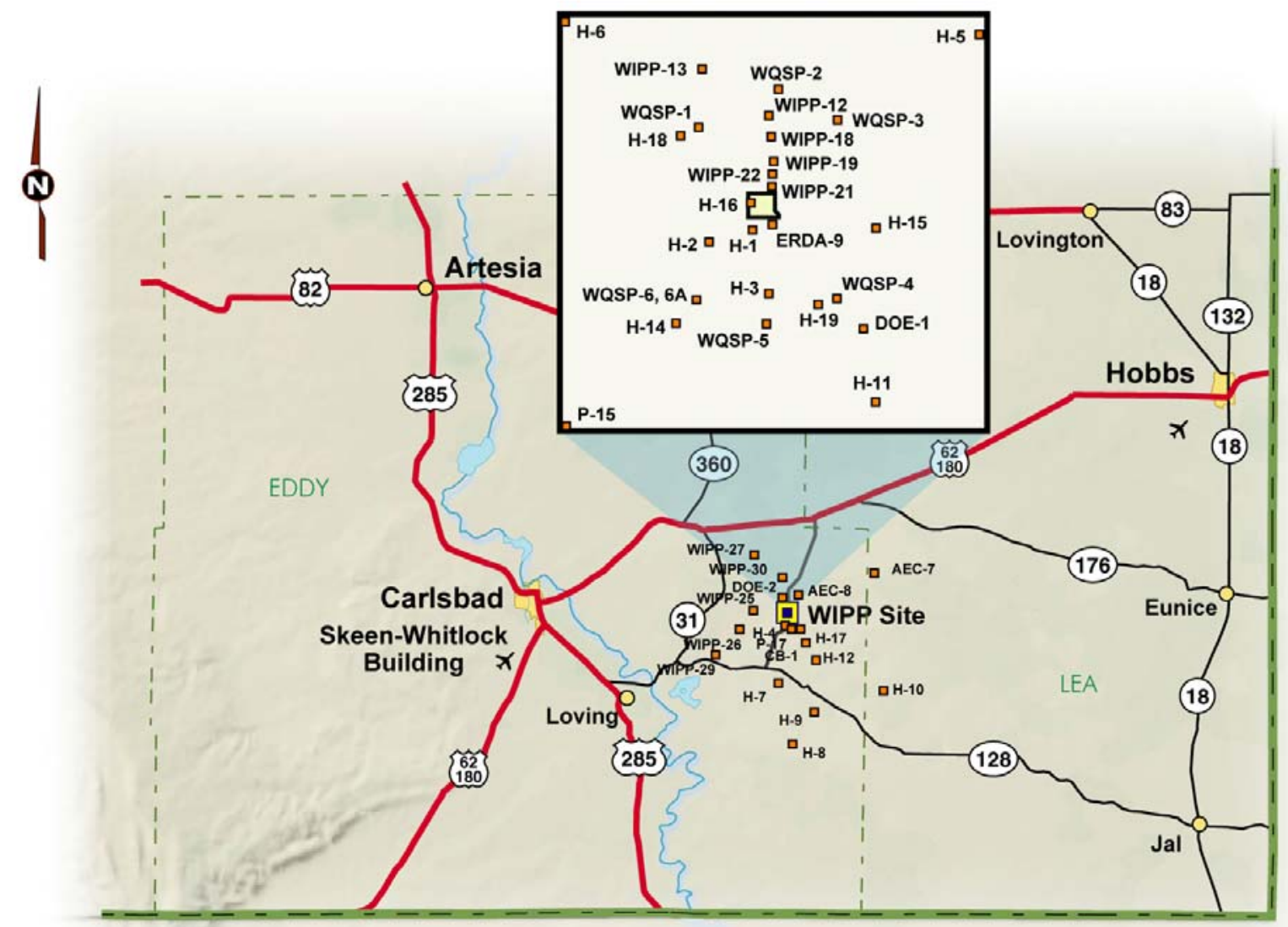

Figure 6.2 Groundwater Level Surveillance Wells 
Table 6.1 lists the analytical parameters included in the year 2000 groundwater sampling program.

During 2000, groundwater surveillance activities removed approximately $74,932 \mathrm{~L}$ $(19,795 \mathrm{gal})$ of water from the Culebra member of the Rustler Formation and 20,502 L (5,416 gal) from the Dewey Lake Formation. The quality of the Culebra water sampled near WIPP is naturally poor and not suitable for human consumption or for agricultural purposes. Total dissolved solids (TDS) concentrations measured in the Culebra ranged from 17,000 to over $220,000 \mathrm{mg} / \mathrm{L}$. The groundwater of the Culebra is considered to be Class III water by EPA guidelines.

Water quality measurements performed in the Dewey Lake Formation indicate the waters are considerably better quality than the Culebra water. TDS values were below $10,000 \mathrm{mg} / \mathrm{L}$. The water is suitable for livestock consumption, and classified as Class II water according to EPA guidance. Saturation of the Dewey Lake Formation in the area of WIPP is discontinuous. No hydrologic connection has been established that would indicate WIPP activities would have a potential impact on the Dewey Lake Formation.

Because of the highly variable transmissivity and TDS values within the Culebra, baseline groundwater quality was defined for each individual well. Tables 6.2 through 6.8 summarize the results of analyses for each parameter or constituent for the two sampling sessions in 2000 (rounds 10 and 11).

In these tables, either the $95^{\text {th }}$ upper tolerance limit value (UTLV) or the $95^{\text {th }}$ percentile value is presented for baseline data with concentrations that were well above the method detection limit prior to 2000. Both values represent the value beneath which 95 percent of the values in a population are expected to occur. UTLVs were calculated for data which exhibited a normal or a lognormal distribution. The $95^{\text {th }}$ percentile was determined for data which were considered non-parametric; having neither a normal nor a lognormal distribution. Due to the large number of nondetectable concentrations of organic compounds, the limits for organic compounds were considered non-parametric and based on the method detection limit reported by the laboratory. These values have been re-computed after baseline sampling was completed in 2000 , and were used for sampling round 11 to evaluate potential contamination of the groundwater wells.

As stated above, TDS, measured as filterable residue, of the Culebra Member in the WIPP area ranged from 12,000 to over $281,000 \mathrm{mg} / \mathrm{L}$. High TDS samples require dilution prior to analysis. The dilution factors have varied between sampling rounds and wells. Three different contract laboratories used recommended EPA methods to perform the groundwater chemistry analyses. Due to the variability in dilution factors and sensitivity of instruments, the concentrations and method detection limits from different laboratories were also different.

The analytical results for detectable constituents are plotted as Time Trend Plots compared to the baseline established prior to 2000 (Appendix F, Figures F.1 through F.127). 
Table 6.1 Analytical parameters for which groundwater was analyzed.

\begin{tabular}{|c|c|c|c|c|c|}
\hline CAS No. ${ }^{a}$ & Parameter & $\begin{array}{c}\text { EPA } \\
\text { Method } \\
\text { Number }\end{array}$ & CAS No. & Parameter & $\begin{array}{c}\text { EPA } \\
\text { Method } \\
\text { Number }\end{array}$ \\
\hline $71-55-6$ & 1,1,1-Trichloroethane & $8260 \mathrm{~B}$ & $7727-37-9$ & Nitrate (as N) & 300.0 \\
\hline $79-34-5$ & 1,1,2,2-Tetrachloroethane & $8260 \mathrm{~B}$ & & Orthophosphate (as P) & 365.2 \\
\hline $79-00-5$ & 1,1,2-Trichloroethane & $8260 \mathrm{~B}$ & & $\mathrm{pH}$ & 150.1 \\
\hline $75-34-3$ & 1,1-Dichloroethane & $8260 \mathrm{~B}$ & & Specific conductance & 120.1 \\
\hline $75-35-4$ & 1,1-Dichloroethylene & $8260 \mathrm{~B}$ & & Sulfate & 300.0 \\
\hline $107-06-2$ & 1,2-Dichloroethane & $8260 \mathrm{~B}$ & & Total dissolved solids & 160.1 \\
\hline $56-23-5$ & Carbon tetrachloride & $8260 \mathrm{~B}$ & & Total organic carbon & 415.1 \\
\hline $108-90-7$ & Chlorobenzene & $8260 \mathrm{~B}$ & & Total organic halogen & $9020 \mathrm{~B}$ \\
\hline $67-66-3$ & Chloroform & 8260B & & Total phenols & 420.1 \\
\hline $540-59-0$ & cis-1,2-Dichloroethylene & 8260B & & Total suspended & 160.2 \\
\hline $78-93-3$ & Methyl ethyl ketone & $8260 B$ & & & \\
\hline $75-09-2$ & Methylene chloride & 8260B & & & \\
\hline $127-18-4$ & Tetrachloroethylene & $8260 \mathrm{~B}$ & $7440-36-0$ & Antimony & $6010 \mathrm{~B}$ \\
\hline $108-88-3$ & Toluene & $8260 \mathrm{~B}$ & $7440-38-2$ & Arsenic & $6010 \mathrm{~B}$ \\
\hline $79-01-6$ & Trichloroethylene & $8260 \mathrm{~B}$ & $7440-39-3$ & Barium & $6010 \mathrm{~B}$ \\
\hline $75-69-4$ & Trichlorofluoromethane & 8260B & $7440-41-7$ & Beryllium & $6010 \mathrm{~B}$ \\
\hline $75-01-4$ & Vinyl chloride & $8260 \mathrm{~B}$ & $7440-42-8$ & Boron & $6010 \mathrm{~B}$ \\
\hline $1330-20-7$ & Xylene & $8260 \mathrm{~B}$ & $7440-43-9$ & Cadmium & $6010 \mathrm{~B}$ \\
\hline $95-50-1$ & 1,2-Dichlorobenzene & $8270 \mathrm{C}$ & $7440-70-2$ & Calcium & $6010 \mathrm{~B}$ \\
\hline $106-46-7$ & 1,4-Dichlorobenzene & $8270 \mathrm{C}$ & $7440-47-3$ & Chromium & $6010 \mathrm{~B}$ \\
\hline $51-28-5$ & 2,4-Dinitrophenol & $8270 \mathrm{C}$ & $7440-48-4$ & Cobalt & $6010 \mathrm{~B}$ \\
\hline $121-14-2$ & 2,4-Dinitrotoluene & $8270 \mathrm{C}$ & $7440-50-8$ & Copper & $6010 \mathrm{~B}$ \\
\hline $95-48-7$ & 2-Methylphenol & $8270 \mathrm{C}$ & $7439-89-6$ & Iron & $6010 \mathrm{~B}$ \\
\hline $108-39-4 /$ & 3-Methylphenol/ & & $7439-92-1$ & Lead & $6010 \mathrm{~B}$ \\
\hline $106-44-5$ & 4-Methylphenol & $8270 \mathrm{C}$ & $7439-93-2$ & Lithium & $6010 \mathrm{~B}$ \\
\hline $118-74-1$ & Hexachlorobenzene & $8270 \mathrm{C}$ & $7439-95-4$ & Magnesium & $6010 \mathrm{~B}$ \\
\hline $67-72-1$ & Hexachloroethane & $8270 \mathrm{C}$ & $7439-97-6$ & Mercury & $7470 \mathrm{~A}$ \\
\hline $98-95-3$ & Nitrobenzene & $8270 \mathrm{C}$ & $7440-02-0$ & Nickel & $6010 \mathrm{~B}$ \\
\hline $87-86-5$ & Pentachlorophenol & $8270 \mathrm{C}$ & $7440-09-7$ & Potassium & $6010 \mathrm{~B}$ \\
\hline $110-86-1$ & Pyridine & $8270 \mathrm{C}$ & $7782-49-2$ & Selenium & $6010 \mathrm{~B}$ \\
\hline \multirow[t]{2}{*}{$78-83-1$} & Isobutanol & 8015B & $7631-86-9$ & Silica & $6010 \mathrm{~B}$ \\
\hline & Alkalinity & 310.1 & $7440-22-4$ & Silver & $6010 \mathrm{~B}$ \\
\hline $7726-95-6$ & Bromide & 300.0 & $7440-23-5$ & Sodium & $6010 \mathrm{~B}$ \\
\hline \multirow[t]{4}{*}{$7782-50-5$} & Chloride & 300.0 & $7440-28-0$ & Thallium & $6010 \mathrm{~B}$ \\
\hline & Density $^{\mathrm{b}}$ & & $7440-31-5$ & Tin & $6010 \mathrm{~B}$ \\
\hline & Fluoride & 300.0 & $7440-62-2$ & Vanadium & $6010 \mathrm{~B}$ \\
\hline & Iodide & 345.1 & $7440-66-6$ & Zinc & $6010 \mathrm{~B}$ \\
\hline
\end{tabular}

${ }^{a}$ Chemical Abstract Service Registry Number

${ }^{\mathrm{b}}$ Analysis method was ASTM (American Society for Testing and Materials) D854-92 


\subsection{Groundwater Level Surveillance}

Groundwater surface elevations in the vicinity of WIPP may be influenced by site activities, such as pumping tests for site characterization, water quality sampling, or shaft sealing. Other influences on groundwater surface elevations may be caused by natural groundwater level fluctuations and industrial influences from agriculture, mining, and resource exploration.

In October 1988, WIPP was tasked with conducting a Groundwater Level Surveillance Program. Seventy well bores were used to perform surveillance of seven water-bearing zones in the WIPP area (Figure 6.2). The two zones of primary interest were the Culebra and Magenta members of the Rustler Formation (see Figure 1.1). Fifty-eight measurements were taken in the Culebra and ten in the Magenta. Three measurements were taken in the Dewey Lake Formation. One measurement each was taken in the Bell Canyon formation, Forty-niner, Rustler/Salado contact and an unnamed lower member of the Rustler formation. In 2000, groundwater level measurements were taken monthly in at least one accessible well bore at each well site for each available formation. Redundant well bores at each well site were measured on a quarterly basis.

Six well bores (WIPP-30 Culebra/Magenta, H-01 Culebra/Magenta, H-03d Dewey Lake/Forty-niner, H-16 Dewey Lake/unnamed lower member, Cabin Baby Culebra/Bell Canyon, and WIPP-25 Culebra/Magenta) were completed at multiple depths. By using packers, these well bores may be monitored in more than one formation.

Groundwater elevation measurements in the Culebra member indicated the generalized directional flow of groundwater was north to south in the vicinity of WIPP (Figure 6.3). Regional groundwater levels taken in Culebra observation wells with four or more data points for the year showed rising trends in water levels in 37 wells and falling trends in 22 wells.
Total fluctuations of more than $0.6 \mathrm{~m}(2 \mathrm{ft})$ in groundwater levels occurred in 11 wells completed to the Culebra. Three wells with fluctuations of more than $0.6 \mathrm{~m}(2 \mathrm{ft})$ (WQSP-2, WQSP-3, and WQSP-6) may have been influenced by groundwater sampling activities. Six wells (DOE-2, H-4b, H-9b, WIPP-25, WIPP-30 and Cabin Baby) experienced waterlevel fluctuations due to maintenance activities. One well (H-2b2) was influenced by maintenance activities at $\mathrm{H}-1$. P-15 water level increases were most likely caused by pressure fluctuation attributable to the drilling of several oil wells within one quarter of a mile of its location.

Groundwater level data were transmitted on a monthly basis to the NMED, EEG, Sandia National Laboratories, CTAC, and technical subcontractors as requested by the CBFO. A copy of the data was placed in the operating record for inspection by authorized agencies.

Calculated flow rates across the Land Withdrawal Area (LWA) range from $2.5 \times 10^{-5}$ feet per day (ft/d) in the Northern section of the eastern third of the LWA to $1.7 \times 10^{-3} \mathrm{ft} / \mathrm{d}$ in the Eastren and Central sections of the WIPP site. Calculated flow rates in the southeastern section of the WIPP site was $1.1 \times 10^{-3} \mathrm{ft} / \mathrm{d}$ (Figure 6.4).

The interpretation of groundwater data collected in 2000 are similar to previous years. To date there is no indication WIPP operations have had a measurable and significant impact on either the level or the quality of groundwater underlying WIPP.

\subsection{Well Maintenance Activities}

Maintenance activities were performed on nine wells in CY 2000. Maintenance is performed to prepare wells for future experiments, repair non-functioning wells, recomplete wells to monitor additional zones of interest, and plugging and abandonment of wells that were no longer useful. 
Wells H-6c and $\mathrm{H}-2 \mathrm{~b} 2$ were cleaned to prepare them for experiments performed by Sandia National Laboratories.

Wells, DOE-2, WIPP-25, and WIPP-30 were cleaned and scraped for maintenance purposes. The Production Injection Packers (PIP) were removed from wells WIPP-25 and WIPP-30, reconditioned, and re-installed in the well in addition to cleaning the casing.

Plugging and abandonment activities took place at H-4a, H-7a, D-268, and H-10c. H-4a and $\mathrm{H}-7$ a were properly cemented to the surface and monumented per applicable laws and regulations. D-268 was plugged, reducing its depth to 250 feet. The casing was then shot perforated in the producing zone of the Dewey Lake formation and the well was turned over to an area rancher for livestock watering purposes.

$\mathrm{H}-10 \mathrm{c}$ was cleaned and logged in preparation for plugging and abandonment however actual cementing and monumenting did not occur in CY 2000. 


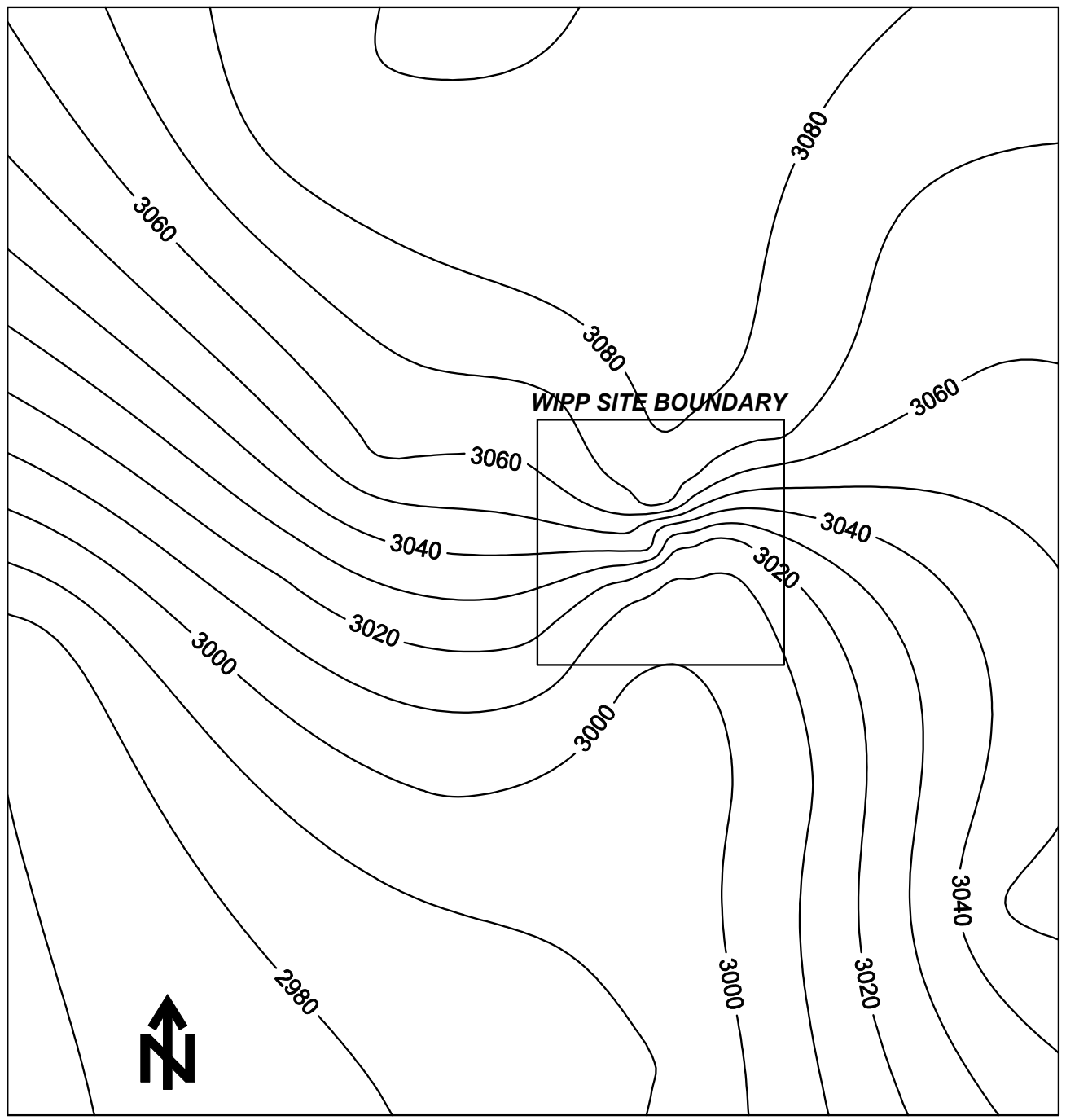

Note: Contour elevations are in feet above mean sea leve

Figure 6.3 Potentiometric Surface, Adjusted to Equivalent Freshwater Head, of the Culebra Dolomite Member of the Rustler Formation near the WIPP Site, December, 2000. 


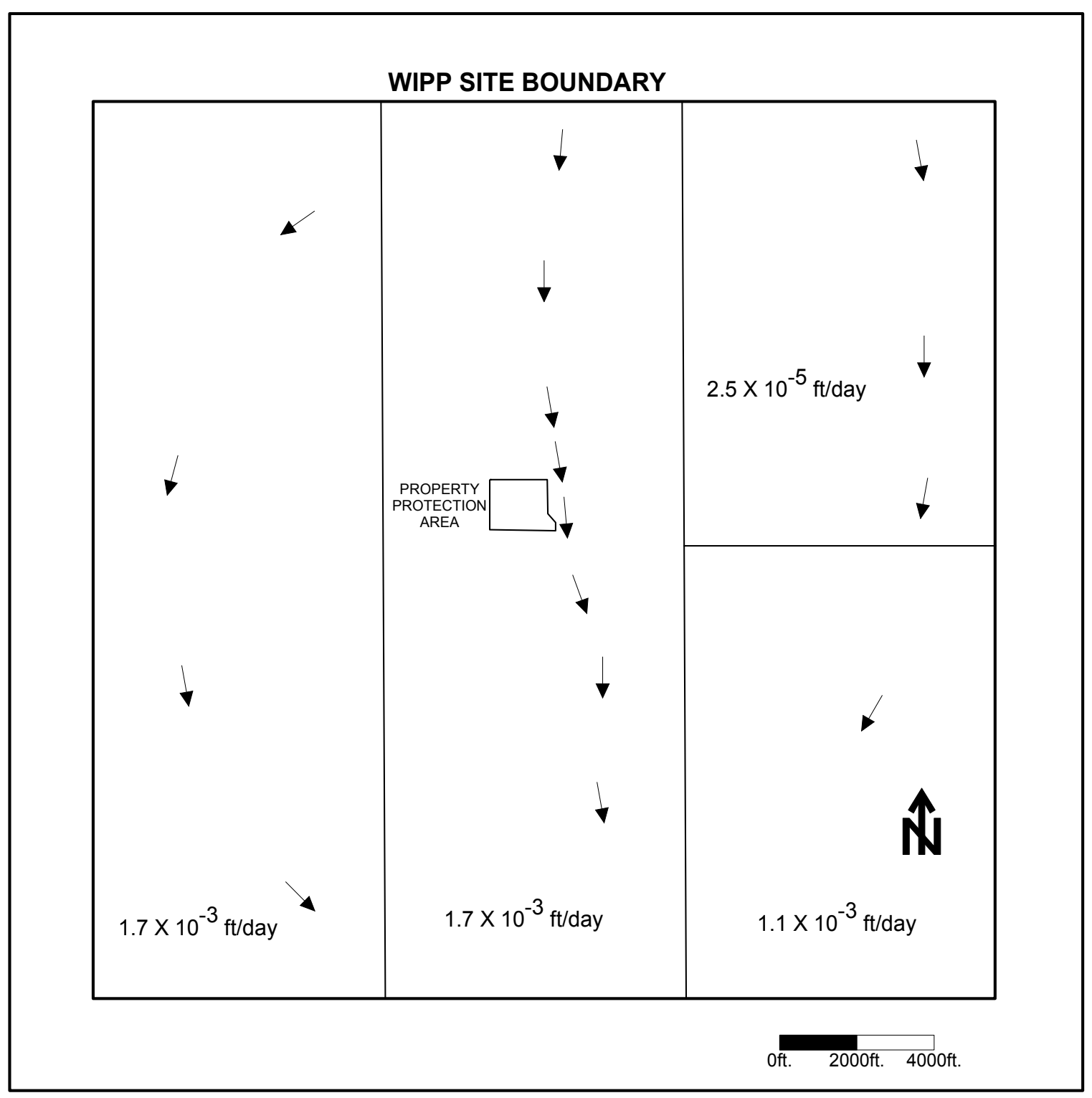

Figure 6.4 Flow Rate and Direction of Groundwater Flowing Across the WIPP Site, December, 2000. 
Table 6.2 Analytical results for groundwater sampled from well WQSP-1.

\begin{tabular}{|c|c|c|c|c|c|c|c|c|}
\hline \multirow[b]{3}{*}{ Parameter } & \multicolumn{7}{|c|}{ Concentration } & \multirow[b]{3}{*}{$\begin{array}{l}\mathbf{9 5}^{\text {th }} \\
\text { UTLV }^{\mathrm{a}}\end{array}$} \\
\hline & \multicolumn{2}{|c|}{ Round 10} & \multicolumn{2}{|c|}{ Round 11} & \multirow[b]{2}{*}{ Units } & \multicolumn{2}{|c|}{ Reporting Limit } & \\
\hline & Sample & Dup. & Sample & Dup. & & $\begin{array}{c}\text { Round } \\
10\end{array}$ & $\begin{array}{c}\text { Round } \\
11 \\
\end{array}$ & \\
\hline 1,1,1-Trichloroethane & $<2$ & $<2$ & $<2$ & $<2$ & $\mu \mathrm{g} / \mathrm{L}$ & 2 & 2 & $<\mathrm{RL}^{\mathrm{b}}$ \\
\hline $1,1,2,2$-Tetrachloroethane & $<2$ & $<2$ & $<2$ & $<2$ & $\mu g / L$ & 2 & 2 & $<\mathrm{RL}$ \\
\hline 1,1,2-Trichloroethane & $<2$ & $<2$ & $<2$ & $<2$ & $\mu \mathrm{g} / \mathrm{L}$ & 2 & 2 & $<\mathrm{RL}$ \\
\hline 1,1-Dichloroethane & $<2$ & $<2$ & $<2$ & $<2$ & $\mu \mathrm{g} / \mathrm{L}$ & 2 & 2 & $<\mathrm{RL}$ \\
\hline 1,1-Dichloroethylene & $<2$ & $<2$ & $<2$ & $<2$ & $\mu g / L$ & 2 & 2 & $<\mathrm{RL}$ \\
\hline 1,2-Dichloroethane & $<2$ & $<2$ & $<2$ & $<2$ & $\mu \mathrm{g} / \mathrm{L}$ & 2 & 2 & $<\mathrm{RL}$ \\
\hline Carbon tetrachloride & $<2$ & $<2$ & $<2$ & $<2$ & $\mu \mathrm{g} / \mathrm{L}$ & 2 & 2 & $<\mathrm{RL}$ \\
\hline Chlorobenzene & $<2$ & $<2$ & $<2$ & $<2$ & $\mu g / L$ & 2 & 2 & $<\mathrm{RL}$ \\
\hline Chloroform & $<2$ & $<2$ & $<2$ & $<2$ & $\mu \mathrm{g} / \mathrm{L}$ & 2 & 2 & $<\mathrm{RL}$ \\
\hline cis-1,2-Dichloroethylene & $<2$ & $<2$ & $<2$ & $<2$ & $\mu \mathrm{g} / \mathrm{L}$ & 2 & 2 & $<\mathrm{RL}$ \\
\hline Methyl ethyl ketone & $<2$ & $<2$ & $<2$ & $<2$ & $\mu \mathrm{g} / \mathrm{L}$ & 2 & 2 & $<\mathrm{RL}$ \\
\hline Methylene chloride & $<5$ & $<5$ & $<5$ & $<5$ & $\mu \mathrm{g} / \mathrm{L}$ & 5 & 5 & $<\mathrm{RL}$ \\
\hline Tetrachloroethylene & $<2$ & $<2$ & $<2$ & $<2$ & $\mu \mathrm{g} / \mathrm{L}$ & 2 & 2 & $<\mathrm{RL}$ \\
\hline Toluene & $<2$ & $<2$ & $<2$ & $<2$ & $\mu \mathrm{g} / \mathrm{L}$ & 2 & 2 & $<\mathrm{RL}$ \\
\hline Trichloroethylene & $<2$ & $<2$ & $<2$ & $<2$ & $\mu g / L$ & 2 & 2 & $<\mathrm{RL}$ \\
\hline Trichlorofluoromethane & $<2$ & $<2$ & $<2$ & $<2$ & $\mu \mathrm{g} / \mathrm{L}$ & 2 & 2 & $<\mathrm{RL}$ \\
\hline Vinyl chloride & $<2$ & $<2$ & $<2$ & $<2$ & $\mu g / L$ & 2 & 2 & $<\mathrm{RL}$ \\
\hline Xylene & $<2$ & $<2$ & $<2$ & $<2$ & $\mu \mathrm{g} / \mathrm{L}$ & 2 & 2 & $<\mathrm{RL}$ \\
\hline 1,2-Dichlorobenzene & $<5$ & $<5$ & $<5$ & $<5$ & $\mu g / L$ & 5 & 5 & $<\mathrm{RL}$ \\
\hline 1,4-Dichlorobenzene & $<5$ & $<5$ & $<5$ & $<5$ & $\mu \mathrm{g} / \mathrm{L}$ & 5 & 5 & $<\mathrm{RL}$ \\
\hline 2,4-Dinitrophenol & $<5$ & $<5$ & $<5$ & $<5$ & $\mu g / L$ & 5 & 5 & $<\mathrm{RL}$ \\
\hline 2,4-Dinitrotoluene & $<5$ & $<5$ & $<5$ & $<5$ & $\mu g / L$ & 5 & 5 & $<\mathrm{RL}$ \\
\hline 2-Methylphenol & $<5$ & $<5$ & $<5$ & $<5$ & $\mu \mathrm{g} / \mathrm{L}$ & 5 & 5 & $<\mathrm{RL}$ \\
\hline $\begin{array}{l}\text { 3-Methylphenol/ } \\
\text { 4-Methylphenol }\end{array}$ & $<5$ & $<5$ & $<5$ & $<5$ & $\mu \mathrm{g} / \mathrm{L}$ & 5 & 5 & $<\mathrm{RL}$ \\
\hline Hexachlorobenzene & $<5$ & $<5$ & $<5$ & $<5$ & $\mu \mathrm{g} / \mathrm{L}$ & 5 & 5 & $<\mathrm{RL}$ \\
\hline Hexachloroethane & $<5$ & $<5$ & $<5$ & $<5$ & $\mu \mathrm{g} / \mathrm{L}$ & 5 & 5 & $<\mathrm{RL}$ \\
\hline Nitrobenzene & $<5$ & $<5$ & $<5$ & $<5$ & $\mu g / L$ & 5 & 5 & $<\mathrm{RL}$ \\
\hline Pentachlorophenol & $<5$ & $<5$ & $<5$ & $<5$ & $\mu \mathrm{g} / \mathrm{L}$ & 5 & 5 & $<\mathrm{RL}$ \\
\hline Pyridine & $<5$ & $<5$ & $<5$ & $<5$ & $\mu \mathrm{g} / \mathrm{L}$ & 5 & 5 & $<\mathrm{RL}$ \\
\hline
\end{tabular}


Table 6.2, cont.

\begin{tabular}{|c|c|c|c|c|c|c|c|c|}
\hline \multirow[b]{3}{*}{ Parameter } & \multicolumn{7}{|c|}{ Concentration } & \multirow[b]{3}{*}{$\begin{array}{c}95^{\text {th }} \\
\text { UTLV }\end{array}$} \\
\hline & \multicolumn{2}{|c|}{ Round 10} & \multicolumn{2}{|c|}{ Round 11} & \multirow[b]{2}{*}{ Units } & \multicolumn{2}{|c|}{ Reporting Limit } & \\
\hline & Sample & Dup. & Sample & Dup. & & $\begin{array}{c}\text { Round } \\
10\end{array}$ & $\begin{array}{c}\text { Round } \\
11\end{array}$ & \\
\hline Isobutanol & $<2$ & $<2$ & $<2$ & $<2$ & $\mu \mathrm{g} / \mathrm{L}$ & 2 & 2 & $<\mathrm{RL}$ \\
\hline Alkalinity & 49 & 49 & 50 & 52 & $\mathrm{mg} / \mathrm{L}$ & 4.0 & 6.0 & 55.7 \\
\hline Bromide & 29 & 30 & 44 & 45 & $\mathrm{mg} / \mathrm{L}$ & 0.2 & 0.2 & 51.8 \\
\hline Chloride & 36,000 & 36,000 & 36,000 & 34,000 & $\mathrm{mg} / \mathrm{L}$ & 0.5 & 2.0 & 40,472 \\
\hline Density & 1.050 & 1.050 & 1.046 & 1.045 & $\mathrm{~g} / \mathrm{ml}$ & $\mathrm{N} / \mathrm{A}^{\mathrm{c}}$ & N/A & 1.072 \\
\hline Fluoride & 2.5 & 2.6 & 1.7 & 1.9 & $\mathrm{mg} / \mathrm{L}$ & 0.1 & 0.1 & 4.36 \\
\hline Iodide & $<2.0$ & $<2.0$ & $<2.0$ & 1.9 & $\mathrm{mg} / \mathrm{L}$ & 2.0 & 2.0 & 2.0 \\
\hline Nitrate (as N) & $<10$ & $<10$ & $<2.0$ & $<2.0$ & $\mathrm{mg} / \mathrm{L}$ & 10 & 2.0 & $<10$ \\
\hline Orthophosphate (as P) & $<0.04$ & $<0.04$ & $<0.040$ & 0.040 & $\mathrm{mg} / \mathrm{L}$ & 0.04 & 0.04 & 0.1 \\
\hline $\mathrm{pH}$ & 7.1 & 7.1 & 7.3 & 7.3 & $\mathrm{SU}^{\mathrm{d}}$ & N/A & $\mathrm{N} / \mathrm{A}$ & $6.89-7.65$ \\
\hline Specific conductance & 130,000 & 130,000 & 84,000 & 85,000 & $\mu \mathrm{mhos} / \mathrm{cm}$ & $\mathrm{N} / \mathrm{A}$ & N/A & 175,000 \\
\hline Sulfate & 4,800 & 4,700 & 4,800 & 4,700 & $\mathrm{mg} / \mathrm{L}$ & 0.5 & 0.5 & 6,477 \\
\hline Total dissolved solids & 65,000 & 65,500 & 57,000 & 69,000 & $\mathrm{mg} / \mathrm{L}$ & 10 & 10 & 77,600 \\
\hline Total organic carbon & 0.8 & 0.8 & $<1.0$ & $<1.0$ & $\mathrm{mg} / \mathrm{L}$ & 1.0 & 1.0 & $<5.0$ \\
\hline Total organic halogen & 0.99 & 0.99 & 2.1 & 2.1 & $\mathrm{mg} / \mathrm{L}$ & N/A & N/A & 14.6 \\
\hline Total phenols & $<0.07$ & $<0.07$ & $<0.07$ & $<0.07$ & $\mathrm{mg} / \mathrm{L}$ & 0.07 & 0.07 & $<0.07$ \\
\hline Total suspended solids & $<1.0$ & $<1.0$ & $<1.0$ & $<1.0$ & $\mathrm{mg} / \mathrm{L}$ & 1.0 & 1.0 & 33.5 \\
\hline Antimony & $<0.05$ & $<0.05$ & $<0.013$ & $<0.013$ & $\mathrm{mg} / \mathrm{L}$ & 0.05 & 0.013 & 0.33 \\
\hline Arsenic & $<0.10$ & $<0.10$ & $<0.05$ & $<0.05$ & $\mathrm{mg} / \mathrm{L}$ & 0.10 & 0.05 & $<0.1$ \\
\hline Barium & 0.042 & 0.03 & $<0.02$ & $<0.02$ & $\mathrm{mg} / \mathrm{L}$ & 0.02 & 0.02 & $<1.0$ \\
\hline Beryllium & 0.005 & 0.002 & 0.003 & 0.002 & $\mathrm{mg} / \mathrm{L}$ & 0.02 & 0.01 & $<0.02$ \\
\hline Boron & 14.3 & 14.0 & 9.96 & 11.9 & $\mathrm{mg} / \mathrm{L}$ & 0.010 & 0.5 & 19.3 \\
\hline Cadmium & $<0.2$ & $<0.2$ & $<0.01$ & $<0.01$ & $\mathrm{mg} / \mathrm{L}$ & 0.2 & 0.01 & $<0.2$ \\
\hline Calcium & 2,030 & 2,160 & 1,670 & 1,680 & $\mathrm{mg} / \mathrm{L}$ & 5.0 & 2.0 & 2,087 \\
\hline Chromium & 0.026 & $<0.05$ & $<0.025$ & $<0.025$ & $\mathrm{mg} / \mathrm{L}$ & 0.05 & 0.025 & $<0.5$ \\
\hline Cobalt & 0.005 & 0.042 & $<0.013$ & $<0.013$ & $\mathrm{mg} / \mathrm{L}$ & 0.05 & 0.013 & 0.11 \\
\hline Copper & 0.045 & 0.042 & $<0.05$ & $<0.05$ & $\mathrm{mg} / \mathrm{L}$ & 0.025 & 0.05 & $<1.0$ \\
\hline Iron & $<0.50$ & $<0.50$ & $<0.50$ & $<0.50$ & $\mathrm{mg} / \mathrm{L}$ & 0.50 & 0.50 & 1.32 \\
\hline Lead & $<0.05$ & $<0.05$ & 0.015 & 0.015 & $\mathrm{mg} / \mathrm{L}$ & 0.05 & 0.02 & 0.105 \\
\hline Lithium & 0.491 & 0.438 & 0.58 & 0.58 & $\mathrm{mg} / \mathrm{L}$ & 0.1 & 0.01 & 0.547 \\
\hline Magnesium & 1,112 & 1,100 & 1,090 & 1,110 & $\mathrm{mg} / \mathrm{L}$ & 5.0 & 2.0 & 1,247 \\
\hline Mercury & $<0.0002$ & $<0.0002$ & $<0.0002$ & $<0.0002$ & $\mathrm{mg} / \mathrm{L}$ & 0.0002 & 0.0002 & $<0.002$ \\
\hline
\end{tabular}


Table 6.2, cont.

\begin{tabular}{|c|c|c|c|c|c|c|c|c|}
\hline \multirow[b]{3}{*}{ Parameter } & \multicolumn{7}{|c|}{ Concentration } & \multirow[b]{3}{*}{$\begin{array}{c}9^{\text {th }} \\
\text { UTLV } \\
\end{array}$} \\
\hline & \multicolumn{2}{|c|}{ Round 10} & \multicolumn{2}{|c|}{ Round 11} & \multirow[b]{2}{*}{ Units } & \multicolumn{2}{|c|}{ Reporting Limit } & \\
\hline & Sample & Dup. & Sample & Dup. & & $\begin{array}{c}\text { Round } \\
10\end{array}$ & $\begin{array}{c}\text { Round } \\
11 \\
\end{array}$ & \\
\hline Nickel & 0.016 & 0.004 & $<0.025$ & $<0.025$ & $\mathrm{mg} / \mathrm{L}$ & 0.04 & 0.025 & 0.490 \\
\hline Potassium & 442 & 441 & 815 & 823 & $\mathrm{mg} / \mathrm{L}$ & 5.0 & 2.0 & 799 \\
\hline Selenium & $<0.01$ & $<0.01$ & $<0.013$ & $<0.013$ & $\mathrm{mg} / \mathrm{L}$ & 0.01 & 0.013 & 0.15 \\
\hline Silica & 17.9 & 17.70 & 5.61 & 5.56 & $\mathrm{mg} / \mathrm{L}$ & 0.10 & 0.50 & 17.9 \\
\hline Silver & 0.016 & $<0.010$ & $<0.013$ & $<0.013$ & $\mathrm{mg} / \mathrm{L}$ & 0.01 & 0.013 & $<0.50$ \\
\hline Sodium & 16,446 & 16,234 & 19,000 & 18,600 & $\mathrm{mg} / \mathrm{L}$ & 5.0 & 2.0 & 22,090 \\
\hline Thallium & $<0.05$ & $<0.05$ & 0.167 & 0.1060 & $\mathrm{mg} / \mathrm{L}$ & 0.050 & 0.013 & 0.98 \\
\hline Tin & $<0.10$ & $<0.10$ & $<0.025$ & $<0.025$ & $\mathrm{mg} / \mathrm{L}$ & 0.10 & 0.025 & 0.46 \\
\hline Vanadium & $<0.1$ & $<0.1$ & $<0.025$ & $<0.025$ & $\mathrm{mg} / \mathrm{L}$ & 0.1 & 0.025 & $<0.1$ \\
\hline Zinc & $<0.20$ & $<0.20$ & 0.019 & 0.014 & $\mathrm{mg} / \mathrm{L}$ & 0.20 & 0.050 & $<5.0$ \\
\hline
\end{tabular}

${ }^{\mathrm{A}} 95^{\text {th }}$ Upper Tolerance Limit Value, equivalent to $95 \%$ Confidence Limit

${ }^{\mathrm{b}}$ Reporting Limit

${ }^{\mathrm{c}}$ Not Applicable

${ }^{d}$ Standard Unit

${ }^{\mathrm{e}}$ Not reported by the laboratory 
Table 6.3 Analytical results for groundwater sampled from well WQSP-2.

\begin{tabular}{|c|c|c|c|c|c|c|c|c|}
\hline \multirow[b]{3}{*}{ Parameter } & \multicolumn{7}{|c|}{ Concentration } & \multirow[b]{3}{*}{$\begin{array}{c}\mathbf{9 5}^{\text {th }} \\
\text { UTLV }^{\mathrm{a}} \\
\end{array}$} \\
\hline & \multicolumn{2}{|c|}{ Round 10} & \multicolumn{2}{|c|}{ Round 11} & \multirow[b]{2}{*}{ Units } & \multicolumn{2}{|c|}{ Reporting Limit } & \\
\hline & Sample & Dup. & Sample & Dup. & & $\begin{array}{c}\text { Round } \\
10\end{array}$ & $\begin{array}{c}\text { Round } \\
11\end{array}$ & \\
\hline 1,1,1-Trichloroethane & $<2$ & $<2$ & $<2$ & $<2$ & $\mu \mathrm{g} / \mathrm{L}$ & 2 & 2 & $<\mathrm{RL}^{\mathrm{b}}$ \\
\hline 1,1,2,2-Tetrachloroethane & $<2$ & $<2$ & $<2$ & $<2$ & $\mu \mathrm{g} / \mathrm{L}$ & 2 & 2 & $<\mathrm{RL}$ \\
\hline 1,1,2-Trichloroethane & $<2$ & $<2$ & $<2$ & $<2$ & $\mu \mathrm{g} / \mathrm{L}$ & 2 & 2 & $<\mathrm{RL}$ \\
\hline 1,1-Dichloroethane & $<2$ & $<2$ & $<2$ & $<2$ & $\mu \mathrm{g} / \mathrm{L}$ & 2 & 2 & $<\mathrm{RL}$ \\
\hline 1,1-Dichloroethylene & $<2$ & $<2$ & $<2$ & $<2$ & $\mu \mathrm{g} / \mathrm{L}$ & 2 & 2 & $<\mathrm{RL}$ \\
\hline 1,2-Dichloroethane & $<2$ & $<2$ & $<2$ & $<2$ & $\mu \mathrm{g} / \mathrm{L}$ & 2 & 2 & $<\mathrm{RL}$ \\
\hline Carbon tetrachloride & $<2$ & $<2$ & $<2$ & $<2$ & $\mu \mathrm{g} / \mathrm{L}$ & 2 & 2 & $<\mathrm{RL}$ \\
\hline Chlorobenzene & $<2$ & $<2$ & $<2$ & $<2$ & $\mu \mathrm{g} / \mathrm{L}$ & 2 & 2 & $<\mathrm{RL}$ \\
\hline Chloroform & $<2$ & $<2$ & $<2$ & $<2$ & $\mu \mathrm{g} / \mathrm{L}$ & 2 & 2 & $<\mathrm{RL}$ \\
\hline cis-1,2-Dichloroethylene & $<2$ & $<2$ & $<2$ & $<2$ & $\mu \mathrm{g} / \mathrm{L}$ & 2 & 2 & $<\mathrm{RL}$ \\
\hline Methyl ethyl ketone & $<2$ & $<2$ & $<5$ & $<5$ & $\mu \mathrm{g} / \mathrm{L}$ & 2 & 5 & $<\mathrm{RL}$ \\
\hline Methylene chloride & $<5$ & $<5$ & $<5$ & $<5$ & $\mu \mathrm{g} / \mathrm{L}$ & 5 & 5 & $<\mathrm{RL}$ \\
\hline Tetrachloroethylene & $<2$ & $<2$ & $<2$ & $<2$ & $\mu \mathrm{g} / \mathrm{L}$ & 2 & 2 & $<\mathrm{RL}$ \\
\hline Toluene & $<2$ & $<2$ & $<2$ & $<2$ & $\mu \mathrm{g} / \mathrm{L}$ & 2 & 2 & $<\mathrm{RL}$ \\
\hline Trichloroethylene & $<2$ & $<2$ & $<2$ & $<2$ & $\mu \mathrm{g} / \mathrm{L}$ & 2 & 2 & $<\mathrm{RL}$ \\
\hline Trichlorofluoromethane & $<2$ & $<2$ & $<2$ & $<2$ & $\mu \mathrm{g} / \mathrm{L}$ & 2 & 2 & $<\mathrm{RL}$ \\
\hline Vinyl chloride & $<2$ & $<2$ & $<2$ & $<2$ & $\mu \mathrm{g} / \mathrm{L}$ & 2 & 2 & $<\mathrm{RL}$ \\
\hline Xylene & $<2$ & $<2$ & $<2$ & $<2$ & $\mu \mathrm{g} / \mathrm{L}$ & 2 & 2 & $<\mathrm{RL}$ \\
\hline 1,2-Dichlorobenzene & $<5$ & $<5$ & $<5$ & $<5$ & $\mu \mathrm{g} / \mathrm{L}$ & 5 & 5 & $<\mathrm{RL}$ \\
\hline 1,4-Dichlorobenzene & $<5$ & $<5$ & $<5$ & $<5$ & $\mu \mathrm{g} / \mathrm{L}$ & 5 & 5 & $<\mathrm{RL}$ \\
\hline 2,4-Dinitrophenol & $<5$ & $<5$ & $<5$ & $<5$ & $\mu \mathrm{g} / \mathrm{L}$ & 5 & 5 & $<\mathrm{RL}$ \\
\hline 2,4-Dinitrotoluene & $<5$ & $<5$ & $<5$ & $<5$ & $\mu \mathrm{g} / \mathrm{L}$ & 5 & 5 & $<\mathrm{RL}$ \\
\hline 2-Methylphenol & $<5$ & $<5$ & $<5$ & $<5$ & $\mu \mathrm{g} / \mathrm{L}$ & 5 & 5 & $<\mathrm{RL}$ \\
\hline $\begin{array}{l}\text { 3-Methylphenol/ } \\
\text { 4-Methylphenol }\end{array}$ & $<5$ & $<5$ & $<5$ & $<5$ & $\mu \mathrm{g} / \mathrm{L}$ & 5 & 5 & $<\mathrm{RL}$ \\
\hline Hexachlorobenzene & $<5$ & $<5$ & $<5$ & $<5$ & $\mu \mathrm{g} / \mathrm{L}$ & 5 & 5 & $<\mathrm{RL}$ \\
\hline Hexachloroethane & $<5$ & $<5$ & $<5$ & $<5$ & $\mu \mathrm{g} / \mathrm{L}$ & 5 & 5 & $<\mathrm{RL}$ \\
\hline Nitrobenzene & $<5$ & $<5$ & $<5$ & $<5$ & $\mu \mathrm{g} / \mathrm{L}$ & 5 & 5 & $<\mathrm{RL}$ \\
\hline Pentachlorophenol & $<5$ & $<5$ & $<5$ & $<5$ & $\mu \mathrm{g} / \mathrm{L}$ & 5 & 5 & $<\mathrm{RL}$ \\
\hline Pyridine & $<5$ & $<5$ & $<5$ & $<5$ & $\mu \mathrm{g} / \mathrm{L}$ & 5 & 5 & $<\mathrm{RL}$ \\
\hline
\end{tabular}


Table 6.3, cont.

\begin{tabular}{|c|c|c|c|c|c|c|c|c|}
\hline \multirow[b]{3}{*}{ Parameter } & \multicolumn{7}{|c|}{ Concentration } & \multirow[b]{3}{*}{$\begin{array}{c}95^{\text {th }} \\
\text { UTLV }\end{array}$} \\
\hline & \multicolumn{2}{|c|}{ Round 10} & \multicolumn{2}{|c|}{ Round 11} & \multirow[b]{2}{*}{ Units } & \multicolumn{2}{|c|}{ Reporting Limit } & \\
\hline & Sample & Dup. & Sample & Dup. & & $\begin{array}{c}\text { Round } \\
10\end{array}$ & $\begin{array}{c}\text { Round } \\
11\end{array}$ & \\
\hline Isobutanol & $<2$ & $<2$ & $<2$ & $<2$ & $\mu \mathrm{g} / \mathrm{L}$ & 2 & 2 & $<\mathrm{RL}$ \\
\hline Alkalinity & 44 & 46 & 51 & 48 & $\mathrm{mg} / \mathrm{L}$ & $\mathrm{NR}^{\mathrm{c}}$ & 6.0 & 70.3 \\
\hline Bromide & 28 & 28 & 48 & 46 & $\mathrm{mg} / \mathrm{L}$ & 0.2 & 0.2 & 63.7 \\
\hline Chloride & 37,000 & 37,000 & 37,000 & 36,000 & $\mathrm{mg} / \mathrm{L}$ & 0.5 & 2.0 & 39,670 \\
\hline Density & 1.050 & 1.050 & 1.048 & 1.045 & $\mathrm{~g} / \mathrm{ml}$ & $\mathrm{N} / \mathrm{A}^{\mathrm{d}}$ & N/A & 1.060 \\
\hline Fluoride & 2.0 & 2.0 & 1.3 & 1.2 & $\mathrm{mg} / \mathrm{L}$ & 0.1 & 0.1 & 20.0 \\
\hline Iodide & $<2.0$ & $<2.0$ & $<2.0$ & $<2.0$ & $\mathrm{mg} / \mathrm{L}$ & 2.0 & 2.0 & 2.0 \\
\hline Nitrate (as N) & $<10$ & $<10$ & $<10$ & $<10$ & $\mathrm{mg} / \mathrm{L}$ & 2.0 & 2.0 & $<10$ \\
\hline Orthophosphate (as P) & $<0.04$ & $<0.04$ & 0.030 & 0.020 & $\mathrm{mg} / \mathrm{L}$ & 0.04 & 0.04 & 0.33 \\
\hline $\mathrm{pH}$ & 7.1 & 7.1 & 7.3 & 7.3 & $\mathrm{SU}^{\mathrm{e}}$ & N/A & N/A & $6.91-7.66$ \\
\hline Specific conductance & 100,000 & 100,000 & 81,000 & 80,000 & $\mu \mathrm{mhos} / \mathrm{cm}$ & N/A & N/A & 124,000 \\
\hline Sulfate & 5,900 & 6,000 & 5,800 & 5,600 & $\mathrm{mg} / \mathrm{L}$ & 0.5 & 0.5 & 6,829 \\
\hline Total dissolved solids & 62,000 & 68,000 & 62,500 & 62,500 & $\mathrm{mg} / \mathrm{L}$ & 10 & 10 & 74,660 \\
\hline Total organic carbon & $<0.7$ & $<0.7$ & 1.1 & $<1.0$ & $\mathrm{mg} / \mathrm{L}$ & 0.7 & 1.0 & 8.150 \\
\hline Total organic halogen & 0.93 & 0.79 & 5.7 & 3.6 & $\mathrm{mg} / \mathrm{L}$ & NR & NR & 63.8 \\
\hline Total phenols & $<0.07$ & $<0.07$ & $<0.07$ & $<0.07$ & $\mathrm{mg} / \mathrm{L}$ & 0.07 & 0.07 & 0.16 \\
\hline Total suspended solids & $<1.0$ & $<1.0$ & $<1.0$ & $<1.0$ & $\mathrm{mg} / \mathrm{L}$ & 1.0 & 1.0 & 44.0 \\
\hline Antimony & $<0.05$ & $<0.05$ & $<0.010$ & $<0.010$ & $\mathrm{mg} / \mathrm{L}$ & 0.05 & 0.010 & $<0.50$ \\
\hline Arsenic & $<0.10$ & $<0.10$ & $<0.05$ & $<0.05$ & $\mathrm{mg} / \mathrm{L}$ & 0.10 & 0.05 & $<0.1$ \\
\hline Barium & 0.047 & 0.037 & $<0.02$ & $<0.02$ & $\mathrm{mg} / \mathrm{L}$ & 0.2 & 0.02 & $<1.0$ \\
\hline Beryllium & 0.003 & 0.003 & $<0.01$ & $<0.01$ & $\mathrm{mg} / \mathrm{L}$ & 0.005 & 0.01 & $<1.0$ \\
\hline Boron & 17.2 & 17.0 & 14.0 & 15.0 & $\mathrm{mg} / \mathrm{L}$ & 0.020 & 0.5 & 19.4 \\
\hline Cadmium & $<0.01$ & $<0.01$ & $<0.01$ & $<0.01$ & $\mathrm{mg} / \mathrm{L}$ & 0.01 & 0.01 & $<0.5$ \\
\hline Calcium & 1,840 & 1,730 & 1,460 & 1,530 & $\mathrm{mg} / \mathrm{L}$ & 5.0 & 1.0 & 1,827 \\
\hline Chromium & 0.011 & 0.0180 & $<0.025$ & $<0.025$ & $\mathrm{mg} / \mathrm{L}$ & 0.010 & 0.025 & $<0.5$ \\
\hline Cobalt & $<0.05$ & 0.018 & $<0.010$ & $<0.010$ & $\mathrm{mg} / \mathrm{L}$ & 0.05 & 0.010 & 0.11 \\
\hline Copper & 0.026 & 0.022 & $<0.05$ & $<0.05$ & $\mathrm{mg} / \mathrm{L}$ & 0.025 & 0.05 & $<1.0$ \\
\hline Iron & $<0.50$ & $<0.50$ & $<0.50$ & $<0.50$ & $\mathrm{mg} / \mathrm{L}$ & 0.50 & 0.50 & 1.32 \\
\hline Lead & $<0.05$ & $<0.05$ & $<0.02$ & $<0.02$ & $\mathrm{mg} / \mathrm{L}$ & 0.05 & 0.02 & 0.163 \\
\hline Lithium & 0.480 & 0.486 & 0.388 & 0.403 & $\mathrm{mg} / \mathrm{L}$ & 0.1 & 0.01 & 0.493 \\
\hline Magnesium & 1,033 & 1,107 & 982 & 1040 & $\mathrm{mg} / \mathrm{L}$ & 5.0 & 1.0 & 1,310 \\
\hline Mercury & $<0.0002$ & $<0.0002$ & $<0.0002$ & $<0.0002$ & $\mathrm{mg} / \mathrm{L}$ & 0.0002 & 0.0002 & $<0.002$ \\
\hline
\end{tabular}


Table 6.3, cont.

\begin{tabular}{|c|c|c|c|c|c|c|c|c|}
\hline \multicolumn{9}{|c|}{ Concentration } \\
\hline \multirow[b]{2}{*}{ Parameter } & \multicolumn{2}{|c|}{ Round 10} & \multicolumn{2}{|c|}{ Round 11} & \multirow[b]{2}{*}{ Units } & \multicolumn{2}{|c|}{ Reporting Limit } & \multirow[b]{2}{*}{$\begin{array}{c}95^{\text {th }} \\
\text { UTLV }\end{array}$} \\
\hline & Sample & Dup. & Sample & Dup. & & $\begin{array}{c}\text { Round } \\
10\end{array}$ & $\begin{array}{c}\text { Round } \\
11\end{array}$ & \\
\hline Nickel & 0.037 & 0.1070 & $<0.025$ & 0.014 & $\mathrm{mg} / \mathrm{L}$ & 0.0010 & 0.025 & 0.490 \\
\hline Potassium & 333 & 380 & 815 & 823 & $\mathrm{mg} / \mathrm{L}$ & 0.04 & 1.00 & 845 \\
\hline Selenium & $<0.01$ & $<0.01$ & $<0.01$ & $<0.01$ & $\mathrm{mg} / \mathrm{L}$ & 0.01 & 0.01 & 0.150 \\
\hline Silica & 23.0 & 23.0 & 2.51 & 2.50 & $\mathrm{mg} / \mathrm{L}$ & 1.0 & 0.50 & 24.0 \\
\hline Silver & $<0.010$ & 0.002 & $<0.010$ & $<0.010$ & $\mathrm{mg} / \mathrm{L}$ & 0.01 & 0.01 & $<0.50$ \\
\hline Sodium & 15,374 & 16,396 & 19,800 & 20,300 & $\mathrm{mg} / \mathrm{L}$ & 5.0 & 1.0 & 21,550 \\
\hline Thallium & $<0.05$ & $<0.05$ & $<0.013$ & $<0.013$ & $\mathrm{mg} / \mathrm{L}$ & 0.050 & 0.013 & 0.98 \\
\hline Tin & $<0.10$ & $<0.10$ & $<0.025$ & $<0.025$ & $\mathrm{mg} / \mathrm{L}$ & 0.10 & 0.025 & 0.46 \\
\hline Vanadium & $<0.1$ & $<0.1$ & $<0.025$ & $<0.025$ & $\mathrm{mg} / \mathrm{L}$ & 0.1 & 0.025 & $<0.1$ \\
\hline Zinc & $<0.20$ & $<0.20$ & $<0.05$ & $<0.05$ & $\mathrm{mg} / \mathrm{L}$ & 0.20 & 0.050 & $<5.0$ \\
\hline
\end{tabular}


Table 6.4 Analytical results for groundwater sampled from well WQSP-3.

\begin{tabular}{|c|c|c|c|c|c|c|c|c|}
\hline \multirow[b]{3}{*}{ Parameter } & \multicolumn{7}{|c|}{ Concentration } & \multirow[b]{3}{*}{$\begin{array}{c}9^{\text {th }} \\
\text { UTLV }^{\mathrm{a}}\end{array}$} \\
\hline & \multicolumn{2}{|c|}{ Round 10} & \multicolumn{2}{|c|}{ Round 11} & \multirow[b]{2}{*}{ Units } & \multicolumn{2}{|c|}{ Reporting Limit } & \\
\hline & Sample & Dup. & Sample & Dup. & & $\begin{array}{c}\text { Round } \\
10\end{array}$ & $\begin{array}{c}\text { Round } \\
11\end{array}$ & \\
\hline 1,1,1-Trichloroethane & $<2$ & $<2$ & $<1$ & $<1$ & $\mu \mathrm{g} / \mathrm{L}$ & 2 & 1 & $<\mathrm{RL}^{\mathrm{b}}$ \\
\hline 1,1,2,2-Tetrachloroethane & $<2$ & $<2$ & $<1$ & $<1$ & $\mu \mathrm{g} / \mathrm{L}$ & 2 & 1 & $<\mathrm{RL}$ \\
\hline 1,1,2-Trichloroethane & $<2$ & $<2$ & $<1$ & $<1$ & $\mu \mathrm{g} / \mathrm{L}$ & 2 & 1 & $<\mathrm{RL}$ \\
\hline 1,1-Dichloroethane & $<2$ & $<2$ & $<1$ & $<1$ & $\mu \mathrm{g} / \mathrm{L}$ & 2 & 1 & $<\mathrm{RL}$ \\
\hline 1,1-Dichloroethylene & $<2$ & $<2$ & $<1$ & $<1$ & $\mu \mathrm{g} / \mathrm{L}$ & 2 & 1 & $<\mathrm{RL}$ \\
\hline 1,2-Dichloroethane & $<2$ & $<2$ & $<1$ & $<1$ & $\mu \mathrm{g} / \mathrm{L}$ & 2 & 1 & $<\mathrm{RL}$ \\
\hline Carbon tetrachloride & $<2$ & $<2$ & $<1$ & $<1$ & $\mu \mathrm{g} / \mathrm{L}$ & 2 & 1 & $<\mathrm{RL}$ \\
\hline Chlorobenzene & $<2$ & $<2$ & $<1$ & $<1$ & $\mu \mathrm{g} / \mathrm{L}$ & 2 & 1 & $<\mathrm{RL}$ \\
\hline Chloroform & $<2$ & $<2$ & $<1$ & $<1$ & $\mu \mathrm{g} / \mathrm{L}$ & 2 & 1 & $<\mathrm{RL}$ \\
\hline cis-1,2-Dichloroethylene & $<2$ & $<2$ & $<1$ & $<1$ & $\mu \mathrm{g} / \mathrm{L}$ & 2 & 1 & $<\mathrm{RL}$ \\
\hline Methyl ethyl ketone & $<2$ & $<2$ & $<5$ & $<5$ & $\mu \mathrm{g} / \mathrm{L}$ & 2 & 5 & $<\mathrm{RL}$ \\
\hline Methylene chloride & $<5$ & $<5$ & $<5$ & $<5$ & $\mu \mathrm{g} / \mathrm{L}$ & 5 & 5 & $<\mathrm{RL}$ \\
\hline Tetrachloroethylene & $<2$ & $<2$ & $<1$ & $<1$ & $\mu \mathrm{g} / \mathrm{L}$ & 2 & 1 & $<\mathrm{RL}$ \\
\hline Toluene & $<2$ & $<2$ & $<1$ & $<1$ & $\mu \mathrm{g} / \mathrm{L}$ & 2 & 1 & $<\mathrm{RL}$ \\
\hline Trichloroethylene & $<2$ & $<2$ & $<1$ & $<1$ & $\mu \mathrm{g} / \mathrm{L}$ & 2 & 1 & $<\mathrm{RL}$ \\
\hline Trichlorofluoromethane & $<2$ & $<2$ & $<1$ & $<1$ & $\mu \mathrm{g} / \mathrm{L}$ & 2 & 1 & $<\mathrm{RL}$ \\
\hline Vinyl chloride & $<2$ & $<2$ & $<1$ & $<1$ & $\mu \mathrm{g} / \mathrm{L}$ & 2 & 1 & $<\mathrm{RL}$ \\
\hline Xylene & $<2$ & $<2$ & $<1$ & $<1$ & $\mu \mathrm{g} / \mathrm{L}$ & 2 & 1 & $<\mathrm{RL}$ \\
\hline 1,2-Dichlorobenzene & $<5$ & $<5$ & $<5$ & $<5$ & $\mu \mathrm{g} / \mathrm{L}$ & 5 & 5 & $<\mathrm{RL}$ \\
\hline 1,4-Dichlorobenzene & $<5$ & $<5$ & $<5$ & $<5$ & $\mu \mathrm{g} / \mathrm{L}$ & 5 & 5 & $<\mathrm{RL}$ \\
\hline 2,4-Dinitrophenol & $<5$ & $<5$ & $<5$ & $<5$ & $\mu \mathrm{g} / \mathrm{L}$ & 5 & 5 & $<\mathrm{RL}$ \\
\hline 2,4-Dinitrotoluene & $<5$ & $<5$ & $<5$ & $<5$ & $\mu \mathrm{g} / \mathrm{L}$ & 5 & 5 & $<\mathrm{RL}$ \\
\hline 2-Methylphenol & $<5$ & $<5$ & $<5$ & $<5$ & $\mu \mathrm{g} / \mathrm{L}$ & 5 & 5 & $<\mathrm{RL}$ \\
\hline $\begin{array}{l}\text { 3-Methylphenol/ } \\
\text { 4-Methylphenol }\end{array}$ & $<5$ & $<5$ & $<5$ & $<5$ & $\mu \mathrm{g} / \mathrm{L}$ & 5 & 5 & $<\mathrm{RL}$ \\
\hline Hexachlorobenzene & $<5$ & $<5$ & $<5$ & $<5$ & $\mu \mathrm{g} / \mathrm{L}$ & 5 & 5 & $<\mathrm{RL}$ \\
\hline Hexachloroethane & $<5$ & $<5$ & $<5$ & $<5$ & $\mu \mathrm{g} / \mathrm{L}$ & 5 & 5 & $<\mathrm{RL}$ \\
\hline Nitrobenzene & $<5$ & $<5$ & $<5$ & $<5$ & $\mu \mathrm{g} / \mathrm{L}$ & 5 & 5 & $<\mathrm{RL}$ \\
\hline Pentachlorophenol & $<5$ & $<5$ & $<5$ & $<5$ & $\mu \mathrm{g} / \mathrm{L}$ & 5 & 5 & $<\mathrm{RL}$ \\
\hline Pyridine & $<5$ & $<5$ & $<5$ & $<5$ & $\mu \mathrm{g} / \mathrm{L}$ & 5 & 5 & $<\mathrm{RL}$ \\
\hline
\end{tabular}


Table 6.4, cont.

\begin{tabular}{|c|c|c|c|c|c|c|c|c|}
\hline \multirow[b]{3}{*}{ Parameter } & \multicolumn{7}{|c|}{ Concentration } & \multirow[b]{3}{*}{$\begin{array}{c}{95^{\text {th }}}^{\text {UTLV }}\end{array}$} \\
\hline & \multicolumn{2}{|c|}{ Round 10} & \multicolumn{2}{|c|}{ Round 11} & \multirow[b]{2}{*}{ Units } & \multicolumn{2}{|c|}{ Reporting Limit } & \\
\hline & Sample & Dup. & Sample & Dup. & & $\begin{array}{c}\text { Round } \\
10\end{array}$ & $\begin{array}{c}\text { Round } \\
11\end{array}$ & \\
\hline Isobutanol & $<2$ & $<2$ & $<2$ & $<2$ & $\mu \mathrm{g} / \mathrm{L}$ & 2 & 2 & $<\mathrm{RL}$ \\
\hline Alkalinity & 55 & 54 & 35 & 36 & $\mathrm{mg} / \mathrm{L}$ & $\mathrm{NR}^{\mathrm{c}}$ & 6.0 & 54.4 \\
\hline Bromide & 110 & 100 & 120 & 110 & $\mathrm{mg} / \mathrm{L}$ & 0.2 & 0.2 & 137 \\
\hline Chloride & 123,000 & 123,000 & 130,000 & 130,000 & $\mathrm{mg} / \mathrm{L}$ & 0.5 & 0.5 & 156,600 \\
\hline Density & 1.150 & 1.150 & 1.145 & 1.151 & $\mathrm{~g} / \mathrm{ml}$ & $\mathrm{N} / \mathrm{A}^{\mathrm{d}}$ & N/A & 1.17 \\
\hline Fluoride & 2.3 & 2.3 & 0.85 & 0.84 & $\mathrm{mg} / \mathrm{L}$ & 0.1 & 0.1 & $<10.0$ \\
\hline Iodide & $<2.0$ & $<2.0$ & $<2.0$ & $<2.0$ & $\mathrm{mg} / \mathrm{L}$ & 2.0 & 2.0 & $<2.0$ \\
\hline Nitrate (as N) & $<10$ & $<10$ & $<10$ & $<10$ & $\mathrm{mg} / \mathrm{L}$ & 0.2 & 10.0 & $<10$ \\
\hline Orthophosphate (as P) & $<0.04$ & $<0.04$ & 0.046 & 0.055 & $\mathrm{mg} / \mathrm{L}$ & 0.04 & 0.04 & 0.41 \\
\hline $\mathrm{pH}$ & 7.1 & 7.1 & 6.9 & 6.9 & $\mathrm{SU}^{\mathrm{e}}$ & N/A & N/A & $6.60-7.20$ \\
\hline Specific conductance & 300,000 & 300,000 & 200,000 & 180,000 & $\mu \mathrm{mhos} / \mathrm{cm}$ & N/A & N/A & 517,000 \\
\hline Sulfate & 7,500 & 7,200 & 7,000 & 6,800 & $\mathrm{mg} / \mathrm{L}$ & 0.5 & 0.5 & 8,015 \\
\hline Total dissolved solids & 211,000 & 281,000 & 220,000 & 240,000 & $\mathrm{mg} / \mathrm{L}$ & 10 & 10 & 261,000 \\
\hline Total organic carbon & 0.7 & $<0.7$ & $<1.0$ & $<1.0$ & $\mathrm{mg} / \mathrm{L}$ & 0.7 & 1.0 & $<5.0$ \\
\hline Total organic halogen & 1.50 & 1.40 & 1.10 & 5.70 & $\mathrm{mg} / \mathrm{L}$ & NR & NR & 56.40 \\
\hline Total phenols & $<0.07$ & $<0.07$ & $<0.10$ & $<0.10$ & $\mathrm{mg} / \mathrm{L}$ & 0.07 & 0.10 & 0.26 \\
\hline Total suspended solids & $<1.0$ & $<1.0$ & $<1.0$ & $<1.0$ & $\mathrm{mg} / \mathrm{L}$ & 1.0 & 1.0 & 113.0 \\
\hline Antimony & 0.137 & $<0.13$ & $<0.010$ & $<0.010$ & $\mathrm{mg} / \mathrm{L}$ & 0.13 & 0.010 & $<1.0$ \\
\hline Arsenic & $<0.207$ & 0.0640 & 0.0360 & $<0.05$ & $\mathrm{mg} / \mathrm{L}$ & 0.010 & 0.050 & 0.27 \\
\hline Barium & 0.0147 & 0.0061 & $<0.02$ & $<0.02$ & $\mathrm{mg} / \mathrm{L}$ & 0.001 & 0.020 & $<1.0$ \\
\hline Beryllium & 0.0035 & 0.0011 & $<0.01$ & $<0.01$ & $\mathrm{mg} / \mathrm{L}$ & 0.001 & 0.010 & $<0.1$ \\
\hline Boron & 46.7 & 44.5 & 41.6 & 44.5 & $\mathrm{mg} / \mathrm{L}$ & 0.020 & 0.5 & 55.9 \\
\hline Cadmium & $<0.02$ & $<0.02$ & $<0.01$ & $<0.01$ & $\mathrm{mg} / \mathrm{L}$ & 0.02 & 0.01 & $<0.5$ \\
\hline Calcium & 1,390 & 1,440 & 1,410 & 1,420 & $\mathrm{mg} / \mathrm{L}$ & 5.0 & 1.0 & 1,680 \\
\hline Chromium & 0.0119 & 0.0057 & $<0.025$ & 0.0110 & $\mathrm{mg} / \mathrm{L}$ & 0.010 & 0.025 & $<2.0$ \\
\hline Cobalt & $<0.13$ & $<0.13$ & $<0.010$ & $<0.010$ & $\mathrm{mg} / \mathrm{L}$ & 0.13 & 0.010 & $<5.0$ \\
\hline Copper & 0.0117 & $<0.130$ & 0.015 & $<0.05$ & $\mathrm{mg} / \mathrm{L}$ & 0.025 & 0.05 & $<1.0$ \\
\hline Iron & $<0.50$ & $<0.50$ & $<0.50$ & $<0.50$ & $\mathrm{mg} / \mathrm{L}$ & 0.50 & 0.50 & $<4.0$ \\
\hline Lead & 0.153 & 0.135 & $<0.02$ & $<0.02$ & $\mathrm{mg} / \mathrm{L}$ & 0.003 & 0.02 & 0.80 \\
\hline Lithium & 1.40 & 1.40 & 0.8130 & 0.9250 & $\mathrm{mg} / \mathrm{L}$ & 0.01 & 0.05 & 2.76 \\
\hline Magnesium & 2,110 & 2,140 & 2,120 & 2,140 & $\mathrm{mg} / \mathrm{L}$ & 5.0 & 1.0 & 2,625 \\
\hline Mercury & 0.0016 & $<0.0002$ & $<0.0002$ & $<0.0002$ & $\mathrm{mg} / \mathrm{L}$ & 0.0002 & 0.0002 & $<0.002$ \\
\hline
\end{tabular}


Table 6.4, cont.

\begin{tabular}{|c|c|c|c|c|c|c|c|c|}
\hline \multirow[b]{3}{*}{ Parameter } & \multicolumn{7}{|c|}{ Concentration } & \multirow[b]{3}{*}{$\begin{array}{c}\mathbf{9 5}^{\text {th }} \\
\text { UTLV }\end{array}$} \\
\hline & \multicolumn{2}{|c|}{ Round 10} & \multicolumn{2}{|c|}{ Round 11} & \multirow[b]{2}{*}{ Units } & \multicolumn{2}{|c|}{ Reporting Limit } & \\
\hline & Sample & Dup. & Sample & Dup. & & $\begin{array}{c}\text { Round } \\
10\end{array}$ & $\begin{array}{c}\text { Round } \\
11\end{array}$ & \\
\hline Nickel & $<0.20$ & $<0.20$ & 0.054 & 0.0150 & $\mathrm{mg} / \mathrm{L}$ & 0.20 & 0.025 & $<5.00$ \\
\hline Potassium & 2,700 & 2,700 & 2,880 & 3,030 & $\mathrm{mg} / \mathrm{L}$ & 5.00 & 1.00 & 3,438 \\
\hline Selenium & 0.0023 & $<0.130$ & 0.018 & 0.012 & $\mathrm{mg} / \mathrm{L}$ & 0.130 & 0.010 & $<2.00$ \\
\hline Silica & 2.10 & 2.040 & 2.80 & 2.26 & $\mathrm{mg} / \mathrm{L}$ & 0.40 & NR & 7.20 \\
\hline Silver & $<0.130$ & $<0.130$ & $<0.010$ & $<0.010$ & $\mathrm{mg} / \mathrm{L}$ & 0.13 & 0.01 & 0.31 \\
\hline Sodium & 75,200 & 75,200 & 77,900 & 77,800 & $\mathrm{mg} / \mathrm{L}$ & 5.0 & 5.0 & 140,400 \\
\hline Thallium & 2,110 & 2,140 & 2,120 & 2,140 & $\mathrm{mg} / \mathrm{L}$ & 5.0 & 1.0 & 2,625 \\
\hline Tin & 0.0016 & $<0.0002$ & $<0.0002$ & $<0.0002$ & $\mathrm{mg} / \mathrm{L}$ & 0.0002 & 0.0002 & $<0.002$ \\
\hline Vanadium & $<0.20$ & $<0.20$ & 0.054 & 0.0150 & $\mathrm{mg} / \mathrm{L}$ & 0.20 & 0.025 & $<5.00$ \\
\hline Zinc & 2,700 & 2,700 & 2,880 & 3,030 & $\mathrm{mg} / \mathrm{L}$ & 5.00 & 1.00 & 3,438 \\
\hline
\end{tabular}

${ }^{\mathrm{b}}$ Reporting Limit

${ }^{\mathrm{c}}$ Not reported by the laboratory

${ }^{\mathrm{d}}$ Not Applicable

${ }^{\mathrm{e}}$ Standard Unit 
Table 6.5 Analytical results for groundwater sampled from well WQSP-4.

\begin{tabular}{|c|c|c|c|c|c|c|c|c|}
\hline \multirow[b]{3}{*}{ Parameter } & \multicolumn{7}{|c|}{ Concentration } & \multirow[b]{3}{*}{$\begin{array}{c}95^{\text {th }} \\
\text { UTLV }^{\mathrm{a}}\end{array}$} \\
\hline & \multicolumn{2}{|c|}{ Round 10} & \multicolumn{2}{|c|}{ Round 11} & \multirow[b]{2}{*}{ Units } & \multicolumn{2}{|c|}{ Reporting Limit } & \\
\hline & Sample & Dup. & Sample & Dup. & & $\begin{array}{c}\text { Round } \\
10\end{array}$ & $\begin{array}{c}\text { Round } \\
11\end{array}$ & \\
\hline 1,1,1-Trichloroethane & $<2$ & $<2$ & $<1$ & $<1$ & $\mu \mathrm{g} / \mathrm{L}$ & 2 & 1 & $<\mathrm{RL}^{\mathrm{b}}$ \\
\hline 1,1,2,2-Tetrachloroethane & $<2$ & $<2$ & $<1$ & $<1$ & $\mu \mathrm{g} / \mathrm{L}$ & 2 & 1 & $<\mathrm{RL}$ \\
\hline 1,1,2-Trichloroethane & $<2$ & $<2$ & $<1$ & $<1$ & $\mu \mathrm{g} / \mathrm{L}$ & 2 & 1 & $<\mathrm{RL}$ \\
\hline 1,1-Dichloroethane & $<2$ & $<2$ & $<1$ & $<1$ & $\mu \mathrm{g} / \mathrm{L}$ & 2 & 1 & $<\mathrm{RL}$ \\
\hline 1,1-Dichloroethylene & $<2$ & $<2$ & $<1$ & $<1$ & $\mu \mathrm{g} / \mathrm{L}$ & 2 & 1 & $<\mathrm{RL}$ \\
\hline 1,2-Dichloroethane & $<2$ & $<2$ & $<1$ & $<1$ & $\mu \mathrm{g} / \mathrm{L}$ & 2 & 1 & $<\mathrm{RL}$ \\
\hline Carbon tetrachloride & $<2$ & $<2$ & $<1$ & $<1$ & $\mu \mathrm{g} / \mathrm{L}$ & 2 & 1 & $<\mathrm{RL}$ \\
\hline Chlorobenzene & $<2$ & $<2$ & $<1$ & $<1$ & $\mu \mathrm{g} / \mathrm{L}$ & 2 & 1 & $<\mathrm{RL}$ \\
\hline Chloroform & $<2$ & $<2$ & $<1$ & $<1$ & $\mu \mathrm{g} / \mathrm{L}$ & 2 & 1 & $<\mathrm{RL}$ \\
\hline cis-1,2-Dichloroethylene & $<2$ & $<2$ & $<1$ & $<1$ & $\mu \mathrm{g} / \mathrm{L}$ & 2 & 1 & $<\mathrm{RL}$ \\
\hline Methyl ethyl ketone & $<2$ & $<2$ & $<5$ & $<5$ & $\mu \mathrm{g} / \mathrm{L}$ & 2 & 5 & $<\mathrm{RL}$ \\
\hline Methylene chloride & $<5$ & $<5$ & $<5$ & $<5$ & $\mu \mathrm{g} / \mathrm{L}$ & 5 & 5 & $<\mathrm{RL}$ \\
\hline Tetrachloroethylene & $<2$ & $<2$ & $<1$ & $<1$ & $\mu \mathrm{g} / \mathrm{L}$ & 2 & 1 & $<\mathrm{RL}$ \\
\hline Toluene & $<2$ & $<2$ & $<1$ & $<1$ & $\mu \mathrm{g} / \mathrm{L}$ & 2 & 1 & $<\mathrm{RL}$ \\
\hline Trichloroethylene & $<2$ & $<2$ & $<1$ & $<1$ & $\mu \mathrm{g} / \mathrm{L}$ & 2 & 1 & $<\mathrm{RL}$ \\
\hline Trichlorofluoromethane & $<2$ & $<2$ & $<1$ & $<1$ & $\mu \mathrm{g} / \mathrm{L}$ & 2 & 1 & $<\mathrm{RL}$ \\
\hline Vinyl chloride & $<2$ & $<2$ & $<1$ & $<1$ & $\mu \mathrm{g} / \mathrm{L}$ & 2 & 1 & $<\mathrm{RL}$ \\
\hline Xylene & $<2$ & $<2$ & $<1$ & $<1$ & $\mu \mathrm{g} / \mathrm{L}$ & 2 & 1 & $<\mathrm{RL}$ \\
\hline 1,2-Dichlorobenzene & $<5$ & $<5$ & $<5$ & $<5$ & $\mu \mathrm{g} / \mathrm{L}$ & 5 & 5 & $<\mathrm{RL}$ \\
\hline 1,4-Dichlorobenzene & $<5$ & $<5$ & $<5$ & $<5$ & $\mu \mathrm{g} / \mathrm{L}$ & 5 & 5 & $<\mathrm{RL}$ \\
\hline 2,4-Dinitrophenol & $<5$ & $<5$ & $<5$ & $<5$ & $\mu \mathrm{g} / \mathrm{L}$ & 5 & 5 & $<\mathrm{RL}$ \\
\hline 2,4-Dinitrotoluene & $<5$ & $<5$ & $<5$ & $<5$ & $\mu \mathrm{g} / \mathrm{L}$ & 5 & 5 & $<\mathrm{RL}$ \\
\hline 2-Methylphenol & $<5$ & $<5$ & $<5$ & $<5$ & $\mu \mathrm{g} / \mathrm{L}$ & 5 & 5 & $<\mathrm{RL}$ \\
\hline $\begin{array}{l}\text { 3-Methylphenol/ } \\
\text { 4-Methylphenol }\end{array}$ & $<5$ & $<5$ & $<5$ & $<5$ & $\mu \mathrm{g} / \mathrm{L}$ & 5 & 5 & $<\mathrm{RL}$ \\
\hline Hexachlorobenzene & $<5$ & $<5$ & $<5$ & $<5$ & $\mu \mathrm{g} / \mathrm{L}$ & 5 & 5 & $<\mathrm{RL}$ \\
\hline Hexachloroethane & $<5$ & $<5$ & $<5$ & $<5$ & $\mu \mathrm{g} / \mathrm{L}$ & 5 & 5 & $<\mathrm{RL}$ \\
\hline Nitrobenzene & $<5$ & $<5$ & $<5$ & $<5$ & $\mu \mathrm{g} / \mathrm{L}$ & 5 & 5 & $<\mathrm{RL}$ \\
\hline Pentachlorophenol & $<5$ & $<5$ & $<5$ & $<5$ & $\mu \mathrm{g} / \mathrm{L}$ & 5 & 5 & $<\mathrm{RL}$ \\
\hline Pyridine & $<5$ & $<5$ & $<5$ & $<5$ & $\mu \mathrm{g} / \mathrm{L}$ & 5 & 5 & $<\mathrm{RL}$ \\
\hline
\end{tabular}


Table 6.5, cont.

\begin{tabular}{|c|c|c|c|c|c|c|c|c|}
\hline \multirow[b]{3}{*}{ Parameter } & \multicolumn{7}{|c|}{ Concentration } & \multirow[b]{3}{*}{$\begin{array}{c}\mathbf{9 5}^{\text {th }} \\
\text { UTLV }\end{array}$} \\
\hline & \multicolumn{2}{|c|}{ Round 10} & \multicolumn{2}{|c|}{ Round 11} & \multirow[b]{2}{*}{ Units } & \multicolumn{2}{|c|}{ Reporting Limit } & \\
\hline & Sample & Dup. & Sample & Dup. & & $\begin{array}{c}\text { Round } \\
10\end{array}$ & $\begin{array}{c}\text { Round } \\
11\end{array}$ & \\
\hline Isobutanol & $<2$ & $<2$ & $<2$ & $<2$ & $\mu \mathrm{g} / \mathrm{L}$ & 2 & 2 & $<\mathrm{RL}$ \\
\hline Alkalinity & 41 & 39 & 36 & 40 & $\mathrm{mg} / \mathrm{L}$ & 4.0 & 4.0 & 47.1 \\
\hline Bromide & 58 & 62 & 46 & 43 & $\mathrm{mg} / \mathrm{L}$ & 0.2 & 0.2 & $<200$ \\
\hline Chloride & 59,000 & 61,000 & 60,000 & 54,000 & $\mathrm{mg} / \mathrm{L}$ & 0.5 & 0.5 & 63,900 \\
\hline Density & 1.070 & 1.070 & 1.0705 & 1.0727 & $\mathrm{~g} / \mathrm{ml}$ & $\mathrm{N} / \mathrm{A}^{\mathrm{c}}$ & N/A & 1.100 \\
\hline Fluoride & 2.20 & 2.70 & 1.40 & 1.50 & $\mathrm{mg} / \mathrm{L}$ & 0.1 & 0.1 & 2.73 \\
\hline Iodide & $<2.0$ & $<2.0$ & $<2.0$ & $<2.0$ & $\mathrm{mg} / \mathrm{L}$ & 2.0 & 2.0 & $<2.0$ \\
\hline Nitrate (as N) & $<10$ & $<10$ & $<0.10$ & $<0.10$ & $\mathrm{mg} / \mathrm{L}$ & 0.20 & 0.10 & $<10$ \\
\hline Orthophosphate (as P) & $<0.04$ & $<0.04$ & $<0.04$ & $<0.04$ & $\mathrm{mg} / \mathrm{L}$ & 0.04 & 0.04 & 0.54 \\
\hline $\mathrm{pH}$ & 7.10 & 7.10 & 7.20 & 7.20 & $\mathrm{SU}^{\mathrm{d}}$ & N/A & N/A & $\begin{array}{c}6.80- \\
7.61\end{array}$ \\
\hline Specific conductance & 127,000 & 126,000 & 120,000 & 120,000 & $\mu \mathrm{mhos} / \mathrm{cm}$ & N/A & N/A & 319,800 \\
\hline Sulfate & 6,700 & 7,300 & 6,700 & 6,300 & $\mathrm{mg} / \mathrm{L}$ & 0.5 & 0.5 & 8,300 \\
\hline Total dissolved solids & 110,000 & 100,000 & 110,000 & 110,000 & $\mathrm{mg} / \mathrm{L}$ & 10 & 10 & 125,000 \\
\hline Total organic carbon & $<0.7$ & $<0.7$ & $<1.0$ & $<1.0$ & $\mathrm{mg} / \mathrm{L}$ & 0.7 & 1.0 & $<5.0$ \\
\hline Total organic halogen & 1.90 & 2.30 & 8.80 & 8.90 & $\mathrm{mg} / \mathrm{L}$ & $\mathrm{NR}^{\mathrm{e}}$ & NR & 84.1 \\
\hline Total phenols & $<0.07$ & $<0.07$ & $<0.07$ & $<0.07$ & $\mathrm{mg} / \mathrm{L}$ & 0.07 & 0.07 & 0.27 \\
\hline Total suspended solids & $<1.0$ & $<1.0$ & $<1.0$ & $<1.0$ & $\mathrm{mg} / \mathrm{L}$ & 1.0 & 1.0 & 59.0 \\
\hline Antimony & $<0.050$ & $<0.050$ & $<0.013$ & $<0.013$ & $\mathrm{mg} / \mathrm{L}$ & 0.05 & 0.013 & 0.80 \\
\hline Arsenic & $<0.05$ & $<0.05$ & $<0.05$ & $<0.05$ & $\mathrm{mg} / \mathrm{L}$ & 0.050 & 0.050 & $<0.50$ \\
\hline Barium & 0.0397 & 0.0234 & $<0.020$ & 0.020 & $\mathrm{mg} / \mathrm{L}$ & 0.10 & 0.020 & $<1.0$ \\
\hline Beryllium & 0.0012 & $<0.050$ & $<0.010$ & $<0.010$ & $\mathrm{mg} / \mathrm{L}$ & 0.050 & 0.010 & 0.250 \\
\hline Boron & 33.2 & 33.3 & 30.0 & 31.9 & $\mathrm{mg} / \mathrm{L}$ & 0.050 & 0.5 & 36.8 \\
\hline Cadmium & 0.0029 & 0.0092 & $<0.01$ & $<0.01$ & $\mathrm{mg} / \mathrm{L}$ & 0.050 & 0.01 & $<0.50$ \\
\hline Calcium & 1,610 & 1,670 & 1,560 & 1,550 & $\mathrm{mg} / \mathrm{L}$ & 0.05 .0 & 5.0 & 1,834 \\
\hline Chromium & $<0.10$ & $<0.10$ & 0.135 & 0.294 & $\mathrm{mg} / \mathrm{L}$ & 0.050 & 0.025 & $<2.0$ \\
\hline Cobalt & 0.030 & 0.0166 & $<0.013$ & $<0.013$ & $\mathrm{mg} / \mathrm{L}$ & 0.050 & 0.013 & $<.50$ \\
\hline Copper & 0.0247 & $<0.050$ & $<0.050$ & $<0.050$ & $\mathrm{mg} / \mathrm{L}$ & 0.050 & 0.050 & $<0.50$ \\
\hline Iron & 0.148 & 0.161 & 0.528 & 1.110 & $\mathrm{mg} / \mathrm{L}$ & 0.30 & 0.50 & $<4.0$ \\
\hline Lead & $<0.10$ & 0.0277 & $<0.02$ & $<0.02$ & $\mathrm{mg} / \mathrm{L}$ & 0.050 & 0.020 & 0.525 \\
\hline Lithium & 0.569 & 0.619 & 0.477 & 0.446 & $\mathrm{mg} / \mathrm{L}$ & 0.050 & 0.010 & 1.380 \\
\hline Magnesium & 1,180 & 1,210 & 1,190 & 1,180 & $\mathrm{mg} / \mathrm{L}$ & 0.05 & 5.00 & 1,472 \\
\hline
\end{tabular}


Table 6.5, cont.

\begin{tabular}{|c|c|c|c|c|c|c|c|c|}
\hline \multirow[b]{3}{*}{ Parameter } & \multicolumn{7}{|c|}{ Concentration } & \multirow[b]{3}{*}{$\begin{array}{c}9^{\text {th }} \\
\text { UTLV }\end{array}$} \\
\hline & \multicolumn{2}{|c|}{ Round 10} & \multicolumn{2}{|c|}{ Round 11} & \multirow[b]{2}{*}{ Units } & \multicolumn{2}{|c|}{ Reporting Limit } & \\
\hline & Sample & Dup. & Sample & Dup. & & $\begin{array}{c}\text { Round } \\
10\end{array}$ & $\begin{array}{c}\text { Round } \\
11\end{array}$ & \\
\hline Mercury & $<0.0002$ & $<0.0002$ & $<0.0002$ & $<0.0002$ & $\mathrm{mg} / \mathrm{L}$ & 0.0002 & 0.0002 & $<0.002$ \\
\hline Nickel & 0.0906 & 0.0910 & 0.1020 & 0.1930 & $\mathrm{mg} / \mathrm{L}$ & 0.10 & 0.025 & $<5.00$ \\
\hline Potassium & 1,350 & 1,350 & 1,320 & 1,320 & $\mathrm{mg} / \mathrm{L}$ & 1.00 & 5.00 & 1,648 \\
\hline Selenium & $<0.050$ & $<0.050$ & $<0.013$ & $<0.013$ & $\mathrm{mg} / \mathrm{L}$ & 0.050 & 0.013 & 2.009 \\
\hline Silica & 4.340 & 3.180 & 1.970 & 1.880 & $\mathrm{mg} / \mathrm{L}$ & 0.10 & 0.50 & 11.40 \\
\hline Silver & $<0.050$ & 0.0024 & $<0.013$ & $<0.013$ & $\mathrm{mg} / \mathrm{L}$ & 0.050 & 0.013 & 0.519 \\
\hline Sodium & 34,000 & 35,200 & 30,700 & 26,100 & $\mathrm{mg} / \mathrm{L}$ & 0.050 & 5.0 & 38,790 \\
\hline Thallium & $<0.050$ & $<0.050$ & $<0.013$ & $<0.013$ & $\mathrm{mg} / \mathrm{L}$ & 0.050 & 0.013 & 1.00 \\
\hline Tin & $<0.10$ & $<0.10$ & $<0.025$ & $<0.025$ & $\mathrm{mg} / \mathrm{L}$ & 0.050 & 0.025 & 5.00 \\
\hline Vanadium & $<0.100$ & $<0.100$ & $<0.025$ & $<0.025$ & $\mathrm{mg} / \mathrm{L}$ & 0.050 & 0.025 & $<5.00$ \\
\hline Zinc & $<0.0236$ & $<0.200$ & $<0.05$ & $<0.05$ & $\mathrm{mg} / \mathrm{L}$ & 0.200 & 0.050 & $<5.00$ \\
\hline $\begin{array}{l}{ }^{\mathrm{A}} 95^{\text {th }} \text { Upper Toleranc } \\
{ }^{\mathrm{b}} \text { Reporting Limit } \\
{ }^{\mathrm{c}} \text { Not Applicable } \\
{ }^{\mathrm{d}} \text { Standard Unit } \\
{ }^{\text {e }} \text { Not reported by the }\end{array}$ & it Value, ec & uivalent to & $95 \%$ Confic & dence Limi & & & & \\
\hline
\end{tabular}


Table 6.6 Analytical results for groundwater sampled from well WQSP-5.

\begin{tabular}{|c|c|c|c|c|c|c|c|c|}
\hline \multirow[b]{3}{*}{ Parameter } & \multicolumn{7}{|c|}{ Concentration } & \multirow[b]{3}{*}{$\begin{array}{c}{95^{\text {th }}} \\
\text { UTLV }^{\mathrm{a}} \\
\end{array}$} \\
\hline & \multicolumn{2}{|c|}{ Round 10} & \multicolumn{2}{|c|}{ Round 11} & \multirow[b]{2}{*}{ Units } & \multicolumn{2}{|c|}{ Reporting Limit } & \\
\hline & Sample & Dup. & Sample & Dup. & & $\begin{array}{c}\text { Round } \\
10\end{array}$ & $\begin{array}{c}\text { Round } \\
11\end{array}$ & \\
\hline 1,1,1-Trichloroethane & $<2$ & $<2$ & $<1$ & $<1$ & $\mu \mathrm{g} / \mathrm{L}$ & 2 & 1 & $<\mathrm{RL}^{\mathrm{b}}$ \\
\hline 1,1,2,2-Tetrachloroethane & $<2$ & $<2$ & $<1$ & $<1$ & $\mu \mathrm{g} / \mathrm{L}$ & 2 & 1 & $<\mathrm{RL}$ \\
\hline 1,1,2-Trichloroethane & $<2$ & $<2$ & $<1$ & $<1$ & $\mu \mathrm{g} / \mathrm{L}$ & 2 & 1 & $<\mathrm{RL}$ \\
\hline 1,1-Dichloroethane & $<2$ & $<2$ & $<1$ & $<1$ & $\mu \mathrm{g} / \mathrm{L}$ & 2 & 1 & $<\mathrm{RL}$ \\
\hline 1,1-Dichloroethylene & $<2$ & $<2$ & $<1$ & $<1$ & $\mu \mathrm{g} / \mathrm{L}$ & 2 & 1 & $<\mathrm{RL}$ \\
\hline 1,2-Dichloroethane & $<2$ & $<2$ & $<1$ & $<1$ & $\mu \mathrm{g} / \mathrm{L}$ & 2 & 1 & $<\mathrm{RL}$ \\
\hline Carbon tetrachloride & $<2$ & $<2$ & $<1$ & $<1$ & $\mu \mathrm{g} / \mathrm{L}$ & 2 & 1 & $<\mathrm{RL}$ \\
\hline Chlorobenzene & $<2$ & $<2$ & $<1$ & $<1$ & $\mu \mathrm{g} / \mathrm{L}$ & 2 & 1 & $<\mathrm{RL}$ \\
\hline Chloroform & $<2$ & $<2$ & $<1$ & $<1$ & $\mu \mathrm{g} / \mathrm{L}$ & 2 & 1 & $<\mathrm{RL}$ \\
\hline cis-1,2-Dichloroethylene & $<2$ & $<2$ & $<1$ & $<1$ & $\mu \mathrm{g} / \mathrm{L}$ & 2 & 1 & $<\mathrm{RL}$ \\
\hline Methyl ethyl ketone & $<2$ & $<2$ & $<5$ & $<5$ & $\mu \mathrm{g} / \mathrm{L}$ & 2 & 5 & $<\mathrm{RL}$ \\
\hline Methylene chloride & $<5$ & $<5$ & $<5$ & $<5$ & $\mu \mathrm{g} / \mathrm{L}$ & 5 & 5 & $<\mathrm{RL}$ \\
\hline Tetrachloroethylene & $<2$ & $<2$ & $<1$ & $<1$ & $\mu \mathrm{g} / \mathrm{L}$ & 2 & 1 & $<\mathrm{RL}$ \\
\hline Toluene & $<2$ & $<2$ & $<1$ & $<1$ & $\mu \mathrm{g} / \mathrm{L}$ & 2 & 1 & $<\mathrm{RL}$ \\
\hline Trichloroethylene & $<2$ & $<2$ & $<1$ & $<1$ & $\mu \mathrm{g} / \mathrm{L}$ & 2 & 1 & $<\mathrm{RL}$ \\
\hline Trichlorofluoromethane & $<2$ & $<2$ & $<1$ & $<1$ & $\mu \mathrm{g} / \mathrm{L}$ & 2 & 1 & $<\mathrm{RL}$ \\
\hline Vinyl chloride & $<2$ & $<2$ & $<1$ & $<1$ & $\mu g / L$ & 2 & 1 & $<\mathrm{RL}$ \\
\hline Xylene & $<2$ & $<2$ & $<1$ & $<1$ & $\mu \mathrm{g} / \mathrm{L}$ & 2 & 1 & $<\mathrm{RL}$ \\
\hline 1,2-Dichlorobenzene & $<5$ & $<5$ & $<5$ & $<5$ & $\mu \mathrm{g} / \mathrm{L}$ & 5 & 5 & $<\mathrm{RL}$ \\
\hline 1,4-Dichlorobenzene & $<5$ & $<5$ & $<5$ & $<5$ & $\mu g / L$ & 5 & 5 & $<\mathrm{RL}$ \\
\hline 2,4-Dinitrophenol & $<5$ & $<5$ & $<5$ & $<5$ & $\mu \mathrm{g} / \mathrm{L}$ & 5 & 5 & $<\mathrm{RL}$ \\
\hline 2,4-Dinitrotoluene & $<5$ & $<5$ & $<5$ & $<5$ & $\mu \mathrm{g} / \mathrm{L}$ & 5 & 5 & $<\mathrm{RL}$ \\
\hline 2-Methylphenol & $<5$ & $<5$ & $<5$ & $<5$ & $\mu \mathrm{g} / \mathrm{L}$ & 5 & 5 & $<\mathrm{RL}$ \\
\hline $\begin{array}{l}\text { 3-Methylphenol/ } \\
\text { 4-Methylphenol }\end{array}$ & $<5$ & $<5$ & $<5$ & $<5$ & $\mu \mathrm{g} / \mathrm{L}$ & 5 & 5 & $<\mathrm{RL}$ \\
\hline Hexachlorobenzene & $<5$ & $<5$ & $<5$ & $<5$ & $\mu \mathrm{g} / \mathrm{L}$ & 5 & 5 & $<\mathrm{RL}$ \\
\hline Hexachloroethane & $<5$ & $<5$ & $<5$ & $<5$ & $\mu \mathrm{g} / \mathrm{L}$ & 5 & 5 & $<\mathrm{RL}$ \\
\hline Nitrobenzene & $<5$ & $<5$ & $<5$ & $<5$ & $\mu \mathrm{g} / \mathrm{L}$ & 5 & 5 & $<\mathrm{RL}$ \\
\hline Pentachlorophenol & $<5$ & $<5$ & $<5$ & $<5$ & $\mu \mathrm{g} / \mathrm{L}$ & 5 & 5 & $<\mathrm{RL}$ \\
\hline Pyridine & $<5$ & $<5$ & $<5$ & $<5$ & $\mu \mathrm{g} / \mathrm{L}$ & 5 & 5 & $<\mathrm{RL}$ \\
\hline
\end{tabular}


Table 6.6, cont.

\begin{tabular}{|c|c|c|c|c|c|c|c|c|}
\hline \multirow[b]{3}{*}{ Parameter } & \multicolumn{7}{|c|}{ Concentration } & \multirow[b]{3}{*}{$\begin{array}{c}95^{\text {th }} \\
\text { UTLV }\end{array}$} \\
\hline & \multicolumn{2}{|c|}{ Round 10} & \multicolumn{2}{|c|}{ Round 11} & \multirow[b]{2}{*}{ Units } & \multicolumn{2}{|c|}{ Reporting Limit } & \\
\hline & Sample & Dup. & Sample & Dup. & & $\begin{array}{c}\text { Round } \\
10\end{array}$ & $\begin{array}{c}\text { Round } \\
11\end{array}$ & \\
\hline Isobutanol & $<2$ & $<2$ & $<2$ & $<2$ & $\mu \mathrm{g} / \mathrm{L}$ & 2 & 2 & $<\mathrm{RL}$ \\
\hline Alkalinity & 48 & 46 & 46 & 48 & $\mathrm{mg} / \mathrm{L}$ & $\mathrm{NR}^{\mathrm{c}}$ & 4.0 & 56 \\
\hline Bromide & 28 & 26 & 19 & 23 & $\mathrm{mg} / \mathrm{L}$ & 0.2 & 0.2 & 59.4 \\
\hline Chloride & 16,000 & 16,000 & 16,000 & 16,000 & $\mathrm{mg} / \mathrm{L}$ & 0.5 & 0.5 & 18,100 \\
\hline Density & 1.030 & 1.030 & 1.0243 & 1.0222 & $\mathrm{~g} / \mathrm{ml}$ & $\mathrm{N} / \mathrm{A}^{\mathrm{d}}$ & N/A & 1.040 \\
\hline Fluoride & 2.80 & 2.80 & 2.70 & 2.60 & $\mathrm{mg} / \mathrm{L}$ & 0.1 & 0.1 & 3.08 \\
\hline Iodide & $<2.0$ & $<2.0$ & $<2.0$ & $<2.0$ & $\mathrm{mg} / \mathrm{L}$ & 2.0 & 2.0 & $<2.0$ \\
\hline Nitrate (as N) & $<10$ & $<10$ & $<0.10$ & $<0.10$ & $\mathrm{mg} / \mathrm{L}$ & 0.20 & 0.10 & $<10$ \\
\hline Orthophosphate (as P) & $<0.04$ & $<0.04$ & $<0.013$ & $<0.013$ & $\mathrm{mg} / \mathrm{L}$ & 0.04 & 0.013 & $<5.0$ \\
\hline $\mathrm{pH}$ & 7.50 & 7.50 & 7.60 & 7.60 & $\mathrm{SU}^{\mathrm{e}}$ & N/A & N/A & $7.40-7.90$ \\
\hline Specific conductance & 45,000 & 45,000 & 44,000 & 43,000 & $\mu \mathrm{mhos} / \mathrm{cm}$ & N/A & N/A & 67,700 \\
\hline Sulfate & 5,400 & 5,200 & 5,200 & 4,800 & $\mathrm{mg} / \mathrm{L}$ & 0.5 & 0.5 & 6,129 \\
\hline Total dissolved solids & 32,000 & 34,000 & 40,000 & 36,000 & $\mathrm{mg} / \mathrm{L}$ & 10 & 10 & 44,100 \\
\hline Total organic carbon & $<0.7$ & $<0.7$ & $<1.0$ & $<1.0$ & $\mathrm{mg} / \mathrm{L}$ & 0.7 & 1.0 & $<5.0$ \\
\hline Total organic halogen & 1.20 & 1.20 & 2.90 & 2.00 & $\mathrm{mg} / \mathrm{L}$ & NR & NR & 8.37 \\
\hline Total phenols & $<0.07$ & $<0.07$ & $<0.07$ & $<0.07$ & $\mathrm{mg} / \mathrm{L}$ & 0.07 & 0.07 & $<0.10$ \\
\hline Total suspended solids & $<1.0$ & $<1.0$ & $<1.0$ & $<1.0$ & $\mathrm{mg} / \mathrm{L}$ & 1.0 & 1.0 & $<10.0$ \\
\hline Antimony & 0.008 & $<0.050$ & $<0.013$ & $<0.013$ & $\mathrm{mg} / \mathrm{L}$ & 0.05 & 0.013 & 0.073 \\
\hline Arsenic & $<0.05$ & 0.087 & $<0.05$ & $<0.05$ & $\mathrm{mg} / \mathrm{L}$ & 0.050 & 0.050 & $<0.50$ \\
\hline Barium & 0.022 & 0.0198 & $<0.020$ & 0.020 & $\mathrm{mg} / \mathrm{L}$ & 0.20 & 0.020 & $<1.0$ \\
\hline Beryllium & 0.0009 & 0.0013 & 0.024 & 0.005 & $\mathrm{mg} / \mathrm{L}$ & 0.005 & 0.010 & 0.020 \\
\hline Boron & 25.8 & 27.6 & 24.4 & 24.0 & $\mathrm{mg} / \mathrm{L}$ & 0.020 & 0.5 & 33.0 \\
\hline Cadmium & $<0.010$ & 0.0001 & $<0.01$ & $<0.01$ & $\mathrm{mg} / \mathrm{L}$ & 0.010 & 0.010 & $<0.050$ \\
\hline Calcium & 1,170 & 1,070 & 1,020 & 1,010 & $\mathrm{mg} / \mathrm{L}$ & 5.0 & 5.0 & 1,303 \\
\hline Chromium & 0.008 & 0.0026 & 0.022 & 0.021 & $\mathrm{mg} / \mathrm{L}$ & 0.050 & 0.025 & $<0.50$ \\
\hline Cobalt & 0.0107 & 0.0140 & 0.040 & 0.030 & $\mathrm{mg} / \mathrm{L}$ & 0.050 & 0.013 & $<0.50$ \\
\hline Copper & 0.009 & 0.0096 & 0.065 & 0.053 & $\mathrm{mg} / \mathrm{L}$ & 0.025 & 0.050 & $<1.0$ \\
\hline Iron & 0.082 & 0.0317 & 0.125 & 0.164 & $\mathrm{mg} / \mathrm{L}$ & 0.10 & 0.50 & 0.795 \\
\hline Lead & 0.0076 & 0.0173 & 0.025 & 0.048 & $\mathrm{mg} / \mathrm{L}$ & 0.050 & 0.020 & $<0.50$ \\
\hline Lithium & 0.507 & 0.504 & 0.446 & 0.456 & $\mathrm{mg} / \mathrm{L}$ & 0.010 & 0.010 & 0.74 \\
\hline Magnesium & 500 & 450 & 454 & 462 & $\mathrm{mg} / \mathrm{L}$ & 5.00 & 5.00 & 547 \\
\hline Mercury & $<0.0002$ & $<0.0002$ & $<0.0002$ & $<0.0002$ & $\mathrm{mg} / \mathrm{L}$ & 0.0002 & 0.0002 & $<0.002$ \\
\hline
\end{tabular}


Table 6.6, cont.

\begin{tabular}{|c|c|c|c|c|c|c|c|c|}
\hline \multirow[b]{3}{*}{ Parameter } & \multicolumn{7}{|c|}{ Concentration } & \multirow[b]{3}{*}{$\begin{array}{c}9^{\text {th }} \\
\text { UTLV }\end{array}$} \\
\hline & \multicolumn{2}{|c|}{ Round 10} & \multicolumn{2}{|c|}{ Round 11} & \multirow[b]{2}{*}{ Units } & \multicolumn{2}{|c|}{ Reporting Limit } & \\
\hline & Sample & Dup. & Sample & Dup. & & $\begin{array}{c}\text { Round } \\
10\end{array}$ & $\begin{array}{c}\text { Round } \\
11\end{array}$ & \\
\hline Nickel & $<0.050$ & 0.0007 & $<0.025$ & $<0.025$ & $\mathrm{mg} / \mathrm{L}$ & 0.050 & 0.025 & $<0.10$ \\
\hline Potassium & 450 & 400 & 395 & 410 & $\mathrm{mg} / \mathrm{L}$ & 5.00 & 5.00 & 622 \\
\hline Selenium & $<0.050$ & $<0.050$ & $<0.013$ & $<0.013$ & $\mathrm{mg} / \mathrm{L}$ & 0.050 & 0.013 & $<0.10$ \\
\hline Silica & 3.87 & 3.96 & 2.60 & 2.64 & $\mathrm{mg} / \mathrm{L}$ & 0.50 & 0.50 & 16.3 \\
\hline Silver & $<0.050$ & $<0.050$ & $<0.013$ & $<0.013$ & $\mathrm{mg} / \mathrm{L}$ & 0.050 & 0.013 & $<0.50$ \\
\hline Sodium & 8,470 & 7,880 & 9,040 & 8,750 & $\mathrm{mg} / \mathrm{L}$ & 0.010 & 5.0 & 11,190 \\
\hline Thallium & $<0.050$ & $<0.050$ & $<0.013$ & $<0.013$ & $\mathrm{mg} / \mathrm{L}$ & 0.050 & 0.013 & 0.209 \\
\hline Tin & $<0.10$ & $<0.10$ & $<0.025$ & $<0.025$ & $\mathrm{mg} / \mathrm{L}$ & 0.10 & 0.025 & $<0.10$ \\
\hline Vanadium & $<0.10$ & $<0.10$ & 0.056 & 0.055 & $\mathrm{mg} / \mathrm{L}$ & 0.10 & 0.025 & 2.70 \\
\hline Zinc & 0.8370 & $<0.200$ & $<0.05$ & $<0.05$ & $\mathrm{mg} / \mathrm{L}$ & 0.200 & 0.050 & $<5.00$ \\
\hline
\end{tabular}

${ }^{\mathrm{a}} 95^{\text {th }}$ Upper Tolerance Limit Value, equivalent to $95 \%$ Confidence Limit

${ }^{\mathrm{b}}$ Reporting Limit

${ }^{\mathrm{c}}$ Not reported by the laboratory

${ }^{\mathrm{d}}$ Not Applicable

${ }^{\mathrm{e}}$ Standard Unit 
Table 6.7 Analytical results for groundwater sampled from well WQSP-6.

\begin{tabular}{|c|c|c|c|c|c|c|c|c|}
\hline \multirow[b]{3}{*}{ Parameter } & \multicolumn{7}{|c|}{ Concentration } & \multirow[b]{3}{*}{$\begin{array}{c}95^{\text {th }} \\
\text { UTLV }^{\text {a }} \\
\end{array}$} \\
\hline & \multicolumn{2}{|c|}{ Round 10} & \multicolumn{2}{|c|}{ Round 11} & \multirow[b]{2}{*}{ Units } & \multicolumn{2}{|c|}{ Reporting Limit } & \\
\hline & Sample & Dup. & Sample & Dup. & & $\begin{array}{c}\text { Round } \\
10\end{array}$ & $\begin{array}{c}\text { Round } \\
11 \\
\end{array}$ & \\
\hline 1,1,1-Trichloroethane & $<2$ & $<2$ & $<1$ & $<1$ & $\mu \mathrm{g} / \mathrm{L}$ & 2 & 1 & $<\mathrm{RL}^{\mathrm{b}}$ \\
\hline $\begin{array}{l}1,1,2,2- \\
\text { Tetrachloroethane }\end{array}$ & $<2$ & $<2$ & $<1$ & $<1$ & $\mu \mathrm{g} / \mathrm{L}$ & 2 & 1 & $<\mathrm{RL}$ \\
\hline 1,1,2-Trichloroethane & $<2$ & $<2$ & $<1$ & $<1$ & $\mu \mathrm{g} / \mathrm{L}$ & 2 & 1 & $<\mathrm{RL}$ \\
\hline 1,1-Dichloroethane & $<2$ & $<2$ & $<1$ & $<1$ & $\mu \mathrm{g} / \mathrm{L}$ & 2 & 1 & $<\mathrm{RL}$ \\
\hline 1,1-Dichloroethylene & $<2$ & $<2$ & $<1$ & $<1$ & $\mu \mathrm{g} / \mathrm{L}$ & 2 & 1 & $<\mathrm{RL}$ \\
\hline 1,2-Dichloroethane & $<2$ & $<2$ & $<1$ & $<1$ & $\mu \mathrm{g} / \mathrm{L}$ & 2 & 1 & $<\mathrm{RL}$ \\
\hline Carbon tetrachloride & $<2$ & $<2$ & $<1$ & $<1$ & $\mu \mathrm{g} / \mathrm{L}$ & 2 & 1 & $<\mathrm{RL}$ \\
\hline Chlorobenzene & $<2$ & $<2$ & $<1$ & $<1$ & $\mu \mathrm{g} / \mathrm{L}$ & 2 & 1 & $<\mathrm{RL}$ \\
\hline Chloroform & $<2$ & $<2$ & $<1$ & $<1$ & $\mu \mathrm{g} / \mathrm{L}$ & 2 & 1 & $<\mathrm{RL}$ \\
\hline $\begin{array}{l}\text { cis-1,2- } \\
\text { Dichloroethylene }\end{array}$ & $<2$ & $<2$ & $<1$ & $<1$ & $\mu \mathrm{g} / \mathrm{L}$ & 2 & 1 & $<\mathrm{RL}$ \\
\hline Methyl ethyl ketone & $<2$ & $<2$ & $<5$ & $<5$ & $\mu \mathrm{g} / \mathrm{L}$ & 2 & 5 & $<\mathrm{RL}$ \\
\hline Methylene chloride & $<5$ & $<5$ & $<5$ & $<5$ & $\mu \mathrm{g} / \mathrm{L}$ & 5 & 5 & $<\mathrm{RL}$ \\
\hline Tetrachloroethylene & $<2$ & $<2$ & $<1$ & $<1$ & $\mu \mathrm{g} / \mathrm{L}$ & 2 & 1 & $<\mathrm{RL}$ \\
\hline Toluene & $<2$ & $<2$ & $<1$ & $<1$ & $\mu \mathrm{g} / \mathrm{L}$ & 2 & 1 & $<\mathrm{RL}$ \\
\hline Trichloroethylene & $<2$ & $<2$ & $<1$ & $<1$ & $\mu \mathrm{g} / \mathrm{L}$ & 2 & 1 & $<\mathrm{RL}$ \\
\hline Trichlorofluoromethane & $<2$ & $<2$ & $<1$ & $<1$ & $\mu \mathrm{g} / \mathrm{L}$ & 2 & 1 & $<\mathrm{RL}$ \\
\hline Vinyl chloride & $<2$ & $<2$ & $<1$ & $<1$ & $\mu \mathrm{g} / \mathrm{L}$ & 2 & 1 & $<\mathrm{RL}$ \\
\hline Xylene & $<2$ & $<2$ & $<1$ & $<1$ & $\mu \mathrm{g} / \mathrm{L}$ & 2 & 1 & $<\mathrm{RL}$ \\
\hline 1,2-Dichlorobenzene & $<5$ & $<5$ & $<5$ & $<5$ & $\mu \mathrm{g} / \mathrm{L}$ & 5 & 5 & $<\mathrm{RL}$ \\
\hline 1,4-Dichlorobenzene & $<5$ & $<5$ & $<5$ & $<5$ & $\mu \mathrm{g} / \mathrm{L}$ & 5 & 5 & $<\mathrm{RL}$ \\
\hline 2,4-Dinitrophenol & $<5$ & $<5$ & $<5$ & $<5$ & $\mu \mathrm{g} / \mathrm{L}$ & 5 & 5 & $<\mathrm{RL}$ \\
\hline 2,4-Dinitrotoluene & $<5$ & $<5$ & $<5$ & $<5$ & $\mu \mathrm{g} / \mathrm{L}$ & 5 & 5 & $<\mathrm{RL}$ \\
\hline 2-Methylphenol & $<5$ & $<5$ & $<5$ & $<5$ & $\mu \mathrm{g} / \mathrm{L}$ & 5 & 5 & $<\mathrm{RL}$ \\
\hline $\begin{array}{l}\text { 3-Methylphenol/ } \\
\text { 4-Methylphenol }\end{array}$ & $<5$ & $<5$ & $<5$ & $<5$ & $\mu \mathrm{g} / \mathrm{L}$ & 5 & 5 & $<\mathrm{RL}$ \\
\hline Hexachlorobenzene & $<5$ & $<5$ & $<5$ & $<5$ & $\mu \mathrm{g} / \mathrm{L}$ & 5 & 5 & $<\mathrm{RL}$ \\
\hline Hexachloroethane & $<5$ & $<5$ & $<5$ & $<5$ & $\mu \mathrm{g} / \mathrm{L}$ & 5 & 5 & $<\mathrm{RL}$ \\
\hline Nitrobenzene & $<5$ & $<5$ & $<5$ & $<5$ & $\mu \mathrm{g} / \mathrm{L}$ & 5 & 5 & $<\mathrm{RL}$ \\
\hline Pentachlorophenol & $<5$ & $<5$ & $<5$ & $<5$ & $\mu \mathrm{g} / \mathrm{L}$ & 5 & 5 & $<\mathrm{RL}$ \\
\hline Pyridine & $<5$ & $<5$ & $<5$ & $<5$ & $\mu \mathrm{g} / \mathrm{L}$ & 5 & 5 & $<\mathrm{RL}$ \\
\hline
\end{tabular}


Table 6.7, cont.

\begin{tabular}{|c|c|c|c|c|c|c|c|c|}
\hline \multirow[b]{3}{*}{ Parameter } & \multicolumn{7}{|c|}{ Concentration } & \multirow[b]{3}{*}{$\begin{array}{c}9^{\text {th }} \\
\text { UTLV }\end{array}$} \\
\hline & \multicolumn{2}{|c|}{ Round 10} & \multicolumn{2}{|c|}{ Round 11} & \multirow[b]{2}{*}{ Units } & \multicolumn{2}{|c|}{ Reporting Limit } & \\
\hline & Sample & Dup. & Sample & Dup. & & $\begin{array}{c}\text { Round } \\
10\end{array}$ & $\begin{array}{c}\text { Round } \\
11\end{array}$ & \\
\hline Isobutanol & $<2$ & $<2$ & $<2$ & $<2$ & $\mu \mathrm{g} / \mathrm{L}$ & 2 & 2 & $<\mathrm{RL}$ \\
\hline Alkalinity & 45 & 45 & 48 & 50 & $\mathrm{mg} / \mathrm{L}$ & $\mathrm{NR}^{\mathrm{c}}$ & 4.0 & 58 \\
\hline Bromide & 12 & 11 & 10 & 10 & $\mathrm{mg} / \mathrm{L}$ & 0.2 & 0.2 & 14.4 \\
\hline Chloride & 5,600 & 5,500 & 5,500 & 5,500 & $\mathrm{mg} / \mathrm{L}$ & 0.5 & 2.0 & 6,200 \\
\hline Density & 1.010 & 1.010 & 1.0135 & 1.0111 & $\mathrm{~g} / \mathrm{ml}$ & $\mathrm{N} / \mathrm{A}^{\mathrm{d}}$ & N/A & 1.020 \\
\hline Fluoride & 2.20 & 2.20 & 2.80 & 2.80 & $\mathrm{mg} / \mathrm{L}$ & 0.10 & 0.10 & 4.85 \\
\hline Iodide & $<2.0$ & $<2.0$ & $<2.0$ & $<2.0$ & $\mathrm{mg} / \mathrm{L}$ & 2.0 & 2.0 & $<2.0$ \\
\hline Nitrate (as N) & $<0.10$ & $<0.10$ & $<2.0$ & $<2.0$ & $\mathrm{mg} / \mathrm{L}$ & 0.10 & 2.0 & 7.45 \\
\hline Orthophosphate (as P) & $<0.04$ & $<0.04$ & $<0.04$ & $<0.04$ & $\mathrm{mg} / \mathrm{L}$ & 0.04 & 0.04 & 0.34 \\
\hline $\mathrm{pH}$ & 7.70 & 7.70 & 7.70 & 7.80 & $\mathrm{SU}^{\mathrm{e}}$ & N/A & N/A & $7.45-7.95$ \\
\hline Specific conductance & 22,000 & 22,000 & 21,000 & 21,000 & $\mu \mathrm{mhos} / \mathrm{cm}$ & N/A & N/A & 27,660 \\
\hline Sulfate & 4,700 & 4,800 & 4,800 & 4,700 & $\mathrm{mg} / \mathrm{L}$ & 0.5 & 0.5 & 6,030 \\
\hline Total dissolved solids & 17,000 & 16,000 & 16,000 & 17,000 & $\mathrm{mg} / \mathrm{L}$ & 13.0 & 10.0 & 22,500 \\
\hline Total organic carbon & $<1.0$ & $<1.0$ & $<1.0$ & $<1.0$ & $\mathrm{mg} / \mathrm{L}$ & 1.0 & 1.0 & 10.14 \\
\hline Total organic halogen & 0.560 & 0.160 & 0.290 & 0.43 & $\mathrm{mg} / \mathrm{L}$ & NR & NR & 1.54 \\
\hline Total phenols & $<0.07$ & $<0.07$ & $<0.07$ & $<0.07$ & $\mathrm{mg} / \mathrm{L}$ & 0.07 & 0.07 & $<0.10$ \\
\hline Total suspended solids & $<1.0$ & $<1.0$ & $<1.0$ & $<1.0$ & $\mathrm{mg} / \mathrm{L}$ & 1.0 & 1.0 & 15.0 \\
\hline Antimony & $<0.05$ & $<0.050$ & $<0.013$ & $<0.013$ & $\mathrm{mg} / \mathrm{L}$ & 0.05 & 0.013 & 0.140 \\
\hline Arsenic & 0.003 & 0.027 & $<0.05$ & $<0.05$ & $\mathrm{mg} / \mathrm{L}$ & 0.050 & 0.050 & $<0.50$ \\
\hline Barium & $<0.040$ & $<0.040$ & $<0.020$ & 0.020 & $\mathrm{mg} / \mathrm{L}$ & 0.040 & 0.020 & $<1.0$ \\
\hline Beryllium & $<0.020$ & $<0.020$ & $<0.010$ & $<0.010$ & $\mathrm{mg} / \mathrm{L}$ & 0.020 & 0.010 & $<0.020$ \\
\hline Boron & 15.30 & 13.30 & 12.50 & 13.90 & $\mathrm{mg} / \mathrm{L}$ & 0.10 & 0.5 & 17.50 \\
\hline Cadmium & $<0.010$ & $<0.010$ & $<0.010$ & $<0.010$ & $\mathrm{mg} / \mathrm{L}$ & 0.010 & 0.010 & $<0.050$ \\
\hline Calcium & 707 & 774 & 747 & 766 & $\mathrm{mg} / \mathrm{L}$ & 50.0 & 5.0 & 796 \\
\hline Chromium & $<0.10$ & $<0.10$ & $<0.025$ & $<0.025$ & $\mathrm{mg} / \mathrm{L}$ & 0.10 & 0.025 & $<0.50$ \\
\hline Cobalt & $<0.050$ & $<0.050$ & $<0.013$ & $<0.013$ & $\mathrm{mg} / \mathrm{L}$ & 0.050 & 0.013 & $<0.50$ \\
\hline Copper & $<0.050$ & $<0.050$ & 0.014 & $<0.050$ & $\mathrm{mg} / \mathrm{L}$ & 0.050 & 0.050 & $<1.0$ \\
\hline Iron & $<1.00$ & $<1.00$ & 0.4320 & $<0.50$ & $\mathrm{mg} / \mathrm{L}$ & 1.00 & 0.500 & 3.105 \\
\hline Lead & $<0.050$ & $<0.050$ & $<0.020$ & $<0.020$ & $\mathrm{mg} / \mathrm{L}$ & 0.050 & 0.020 & 0.150 \\
\hline Lithium & 0.426 & 0.382 & 0.339 & 0.339 & $\mathrm{mg} / \mathrm{L}$ & 0.10 & 0.010 & 0.468 \\
\hline Magnesium & 222 & 240 & 226 & 236 & $\mathrm{mg} / \mathrm{L}$ & 0.50 & 5.00 & 255 \\
\hline Mercury & $<0.0002$ & $<0.0002$ & $<0.0002$ & $<0.0002$ & $\mathrm{mg} / \mathrm{L}$ & 0.0002 & 0.0002 & $<0.002$ \\
\hline
\end{tabular}


Table 6.7, cont.

\begin{tabular}{|c|c|c|c|c|c|c|c|c|}
\hline \multicolumn{9}{|c|}{ Concentration } \\
\hline \multirow[b]{2}{*}{ Parameter } & \multicolumn{2}{|c|}{ Round 10} & \multicolumn{2}{|c|}{ Round 11} & \multirow[b]{2}{*}{ Units } & \multicolumn{2}{|c|}{ Reporting Limit } & \multirow[b]{2}{*}{$\begin{array}{c}9^{\text {th }} \\
\text { UTLV }\end{array}$} \\
\hline & Sample & Dup. & Sample & Dup. & & $\begin{array}{c}\text { Round } \\
10\end{array}$ & $\begin{array}{c}\text { Round } \\
11\end{array}$ & \\
\hline Nickel & $<0.100$ & $<0.100$ & $<0.025$ & $<0.025$ & $\mathrm{mg} / \mathrm{L}$ & 0.100 & 0.025 & $<0.50$ \\
\hline Potassium & 184 & 200 & 224 & 227 & $\mathrm{mg} / \mathrm{L}$ & 0.50 & 5.00 & 270 \\
\hline Selenium & $<0.050$ & $<0.050$ & $<0.013$ & $<0.013$ & $\mathrm{mg} / \mathrm{L}$ & 0.050 & 0.013 & $<0.10$ \\
\hline Silica & 17.4 & 15.8 & 2.15 & 2.37 & $\mathrm{mg} / \mathrm{L}$ & 0.150 & 0.500 & 18.2 \\
\hline Silver & $<0.050$ & $<0.050$ & $<0.013$ & $<0.013$ & $\mathrm{mg} / \mathrm{L}$ & 0.050 & 0.013 & $<0.050$ \\
\hline Sodium & 4,280 & 4,740 & 4,120 & 4,280 & $\mathrm{mg} / \mathrm{L}$ & 0.500 & 5.00 & 6,290 \\
\hline Thallium & 0.110 & 0.097 & $<0.013$ & $<0.013$ & $\mathrm{mg} / \mathrm{L}$ & 0.100 & 0.013 & 0.560 \\
\hline Tin & $<0.10$ & $<0.10$ & $<0.025$ & $<0.025$ & $\mathrm{mg} / \mathrm{L}$ & 0.100 & 0.025 & $<0.10$ \\
\hline Vanadium & $<0.100$ & $<0.100$ & $<0.025$ & $<0.025$ & $\mathrm{mg} / \mathrm{L}$ & 0.100 & 0.025 & $<0.10$ \\
\hline Zinc & $<0.200$ & $<0.200$ & 0.040 & $<0.050$ & $\mathrm{mg} / \mathrm{L}$ & 0.200 & 0.050 & $<5.00$ \\
\hline $\begin{array}{l}{ }^{\mathrm{A}} 95^{\text {th }} \text { Upper Tolerar } \\
{ }^{\mathrm{b}} \text { Reporting Limit } \\
{ }^{\mathrm{c}} \text { Not reported by th } \\
{ }^{\mathrm{d}} \text { Not Applicable } \\
{ }^{\mathrm{e}} \text { Standard Unit }\end{array}$ & $\begin{array}{l}\text { mit Value } \\
\text { ratory }\end{array}$ & quivale & o 95\% & fidenc & & & & \\
\hline
\end{tabular}


Table 6.8 Analytical results for groundwater sampled from well WQSP-6A.

\begin{tabular}{|c|c|c|c|c|c|c|c|c|}
\hline \multicolumn{9}{|c|}{ Concentration } \\
\hline \multirow[b]{2}{*}{ Parameter } & \multicolumn{2}{|c|}{ Round 10} & \multicolumn{2}{|c|}{ Round 11} & \multirow[b]{2}{*}{ Units } & \multicolumn{2}{|c|}{ Reporting Limit } & \multirow[b]{2}{*}{$\begin{array}{c}95^{\text {th }} \\
\text { UTLV }^{\mathrm{a}} \\
\end{array}$} \\
\hline & Sample & Dup. & Sample & Dup. & & $\begin{array}{c}\text { Round } \\
10\end{array}$ & $\begin{array}{c}\text { Round } \\
11\end{array}$ & \\
\hline 1,1,1-Trichloroethane & $<2$ & $<2$ & $<1$ & $<1$ & $\mu \mathrm{g} / \mathrm{L}$ & 2 & 1 & $<\mathrm{RL}^{\mathrm{b}}$ \\
\hline 1,1,2,2-Tetrachloroethane & $<2$ & $<2$ & $<1$ & $<1$ & $\mu \mathrm{g} / \mathrm{L}$ & 2 & 1 & $<\mathrm{RL}$ \\
\hline 1,1,2-Trichloroethane & $<2$ & $<2$ & $<1$ & $<1$ & $\mu \mathrm{g} / \mathrm{L}$ & 2 & 1 & $<\mathrm{RL}$ \\
\hline 1,1-Dichloroethane & $<2$ & $<2$ & $<1$ & $<1$ & $\mu \mathrm{g} / \mathrm{L}$ & 2 & 1 & $<\mathrm{RL}$ \\
\hline 1,1-Dichloroethylene & $<2$ & $<2$ & $<1$ & $<1$ & $\mu \mathrm{g} / \mathrm{L}$ & 2 & 1 & $<\mathrm{RL}$ \\
\hline 1,2-Dichloroethane & $<2$ & $<2$ & $<1$ & $<1$ & $\mu \mathrm{g} / \mathrm{L}$ & 2 & 1 & $<\mathrm{RL}$ \\
\hline Carbon tetrachloride & $<2$ & $<2$ & $<1$ & $<1$ & $\mu \mathrm{g} / \mathrm{L}$ & 2 & 1 & $<\mathrm{RL}$ \\
\hline Chlorobenzene & $<2$ & $<2$ & $<1$ & $<1$ & $\mu \mathrm{g} / \mathrm{L}$ & 2 & 1 & $<\mathrm{RL}$ \\
\hline Chloroform & $<2$ & $<2$ & $<1$ & $<1$ & $\mu \mathrm{g} / \mathrm{L}$ & 2 & 1 & $<\mathrm{RL}$ \\
\hline cis-1,2-Dichloroethylene & $<2$ & $<2$ & $<1$ & $<1$ & $\mu \mathrm{g} / \mathrm{L}$ & 2 & 1 & $<\mathrm{RL}$ \\
\hline Methyl ethyl ketone & $<2$ & $<2$ & $<5$ & $<5$ & $\mu \mathrm{g} / \mathrm{L}$ & 2 & 5 & $<\mathrm{RL}$ \\
\hline Methylene chloride & $<5$ & $<5$ & $<5$ & $<5$ & $\mu \mathrm{g} / \mathrm{L}$ & 5 & 5 & $<\mathrm{RL}$ \\
\hline Tetrachloroethylene & $<2$ & $<2$ & $<1$ & $<1$ & $\mu \mathrm{g} / \mathrm{L}$ & 2 & 1 & $<\mathrm{RL}$ \\
\hline Toluene & $<2$ & $<2$ & $<1$ & $<1$ & $\mu \mathrm{g} / \mathrm{L}$ & 2 & 1 & $<\mathrm{RL}$ \\
\hline Trichloroethylene & $<2$ & $<2$ & $<1$ & $<1$ & $\mu \mathrm{g} / \mathrm{L}$ & 2 & 1 & $<\mathrm{RL}$ \\
\hline Trichlorofluoromethane & $<2$ & $<2$ & $<1$ & $<1$ & $\mu \mathrm{g} / \mathrm{L}$ & 2 & 1 & $<\mathrm{RL}$ \\
\hline Vinyl chloride & $<2$ & $<2$ & $<1$ & $<1$ & $\mu \mathrm{g} / \mathrm{L}$ & 2 & 1 & $<\mathrm{RL}$ \\
\hline Xylene & $<2$ & $<2$ & $<1$ & $<1$ & $\mu \mathrm{g} / \mathrm{L}$ & 2 & 1 & $<\mathrm{RL}$ \\
\hline 1,2-Dichlorobenzene & $<5$ & $<5$ & $<5$ & $<5$ & $\mu \mathrm{g} / \mathrm{L}$ & 5 & 5 & $<\mathrm{RL}$ \\
\hline 1,4-Dichlorobenzene & $<5$ & $<5$ & $<5$ & $<5$ & $\mu \mathrm{g} / \mathrm{L}$ & 5 & 5 & $<\mathrm{RL}$ \\
\hline 2,4-Dinitrophenol & $<5$ & $<5$ & $<5$ & $<5$ & $\mu \mathrm{g} / \mathrm{L}$ & 5 & 5 & $<\mathrm{RL}$ \\
\hline 2,4-Dinitrotoluene & $<5$ & $<5$ & $<5$ & $<5$ & $\mu \mathrm{g} / \mathrm{L}$ & 5 & 5 & $<\mathrm{RL}$ \\
\hline 2-Methylphenol & $<5$ & $<5$ & $<5$ & $<5$ & $\mu \mathrm{g} / \mathrm{L}$ & 5 & 5 & $<\mathrm{RL}$ \\
\hline $\begin{array}{l}\text { 3-Methylphenol/ } \\
\text { 4-Methylphenol }\end{array}$ & $<5$ & $<5$ & $<5$ & $<5$ & $\mu \mathrm{g} / \mathrm{L}$ & 5 & 5 & $<\mathrm{RL}$ \\
\hline Hexachlorobenzene & $<5$ & $<5$ & $<5$ & $<5$ & $\mu \mathrm{g} / \mathrm{L}$ & 5 & 5 & $<\mathrm{RL}$ \\
\hline Hexachloroethane & $<5$ & $<5$ & $<5$ & $<5$ & $\mu \mathrm{g} / \mathrm{L}$ & 5 & 5 & $<\mathrm{RL}$ \\
\hline Nitrobenzene & $<5$ & $<5$ & $<5$ & $<5$ & $\mu \mathrm{g} / \mathrm{L}$ & 5 & 5 & $<\mathrm{RL}$ \\
\hline Pentachlorophenol & $<5$ & $<5$ & $<5$ & $<5$ & $\mu \mathrm{g} / \mathrm{L}$ & 5 & 5 & $<\mathrm{RL}$ \\
\hline Pyridine & $<5$ & $<5$ & $<5$ & $<5$ & $\mu \mathrm{g} / \mathrm{L}$ & 5 & 5 & $<\mathrm{RL}$ \\
\hline
\end{tabular}


Table 6.8, cont.

\begin{tabular}{|c|c|c|c|c|c|c|c|c|}
\hline \multirow[b]{3}{*}{ Parameter } & \multicolumn{7}{|c|}{ Concentration } & \multirow[b]{3}{*}{$\begin{array}{c}95^{\text {th }} \\
\text { UTLV }\end{array}$} \\
\hline & \multicolumn{2}{|c|}{ Round 10} & \multicolumn{2}{|c|}{ Round 11} & \multirow[b]{2}{*}{ Units } & \multicolumn{2}{|c|}{ Reporting Limit } & \\
\hline & Sample & Dup. & Sample & Dup. & & $\begin{array}{c}\text { Round } \\
10\end{array}$ & $\begin{array}{c}\text { Round } \\
11\end{array}$ & \\
\hline Isobutanol & $<2$ & $<2$ & $<2$ & $<2$ & $\mu \mathrm{g} / \mathrm{L}$ & 2 & 2 & $<\mathrm{RL}$ \\
\hline Alkalinity & 108 & 103 & 108 & 102 & $\mathrm{mg} / \mathrm{L}$ & 6.0 & 4.0 & 113 \\
\hline Bromide & 1.0 & 1.2 & $<1.0$ & $<1.0$ & $\mathrm{mg} / \mathrm{L}$ & 0.2 & 0.2 & 14.5 \\
\hline Chloride & 530 & 510 & 480 & 480 & $\mathrm{mg} / \mathrm{L}$ & 0.5 & 0.5 & 1,040 \\
\hline Density & 1.00 & 1.00 & 1.0009 & 1.0009 & $\mathrm{~g} / \mathrm{ml}$ & $\mathrm{N} / \mathrm{A}^{\mathrm{c}}$ & N/A & 1.010 \\
\hline Fluoride & 2.10 & 2.00 & 2.00 & 2.00 & $\mathrm{mg} / \mathrm{L}$ & 0.20 & 0.20 & 2.95 \\
\hline Iodide & $<2.0$ & $<2.0$ & $<2.0$ & $<2.0$ & $\mathrm{mg} / \mathrm{L}$ & 2.0 & 2.0 & $<2.0$ \\
\hline Nitrate (as N) & 7.50 & 7.40 & 6.70 & 6.50 & $\mathrm{mg} / \mathrm{L}$ & 0.20 & 2.0 & 11.70 \\
\hline Orthophosphate (as P) & $<0.04$ & $<0.04$ & $<0.04$ & $<0.04$ & $\mathrm{mg} / \mathrm{L}$ & 0.04 & 0.04 & 0.110 \\
\hline $\mathrm{pH}$ & 7.39 & 7.39 & 7.80 & 7.80 & $\mathrm{SU}^{\mathrm{d}}$ & N/A & N/A & $6.80-8.00$ \\
\hline Specific conductance & 4,500 & 4,500 & 4,300 & 4,300 & $\mu \mathrm{mhos} / \mathrm{cm}$ & N/A & N/A & 5,000 \\
\hline Sulfate & 2,100 & 2,000 & 1,900 & 1,900 & $\mathrm{mg} / \mathrm{L}$ & 0.5 & 0.5 & 2,543 \\
\hline Total dissolved solids & 3,800 & 3,800 & 3,700 & 3,800 & $\mathrm{mg} / \mathrm{L}$ & 10.0 & 10.0 & 11,000 \\
\hline Total organic carbon & $<1.0$ & $<1.0$ & $<1.0$ & $<1.0$ & $\mathrm{mg} / \mathrm{L}$ & $\mathrm{NR}^{\mathrm{e}}$ & 1.0 & 15.60 \\
\hline Total organic halogen & 0.0460 & 0.0780 & 0.0540 & 0.0440 & $\mathrm{mg} / \mathrm{L}$ & NR & NR & 0.190 \\
\hline Total phenols & $<0.07$ & $<0.07$ & $<0.07$ & $<0.07$ & $\mathrm{mg} / \mathrm{L}$ & 0.07 & 0.07 & $<0.28$ \\
\hline Total suspended solids & $<1.0$ & $<1.0$ & $<1.0$ & $<1.0$ & $\mathrm{mg} / \mathrm{L}$ & 1.0 & 1.0 & 91.0 \\
\hline Antimony & $<0.010$ & $<0.010$ & $<0.013$ & $<0.013$ & $\mathrm{mg} / \mathrm{L}$ & 0.010 & 0.013 & 0.480 \\
\hline Arsenic & $<0.010$ & $<0.010$ & 0.010 & $<0.05$ & $\mathrm{mg} / \mathrm{L}$ & 0.050 & 0.050 & $<0.50$ \\
\hline Barium & $<0.008$ & $<0.008$ & $<0.020$ & 0.020 & $\mathrm{mg} / \mathrm{L}$ & 0.10 & 0.020 & $<0.10$ \\
\hline Beryllium & $<0.004$ & $<0.004$ & $<0.010$ & $<0.010$ & $\mathrm{mg} / \mathrm{L}$ & 0.004 & 0.010 & $<0.010$ \\
\hline Boron & 0.378 & 0.362 & 0.336 & $<0.500$ & $\mathrm{mg} / \mathrm{L}$ & 0.10 & 0.5 & $<0.50$ \\
\hline Cadmium & $<0.005$ & $<0.005$ & $<0.010$ & $<0.010$ & $\mathrm{mg} / \mathrm{L}$ & 0.010 & 0.010 & $<0.50$ \\
\hline Calcium & 681 & 664 & 655 & 658 & $\mathrm{mg} / \mathrm{L}$ & 0.5 & 5.0 & 733 \\
\hline Chromium & $<0.020$ & $<0.020$ & $<0.025$ & $<0.025$ & $\mathrm{mg} / \mathrm{L}$ & 0.020 & 0.025 & $<0.50$ \\
\hline Cobalt & $<0.010$ & $<0.010$ & $<0.013$ & $<0.013$ & $\mathrm{mg} / \mathrm{L}$ & 0.010 & 0.013 & $<0.50$ \\
\hline Copper & 0.0007 & $<0.010$ & $<0.050$ & 0.020 & $\mathrm{mg} / \mathrm{L}$ & 0.010 & 0.050 & $<1.0$ \\
\hline Iron & 0.0037 & $<0.20$ & $<0.50$ & $<0.50$ & $\mathrm{mg} / \mathrm{L}$ & 0.10 & 0.500 & $<1.0$ \\
\hline Lead & $<0.0050$ & $<0.0050$ & $<0.020$ & $<0.020$ & $\mathrm{mg} / \mathrm{L}$ & 0.0050 & 0.020 & $<0.05$ \\
\hline Lithium & 0.138 & 0.134 & 0.137 & 0.141 & $\mathrm{mg} / \mathrm{L}$ & 0.010 & 0.010 & $<0.50$ \\
\hline Magnesium & 167 & 162 & 187 & 179 & $\mathrm{mg} / \mathrm{L}$ & 0.50 & 5.00 & 188 \\
\hline Mercury & $<0.0002$ & $<0.0002$ & $<0.0002$ & $<0.0002$ & $\mathrm{mg} / \mathrm{L}$ & 0.0002 & 0.0002 & $<0.002$ \\
\hline
\end{tabular}


Table 6.8, cont.

\begin{tabular}{|c|c|c|c|c|c|c|c|c|}
\hline \multirow[b]{3}{*}{ Parameter } & \multicolumn{7}{|c|}{ Concentration } & \multirow[b]{3}{*}{$\begin{array}{c}\mathbf{9 5}^{\text {th }} \\
\text { UTLV }\end{array}$} \\
\hline & \multicolumn{2}{|c|}{ Round 10} & \multicolumn{2}{|c|}{ Round 11} & \multirow[b]{2}{*}{ Units } & \multicolumn{2}{|c|}{ Reporting Limit } & \\
\hline & Sample & Dup. & Sample & Dup. & & $\begin{array}{c}\text { Round } \\
10\end{array}$ & $\begin{array}{c}\text { Round } \\
11\end{array}$ & \\
\hline Nickel & $<0.020$ & $<0.020$ & $<0.025$ & $<0.025$ & $\mathrm{mg} / \mathrm{L}$ & 0.020 & 0.025 & 0.284 \\
\hline Potassium & 5.20 & 5.40 & 3.28 & 2.97 & $\mathrm{mg} / \mathrm{L}$ & 1.00 & 5.00 & 10.1 \\
\hline Selenium & 0.0129 & 0.0107 & $<0.013$ & $<0.013$ & $\mathrm{mg} / \mathrm{L}$ & 0.050 & 0.013 & 0.220 \\
\hline Silica & 0.354 & 0.345 & 5.350 & 5.430 & $\mathrm{mg} / \mathrm{L}$ & 0.010 & 0.500 & 40.10 \\
\hline Silver & $<0.010$ & $<0.010$ & $<0.013$ & $<0.013$ & $\mathrm{mg} / \mathrm{L}$ & 0.050 & 0.013 & $<0.50$ \\
\hline Sodium & 279 & 291 & 258 & 250 & $\mathrm{mg} / \mathrm{L}$ & 0.500 & 5.00 & 384 \\
\hline Thallium & 0.0176 & 0.0243 & $<0.013$ & $<0.013$ & $\mathrm{mg} / \mathrm{L}$ & 0.050 & 0.013 & 0.558 \\
\hline Tin & $<0.020$ & $<0.020$ & $<0.025$ & $<0.025$ & $\mathrm{mg} / \mathrm{L}$ & 0.025 & 0.025 & 0.230 \\
\hline Vanadium & 0.0411 & 0.0411 & $<0.025$ & 0.024 & $\mathrm{mg} / \mathrm{L}$ & 0.100 & 0.025 & $<0.50$ \\
\hline Zinc & $<0.040$ & $<0.040$ & 0.050 & $<0.050$ & $\mathrm{mg} / \mathrm{L}$ & 0.100 & 0.050 & $<5.00$ \\
\hline
\end{tabular}

${ }^{\mathrm{b}}$ Reporting Limit

${ }^{\mathrm{c}}$ Not Applicable

${ }^{d}$ Standard Unit

${ }^{\mathrm{e}}$ Not reported by the laboratory 


\section{Chapter 7 \\ Radiological Dose Assessment}

It is the policy of DOE “. . . to conduct its operations in an environmentally safe and sound manner. Protection of the environment and the public are responsibilities of paramount importance and concern to DOE" (DOE Order 5400.1). "It is also a DOE objective that potential exposures to members of the public be as far below the limits as is reasonably achievable. .." (DOE Order 5400.5).

Chapter 4 of this report summarized the amount of radioactivity in various media sampled in the WIPP environment in 2000. It is the purpose of this chapter to summarize what those levels mean in regards to the potential dose from WIPP operations.

Specifically, this chapter summarizes:

- introductory information on human radiation dose limits and risks from radiation;

- the national average dose from naturallyoccurring sources of radiation;

- the estimated dose from air emissions from WIPP;

- the total potential dose from WIPP operations, and

- $\quad$ potential doses to non-human biota from radioactivity measured near WIPP.

\subsection{Introduction and Dose Limits}

In this chapter, the term "dose" will refer to the committed effective dose equivalent, unless another term is specifically stated. Dose was calculated by summing the committed dose equivalents to organs, each multiplied by a weighting factor proportional to each organ's sensitivity to radiation. Additional methods for calculating dose are discussed in the following sections on specific pathways.

For more than 50 years, extensive research has been conducted on the effects of radiation on humans and the environment. Much of this research used standard epidemiological and toxicological approaches to characterize the response of populations and individuals to high radiation doses. From this, a good understanding of the risks associated with high radiation doses was achieved. However, there is still uncertainty as to what risks are incurred from low radiation doses and dose rates. Because of the low rate of cancer incidence at low levels of radiation exposure, and the large sample sizes needed to study this relationship, risks due to low levels of radiation exposure are difficult to obtain; therefore, models have been used to predict risks from low radiation doses (Figure 7.1).

Environmental radiation protection standards for the management and disposal of TRU wastes set limits on the total annual radiation dose to members of the public at 0.25 $\mathrm{mSv}(25 \mathrm{mrem})$ to the whole body and $0.75 \mathrm{mSv}$ (75 mrem) to any critical organ (40 CFR § 191.03). National standards for emissions of radionuclides from DOE facilities state that the maximum annual dose to any member of the public from air emissions must be no greater than $0.1 \mathrm{mSv}$ (10 mrem) (40 CFR $\S 61.92)$. The Safe Drinking Water Act (40 CFR § 141.16) states that average annual concentrations of beta- and gamma-emitting human-made radionuclides in drinking water shall not result in an annual dose greater than $0.04 \mathrm{mSv}$ (4 mrem). It is important to note that all of these dose limits are set for radionuclides released to the environment from DOE operations. They do not include, but are limits in addition to, doses from natural background radiation or from medical procedures. 


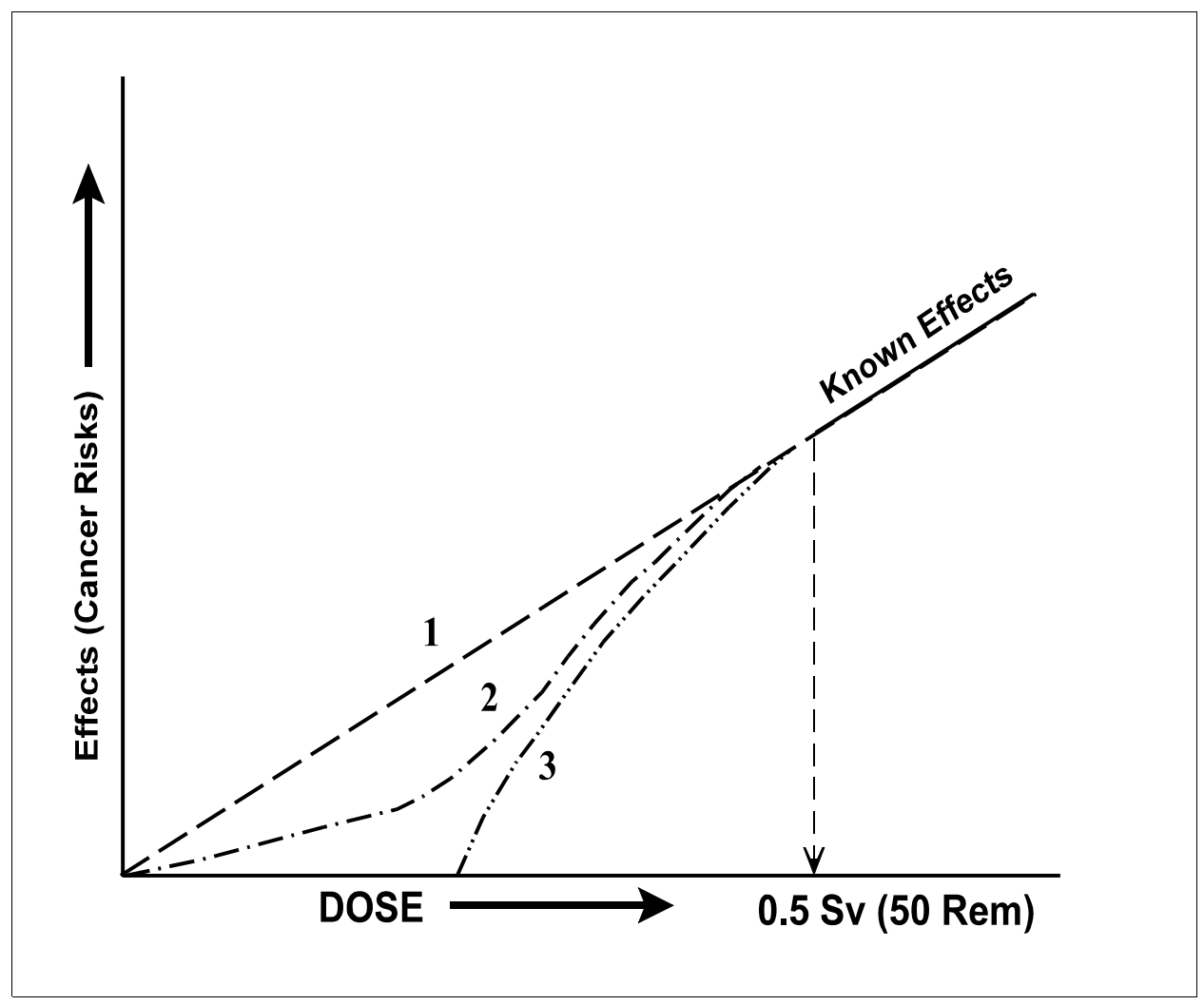

Figure 7.1 Three general models used to predict risk from radiation dose. Models are used because scientists have yet to reliably detect changes in cancer incidence following low doses of radiation. Risks from radiation are primarily based on effects observed from persons receiving high doses (e.g., Hiroshima and Nagasaki atomic bomb survivors). Regulatory dose limits are set well below levels where any health effects have been observed (Figure adapted from NRC 1999).

\subsection{Background Radiation}

Radiation is a naturally-occurring phenomenon that has been in the environment since the beginning of time. There are several sources of natural radiation: cosmic and cosmogenic radiation (from outer space and the earth's atmosphere), terrestrial radiation (from the earth's crust), and internal radiation (naturally-occurring radiation in our bodies, such as ${ }^{40} \mathrm{~K}$ ). The most common sources of terrestrial radiation are uranium, thorium, and their decay products. Potassium-40 is another source of terrestrial radiation. While not a major radiation source, ${ }^{40} \mathrm{~K}$ may be enhanced in the southeastern New Mexico environment due to local potash mining. Radon gas, a decay product of uranium, is the most widely known naturally-occurring terrestrial radionuclide. In addition to natural radioactivity, small amounts of radioactivity from above-ground nuclear weapons tests that occurred from 1945 through 1980 and the 1986 Chernobyl nuclear accident are also present in the environment. Together, these sources of radiation are called "background" radiation. Every human is constantly exposed to background radiation. Exposure to radioactivity from weapons testing fallout is quite small compared to natural radioactivity and continually gets smaller as radionuclides decay. 
Naturally-occurring radiation in our environment can deliver both internal and external doses. Internal dose is received as a result of the intake of radionuclides. The major routes of intake of radionuclides for members of the public are ingestion and inhalation.

Ingestion includes the intake of the radionuclides from eating and drinking contaminated food or drink. Inhalation includes the intake of radionuclides through breathing dust particles containing radioactive materials or radon gas. External dose can occur from submersion in contaminated air or deposition of contaminants on surfaces. The average annual dose received by a member of the public from naturally-occurring radionuclides is about 3 mSv (300 mrem) (Table 7.1).

Table 7.1 Annual estimated average radiation dose received by a member of the population of the United States from naturally-occurring radiation sources (adapted from NCRP-1987).

\begin{tabular}{lcc}
\hline \multicolumn{1}{c}{ Source } & \multicolumn{2}{c}{ Average Annual Effective Dose Equivalent } \\
\cline { 2 - 3 } & $(\mathbf{m S v})$ & (mrem) \\
\hline Inhaled (Radon and Decay Products) & 2 & 200 \\
Internal Radionuclides & 0.39 & 39 \\
Terrestrial Radiation & 0.28 & 28 \\
Cosmic Radiation & 0.27 & 27 \\
Cosmogenic Radioactivity & 0.01 & 1 \\
& & \\
Rounded Total From Natural Sources & 3 & 300 \\
\hline
\end{tabular}

\subsection{Dose from Air Emissions}

The National Emission Standards for Hazardous Air Pollutants issued by the EPA set limits for radionuclide emissions to air (40 CFR § 61). Compliance procedures for DOE facilities [40 CFR $\S 61.93(\mathrm{a})]$ require the use of CAP88 or AIRDOS-PC computer models, or an equivalent, to calculate dose to members of the public. For the determination of the radiation dose received by members of the public, WIPP used the computer model CAP88-PC, version 2.0. Source term input for the program was determined by radiochemical analyses of periodic air samples taken from the effluent Stations A, B, and C (see Section 4.1). Air samples were analyzed for ${ }^{241} \mathrm{Am},{ }^{239+240} \mathrm{Pu}$, and ${ }^{238} \mathrm{Pu}$ because they constitute over 98 percent of the dose potential from contact-handled waste. Measured activity values greater than the MDA were used as a part of the source term for the air emission pathway and, for measured results less than the MDA, the MDA value was used as part of the source term (see Table 4.1). CAP88 dose calculations are based on the assumption that exposed persons remain at home during the entire year and all vegetables, milk, and meat consumed are home produced. Thus, this dose calculation is a maximum potential dose which encompasses dose from inhalation, submersion, deposition, and ingestion of air emitted radionuclides.

\subsubsection{Maximally Exposed Individual from Air Emission Pathway}

For 2000, the CAP88 model predicted the highest dose to someone residing near WIPP to be at the Smith Ranch approximately $8 \mathrm{~km}$ (5 mi) northwest of WIPP. Results showed the 
whole body dose potentially received by someone residing at this location to be about $5.18 \times 10^{-8} \mathrm{mSv}\left(5.18 \times 10^{-6} \mathrm{mrem}\right)$ per year. The critical organ dose was less than $9.01 \times 10^{-7} \mathrm{mSv}$ $\left(9.01 \times 10^{-5} \mathrm{mrem}\right)$ per year.

\subsection{Total Potential Dose from WIPP Operations}

The radiation dose received by members of the public as a result of the management and storage of TRU radioactive wastes at any disposal facility operated by DOE is regulated under 40 CFR § 191 Subpart A. Specific standards state that the combined annual dose to any member of the public in the general environment shall not exceed $0.25 \mathrm{mSv}(25$ mrem) to the whole body and $0.75 \mathrm{mSv}$ (75 mrem) to any critical organ. Section 7.3 discussed the potential dose received from radionuclides released to the air from WIPP. The following sections discuss the potential dose through other pathways and the total potential dose a member of the public may have received from WIPP operations during 2000.

\subsubsection{Potential Dose from Water Ingestion Pathway}

The potential dose to individuals from the ingestion of WIPP-related radionuclides transported in water is estimated to be nonexistent for several reasons. Drinking water for communities near WIPP comes from groundwater sources which are not expected to be affected by potential WIPP contaminants (based on current radionuclide transport scenarios summarized in the WIPP Safety Analysis Report [DOE/WIPP 95-2065, Rev. 3]). The only credible pathway for contaminants from WIPP to accessible groundwater is through the Culebra member of the Rustler Formation and the Dewey Lake Formation (DOE/CAO 96-2184). Water from the Culebra is naturally not potable due to high levels of TDS. Water from the Dewey Lake Formation is suitable for livestock consumption having TDS values below $10,000 \mathrm{mg} / \mathrm{L}$. Groundwater and surface water samples collected around WIPP during 2000 did not contain radionuclide concentrations discernable from those in samples collected prior to WIPP receiving waste.

\subsubsection{Potential Dose From Wild Game Ingestion}

Game animals sampled during 2000 were mule deer, quail, and fish. The only radionuclides detected were not different from background levels measured prior to commencement of waste shipments to WIPP. Therefore, no dose from WIPP related radionuclides is estimated to have been received by any individual from this pathway during 2000.

\subsubsection{Total Potential Dose From All Pathways}

The only pathway for which a dose could be estimated was that of air emissions. Air emissions from WIPP were not above background ambient air levels. Estimated concentrations of radionuclides in air emissions accounted for the calculable dose from WIPP operations during 2000 . The dose potentially received by someone residing $8 \mathrm{~km}(5 \mathrm{mi})$ northwest of WIPP was calculated to be $5.18 \times 10^{-8} \mathrm{mSv}\left(5.18 \times 10^{-6} \mathrm{mrem}\right)$ per year whole body, and $9.01 \times 10^{-7} \mathrm{mSv}\left(9.01 \times 10^{-5} \mathrm{mrem}\right)$ per year to the critical organ. This potential whole body dose is $5.18 \times 10^{-5}$ percent of the whole body dose limits of $0.1 \mathrm{mSv}$ (10 mrem) per year specified in $40 \mathrm{CFR} \S 61.92$.

The dose to a hypothetical person residing year-round at the WIPP fence line was estimated to be $9.35 \times 10^{-7} \mathrm{mSv}\left(9.35 \times 10^{-5} \mathrm{mrem}\right)$ per year whole body and $1.63 \times 10^{-5} \mathrm{mSv}\left(1.63 \times 10^{-3}\right.$ mrem) per year to the critical organ. This is $3.7 \times 10^{-4}$ percent of the whole body dose limits of $0.25 \mathrm{mSv}$ ( $25 \mathrm{mrem}$ ) per year whole body dose and $2.2 \times 10^{-3}$ percent of the dose limit of $0.75 \mathrm{mSv}$ (75 mrem) per year specified in 40 CFR $\S 191.03(b)$.

\subsection{Dose to non-human Biota}

DOE Order 5400.5 lists the environmental radiation protection requirements that WIPP 
must meet to protect aquatic animals. In addition, dose limits below which no deleterious effects on populations of aquatic and terrestrial organisms have been observed have been discussed by the National Council on Radiation Protection and Measurements (NCRP-109) and the International Atomic Energy Agency (IAEA Technical Report Series No. 332). Those dose limits are:

- Aquatic Animals - $10 \mathrm{mGy} / \mathrm{d}(1 \mathrm{rad} / \mathrm{d})$

- Terrestrial Plants - $10 \mathrm{mGy} / \mathrm{d}(1 \mathrm{rad} / \mathrm{d})$

- Terrestrial Animals - $1 \mathrm{mGy} / \mathrm{d}(0.1 \mathrm{rad} / \mathrm{d})$

DOE has considered proposing these dose standards for aquatic and terrestrial biota under proposed rule 10 CFR $\S 834$, "Radiation protection of the public and the environment" but has delayed until guidance for demonstrating compliance was developed. The DOE-STDXXXX-00, A Graded Approach for Evaluating Radiation Doses to Aquatic and Terrestrial Biota, was developed to meet this need. Although the proposed rule has not been implemented, DOE requires reporting of radiation doses to non-human biota in the Annual Site Environmental Report using the Interim Technical Standard.
The Interim Technical Standard uses a multi-phase approach, including an initial screening phase with conservative assumptions. Software is provided with the Interim Technical Standard to conduct the screening evaluation. In the initial screen, Biota Concentration Guides (BCG) are derived using very conservative assumptions for a variety of generic organisms. Maximum concentrations of radionuclides detected in soil, sediment, and water during environmental monitoring are divided by the BCGs and the results are summed for each organism (DOE-STD-XXXX-00). If the sum of these fractions is less than 1 , the site is deemed to have passed the screen and no further action is required. This screening evaluation is intended to provide a very conservative evaluation of whether the site is in compliance with the recommended limits.

This guidance was used to screen radionuclide concentrations observed around WIPP during 2000 using the maximum radionuclide concentrations listed in Table 7.2. The sum of fractions was less than one for all media, demonstrating compliance with the proposed rule. Radiation in the environment surrounding WIPP does not have a deleterious effect on populations of plants and animals. 
Table 7.2 General screening results for potential radiation dose to non-human biota from radionuclide concentrations in surface water $(\mathrm{Bq} / \mathrm{l})$, sediment $(\mathrm{Bq} / \mathrm{g})$, and soil $(\mathrm{Bq} / \mathrm{g})$ near the WIPP site. Maximum detected concentrations were compared with Biota Concentration Guide ${ }^{\mathrm{a}}$ (BCG) values to assess potential dose to biota. As long as the sum of the ratios between observed maximum concentrations and the associated BCG is below 1.0, no adverse effects on plant or animal populations are expected (DOE-STD-XXXX-00).

\begin{tabular}{|c|c|c|c|c|}
\hline Medium & Radionuclide & $\begin{array}{c}\text { Maximum } \\
\text { observed } \\
\text { concentration }\end{array}$ & BCG & Concentration/BCG \\
\hline \multicolumn{5}{|c|}{ Aquatic system evaluation } \\
\hline \multirow[t]{6}{*}{ Sediment $(\mathrm{Bq} / \mathrm{g})$} & ${ }^{60} \mathrm{Co}$ & $7.74 \times 10^{-3}$ & $5.00 \times 10^{1}$ & $1.55 \times 10^{-4}$ \\
\hline & ${ }^{137} \mathrm{Cs}$ & $1.86 \times 10^{-2}$ & $1.00 \times 10^{2}$ & $1.86 \times 10^{-4}$ \\
\hline & ${ }^{234} \mathrm{U}$ & $4.75 \times 10^{-2}$ & $2.00 \times 10^{2}$ & $2.38 \times 10^{-4}$ \\
\hline & ${ }^{235} \mathrm{U}$ & $5.68 \times 10^{-3}$ & $1.00 \times 10^{2}$ & $5.68 \times 10^{-5}$ \\
\hline & ${ }^{238} \mathrm{U}$ & $3.38 \times 10^{-2}$ & $9.00 \times 10^{1}$ & $3.76 \times 10^{-4}$ \\
\hline & ${ }^{241} \mathrm{Am}$ & $3.70 \times 10^{-4}$ & $2.00 \times 10^{2}$ & $1.85 \times 10^{-6}$ \\
\hline \multirow[t]{7}{*}{ Water $^{\mathrm{b}}(\mathrm{Bq} / \mathrm{l})$} & ${ }^{60} \mathrm{Co}$ & $6.75 \times 10^{-1}$ & $1.00 \times 10^{2}$ & $6.75 \times 10^{-3}$ \\
\hline & ${ }^{137} \mathrm{Cs}$ & $8.94 \times 10^{-1}$ & $2.00 \times 10^{0}$ & $4.47 \times 10^{-1}$ \\
\hline & ${ }^{234} \mathrm{U}$ & $1.90 \times 10^{-1}$ & $7.00 \times 10^{0}$ & $2.71 \times 10^{-2}$ \\
\hline & ${ }^{235} \mathrm{U}$ & $6.09 \times 10^{-3}$ & $8.00 \times 10^{0}$ & $7.62 \times 10^{-4}$ \\
\hline & ${ }^{238} \mathrm{U}$ & $8.72 \times 10^{-2}$ & $8.00 \times 10^{0}$ & $1.09 \times 10^{-2}$ \\
\hline & ${ }^{241} \mathrm{Am}$ & $4.92 \times 10^{-4}$ & $2.00 \times 10^{1}$ & $2.46 \times 10^{-5}$ \\
\hline & & & $\begin{array}{c}\text { Sum of } \\
\text { Fractions }\end{array}$ & $4.94 \times 10^{-1}$ \\
\hline \multicolumn{5}{|c|}{ Terrestrial system evaluation } \\
\hline \multirow[t]{6}{*}{ Soil (Bq/g) } & ${ }^{60} \mathrm{Co}$ & $5.55 \times 10^{-3}$ & $3.00 \times 10^{1}$ & $1.85 \times 10^{-4}$ \\
\hline & ${ }^{137} \mathrm{Cs}$ & $1.37 \times 10^{-2}$ & $8.00 \times 10^{-1}$ & $1.72 \times 10^{-2}$ \\
\hline & ${ }^{234} \mathrm{U}$ & $2.01 \times 10^{-2}$ & $2.00 \times 10^{2}$ & $1.00 \times 10^{-4}$ \\
\hline & ${ }^{235} \mathrm{U}$ & $1.77 \times 10^{-3}$ & $1.00 \times 10^{2}$ & $1.77 \times 10^{-5}$ \\
\hline & ${ }^{238} \mathrm{U}$ & $2.35 \times 10^{-2}$ & $6.00 \times 10^{1}$ & $3.92 \times 10^{-4}$ \\
\hline & ${ }^{241} \mathrm{Am}$ & $3.70 \times 10^{-4}$ & $1.00 \times 10^{2}$ & $3.70 \times 10^{-6}$ \\
\hline \multirow[t]{7}{*}{ Water $(\mathrm{Bq} / \mathrm{l})$} & ${ }^{60} \mathrm{Co}$ & $6.75 \times 10^{-1}$ & $4.00 \times 10^{4}$ & $1.69 \times 10^{-5}$ \\
\hline & ${ }^{137} \mathrm{Cs}$ & $8.94 \times 10^{-1}$ & $2.00 \times 10^{4}$ & $4.47 \times 10^{-5}$ \\
\hline & ${ }^{234} \mathrm{U}$ & $1.90 \times 10^{-1}$ & $1.00 \times 10^{4}$ & $1.90 \times 10^{-5}$ \\
\hline & ${ }^{235} \mathrm{U}$ & $6.09 \times 10^{-3}$ & $2.00 \times 10^{4}$ & $3.05 \times 10^{-7}$ \\
\hline & ${ }^{238} \mathrm{U}$ & $8.72 \times 10^{-2}$ & $2.00 \times 10^{4}$ & $4.36 \times 10^{-6}$ \\
\hline & ${ }^{241} \mathrm{Am}$ & $4.92 \times 10^{-4}$ & $7.00 \times 10^{3}$ & $7.03 \times 10^{-8}$ \\
\hline & & & $\begin{array}{c}\text { Sum of } \\
\text { Fractions }\end{array}$ & $1.80 \times 10^{-2}$ \\
\hline
\end{tabular}

${ }^{\mathrm{a}}$ The radionuclide concentration in the medium that would produce a radiation dose in the organism equal to the dose limit under the conservative assumptions in the model.

${ }^{\mathrm{b}}$ Sediment and water samples were assumed to be co-located. 


\section{Chapter 8 \\ Quality Assurance}

The fundamental objective of a QA program is to ensure high-quality measurements are produced and reported from the analytical laboratory. The defensibility of data generated by laboratories must be based on sound scientific principles, method evaluations, and data verification and validation. Wastren, in Grand Junction, Colorado; Air Toxics, LTD, in Folsom, California; and Trace Analysis, in Lubbock, Texas, were the contract laboratories that performed the radiological and nonradiological analyses for WIPP environmental samples. The WIPP laboratory performed the gross alpha and beta analyses on weekly air particulate samples.

All laboratories were required to have documented QA programs and standard procedures to perform the work, and to participate in some comparison programs with the National Institute of Standards and Technology (NIST), the Environmental Monitoring Laboratory, the DOE Environmental Measurements Laboratory Quality Assurance Program (QAP), the Environmental Resource Associates interlaboratory assessment, and/or any other reputable intercomparison program. The contract laboratories used one or more of these accepted protocols in their QA program.

- $\quad$ ASME NQA-1-1994, Quality Assurance Program Requirements for Nuclear Facilities.

- 10 CFR 50, Appendix B, Quality Assurance Criteria for Nuclear Power Plants and Fuel Reprocessing Plants.

- EPA/600 14-83-004, QAMS-005/80, Interim Guidelines and Specification for Preparing Quality Assurance Project Plans.
- $\quad$ NRC Regulatory Guide 4.15, Rev. 1, Quality Assurance for Radiological Monitoring Program-Effluent Streams and the Environment.

- HPS N13.30 ANSI, Performance Criteria for Radiobioassay.

- $\quad$ Proposed ANSI/ASQC-E4, Quality Assurance Program Requirements for Environmental Programs.

The WIPP Environmental Monitoring Section performed assessments and audits to ensure the quality of the systems, processes, and deliverables were maintained or improved. Along with these regulatory requirements, the Environmental Monitoring Section also implements DOE Order 414.1A, Quality Assurance. The parameters for performance evaluations (PEs) are completeness, reproducibility, accuracy, comparability, and representativeness.

\subsection{Completeness}

The completeness parameter was calculated as the ratio of the number of valid results to the total number of samples collected and analyzed. The gross alpha/beta analyses were 98.1 percent complete for 2000. Samples for air particulates were 97.8 percent complete. Samples and measurements for all other media (groundwater, surface water, soil, sediment, and animal and plant tissues) were 100 percent complete. The data quality objective established for the environmental program is 98 percent complete. The Environmental Monitoring Program exceeded the objective in 2000 for environmental samples. Samples having analysis recoveries outside the range of 50 to 120 percent were reanalyzed. 


\subsection{Reproducibility}

The reproducibility of the measurements was validated through analyses of duplicate samples. A low-volume air sampler was rotated in each quarter from location to location, and sampled along with routine samples. The results of these duplicate comparisons are shown in Tables 8.1, 8.2, 8.3, and 8.4 for the four quarters of 2000. The duplicate samples for other matrices were collected at the same time, same place, and under similar conditions as routine samples. These samples were analyzed in the same analytical batch and/or sample delivery group using similar methods for radiochemical separation and counting as the original samples.

Reproducibility is partially influenced by statistical counting uncertainty, so variances were expected between samples with very low activities (environmental levels). The reproducibility was evaluated by calculating the Relative Error Ratio (RER):

$$
R E R=\frac{\mid(\text { Mean Activity })_{\text {ori }}-(\text { Mean Activity })_{\text {dup }} \mid}{\sqrt{(2 \times S D)_{\text {ori }}^{2}+(2 \times S D)_{\text {dup }}^{2}}}
$$

Where:

$$
\begin{aligned}
& (\text { Mean Activity })_{\text {ori }}=\text { Mean Activity of Original } \\
& \text { Sample } \\
& (\text { Mean Activity })_{\text {dup }}=\text { Mean Activity of Dupli- } \\
& \text { cate Sample } \\
& \mathrm{SD}=\text { Standard Deviation of Original and Dup- } \\
& \text { licate Samples }
\end{aligned}
$$

RER results equal to or less than one are acceptable and considered to demonstrate reproducibility. Two results from the fourth quarter were greater than one (Table 8.4).

\subsection{Accuracy and Comparability}

The accuracy of the analyses were assured/controlled by using NIST-traceable standards for instrument calibration. Internal quality control is performed by using spiked laboratory control samples. Intercomparisons were performed with the DOE Environmental Measurements Laboratory (EML) to ensure the reliability of radiochemical separation methods and counting instruments. Accuracy, expressed as percent bias, was calculated by:

$$
\% B I A S=\left[\frac{A_{m}-A_{k}}{A_{k}}\right] * 100
$$

Where:

$$
\begin{array}{cl}
\% \text { BIAS } & =\text { Percent Bias } \\
\mathrm{A}_{\mathrm{m}} & =\text { Measured Sample Activity } \\
\mathrm{A}_{\mathrm{k}} & =\text { Known Sample Activity }
\end{array}
$$

The DOE EML QAP prepares quality control samples containing various alpha-, beta-, and gamma-emitting nuclides in water, soil, air filter, vegetation, and tissue media and distributes them to numerous DOE contractor laboratories. The program is an interlaboratory comparison in that results from the participants are compared with the experimentally determined results of EML. Also, EML assesses the results as acceptable or not within a range of bias from the EML result.

The Wastren Laboratory participated in this program. The results are provided in Tables 8.5, 8.6, 8.7, and 8.8 for air, soil, vegetation, and water, respectively. The contract laboratory's percent bias in evaluating air filters was acceptable for all radionuclides and all media except for ${ }^{40} \mathrm{~K}$ in soil and vegetation during the December inter-comparison (QAP 53). This failure was due to a lack of precision in gamma spectroscopy calibration for ${ }^{40} \mathrm{~K}$, and the problem has been corrected by the laboratory. The laboratory passed the test for ${ }^{40} \mathrm{~K}$ in the controlled samples before and after QAP 53, and the incorrect calibration occurred at a time when it did not affect any of WIPP's sample analyses. 
Table 8.1 Comparison of duplicate air monitoring results (first quarter of 2000) from WIPP Environmental Monitoring Laboratory data from Smith Ranch (SMR) sampling location.

\begin{tabular}{|c|c|c|c|c|c|c|c|c|c|c|}
\hline \multirow{2}{*}{$\begin{array}{c}\text { Week } \\
\text { Beginning }\end{array}$} & \multicolumn{5}{|c|}{ Gross Alpha $\left(\mathrm{Bq} / \mathrm{m}^{3}\right)$} & \multicolumn{5}{|c|}{ Gross Beta $\left(\mathrm{Bq} / \mathrm{m}^{3}\right)$} \\
\hline & Sample & $2 \times$ TPU $^{\mathbf{a}}$ & Duplicate & $2 \times \mathrm{TPU}$ & $\mathbf{R E R}^{\mathbf{b}}$ & Sample & $2 \times \mathrm{TPU}$ & Duplicate & $2 \times$ TPU & RER \\
\hline $01 / 03$ & $3.89 \times 10^{-5}$ & $2.15 \times 10^{-5}$ & $4.31 \times 10^{-5}$ & $2.38 \times 10^{-5}$ & 0.13 & $7.92 \times 10^{-4}$ & $1.13 \times 10^{-4}$ & $8.44 \times 10^{-4}$ & $1.22 \times 10^{-4}$ & 0.31 \\
\hline $01 / 10$ & $3.12 \times 10^{-5}$ & $1.90 \times 10^{-5}$ & $5.53 \times 10^{-5}$ & $2.45 \times 10^{-5}$ & 0.78 & $1.22 \times 10^{-3}$ & $1.56 \times 10^{-4}$ & $1.13 \times 10^{-3}$ & $1.46 \times 10^{-4}$ & 0.42 \\
\hline $01 / 17$ & $8.55 \times 10^{-5}$ & $3.01 \times 10^{-5}$ & $9.22 \times 10^{-5}$ & $3.16 \times 10^{-5}$ & 0.15 & $1.33 \times 10^{-3}$ & $1.64 \times 10^{-4}$ & $1.24 \times 10^{-3}$ & $1.56 \times 10^{-4}$ & 0.40 \\
\hline $01 / 24$ & $5.30 \times 10^{-5}$ & $2.34 \times 10^{-5}$ & $7.36 \times 10^{-5}$ & $2.79 \times 10^{-5}$ & 0.57 & $1.25 \times 10^{-3}$ & $1.57 \times 10^{-4}$ & $1.25 \times 10^{-3}$ & $1.57 \times 10^{-4}$ & 0.00 \\
\hline $01 / 31$ & $3.68 \times 10^{-5}$ & $1.98 \times 10^{-5}$ & $4.47 \times 10^{-5}$ & $2.19 \times 10^{-5}$ & 0.27 & $1.03 \times 10^{-3}$ & $1.35 \times 10^{-4}$ & $1.10 \times 10^{-3}$ & $1.42 \times 10^{-4}$ & 0.36 \\
\hline $02 / 07$ & $4.21 \times 10^{-5}$ & $2.18 \times 10^{-5}$ & $7.01 \times 10^{-5}$ & $2.79 \times 10^{-5}$ & 0.79 & $7.52 \times 10^{-4}$ & $1.08 \times 10^{-4}$ & $8.50 \times 10^{-4}$ & $1.17 \times 10^{-4}$ & 0.62 \\
\hline $02 / 14$ & $6.10 \times 10^{-5}$ & $2.63 \times 10^{-5}$ & $7.54 \times 10^{-5}$ & $2.90 \times 10^{-5}$ & 0.37 & $9.95 \times 10^{-4}$ & $1.33 \times 10^{-4}$ & $9.23 \times 10^{-4}$ & $1.25 \times 10^{-4}$ & 0.39 \\
\hline $02 / 21$ & $6.44 \times 10^{-5}$ & $2.61 \times 10^{-5}$ & $5.05 \times 10^{-5}$ & $2.33 \times 10^{-5}$ & 0.40 & $6.98 \times 10^{-4}$ & $1.00 \times 10^{-4}$ & $6.13 \times 10^{-4}$ & $9.21 \times 10^{-5}$ & 0.63 \\
\hline $02 / 28$ & $8.51 \times 10^{-5}$ & $3.16 \times 10^{-5}$ & $9.27 \times 10^{-5}$ & $3.30 \times 10^{-5}$ & 0.17 & $5.69 \times 10^{-4}$ & $8.92 \times 10^{-5}$ & $5.12 \times 10^{-4}$ & $8.30 \times 10^{-5}$ & 0.47 \\
\hline 03/06 & $3.88 \times 10^{-5}$ & $2.02 \times 10^{-5}$ & $4.19 \times 10^{-5}$ & $2.12 \times 10^{-5}$ & 0.11 & $7.94 \times 10^{-4}$ & $1.11 \times 10^{-4}$ & $7.45 \times 10^{-4}$ & $1.06 \times 10^{-4}$ & 0.32 \\
\hline $03 / 13$ & $2.84 \times 10^{-5}$ & $1.92 \times 10^{-5}$ & $1.91 \times 10^{-5}$ & $1.59 \times 10^{-5}$ & 0.37 & $5.69 \times 10^{-4}$ & $9.04 \times 10^{-5}$ & $6.23 \times 10^{-4}$ & $9.49 \times 10^{-5}$ & 0.41 \\
\hline $03 / 20$ & $8.82 \times 10^{-5}$ & $3.65 \times 10^{-5}$ & $5.66 \times 10^{-5}$ & $3.04 \times 10^{-5}$ & 0.67 & $7.87 \times 10^{-4}$ & $1.22 \times 10^{-4}$ & $9.20 \times 10^{-4}$ & $1.38 \times 10^{-4}$ & 0.72 \\
\hline $03 / 27$ & $2.87 \times 10^{-5}$ & $1.74 \times 10^{-5}$ & $2.97 \times 10^{-5}$ & $1.80 \times 10^{-5}$ & 0.04 & $6.35 \times 10^{-4}$ & $9.28 \times 10^{-5}$ & $6.65 \times 10^{-4}$ & $9.69 \times 10^{-5}$ & 0.22 \\
\hline
\end{tabular}

${ }^{\mathrm{a}}$ Total propagated uncertainty

${ }^{\mathrm{b}}$ Relative error ratio 
Table 8.2 Comparison of duplicate air monitoring results (second quarter of 2000) from WIPP Environmental Monitoring Laboratory data from Carlsbad (CBD) sampling location.

\begin{tabular}{|c|c|c|c|c|c|c|c|c|c|c|}
\hline \multirow{2}{*}{ Week Beginning } & \multicolumn{5}{|c|}{ Gross Alpha $\left(\mathrm{Bq} / \mathrm{m}^{3}\right)$} & \multicolumn{5}{|c|}{ Gross Beta $\left(\mathrm{Bq} / \mathrm{m}^{3}\right)$} \\
\hline & Sample & $2 \times T^{\mathrm{T}} \mathbf{U}^{\mathrm{a}}$ & Duplicate & $2 \times$ TPU & $\mathbf{R E R}^{\mathbf{b}}$ & Sample & $2 \times$ TPU & Duplicate & $2 \times \mathrm{TPU}$ & RER \\
\hline $01 / 03$ & $1.36 \times 10^{-4}$ & $3.80 \times 10^{-5}$ & $1.05 \times 10^{-4}$ & $3.38 \times 10^{-5}$ & 0.61 & $7.34 \times 10^{-4}$ & $1.06 \times 10^{-4}$ & $6.79 \times 10^{-4}$ & $1.02 \times 10^{-4}$ & 0.37 \\
\hline $01 / 10$ & $3.25 \times 10^{-5}$ & $2.01 \times 10^{-5}$ & $4.33 \times 10^{-5}$ & $2.37 \times 10^{-5}$ & 0.35 & $6.66 \times 10^{-4}$ & $9.68 \times 10^{-5}$ & $7.27 \times 10^{-4}$ & $1.05 \times 10^{-4}$ & 0.43 \\
\hline $01 / 17$ & $3.74 \times 10^{-5}$ & $2.21 \times 10^{-5}$ & $1.90 \times 10^{-5}$ & $1.71 \times 10^{-5}$ & 0.66 & $6.91 \times 10^{-4}$ & $1.01 \times 10^{-4}$ & $6.83 \times 10^{-4}$ & $1.00 \times 10^{-4}$ & 0.06 \\
\hline $01 / 24$ & $1.34 \times 10^{-4}$ & $4.16 \times 10^{-5}$ & $1.08 \times 10^{-4}$ & $3.60 \times 10^{-5}$ & 0.47 & $7.31 \times 10^{-4}$ & $1.09 \times 10^{-4}$ & $7.54 \times 10^{-4}$ & $1.09 \times 10^{-4}$ & 0.15 \\
\hline $01 / 31$ & $9.65 \times 10^{-5}$ & $2.99 \times 10^{-5}$ & $9.18 \times 10^{-5}$ & $2.90 \times 10^{-5}$ & 0.11 & $8.92 \times 10^{-4}$ & $1.19 \times 10^{-4}$ & $9.67 \times 10^{-4}$ & $1.27 \times 10^{-4}$ & 0.43 \\
\hline $02 / 07$ & $1.01 \times 10^{-4}$ & $3.55 \times 10^{-5}$ & $9.68 \times 10^{-5}$ & $3.37 \times 10^{-5}$ & 0.09 & $7.26 \times 10^{-4}$ & $1.08 \times 10^{-4}$ & $7.95 \times 10^{-4}$ & $1.13 \times 10^{-4}$ & 0.44 \\
\hline $02 / 14$ & $4.29 \times 10^{-5}$ & $2.26 \times 10^{-5}$ & $4.66 \times 10^{-5}$ & $2.38 \times 10^{-5}$ & 0.11 & $8.73 \times 10^{-4}$ & $1.20 \times 10^{-4}$ & $7.96 \times 10^{-4}$ & $1.13 \times 10^{-4}$ & 0.47 \\
\hline $02 / 21$ & $5.28 \times 10^{-5}$ & $2.46 \times 10^{-5}$ & $6.50 \times 10^{-5}$ & $2.76 \times 10^{-5}$ & 0.33 & $9.15 \times 10^{-4}$ & $1.24 \times 10^{-4}$ & $8.25 \times 10^{-4}$ & $1.15 \times 10^{-4}$ & 0.53 \\
\hline $02 / 28$ & $8.44 \times 10^{-5}$ & $3.09 \times 10^{-5}$ & $8.44 \times 10^{-5}$ & $3.09 \times 10^{-5}$ & 0.00 & $7.66 \times 10^{-4}$ & $1.09 \times 10^{-4}$ & $7.98 \times 10^{-4}$ & $1.12 \times 10^{-4}$ & 0.20 \\
\hline $03 / 06$ & $5.80 \times 10^{-5}$ & $2.55 \times 10^{-5}$ & $8.63 \times 10^{-5}$ & $3.16 \times 10^{-5}$ & 0.70 & $8.51 \times 10^{-4}$ & $1.17 \times 10^{-4}$ & $9.16 \times 10^{-4}$ & $1.25 \times 10^{-4}$ & 0.38 \\
\hline $03 / 13$ & $1.03 \times 10^{-4}$ & $3.45 \times 10^{-5}$ & $1.26 \times 10^{-4}$ & $3.74 \times 10^{-5}$ & 0.45 & $4.47 \times 10^{-4}$ & $7.69 \times 10^{-5}$ & $5.26 \times 10^{-4}$ & $8.38 \times 10^{-5}$ & 0.69 \\
\hline $03 / 20$ & $1.70 \times 10^{-4}$ & $4.48 \times 10^{-5}$ & $1.14 \times 10^{-4}$ & $3.59 \times 10^{-5}$ & 0.98 & $6.72 \times 10^{-4}$ & $9.92 \times 10^{-5}$ & $6.69 \times 10^{-4}$ & $9.87 \times 10^{-5}$ & 0.02 \\
\hline $03 / 27$ & $1.33 \times 10^{-4}$ & $3.85 \times 10^{-5}$ & $1.42 \times 10^{-4}$ & $3.99 \times 10^{-5}$ & 0.16 & $7.37 \times 10^{-4}$ & $1.05 \times 10^{-4}$ & $7.77 \times 10^{-4}$ & $1.09 \times 10^{-4}$ & 0.26 \\
\hline
\end{tabular}

${ }^{\mathrm{a}}$ Total propagated uncertainty

${ }^{\mathrm{b}}$ Relative error ratio 
Table 8.3 Comparison of duplicate air monitoring results (third quarter of 2000) from WIPP Environmental Monitoring Laboratory data from South East Control (SEC) sampling location.

\begin{tabular}{|c|c|c|c|c|c|c|c|c|c|c|}
\hline \multirow{2}{*}{ Week Beginning } & \multicolumn{5}{|c|}{ Gross Alpha $\left(\mathrm{Bq} / \mathrm{m}^{3}\right)$} & \multicolumn{5}{|c|}{ Gross Beta $\left(\mathrm{Bq} / \mathrm{m}^{3}\right)$} \\
\hline & Sample & $2 \times$ TPU $^{\mathrm{a}}$ & Duplicate & $2 \times \mathrm{TPU}$ & $\mathbf{R E R}^{\mathrm{b}}$ & Sample & $2 \times \mathrm{TPU}$ & Duplicate & $2 \times$ TPU & RER \\
\hline $01 / 03$ & $1.61 \times 10^{-4}$ & $4.29 \times 10^{-5}$ & $1.75 \times 10^{-4}$ & $4.60 \times 10^{-5}$ & 0.22 & $9.36 \times 10^{-4}$ & $1.25 \times 10^{-4}$ & $9.46 \times 10^{-4}$ & $1.27 \times 10^{-4}$ & 0.06 \\
\hline $01 / 10$ & $1.44 \times 10^{-4}$ & $4.08 \times 10^{-5}$ & $1.59 \times 10^{-4}$ & $4.25 \times 10^{-5}$ & 0.25 & $9.01 \times 10^{-4}$ & $1.22 \times 10^{-4}$ & $1.02 \times 10^{-3}$ & $1.34 \times 10^{-4}$ & 0.66 \\
\hline $01 / 17$ & $1.41 \times 10^{-4}$ & $4.10 \times 10^{-5}$ & $1.48 \times 10^{-4}$ & $4.22 \times 10^{-5}$ & 0.12 & $1.08 \times 10^{-3}$ & $1.41 \times 10^{-4}$ & $1.06 \times 10^{-3}$ & $1.39 \times 10^{-4}$ & 0.10 \\
\hline $01 / 24$ & $1.58 \times 10^{-4}$ & $4.06 \times 10^{-5}$ & $1.46 \times 10^{-4}$ & $3.91 \times 10^{-5}$ & 0.21 & $1.18 \times 10^{-3}$ & $1.47 \times 10^{-4}$ & $1.17 \times 10^{-3}$ & $1.46 \times 10^{-4}$ & 0.25 \\
\hline $01 / 31$ & $6.43 \times 10^{-5}$ & $2.98 \times 10^{-5}$ & $6.60 \times 10^{-5}$ & $3.06 \times 10^{-5}$ & 0.04 & $7.99 \times 10^{-4}$ & $1.18 \times 10^{-4}$ & $8.42 \times 10^{-4}$ & $1.23 \times 10^{-4}$ & 0.05 \\
\hline $02 / 07$ & $1.24 \times 10^{-4}$ & $3.98 \times 10^{-5}$ & $1.02 \times 10^{-4}$ & $3.54 \times 10^{-5}$ & 0.41 & $8.80 \times 10^{-4}$ & $1.24 \times 10^{-4}$ & $9.35 \times 10^{-4}$ & $1.29 \times 10^{-4}$ & 0.25 \\
\hline $02 / 14$ & $1.26 \times 10^{-4}$ & $3.65 \times 10^{-5}$ & $9.53 \times 10^{-5}$ & $3.08 \times 10^{-5}$ & 0.64 & $6.37 \times 10^{-4}$ & $9.37 \times 10^{-5}$ & $7.57 \times 10^{-4}$ & $1.05 \times 10^{-4}$ & 0.31 \\
\hline $02 / 21$ & $5.93 \times 10^{-5}$ & $2.67 \times 10^{-5}$ & $4.48 \times 10^{-5}$ & $2.31 \times 10^{-5}$ & 0.41 & $7.31 \times 10^{-4}$ & $1.06 \times 10^{-4}$ & $8.03 \times 10^{-4}$ & $1.12 \times 10^{-4}$ & 0.85 \\
\hline $02 / 28$ & $1.23 \times 10^{-4}$ & $3.84 \times 10^{-5}$ & $8.75 \times 10^{-5}$ & $3.18 \times 10^{-5}$ & 0.71 & $1.08 \times 10^{-3}$ & $1.42 \times 10^{-4}$ & $1.20 \times 10^{-3}$ & $1.53 \times 10^{-4}$ & 0.47 \\
\hline $03 / 06$ & $8.97 \times 10^{-5}$ & $3.21 \times 10^{-5}$ & $1.17 \times 10^{-4}$ & $3.65 \times 10^{-5}$ & 0.56 & $1.22 \times 10^{-3}$ & $1.56 \times 10^{-4}$ & $1.18 \times 10^{-3}$ & $1.51 \times 10^{-4}$ & 0.57 \\
\hline $03 / 13$ & $6.19 \times 10^{-5}$ & $2.62 \times 10^{-5}$ & $8.72 \times 10^{-5}$ & $3.16 \times 10^{-5}$ & 0.62 & $1.20 \times 10^{-3}$ & $1.52 \times 10^{-4}$ & $1.34 \times 10^{-3}$ & $1.68 \times 10^{-4}$ & 0.18 \\
\hline $03 / 20$ & $7.04 \times 10^{-5}$ & $2.79 \times 10^{-5}$ & $8.59 \times 10^{-5}$ & $3.05 \times 10^{-5}$ & 0.37 & $8.64 \times 10^{-4}$ & $1.18 \times 10^{-4}$ & $9.77 \times 10^{-4}$ & $1.28 \times 10^{-4}$ & 0.62 \\
\hline $03 / 27$ & $1.22 \times 10^{-4}$ & $3.74 \times 10^{-5}$ & $1.30 \times 10^{-4}$ & $3.96 \times 10^{-5}$ & 0.15 & $1.26 \times 10^{-3}$ & $1.60 \times 10^{-4}$ & $1.45 \times 10^{-3}$ & $1.80 \times 10^{-4}$ & 0.79 \\
\hline
\end{tabular}

${ }^{\mathrm{a}}$ Total propagated uncertainty

${ }^{\mathrm{b}}$ Relative error ratio 
Table 8.4 Comparison of duplicate air monitoring results (fourth quarter of 2000) from WIPP Environmental Monitoring Laboratory data from WIPP Far Field (WFF) sampling location.

\begin{tabular}{|c|c|c|c|c|c|c|c|c|c|c|}
\hline \multirow{2}{*}{ Week Beginning } & \multicolumn{5}{|c|}{ Gross Alpha $\left(\mathrm{Bq} / \mathrm{m}^{3}\right)$} & \multicolumn{5}{|c|}{ Gross Beta $\left(\mathrm{Bq} / \mathrm{m}^{3}\right)$} \\
\hline & Sample & $2 \times \mathbf{T P U}^{\mathbf{a}}$ & Duplicate & $2 \times$ TPU & $\mathbf{R E R}^{\mathbf{b}}$ & Sample & $2 \times$ TPU & Duplicate & $2 \times$ TPU & RER \\
\hline $01 / 03$ & $1.03 \times 10^{-4}$ & $3.36 \times 10^{-5}$ & $1.12 \times 10^{-4}$ & $3.48 \times 10^{-5}$ & 0.19 & $1.27 \times 10^{-3}$ & $1.58 \times 10^{-4}$ & $1.15 \times 10^{-3}$ & $1.47 \times 10^{-4}$ & 0.56 \\
\hline $01 / 10$ & $3.58 \times 10^{-5}$ & $1.99 \times 10^{-5}$ & $3.24 \times 10^{-5}$ & $1.88 \times 10^{-5}$ & 0.12 & $6.68 \times 10^{-4}$ & $9.81 \times 10^{-5}$ & $6.31 \times 10^{-4}$ & $9.50 \times 10^{-5}$ & 0.27 \\
\hline $01 / 17$ & $4.34 \times 10^{-5}$ & $2.13 \times 10^{-5}$ & $6.13 \times 10^{-5}$ & $2.54 \times 10^{-5}$ & 0.54 & $6.34 \times 10^{-4}$ & $9.43 \times 10^{-5}$ & $6.32 \times 10^{-4}$ & $9.38 \times 10^{-5}$ & 0.02 \\
\hline $01 / 24$ & $6.93 \times 10^{-5}$ & $2.72 \times 10^{-5}$ & $5.73 \times 10^{-5}$ & $2.48 \times 10^{-5}$ & 0.33 & $6.91 \times 10^{-4}$ & $1.01 \times 10^{-4}$ & $6.42 \times 10^{-4}$ & $9.54 \times 10^{-5}$ & 0.35 \\
\hline $01 / 31$ & $3.11 \times 10^{-5}$ & $1.81 \times 10^{-5}$ & $2.43 \times 10^{-5}$ & $1.62 \times 10^{-5}$ & 0.28 & $4.94 \times 10^{-4}$ & $7.97 \times 10^{-5}$ & $5.36 \times 10^{-4}$ & $8.37 \times 10^{-5}$ & 0.36 \\
\hline $02 / 07$ & $1.49 \times 10^{-4}$ & $4.13 \times 10^{-5}$ & $2.13 \times 10^{-4}$ & $4.97 \times 10^{-5}$ & 0.99 & $2.05 \times 10^{-3}$ & $2.36 \times 10^{-4}$ & $1.23 \times 10^{-3}$ & $1.55 \times 10^{-4}$ & 2.90 \\
\hline $02 / 14$ & $2.10 \times 10^{-4}$ & $5.40 \times 10^{-5}$ & $2.62 \times 10^{-4}$ & $6.02 \times 10^{-5}$ & 0.64 & $1.95 \times 10^{-3}$ & $2.32 \times 10^{-4}$ & $2.09 \times 10^{-3}$ & $2.47 \times 10^{-4}$ & 0.41 \\
\hline $02 / 21$ & $1.59 \times 10^{-4}$ & $4.03 \times 10^{-5}$ & $1.69 \times 10^{-4}$ & $4.18 \times 10^{-5}$ & 0.17 & $1.73 \times 10^{-3}$ & $2.01 \times 10^{-4}$ & $1.02 \times 10^{-3}$ & $1.30 \times 10^{-4}$ & 2.97 \\
\hline $02 / 28$ & $1.44 \times 10^{-4}$ & $4.00 \times 10^{-5}$ & $1.31 \times 10^{-4}$ & $3.77 \times 10^{-5}$ & 0.24 & $1.48 \times 10^{-3}$ & $1.80 \times 10^{-4}$ & $1.50 \times 10^{-3}$ & $1.82 \times 10^{-4}$ & 0.08 \\
\hline $03 / 06$ & $9.65 \times 10^{-5}$ & $3.23 \times 10^{-5}$ & $7.72 \times 10^{-5}$ & $2.80 \times 10^{-5}$ & 0.45 & $1.28 \times 10^{-3}$ & $1.58 \times 10^{-4}$ & $1.15 \times 10^{-3}$ & $1.48 \times 10^{-4}$ & 0.60 \\
\hline $03 / 13$ & $4.59 \times 10^{-5}$ & $2.18 \times 10^{-5}$ & $6.30 \times 10^{-5}$ & $2.56 \times 10^{-5}$ & 0.51 & $8.42 \times 10^{-4}$ & $1.15 \times 10^{-4}$ & $7.19 \times 10^{-4}$ & $1.03 \times 10^{-4}$ & 0.80 \\
\hline $03 / 20$ & $7.02 \times 10^{-5}$ & $2.76 \times 10^{-5}$ & $4.68 \times 10^{-5}$ & $2.24 \times 10^{-5}$ & 0.66 & $1.13 \times 10^{-3}$ & $1.45 \times 10^{-4}$ & $1.19 \times 10^{-3}$ & $1.52 \times 10^{-4}$ & 0.29 \\
\hline $03 / 27$ & $9.14 \times 10^{-5}$ & $3.08 \times 10^{-5}$ & $7.71 \times 10^{-5}$ & $2.86 \times 10^{-5}$ & 0.34 & $1.61 \times 10^{-3}$ & $1.94 \times 10^{-4}$ & $1.41 \times 10^{-3}$ & $1.72 \times 10^{-4}$ & 0.77 \\
\hline
\end{tabular}

${ }^{\mathrm{a}}$ Total propagated uncertainty

${ }^{\mathrm{b}}$ Relative error ratio 
Table 8.5 Environmental Measurements Laboratory Assessments for Wastren, 2000

MATRIX: Air Filter (Bq/filter)

\begin{tabular}{|c|c|c|c|c|c|c|c|c|c|c|}
\hline \multirow[b]{3}{*}{$\mathbf{R N}^{\mathbf{c}}$} & \multicolumn{5}{|c|}{ QAP $^{\text {a }} 52$ June 2000 } & \multicolumn{4}{|c|}{ QAP 53 December 2000 } & \multirow[b]{3}{*}{$\%$ Bias } \\
\hline & \multicolumn{2}{|c|}{ Reported } & \multicolumn{2}{|c|}{ EML $^{\mathbf{b}}$} & \multirow[b]{2}{*}{$\%$ Bias } & \multicolumn{2}{|c|}{ Reported } & \multicolumn{2}{|c|}{ EML } & \\
\hline & Value & Error & Value & Error & & Value & Error & Value & Error & \\
\hline${ }^{241} \mathrm{Am}$ & 0.081 & 0.010 & 0.088 & 0.005 & -7.95 & 0.033 & 0.007 & 0.032 & 0.001 & 3.13 \\
\hline${ }^{57} \mathrm{Co}$ & 5.000 & 1.000 & 5.310 & 0.220 & -5.84 & 19.000 & 2.000 & 14.550 & 0.460 & 30.58 \\
\hline${ }^{60} \mathrm{Co}$ & 6.000 & 1.000 & 5.320 & 0.260 & 12.78 & 10.000 & 1.000 & 8.430 & 0.480 & 18.62 \\
\hline${ }^{137} \mathrm{Cs}$ & 6.000 & 1.000 & 6.100 & 0.300 & -1.64 & 9.000 & 2.000 & 7.410 & 0.360 & 21.46 \\
\hline Gross $\alpha$ & 2.567 & 0.248 & 3.020 & 0.300 & -15.00 & 2.520 & 0.280 & 2.350 & 0.150 & 7.23 \\
\hline Gross $\beta$ & 2.607 & 0.264 & 2.420 & 0.260 & 0.20 & 1.380 & 0.160 & 1.520 & 0.150 & -9.21 \\
\hline${ }^{54} \mathrm{Mn}$ & 27.000 & 9.000 & 27.200 & 0.800 & -0.74 & 54.000 & 8.000 & 43.200 & 1.300 & 25.00 \\
\hline${ }^{238} \mathrm{Pu}$ & 0.077 & 0.012 & 0.080 & 0.001 & -3.75 & 0.047 & 0.008 & 0.045 & 0.001 & 4.44 \\
\hline${ }^{239} \mathrm{Pu}$ & 0.089 & 0.014 & 0.089 & 0.003 & 0.00 & 0.076 & 0.011 & 0.074 & 0.007 & 2.70 \\
\hline${ }^{90} \mathrm{Sr}$ & 0.208 & 0.027 & 0.242 & 0.005 & -14.05 & 1.450 & 0.080 & 1.640 & 0.110 & -11.59 \\
\hline${ }^{234} \mathrm{U}$ & 0.061 & 0.010 & 0.062 & 0.001 & -1.61 & 0.038 & 0.006 & 0.041 & 0.003 & -7.32 \\
\hline${ }^{238} \mathrm{U}$ & 0.061 & 0.010 & 0.062 & 0.001 & -1.61 & 0.039 & 0.007 & 0.041 & 0.002 & 4.87 \\
\hline тот U( $\mu \mathrm{g})$ & 5.124 & $\mathrm{~N} / \mathrm{A}^{\mathrm{d}}$ & 4.980 & 0.030 & 2.89 & 3.100 & N/A & 3.330 & 0.140 & -6.91 \\
\hline
\end{tabular}

Table 8.6 Environmental Measurements Laboratory Assessments for Wastren, 2000.

MATRIX: Soil (Bq/kg)

\begin{tabular}{|c|c|c|c|c|c|c|c|c|c|c|}
\hline \multirow[b]{3}{*}{$\mathbf{R} \mathbf{N}^{\mathrm{c}}$} & \multicolumn{5}{|c|}{ QAP $^{\text {a }} 52$ June 2000 } & \multicolumn{4}{|c|}{ QAP 53 December 2000 } & \multirow[b]{3}{*}{$\%$ Bias } \\
\hline & \multicolumn{2}{|c|}{ Reported } & \multicolumn{2}{|c|}{$\mathbf{E M L}^{\mathbf{b}}$} & \multirow[b]{2}{*}{$\%$ Bias } & \multicolumn{2}{|c|}{ Reported } & \multicolumn{2}{|c|}{ EML } & \\
\hline & Value & Error & Value & Error & & Value & Error & Value & Error & \\
\hline$\overline{{ }^{228} \mathrm{Ac}}$ & 136.00 & 11.00 & 97.60 & 4.20 & 39.34 & $\mathrm{~N} / \mathrm{A}^{\mathrm{d}}$ & $\overline{\mathrm{N} / \mathrm{A}}$ & $\overline{\mathrm{N} / \mathrm{A}}$ & $\overline{\mathrm{N} / \mathrm{A}}$ & $\overline{\mathrm{N} / \mathrm{A}}$ \\
\hline${ }^{241} \mathrm{Am}$ & 2.79 & 0.62 & 3.36 & 0.51 & -16.96 & 8.11 & 1.04 & 8.27 & 0.98 & -1.93 \\
\hline${ }^{214} \mathrm{Bi}$ & N/A & N/A & N/A & N/A & N/A & 8.11 & 1.04 & 8.27 & 0.70 & -1.93 \\
\hline${ }^{137} \mathrm{Cs}$ & 443.00 & 24.00 & 339.00 & 9.30 & 30.68 & 1033.00 & 118.00 & 1020.00 & 51.00 & 1.27 \\
\hline${ }^{40} \mathrm{~K}$ & 1221.00 & 68.00 & 811.00 & 29.00 & 50.55 & 1113.00 & 348.00 & 713.00 & 38.00 & $56.10^{\mathrm{e}}$ \\
\hline${ }^{212} \mathrm{~Pb}$ & N/A & N/A & N/A & N/A & N/A & 86.00 & 10.00 & 79.30 & 4.30 & 8.45 \\
\hline${ }^{214} \mathrm{~Pb}$ & N/A & N/A & N/A & N/A & N/A & 127.00 & 10.00 & 86.30 & 4.30 & 47.16 \\
\hline${ }^{238} \mathrm{Pu}$ & 18.20 & 1.90 & 18.60 & 0.50 & -2.15 & N/A & $\mathrm{N} / \mathrm{A}$ & N/A & N/A & N/A \\
\hline${ }^{239} \mathrm{Pu}$ & 6.97 & 0.94 & 7.00 & 0.34 & -0.43 & 17.72 & 1.78 & 16.80 & 0.30 & 5.48 \\
\hline 帛 $\mathrm{Sr}$ & 18.90 & 3.50 & 20.20 & 0.20 & -6.44 & 47.20 & 4.70 & 50.40 & 2.00 & -6.35 \\
\hline${ }^{234} \mathrm{Th}$ & 103.00 & 34.00 & 130.00 & 5.00 & -20.77 & 172.00 & 20.00 & 148.00 & 10.00 & 16.22 \\
\hline${ }^{234} \mathrm{U}$ & 122.06 & 10.16 & 111.00 & 11.00 & 9.96 & 140.50 & 12.70 & 157.00 & 10.00 & -10.51 \\
\hline${ }^{238} \mathrm{U}$ & 124.40 & 10.29 & 114.00 & 12.00 & 9.12 & 146.30 & 13.10 & 163.00 & 10.00 & -10.25 \\
\hline TотU $(\mu \mathrm{g})$ & 10.08 & N/A & 9.15 & 0.91 & 10.16 & 12.30 & N/A & 13.20 & 0.50 & -6.82 \\
\hline
\end{tabular}


Table 8.7 Environmental Measurements Laboratory Assessments for Wastren, 2000.

MATRIX: Vegetation $(\mathrm{Bq} / \mathrm{kg})$

\begin{tabular}{|c|c|c|c|c|c|c|c|c|c|c|}
\hline \multirow[b]{3}{*}{$\mathbf{R} \mathbf{N}^{\mathbf{c}}$} & \multicolumn{5}{|c|}{ QAP $^{\mathrm{a}} 52$ June 2000} & \multicolumn{4}{|c|}{ QAP 53 December 2000} & \multirow[b]{3}{*}{$\%$ Bias } \\
\hline & \multicolumn{2}{|c|}{ Reported } & \multicolumn{2}{|c|}{ EML $^{b}$} & \multirow[b]{2}{*}{$\%$ Bias } & \multicolumn{2}{|c|}{ Reported } & \multicolumn{2}{|c|}{ EML } & \\
\hline & Value & Error & Value & Error & & Value & Error & Value & Error & \\
\hline${ }^{241} \mathrm{Am}$ & 9.75 & 0.99 & 10.40 & 1.40 & -6.25 & 5.84 & 0.67 & 5.60 & 0.67 & 4.29 \\
\hline${ }^{244} \mathrm{Cm}$ & 5.84 & 0.69 & 5.00 & 1.80 & 16.80 & 3.66 & 0.49 & 3.60 & 0.27 & 1.67 \\
\hline${ }^{60} \mathrm{Co}$ & 61.00 & 5.00 & 52.80 & 1.00 & 15.53 & 37.00 & 4.00 & 32.80 & 1.30 & 12.80 \\
\hline${ }^{137} \mathrm{Cs}$ & 1505.00 & 160.00 & 1380.00 & 20.00 & 9.06 & 826.00 & 98.00 & 867.00 & 44.00 & -4.73 \\
\hline${ }^{40} \mathrm{~K}$ & 722.00 & 84.00 & 521.00 & 20.00 & 38.58 & 1065.00 & 332.00 & 639.00 & 34.00 & $66.67^{\mathrm{d}}$ \\
\hline${ }^{239} \mathrm{Pu}$ & 14.25 & 1.52 & 15.50 & 2.10 & -8.06 & 8.76 & 0.99 & 9.60 & 0.80 & -8.75 \\
\hline${ }^{90} \mathrm{Sr}$ & 1851.00 & 97.00 & 1780.00 & 17.80 & 3.99 & 1206.00 & 66.00 & 1150.00 & 94.00 & 4.87 \\
\hline
\end{tabular}

${ }^{a}$ Quality Assurance Program

${ }^{\mathrm{b}}$ Environmental Measurements Laboratory

${ }^{\mathrm{c}}$ Radionuclide

${ }^{\mathrm{d}}$ Not Acceptable

Table 8.8 Environmental Measurements Laboratory Assessments for Wastren, 2000.

MATRIX: Water $(\mathrm{Bq} / \mathrm{L})$

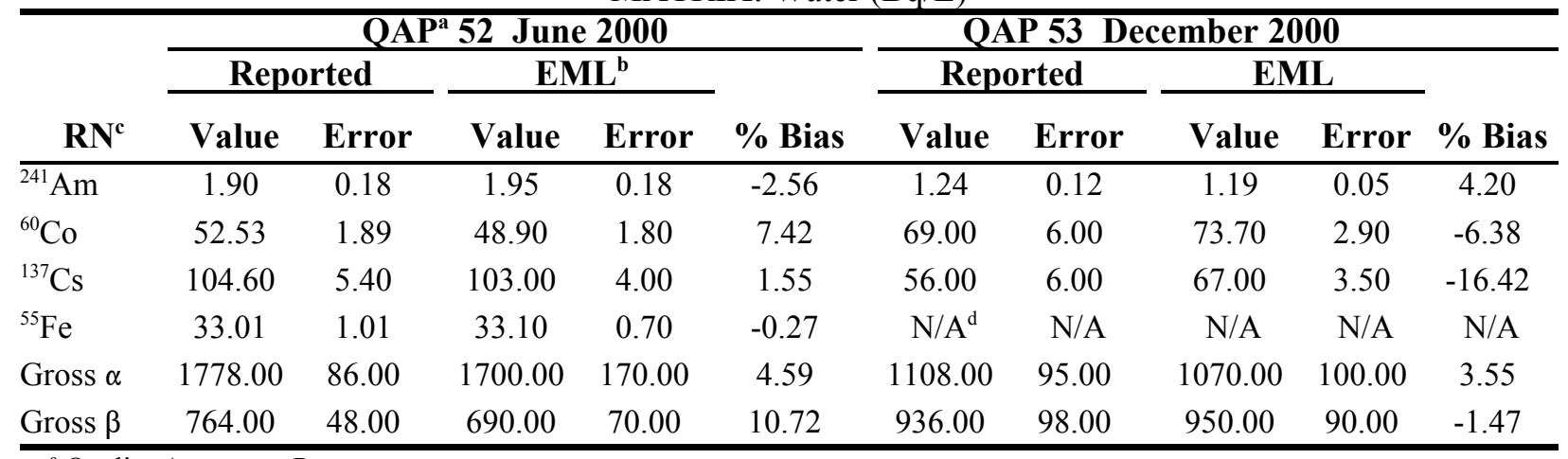

${ }^{\text {a }}$ Quality Assurance Program

${ }^{\mathrm{b}}$ Environmental Measurements Laboratory

${ }^{\mathrm{c}}$ Radionuclide

${ }^{\mathrm{d}}$ Not Applicable 


\subsection{Representativeness}

The primary objective of environmental monitoring has been to protect the health and safety of the population surrounding the WIPP facility. The quality objective of representativeness was based on potential radiation exposure of the population through inhalation and ingestion. Samples of ambient air, surface water, sediment, groundwater, and biota were collected from areas representative of potential pathways for intake.

The samples were collected using generally accepted methodologies for environmental sampling and approved procedures, ensuring they were representative of the media sampled. These samples were analyzed for natural radioactivity, fallout radioactivity from nuclear weapons tests, and other anthropogenic radionuclides. The reported concentrations at various locations were representative of the baseline information for radionuclides of interest at the WIPP facility.

Air Toxics, Inc., participated in the Environmental Laboratory Approval Program, associated with the New York State Department of Health, for 34 volatile organic compounds (VOCs) in non-potable water. Results were $100 \%$ satisfactory (Table 8.9). Environmental Resource Associates provided a similar interlaboratory performance assessment of Air Toxics, Inc, 49 VOCs in non-potable water. The InterLaB ${ }^{\mathrm{TM}}$ score was $100 \%$, with an overall assessment of "Excellent" (Table 8.10)

Trace Analysis, Inc., participated in several Environmental Associates interlaboratory assessments. For the initial (September 11, 2000) run of QuiK ${ }^{\mathrm{TM}}$ response performance standards for PotableWatR ${ }^{\mathrm{TM}}$ Metals (Table $8.11), 16$ of 21 (76.2\%) parameters were acceptable. Subsequently, 4 analytes were reevaluated and all were acceptable. Other PE results from Environmental Resource Associates interlaboratory comparisons for Trace Analysis,
Inc., were for diverse suite of analytes and parameters in groundwater (Tables 8.12 through $8.17)$, many of which were evaluated several times during the year.

Table by table, InterLaB ${ }^{\mathrm{TM}}$ scores and Overall Assessments were:

- $\quad$ Table $8.12-86.5 \%$, Very Good.

- Table $8.13-50 \%$, Needs Improvement

- Table 8.14-82.5\%, Good

- Table $8.15-96.0 \%$, Excellent

- Table 8.16-97.2\%, Excellent

- $\quad$ Table 8.17

- Without Pesticides - 95\%, Excellent

- With Pesticides - 90.2\%, Very Good

- Pesticides only $-35.3 \%$, Needs Improvement.

In most cases where the Overall Assessment was less than Excellent, Trace Analysis, Inc., was able to review procedures, check calibrations, identify changes in lab personnel, and otherwise determine why failures occurred and provide corrective actions to improve future performance. Regarding the poor performance reported in Table 8.13, Trace Analysis, Inc., reported two unrelated sample batches were in the laboratory at the same time. The analyst mistakenly applied the preparation instructions for one batch to both, thus halving the dilution and doubling the concentration. If half the reported value were used, 39 of 40 analytes $(97.5 \%)$ would fall within the acceptable range and the overall assessment would have been excellent.

The pesticide results reported in Table 8.17 represent the only interlaboratory comparison by Environmental Resource Associates for pesticides in which Trace Analysis, Inc. participated in 2000. This intercomparison was conducted in mid-December, 2000, and no internal evaluation and corrective action was available during the period covered by this Annual Site Environmental Report. 
Table 8.9 Performance evaluation of Air Toxics,Inc., for volatile organic compounds in non-potable water $^{\mathrm{a}}(\mu \mathrm{g} / \mathrm{L})$.

\begin{tabular}{|c|c|c|c|c|c|c|c|c|}
\hline \multirow[b]{2}{*}{ Analyte } & \multicolumn{4}{|c|}{ Date: January 24, 2000} & \multicolumn{4}{|c|}{ Date: July 24, 2000} \\
\hline & Result & Target & Limits & Score & Result & Target & Limits & Score \\
\hline \multicolumn{9}{|l|}{ Non-Potable Water } \\
\hline \multicolumn{9}{|l|}{ Purgable Aromatics } \\
\hline 1,3 Dichlorobenzene & 14.2 & 14.0 & $10-18$ & $\mathrm{~S}^{\mathrm{b}}$ & 39.2 & 37.3 & $26.9-47.7$ & $\mathrm{~S}$ \\
\hline Benzene & 53.6 & 55.3 & $40-70$ & $\mathrm{~S}$ & 31.7 & 32.1 & $22.9-41.4$ & $\mathrm{~S}$ \\
\hline Chlorobenzene & 30.8 & 29.6 & $22-37$ & $\mathrm{~S}$ & 23.9 & 23.0 & $16.7-29.3$ & $\mathrm{~S}$ \\
\hline Ethyl Benzene & 35.6 & 33.3 & $23-43$ & $\mathrm{~S}$ & 46.6 & 44.6 & $30.2-59.1$ & $\mathrm{~S}$ \\
\hline Toluene & 17.0 & 17.1 & $13-22$ & $\mathrm{~S}$ & 32.4 & 31.5 & $22.8-40.2$ & $\mathrm{~S}$ \\
\hline Total Xylene & 20.9 & 20.5 & $11-30$ & $\mathrm{~S}$ & 30.4 & 29.1 & $16.0-42.1$ & $\mathrm{~S}$ \\
\hline \multicolumn{9}{|l|}{ Purgable Halocarbons } \\
\hline $1,1,1$, -Trichlorethane & 26.0 & 25.6 & $17-34$ & $\mathrm{~S}$ & 37.9 & 37.9 & $25.0-50.8$ & S \\
\hline 1,1,2,2-Tetrachlorethane & 16.4 & 15.3 & $09-22$ & $\mathrm{~S}$ & 37.6 & 34.5 & $20.0-48.9$ & $\mathrm{~S}$ \\
\hline 1,1-Dichloroethene & 28.1 & 29.8 & $15-45$ & $\mathrm{~S}$ & 17.9 & 19.8 & $08.7-30.8$ & S \\
\hline 1,2-Dichloroethane & 55.6 & 52.8 & $37-69$ & $\mathrm{~S}$ & 39.8 & 37.5 & $25.6-49.3$ & S \\
\hline Carbon Tetrachloride & 40.9 & 39.2 & $24-54$ & $\mathrm{~S}$ & 24.8 & 25.3 & $15.5-35.0$ & $\mathrm{~S}$ \\
\hline Bromomethane & 25.8 & 38.0 & $10-66$ & $\mathrm{~S}$ & 35.9 & 66.5 & $17.5-116$ & $\mathrm{~S}$ \\
\hline Dibromochloromethane & 59.6 & 56.6 & $38-75$ & $\mathrm{~S}$ & 25.6 & 24.6 & $16.3-32.9$ & $\mathrm{~S}$ \\
\hline Chlorethane & 45.5 & 48.5 & $21-76$ & $\mathrm{~S}$ & 34.8 & 36.5 & $16.1-57.0$ & S \\
\hline Chloroform & 16.5 & 16.4 & $12-21$ & $\mathrm{~S}$ & 27.6 & 27.4 & $19.3-35.4$ & $\mathrm{~S}$ \\
\hline Methylene chloride & 53.7 & 51.8 & $33-71$ & $\mathrm{~S}$ & 20.2 & 21.1 & $13.1-29.1$ & $\mathrm{~S}$ \\
\hline Trichlorlethene & 23.0 & 22.4 & $15-29$ & $\mathrm{~S}$ & 57.0 & 53.5 & $35.7-71.2$ & $\mathrm{~S}$ \\
\hline
\end{tabular}

a Performed as part of the Environmental Laboratory Approval Program by the New York State Department of Health, Wadsworth Center.

b Satisfactory 
Table 8.10 Environmental Resource Associates performance evaluation of Air Toxics, Inc., for volatile organic compounds in non-potable water.

\begin{tabular}{|c|c|c|c|c|c|}
\hline Analyte & Units & $\begin{array}{l}\text { Reported } \\
\text { Value }\end{array}$ & $\begin{array}{l}\text { Assigned } \\
\text { Value }\end{array}$ & $\begin{array}{l}\text { Acceptance } \\
\text { Limits }\end{array}$ & $\begin{array}{c}\text { Performance } \\
\text { Evaluation }\end{array}$ \\
\hline Acetone & $\mu \mathrm{g} / \mathrm{L}$ & $<10.0$ & $<5.00$ & $\mathrm{NR}^{\mathrm{a}}$ & Acceptable \\
\hline Acetonitrile & $\mu \mathrm{g} / \mathrm{L}$ & $<10.0$ & $<5.00$ & NR & Acceptable \\
\hline Acrylonite & $\mu \mathrm{g} / \mathrm{L}$ & $<2.00$ & $<5.00$ & NR & Acceptable \\
\hline Acrolein & $\mu \mathrm{g} / \mathrm{L}$ & $<10.0$ & $<5.00$ & NR & Acceptable \\
\hline Benzene & $\mu \mathrm{g} / \mathrm{L}$ & 33.7 & 33.6 & $24.1-43.4$ & Acceptable \\
\hline Bromodichloromethane & $\mu \mathrm{g} / \mathrm{L}$ & 68.8 & 57.8 & $41.0-75.2$ & Acceptable \\
\hline Bromoform & $\mu \mathrm{g} / \mathrm{L}$ & 25.0 & 24.3 & $15.2-33.4$ & Acceptable \\
\hline Bromomethane & $\mu \mathrm{g} / \mathrm{L}$ & $<2.00$ & $<5.00$ & NR & Acceptable \\
\hline 2-Butanone & $\mu \mathrm{g} / \mathrm{L}$ & $<10.00$ & $<5.00$ & NR & Acceptable \\
\hline Carbon disulfide & $\mu \mathrm{g} / \mathrm{L}$ & $<2.00$ & $<5.00$ & NR & Acceptable \\
\hline Carbon tetrachloride & $\mu \mathrm{g} / \mathrm{L}$ & 18.9 & 18.1 & $11.4-25.6$ & Acceptable \\
\hline Chlorobenzene & $\mu \mathrm{g} / \mathrm{L}$ & 48.8 & 45.9 & $32.5-58.4$ & Acceptable \\
\hline Chlorodibromomethane & $\mu \mathrm{g} / \mathrm{L}$ & 60.5 & 54.1 & $35.8-71.9$ & Acceptable \\
\hline Chloroethane & $\mu \mathrm{g} / \mathrm{L}$ & $<2.00$ & $<5.00$ & NR & Acceptable \\
\hline 2-Chloroethylvinylether & $\mu \mathrm{g} / \mathrm{L}$ & $<10.00$ & $<5.00$ & NR & Acceptable \\
\hline Chloroform & $\mu \mathrm{g} / \mathrm{L}$ & 74.5 & 70.0 & $48.4-89.6$ & Acceptable \\
\hline Chloromethane & $\mu \mathrm{g} / \mathrm{L}$ & $<2.00$ & $<5.00$ & NR & Acceptable \\
\hline $\mathrm{DBCP}$ & $\mu \mathrm{g} / \mathrm{L}$ & $<10.00$ & $<5.00$ & NR & Acceptable \\
\hline 1,2-Dibromoethane & $\mu \mathrm{g} / \mathrm{L}$ & $<2.00$ & $<5.00$ & NR & Acceptable \\
\hline Dibromoethane & $\mu \mathrm{g} / \mathrm{L}$ & $<2.00$ & $<5.00$ & NR & Acceptable \\
\hline 1,2-Dichlorobenzene & $\mu \mathrm{g} / \mathrm{L}$ & 32.8 & 30.0 & $21.0-38.2$ & Acceptable \\
\hline 1,3-Dichlorobenzene & $\mu \mathrm{g} / \mathrm{L}$ & 14.4 & 13.6 & $9.32-17.4$ & Acceptable \\
\hline 1,4-Dichlorobenzene & $\mu \mathrm{g} / \mathrm{L}$ & 13.9 & 12.6 & $8.5-16.7$ & Acceptable \\
\hline Dichlorodifluoromethane & $\mu \mathrm{g} / \mathrm{L}$ & $<2.00$ & $<5.00$ & NR & Acceptable \\
\hline 1,1-Dichloroethane & $\mu \mathrm{g} / \mathrm{L}$ & $<1.00$ & $<5.00$ & NR & Acceptable \\
\hline 1,2-Dichloroethane & $\mu \mathrm{g} / \mathrm{L}$ & 63.1 & 58.2 & $40.2-77.4$ & Acceptable \\
\hline 1,1-Dichloroethylene & $\mu \mathrm{g} / \mathrm{L}$ & $<2.00$ & $<5.00$ & NR & Acceptable \\
\hline cis-1,2-Dichloroethylene & $\mu \mathrm{g} / \mathrm{L}$ & $<2.00$ & $<5.00$ & NR & Acceptable \\
\hline trans-1,2-Dichloroethylene & $\mu \mathrm{g} / \mathrm{L}$ & $<2.00$ & $<5.00$ & NR & Acceptable \\
\hline 1,2-Dichloropropane & $\mu \mathrm{g} / \mathrm{L}$ & 23.0 & 23.2 & $16.7-29.1$ & Acceptable \\
\hline cis-1,3-Dichloropropylene & $\mu \mathrm{g} / \mathrm{L}$ & $<2.00$ & $<5.00$ & NR & Acceptable \\
\hline trans-1,3-Dichloropropylene & $\mu \mathrm{g} / \mathrm{L}$ & $<2.00$ & $<5.00$ & NR & Acceptable \\
\hline Ethylbenzene & $\mu \mathrm{g} / \mathrm{L}$ & 29.6 & 27.5 & $18.5-35.8$ & Acceptable \\
\hline 2-Hexanone & $\mu \mathrm{g} / \mathrm{L}$ & $<10.00$ & $<5.00$ & NR & Acceptable \\
\hline Methylene chloride & $\mu \mathrm{g} / \mathrm{L}$ & 33.6 & 31.5 & $19.9-43.8$ & Acceptable \\
\hline 4-Methyl-2-pentanone (MIBK) & $\mu \mathrm{g} / \mathrm{L}$ & 167.0 & 173 & $66.0-270$ & Acceptable \\
\hline Styrene & $\mu \mathrm{g} / \mathrm{L}$ & $<2.00$ & $<5.00$ & NR & Acceptable \\
\hline 1,1,1,2-Tetrachloroethane & $\mu \mathrm{g} / \mathrm{L}$ & $<2.00$ & $<5.00$ & NR & Acceptable \\
\hline
\end{tabular}


Table 8.10, cont.

\begin{tabular}{lccccc}
\hline \multicolumn{1}{c}{ Analyte } & Units & $\begin{array}{c}\text { Reported } \\
\text { Value }\end{array}$ & $\begin{array}{c}\text { Assigned } \\
\text { Value }\end{array}$ & $\begin{array}{c}\text { Acceptance } \\
\text { Limits }\end{array}$ & $\begin{array}{c}\text { Performance } \\
\text { Evaluation }\end{array}$ \\
\hline 1,1,2,2-Tetrachloroethane & $\mu \mathrm{g} / \mathrm{L}$ & 73.3 & 68.4 & $39.9-95.6$ & Acceptable \\
Tetrachloroethylene & $\mu \mathrm{g} / \mathrm{L}$ & 35.6 & 34.9 & $23.1-44.9$ & Acceptable \\
Toluene & $\mu \mathrm{g} / \mathrm{L}$ & 39.0 & 34.1 & $24.4-42.8$ & Acceptable \\
$1,1,1-$ Trichloroethane & $\mu \mathrm{g} / \mathrm{L}$ & 24.5 & 22.7 & $14.9-29.9$ & Acceptable \\
$1,1,2-$ Trichloroethane & $\mu \mathrm{g} / \mathrm{L}$ & $<2.00$ & $<5.00$ & $\mathrm{NR}$ & Acceptable \\
Trichloroethylene & $\mu \mathrm{g} / \mathrm{L}$ & 30.3 & 30.1 & $19.6-39.0$ & Acceptable \\
Trichlorofluoromethane & $\mu \mathrm{g} / \mathrm{L}$ & $<2.00$ & $<5.00$ & $\mathrm{NR}$ & Acceptable \\
1,2,3-Trichloropropane & $\mu \mathrm{g} / \mathrm{L}$ & $<2.00$ & $<5.00$ & $\mathrm{NR}$ & Acceptable \\
Vinyl acetate & $\mu \mathrm{g} / \mathrm{L}$ & $<10.00$ & $<5.00$ & $\mathrm{NR}$ & Acceptable \\
Vinyl chloride & $\mu \mathrm{g} / \mathrm{L}$ & $<2.00$ & $<5.00$ & $\mathrm{NR}$ & Acceptable \\
Xylenes, total & $\mu \mathrm{g} / \mathrm{L}$ & 85.9 & 84.1 & $47.8-114$ & Acceptable \\
\hline
\end{tabular}

${ }^{\text {a }}$ Not Reported

Table 8.11 Environmental Resource Associates performance evaluation (PotableWatR ${ }^{\mathrm{TM}}$ ) of Trace Analysis, Inc., for metals in potable water $(\mu \mathrm{g} / \mathrm{L})$.

\begin{tabular}{|c|c|c|c|c|c|c|c|c|}
\hline \multirow[b]{2}{*}{ Parameter } & \multicolumn{4}{|c|}{ September 11, 2000 } & \multicolumn{4}{|c|}{ September 14,2000} \\
\hline & $\begin{array}{c}\text { Reported } \\
\text { Value }\end{array}$ & $\begin{array}{l}\text { Certified } \\
\text { Value }\end{array}$ & $\begin{array}{l}\text { QuiK }^{\mathrm{TM}} \\
\text { Limits }\end{array}$ & Comment & $\begin{array}{c}\text { Reported } \\
\text { Value }\end{array}$ & $\begin{array}{c}\text { Certified } \\
\text { Value }\end{array}$ & $\begin{array}{c}\text { QuiK }^{\mathrm{TM}} \\
\text { Limits }\end{array}$ & Comment \\
\hline$\overline{\text { Aluminum }}$ & 632 & 625 & $536-725$ & $\mathrm{~A}^{\mathrm{a}}$ & $\mathrm{NR}^{\mathrm{b}}$ & $\overline{\mathrm{NR}}$ & $\mathrm{NR}$ & NR \\
\hline Antimony & 11.4 & 20.8 & $14.6-27.0$ & $\mathrm{NA}^{\mathrm{c}}$ & 17.9 & 17.6 & $12.3-22.9$ & A \\
\hline Arsenic & 38.1 & 41.7 & $33.4-50.0$ & A & NR & NR & NR & NR \\
\hline Barium & 835 & 853 & $725-981$ & A & NR & NR & NR & NR \\
\hline Beryullium & 4.8 & 5.83 & $4.96-6.70$ & NA & 6.60 & 6.64 & $5.64-7.64$ & A \\
\hline Boron & 1030 & 1040 & $891-1243$ & A & NR & NR & NR & NR \\
\hline Cadmium & 5.8 & 8.33 & $6.66-10.0$ & NA & 15.9 & 16.7 & $13.4-20.0$ & A \\
\hline Calcium (mg/L) & 49.9 & 50.9 & $44.3-59.3$ & A & NR & NR & NR & NR \\
\hline Chromium & 40.4 & 41.7 & $35.4-48.0$ & A & NR & NR & NR & NR \\
\hline Copper & 163 & 167 & $150-184$ & A & NR & NR & NR & NR \\
\hline Iron & 104 & 125 & $97.3-152$ & A & NR & NR & NR & NR \\
\hline Lead & 22.5 & 25.0 & $17.5-32.5$ & A & NR & NR & NR & NR \\
\hline Manganese & 627 & 625 & $531-719$ & A & NR & NR & NR & NR \\
\hline Mercury & 6.18 & 5.00 & $3.50-6.50$ & A & NR & NR & NR & NR \\
\hline Molybdenum & 35.7 & 41.7 & $34.4-48.9$ & A & NR & NR & NR & NR \\
\hline Nickel & 161 & 167 & $142-192$ & A & NR & NR & NR & NR \\
\hline Selenium & 17.5 & 25.0 & $20.0-30.0$ & NA & 52.5 & 50.9 & $40.7-61.1$ & A \\
\hline Silver & 41.8 & 41.7 & $35.9-47.2$ & A & NR & NR & NR & NR \\
\hline Thallium & 21.4 & 5.0 & $3.50-6.50$ & NA & NR & NR & NR & NR \\
\hline Zinc & 814 & 833 & $707-997$ & A & NR & NR & NR & NR \\
\hline Hardness as $\mathrm{CaCO}_{3}$ & 125 & 127 & $113-150$ & A & NR & NR & NR & NR \\
\hline
\end{tabular}


Table 8.12 Environmental Resource Associates assessment of Trace Analysis, Inc., WS-43, April 19, 2000 .

\begin{tabular}{|c|c|c|c|c|c|}
\hline Parameter & Units & $\begin{array}{c}\text { Reported } \\
\text { Value }\end{array}$ & $\begin{array}{c}\text { Assigned } \\
\text { Value }\end{array}$ & $\begin{array}{l}\text { Acceptance } \\
\text { Limits }\end{array}$ & $\begin{array}{c}\text { Performance } \\
\text { Evaluation }\end{array}$ \\
\hline $\mathrm{pH}$ & & 7.73 & 7.8 & $7.02-8.58$ & Acceptable \\
\hline Bromide & $\mathrm{mg} / \mathrm{L}$ & 0.410 & 0.371 & $0.318-0.430$ & Acceptable \\
\hline Chloride & $\mathrm{mg} / \mathrm{L}$ & 6.49 & 6.68 & $4.92-8.58$ & Acceptable \\
\hline Conductivity & $\mu \mathrm{mhos}$ & 481 & 502 & $420-571$ & Acceptable \\
\hline Fluoride & $\mathrm{mg} / \mathrm{L}$ & 7.15 & 7.06 & $6.35-7.77$ & Acceptable \\
\hline Nitrate as $\mathrm{N}$ & $\mathrm{mg} / \mathrm{L}$ & 7.28 & 7.96 & $7.16-8.76$ & Acceptable \\
\hline Potassium & $\mathrm{mg} / \mathrm{L}$ & 40.4 & 36.9 & $31.7-43.0$ & Acceptable \\
\hline Sulfate & $\mathrm{mg} / \mathrm{L}$ & 71.0 & 72.3 & $65.1-79.3$ & Acceptable \\
\hline Total Dissolved Solids & $\mathrm{mg} / \mathrm{L}$ & 366 & 429 & $275-583$ & Acceptable \\
\hline Alkalinity (as $\mathrm{CaCO}_{3}$ ) & $\mathrm{mg} / \mathrm{L}$ & 35.0 & 37.7 & $35.9-42.7$ & Not Acceptable \\
\hline Sodium & $\mathrm{mg} / \mathrm{L}$ & 15.7 & 16.9 & $15.6-18.7$ & Acceptable \\
\hline Turbidity & NTU & 5.26 & 5.15 & $4.53-6.11$ & Acceptable \\
\hline Total residual chlorine & $\mathrm{mg} / \mathrm{L}$ & 3.60 & 3.52 & $2.63-4.18$ & Acceptable \\
\hline Nitrate as $\mathrm{N}$ & $\mathrm{mg} / \mathrm{L}$ & 1.23 & 1.22 & $1.04-1.40$ & Acceptable \\
\hline ortho-Phosphate as $\mathrm{P}$ & $\mathrm{mg} / \mathrm{L}$ & 1.37 & 1.45 & $1.37-1.52$ & Acceptable \\
\hline Cyanide & $\mathrm{mg} / \mathrm{L}$ & 0.093 & 0.207 & $0.155-0.259$ & Not Acceptable \\
\hline Aluminum & $\mu \mathrm{g} / \mathrm{L}$ & 561 & 559 & $473-655$ & Acceptable \\
\hline Antimony & $\mu \mathrm{g} / \mathrm{L}$ & 50.0 & 36.1 & $25.3-46.9$ & Not Acceptable \\
\hline Arsenic & $\mu \mathrm{g} / \mathrm{L}$ & 72.0 & 73.5 & $64.3-82.1$ & Acceptable \\
\hline Barium & $\mu \mathrm{g} / \mathrm{L}$ & 2020 & 1920 & $1630-2210$ & Acceptable \\
\hline Beryllium & $\mu \mathrm{g} / \mathrm{L}$ & 7.00 & 6.63 & $5.64-7.62$ & Acceptable \\
\hline Boron & $\mu \mathrm{g} / \mathrm{L}$ & 1680 & 1680 & $1550-1860$ & Acceptable \\
\hline Cadmium & $\mu \mathrm{g} / \mathrm{L}$ & 5.00 & 5.63 & $4.50-6.76$ & Acceptable \\
\hline Calcium & $\mathrm{mg} / \mathrm{L}$ & 73.3 & 66.7 & $58.0-77.7$ & Acceptable \\
\hline Chromium & $\mu \mathrm{g} / \mathrm{L}$ & 26.0 & 25.5 & $21.7-29.3$ & Acceptable \\
\hline Copper & $\mu \mathrm{g} / \mathrm{L}$ & 186 & 179 & $161-197$ & Acceptable \\
\hline Iron & $\mu \mathrm{g} / \mathrm{L}$ & 140 & 132 & $103-161$ & Acceptable \\
\hline Lead & $\mu \mathrm{g} / \mathrm{L}$ & 20.0 & 17.7 & $12.4-23.0$ & Acceptable \\
\hline Manganese & $\mu \mathrm{g} / \mathrm{L}$ & 493 & 489 & $455-514$ & Acceptable \\
\hline Molybdenum & $\mu \mathrm{g} / \mathrm{L}$ & 95.0 & 85.9 & $72.2-99.0$ & Acceptable \\
\hline Nickel & $\mu \mathrm{g} / \mathrm{L}$ & 127 & 130 & $111-150$ & Acceptable \\
\hline Selenium & $\mu \mathrm{g} / \mathrm{L}$ & 62.0 & 60.6 & $48.5-72.7$ & Acceptable \\
\hline Silver & $\mu \mathrm{g} / \mathrm{L}$ & 94.0 & 94.6 & $81.4-109$ & Acceptable \\
\hline Thallium & $\mu \mathrm{g} / \mathrm{L}$ & 5.00 & 4.12 & $2.88-5.36$ & Acceptable \\
\hline Zinc & $\mu \mathrm{g} / \mathrm{L}$ & 977 & 972 & $893-1040$ & Acceptable \\
\hline $\mathrm{Ca}$ Hardness as $\mathrm{CaCO}_{3}$ & $\mu \mathrm{g} / \mathrm{L}$ & 183 & 167 & $156-178$ & Not Acceptable \\
\hline Mercury & $\mu \mathrm{g} / \mathrm{L}$ & 2.45 & 3.65 & $2.56-4.75$ & Not Acceptable \\
\hline
\end{tabular}


Table 8.13 Environmental Resource Associates assessment of Trace Analysis, Inc., WS-45, June 26, 2000 .

\begin{tabular}{|c|c|c|c|c|c|}
\hline Parameter & Units & $\begin{array}{l}\text { Reported } \\
\text { Value }\end{array}$ & $\begin{array}{c}\text { Assigned } \\
\text { Value }\end{array}$ & $\begin{array}{l}\text { Acceptance } \\
\text { Limits }\end{array}$ & $\begin{array}{c}\text { Performance } \\
\text { Evaluation }\end{array}$ \\
\hline $\mathrm{pH}$ & & 5.94 & 5.9 & $5.31-6.49$ & Acceptable \\
\hline Bromide & $\mu \mathrm{g} / \mathrm{L}$ & 410 & 284 & $243-330$ & Not Acceptable \\
\hline Chloride & $\mathrm{mg} / \mathrm{L}$ & 14.0 & 15.1 & $13.0-16.4$ & Acceptable \\
\hline Conductivity & $\mu$ mhos & 457 & 440 & $417-463$ & Acceptable \\
\hline Fluoride & $\mathrm{mg} / \mathrm{L}$ & 6.26 & 6.3 & $5.67-6.93$ & Acceptable \\
\hline Nitrate as $\mathrm{N}$ & $\mathrm{mg} / \mathrm{L}$ & 4.14 & 4.31 & $3.88-4.74$ & Acceptable \\
\hline Potassium & $\mathrm{mg} / \mathrm{L}$ & 27.7 & 26.2 & $23.8-28.7$ & Acceptable \\
\hline Sulfate & $\mathrm{mg} / \mathrm{L}$ & 46.8 & 44.5 & $39.7-49.0$ & Acceptable \\
\hline Total Dissolved Solids & $\mathrm{mg} / \mathrm{L}$ & 389 & 404 & $259-549$ & Acceptable \\
\hline Alkalinity (as $\mathrm{CaCO}_{3}$ ) & $\mathrm{mg} / \mathrm{L}$ & 30.0 & 31.3 & $29.8-35.8$ & Acceptable \\
\hline Sodium & $\mathrm{mg} / \mathrm{L}$ & 13.1 & 13.5 & $12.4-15.0$ & Acceptable \\
\hline Turbidity & NTU & 1.37 & 1.31 & $1.09-1.72$ & Acceptable \\
\hline Total residual chlorine & $\mathrm{mg} / \mathrm{L}$ & 2.30 & 2.32 & $1.74-2.90$ & Acceptable \\
\hline Nitrate as $\mathrm{N}$ & $\mathrm{mg} / \mathrm{L}$ & 1.60 & 1.58 & $1.34-1.82$ & Acceptable \\
\hline ortho-Phosphate as $\mathrm{P}$ & $\mathrm{mg} / \mathrm{L}$ & 1.15 & 1.23 & $1.15-1.30$ & Acceptable \\
\hline Cyanide & $\mathrm{mg} / \mathrm{L}$ & 0.291 & .0312 & $0.234-0.390$ & Acceptable \\
\hline \multicolumn{6}{|l|}{$\underline{\text { Hardness }}$} \\
\hline Total Hardness as $\mathrm{CaCO}_{3}$ & $\mathrm{mg} / \mathrm{L}$ & 211 & 199 & $169-229$ & Acceptable \\
\hline Calcium Hardness as $\mathrm{CaCO}_{3}$ & $\mathrm{mg} / \mathrm{L}$ & 132 & 123 & $115-133$ & Acceptable \\
\hline Calcium & $\mathrm{mg} / \mathrm{L}$ & 52.9 & 49.3 & $44.1-55.8$ & Acceptable \\
\hline Magnesium & $\mathrm{mg} / \mathrm{L}$ & 19.3 & 18.4 & $16.6-20.0$ & Acceptable \\
\hline \multicolumn{6}{|l|}{$\underline{\text { Metals }}$} \\
\hline Aluminum & $\mu \mathrm{g} / \mathrm{L}$ & 631 & 340 & $300-382$ & Not Acceptable \\
\hline Antimony & $\mu \mathrm{g} / \mathrm{L}$ & 54.4 & 34.1 & $23.9-44.3$ & Not Acceptable \\
\hline Arsenic & $\mu \mathrm{g} / \mathrm{L}$ & 144 & 78.2 & $68.4-87.3$ & Not Acceptable ${ }^{a}$ \\
\hline Barium & $\mu \mathrm{g} / \mathrm{L}$ & 2570 & 1190 & $1010-1370$ & Not Acceptable ${ }^{a}$ \\
\hline Beryllium & $\mu \mathrm{g} / \mathrm{L}$ & 16.1 & 8.33 & $7.08-9.58$ & Not Acceptable ${ }^{a}$ \\
\hline Boron & $\mu \mathrm{g} / \mathrm{L}$ & 2170 & 1090 & $1010-1210$ & Not Acceptable \\
\hline Cadmium & $\mu \mathrm{g} / \mathrm{L}$ & 35.4 & 18.6 & $14.9-22.3$ & Not Acceptable \\
\hline Chromium & $\mu \mathrm{g} / \mathrm{L}$ & 213 & 111 & $94.4-128$ & Not Acceptable \\
\hline Copper & $\mu \mathrm{g} / \mathrm{L}$ & 2880 & 1380 & $1240-1520$ & Not Acceptable \\
\hline Iron & $\mu \mathrm{g} / \mathrm{L}$ & 835 & 393 & $359-429$ & Not Acceptable \\
\hline Lead & $\mu \mathrm{g} / \mathrm{L}$ & 42.6 & 20.8 & $14.6-27.0$ & Not Acceptable \\
\hline Manganese & $\mu \mathrm{g} / \mathrm{L}$ & 999 & 499 & $464-525$ & Not Acceptable \\
\hline Molybdenum & $\mu \mathrm{g} / \mathrm{L}$ & 128 & 63.3 & $53.1-73.1$ & Not Acceptable \\
\hline Nickel & $\mu \mathrm{g} / \mathrm{L}$ & 197 & 94.1 & $80.0-108$ & Not Acceptable \\
\hline Selenium & $\mu \mathrm{g} / \mathrm{L}$ & 112 & 55.6 & $44.5-66.7$ & Not Acceptable \\
\hline Silver & $\mu \mathrm{g} / \mathrm{L}$ & 106 & 54.3 & $46.7-57.7$ & Not Acceptable \\
\hline
\end{tabular}


Table 8.13, cont.

\begin{tabular}{lccccc}
\hline \multicolumn{1}{c}{ Parameter } & Units & $\begin{array}{c}\text { Reported } \\
\text { Value }\end{array}$ & $\begin{array}{c}\text { Assigned } \\
\text { Value }\end{array}$ & $\begin{array}{c}\text { Acceptance } \\
\text { Limits }\end{array}$ & $\begin{array}{c}\text { Performance } \\
\text { Evaluation }\end{array}$ \\
\hline Thallium & $\mu \mathrm{g} / \mathrm{L}$ & $<5.00$ & 8.26 & $5.78-10.7$ & Not Acceptable $^{\mathrm{a}}$ \\
Vanadium & $\mu \mathrm{g} / \mathrm{L}$ & 1700 & 870 & $812-927$ & Not Acceptable $^{\mathrm{a}}$ \\
Zinc & $\mu \mathrm{g} / \mathrm{L}$ & 4330 & 2200 & $2030-2360$ & Not Acceptable $^{\mathrm{a}}$ \\
Mercury & $\mu \mathrm{g} / \mathrm{L}$ & 8.50 & 8.16 & $5.71-10.6$ & Acceptable \\
\hline${ }^{\mathrm{a}}$ Dilution error. See text for details. & & & & &
\end{tabular}

${ }^{a}$ Dilution error. See text for details. 
Table 8.14 Environmental Resource Associates assessment of Trace Analysis, Inc., WS-51, December 20, 2000.

\begin{tabular}{|c|c|c|c|c|c|}
\hline Parameter & Units & $\begin{array}{l}\text { Reported } \\
\text { Value }\end{array}$ & $\begin{array}{c}\text { Assigned } \\
\text { Value }\end{array}$ & $\begin{array}{l}\text { Acceptance } \\
\text { Limits }\end{array}$ & $\begin{array}{c}\text { Performance } \\
\text { Evaluation }\end{array}$ \\
\hline $\mathrm{pH}$ & & 9.8 & 9.60 & $8.64-10.6$ & Acceptable \\
\hline Chloride & $\mathrm{mg} / \mathrm{L}$ & 63.0 & 64.9 & $60.4-69.0$ & Acceptable \\
\hline Conductivity & $\mu$ mhos & 475 & 474 & $449-499$ & Acceptable \\
\hline Fluoride & $\mathrm{mg} / \mathrm{L}$ & 3.33 & 3.36 & $3.02-3.70$ & Acceptable \\
\hline Nitrate as $\mathrm{N}$ & $\mathrm{mg} / \mathrm{L}$ & 4.23 & 4.42 & $3.98-4.86$ & Acceptable \\
\hline Potassium & $\mathrm{mg} / \mathrm{L}$ & 23.1 & 19.7 & $17.8-21.6$ & Not Acceptable \\
\hline Sulfate & $\mathrm{mg} / \mathrm{L}$ & 40.5 & 41.9 & $37.4-46.2$ & Acceptable \\
\hline Total Dissolved Solids & $\mathrm{mg} / \mathrm{L}$ & 318 & 313 & $204-442$ & Acceptable \\
\hline Alkalinity (as $\mathrm{CaCO}_{3}$ ) & $\mathrm{mg} / \mathrm{L}$ & 46.0 & 45.5 & $43.2-51.0$ & Acceptable \\
\hline Sodium & $\mathrm{mg} / \mathrm{L}$ & 69.7 & 20.0 & $18.5-22.0$ & Not Acceptable \\
\hline Turbidity & NTU & 4.51 & 4.47 & $3.92-5.34$ & Acceptable \\
\hline Total residual chlorine & $\mathrm{mg} / \mathrm{L}$ & 1.36 & 1.43 & $1.07-1.79$ & Acceptable \\
\hline Nitrate as $\mathrm{N}$ & $\mathrm{mg} / \mathrm{L}$ & 1.35 & 1.32 & $1.12-1.52$ & Acceptable \\
\hline ortho-Phosphate as $\mathrm{P}$ & $\mathrm{mg} / \mathrm{L}$ & 0.633 & 0.680 & $0.609-0.731$ & Acceptable \\
\hline Cyanide & $\mathrm{mg} / \mathrm{L}$ & 0.353 & 0.392 & $0.294-0.490$ & Acceptable \\
\hline Total organic carbon & $\mathrm{mg} / \mathrm{L}$ & 1.57 & 1.87 & $1.59-2.29$ & Not Acceptable \\
\hline \multicolumn{6}{|l|}{ Hardness } \\
\hline Total Hardness as $\mathrm{CaCO}_{3}$ & $\mathrm{mg} / \mathrm{L}$ & 133 & 133 & $113-153$ & Acceptable \\
\hline Calcium Hardness as $\mathrm{CaCO}_{3}$ & $\mathrm{mg} / \mathrm{L}$ & 118 & 119 & $111-129$ & Acceptable \\
\hline Calcium & $\mathrm{mg} / \mathrm{L}$ & 47.5 & 47.6 & $42.5-54.0$ & Acceptable \\
\hline Magnesium & $\mathrm{mg} / \mathrm{L}$ & 3.66 & 3.52 & $3.19-3.85$ & Acceptable \\
\hline \multicolumn{6}{|l|}{$\underline{\text { Metals }}$} \\
\hline Aluminum & $\mu \mathrm{g} / \mathrm{L}$ & 342 & 379 & $335-424$ & Acceptable \\
\hline Antimony & $\mu \mathrm{g} / \mathrm{L}$ & 21.0 & 32.8 & $23.0-42.6$ & Not Acceptable \\
\hline Arsenic & $\mu \mathrm{g} / \mathrm{L}$ & 119 & 125 & $109-140$ & Acceptable \\
\hline Barium & $\mu \mathrm{g} / \mathrm{L}$ & 798 & 829 & $705-953$ & Acceptable \\
\hline Beryllium & $\mu \mathrm{g} / \mathrm{L}$ & 2.70 & 4.82 & $4.10-5.54$ & Not Acceptable \\
\hline Boron & $\mu \mathrm{g} / \mathrm{L}$ & 1230 & 1270 & $1180-1410$ & Acceptable \\
\hline Cadmium & $\mu \mathrm{g} / \mathrm{L}$ & 37.5 & 40.9 & $32.7-49.1$ & Acceptable \\
\hline Chromium & $\mu \mathrm{g} / \mathrm{L}$ & 99.5 & 103 & $87.6-118$ & Acceptable \\
\hline Copper & $\mu \mathrm{g} / \mathrm{L}$ & 1130 & 1180 & $1060-1300$ & Acceptable \\
\hline Iron & $\mu \mathrm{g} / \mathrm{L}$ & 2470 & 2560 & $2360-2760$ & Acceptable \\
\hline Lead & $\mu \mathrm{g} / \mathrm{L}$ & 62.8 & 74.0 & $51.8-96.2$ & Acceptable \\
\hline Manganese & $\mu \mathrm{g} / \mathrm{L}$ & 582 & 587 & $547-617$ & Acceptable \\
\hline Molybdenum & $\mu \mathrm{g} / \mathrm{L}$ & $<10.0$ & 12.0 & $9.63-14.5$ & Not Acceptable \\
\hline Nickel & $\mu \mathrm{g} / \mathrm{L}$ & 125 & 145 & $123-167$ & Acceptable \\
\hline
\end{tabular}


Table 8.14, cont.

\begin{tabular}{lccccc}
\hline \multicolumn{1}{c}{ Parameter } & Units & $\begin{array}{c}\text { Reported } \\
\text { Value }\end{array}$ & $\begin{array}{c}\text { Assigned } \\
\text { Value }\end{array}$ & $\begin{array}{c}\text { Acceptance } \\
\text { Limits }\end{array}$ & $\begin{array}{c}\text { Performance } \\
\text { Evaluation }\end{array}$ \\
\hline Selenium & $\mu \mathrm{g} / \mathrm{L}$ & 73.6 & 78.0 & $62.4-93.6$ & Acceptable \\
Silver & $\mu \mathrm{g} / \mathrm{L}$ & 250 & 244 & $221-268$ & Acceptable \\
Thallium & $\mu \mathrm{g} / \mathrm{L}$ & $<50.0$ & 4.43 & $3.10-5.76$ & Not Acceptable \\
Vanadium & $\mu \mathrm{g} / \mathrm{L}$ & 476 & 489 & $455-520$ & Acceptable \\
Zinc & $\mu \mathrm{g} / \mathrm{L}$ & 636 & 629 & $577-677$ & Acceptable \\
Mercury & $\mu \mathrm{g} / \mathrm{L}$ & 5.00 & 4.65 & $3.26-6.05$ & Acceptable \\
\hline
\end{tabular}


Table 8.15 Environmental Resource Associates assessment of Trace Analysis, Inc., WP-62, May 23, 2000 .

\begin{tabular}{|c|c|c|c|c|c|}
\hline Parameter & Units & $\begin{array}{l}\text { Reported } \\
\text { Value }\end{array}$ & $\begin{array}{l}\text { Assigned } \\
\text { Value }\end{array}$ & $\begin{array}{l}\text { Acceptance } \\
\text { Limits }\end{array}$ & $\begin{array}{c}\text { Performance } \\
\text { Evaluation }\end{array}$ \\
\hline $\mathrm{pH}$ & & 9.32 & 9.5 & $9.21-9.79$ & Acceptable \\
\hline Cyanide & $\mathrm{mg} / \mathrm{L}$ & 0.980 & 0.906 & $0.631-1.16$ & Acceptable \\
\hline Phenolics, total (a) & $\mathrm{mg} / \mathrm{L}$ & 1.58 & 1.22 & $0.671-1.77$ & Acceptable \\
\hline Grease \& Oil & $\mathrm{mg} / \mathrm{L}$ & 46.2 & 45.6 & $30.5-51.5$ & Acceptable \\
\hline Total Residual Chlorine & $\mathrm{mg} / \mathrm{L}$ & 3.17 & 3.15 & $2.59-3.71$ & Acceptable \\
\hline Mercury & $\mu \mathrm{g} / \mathrm{L}$ & 3.76 & 6.11 & $4.50-7.70$ & Not Acceptable \\
\hline \multicolumn{6}{|l|}{$\underline{\text { Minerals }}$} \\
\hline Total solids at $105^{\circ} \mathrm{C}$ & $\mathrm{mg} / \mathrm{L}$ & 298 & 315 & $274-352$ & Acceptable \\
\hline Total Dissolved Solids & $\mathrm{mg} / \mathrm{L}$ & 291 & 299 & $224-374$ & Acceptable \\
\hline Conductivity at $25^{\circ} \mathrm{C}$ & $\mu$ mhos & 283 & 339 & $313-365$ & Not Acceptable \\
\hline Alkalinity as $\mathrm{CaCO} 3$ & $\mathrm{mg} / \mathrm{L}$ & 93.0 & 95.7 & $86.9-104$ & Acceptable \\
\hline Chloride & $\mathrm{mg} / \mathrm{L}$ & 35.5 & 37.6 & $33.0-41.6$ & Acceptable \\
\hline Fluoride & $\mathrm{mg} / \mathrm{L}$ & 3.15 & 3.22 & $2.81-3.59$ & Acceptable \\
\hline Potassium & $\mathrm{mg} / \mathrm{L}$ & 19.9 & 16.2 & $13.8-18.6$ & Not Acceptable \\
\hline Sodium & $\mathrm{mg} / \mathrm{L}$ & 67.2 & 67.2 & $60.6-73.7$ & Acceptable \\
\hline Sulfate & $\mathrm{mg} / \mathrm{L}$ & 10.9 & 11.7 & $8.54-14.6$ & Acceptable \\
\hline \multicolumn{6}{|l|}{$\underline{\text { Hardness }}$} \\
\hline Total suspended solids & $\mathrm{mg} / \mathrm{L}$ & 76.0 & 81.8 & $63.3-88.3$ & Acceptable \\
\hline Calcium & $\mathrm{mg} / \mathrm{L}$ & 15.1 & 14.5 & $12.7-16.7$ & Acceptable \\
\hline Magnesium & $\mathrm{mg} / \mathrm{L}$ & 26.6 & 25.6 & $22.4-28.7$ & Acceptable \\
\hline Calcium hardness as $\mathrm{CaCO}_{3}$ & $\mathrm{mg} / \mathrm{L}$ & 37.7 & 36.1 & $30.7-41.5$ & Acceptable \\
\hline Total hardness as $\mathrm{CaCO}_{3}$ & $\mathrm{mg} / \mathrm{L}$ & 147 & 142 & $129-156$ & Acceptable \\
\hline \multicolumn{6}{|l|}{$\underline{\text { Demand }}$} \\
\hline BOD & $\mathrm{mg} / \mathrm{L}$ & 68.2 & 78.5 & $39.6-117$ & Acceptable \\
\hline CBOD & $\mathrm{mg} / \mathrm{L}$ & 5.08 & 67.5 & $30.3-105$ & Acceptable \\
\hline COD & $\mathrm{mg} / \mathrm{L}$ & 90.2 & 127 & $96.0-147$ & Not Acceptable \\
\hline \multicolumn{6}{|l|}{$\underline{\text { Nutrients - Simple }}$} \\
\hline Ammonia as $\mathrm{N}$ & $\mathrm{mg} / \mathrm{L}$ & 1.32 & 1.40 & $1.00-1.81$ & Acceptable \\
\hline Nitrate as $\mathrm{N}$ & $\mathrm{mg} / \mathrm{L}$ & 5.01 & 5.34 & $4.20-6.37$ & Acceptable \\
\hline Ortho-phophate as P & $\mathrm{mg} / \mathrm{L}$ & 5.28 & 5.34 & $4.56-6.16$ & Acceptable \\
\hline \multicolumn{6}{|l|}{ Nutrients - complex } \\
\hline Total phosphorus as $\mathrm{P}$ & $\mathrm{mg} / \mathrm{L}$ & 5.55 & 5.95 & $4.52-6.69$ & Acceptable \\
\hline Total kjeldahl nitrogen as $\mathrm{N}$ & $\mathrm{mg} / \mathrm{L}$ & 6.44 & 5.78 & $3.97-7.51$ & Acceptable \\
\hline \multicolumn{6}{|l|}{$\underline{\text { Trace Metals }}$} \\
\hline Aluminum & $\mu \mathrm{g} / \mathrm{L}$ & 2300 & 2330 & $2000-2640$ & Acceptable \\
\hline
\end{tabular}


Table 8.15, cont.

\begin{tabular}{|c|c|c|c|c|c|}
\hline Parameter & Units & $\begin{array}{c}\text { Reported } \\
\text { Value }\end{array}$ & $\begin{array}{c}\text { Assigned } \\
\text { Value }\end{array}$ & $\begin{array}{c}\text { Acceptance } \\
\text { Limits }\end{array}$ & $\begin{array}{c}\text { Performance } \\
\text { Evaluation }\end{array}$ \\
\hline Antimony & $\mu \mathrm{g} / \mathrm{L}$ & 402 & 373 & $257-451$ & Acceptable \\
\hline Arsenic & $\mu \mathrm{g} / \mathrm{L}$ & 705 & 701 & $589-820$ & Acceptable \\
\hline Barium & $\mu \mathrm{g} / \mathrm{L}$ & 403 & 395 & $342-452$ & Acceptable \\
\hline Beryllium & $\mu \mathrm{g} / \mathrm{L}$ & 603 & 593 & $504-670$ & Acceptable \\
\hline Boron & $\mu \mathrm{g} / \mathrm{L}$ & 189 & 195 & $123-248$ & Acceptable \\
\hline Cadmium & $\mu \mathrm{g} / \mathrm{L}$ & 77.7 & 77.8 & $65.6-89.5$ & Acceptable \\
\hline Chromium & $\mu \mathrm{g} / \mathrm{L}$ & 815 & 791 & $690-894$ & Acceptable \\
\hline Cobalt & $\mu \mathrm{g} / \mathrm{L}$ & 446 & 441 & $387-495$ & Acceptable \\
\hline Copper & $\mu \mathrm{g} / \mathrm{L}$ & 352 & 348 & $314-384$ & Acceptable \\
\hline Iron & $\mu \mathrm{g} / \mathrm{L}$ & 2680 & 2610 & $2310-2940$ & Acceptable \\
\hline Lead & $\mu \mathrm{g} / \mathrm{L}$ & 107 & 106 & $86.4-126$ & Acceptable \\
\hline Manganese & $\mu \mathrm{g} / \mathrm{L}$ & 830 & 787 & $707-874$ & Acceptable \\
\hline Molybdenum & $\mu \mathrm{g} / \mathrm{L}$ & 596 & 573 & $493-655$ & Acceptable \\
\hline Nickel & $\mu \mathrm{g} / \mathrm{L}$ & 1200 & 1210 & $1100-1350$ & Acceptable \\
\hline Selenium & $\mu \mathrm{g} / \mathrm{L}$ & 393 & 406 & $320-471$ & Acceptable \\
\hline Silver & $\mu \mathrm{g} / \mathrm{L}$ & 461 & 457 & $392-524$ & Acceptable \\
\hline Strontium & $\mu \mathrm{g} / \mathrm{L}$ & 171 & 164 & $139-188$ & Acceptable \\
\hline Thallium & $\mu \mathrm{g} / \mathrm{L}$ & 510 & 471 & $379-547$ & Acceptable \\
\hline Vanadium & $\mu \mathrm{g} / \mathrm{L}$ & 527 & 509 & $457-558$ & Acceptable \\
\hline Zinc & $\mu \mathrm{g} / \mathrm{L}$ & 1020 & 1050 & $931-1180$ & Acceptable \\
\hline \multicolumn{6}{|l|}{$\underline{\text { PCB's in } \mathrm{H}_{2}} \underline{\mathrm{O}}$} \\
\hline Aroclor 1254 & $\mu \mathrm{g} / \mathrm{L}$ & 2.70 & 3.88 & $1.78-5.14$ & Acceptable \\
\hline PCB Aroclor Identity $(\operatorname{Std} 1)^{\mathrm{a}}$ & & 1254 & 1254 & 1254 & Acceptable \\
\hline Aroclor 1248 & $\mu \mathrm{g} / \mathrm{L}$ & 3.20 & 4.22 & $1.75-5.94$ & Acceptable \\
\hline PCB Aroclor Identy $(\operatorname{Std} 2)^{\mathrm{a}}$ & & 1248 & 1248 & 1248 & Acceptable \\
\hline \multicolumn{6}{|l|}{$\underline{\text { PCB's in Oil }}$} \\
\hline Aroclor 1242 & $\mu \mathrm{g} / \mathrm{L}$ & 30.4 & 25.7 & $3.72-36.7$ & Acceptable \\
\hline PCB Aroclor Identity (Std 1) ${ }^{\mathrm{a}}$ & & $1016 / 1242$ & 1242 & 1242 & Acceptable \\
\hline Aroclor 1260 & $\mu \mathrm{g} / \mathrm{L}$ & 19.1 & 24.1 & $4.49-34.3$ & Acceptable \\
\hline PCB Aroclor Identity (Std 2) & & 1260 & 1260 & 1260 & Acceptable \\
\hline \multicolumn{6}{|l|}{$\underline{\text { Volatiles }}$} \\
\hline Acetone & $\mu \mathrm{g} / \mathrm{L}$ & $<10.0$ & $<5.00$ & $\mathrm{NR}^{\mathrm{b}}$ & Acceptable \\
\hline Acrylonite & $\mu \mathrm{g} / \mathrm{L}$ & $<2.00$ & $<5.00$ & NR & Acceptable \\
\hline Benzene & $\mu \mathrm{g} / \mathrm{L}$ & 34.2 & 31.6 & $22.6-40.9$ & Acceptable \\
\hline Bromodichloromethane & $\mu \mathrm{g} / \mathrm{L}$ & 47.2 & 43.8 & $31.0-57.0$ & Acceptable \\
\hline Bromoform & $\mu \mathrm{g} / \mathrm{L}$ & 46.0 & 50.3 & $32.7-68.9$ & Acceptable \\
\hline Bromomethane & $\mu \mathrm{g} / \mathrm{L}$ & $<2.00$ & $<5.00$ & NR & Acceptable \\
\hline 2-Butanone & $\mu \mathrm{g} / \mathrm{L}$ & $<2.00$ & $<5.00$ & NR & Acceptable \\
\hline Carbon disulfide & $\mu \mathrm{g} / \mathrm{L}$ & $<2.00$ & $<5.00$ & NR & Acceptable \\
\hline Carbon tetrachloride & $\mu \mathrm{g} / \mathrm{L}$ & 31.2 & 28.6 & $17.8-40.4$ & Acceptable \\
\hline Chlorobenzene & $\mu \mathrm{g} / \mathrm{L}$ & 78 & 67.8 & $47.6-86.5$ & Acceptable \\
\hline Chlorodibromomethane & $\mu \mathrm{g} / \mathrm{L}$ & 59.2 & 60.5 & $40.0-80.4$ & Acceptable \\
\hline
\end{tabular}


Table 8.15, cont.

\begin{tabular}{|c|c|c|c|c|c|}
\hline Parameter & Units & $\begin{array}{l}\text { Reported } \\
\text { Value }\end{array}$ & $\begin{array}{l}\text { Assigned } \\
\text { Value }\end{array}$ & $\begin{array}{l}\text { Acceptance } \\
\text { Limits }\end{array}$ & $\begin{array}{c}\text { Performance } \\
\text { Evaluation }\end{array}$ \\
\hline Chloroethane & $\mu \mathrm{g} / \mathrm{L}$ & $<2.00$ & $<5.00$ & NR & Acceptable \\
\hline 2-Chloroethylvinylether & $\mu \mathrm{g} / \mathrm{L}$ & $<2.00$ & $<5.00$ & NR & Acceptable \\
\hline Chloroform & $\mu \mathrm{g} / \mathrm{L}$ & 15.0 & 13.4 & $9.63-17.5$ & Acceptable \\
\hline Chloromethane & $\mu \mathrm{g} / \mathrm{L}$ & $<2.00$ & $<5.00$ & NR & Acceptable \\
\hline DBCP & $\mu \mathrm{g} / \mathrm{L}$ & $<5.00$ & $<5.00$ & NR & Acceptable \\
\hline 1,2-Dibromoethane & $\mu \mathrm{g} / \mathrm{L}$ & $<2.00$ & $<5.00$ & NR & Acceptable \\
\hline Dibromoethane & $\mu \mathrm{g} / \mathrm{L}$ & $<2.00$ & $<5.00$ & NR & Acceptable \\
\hline 1,2-Dichlorobenzene & $\mu \mathrm{g} / \mathrm{L}$ & 19.6 & 18.2 & $12.6-23.5$ & Acceptable \\
\hline 1,3-Dichlorobenzene & $\mu \mathrm{g} / \mathrm{L}$ & 35.5 & 31.8 & $22.3-39.8$ & Acceptable \\
\hline 1,4-Dichlorobenzene & $\mu \mathrm{g} / \mathrm{L}$ & 13.0 & 11.5 & $7.74-15.3$ & Acceptable \\
\hline Dichlorodifluoromethane & $\mu \mathrm{g} / \mathrm{L}$ & $<2.00$ & $<5.00$ & NR & Acceptable \\
\hline 1,1-Dichloroethane & $\mu \mathrm{g} / \mathrm{L}$ & 66.0 & 58.8 & $31.0-95.8$ & Acceptable \\
\hline 1,2-Dichloroethane & $\mu \mathrm{g} / \mathrm{L}$ & 29.8 & 27.9 & $19.4-37.5$ & Acceptable \\
\hline 1,1-Dichloroethylene & $\mu \mathrm{g} / \mathrm{L}$ & 7.37 & $<5.00$ & NR & No Evaluation \\
\hline cis-1,2-DIchloroethylene & $\mu \mathrm{g} / \mathrm{L}$ & $<2.00$ & $<5.00$ & NR & Acceptable \\
\hline trans-1,2-Dichloroethylene & $\mu \mathrm{g} / \mathrm{L}$ & $<2.00$ & $<5.00$ & NR & Acceptable \\
\hline 1,2-Dichloropropane & $\mu \mathrm{g} / \mathrm{L}$ & $<2.00$ & $<5.00$ & NR & Acceptable \\
\hline cis-1,3-Dichloropropylene & $\mu \mathrm{g} / \mathrm{L}$ & $<2.00$ & $<5.00$ & NR & Acceptable \\
\hline trans-1,3-Dichloropropylene & $\mu \mathrm{g} / \mathrm{L}$ & $<2.00$ & $<5.00$ & NR & Acceptable \\
\hline Ethylbenzene & $\mu \mathrm{g} / \mathrm{L}$ & 34.2 & 31.7 & $21.3-41.3$ & Acceptable \\
\hline 2-Hexanone & $\mu \mathrm{g} / \mathrm{L}$ & $<2.00$ & $<5.00$ & NR & Acceptable \\
\hline Methylene chloride & $\mu \mathrm{g} / \mathrm{L}$ & 44.6 & 43.4 & $27.4-59.9$ & Acceptable \\
\hline $\begin{array}{l}\text { 4-Methyl-2-pentanone } \\
\text { (MIBK) }\end{array}$ & $\mu \mathrm{g} / \mathrm{L}$ & 54.5 & 60.6 & $D^{c}-162$ & Acceptable \\
\hline Styrene & $\mu \mathrm{g} / \mathrm{L}$ & $<2.00$ & $<5.00$ & NR & Acceptable \\
\hline 1,1,1,2-Tetrachloroethane & $\mu \mathrm{g} / \mathrm{L}$ & 197 & 183 & $112-267$ & Acceptable \\
\hline 1,1,2,2-Tetrachloroethane & $\mu \mathrm{g} / \mathrm{L}$ & $<2.00$ & $<5.00$ & NR & Acceptable \\
\hline Tetrachloroethylene & $\mu \mathrm{g} / \mathrm{L}$ & 60.4 & 55.1 & $36.5-70.5$ & Acceptable \\
\hline Toluene & $\mu \mathrm{g} / \mathrm{L}$ & 9.99 & 8.67 & $5.86-11.4$ & Acceptable \\
\hline 1,1,1-Trichloroethane & $\mu \mathrm{g} / \mathrm{L}$ & 71.9 & 62.5 & $40.3-82.5$ & Acceptable \\
\hline 1,1,2-Trichloroethane & $\mu \mathrm{g} / \mathrm{L}$ & 206 & 190 & $128-248$ & Acceptable \\
\hline Trichloroethylene & $\mu \mathrm{g} / \mathrm{L}$ & 20.9 & 18.3 & $12.0-23.8$ & Acceptable \\
\hline Trichlorofluoromethane & $\mu \mathrm{g} / 1$ & $<2.00$ & $<5.00$ & NR & Acceptable \\
\hline 1,2,3-Trichloropropane & $\mu \mathrm{g} / \mathrm{L}$ & $<2.00$ & $<5.00$ & NR & Acceptable \\
\hline Vinyl acetate & $\mu \mathrm{g} / \mathrm{L}$ & $<10.00$ & $<5.00$ & NR & Acceptable \\
\hline Vinyl chloride & $\mu \mathrm{g} / \mathrm{L}$ & $<2.00$ & $<5.00$ & NR & Acceptable \\
\hline Xylenes, total & $\mu \mathrm{g} / \mathrm{L}$ & 183 & 171 & $98.2-229$ & Acceptable \\
\hline \multicolumn{6}{|l|}{ Acids } \\
\hline Benzoic acid & $\mu \mathrm{g} / \mathrm{L}$ & $<5.00$ & $<10.00$ & NR & Acceptable \\
\hline 4-Chloro-3-methylphenol & $\mu \mathrm{g} / \mathrm{L}$ & $<5.00$ & $<10.00$ & NR & Acceptable \\
\hline 2-Chlorophenol. & $\mu \mathrm{g} / \mathrm{L}$ & $<5.00$ & $<10.00$ & NR & Acceptable \\
\hline 2,4-Dichlorophenol & $\mu \mathrm{g} / \mathrm{L}$ & $<5.00$ & $<10.00$ & NR & Acceptable \\
\hline
\end{tabular}


Table 8.15, cont.

\begin{tabular}{|c|c|c|c|c|c|}
\hline Parameter & Units & $\begin{array}{l}\text { Reported } \\
\text { Value }\end{array}$ & $\begin{array}{c}\text { Assigned } \\
\text { Value }\end{array}$ & $\begin{array}{c}\text { Acceptance } \\
\text { Limits }\end{array}$ & $\begin{array}{c}\text { Performance } \\
\text { Evaluation }\end{array}$ \\
\hline 2,6-Dichlorophenol & $\mu \mathrm{g} / \mathrm{L}$ & $<5.00$ & $<10.00$ & NR & Acceptable \\
\hline 2,4-Dimethylphenol & $\mu \mathrm{g} / \mathrm{L}$ & 79.3 & 113 & $24.1-148$ & Acceptable \\
\hline 4,6-Dinitro-2-methylphenol & $\mu \mathrm{g} / \mathrm{L}$ & $<5.00$ & $<10.00$ & NR & Acceptable \\
\hline 2,4-Dinitrophenol & $\mu \mathrm{g} / \mathrm{L}$ & $<5.00$ & $<10.00$ & NR & Acceptable \\
\hline 2-Methlyphenol & $\mu \mathrm{g} / \mathrm{L}$ & 73.4 & 118 & $12.9-161$ & Acceptable \\
\hline 3-Methylphenol & $\mu \mathrm{g} / \mathrm{L}$ & $<5.00$ & $<10.00$ & NR & Acceptable \\
\hline 4-Methylphenol & $\mu \mathrm{g} / \mathrm{L}$ & $<5.00$ & $<10.00$ & NR & Acceptable \\
\hline 2-Nitrophenol & $\mu \mathrm{g} / \mathrm{L}$ & $<5.00$ & $<10.00$ & NR & Acceptable \\
\hline 3-Nitrophenol & $\mu \mathrm{g} / \mathrm{L}$ & $<5.00$ & $<10.00$ & NR & Acceptable \\
\hline 4-Nitrophenol & $\mu \mathrm{g} / \mathrm{L}$ & $<5.00$ & $<10.00$ & NR & Acceptable \\
\hline Pentachlorophenol & $\mu \mathrm{g} / \mathrm{L}$ & 37.1 & 89.1 & $21.9-123$ & Acceptable \\
\hline Phenol & $\mu \mathrm{g} / \mathrm{L}$ & $<5.00$ & $<10.00$ & NR & Acceptable \\
\hline 2,4,5-Trichlorophenol & $\mu \mathrm{g} / \mathrm{L}$ & 40.9 & 54.0 & $24.9-68.1$ & Acceptable \\
\hline 2,4,6-Trichlorophenol & $\mu \mathrm{g} / \mathrm{L}$ & 119 & 171 & $55.1-227$ & Acceptable \\
\hline \multicolumn{6}{|l|}{ Base Neturals } \\
\hline Acenaphthene & $\mu \mathrm{g} / \mathrm{L}$ & $<5.00$ & $<10.00$ & NR & Acceptable \\
\hline Acenaphthylene & $\mu \mathrm{g} / 1$ & $<5.00$ & $<10.00$ & NR & Acceptable \\
\hline Anline & $\mu \mathrm{g} / \mathrm{L}$ & $<5.00$ & $<10.00$ & NR & Acceptable \\
\hline Anthracene & $\mu \mathrm{g} / \mathrm{L}$ & 51.9 & 65.7 & $25.8-84.9$ & Acceptable \\
\hline Benzidine & $\mu \mathrm{g} / \mathrm{L}$ & $<5.00$ & $<10.00$ & NR & Acceptable \\
\hline Benzo(a)anthracene & $\mu \mathrm{g} / \mathrm{L}$ & 16.8 & 18.7 & $12.6-19.8$ & Acceptable \\
\hline Benzo(b)flouranthene & $\mu \mathrm{g} / \mathrm{L}$ & $<5.00$ & 20.3 & $11.0-25.8$ & Not Acceptable \\
\hline Benzo(k)flouranthene & $\mu \mathrm{g} / \mathrm{L}$ & $<5.00$ & $<10.00$ & NR & Acceptable \\
\hline Benzo(g,h,i)perylene & $\mu \mathrm{g} / 1$ & $<5.00$ & $<10.00$ & NR & Acceptable \\
\hline Benzo(a)pyrene & $\mu \mathrm{g} / \mathrm{L}$ & 25.4 & $<10.00$ & NR & No Evaluation \\
\hline Benzyl alcohol & $\mu \mathrm{g} / \mathrm{L}$ & $<5.00$ & $<10.00$ & NR & Acceptable \\
\hline 4-Bromophenyl-phenylether & $\mu \mathrm{g} / \mathrm{L}$ & $<5.00$ & $<10.00$ & NR & Acceptable \\
\hline Butylbenzylphthalate & $\mu \mathrm{g} / \mathrm{L}$ & $<5.00$ & $<10.00$ & NR & Acceptable \\
\hline 4-Chloraniline & $\mu \mathrm{g} / \mathrm{L}$ & $<5.00$ & $<10.00$ & NR & Acceptable \\
\hline bis(2-Chloroethoxy)methane & $\mu \mathrm{g} / 1$ & $<5.00$ & $<10.00$ & NR & Acceptable \\
\hline bis(2-Chloroethly)ether & $\mu \mathrm{g} / \mathrm{L}$ & $<5.00$ & $<10.00$ & NR & Acceptable \\
\hline 1-Chloronaphthalene & $\mu \mathrm{g} / \mathrm{L}$ & $<5.00$ & $<10.00$ & NR & Acceptable \\
\hline 2-Chloronaphthalene & $\mu \mathrm{g} / \mathrm{L}$ & $<5.00$ & $<10.00$ & NR & Acceptable \\
\hline 4-Chlorophenyl-phenylether & $\mu \mathrm{g} / \mathrm{L}$ & $<5.00$ & $<10.00$ & NR & Acceptable \\
\hline Chrysene & $\mu \mathrm{g} / \mathrm{L}$ & 77.0 & 66.6 & $26.6-87.1$ & Acceptable \\
\hline Dibenz(a,h)aanthracene & $\mu \mathrm{g} / \mathrm{L}$ & $<5.00$ & $<10.00$ & NR & Acceptable \\
\hline Dibenzofuran & $\mu \mathrm{g} / 1$ & 46.7 & 61.8 & $19.6-78.3$ & Acceptable \\
\hline Di-n-butylphthalate & $\mu \mathrm{g} / \mathrm{L}$ & $<5.00$ & $<10.00$ & NR & Acceptable \\
\hline 1,2-Dichlorobenzene & $\mu \mathrm{g} / \mathrm{L}$ & 38.0 & 34.5 & $24.2-44.9$ & Acceptable \\
\hline 1,3-Dichlorobenzene & $\mu \mathrm{g} / \mathrm{L}$ & $<5.00$ & $<10.00$ & NR & Acceptable \\
\hline 1,4-Dichlorobenzene & $\mu \mathrm{g} / \mathrm{L}$ & 38.8 & 41.0 & $28.7-53.3$ & Acceptable \\
\hline 3,3'-Dichlorobenzidine & $\mu \mathrm{g} / \mathrm{L}$ & $<5.00$ & $<10.00$ & NR & Acceptable \\
\hline
\end{tabular}


Table 8.15, cont.

\begin{tabular}{|c|c|c|c|c|c|}
\hline Parameter & Units & $\begin{array}{l}\text { Reported } \\
\text { Value }\end{array}$ & $\begin{array}{l}\text { Assigned } \\
\text { Value }\end{array}$ & $\begin{array}{l}\text { Acceptance } \\
\text { Limits }\end{array}$ & $\begin{array}{c}\text { Performance } \\
\text { Evaluation }\end{array}$ \\
\hline Diethjylphthalate & $\mu \mathrm{g} / \mathrm{L}$ & $<5.00$ & $<10.00$ & NR & Acceptable \\
\hline Dimethlyphthalate & $\mu \mathrm{g} / \mathrm{L}$ & $<5.00$ & $<10.00$ & NR & Acceptable \\
\hline 2,4-Dinitrotoluene & $\mu \mathrm{g} / \mathrm{L}$ & 22.2 & 30.4 & $8.48-39.5$ & Acceptable \\
\hline 2,6-Dinitrotoyulene & $\mu \mathrm{g} / \mathrm{L}$ & $<5.00$ & $<10.00$ & NR & Acceptable \\
\hline Di-n-octylphthalate & $\mu \mathrm{g} / \mathrm{L}$ & $<5.00$ & $<10.00$ & NR & Acceptable \\
\hline bis(2-ethylhexyl)phthalate & $\mu \mathrm{g} / \mathrm{L}$ & 91.5 & 120 & $19.5-176$ & Acceptable \\
\hline Flouranthene & $\mu \mathrm{g} / \mathrm{L}$ & $<5.00$ & $<10.00$ & NR & Acceptable \\
\hline Fluorene & $\mu \mathrm{g} / 1$ & $<5.00$ & $<10.00$ & NR & Acceptable \\
\hline Hexachlorobenzene & $\mu \mathrm{g} / \mathrm{L}$ & $<5.00$ & $<10.00$ & NR & Acceptable \\
\hline Hexachlorobutadiene & $\mu \mathrm{g} / \mathrm{L}$ & $<5.00$ & $<10.00$ & NR & Acceptable \\
\hline Hexachlorocyclopentadiene & $\mu \mathrm{g} / \mathrm{L}$ & $<5.00$ & $<10.00$ & NR & Acceptable \\
\hline Hexachloroethane & $\mu \mathrm{g} / \mathrm{L}$ & 59.7 & 82.8 & $8.27-104$ & Acceptable \\
\hline Indeno(1,2,3-cd)pyrene & $\mu \mathrm{g} / 1$ & $<5.00$ & $<10.00$ & NR & Acceptable \\
\hline Isophorone & $\mu \mathrm{g} / \mathrm{L}$ & 74.1 & 85.8 & $30.4-114$ & Acceptable \\
\hline 1-Methylnaphthalene & $\mu \mathrm{g} / \mathrm{L}$ & $<5.00$ & $<10.00$ & NR & Acceptable \\
\hline 2-Methylnaphthalene & $\mu \mathrm{g} / \mathrm{L}$ & $<5.00$ & $<10.00$ & NR & Acceptable \\
\hline Naphthalene & $\mu \mathrm{g} / \mathrm{L}$ & 64.4 & 89.2 & $23.2-116$ & Acceptable \\
\hline 2-Nitroaniline & $\mu \mathrm{g} / \mathrm{L}$ & $<5.00$ & $<10.00$ & NR & Acceptable \\
\hline 3-Nitroaniline & $\mu \mathrm{g} / \mathrm{L}$ & $<5.00$ & $<10.00$ & NR & Acceptable \\
\hline 4-Nitroaniline & $\mu \mathrm{g} / 1$ & $<5.00$ & $<10.00$ & NR & Acceptable \\
\hline Nitrobenzene & $\mu \mathrm{g} / \mathrm{L}$ & $<5.00$ & $<10.00$ & NR & Acceptable \\
\hline N-Nitrosodimethylamine & $\mu \mathrm{g} / \mathrm{L}$ & 34.8 & 49.5 & DL - 61.4 & Acceptable \\
\hline N-Nitrosodiphenylamine & $\mu \mathrm{g} / \mathrm{L}$ & $<5.00$ & $<10.00$ & NR & Acceptable \\
\hline N-Nitroso-di-n-propylamine & $\mu \mathrm{g} / \mathrm{L}$ & $<5.00$ & $<10.00$ & NR & Acceptable \\
\hline Phenanthrene & $\mu \mathrm{g} / \mathrm{L}$ & $<5.00$ & $<10.00$ & NR & Acceptable \\
\hline Pyrene & $\mu \mathrm{g} / 1$ & 43.2 & 58.1 & $19.1-81.5$ & Acceptable \\
\hline Pyridine & $\mu \mathrm{g} / \mathrm{L}$ & $<5.00$ & $<10.00$ & NR & Acceptable \\
\hline 1,2,4-Trichlorobenzene & $\mu \mathrm{g} / \mathrm{L}$ & 47.6 & 61.6 & $17.8-75.2$ & Acceptable \\
\hline
\end{tabular}

${ }^{\text {a }}$ PCB Aroclor identity values report compound identity only, not quantity.

b Not Reported

${ }^{\mathrm{c}}$ Detection Limit 
Table 8.16 Environmental Resource Associates assessment of Trace Analysis, Inc., WP-63, June 20, 2000 .

\begin{tabular}{|c|c|c|c|c|c|}
\hline Parameter & Units & $\begin{array}{l}\text { Reported } \\
\text { Value }\end{array}$ & $\begin{array}{c}\text { Assigned } \\
\text { Value }\end{array}$ & $\begin{array}{l}\text { Acceptance } \\
\text { Limits }\end{array}$ & $\begin{array}{c}\text { Performance } \\
\text { Evaluation }\end{array}$ \\
\hline $\mathrm{pH}$ & & 8.05 & 8.10 & $7.87-7.94$ & Acceptable \\
\hline Cyanide & $\mathrm{mg} / \mathrm{L}$ & 0.366 & 0.415 & $0.284-0.537$ & Acceptable \\
\hline Phenolics, total (a) & $\mathrm{mg} / \mathrm{L}$ & 1.33 & 0.953 & $.0523-1.38$ & Check for Error \\
\hline Grease \& Oil (Gravimetric) & $\mathrm{mg} / \mathrm{L}$ & 22.7 & 22.8 & $13.6-27.7$ & Acceptable \\
\hline Total Residual Chlorine & $\mathrm{mg} / \mathrm{L}$ & 4.35 & 4.3 & $3.56-5.04$ & Acceptable \\
\hline Mercury & $\mu \mathrm{g} / \mathrm{L}$ & 7.16 & 12.5 & $9.35-15.6$ & Not Acceptable \\
\hline \multicolumn{6}{|l|}{$\underline{\text { Minerals }}$} \\
\hline Total solids at $105^{\circ} \mathrm{C}$ & $\mathrm{mg} / \mathrm{L}$ & 345 & 350 & $307-387$ & Acceptable \\
\hline Total Dissolved Solids & $\mathrm{mg} / \mathrm{L}$ & 317 & 338 & $255-421$ & Acceptable \\
\hline Conductivity at $25^{\circ} \mathrm{C}$ & $\mu$ mhos & 537 & 515 & $474-556$ & Acceptable \\
\hline Alkalinity as $\mathrm{CaCO} 3$ & $\mathrm{mg} / \mathrm{L}$ & 58.0 & 58.6 & $52.3-65.2$ & Acceptable \\
\hline Chloride & $\mathrm{mg} / \mathrm{L}$ & 98.8 & 104 & $94.5-113$ & Acceptable \\
\hline Fluoride & $\mathrm{mg} / \mathrm{L}$ & 1.34 & 1.36 & $1.17-1.54$ & Acceptable \\
\hline Potassium & $\mathrm{mg} / \mathrm{L}$ & 25.5 & 21.5 & $18.5-24.6$ & Not Acceptable \\
\hline Sodium & $\mathrm{mg} / \mathrm{L}$ & 92.8 & 95.0 & $85.9-101$ & Acceptable \\
\hline Sulfate & $\mathrm{mg} / \mathrm{L}$ & 20.3 & 21.6 & $16.9-25.8$ & Acceptable \\
\hline \multicolumn{6}{|l|}{$\underline{\text { Hardness }}$} \\
\hline Total suspended solids & $\mathrm{mg} / \mathrm{L}$ & 83.0 & 81.2 & $62.8-87.6$ & Acceptable \\
\hline Calcium & $\mathrm{mg} / \mathrm{L}$ & 65.8 & 62.8 & $56.1-71.2$ & Acceptable \\
\hline Magnesium & $\mathrm{mg} / \mathrm{L}$ & 14.6 & 13.9 & $12.1-15.6$ & Acceptable \\
\hline Calcium hardness as $\mathrm{CaCO}_{3}$ & $\mathrm{mg} / \mathrm{L}$ & 164 & 157 & $133-181$ & Acceptable \\
\hline Total hardness as $\mathrm{CaCO}_{3}$ & $\mathrm{mg} / \mathrm{L}$ & 224 & 214 & $195-234$ & Acceptable \\
\hline \multicolumn{6}{|l|}{$\underline{\text { Demand }}$} \\
\hline BOD & $\mathrm{mg} / \mathrm{L}$ & 138 & 149 & $75.3-222$ & Acceptable \\
\hline CBOD & $\mathrm{mg} / \mathrm{L}$ & 114 & 128 & $57.3-198$ & Acceptable \\
\hline COD & $\mathrm{mg} / \mathrm{L}$ & 243 & 240 & $188-270$ & Acceptable \\
\hline TOC & $\mathrm{mg} / \mathrm{L}$ & 93.7 & 94.8 & $79.3-109$ & Acceptable \\
\hline \multicolumn{6}{|l|}{ Nutrients - Simple } \\
\hline Ammonia as $\mathrm{N}$ & $\mathrm{mg} / \mathrm{L}$ & 5.43 & 5.79 & $4.45-7.09$ & Acceptable \\
\hline Nitrate as $\mathrm{N}$ & $\mathrm{mg} / \mathrm{L}$ & 27.5 & 26.9 & $21.3-31.9$ & Acceptable \\
\hline Ortho-phophate as P & $\mathrm{mg} / \mathrm{L}$ & 3.46 & 3.58 & $3.05-4.14$ & Acceptable \\
\hline \multicolumn{6}{|l|}{$\underline{\text { Nutrients - complex }}$} \\
\hline Total phosphorus as $\mathrm{P}$ & $\mathrm{mg} / \mathrm{L}$ & 3.71 & 3.58 & $2.72-4.21$ & Acceptable \\
\hline Total kjeldahl nitrogen as $\mathrm{N}$ & $\mathrm{mg} / \mathrm{L}$ & 9.52 & 10.8 & $7.72-13.6$ & Acceptable \\
\hline \multicolumn{6}{|l|}{ Trace Metals } \\
\hline Aluminum & $\mu \mathrm{g} / \mathrm{L}$ & 481 & 499 & $417-581$ & Acceptable \\
\hline Antimony & $\mu \mathrm{g} / \mathrm{L}$ & 209 & 204 & $135-249$ & Acceptable \\
\hline
\end{tabular}


Table 8.16, cont.

\begin{tabular}{|c|c|c|c|c|c|}
\hline Parameter & Units & $\begin{array}{l}\text { Reported } \\
\text { Value }\end{array}$ & $\begin{array}{l}\text { Assigned } \\
\text { Value }\end{array}$ & $\begin{array}{l}\text { Acceptance } \\
\text { Limits }\end{array}$ & $\begin{array}{c}\text { Performance } \\
\text { Evaluation }\end{array}$ \\
\hline Arsenic & $\mu \mathrm{g} / \mathrm{L}$ & 328 & 347 & $289-408$ & Acceptable \\
\hline Barium & $\mu \mathrm{g} / \mathrm{L}$ & 88.7 & 75.1 & $71.5-90.7$ & Acceptable \\
\hline Beryllium & $\mu \mathrm{g} / \mathrm{L}$ & 250 & 252 & $214-286$ & Acceptable \\
\hline Boron & $\mu \mathrm{g} / \mathrm{L}$ & 239 & 196 & $137-305$ & Acceptable \\
\hline Cadmium & $\mu \mathrm{g} / \mathrm{L}$ & 226 & 233 & $198-265$ & Acceptable \\
\hline Chromium & $\mu \mathrm{g} / \mathrm{L}$ & 979 & 966 & $843-1090$ & Acceptable \\
\hline Cobalt & $\mu \mathrm{g} / \mathrm{L}$ & 899 & 851 & $749-953$ & Acceptable \\
\hline Copper & $\mu \mathrm{g} / \mathrm{L}$ & 858 & 818 & $744-897$ & Acceptable \\
\hline Iron & $\mu \mathrm{g} / \mathrm{L}$ & 3390 & 3240 & $2870-3640$ & Acceptable \\
\hline Lead & $\mu \mathrm{g} / \mathrm{L}$ & 659 & 625 & $545-702$ & Acceptable \\
\hline Manganese & $\mu \mathrm{g} / \mathrm{L}$ & 2850 & 2820 & $2540-3130$ & Acceptable \\
\hline Molybdenum & $\mu \mathrm{g} / \mathrm{L}$ & 342 & 335 & $287-384$ & Acceptable \\
\hline Nickel & $\mu \mathrm{g} / \mathrm{L}$ & 251 & 208 & $182-236$ & Not Acceptable \\
\hline Selenium & $\mu \mathrm{g} / \mathrm{L}$ & 1050 & 1060 & $843-1230$ & Acceptable \\
\hline Silver & $\mu \mathrm{g} / \mathrm{L}$ & 485 & 488 & $419-559$ & Acceptable \\
\hline Strontium & $\mu \mathrm{g} / \mathrm{L}$ & 227 & 267 & $227-306$ & Acceptable \\
\hline Thallium & $\mu \mathrm{g} / \mathrm{L}$ & 893 & 861 & $695-998$ & Acceptable \\
\hline Vanadium & $\mu \mathrm{g} / \mathrm{L}$ & 658 & 652 & $586-716$ & Acceptable \\
\hline Zinc & $\mu \mathrm{g} / \mathrm{L}$ & 1660 & 1670 & $1480-1870$ & Acceptable \\
\hline \multicolumn{6}{|l|}{$\underline{\text { PCB's in } \mathrm{H}_{2} \mathrm{O}}$} \\
\hline Aroclor 1242 & $\mu \mathrm{g} / \mathrm{L}$ & 11.3 & 10.2 & $2.74-14.4$ & Acceptable \\
\hline PCB Aroclor Identity (Std 1) ${ }^{\mathrm{a}}$ & $\mu \mathrm{g} / \mathrm{L}$ & $1016 / 1242$ & 1242 & 1242 & Acceptable \\
\hline Aroclor 1260 & $\mu \mathrm{g} / \mathrm{L}$ & 3.60 & 4.30 & $2.30-5.62$ & Acceptable \\
\hline PCB Aroclor Identy (Std 2) ${ }^{\mathrm{a}}$ & $\mu \mathrm{g} / \mathrm{L}$ & 1260 & 1260 & 1260 & Acceptable \\
\hline \multicolumn{6}{|l|}{$\underline{\text { PCB's in Oil }}$} \\
\hline Aroclor 1254 & $\mathrm{mg} / \mathrm{Kg}$ & 22.6 & 28.9 & $3.40-43.6$ & Acceptable \\
\hline PCB Aroclor Identity (Std 1) & $\mathrm{mg} / \mathrm{Kg}$ & 1254 & 1254 & 1254 & Acceptable \\
\hline Aroclor 1242 & $\mathrm{mg} / \mathrm{Kg}$ & 44.8 & 39.7 & $7.22-53.4$ & Acceptable \\
\hline PCB Aroclor Identity $(\operatorname{Std} 2)^{\mathrm{a}}$ & $\mathrm{mg} / \mathrm{Kg}$ & $1016 / 1242$ & 12423 & 1242 & Acceptable \\
\hline \multicolumn{6}{|l|}{$\underline{\text { Volatiles }}$} \\
\hline Acetone & $\mu \mathrm{g} / \mathrm{L}$ & $<10.0$ & $<5.00$ & $\mathrm{NR}^{\mathrm{b}}$ & Acceptable \\
\hline Acrylonite & $\mu \mathrm{g} / \mathrm{L}$ & $<2.00$ & $<5.00$ & NR & Acceptable \\
\hline Benzene & $\mu \mathrm{g} / \mathrm{L}$ & 34.0 & 33.6 & $24.1-43.4$ & Acceptable \\
\hline Bromodichloromethane & $\mu \mathrm{g} / \mathrm{L}$ & 64.7 & 57.8 & $41.0-75.2$ & Acceptable \\
\hline Bromoform & $\mu \mathrm{g} / \mathrm{L}$ & 26.0 & 24.3 & $15.2-33.4$ & Acceptable \\
\hline Bromomethane & $\mu \mathrm{g} / \mathrm{L}$ & $<2.00$ & $<5.00$ & NR & Acceptable \\
\hline 2-Butanone & $\mu \mathrm{g} / \mathrm{L}$ & $<2.00$ & $<5.00$ & NR & Acceptable \\
\hline Carbon disulfide & $\mu \mathrm{g} / \mathrm{L}$ & $<2.00$ & $<5.00$ & NR & Acceptable \\
\hline Carbon tetrachloride & $\mu \mathrm{g} / \mathrm{L}$ & 18.0 & 18.1 & $11.4-25.6$ & Acceptable \\
\hline Chlorobenzene & $\mu \mathrm{g} / \mathrm{L}$ & 50.0 & 45.9 & $32.5-58.4$ & Acceptable \\
\hline Chlorodibromomethane & $\mu \mathrm{g} / \mathrm{L}$ & 61.5 & 54.1 & $35.8-71.9$ & Acceptable \\
\hline Chloroethane & $\mu \mathrm{g} / \mathrm{L}$ & $<2.00$ & $<5.00$ & NR & Acceptable \\
\hline
\end{tabular}


Table 8.16, cont.

\begin{tabular}{|c|c|c|c|c|c|}
\hline Parameter & Units & $\begin{array}{l}\text { Reported } \\
\text { Value }\end{array}$ & $\begin{array}{l}\text { Assigned } \\
\text { Value }\end{array}$ & $\begin{array}{l}\text { Acceptance } \\
\text { Limits }\end{array}$ & $\begin{array}{l}\text { Performance } \\
\text { Evaluation }\end{array}$ \\
\hline 2-Chloroethylvinylether & $\mu \mathrm{g} / \mathrm{L}$ & $<2.00$ & $<5.00$ & NR & Acceptable \\
\hline Chloroform & $\mu \mathrm{g} / \mathrm{L}$ & 74.8 & 70.0 & $48.4-89.6$ & Acceptable \\
\hline Chloromethane & $\mu \mathrm{g} / \mathrm{L}$ & $<2.00$ & $<5.00$ & NR & Acceptable \\
\hline $\mathrm{DBCP}$ & $\mu \mathrm{g} / \mathrm{L}$ & $<5.00$ & $<5.00$ & NR & Acceptable \\
\hline 1,2-Dibromoethane & $\mu \mathrm{g} / \mathrm{L}$ & $<2.00$ & $<5.00$ & NR & Acceptable \\
\hline Dibromoethane & $\mu \mathrm{g} / \mathrm{L}$ & $<2.00$ & $<5.00$ & NR & Acceptable \\
\hline 1,2-Dichlorobenzene & $\mu \mathrm{g} / \mathrm{L}$ & 32.2 & 30.0 & $21.0-38.2$ & Acceptable \\
\hline 1,3-Dichlorobenzene & $\mu \mathrm{g} / \mathrm{L}$ & 14.8 & 13.6 & $9.32-17.4$ & Acceptable \\
\hline 1,4-Dichlorobenzene & $\mu \mathrm{g} / \mathrm{L}$ & 14.0 & 12.6 & $8.50-16.7$ & Acceptable \\
\hline Dichlorodifluoromethane & $\mu \mathrm{g} / \mathrm{L}$ & $<2.00$ & $<5.00$ & NR & Acceptable \\
\hline 1,1-Dichloroethane & $\mu \mathrm{g} / \mathrm{L}$ & $<2.00$ & $<5.00$ & NR & Acceptable \\
\hline 1,2-Dichloroethane & $\mu \mathrm{g} / \mathrm{L}$ & 63.2 & 58.2 & $40.2-77.4$ & Acceptable \\
\hline 1,1-Dichloroethylene & $\mu \mathrm{g} / \mathrm{L}$ & $<2.00$ & $<5.00$ & NR & Acceptable \\
\hline cis-1,2-Dichloroethylene & $\mu \mathrm{g} / \mathrm{L}$ & $<2.00$ & $<5.00$ & NR & Acceptable \\
\hline trans-1,2-Dichloroethylene & $\mu \mathrm{g} / \mathrm{L}$ & $<2.00$ & $<5.00$ & NR & Acceptable \\
\hline 1,2-Dichloropropane & $\mu \mathrm{g} / \mathrm{L}$ & 25.1 & 23.2 & $16.7-29.1$ & Acceptable \\
\hline cis-1,3-Dichloropropylene & $\mu \mathrm{g} / \mathrm{L}$ & $<2.00$ & $<5.00$ & NR & Acceptable \\
\hline trans-1,3-Dichloropropylene & $\mu \mathrm{g} / \mathrm{L}$ & $<2.00$ & $<5.00$ & NR & Acceptable \\
\hline Ethylbenzene & $\mu \mathrm{g} / \mathrm{L}$ & 29.9 & 27.5 & $18.5-35.8$ & Acceptable \\
\hline 2-Hexanone & $\mu \mathrm{g} / \mathrm{L}$ & $<2.00$ & $<5.00$ & NR & Acceptable \\
\hline Methylene chloride & $\mu \mathrm{g} / \mathrm{L}$ & 34.2 & 31.5 & $19.9-43.8$ & Acceptable \\
\hline $\begin{array}{l}\text { 4-Methyl-2-pentanone } \\
\text { (MIBK) }\end{array}$ & $\mu \mathrm{g} / \mathrm{L}$ & 191 & 173 & $66.0-270$ & Acceptable \\
\hline Styrene & $\mu \mathrm{g} / \mathrm{L}$ & $<2.00$ & $<5.00$ & NR & Acceptable \\
\hline 1,1,1,2-Tetrachloroethane & $\mu \mathrm{g} / \mathrm{L}$ & $<2.00$ & $<5.00$ & NR & Acceptable \\
\hline 1,1,2,2-Tetrachloroethane & $\mu \mathrm{g} / \mathrm{L}$ & 76.0 & 68.4 & $39.9-95.6$ & Acceptable \\
\hline Tetrachloroethylene & $\mu \mathrm{g} / \mathrm{L}$ & 30.7 & 34.9 & $23.1-44.9$ & Acceptable \\
\hline Toluene & $\mu \mathrm{g} / \mathrm{L}$ & 38.4 & 34.1 & $24.4-42.8$ & Acceptable \\
\hline 1,1,1-Trichloroethane & $\mu \mathrm{g} / \mathrm{L}$ & 24.3 & 22.7 & $14.9-29.9$ & Acceptable \\
\hline 1,1,2-Trichloroethane & $\mu \mathrm{g} / \mathrm{L}$ & $<2.00$ & $<5.00$ & NR & Acceptable \\
\hline Trichloroethylene & $\mu \mathrm{g} / \mathrm{L}$ & 31.4 & 30.1 & $19.6-39.0$ & Acceptable \\
\hline Trichlorofluoromethane & $\mu \mathrm{g} / 1$ & $<2.00$ & $<5.00$ & NR & Acceptable \\
\hline 1,2,3-Trichloropropane & $\mu \mathrm{g} / \mathrm{L}$ & $<2.00$ & $<5.00$ & NR & Acceptable \\
\hline Vinyl chloride & $\mu \mathrm{g} / \mathrm{L}$ & $<2.00$ & $<5.00$ & NR & Acceptable \\
\hline Xylenes, total & $\mu \mathrm{g} / \mathrm{L}$ & 93.1 & 84.1 & $47.8-114$ & Acceptable \\
\hline \multicolumn{6}{|l|}{$\underline{\text { Acids }}$} \\
\hline Benzoic acid & $\mu \mathrm{g} / \mathrm{L}$ & $<5.00$ & $<10.00$ & NR & Acceptable \\
\hline 4-Chloro-3-methylphenol & $\mu \mathrm{g} / \mathrm{L}$ & $<5.00$ & $<10.00$ & NR & Acceptable \\
\hline 2-Chlorophenol. & $\mu \mathrm{g} / \mathrm{L}$ & 102 & 160 & $45.2-201$ & Acceptable \\
\hline 2,4-Dichlorophenol & $\mu \mathrm{g} / \mathrm{L}$ & $<5.00$ & $<10.00$ & NR & Acceptable \\
\hline 2,6-Dichlorophenol & $\mu \mathrm{g} / \mathrm{L}$ & $<5.00$ & $<10.00$ & NR & Acceptable \\
\hline 2,4-Dimethylphenol & $\mu \mathrm{g} / \mathrm{L}$ & $<5.00$ & $<10.00$ & NR & Acceptable \\
\hline
\end{tabular}


Table 8.16, cont.

\begin{tabular}{|c|c|c|c|c|c|}
\hline Parameter & Units & $\begin{array}{l}\text { Reported } \\
\text { Value }\end{array}$ & $\begin{array}{l}\text { Assigned } \\
\text { Value }\end{array}$ & $\begin{array}{l}\text { Acceptance } \\
\text { Limits }\end{array}$ & $\begin{array}{c}\text { Performance } \\
\text { Evaluation }\end{array}$ \\
\hline 4,6-Dinitro-2-methylphenol & $\mu \mathrm{g} / \mathrm{L}$ & $<5.00$ & $<10.00$ & NR & Acceptable \\
\hline 2,4-Dinitrophenol & $\mu \mathrm{g} / \mathrm{L}$ & $<5.00$ & $<10.00$ & NR & Acceptable \\
\hline 2-Methlyphenol & $\mu \mathrm{g} / \mathrm{L}$ & 37.0 & 66.8 & $\mathrm{DL}^{\mathrm{c}}-93.5$ & Acceptable \\
\hline 3-Methylphenol & $\mu \mathrm{g} / \mathrm{L}$ & $<5.00$ & $<10.00$ & NR & Acceptable \\
\hline 4-Methylphenol & $\mu \mathrm{g} / \mathrm{L}$ & $<5.00$ & $<10.00$ & NR & Acceptable \\
\hline 2-Nitrophenol & $\mu \mathrm{g} / \mathrm{L}$ & $<5.00$ & $<10.00$ & NR & Acceptable \\
\hline 3-Nitrophenol & $\mu \mathrm{g} / \mathrm{L}$ & $<5.00$ & $<10.00$ & NR & Acceptable \\
\hline 4-Nitrophenol & $\mu \mathrm{g} / \mathrm{L}$ & $<5.00$ & $<10.00$ & NR & Acceptable \\
\hline Pentachlorophenol & $\mu \mathrm{g} / \mathrm{L}$ & 33.0 & 61.3 & $13.1-84.7$ & Acceptable \\
\hline Phenol & $\mu \mathrm{g} / \mathrm{L}$ & $<5.00$ & 170 & DL - 227 & Acceptable \\
\hline 2,4,5-Trichlorophenol & $\mu \mathrm{g} / \mathrm{L}$ & 97.0 & 122 & $45.7-155$ & Acceptable \\
\hline 2,4,6-Trichlorophenol & $\mu \mathrm{g} / \mathrm{L}$ & 44.0 & 53.5 & $18.7-70.1$ & Acceptable \\
\hline \multicolumn{6}{|l|}{$\underline{\text { Base Neturals }}$} \\
\hline Acenaphthene & $\mu \mathrm{g} / \mathrm{L}$ & $<5.00$ & $<10.00$ & NR & Acceptable \\
\hline Acenaphthylene & $\mu \mathrm{g} / 1$ & $<5.00$ & $<10.00$ & NR & Acceptable \\
\hline Anline & $\mu \mathrm{g} / \mathrm{L}$ & $<5.00$ & $<10.00$ & NR & Acceptable \\
\hline Anthracene & $\mu \mathrm{g} / \mathrm{L}$ & 102 & 129 & $44.2-167$ & Acceptable \\
\hline Benzidine & $\mu \mathrm{g} / \mathrm{L}$ & $<5.00$ & $<10.00$ & NR & Acceptable \\
\hline Benzo(a)anthracene & $\mu \mathrm{g} / \mathrm{L}$ & $<5.00$ & $<10.00$ & NR & Acceptable \\
\hline Benzo(b)flouranthene & $\mu \mathrm{g} / \mathrm{L}$ & $<5.00$ & $<10.00$ & NR & Not Acceptable \\
\hline Benzo(k)flouranthene & $\mu \mathrm{g} / \mathrm{L}$ & $<5.00$ & $<10.00$ & NR & Acceptable \\
\hline Benzo(g,h,i)perylene & $\mu \mathrm{g} / 1$ & 17.0 & 14.2 & DL - 21.6 & Acceptable \\
\hline Benzo(a)pyrene & $\mu \mathrm{g} / \mathrm{L}$ & 25.4 & $<10.00$ & NR & No Evaluation \\
\hline Benzyl alcohol & $\mu \mathrm{g} / \mathrm{L}$ & $<5.00$ & $<10.00$ & NR & Acceptable \\
\hline 4-Bromophenyl-phenylether & $\mu \mathrm{g} / \mathrm{L}$ & 81.0 & 92.4 & $40.0-118$ & Acceptable \\
\hline Butylbenzylphthalate & $\mu \mathrm{g} / \mathrm{L}$ & 94.0 & 105 & DL - 166 & Acceptable \\
\hline Carbazole & $\mu \mathrm{g} / \mathrm{L}$ & $<5.00$ & $<10.00$ & NR & Acceptable \\
\hline 4-Chloraniline & $\mu \mathrm{g} / \mathrm{L}$ & $<5.00$ & $<10.00$ & NR & Acceptable \\
\hline bis(2-Chloroethoxy)methane & $\mu \mathrm{g} / 1$ & $<5.00$ & $<10.00$ & NR & Acceptable \\
\hline bis(2-Chloroethly)ether & $\mu \mathrm{g} / \mathrm{L}$ & 65.0 & 87.0 & $24.0-107$ & Acceptable \\
\hline 1-Chloronaphthalene & $\mu \mathrm{g} / \mathrm{L}$ & $<5.00$ & $<10.00$ & NR & Acceptable \\
\hline 2-Chloronaphthalene & $\mu \mathrm{g} / \mathrm{L}$ & $<5.00$ & $<10.00$ & NR & Acceptable \\
\hline 4-Chlorophenyl-phenylether & $\mu \mathrm{g} / \mathrm{L}$ & $<5.00$ & $<10.00$ & NR & Acceptable \\
\hline Chrysene & $\mu \mathrm{g} / \mathrm{L}$ & 28.0 & 21.8 & $11.7-27.3$ & Not Acceptable \\
\hline Dibenz(a,h)aanthracene & $\mu \mathrm{g} / \mathrm{L}$ & $<5.00$ & $<10.00$ & NR & Acceptable \\
\hline Dibenzofuran & $\mu \mathrm{g} / 1$ & 82.0 & 104 & $25.6-134$ & Acceptable \\
\hline Di-n-butylphthalate & $\mu \mathrm{g} / \mathrm{L}$ & $<5.00$ & $<10.00$ & NR & Acceptable \\
\hline 1,2-Dichlorobenzene & $\mu \mathrm{g} / \mathrm{L}$ & 43.0 & 41.5 & $29.1-54$ & Acceptable \\
\hline 1,3-Dichlorobenzene & $\mu \mathrm{g} / \mathrm{L}$ & $<5.00$ & $<10.00$ & NR & Acceptable \\
\hline 1,4-Dichlorobenzene & $\mu \mathrm{g} / \mathrm{L}$ & $<5.00$ & $<10.00$ & NR & Acceptable \\
\hline 3,3'-Dichlorobenzidine & $\mu \mathrm{g} / \mathrm{L}$ & $<5.00$ & $<10.00$ & NR & Acceptable \\
\hline Diethjylphthalate & $\mu \mathrm{g} / 1$ & $<5.00$ & $<10.00$ & NR & Acceptable \\
\hline
\end{tabular}


Table 8.16, cont.

\begin{tabular}{|c|c|c|c|c|c|}
\hline Parameter & Units & $\begin{array}{c}\text { Reported } \\
\text { Value }\end{array}$ & $\begin{array}{l}\text { Assigned } \\
\text { Value }\end{array}$ & $\begin{array}{c}\text { Acceptance } \\
\text { Limits }\end{array}$ & $\begin{array}{c}\text { Performance } \\
\text { Evaluation }\end{array}$ \\
\hline Dimethlyphthalate & $\mu \mathrm{g} / \mathrm{L}$ & $<5.00$ & $<10.00$ & NR & Acceptable \\
\hline 2,4-Dinitrotoluene & $\mu \mathrm{g} / \mathrm{L}$ & 98.0 & 132 & $55.6-176$ & Acceptable \\
\hline 2,6-Dinitrotoyulene & $\mu \mathrm{g} / \mathrm{L}$ & $<5.00$ & $<10.00$ & NR & Acceptable \\
\hline Di-n-octylphthalate & $\mu \mathrm{g} / \mathrm{L}$ & $<5.00$ & $<10.00$ & NR & Acceptable \\
\hline bis(2-ethylhexyl)phthalate & $\mu \mathrm{g} / \mathrm{L}$ & 29.0 & 30.2 & $15.7-43$ & Acceptable \\
\hline Flouranthene & $\mu \mathrm{g} / \mathrm{L}$ & $<5.00$ & $<10.00$ & NR & Acceptable \\
\hline Fluorene & $\mu \mathrm{g} / 1$ & 100 & 12 & $51.1-156$ & Acceptable \\
\hline Hexachlorobenzene & $\mu \mathrm{g} / \mathrm{L}$ & $<5.00$ & $<10.00$ & NR & Acceptable \\
\hline Hexachlorobutadiene & $\mu \mathrm{g} / \mathrm{L}$ & $<5.00$ & $<10.00$ & NR & Acceptable \\
\hline Hexachlorocyclopentadiene & $\mu \mathrm{g} / \mathrm{L}$ & $<5.00$ & $<10.00$ & NR & Acceptable \\
\hline Hexachloroethane & $\mu \mathrm{g} / \mathrm{L}$ & $<5.00$ & $<10.00$ & NR & Acceptable \\
\hline Indeno(1,2,3-cd)pyrene & $\mu \mathrm{g} / 1$ & $<5.00$ & $<10.00$ & NR & Acceptable \\
\hline Isophorone & $\mu \mathrm{g} / \mathrm{L}$ & $<5.00$ & $<10.00$ & NR & Acceptable \\
\hline 1-Methylnaphthalene & $\mu \mathrm{g} / \mathrm{L}$ & $<5.00$ & $<10.00$ & NR & Acceptable \\
\hline 2-Methylnaphthalene & $\mu \mathrm{g} / \mathrm{L}$ & 13.0 & 24.2 & DL - 36.7 & Acceptable \\
\hline Naphthalene & $\mu \mathrm{g} / \mathrm{L}$ & 28.0 & 34.6 & $11.8-45.7$ & Acceptable \\
\hline 2-Nitroaniline & $\mu \mathrm{g} / \mathrm{L}$ & $<5.00$ & $<10.00$ & NR & Acceptable \\
\hline 3-Nitroaniline & $\mu \mathrm{g} / \mathrm{L}$ & $<5.00$ & $<10.00$ & NR & Acceptable \\
\hline 4-Nitroaniline & $\mu \mathrm{g} / 1$ & $<5.00$ & $<10.00$ & NR & Acceptable \\
\hline Nitrobenzene & $\mu \mathrm{g} / \mathrm{L}$ & $<5.00$ & $<10.00$ & NR & Acceptable \\
\hline N-Nitrosodimethylamine & $\mu \mathrm{g} / \mathrm{L}$ & $<5.00$ & $<10.00$ & NR & Acceptable \\
\hline N-Nitrosodiphenylamine & $\mu \mathrm{g} / \mathrm{L}$ & $<5.00$ & $<10.00$ & NR & Acceptable \\
\hline N-Nitroso-di-n-propylamine & $\mu \mathrm{g} / \mathrm{L}$ & $<5.00$ & $<10.00$ & NR & Acceptable \\
\hline Phenanthrene & $\mu \mathrm{g} / \mathrm{L}$ & $<5.00$ & $<10.00$ & NR & Acceptable \\
\hline Pyrene & $\mu \mathrm{g} / 1$ & 96.0 & 116 & $38.5-157$ & Acceptable \\
\hline Pyridine & $\mu \mathrm{g} / \mathrm{L}$ & $<5.00$ & $<10.00$ & NR & Acceptable \\
\hline 1,2,4-Trichlorobenzene & $\mu \mathrm{g} / \mathrm{L}$ & 21.0 & 25.9 & $7.18-34.1$ & Acceptable \\
\hline
\end{tabular}


Table 8.17 Environmental Resource Associates assessment of Trace Analysis, Inc., WP-69, December 14, 2000.

\begin{tabular}{|c|c|c|c|c|c|}
\hline Parameter & Units & $\begin{array}{l}\text { Reported } \\
\text { Value }\end{array}$ & $\begin{array}{c}\text { Assigned } \\
\text { Value }\end{array}$ & $\begin{array}{l}\text { Acceptance } \\
\text { Limits }\end{array}$ & $\begin{array}{c}\text { Performance } \\
\text { Evaluation }\end{array}$ \\
\hline $\mathrm{pH}$ & & 8.42 & 8.40 & $8.15-8.64$ & Acceptable \\
\hline Cyanide & $\mathrm{mg} / \mathrm{L}$ & 0.664 & 0.686 & $0.476-0.882$ & Acceptable \\
\hline Phenolics, total & $\mathrm{mg} / \mathrm{L}$ & 0.203 & 0.175 & $0.0886-0.261$ & Check for Error \\
\hline Grease \& Oil (Gravimetric) & $\mathrm{mg} / \mathrm{L}$ & 36.3 & 40.5 & $26.7-46.2$ & Acceptable \\
\hline Total Residual Chlorine & $\mathrm{mg} / \mathrm{L}$ & 0.930 & 0.958 & $0.737-1.18$ & Acceptable \\
\hline Mercury & $\mu \mathrm{g} / \mathrm{L}$ & 3.20 & 2.72 & $1.93-3.50$ & Not Acceptable \\
\hline \multicolumn{6}{|l|}{ Minerals } \\
\hline Total solids at $105^{\circ} \mathrm{C}$ & $\mathrm{mg} / \mathrm{L}$ & 316 & 309 & $268-346$ & Acceptable \\
\hline Total Dissolved Solids & $\mathrm{mg} / \mathrm{L}$ & 296 & 291 & $218-364$ & Acceptable \\
\hline Conductivity at $25^{\circ} \mathrm{C}$ & $\mu$ mhos & 382 & 381 & $351-411$ & Acceptable \\
\hline Alkalinity as $\mathrm{CaCO} 3$ & $\mathrm{mg} / \mathrm{L}$ & 68.0 & 71.3 & $64.1-78.4$ & Acceptable \\
\hline Chloride & $\mathrm{mg} / \mathrm{L}$ & 45.2 & 48.0 & $42.7-52.8$ & Acceptable \\
\hline Fluoride & $\mathrm{mg} / \mathrm{L}$ & 2.66 & 2.7 & $2.35-3.02$ & Acceptable \\
\hline Potassium & $\mathrm{mg} / \mathrm{L}$ & 26.5 & 28.6 & $24.7-32.6$ & Acceptable \\
\hline Sodium & $\mathrm{mg} / \mathrm{L}$ & 52.0 & 63.9 & $57.6-70.2$ & Not Acceptable \\
\hline Sulfate & $\mathrm{mg} / \mathrm{L}$ & 26.5 & 28.3 & $22.5-33.3$ & Acceptable \\
\hline \multicolumn{6}{|l|}{$\underline{\text { Hardness }}$} \\
\hline Total suspended solids & $\mathrm{mg} / \mathrm{L}$ & 44.0 & 43.3 & $32.3-46.3$ & Acceptable \\
\hline Calcium & $\mathrm{mg} / \mathrm{L}$ & 51.0 & 54.4 & $48.6-61.7$ & Acceptable \\
\hline Magnesium & $\mathrm{mg} / \mathrm{L}$ & 9.18 & 9.68 & $8.41-10.9$ & Acceptable \\
\hline Calcium hardness as $\mathrm{CaCO}_{3}$ & $\mathrm{mg} / \mathrm{L}$ & 127 & 136 & $116-193$ & Acceptable \\
\hline Total hardness as $\mathrm{CaCO}_{3}$ & $\mathrm{mg} / \mathrm{L}$ & 165 & 176 & $160-193$ & Check for Error \\
\hline \multicolumn{6}{|l|}{ Demand } \\
\hline BOD & $\mathrm{mg} / \mathrm{L}$ & 121 & 126 & $63.7-188$ & Acceptable \\
\hline CBOD & $\mathrm{mg} / \mathrm{L}$ & 75.0 & 108 & $48.5-168$ & Acceptable \\
\hline COD & $\mathrm{mg} / \mathrm{L}$ & 213 & 204 & $158-231$ & Acceptable \\
\hline TOC & $\mathrm{mg} / \mathrm{L}$ & 95.0 & 80.6 & $67.4-92.6$ & Not Acceptable \\
\hline \multicolumn{6}{|l|}{ Nutrients - Simple } \\
\hline Ammonia as $\mathrm{N}$ & $\mathrm{mg} / \mathrm{L}$ & 14.9 & 17.8 & $13.9-21.6$ & Check for Error \\
\hline Nitrate as $\mathrm{N}$ & $\mathrm{mg} / \mathrm{L}$ & 19.2 & 19.1 & $15.1-22.7$ & Acceptable \\
\hline Ortho-phophate as P & $\mathrm{mg} / \mathrm{L}$ & 4.37 & 4.43 & $3.78-5.12$ & Acceptable \\
\hline \multicolumn{6}{|l|}{ Nutrients - complex } \\
\hline Total phosphorus as $\mathrm{P}$ & $\mathrm{mg} / \mathrm{L}$ & 0.503 & 0.503 & $0.398-0.664$ & Acceptable \\
\hline Total kjeldahl nitrogen as $\mathrm{N}$ & $\mathrm{mg} / \mathrm{L}$ & 6.44 & 6.31 & $4.37-8.15$ & Acceptable \\
\hline \multicolumn{6}{|l|}{ Trace Metals } \\
\hline Aluminum & $\mu \mathrm{g} / \mathrm{L}$ & 934 & 891 & $757-1020$ & Acceptable \\
\hline Antimony & $\mu \mathrm{g} / \mathrm{L}$ & 812 & 700 & $494-841$ & Check for Error \\
\hline
\end{tabular}


Table 8.17, cont.

\begin{tabular}{|c|c|c|c|c|c|}
\hline Parameter & Units & $\begin{array}{l}\text { Reported } \\
\text { Value }\end{array}$ & $\begin{array}{l}\text { Assigned } \\
\text { Value }\end{array}$ & $\begin{array}{l}\text { Acceptance } \\
\text { Limits }\end{array}$ & $\begin{array}{l}\text { Performance } \\
\text { Evaluation }\end{array}$ \\
\hline Arsenic & $\mu \mathrm{g} / \mathrm{L}$ & 316 & 317 & $264-373$ & Acceptable \\
\hline Barium & $\mu \mathrm{g} / \mathrm{L}$ & 1540 & 1540 & $1310-1750$ & Acceptable \\
\hline Beryllium & $\mu \mathrm{g} / \mathrm{L}$ & 350 & 342 & $290-386$ & Acceptable \\
\hline Boron & $\mu \mathrm{g} / \mathrm{L}$ & 797 & 781 & $570-993$ & Acceptable \\
\hline Cadmium & $\mu \mathrm{g} / \mathrm{L}$ & 470 & 493 & $421-560$ & Acceptable \\
\hline Chromium & $\mu \mathrm{g} / \mathrm{L}$ & 773 & 759 & $662-858$ & Acceptable \\
\hline Cobalt & $\mu \mathrm{g} / \mathrm{L}$ & 540 & 529 & $465-593$ & Acceptable \\
\hline Copper & $\mu \mathrm{g} / \mathrm{L}$ & 449 & 446 & $404-491$ & Acceptable \\
\hline Iron & $\mu \mathrm{g} / \mathrm{L}$ & 1080 & 1090 & $964-1230$ & Acceptable \\
\hline Lead & $\mu \mathrm{g} / \mathrm{L}$ & 800 & 785 & $687-880$ & Acceptable \\
\hline Manganese & $\mu \mathrm{g} / \mathrm{L}$ & 585 & 574 & $515-638$ & Acceptable \\
\hline Molybdenum & $\mu \mathrm{g} / \mathrm{L}$ & 173 & 168 & $142-193$ & Acceptable \\
\hline Nickel & $\mu \mathrm{g} / \mathrm{L}$ & 1980 & 1950 & $1770-2170$ & Acceptable \\
\hline Selenium & $\mu \mathrm{g} / \mathrm{L}$ & 898 & 885 & $703-1020$ & Acceptable \\
\hline Silver & $\mu \mathrm{g} / \mathrm{L}$ & 287 & 272 & $233-312$ & Acceptable \\
\hline Strontium & $\mu \mathrm{g} / \mathrm{L}$ & 156 & 150 & $127-172$ & Acceptable \\
\hline Thallium & $\mu \mathrm{g} / \mathrm{L}$ & 399 & 477 & $384-554$ & Check for Error \\
\hline Vanadium & $\mu \mathrm{g} / \mathrm{L}$ & 5020 & 4940 & $4460-5430$ & Acceptable \\
\hline Zinc & $\mu \mathrm{g} / \mathrm{L}$ & 652 & 630 & $557-710$ & Acceptable \\
\hline \multicolumn{6}{|l|}{ 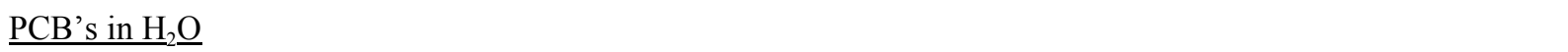 } \\
\hline Aroclor 1248 & $\mu \mathrm{g} / \mathrm{L}$ & 1.10 & 2.84 & $1.17-3.95$ & Not Acceptable \\
\hline PCB Aroclor Identity $(\operatorname{Std} 1)^{\mathrm{a}}$ & $\mu \mathrm{g} / \mathrm{L}$ & 1248 & 1248 & 1248 & Acceptable \\
\hline Aroclor 1260 & $\mu \mathrm{g} / \mathrm{L}$ & 2.20 & 1.92 & $0.816-2.58$ & Acceptable \\
\hline PCB Aroclor Identy (Std 2) ${ }^{\mathrm{a}}$ & $\mu \mathrm{g} / \mathrm{L}$ & 1260 & 1260 & 1260 & Acceptable \\
\hline \multicolumn{6}{|l|}{ PCB's in Oil } \\
\hline Aroclor $1016 / 1242$ & $\mathrm{mg} / \mathrm{Kg}$ & 25.6 & 26.6 & $3.95-37.8$ & Acceptable \\
\hline PCB Aroclor Identity (Std 1) & $\mathrm{mg} / \mathrm{Kg}$ & $1016 / 1242$ & 1242 & 1242 & Acceptable \\
\hline Aroclor 1254 & $\mathrm{mg} / \mathrm{Kg}$ & 27.2 & 26.3 & $2.71-40.1$ & Acceptable \\
\hline PCB Aroclor Identity $(\operatorname{Std} 2)^{\mathrm{a}}$ & $\mathrm{mg} / \mathrm{Kg}$ & 1254 & 1254 & 1254 & Acceptable \\
\hline \multicolumn{6}{|l|}{$\underline{\text { Volatiles }}$} \\
\hline Acetone & $\mu \mathrm{g} / \mathrm{L}$ & $<10.0$ & $<5.00$ & $\mathrm{NR}^{\mathrm{b}}$ & Acceptable \\
\hline Acrylonite & $\mu \mathrm{g} / \mathrm{L}$ & $<1.00$ & $<5.00$ & NR & Acceptable \\
\hline Benzene & $\mu \mathrm{g} / \mathrm{L}$ & 30.5 & 29.3 & $20.9-38.0$ & Acceptable \\
\hline Bromodichloromethane & $\mu \mathrm{g} / \mathrm{L}$ & 63.0 & 59.1 & $42.0-76.9$ & Acceptable \\
\hline Bromoform & $\mu \mathrm{g} / \mathrm{L}$ & 56.4 & 55.9 & $36.5-76.5$ & Acceptable \\
\hline Bromomethane & $\mu \mathrm{g} / \mathrm{L}$ & $<1.00$ & $<5.00$ & NR & Acceptable \\
\hline 2-Butanone & $\mu \mathrm{g} / \mathrm{L}$ & $<5.00$ & $<5.00$ & NR & Acceptable \\
\hline Carbon disulfide & $\mu \mathrm{g} / \mathrm{L}$ & $<1.00$ & $<5.00$ & NR & Acceptable \\
\hline Carbon tetrachloride & $\mu \mathrm{g} / \mathrm{L}$ & 58.5 & 61.1 & $37.7-86.2$ & Acceptable \\
\hline Chlorobenzene & $\mu \mathrm{g} / \mathrm{L}$ & 37.7 & 35.1 & $25.0-44.6$ & Acceptable \\
\hline Chlorodibromomethane & $\mu \mathrm{g} / \mathrm{L}$ & 49.0 & 46.0 & $30.4-61.1$ & Acceptable \\
\hline
\end{tabular}


Table 8.17, cont.

\begin{tabular}{|c|c|c|c|c|c|}
\hline Parameter & Units & $\begin{array}{l}\text { Reported } \\
\text { Value }\end{array}$ & $\begin{array}{l}\text { Assigned } \\
\text { Value }\end{array}$ & $\begin{array}{l}\text { Acceptance } \\
\text { Limits }\end{array}$ & $\begin{array}{l}\text { Performance } \\
\text { Evaluation }\end{array}$ \\
\hline Chloroethane & $\mu \mathrm{g} / \mathrm{L}$ & $<1.00$ & $<5.00$ & NR & Acceptable \\
\hline 2-Chloroethylvinylether & $\mu \mathrm{g} / \mathrm{L}$ & $<5.00$ & $<5.00$ & NR & Acceptable \\
\hline Chloroform & $\mu \mathrm{g} / \mathrm{L}$ & 51.6 & 48.4 & $33.6-62.1$ & Acceptable \\
\hline Chloromethane & $\mu \mathrm{g} / \mathrm{L}$ & $<1.00$ & $<5.00$ & NR & Acceptable \\
\hline $\mathrm{DBCP}$ & $\mu \mathrm{g} / \mathrm{L}$ & $<5.00$ & $<5.00$ & NR & Acceptable \\
\hline 1,2-Dibromoethane & $\mu \mathrm{g} / \mathrm{L}$ & $<1.00$ & $<5.00$ & NR & Acceptable \\
\hline Dibromoethane & $\mu \mathrm{g} / \mathrm{L}$ & $<1.00$ & $<5.00$ & NR & Acceptable \\
\hline 1,2-Dichlorobenzene & $\mu \mathrm{g} / \mathrm{L}$ & 25.7 & 24.8 & $17.3-31.8$ & Acceptable \\
\hline 1,3-Dichlorobenzene & $\mu \mathrm{g} / \mathrm{L}$ & 41.1 & 38.4 & $27.1-48.0$ & Acceptable \\
\hline 1,4-Dichlorobenzene & $\mu \mathrm{g} / \mathrm{L}$ & 50.4 & 46.4 & $31.9-59.8$ & Acceptable \\
\hline Dichlorodifluoromethane & $\mu \mathrm{g} / \mathrm{L}$ & $<1.00$ & $<5.00$ & NR & Acceptable \\
\hline 1,1-Dichloroethane & $\mu \mathrm{g} / \mathrm{L}$ & $<1.00$ & $<5.00$ & NR & Acceptable \\
\hline 1,2-Dichloroethane & $\mu \mathrm{g} / \mathrm{L}$ & 48.6 & 44.7 & $30.9-59.6$ & Acceptable \\
\hline 1,1-Dichloroethylene & $\mu \mathrm{g} / \mathrm{L}$ & 13.3 & 12.4 & $5.07-21.5$ & Acceptable \\
\hline cis-1,2-Dichloroethylene & $\mu \mathrm{g} / \mathrm{L}$ & $<1.00$ & $<5.00$ & NR & Acceptable \\
\hline trans-1,2-Dichloroethylene & $\mu \mathrm{g} / \mathrm{L}$ & $<1.00$ & $<5.00$ & NR & Acceptable \\
\hline 1,2-Dichloropropane & $\mu \mathrm{g} / \mathrm{L}$ & $<1.00$ & $<5.00$ & NR & Acceptable \\
\hline cis-1,3-Dichloropropylene & $\mu \mathrm{g} / \mathrm{L}$ & $<1.00$ & $<5.00$ & NR & Acceptable \\
\hline trans-1,3-Dichloropropylene & $\mu \mathrm{g} / \mathrm{L}$ & $<1.00$ & $<5.00$ & NR & Acceptable \\
\hline Ethylbenzene & $\mu \mathrm{g} / \mathrm{L}$ & 15.9 & 15.0 & $10.3-19.4$ & Acceptable \\
\hline 2-Hexanone & $\mu \mathrm{g} / \mathrm{L}$ & $<5.00$ & $<5.00$ & NR & Acceptable \\
\hline Methylene chloride & $\mu \mathrm{g} / \mathrm{L}$ & 30.2 & 29.8 & $18.8-41.5$ & Acceptable \\
\hline 4-Methyl-2-pentanone (MIBK) & $\mu \mathrm{g} / \mathrm{L}$ & 79.9 & 83.1 & $31.9-129$ & Acceptable \\
\hline Styrene & $\mu \mathrm{g} / \mathrm{L}$ & $<1.00$ & $<5.00$ & NR & Acceptable \\
\hline 1,1,1,2-Tetrachloroethane & $\mu \mathrm{g} / \mathrm{L}$ & $<1.00$ & $<5.00$ & NR & Acceptable \\
\hline 1,1,2,2-Tetrachloroethane & $\mu \mathrm{g} / \mathrm{L}$ & $<1.00$ & $<5.00$ & NR & Acceptable \\
\hline Tetrachloroethylene & $\mu \mathrm{g} / \mathrm{L}$ & 29.5 & 36.2 & $23.9-46.5$ & Acceptable \\
\hline Toluene & $\mu \mathrm{g} / \mathrm{L}$ & 20.0 & 19.3 & $13.6-24.5$ & Acceptable \\
\hline 1,1,1-Trichloroethane & $\mu \mathrm{g} / \mathrm{L}$ & 36.4 & 34.7 & $22.6-45.8$ & Acceptable \\
\hline 1,1,2-Trichloroethane & $\mu \mathrm{g} / \mathrm{L}$ & 131 & 129 & $87.2-168$ & Acceptable \\
\hline Trichloroethylene & $\mu \mathrm{g} / \mathrm{L}$ & 35.0 & 35.6 & $23.2-46.1$ & Acceptable \\
\hline Trichlorofluoromethane & $\mu \mathrm{g} / \mathrm{L}$ & $<1.00$ & $<5.00$ & NR & Acceptable \\
\hline 1,2,3-Trichloropropane & $\mu \mathrm{g} / \mathrm{L}$ & $<1.00$ & $<5.00$ & NR & Acceptable \\
\hline Vinyl chloride & $\mu \mathrm{g} / \mathrm{L}$ & $<1.00$ & $<5.00$ & NR & Acceptable \\
\hline Xylenes, total & $\mu \mathrm{g} / \mathrm{L}$ & 64.1 & 60.3 & $34.0-82.9$ & Acceptable \\
\hline \multicolumn{6}{|l|}{ Acids } \\
\hline Benzoic acid & $\mu \mathrm{g} / \mathrm{L}$ & $<5.00$ & $<10.00$ & NR & Acceptable \\
\hline 4-Chloro-3-methylphenol & $\mu \mathrm{g} / \mathrm{L}$ & 33.0 & 58.5 & $221.8-75.3$ & Acceptable \\
\hline 2-Chlorophenol. & $\mu \mathrm{g} / \mathrm{L}$ & 69.0 & 131 & $37.5-164$ & Acceptable \\
\hline 2,4-Dichlorophenol & $\mu \mathrm{g} / \mathrm{L}$ & 64.0 & 112 & $40.4-135$ & Acceptable \\
\hline 2,6-Dichlorophenol & $\mu \mathrm{g} / \mathrm{L}$ & $<5.00$ & $<10.00$ & NR & Acceptable \\
\hline
\end{tabular}


Table 8.17, cont.

\begin{tabular}{|c|c|c|c|c|c|}
\hline Parameter & Units & $\begin{array}{l}\text { Reported } \\
\text { Value }\end{array}$ & $\begin{array}{l}\text { Assigned } \\
\text { Value }\end{array}$ & $\begin{array}{l}\text { Acceptance } \\
\text { Limits }\end{array}$ & $\begin{array}{c}\text { Performance } \\
\text { Evaluation }\end{array}$ \\
\hline 2,4-Dimethylphenol & $\mu \mathrm{g} / \mathrm{L}$ & 53.0 & 92.2 & $19.0-121$ & Acceptable \\
\hline 4,6-Dinitro-2-methylphenol & $\mu \mathrm{g} / \mathrm{L}$ & $<5.00$ & $<10.00$ & NR & Acceptable \\
\hline 2,4-Dinitrophenol & $\mu \mathrm{g} / \mathrm{L}$ & 56.8 & 105 & $D^{c}-142$ & Acceptable \\
\hline 2-Methlyphenol & $\mu \mathrm{g} / \mathrm{L}$ & 10.0 & 20.5 & DL - 28.2 & Acceptable \\
\hline 3-Methylphenol & $\mu \mathrm{g} / \mathrm{L}$ & $<5.00$ & $<10.00$ & NR & Acceptable \\
\hline 4-Methylphenol & $\mu \mathrm{g} / \mathrm{L}$ & $<5.00$ & $<10.00$ & NR & Acceptable \\
\hline 2-Nitrophenol & $\mu \mathrm{g} / \mathrm{L}$ & 13.7 & 21.3 & $7.35-27.0$ & Acceptable \\
\hline 4-Nitrophenol & $\mu \mathrm{g} / \mathrm{L}$ & 15.0 & 78.4 & DL - 110 & Acceptable \\
\hline Pentachlorophenol & $\mu \mathrm{g} / \mathrm{L}$ & 69.6 & 128 & $34.1-177$ & Acceptable \\
\hline Phenol & $\mu \mathrm{g} / \mathrm{L}$ & 8.64 & 41.2 & DL - 57.9 & Acceptable \\
\hline 2,4,5-Trichlorophenol & $\mu \mathrm{g} / \mathrm{L}$ & 90.6 & 147 & $53.5-187$ & Acceptable \\
\hline 2,4,6-Trichlorophenol & $\mu \mathrm{g} / \mathrm{L}$ & 95.8 & 152 & $49.2-202$ & Acceptable \\
\hline \multicolumn{6}{|l|}{$\underline{\text { Base Neturals }}$} \\
\hline Acenaphthene & $\mu \mathrm{g} / \mathrm{L}$ & $<5.00$ & $<10.00$ & NR & Acceptable \\
\hline Acenaphthylene & $\mu \mathrm{g} / 1$ & 29.4 & 39.8 & $15.2-49.8$ & Acceptable \\
\hline Anline & $\mu \mathrm{g} / \mathrm{L}$ & $<5.00$ & $<10.00$ & NR & Acceptable \\
\hline Anthracene & $\mu \mathrm{g} / \mathrm{L}$ & 56.9 & 91.1 & $33.2-118$ & Acceptable \\
\hline Benzidine & $\mu \mathrm{g} / \mathrm{L}$ & $<5.00$ & $<10.00$ & NR & Acceptable \\
\hline Benzo(a)anthracene & $\mu \mathrm{g} / \mathrm{L}$ & 28.6 & 42.7 & $23.9-50.4$ & Acceptable \\
\hline Benzo(b)flouranthene & $\mu \mathrm{g} / \mathrm{L}$ & $<5.00$ & 57.6 & $16.5-80.8$ & Not Acceptable \\
\hline Benzo(k)flouranthene & $\mu \mathrm{g} / \mathrm{L}$ & $<5.00$ & $<10.00$ & NR & Acceptable \\
\hline Benzo(g,h,i)perylene & $\mu \mathrm{g} / \mathrm{L}$ & 15.1 & 22.8 & $0.719-34.4$ & Acceptable \\
\hline Benzo(a)pyrene & $\mu \mathrm{g} / \mathrm{L}$ & 43.3 & $<10.00$ & NR & No Evaluation \\
\hline Benzyl alcohol & $\mu \mathrm{g} / \mathrm{L}$ & $<5.00$ & $<10.00$ & NR & Acceptable \\
\hline 4-Bromophenyl-phenylether & $\mu \mathrm{g} / \mathrm{L}$ & $<5.00$ & $<10.00$ & NR & Acceptable \\
\hline Butylbenzylphthalate & $\mu \mathrm{g} / \mathrm{L}$ & $<5.00$ & $<10.00$ & NR & Acceptable \\
\hline 4-Chloraniline & $\mu \mathrm{g} / \mathrm{L}$ & $<5.00$ & $<10.00$ & NR & Acceptable \\
\hline bis(2-Chloroethoxy)methane & $\mu \mathrm{g} / \mathrm{L}$ & 34.9 & 47.2 & $18.4-57.3$ & Acceptable \\
\hline bis(2-Chloroethly)ether & $\mu \mathrm{g} / \mathrm{L}$ & $<5.00$ & $<10.00$ & NR & Acceptable \\
\hline bis(2-Chloroisopropyl)ether & $\mu \mathrm{g} / \mathrm{L}$ & 19.0 & 33.4 & $8.79-40.3$ & Acceptable \\
\hline 1-Chloronaphthalene & $\mu \mathrm{g} / \mathrm{L}$ & $<5.00$ & $<10.00$ & NR & Acceptable \\
\hline 2-Chloronaphthalene & $\mu \mathrm{g} / \mathrm{L}$ & 73.6 & 124 & $49.8-140$ & Acceptable \\
\hline 4-Chlorophenyl-phenylether & $\mu \mathrm{g} / \mathrm{L}$ & 61.0 & 95.2 & $36.2-131$ & Acceptable \\
\hline Chrysene & $\mu \mathrm{g} / \mathrm{L}$ & 60.7 & 60.3 & $24.5-78.7$ & Acceptable \\
\hline Dibenz(a,h)aanthracene & $\mu \mathrm{g} / \mathrm{L}$ & 26.6 & 29.8 & $7.21-42.3$ & Acceptable \\
\hline Dibenzofuran & $\mu \mathrm{g} / 1$ & 86.3 & 148 & $12.1-212$ & Acceptable \\
\hline Di-n-butylphthalate & $\mu \mathrm{g} / \mathrm{L}$ & 23.8 & 37.6 & $13.9-54.5$ & Acceptable \\
\hline 1,2-Dichlorobenzene & $\mu \mathrm{g} / \mathrm{L}$ & 24.0 & 37.0 & $25.9-48.1$ & Not Acceptable \\
\hline 1,3-Dichlorobenzene & $\mu \mathrm{g} / \mathrm{L}$ & $<5.00$ & $<10.00$ & NR & Acceptable \\
\hline 1,4-Dichlorobenzene & $\mu \mathrm{g} / \mathrm{L}$ & 56.5 & 98.0 & $68.6-127$ & Not Acceptable \\
\hline 3,3'-Dichlorobenzidine & $\mu \mathrm{g} / \mathrm{L}$ & $<5.00$ & $<10.00$ & NR & Acceptable \\
\hline
\end{tabular}


Table 8.17, cont.

\begin{tabular}{|c|c|c|c|c|c|}
\hline Parameter & Units & $\begin{array}{l}\text { Reported } \\
\text { Value }\end{array}$ & $\begin{array}{l}\text { Assigned } \\
\text { Value }\end{array}$ & $\begin{array}{l}\text { Acceptance } \\
\text { Limits }\end{array}$ & $\begin{array}{l}\text { Performance } \\
\text { Evaluation }\end{array}$ \\
\hline Diethjylphthalate & $\mu \mathrm{g} / \mathrm{l}$ & 51.2 & 80.9 & $1.75-123$ & Acceptable \\
\hline Dimethlyphthalate & $\mu \mathrm{g} / \mathrm{L}$ & 33.2 & 58.6 & $0.446-89.5$ & Acceptable \\
\hline 2,4-Dinitrotoluene & $\mu \mathrm{g} / \mathrm{L}$ & 42.1 & 57.0 & $20.8-75.2$ & Acceptable \\
\hline 2,6-Dinitrotoyulene & $\mu \mathrm{g} / \mathrm{L}$ & $<5.00$ & $<10.00$ & NR & Acceptable \\
\hline Di-n-octylphthalate & $\mu \mathrm{g} / \mathrm{L}$ & $<5.00$ & $<10.00$ & NR & Acceptable \\
\hline bis(2-ethylhexyl)phthalate & $\mu \mathrm{g} / \mathrm{L}$ & 74.3 & 121 & $19.6-177$ & Acceptable \\
\hline Flouranthene & $\mu \mathrm{g} / \mathrm{L}$ & $<5.00$ & $<10.00$ & NR & Acceptable \\
\hline Fluorene & $\mu \mathrm{g} / 1$ & 30.4 & 42.2 & $17.9-54.9$ & Acceptable \\
\hline Hexachlorobenzene & $\mu \mathrm{g} / \mathrm{L}$ & $<5.00$ & $<10.00$ & NR & Acceptable \\
\hline Hexachlorobutadiene & $\mu \mathrm{g} / \mathrm{L}$ & 92.2 & 166 & $29.5-198$ & Acceptable \\
\hline Hexachlorocyclopentadiene & $\mu \mathrm{g} / \mathrm{L}$ & $<5.00$ & $<10.00$ & NR & Acceptable \\
\hline Hexachloroethane & $\mu \mathrm{g} / \mathrm{L}$ & $<5.00$ & $<10.00$ & NR & Acceptable \\
\hline Indeno(1,2,3-cd)pyrene & $\mu \mathrm{g} / 1$ & 23.5 & 37.8 & $6.93-50.6$ & Acceptable \\
\hline Isophorone & $\mu \mathrm{g} / \mathrm{L}$ & 97.3 & 139 & $46.9-185$ & Acceptable \\
\hline 1-Methylnaphthalene & $\mu \mathrm{g} / \mathrm{L}$ & $<5.00$ & $<10.00$ & NR & Acceptable \\
\hline 2-Methylnaphthalene & $\mu \mathrm{g} / \mathrm{L}$ & $<5.00$ & $<10.00$ & NR & Acceptable \\
\hline Naphthalene & $\mu \mathrm{g} / \mathrm{L}$ & 78.5 & 140 & $33.9-182$ & Acceptable \\
\hline 2-Nitroaniline & $\mu \mathrm{g} / \mathrm{L}$ & $<5.00$ & $<10.00$ & NR & Acceptable \\
\hline 3-Nitroaniline & $\mu \mathrm{g} / \mathrm{L}$ & $<5.00$ & $<10.00$ & NR & Acceptable \\
\hline 4-Nitroaniline & $\mu \mathrm{g} / 1$ & $<5.00$ & $<10.00$ & NR & Acceptable \\
\hline Nitrobenzene & $\mu \mathrm{g} / \mathrm{L}$ & 38.4 & 56.8 & $19.6-73.9$ & Acceptable \\
\hline N-Nitrosodiphenylamine & $\mu \mathrm{g} / \mathrm{L}$ & $<5.00$ & $<10.00$ & NR & Acceptable \\
\hline N-Nitroso-di-n-propylamine & $\mu \mathrm{g} / \mathrm{L}$ & 83.8 & 131 & $40.8-170$ & Acceptable \\
\hline Phenanthrene & $\mu \mathrm{g} / \mathrm{L}$ & 38.0 & 53.5 & $25.5-67.8$ & Acceptable \\
\hline Pyrene & $\mu \mathrm{g} / 1$ & 22.8 & 35.4 & $11.4-52.0$ & Acceptable \\
\hline Pyridine & $\mu \mathrm{g} / \mathrm{L}$ & $<5.00$ & $<10.00$ & NR & Acceptable \\
\hline 1,2,4-Trichlorobenzene & $\mu \mathrm{g} / \mathrm{L}$ & 68.6 & 114 & $33.3-135$ & Acceptable \\
\hline \multicolumn{6}{|l|}{$\underline{\text { Pesticides }}$} \\
\hline Aldrin & $\mu \mathrm{g} / \mathrm{L}$ & 1.80 & 1.32 & $0.336-1.79$ & Not Acceptable \\
\hline alpha-BHC & $\mu \mathrm{g} / \mathrm{L}$ & 6.80 & 4.68 & $1.82-6.43$ & Not Acceptable \\
\hline beta-BHC & $\mu \mathrm{g} / \mathrm{L}$ & 3.30 & 2.46 & $0.767-3.74$ & Acceptable \\
\hline delta-BHC & $\mu \mathrm{g} / \mathrm{L}$ & 0.240 & $<0.100$ & NR & No Evaluation \\
\hline gamma-BHC (Lindane) & $\mu \mathrm{g} / \mathrm{L}$ & 10.5 & 7.42 & $2.48-10.7$ & Acceptable \\
\hline alpha-Chlordane & $\mu \mathrm{g} / \mathrm{L}$ & 6.00 & 4.40 & $0.980-7.28$ & Acceptable \\
\hline gamma-Chlordane & $\mu \mathrm{g} / \mathrm{L}$ & 0.660 & $<0.100$ & NR & No Evaluation \\
\hline 4,4'-DDD & $\mu \mathrm{g} / \mathrm{L}$ & 7.90 & 4.94 & $2.43-6.89$ & Not Acceptable \\
\hline 4,4'-DDE & $\mu \mathrm{g} / \mathrm{L}$ & 3.90 & 2.23 & $1.05-3.04$ & Not Acceptable \\
\hline 4,4'-DDT & $\mu \mathrm{g} / \mathrm{L}$ & 8.20 & 4.02 & $1.84-5.44$ & Not Acceptable \\
\hline Dieldrin & $\mu \mathrm{g} / \mathrm{L}$ & 3.20 & 2.02 & $1.04-2.79$ & Not Acceptable \\
\hline Endrin & $\mu \mathrm{g} / \mathrm{L}$ & 9.20 & 7.24 & $2.78-10.3$ & Acceptable \\
\hline Endrin aldehyde & $\mu \mathrm{g} / \mathrm{L}$ & 0.380 & $<0.100$ & NR & No Evaluation \\
\hline
\end{tabular}


Table 8.17, cont.

\begin{tabular}{lccccc}
\hline \multicolumn{1}{c}{ Parameter } & Units & $\begin{array}{c}\text { Reported } \\
\text { Value }\end{array}$ & $\begin{array}{c}\text { Assigned } \\
\text { Value }\end{array}$ & $\begin{array}{c}\text { Acceptance } \\
\text { Limits }\end{array}$ & $\begin{array}{c}\text { Performance } \\
\text { Evaluation }\end{array}$ \\
\hline Endrin ketone & $\mu \mathrm{g} / \mathrm{L}$ & 1.80 & $<0.100$ & $\mathrm{NR}$ & No Evaluation \\
Endosulfan I & $\mu \mathrm{g} / \mathrm{L}$ & 0.110 & $<0.100$ & $\mathrm{NR}$ & No Evaluation \\
Endosulfan II & $\mu \mathrm{g} / \mathrm{L}$ & 24.6 & 27.5 & $5.40-44.1$ & Acceptable \\
Endosulfan sulfate & $\mu \mathrm{g} / \mathrm{L}$ & 24.1 & 18.8 & $3.20-30.9$ & Acceptable \\
Hepathlor & $\mu \mathrm{g} / \mathrm{L}$ & 2.00 & 1.44 & $0.384-2.00$ & Check for Error \\
Hepatachlor epoxide & $\mu \mathrm{g} / \mathrm{L}$ & 3.40 & 2.00 & $1.02-2.57$ & Not Acceptable \\
Methoxychlor & $\mu \mathrm{g} / \mathrm{L}$ & 6.80 & 2.71 & $0.775-4.69$ & Not Acceptable \\
Chlordane, technical & $\mu \mathrm{g} / \mathrm{L}$ & 7.10 & 4.20 & $1.84-5.97$ & Not Acceptable \\
Toxaphene & $\mu \mathrm{g} / \mathrm{L}$ & 5.10 & 2.99 & $0.794-4.93$ & Not Acceptable \\
\hline
\end{tabular}

${ }^{a}$ PCB Aroclor identity values report compound identity only, not quantity.

B Not Reported

${ }^{c}$ Detection Limit 
This page intentionally left blank. 


\section{References}

10 CFR § 50, Appendix B. Quality Assurance Criteria for Nuclear Power Plants and Fuel Reprocessing Plants. Code of Federal Regulations. Office of the Federal Register, National Archives and Records Administration, Washington D.C.

10 CFR $\S 61$. Licensing Requirements For Land Disposal of Radioactive Waste. Code of Federal Regulations. Office of the Federal Register, National Archives and Records Administration, Washington D.C.

10 CFR $\S 71$. Packaging and Transportation of Radioactive Material. Code of Federal Regulations. Office of the Federal Register, National Archives and Records Administration, Washington D.C.

10 CFR $\S 834$. Radiation Protection of the Public and the Environment; Proposed Rule. Code of Federal Regulations. Office of the Federal Register, National Archives and Records Administration, Washington D.C.

10 CFR § 835. Occupational Radiation Protection. Code of Federal Regulations. Office of the Federal Register, National Archives and Records Administration, Washington D.C.

10 CFR § 1021. National Environmental Policy Act Implementing Procedures. Code of Federal Regulations. Office of the Federal Register, National Archives and Records Administration, Washington D.C.

10 CFR $\S 1021.331$. National Environmental Policy Act Implementing Procedures, Mitigation action plans. Code of Federal Regulations. Office of the Federal Register, National Archives and Records Administration, Washington D.C.
40 CFR $\S 61$. National Emission Standards for Hazardous Air Pollutants. Code of Federal Regulations. Office of the Federal Register, National Archives and Records Administration, Washington D.C.

40 CFR § 61.09. National Emission Standards for Hazardous Air Pollutants, Notification of startup. Code of Federal Regulations. Office of the Federal Register, National Archives and Records Administration, Washington D.C.

40 CFR $\S$ 61.92. National Emission Standards for Hazardous Air Pollutants, Standard. Code of Federal Regulations. Office of the Federal Register, National Archives and Records Administration, Washington D.C.

40 CFR § 61.93(a). National Emission Standards for Hazardous Air Pollutants, Emission monitoring and test procedures. Code of Federal Regulations. Office of the Federal Register, National Archives and Records Administration, Washington D.C.

40 CFR § 122. EPA Administered Permit Programs: the National Pollutant Discharge Elimination System. Code of Federal Regulations. Office of the Federal Register, National Archives and Records Administration, Washington D.C.

40 CFR $\S 191$. Environmental radiation protection standards for the management and disposal of spent nuclear fuel, high-level and transuranic radioactive wastes. Code of Federal Regulations. Office of the Federal Register, National Archives and Records Administration, Washington D.C. 
40 CFR $\S 194$. Criteria for the certification and re-certification of the Waste Isolation Pilot Plant's compliance with the 40 CFR Part 191 disposal regulations. Code of Federal Regulations. Office of the Federal Register, National Archives and Records Administration, Washington D.C.

40 CFR $\S 262$. Standards Applicable to Generators of Hazardous Waste. Code of Federal Regulations. Office of the Federal Register, National Archives and Records Administration, Washington D.C.

40 CFR $\S 264$. Standards for owners and operators of hazardous waste treatment, storage, and disposal facilities. Code of Federal Regulations. Office of the Federal Register, National Archives and Records Administration, Washington D.C.

40 CFR $\S 300$. National Oil and Hazardous Substances Pollution Contingency Plan. Code of Federal Regulations. Office of the Federal Register, National Archives and Records Administration, Washington D.C.

40 CFR $\S 302$. Designation, Reportable Quantities, and Notification. Code of Federal Regulations. Office of the Federal Register, National Archives and Records Administration, Washington D.C.

40 CFR $\S \S 1500-1508$. Council on Environmental Quality. Office of the Federal Register, National Archives and Records Administration, Washington D.C.

49 CFR. Transportation. Code of Federal Regulations. Office of the Federal Register, National Archives and Records Administration, Washington D.C.

49 CFR $\S \S 106-179$. Transportation, Research and Special Programs Administration, Department of Transportation. Code of Federal Regulations. Office of the Federal Register, National Archives and Records Administration, Washington D.C.
65 FR 82985. Revision to the Record of Decision for the Department of Energy's Waste Management Program: Treatment and Storage of Transuranic Waste. Office of the Federal Register, National Archives and Records Administration, Washington D.C.

20 NMAC 2. Air Quality. Title 20, New Mexico Administrative Code, Chapter 2. Sante Fe, NM.

20 NMAC 2.72. Construction Permits. Title 20, New Mexico Administrative Code, Chapter 2, Part 72. (Air Quality Control Regulation 702). Santa Fe, NM.

20 NMAC 4.1. Hazardous Waste Management. Title 20, New Mexico Administrative Code, Chapter 4, Part 1. Sante Fe, NM.

7 U.S.C. § 136-136y. Federal Insecticide, Fungicide, and Rodenticide Act, as amended. U.S. Government Printing Office. Washington, D.C.

15 U.S.C. $\S 2301$ et seq. Toxic Substances Control Act. U.S. Government Printing Office. Washington, D.C.

16 U.S.C. § 1531-1544, 87 Stat. 884. Endangered Species Act of 1973. U.S. Government Printing Office. Washington, D.C.

16 U.S.C. $\S 470$ et seq. National Historic Preservation Act. U.S. Government Printing Office. Washington, D.C.

33 U.S.C. § 1251-1376; Chapter 758; PL 845; 62 Stat. 1155. Federal Water Pollution Control Act of 1948 (Clean Water Act), Section 402. U.S. Government Printing Office. Washington, D.C.

42 U.S.C. $\S 2278$ a. Atomic Energy Act of 1954. U.S. Government Printing Office. Washington, D.C. 
42 U.S.C. $§ 300 f$ et seq. Safe Drinking Water Act. U.S. Government Printing Office. Washington, D.C.

42 U.S.C. $\S 3251$ et seq. Resource Conservation and Recovery Act. U.S. Government Printing Office. Washington, D.C.

42 U.S.C. § 4321-4345. National Environmental Policy Act. U.S. Government Printing Office. Washington, D.C.

42 U.S.C. § 7112. Department of Energy Organization Act. U.S. Government Printing Office. Washington, D.C.

42 U.S.C. $\S 7401$ et seq. Clean Air Act. U.S. Government Printing Office. Washington, D.C.

42 U.S.C. $§ 9601$ et seq. Comprehensive Environmental Response, Compensation, and Liability Act (including the Superfund Amendments and Reauthorization Act of 1986). U.S. Government Printing Office. Washington, D.C.

42 U.S.C. $\S 10101$ et seq. Nuclear Waste Policy Act of 1982. U.S. Government Printing Office. Washington, D.C.

43 U.S.C. $§ 1751$ et seq. Federal Land Policy and Management Act, 1976. U.S. Government Printing Office. Washington, D.C.

49 App. U.S.C. $§ 1801$ et seq.; 49 CFR $\S 106-179$. Hazardous Materials Transportation Act. U.S. Government Printing Office. Washington, D.C.

310-M-2. 1993. Air Quality Permit. New Mexico Environment Department, Santa Fe.
ANSI/ASQC - E4. Proposed. Quality Assurance Program Requirements for Environmental Programs. American National Standards Institute/ American Society for Quality Control, Washington, DC.

HPS N13.30. 1996. Performance Criteria for Radiobioassay. Health Physics Society, Washington, DC.

NQA-1-1994. 1994. Quality Assurance Program Requirements for Nuclear Facilities. American National Standards Institute, Washington, DC.

Dawson, J.W., S.C. Tygielski, and A.P. Hocker. 2000. Waste Isolation Pilot Plant WIPP Raptor Program 1999 Annual Report. Sonora Environmental Consultants, Inc.

DOE/CAO 96-2184. 1996. Compliance Certification Application, October 1996. U.S. Department of Energy, Carlsbad Area Office. Carlsbad, NM.

DOE/EH-0173T. 1991. Environmental Regulatory Guide for Radiological Effluent Monitoring and Environmental Surveillance. U.S. Department of Energy, Washington, D.C.

DOE/EIS-0026. 1980. Final Environmental Impact Statement, Waste Isolation Pilot Plant, Volumes 1 and 2. U.S. Department of Energy, Washington, D.C.

DOE/EIS-0026-FS. 1990. Final Supplemental Environmental Impact Statement (SEIS-I), Volumes 1-3. U.S. Department of Energy, Washington, D.C.

DOE/EIS-0026-S-2. 1997. Waste Isolation Pilot Plant Disposal Phase Final Supplemental Environmental Impact Statement (SEIS-II), Volumes 1-3. U.S. Department of Energy, Washington, D.C. 
DOE/EIS-0200-SA01. 2000. Supplement Analysis and Determination for the Proposed Characterization for Disposal of Contact-handled Transuranic Waste at the Waste Isolation Pilot Plant. U.S. Department of Energy, Washington, D.C.

DOE Order 151.1. 1996. Comprehensive Emergency Management System. U.S. Department of Energy, Washington, D.C.

DOE Order 225.1A. 1997. Accident Investigation. U.S. Department of Energy, Washington, D.C.

DOE Order 231.1. 1996. Environmental, Safety, and Health Reporting. U.S. Department of Energy, Washington, D.C.

DOE Order 414.1. 1998. Quality Assurance. U.S. Department of Energy, Washington, D.C.

DOE Order 430.1. 1995. Life-Cycle Assessment Management. U.S. Department of Energy, Washington, D.C.

DOE Order 435.1. 1999. Radioactive Waste Management. U.S. Department of Energy, Washington, D.C.

DOE Order 451.1A. 1995. National Environmental Compliance Policy Act Compliance Program. U.S. Department of Energy, Washington, D.C.

DOE Order 460.1A. 1996. Packaging and Transportation Safety. U.S. Department of Energy, Washington, D.C.

DOE Order 5400.1. 1990. General Environmental Protection Programs. U.S. Department of Energy, Washington, D.C.

DOE Order 5400.5. 1988. Radiation Protection of the Public and the Environment. U.S. Department of Energy, Washington, D.C.
DOE Order 5480.23. 1994. Nuclear Safety Analysis Reports. U.S. Department of Energy, Washington, D.C.

DOE Order 5484.1. 1987. Environmental Protection, Safety, and Health Protection Information Reporting Requirements. U.S. Department of Energy, Washington, D.C.

DOE-STD-XXXX-00 (Proposed). 2000. A Graded Approach for Evaluating Radiation Doses to Aquatic and Terrestrial Biota. National Technical Information Service, Washington, D.C.

DOE/WIPP 91-005. 1997. Resource Conservation and Recovery Act Part B Permit Application, Revision 6.5. Waste Isolation Pilot Plant, Carlsbad, NM.

DOE/WIPP-93-004. 1993. Waste Isolation Pilot Plant Land Management Plan. Waste Isolation Pilot Plant, Carlsbad, NM.

DOE/WIPP 95-2065, Rev. 3. 1998. WIPP Safety Analysis Report. Waste Isolation Pilot Plant, Carlsbad, NM.

DOE/WIPP 96-2199. 1996. Environmental Protection Implementation Plan for the Waste Isolation Pilot Plant. Waste Isolation Pilot Plant, Carlsbad, NM.

DOE/WIPP 98-2171. 1998. WIPP Biennial Environmental Compliance Report. Waste Isolation Pilot Plant, Carlsbad, NM.

DOE/WIPP 98-2285. 1998. Waste Isolation Pilot Plant RCRA Background Groundwater Quality Baseline Report. Waste Isolation Pilot Plant, Carlsbad, NM.

DOE/WIPP 99-2194. 1999. WIPP Environmental Monitoring Plan. Waste Isolation Pilot Plant, Carlsbad, NM.

DP-831. 1997. WIPP Sewage System Discharge Plan. New Mexico Environment Department. Santa Fe. 
Executive Order 13101, Greening the Government Through Waste Prevention, Recycling, and Federal Acquisition. Office of the President. Washington, D.C.

IAEA Technical Report Series No. 332. 1992. Effects of Ionizing Radiation on Plants and Animals at Levels Implied by Current Radiation Protection Standards. International Atomic Energy Agency. Vienna, Austria.

ISO 14001. Environmental Management System Standards. International Standards Organization. Geneva, Switzerland.

NCRP-94. 1987. Exposure of the Population in the United States and Canada from Natural Background. National Council on Radiation Protection and Measurements. Bethesda, MD.

NCRP-109. 1991. Effects of Ionizing Radiation on Aquatic Organisms. National Council on Radiation Protection and Measurements. Bethesda, MD.

NEPA ID \# WIP:99:001. 1999.1998 Annual Mitigation Report for the Waste Isolation Pilot Plant. Waste Isolation Pilot Plant, Carlsbad, NM.

NM4890139088-TSDF. 1999. Waste Isolation Pilot Plant Hazardous Waste Permit. New Mexico Environment Department, Santa Fe.

NMED/DOE/AIP 94/1. 1994. Resource Conservation and Recovery Act Facility Assessment. New Mexico Environment Department, Santa Fe.

NMR05A225. 1998. New Mexico NPDES Multi-Sector General Permit. New Mexico Environment Department, Santa Fe.

NMSA $1978 \S 17-2-37$ to 17-2-46. Wildlife Conservation Act. New Mexico Statutes Annotated 1978. State of New Mexico, Santa Fe.
NMSA $1978 \S 74-2$. Air Quality Control Act. New Mexico Statutes Annotated 1978. State of New Mexico, Santa Fe.

NMSA 1978 § 74-6. Water Quality Act. New Mexico Statutes Annotated 1978. State of New Mexico, Santa Fe.

Public Law 96-164. National Security and Military Applications of Nuclear Energy Authorization Act of 1980.

Public Law 102-579, 106 stat. 4777. Waste Isolation Pilot Plant Land Withdrawal act. October 1992, as amended October 1996 by Public Law 104-201.

PPOA 99-02. 1999. Pollution Prevention Opportunity Assessment, CRC Lectra Motive Replacement. Waste Isolation Pilot Plant, Carlsbad, NM.

QAMS-005/80. 1980. Interim Guidelines and Specifications for Preparing Quality Assurance Project Plans. U.S. Environmental Protection Agency, Washington, D.C.

Regulatory Guide 4.15, Rev. 1. 1979. Quality Assurance for Radiological Monitoring Programs-Effluent Streams and the Environment. U.S. Nuclear Regulatory Commission, Washington, D.C.

TO-14A. 1997. Compendium of Methods for the Determination of Toxic Organic Compounds in Ambient Air. U.S. Environmental Protection Agency, Washington, D.C.

U.S. Department of Energy. 1986. Environmental Policy Statement, Secretary Herrington. U.S. Department of Energy. Washington, D.C.

U.S. Nuclear Regulatory Commission. 1999. The Biological Effects of Radiation, Webpage. $<$ http://www.nrc.gov/NRC/EDUCATE /REACTOR/06-BIO/fig05.html> 
VCAAO 1.0. 1994. Volatile Organics Analysis of Ambient Air in Canisters. U.S. Environmental Protection Agency, Washington, D.C.

WP 02-EC.0, Rev. 3. 1999. Environmental Management System Implementation Document. Waste Isolation Pilot Plant, Carlsbad, NM.

WP 02-EC.07. 1999. Affirmative Procurement Program Plan. Waste Isolation Pilot Plant, Carlsbad, NM.
WP 02-EM 3004, Rev. 0. 1998. Radiological Data Verification and Validation.

Waste Isolation Pilot Plant, Carlsbad, NM.

WP02-1, Rev. 5. 1999. Groundwater

Surveillance Program Plan. Waste Isolation Pilot Plant, Carlsbad, NM.

WP 12-VC.01, Rev. 2. 1999. Confirmatory Volatile Organic Compound Monitoring Plan. Waste Isolation Pilot Plant, Carlsbad, NM. 


\title{
Appendix A \\ Acronyms, Abbreviations, and Symbols
}

\author{
A \\ ac acre \\ ACAA \\ AMSL \\ ANOVA \\ Accelerated Corrective Action Approach \\ Above Mean Sea Level \\ ANSI \\ AOC \\ Analysis of Variance \\ American National Standards Institute \\ ASME \\ Area Of Concern \\ ASTM \\ American Society of Mechanical Engineers \\ American Society for Testing and Materials \\ B \\ BCG \\ Biota Concentration Guides \\ BLM \\ $\mathrm{Bq}$ \\ $\mathrm{Bq} / \mathrm{L}$ \\ $\mathrm{Bq} / \mathrm{m}^{3}$ \\ United States Department of the Interior, Bureau of Land Management \\ Becquerel \\ Becquerel per liter \\ Becquerel per cubic meter \\ C \\ $\mathrm{C}$ of $\mathrm{C}$ \\ CAP88 \\ CBFO \\ CCA \\ CERCLA \\ CFR \\ $\mathrm{Ci}$ \\ $\mathrm{cm}$ \\ CMS \\ CTAC \\ Certificate of Compliance \\ Computer code for calculating both dose and risk from radionuclide emissions \\ Carlsbad Field Office \\ Compliance Certification Application \\ Comprehensive Environmental Response, Compensation and Liability Act \\ Code of Federal Regulations \\ Curie \\ centimeter \\ Corrective Measures Study \\ CY \\ CBFO Technical Assistance Contractors \\ Calendar Year \\ D \\ d day \\ DOE United States Department of Energy \\ DOT United States Department of Transportation \\ E \\ EA \\ EEG \\ Environmental Assessment \\ Eh \\ Environmental Evaluation Group \\ EIS \\ Intensity factor \\ EML \\ Environmental Impact Statement \\ EMP \\ Environmental Measurements Laboratory \\ EMS \\ WIPP Environmental Monitoring Plan \\ EPA \\ Environmental Management System \\ United States Environmental Protection Agency
}




$\begin{array}{ll}\mathbf{F} & \\ \mathrm{ft} & \text { foot } \\ \mathrm{ft}^{3} & \text { cubic foot } \\ \text { FEIS } & \text { Final Environmental Impact Statement } \\ \text { FR } & \text { Federal Register } \\ \text { FWE } & \text { Fresh Water Elevation } \\ \text { FY } & \text { Fiscal year } \\ & \\ \mathbf{G} & \\ \mathrm{g} & \text { gram } \\ \text { gal } & \text { gallon } \\ \text { GOCO } & \text { Government-Owned, Contractor-Operated } \\ \text { Gy } & \text { Gray }\end{array}$

\section{H}

ha hectare

HalfPACT Short Transuranic Package Transporter

HAP

HEPA

Hazardous Air Pollutant

high efficiency particulate arresting

I

ISMS Integrated Safety Management System

ISO International Organization for Standards

K

$\mathrm{kg} \quad$ kilogram

$\mathrm{km} \quad$ kilometer

$\mathrm{km}^{2} \quad$ square kilometers

KOP kick off point

L

L

LMP

LUR

liter

Land Management Plan

Land Use Request

$\mathbf{M}$

$\mathrm{m}^{3}$

$\mathrm{mBq}$

MDA

MDC

MDL

$\mathrm{mg}$

$\mathrm{mg} / \mathrm{L}$

$\mathrm{mi}$

$\mathrm{mi}^{2}$

$\mathrm{ml}$

MOU

mrem

$\mathrm{mrem} / \mathrm{yr}$

cubic meters

millibecquerel

Minimum Detectable Activity

Minimum Detectable Concentration

Method Detection Limit

milligram

milligram per liter

mile

square miles

milliliter

Memorandum Of Understanding

millirem

millirem per year 


\begin{tabular}{|c|c|}
\hline $\begin{array}{l}\mathrm{mSv} \\
\mathrm{mSv} / \mathrm{yr} \\
\mathrm{mt}\end{array}$ & $\begin{array}{l}\text { millisievert } \\
\text { millisievert per year } \\
\text { metric tons }\end{array}$ \\
\hline \multicolumn{2}{|l|}{$\mathbf{N}$} \\
\hline $\mathrm{N} / \mathrm{A}$ & Not Applicable \\
\hline NA & Not Available \\
\hline $\mathrm{NC}$ & Not Collected \\
\hline NCRP & National Council for Radiation Protection \\
\hline NEPA & National Environmental Policy Act \\
\hline NESHAP & National Emission Standards for Hazardous Air Pollutants \\
\hline NHPA & National Historic Preservation Act \\
\hline NIST & National Institute of Standards and Technology \\
\hline NMAC & New Mexico Administrative Codes \\
\hline NMDG\&F & New Mexico Department of Game and Fish \\
\hline NMED & New Mexico Environment Department \\
\hline NMIMT & New Mexico Institute of Mining Technology \\
\hline NOI & Notice of Intent \\
\hline NPDES & National Pollutant Discharge Elimination System \\
\hline NQA & Nuclear Quality Assurance \\
\hline NR & Not Reported \\
\hline NRC & Nuclear Regulatory Commission \\
\hline NWFP & New Mexico Hazardous Waste Facility Permit \\
\hline \multicolumn{2}{|l|}{$\mathbf{O}$} \\
\hline $\mathrm{OZ}$ & ounce \\
\hline \multicolumn{2}{|l|}{$\mathbf{P}$} \\
\hline $\mathrm{P} 2$ & Pollution Prevention \\
\hline P.L. & Public Law \\
\hline PCB & Polychlorinated Biphenyl \\
\hline $\mathrm{pCi}$ & picocuries \\
\hline $\mathrm{pCi} / \mathrm{L}$ & picocuries per liter \\
\hline $\mathrm{PE}$ & Performance Evaluation \\
\hline ppbv & parts per billion by volume \\
\hline PPOA & Pollution Prevention Opportunity Assessment \\
\hline \multicolumn{2}{|l|}{$\mathbf{Q}$} \\
\hline QA & Quality Assurance \\
\hline QAP & Quality Assurance Program \\
\hline QC & Quality Control \\
\hline $\mathrm{qt}$ & quart \\
\hline \multicolumn{2}{|l|}{$\mathbf{R}$} \\
\hline RCRA & Resource Conservation and Recovery Act \\
\hline rem & Roentgen equivalent man \\
\hline RER & Relative Error Ratio \\
\hline RFA & RCRA Facility Assessment \\
\hline RFI & RCRA Facility Investigation \\
\hline
\end{tabular}




$\begin{array}{ll}\text { RFI/CMS } & \text { RCRA Facility Investigation/Corrective Measures Study } \\ \text { RL } & \begin{array}{l}\text { Reporting Limit } \\ \text { ROD }\end{array} \\ \text { RN } & \text { Radionuclide } \\ \text { S } & \\ \text { SAP } & \text { Sampling and Analysis Plan } \\ \text { SARA } & \text { Superfund Amendments and Reauthorization Act } \\ \text { SARP } & \text { Safety Analysis Report for Packaging } \\ \text { SD } & \text { Soil Deep } \\ \text { SD } & \text { Standard Deviation } \\ \text { SDWA } & \text { Safe Drinking Water Act } \\ \text { SEIS-I } & \text { First Supplemental Environmental Impact Statement } \\ \text { SEIS-II } & \text { Second Supplemental Environmental Impact Statement } \\ \text { SI } & \text { Soil Intermediate } \\ \text { SMA } & \text { Special Management Area } \\ \text { SNL } & \text { Sandia National Laboratories } \\ \text { SPDV } & \text { Site Preliminary Design and Validation } \\ \text { SS } & \text { Soil Surface } \\ \text { SU } & \text { Standard Unit } \\ \text { SWMU } & \text { Solid Waste Management Unit } \\ \text { Sv } & \text { Sievert }\end{array}$

$\begin{array}{ll}\text { T } & \\ \text { TCLP } & \text { Toxicity Characteristic Leaching Procedure } \\ \text { TDS } & \text { Total Dissolved Solid } \\ \text { TENORM } & \text { Technologically enhanced naturally occurring radioactive materials } \\ \text { TOC } & \text { Top of Casing } \\ \text { TPU } & \text { Total Propagated Uncertainty } \\ \text { TRANSCOM } & \text { Transportation Tracking and Communications (system) } \\ \text { TRU } & \text { Transuranic (waste) } \\ \text { TRUPACT-II } & \text { Transuranic Package Transporter Model II } \\ \text { U } & \\ \text { U.S.C. } & \text { United States Code } \\ \text { USF\&WS } & \text { United States Department of the Interior, Fish and Wildlife Service } \\ \text { USGS } & \text { United States Geological Survey } \\ \text { UTLV } & \text { Upper Tolerance Limit Value } \\ \text { V } & \\ \text { VOC } & \\ \text { VPP } & \text { Volatile Organic Compound } \\ \text { W } & \text { Voluntary Protection Program } \\ \text { WIPP } & \\ \text { WQSP } & \\ \text { WRP } & \text { Waste Isolation Pilot Plant } \\ \text { WTS } & \text { WIPP Groundwater Quality Sampling Program } \\ & \text { WIPP Raptor Program } \\ & \text { Westinghouse TRU Solutions, LLC }\end{array}$


Y

$\mathrm{y}$

year

$\sigma$

${ }^{\circ} \mathrm{C}$

${ }^{\circ} \mathrm{F}$

$\mu \mathrm{Ci}$

$\mu \mathrm{g}$

umhos

$\%$

[RN]

\section{Symbols}

sigma

Degrees Celsius

Degrees Fahrenheit

microcurie

microgram

micromhos

Percent

Radionuclide concentration 
This page intentionally left blank. 


\section{Appendix B \\ Location Codes}

Table B.1 Codes used to identify the sites from which samples were collected.

\begin{tabular}{llll}
\hline Code & \multicolumn{1}{c}{ Location } & Code & \multicolumn{1}{c}{ Location } \\
\hline BHT & Bottom of the Hill Tank & RCP & Rainwater Catchment Pond \\
BRA & Brantley Lake & RED & Red Tank \\
CBD & Carlsbad & RNS & Rinse Aid Blank \\
COW & Coyote Well (deionized water blank) & SE1 & South East 1 \\
COY & Coyote (surface water duplicate) & SE2 & South East 2 \\
CT1 & Control 1 & SEC & South East Control \\
CT2 & Control 2 & SMR & Smith Ranch \\
FWT & Fresh Water Tank & SOO & Sample Of Opportunity \\
HIL & Hill Tank & SWL & Sewage Lagoons \\
IDN & Indian Tank & TUT & Tut Tank \\
LAG & Laguna Grande del Sol & UPR & Upper Pecos River \\
LST & Lost Tank & WAB & WIPP Air Blank \\
MLR & Mills Ranch & WE1 & WIPP East 1 \\
NOY & Noya Tank & WEE & WIPP East \\
NW1 & NorthWest1 & WIP & WIPP 16 Sections \\
NW2 & NorthWest2 & WFF & WIPP Far Field \\
PCN & Pierce Canyon & WQSP & Water Quality Sample Program \\
PEC & Pecos River & WSS & WIPP South \\
PKT & Poker Trap & & \\
\hline & & &
\end{tabular}


This page intentionally left blank. 


\section{Appendix C Equations}

\section{Minimum Detectable Activity (MDA)}

MDA is equal to the mean of a distribution such that 95 percent of the measurements of the distribution will produce analytical results that have the activity above that of a blank. It is possible to achieve a very low level of detection by analyzing a large sample size and counting for a very long time.

The laboratory used the following equation for calculating the MDAs for each radionuclide in various sample matrices:

$$
M D A=\frac{4.65 S_{b}}{K_{0.05} T}+\frac{3}{K_{0.05} T}
$$

Where:

$$
\begin{array}{lll}
S_{b} & = & \text { Standard deviation of the background } \\
K_{0.05} & = & \text { Type I and Type II errors } \\
T & = & \text { Counting time }
\end{array}
$$

For further evaluation of MDA, refer to HPS N13.30-1996, Performance Criteria for Bioassay.

\section{Total Propagated Uncertainty (TPU)}

Total propagated uncertainty for each data point must be reported at $2 \sigma$ level. The TPU was calculated by using the following equation:

$$
T P U_{1 \sigma}=\sigma_{A C T}=\frac{\sqrt{\sigma_{N C R}^{2}+(N C R)^{2} *\left(R E_{E F F}^{2}+R E_{A L I}^{2}+R E_{R}^{2}+\Sigma R E_{C F}^{2}\right)}}{2.22 * E F F * A L I * R * A B N_{S} * e^{-\lambda t} * C F}
$$

Where:

$$
\begin{aligned}
& \mathrm{EFF}= \\
& \mathrm{ALI}= \\
& \mathrm{R}= \\
& \mathrm{ABN}_{\mathrm{s}}= \\
& \sigma^{2}{ }_{\mathrm{NCR}}= \\
& \mathrm{NCR}= \\
& \mathrm{RE}^{2}{ }_{\mathrm{EFF}}= \\
& \mathrm{RE}^{2}= \\
& \mathrm{RE}^{2}{ }_{\mathrm{R}}= \\
& \mathrm{RE}^{2}= \\
& \lambda \quad=
\end{aligned}
$$$$
\text { Detector Efficiency }
$$$$
\text { Sample Aliquot Volume or Mass }
$$$$
\text { Sample Tracer/Carrier Recovery }
$$$$
\text { Abundance Fraction of the Emissions Used for Identification/Quantification }
$$$$
\text { Variance of the Net Sample Count Rate }
$$$$
\text { Net Sample Count Rate }
$$$$
\text { Square of the Relative Error of the Efficiency Term }
$$$$
\text { Square of the Relative Error of the Aliquot }
$$$$
\text { Square of the Relative Error of the Sample Recovery }
$$$$
\text { Square of the Relative Error of Other Correction Factors }
$$
Analyte Decay Constant $=\ln 2 /$ (half-life) [Same units as the half-life used to compute $\lambda]$ 


$\begin{array}{ll}\mathrm{t}= & \text { Time from Sample Collection to Radionuclide Separation or Mid-Point of } \\ & \text { Count Time (Same units as half-life) } \\ \mathrm{CF}= & \text { Other Correction Factors as Appropriate (i.e., Ingrowth factor, self-absorption } \\ \text { factor, etc.) }\end{array}$

\section{Relative Error Ratio (RER)}

The Relative Error Ratio is a method, similar to a t-test, with which to compare duplicate results (see Chapters 4 and 8; WP 02-EM 3004).

$$
R E R=\frac{\left|x_{A}-x_{B}\right|}{\sqrt{\left(2 \sigma_{A}\right)^{2}+\left(2 \sigma_{R}\right)^{2}}}
$$

Where:

$$
\begin{array}{lll}
X_{A} & = & \text { Mean Activity of Population A } \\
X_{B} & = & \text { Mean Activity of Population B } \\
\sigma_{\mathrm{A}} & = & \text { Standard Deviation of Population A } \\
\sigma_{B} & = & \text { Standard Deviation of Population B. }
\end{array}
$$

\section{Percent Bias (\% Bias)}

A measure of the accuracy of radiochemical separation methods and counting instruments; that is, a measure of how reliable the results of analyses are when compared to the actual values.

$$
\% B I A S=\left[\frac{A_{m}-A_{k}}{A_{k}}\right] * 100
$$

Where:
$\%$ BIAS $=$
Percent Bias
$\mathrm{A}_{\mathrm{m}} \quad=$
Measured Sample Activity
$\mathrm{A}_{\mathrm{k}} \quad=$
Known Sample Activity. 


\section{Appendix D \\ Concentrations of Alpha and Beta Activities in Air Particulate}

Table D.1 Results of gross alpha and gross beta analyses in air particulates $\left(\mathrm{Bq} / \mathrm{m}^{3}\right)$.

\begin{tabular}{|c|c|c|c|c|c|}
\hline \multirow[b]{2}{*}{ Week } & \multirow[b]{2}{*}{ Sample ID } & \multicolumn{2}{|c|}{ Gross Alpha } & \multicolumn{2}{|c|}{ Gross Beta } \\
\hline & & Concentration & $2 \times$ TPU $^{\mathbf{a}}$ & Concentration & $2 \times \mathrm{TPU}$ \\
\hline \multicolumn{6}{|c|}{ Carlsbad } \\
\hline 1 & AL-CBD-20000105 1.1 & $4.95 \times 10^{-5}$ & $2.41 \times 10^{-5}$ & $9.44 \times 10^{-4}$ & $1.29 \times 10^{-4}$ \\
\hline 2 & AL-CBD-20000112 1.1 & $6.47 \times 10^{-5}$ & $2.75 \times 10^{-5}$ & $1.40 \times 10^{-3}$ & $1.75 \times 10^{-4}$ \\
\hline 3 & AL-CBD-20000119 1.1 & $9.19 \times 10^{-5}$ & $3.19 \times 10^{-5}$ & $1.36 \times 10^{-3}$ & $1.69 \times 10^{-4}$ \\
\hline 4 & AL-CBD-20000126 1.1 & $6.60 \times 10^{-5}$ & $2.55 \times 10^{-5}$ & $1.46 \times 10^{-3}$ & $1.76 \times 10^{-4}$ \\
\hline 5 & AL-CBD-20000202 1.1 & $7.12 \times 10^{-5}$ & $2.79 \times 10^{-5}$ & $9.89 \times 10^{-4}$ & $1.32 \times 10^{-4}$ \\
\hline 6 & AL-CBD-20000209 1.1 & $5.11 \times 10^{-5}$ & $2.36 \times 10^{-5}$ & $7.69 \times 10^{-4}$ & $1.09 \times 10^{-4}$ \\
\hline 7 & AL-CBD-20000216 1.1 & $5.15 \times 10^{-5}$ & $2.32 \times 10^{-5}$ & $9.36 \times 10^{-4}$ & $1.25 \times 10^{-4}$ \\
\hline 8 & AL-CBD-20000223 1.1 & $6.11 \times 10^{-5}$ & $2.63 \times 10^{-5}$ & $5.89 \times 10^{-4}$ & $9.10 \times 10^{-5}$ \\
\hline 9 & AL-CBD-20000301 1.1 & $1.38 \times 10^{-4}$ & $4.10 \times 10^{-5}$ & $6.20 \times 10^{-4}$ & $9.51 \times 10^{-5}$ \\
\hline 10 & AL-CBD-20000308 1.1 & $4.52 \times 10^{-5}$ & $2.16 \times 10^{-5}$ & $7.38 \times 10^{-4}$ & $1.04 \times 10^{-4}$ \\
\hline 11 & AL-CBD-20000315 1.1 & $8.20 \times 10^{-6}$ & $1.15 \times 10^{-5}$ & $6.24 \times 10^{-4}$ & $9.39 \times 10^{-5}$ \\
\hline 12 & AL-CBD-20000322 1.1 & $4.96 \times 10^{-5}$ & $2.43 \times 10^{-5}$ & $7.16 \times 10^{-4}$ & $1.06 \times 10^{-4}$ \\
\hline 13 & AL-CBD-20000329 1.1 & $4.07 \times 10^{-5}$ & $2.18 \times 10^{-5}$ & $5.97 \times 10^{-4}$ & $9.26 \times 10^{-5}$ \\
\hline 14 & AL-CBD-20000405 1.2 & $1.36 \times 10^{-4}$ & $3.80 \times 10^{-5}$ & $7.34 \times 10^{-4}$ & $1.06 \times 10^{-4}$ \\
\hline 15 & AL-CBD-20000412 1.2 & $3.25 \times 10^{-5}$ & $2.01 \times 10^{-5}$ & $6.66 \times 10^{-4}$ & $9.68 \times 10^{-5}$ \\
\hline 16 & AL-CBD-20000419 1.2 & $3.74 \times 10^{-5}$ & $2.21 \times 10^{-5}$ & $6.91 \times 10^{-4}$ & $1.01 \times 10^{-4}$ \\
\hline 17 & AL-CBD-20000426 1.2 & $1.34 \times 10^{-4}$ & $4.16 \times 10^{-5}$ & $7.31 \times 10^{-4}$ & $1.09 \times 10^{-4}$ \\
\hline 18 & AL-CBD-20000503 1.2 & $9.65 \times 10^{-5}$ & $2.99 \times 10^{-5}$ & $8.92 \times 10^{-4}$ & $1.19 \times 10^{-4}$ \\
\hline 19 & AL-CBD-20000510 1.2 & $1.01 \times 10^{-4}$ & $3.55 \times 10^{-5}$ & $7.26 \times 10^{-4}$ & $1.08 \times 10^{-4}$ \\
\hline 20 & AL-CBD-20000517 1.2 & $4.29 \times 10^{-5}$ & $2.26 \times 10^{-5}$ & $8.73 \times 10^{-4}$ & $1.20 \times 10^{-4}$ \\
\hline 21 & AL-CBD-20000524 1.2 & $5.28 \times 10^{-5}$ & $2.46 \times 10^{-5}$ & $9.15 \times 10^{-4}$ & $1.24 \times 10^{-4}$ \\
\hline 22 & AL-CBD-20000531 1.2 & $8.44 \times 10^{-5}$ & $3.09 \times 10^{-5}$ & $7.66 \times 10^{-4}$ & $1.09 \times 10^{-4}$ \\
\hline 23 & AL-CBD-20000607 1.2 & $5.80 \times 10^{-5}$ & $2.55 \times 10^{-5}$ & $8.51 \times 10^{-4}$ & $1.17 \times 10^{-4}$ \\
\hline 24 & AL-CBD-20000614 1.2 & $1.03 \times 10^{-4}$ & $3.45 \times 10^{-5}$ & $4.47 \times 10^{-4}$ & $7.69 \times 10^{-5}$ \\
\hline 25 & AL-CBD-20000621 1.2 & $1.70 \times 10^{-4}$ & $4.48 \times 10^{-5}$ & $6.72 \times 10^{-4}$ & $9.92 \times 10^{-5}$ \\
\hline 26 & AL-CBD-20000628 1.2 & $1.33 \times 10^{-4}$ & $3.85 \times 10^{-5}$ & $7.37 \times 10^{-4}$ & $1.05 \times 10^{-4}$ \\
\hline 27 & AL-CBD-20000705 1.1 & $1.99 \times 10^{-4}$ & $5.01 \times 10^{-5}$ & $7.91 \times 10^{-4}$ & $1.12 \times 10^{-4}$ \\
\hline 28 & AL-CBD-20000712 1.1 & $8.50 \times 10^{-5}$ & $3.13 \times 10^{-5}$ & $8.17 \times 10^{-4}$ & $1.14 \times 10^{-4}$ \\
\hline 29 & AL-CBD-20000719 1.1 & $1.30 \times 10^{-4}$ & $4.03 \times 10^{-5}$ & $9.45 \times 10^{-4}$ & $1.30 \times 10^{-4}$ \\
\hline 30 & AL-CBD-20000726 1.1 & $1.25 \times 10^{-4}$ & $3.72 \times 10^{-5}$ & $1.22 \times 10^{-3}$ & $1.53 \times 10^{-4}$ \\
\hline 31 & AL-CBD-20000802 1.1 & $6.80 \times 10^{-5}$ & $3.07 \times 10^{-5}$ & $8.11 \times 10^{-4}$ & $1.19 \times 10^{-4}$ \\
\hline 32 & AL-CBD-20000809 1.1 & $1.16 \times 10^{-4}$ & $3.81 \times 10^{-5}$ & $7.82 \times 10^{-4}$ & $1.14 \times 10^{-4}$ \\
\hline 33 & AL-CBD-20000816 1.1 & $1.11 \times 10^{-4}$ & $3.31 \times 10^{-5}$ & $8.38 \times 10^{-4}$ & $1.13 \times 10^{-4}$ \\
\hline 34 & AL-CBD-20000823 1.1 & $8.95 \times 10^{-5}$ & $3.24 \times 10^{-5}$ & $7.82 \times 10^{-4}$ & $1.11 \times 10^{-4}$ \\
\hline 35 & AL-CBD-20000830 1.1 & $9.78 \times 10^{-5}$ & $3.40 \times 10^{-5}$ & $1.05 \times 10^{-3}$ & $1.39 \times 10^{-4}$ \\
\hline
\end{tabular}


Table D.1, cont.

\begin{tabular}{|c|c|c|c|c|c|}
\hline \multirow[b]{2}{*}{ Week } & \multirow[b]{2}{*}{ Sample ID } & \multicolumn{2}{|c|}{ Gross Alpha } & \multicolumn{2}{|c|}{ Gross Beta } \\
\hline & & Concentration & $2 \times \mathrm{TPU}$ & Concentration & $2 \times \mathrm{TPU}$ \\
\hline 36 & AL-CBD-20000906 1.1 & $7.16 \times 10^{-5}$ & $2.86 \times 10^{-5}$ & $1.14 \times 10^{-3}$ & $1.48 \times 10^{-4}$ \\
\hline 37 & AL-CBD-20000913 1.1 & $5.50 \times 10^{-5}$ & $2.55 \times 10^{-5}$ & $1.45 \times 10^{-3}$ & $1.80 \times 10^{-4}$ \\
\hline 38 & AL-CBD-20000920 1.1 & $5.49 \times 10^{-5}$ & $2.46 \times 10^{-5}$ & $8.87 \times 10^{-4}$ & $1.20 \times 10^{-4}$ \\
\hline 39 & AL-CBD-20000927 1.1 & $1.19 \times 10^{-4}$ & $3.66 \times 10^{-5}$ & $1.17 \times 10^{-3}$ & $1.49 \times 10^{-4}$ \\
\hline 40 & AL-CBD-20001004 1.1 & $1.15 \times 10^{-4}$ & $3.52 \times 10^{-5}$ & $1.19 \times 10^{-3}$ & $1.51 \times 10^{-4}$ \\
\hline 41 & AL-CBD-20001011 1.1 & $4.84 \times 10^{-5}$ & $2.24 \times 10^{-5}$ & $7.29 \times 10^{-4}$ & $1.04 \times 10^{-4}$ \\
\hline 42 & AL-CBD-20001018 1.1 & $8.72 \times 10^{-5}$ & $3.16 \times 10^{-5}$ & $7.02 \times 10^{-4}$ & $1.03 \times 10^{-4}$ \\
\hline 43 & AL-CBD-20001025 1.1 & $8.62 \times 10^{-5}$ & $3.12 \times 10^{-5}$ & $7.42 \times 10^{-4}$ & $1.07 \times 10^{-4}$ \\
\hline 44 & AL-CBD-20001101 1.1 & $6.43 \times 10^{-5}$ & $2.62 \times 10^{-5}$ & $7.10 \times 10^{-4}$ & $1.02 \times 10^{-4}$ \\
\hline 45 & AL-CBD-20001108 1.1 & $1.60 \times 10^{-4}$ & $4.25 \times 10^{-5}$ & $1.05 \times 10^{-3}$ & $1.36 \times 10^{-4}$ \\
\hline 46 & AL-CBD-20001115 1.1 & $1.88 \times 10^{-4}$ & $5.16 \times 10^{-5}$ & $1.71 \times 10^{-3}$ & $2.10 \times 10^{-4}$ \\
\hline 47 & AL-CBD-20001122 1.1 & $1.77 \times 10^{-4}$ & $4.27 \times 10^{-5}$ & $1.75 \times 10^{-3}$ & $2.03 \times 10^{-4}$ \\
\hline 48 & AL-CBD-20001129 1.1 & $1.44 \times 10^{-4}$ & $4.03 \times 10^{-5}$ & $1.27 \times 10^{-3}$ & $1.59 \times 10^{-4}$ \\
\hline 49 & AL-CBD-20001206 1.1 & $8.59 \times 10^{-5}$ & $3.07 \times 10^{-5}$ & $1.12 \times 10^{-3}$ & $1.45 \times 10^{-4}$ \\
\hline 50 & AL-CBD-20001213 1.1 & $5.77 \times 10^{-5}$ & $2.49 \times 10^{-5}$ & $7.32 \times 10^{-4}$ & $1.05 \times 10^{-4}$ \\
\hline 51 & AL-CBD-200012201.1 & $7.18 \times 10^{-5}$ & $2.73 \times 10^{-5}$ & $1.11 \times 10^{-3}$ & $1.43 \times 10^{-4}$ \\
\hline 52 & AL-CBD-20001227 1.1 & $9.85 \times 10^{-5}$ & $3.24 \times 10^{-5}$ & $1.39 \times 10^{-3}$ & $1.71 \times 10^{-4}$ \\
\hline
\end{tabular}

\section{Mills Ranch}

\begin{tabular}{|c|c|c|c|c|c|}
\hline 1 & AL-MLR-20000105 1.1 & $3.18 \times 10^{-5}$ & $1.91 \times 10^{-5}$ & $8.25 \times 10^{-4}$ & $1.15 \times 10^{-4}$ \\
\hline 2 & AL-MLR-20000112 1.1 & $3.41 \times 10^{-5}$ & $1.98 \times 10^{-5}$ & $1.07 \times 10^{-3}$ & $1.42 \times 10^{-4}$ \\
\hline 3 & AL-MLR-20000119 1.1 & $8.97 \times 10^{-5}$ & $3.25 \times 10^{-5}$ & $1.34 \times 10^{-3}$ & $1.69 \times 10^{-4}$ \\
\hline 4 & AL-MLR-20000126 1.1 & $8.95 \times 10^{-5}$ & $2.93 \times 10^{-5}$ & $1.27 \times 10^{-3}$ & $1.56 \times 10^{-4}$ \\
\hline 5 & AL-MLR-20000202 1.1 & $4.92 \times 10^{-5}$ & $2.34 \times 10^{-5}$ & $1.22 \times 10^{-3}$ & $1.56 \times 10^{-4}$ \\
\hline 6 & AL-MLR-20000209 1.1 & $5.35 \times 10^{-5}$ & $2.30 \times 10^{-5}$ & $7.37 \times 10^{-4}$ & $1.03 \times 10^{-4}$ \\
\hline 7 & AL-MLR-20000216 1.1 & $4.17 \times 10^{-5}$ & $2.15 \times 10^{-5}$ & $9.37 \times 10^{-4}$ & $1.26 \times 10^{-4}$ \\
\hline 8 & AL-MLR-20000223 1.1 & $3.49 \times 10^{-5}$ & $2.01 \times 10^{-5}$ & $6.84 \times 10^{-4}$ & $1.01 \times 10^{-4}$ \\
\hline 9 & AL-MLR-20000301 1.1 & $1.23 \times 10^{-4}$ & $3.67 \times 10^{-5}$ & $5.48 \times 10^{-4}$ & $8.43 \times 10^{-5}$ \\
\hline 10 & AL-MLR-20000308 1.1 & $4.37 \times 10^{-5}$ & $2.09 \times 10^{-5}$ & $8.06 \times 10^{-4}$ & $1.10 \times 10^{-4}$ \\
\hline 11 & AL-MLR-20000315 1.1 & $1.53 \times 10^{-5}$ & $1.38 \times 10^{-5}$ & $4.78 \times 10^{-4}$ & $7.71 \times 10^{-5}$ \\
\hline 12 & AL-MLR-20000322 1.1 & $7.23 \times 10^{-5}$ & $2.75 \times 10^{-5}$ & $7.40 \times 10^{-4}$ & $1.05 \times 10^{-4}$ \\
\hline 13 & AL-MLR-20000329 1.1 & $3.88 \times 10^{-5}$ & $1.95 \times 10^{-5}$ & $5.46 \times 10^{-4}$ & $8.27 \times 10^{-5}$ \\
\hline 14 & AL-MLR-20000405 1.1 & $9.43 \times 10^{-5}$ & $3.19 \times 10^{-5}$ & $8.22 \times 10^{-4}$ & $1.17 \times 10^{-4}$ \\
\hline 15 & AL-MLR-20000412 1.1 & $6.17 \times 10^{-5}$ & $2.77 \times 10^{-5}$ & $7.11 \times 10^{-4}$ & $1.04 \times 10^{-4}$ \\
\hline 16 & AL-MLR-20000419 1.1 & $4.07 \times 10^{-5}$ & $2.16 \times 10^{-5}$ & $6.78 \times 10^{-4}$ & $9.70 \times 10^{-5}$ \\
\hline 17 & AL-MLR-20000426 1.1 & $1.51 \times 10^{-4}$ & $4.51 \times 10^{-5}$ & $6.66 \times 10^{-4}$ & $1.04 \times 10^{-4}$ \\
\hline 18 & AL-MLR-20000503 1.1 & $8.69 \times 10^{-5}$ & $2.94 \times 10^{-5}$ & $1.00 \times 10^{-3}$ & $1.33 \times 10^{-4}$ \\
\hline 19 & AL-MLR-20000510 1.1 & $7.10 \times 10^{-5}$ & $2.84 \times 10^{-5}$ & $7.92 \times 10^{-4}$ & $1.11 \times 10^{-4}$ \\
\hline 20 & AL-MLR-20000517 1.1 & $5.39 \times 10^{-5}$ & $2.40 \times 10^{-5}$ & $6.79 \times 10^{-4}$ & $9.75 \times 10^{-5}$ \\
\hline 21 & AL-MLR-20000524 1.1 & $5.91 \times 10^{-5}$ & $2.68 \times 10^{-5}$ & $9.37 \times 10^{-4}$ & $1.28 \times 10^{-4}$ \\
\hline 22 & AL-MLR-20000531 1.1 & $5.80 \times 10^{-5}$ & $2.54 \times 10^{-5}$ & $8.27 \times 10^{-4}$ & $1.15 \times 10^{-4}$ \\
\hline 23 & AL-MLR-20000607 1.1 & $1.07 \times 10^{-4}$ & $3.40 \times 10^{-5}$ & $8.88 \times 10^{-4}$ & $1.20 \times 10^{-4}$ \\
\hline 24 & AL-MLR-20000614 1.1 & $1.77 \times 10^{-4}$ & $4.67 \times 10^{-5}$ & $5.16 \times 10^{-4}$ & $8.48 \times 10^{-5}$ \\
\hline 25 & AL-MLR-20000621 1.1 & $1.40 \times 10^{-4}$ & $4.00 \times 10^{-5}$ & $6.42 \times 10^{-4}$ & $9.59 \times 10^{-5}$ \\
\hline 26 & AL-MLR-20000628 1.1 & $1.29 \times 10^{-4}$ & $3.91 \times 10^{-5}$ & $7.74 \times 10^{-4}$ & $1.11 \times 10^{-4}$ \\
\hline 27 & AL-MLR-20000705 1.1 & $2.08 \times 10^{-4}$ & $4.89 \times 10^{-5}$ & $8.13 \times 10^{-4}$ & $1.11 \times 10^{-4}$ \\
\hline 28 & AL-MLR-20000712 1.1 & $1.07 \times 10^{-4}$ & $3.55 \times 10^{-5}$ & $8.55 \times 10^{-4}$ & $1.19 \times 10^{-4}$ \\
\hline 29 & AL-MLR-20000719 1.1 & $1.62 \times 10^{-4}$ & $4.53 \times 10^{-5}$ & $1.06 \times 10^{-3}$ & $1.41 \times 10^{-4}$ \\
\hline
\end{tabular}


Table D.1, cont.

\begin{tabular}{|c|c|c|c|c|c|}
\hline \multirow[b]{2}{*}{ Week } & \multirow[b]{2}{*}{ Sample ID } & \multicolumn{2}{|c|}{ Gross Alpha } & \multicolumn{2}{|c|}{ Gross Beta } \\
\hline & & Concentration & $2 \times \mathrm{TPU}$ & Concentration & $2 \times \mathrm{TPU}$ \\
\hline 30 & AL-MLR-20000726 1.1 & $1.39 \times 10^{-4}$ & $3.86 \times 10^{-5}$ & $1.27 \times 10^{-3}$ & $1.57 \times 10^{-4}$ \\
\hline 31 & AL-MLR-20000802 1.1 & $9.73 \times 10^{-5}$ & $3.63 \times 10^{-5}$ & $8.02 \times 10^{-4}$ & $1.18 \times 10^{-4}$ \\
\hline 32 & AL-MLR-20000809 1.1 & $1.13 \times 10^{-4}$ & $3.86 \times 10^{-5}$ & $9.34 \times 10^{-4}$ & $1.31 \times 10^{-4}$ \\
\hline 33 & AL-MLR-20000816 1.1 & $1.08 \times 10^{-4}$ & $3.33 \times 10^{-5}$ & $8.34 \times 10^{-4}$ & $1.13 \times 10^{-4}$ \\
\hline 34 & AL-MLR-20000823 1.1 & $5.98 \times 10^{-5}$ & $2.63 \times 10^{-5}$ & $6.78 \times 10^{-4}$ & $9.93 \times 10^{-5}$ \\
\hline 35 & AL-MLR-20000830 1.1 & $9.73 \times 10^{-5}$ & $3.38 \times 10^{-5}$ & $1.09 \times 10^{-3}$ & $1.42 \times 10^{-4}$ \\
\hline 36 & AL-MLR-20000906 1.1 & $9.30 \times 10^{-5}$ & $3.20 \times 10^{-5}$ & $1.09 \times 10^{-3}$ & $1.42 \times 10^{-4}$ \\
\hline 37 & AL-MLR-20000913 1.1 & $5.83 \times 10^{-5}$ & $2.63 \times 10^{-5}$ & $1.24 \times 10^{-3}$ & $1.59 \times 10^{-4}$ \\
\hline 38 & AL-MLR-20000920 1.1 & $5.45 \times 10^{-5}$ & $2.44 \times 10^{-5}$ & $8.82 \times 10^{-4}$ & $1.19 \times 10^{-4}$ \\
\hline 39 & AL-MLR-20000927 1.1 & $1.05 \times 10^{-4}$ & $3.44 \times 10^{-5}$ & $1.12 \times 10^{-3}$ & $1.45 \times 10^{-4}$ \\
\hline 40 & AL-MLR-20001004 1.1 & $1.26 \times 10^{-4}$ & $3.73 \times 10^{-5}$ & $1.35 \times 10^{-3}$ & $1.67 \times 10^{-4}$ \\
\hline 41 & AL-MLR-20001011 1.1 & $4.80 \times 10^{-5}$ & $2.28 \times 10^{-5}$ & $6.20 \times 10^{-4}$ & $9.33 \times 10^{-5}$ \\
\hline 42 & AL-MLR-20001018 1.1 & $3.98 \times 10^{-5}$ & $2.07 \times 10^{-5}$ & $6.02 \times 10^{-4}$ & $9.16 \times 10^{-5}$ \\
\hline 43 & AL-MLR-20001025 1.1 & $6.88 \times 10^{-5}$ & $2.66 \times 10^{-5}$ & $7.25 \times 10^{-4}$ & $1.03 \times 10^{-4}$ \\
\hline 44 & AL-MLR-20001101 1.1 & $2.80 \times 10^{-5}$ & $1.70 \times 10^{-5}$ & $6.42 \times 10^{-4}$ & $9.43 \times 10^{-5}$ \\
\hline 45 & AL-MLR-20001108 1.1 & $1.99 \times 10^{-4}$ & $4.92 \times 10^{-5}$ & $1.27 \times 10^{-3}$ & $1.60 \times 10^{-4}$ \\
\hline 46 & AL-MLR-20001115 1.1 & $1.95 \times 10^{-4}$ & $5.15 \times 10^{-5}$ & $1.79 \times 10^{-3}$ & $2.16 \times 10^{-4}$ \\
\hline 47 & AL-MLR-20001122 1.1 & $1.49 \times 10^{-4}$ & $3.94 \times 10^{-5}$ & $1.62 \times 10^{-3}$ & $1.91 \times 10^{-4}$ \\
\hline 48 & AL-MLR-20001129 1.1 & $\mathrm{~N} / \mathrm{C}^{\mathrm{b}}$ & $\mathrm{N} / \mathrm{C}$ & $\mathrm{N} / \mathrm{C}$ & $\mathrm{N} / \mathrm{C}$ \\
\hline 49 & AL-MLR-20001206 1.1 & $1.46 \times 10^{-4}$ & $4.04 \times 10^{-5}$ & $1.18 \times 10^{-3}$ & $1.50 \times 10^{-4}$ \\
\hline 50 & AL-MLR-20001213 1.1 & $3.99 \times 10^{-5}$ & $2.07 \times 10^{-5}$ & $6.82 \times 10^{-4}$ & $9.98 \times 10^{-5}$ \\
\hline 51 & AL-MLR-20001220 1.1 & $5.85 \times 10^{-5}$ & $2.48 \times 10^{-5}$ & $9.90 \times 10^{-4}$ & $1.31 \times 10^{-4}$ \\
\hline 52 & AL-MLR-20001227 1.1 & $7.27 \times 10^{-5}$ & $2.70 \times 10^{-5}$ & $1.38 \times 10^{-3}$ & $1.69 \times 10^{-4}$ \\
\hline
\end{tabular}

Southeast Control

\begin{tabular}{|c|c|c|c|c|c|}
\hline 1 & AL-SEC-20000105 1.1 & $4.31 \times 10^{-5}$ & $2.16 \times 10^{-5}$ & $9.97 \times 10^{-4}$ & $1.32 \times 10^{-4}$ \\
\hline 2 & AL-SEC-20000112 1.1 & $3.96 \times 10^{-5}$ & $2.06 \times 10^{-5}$ & $1.21 \times 10^{-3}$ & $1.53 \times 10^{-4}$ \\
\hline 3 & AL-SEC-20000119 1.1 & $1.45 \times 10^{-4}$ & $3.96 \times 10^{-5}$ & $1.39 \times 10^{-3}$ & $1.70 \times 10^{-4}$ \\
\hline 4 & AL-SEC-20000126 1.1 & $6.42 \times 10^{-5}$ & $2.52 \times 10^{-5}$ & $1.38 \times 10^{-3}$ & $1.68 \times 10^{-4}$ \\
\hline 5 & AL-SEC-20000202 1.1 & $5.06 \times 10^{-5}$ & $2.29 \times 10^{-5}$ & $1.12 \times 10^{-3}$ & $1.44 \times 10^{-4}$ \\
\hline 6 & AL-SEC-20000209 1.1 & $7.03 \times 10^{-5}$ & $2.85 \times 10^{-5}$ & $8.73 \times 10^{-4}$ & $1.21 \times 10^{-4}$ \\
\hline 7 & AL-SEC-20000216 1.1 & $6.33 \times 10^{-5}$ & $2.61 \times 10^{-5}$ & $9.09 \times 10^{-4}$ & $1.23 \times 10^{-4}$ \\
\hline 8 & AL-SEC-20000223 1.1 & $2.05 \times 10^{-5}$ & $1.53 \times 10^{-5}$ & $6.41 \times 10^{-4}$ & $9.57 \times 10^{-5}$ \\
\hline 9 & AL-SEC-20000301 1.1 & $1.38 \times 10^{-4}$ & $3.87 \times 10^{-5}$ & $5.94 \times 10^{-4}$ & $8.87 \times 10^{-5}$ \\
\hline 10 & AL-SEC-20000308 1.1 & $3.43 \times 10^{-5}$ & $1.92 \times 10^{-5}$ & $7.06 \times 10^{-4}$ & $1.02 \times 10^{-4}$ \\
\hline 11 & AL-SEC-20000315 1.1 & $\mathrm{~N} / \mathrm{C}$ & $\mathrm{N} / \mathrm{C}$ & $\mathrm{N} / \mathrm{C}$ & $\mathrm{N} / \mathrm{C}$ \\
\hline 12 & AL-SEC-20000322 1.1 & $5.05 \times 10^{-5}$ & $2.34 \times 10^{-5}$ & $7.12 \times 10^{-4}$ & $1.03 \times 10^{-4}$ \\
\hline 13 & AL-SEC-20000329 1.1 & $3.40 \times 10^{-5}$ & $1.83 \times 10^{-5}$ & $6.59 \times 10^{-4}$ & $9.41 \times 10^{-5}$ \\
\hline 14 & AL-SEC-20000405 1.1 & $1.29 \times 10^{-4}$ & $3.73 \times 10^{-5}$ & $8.31 \times 10^{-4}$ & $1.17 \times 10^{-4}$ \\
\hline 15 & AL-SEC-20000412 1.1 & $6.72 \times 10^{-5}$ & $2.83 \times 10^{-5}$ & $7.33 \times 10^{-4}$ & $1.05 \times 10^{-4}$ \\
\hline 16 & AL-SEC-20000419 1.1 & $4.30 \times 10^{-5}$ & $2.28 \times 10^{-5}$ & $7.60 \times 10^{-4}$ & $1.07 \times 10^{-4}$ \\
\hline 17 & AL-SEC-20000426 1.1 & $1.56 \times 10^{-4}$ & $4.34 \times 10^{-5}$ & $7.54 \times 10^{-4}$ & $1.09 \times 10^{-4}$ \\
\hline 18 & AL-SEC-20000503 1.1 & $\mathrm{~N} / \mathrm{C}$ & $\mathrm{N} / \mathrm{C}$ & $\mathrm{N} / \mathrm{C}$ & $\mathrm{N} / \mathrm{C}$ \\
\hline 19 & AL-SEC-20000510 1.1 & $1.06 \times 10^{-4}$ & $3.69 \times 10^{-5}$ & $8.00 \times 10^{-4}$ & $1.16 \times 10^{-4}$ \\
\hline 20 & AL-SEC-20000517 1.1 & $5.31 \times 10^{-5}$ & $2.49 \times 10^{-5}$ & $7.39 \times 10^{-4}$ & $1.06 \times 10^{-4}$ \\
\hline 21 & AL-SEC-20000524 1.1 & $9.69 \times 10^{-5}$ & $3.29 \times 10^{-5}$ & $1.00 \times 10^{-3}$ & $1.32 \times 10^{-4}$ \\
\hline 22 & AL-SEC-20000531 1.1 & $1.19 \times 10^{-4}$ & $3.69 \times 10^{-5}$ & $7.38 \times 10^{-4}$ & $1.06 \times 10^{-4}$ \\
\hline 23 & AL-SEC-20000607 1.1 & $8.96 \times 10^{-5}$ & $3.14 \times 10^{-5}$ & $8.26 \times 10^{-4}$ & $1.14 \times 10^{-4}$ \\
\hline
\end{tabular}


Table D.1, cont.

\begin{tabular}{|c|c|c|c|c|c|}
\hline \multirow[b]{2}{*}{ Week } & \multirow[b]{2}{*}{ Sample ID } & \multicolumn{2}{|c|}{ Gross Alpha } & \multicolumn{2}{|c|}{ Gross Beta } \\
\hline & & Concentration & $2 \times \mathrm{TPU}$ & Concentration & $2 \times \mathrm{TPU}$ \\
\hline 24 & AL-SEC-20000614 1.1 & $1.39 \times 10^{-4}$ & $3.89 \times 10^{-5}$ & $5.53 \times 10^{-4}$ & $8.57 \times 10^{-5}$ \\
\hline 25 & AL-SEC-20000621 1.1 & $1.45 \times 10^{-4}$ & $4.03 \times 10^{-5}$ & $6.71 \times 10^{-4}$ & $9.80 \times 10^{-5}$ \\
\hline 26 & AL-SEC-20000628 1.1 & $1.07 \times 10^{-4}$ & $3.48 \times 10^{-5}$ & $6.76 \times 10^{-4}$ & $9.96 \times 10^{-5}$ \\
\hline 27 & AL-SEC-20000705 1.2 & $1.61 \times 10^{-4}$ & $4.29 \times 10^{-5}$ & $9.36 \times 10^{-4}$ & $1.25 \times 10^{-4}$ \\
\hline 28 & AL-SEC-20000712 1.2 & $1.44 \times 10^{-4}$ & $4.08 \times 10^{-5}$ & $9.01 \times 10^{-4}$ & $1.22 \times 10^{-4}$ \\
\hline 29 & AL-SEC-20000719 1.2 & $1.41 \times 10^{-4}$ & $4.10 \times 10^{-5}$ & $1.08 \times 10^{-3}$ & $1.41 \times 10^{-4}$ \\
\hline 30 & AL-SEC-20000726 1.2 & $1.58 \times 10^{-4}$ & $4.06 \times 10^{-5}$ & $1.18 \times 10^{-3}$ & $1.47 \times 10^{-4}$ \\
\hline 31 & AL-SEC-20000802 1.2 & $6.43 \times 10^{-5}$ & $2.98 \times 10^{-5}$ & $7.99 \times 10^{-4}$ & $1.18 \times 10^{-4}$ \\
\hline 32 & AL-SEC-20000809 1.2 & $1.24 \times 10^{-4}$ & $3.98 \times 10^{-5}$ & $8.80 \times 10^{-4}$ & $1.24 \times 10^{-4}$ \\
\hline 33 & AL-SEC-20000816 1.2 & $1.26 \times 10^{-4}$ & $3.65 \times 10^{-5}$ & $6.37 \times 10^{-4}$ & $9.37 \times 10^{-5}$ \\
\hline 34 & AL-SEC-20000823 1.2 & $5.93 \times 10^{-5}$ & $2.67 \times 10^{-5}$ & $7.31 \times 10^{-4}$ & $1.06 \times 10^{-4}$ \\
\hline 35 & AL-SEC-20000830 1.2 & $1.23 \times 10^{-4}$ & $3.84 \times 10^{-5}$ & $1.08 \times 10^{-3}$ & $1.42 \times 10^{-4}$ \\
\hline 36 & AL-SEC-20000906 1.2 & $8.97 \times 10^{-5}$ & $3.21 \times 10^{-5}$ & $1.22 \times 10^{-3}$ & $1.56 \times 10^{-4}$ \\
\hline 37 & AL-SEC-20000913 1.2 & $6.19 \times 10^{-5}$ & $2.62 \times 10^{-5}$ & $1.20 \times 10^{-3}$ & $1.52 \times 10^{-4}$ \\
\hline 38 & AL-SEC-20000920 1.2 & $7.04 \times 10^{-5}$ & $2.79 \times 10^{-5}$ & $8.64 \times 10^{-4}$ & $1.18 \times 10^{-4}$ \\
\hline 39 & AL-SEC-20000927 1.2 & $1.22 \times 10^{-4}$ & $3.74 \times 10^{-5}$ & $1.26 \times 10^{-3}$ & $1.60 \times 10^{-4}$ \\
\hline 40 & AL-SEC-20001004 1.1 & $1.20 \times 10^{-4}$ & $3.64 \times 10^{-5}$ & $1.34 \times 10^{-3}$ & $1.66 \times 10^{-4}$ \\
\hline 41 & AL-SEC-20001011 1.1 & $4.02 \times 10^{-5}$ & $2.09 \times 10^{-5}$ & $6.11 \times 10^{-4}$ & $9.22 \times 10^{-5}$ \\
\hline 42 & AL-SEC-20001018 1.1 & $7.36 \times 10^{-5}$ & $2.79 \times 10^{-5}$ & $5.50 \times 10^{-4}$ & $8.54 \times 10^{-5}$ \\
\hline 43 & AL-SEC-20001025 1.1 & $7.04 \times 10^{-5}$ & $2.72 \times 10^{-5}$ & $6.54 \times 10^{-4}$ & $9.61 \times 10^{-5}$ \\
\hline 44 & AL-SEC-20001101 1.1 & $3.55 \times 10^{-5}$ & $1.92 \times 10^{-5}$ & $6.15 \times 10^{-4}$ & $9.17 \times 10^{-5}$ \\
\hline 45 & AL-SEC-20001108 1.1 & $1.81 \times 10^{-4}$ & $4.65 \times 10^{-5}$ & $1.10 \times 10^{-3}$ & $1.43 \times 10^{-4}$ \\
\hline 46 & AL-SEC-20001115 1.1 & $1.79 \times 10^{-4}$ & $4.89 \times 10^{-5}$ & $1.76 \times 10^{-3}$ & $2.13 \times 10^{-4}$ \\
\hline 47 & AL-SEC-20001122 1.1 & $1.53 \times 10^{-4}$ & $3.92 \times 10^{-5}$ & $1.81 \times 10^{-3}$ & $2.08 \times 10^{-4}$ \\
\hline 48 & AL-SEC-20001129 1.1 & $1.35 \times 10^{-4}$ & $3.86 \times 10^{-5}$ & $1.38 \times 10^{-3}$ & $1.70 \times 10^{-4}$ \\
\hline 49 & AL-SEC-20001206 1.1 & $1.07 \times 10^{-4}$ & $3.40 \times 10^{-5}$ & $1.24 \times 10^{-3}$ & $1.56 \times 10^{-4}$ \\
\hline 50 & AL-SEC-20001213 1.1 & $3.65 \times 10^{-5}$ & $1.96 \times 10^{-5}$ & $5.76 \times 10^{-4}$ & $8.80 \times 10^{-5}$ \\
\hline 51 & AL-SEC-20001220 1.1 & $5.95 \times 10^{-5}$ & $2.52 \times 10^{-5}$ & $1.15 \times 10^{-3}$ & $1.48 \times 10^{-4}$ \\
\hline 52 & AL-SEC-20001227 1.1 & $1.12 \times 10^{-4}$ & $3.47 \times 10^{-5}$ & $1.33 \times 10^{-3}$ & $1.66 \times 10^{-4}$ \\
\hline
\end{tabular}

Smith Ranch

\begin{tabular}{cccccc}
\hline 1 & AL-SMR-20000105 1.2 & $3.89 \times 10^{-5}$ & $2.15 \times 10^{-5}$ & $7.92 \times 10^{-4}$ & $1.13 \times 10^{-4}$ \\
2 & AL-SMR-20000112 1.2 & $3.12 \times 10^{-5}$ & $1.90 \times 10^{-5}$ & $1.22 \times 10^{-3}$ & $1.56 \times 10^{-4}$ \\
3 & AL-SMR-20000119 1.2 & $8.55 \times 10^{-5}$ & $3.01 \times 10^{-5}$ & $1.33 \times 10^{-3}$ & $1.64 \times 10^{-4}$ \\
4 & AL-SMR-20000126 1.2 & $5.30 \times 10^{-5}$ & $2.34 \times 10^{-5}$ & $1.25 \times 10^{-3}$ & $1.57 \times 10^{-4}$ \\
5 & AL-SMR-20000202 1.2 & $3.68 \times 10^{-5}$ & $1.98 \times 10^{-5}$ & $1.03 \times 10^{-3}$ & $1.35 \times 10^{-4}$ \\
6 & AL-SMR-20000209 1.2 & $4.21 \times 10^{-5}$ & $2.18 \times 10^{-5}$ & $7.52 \times 10^{-4}$ & $1.08 \times 10^{-4}$ \\
7 & AL-SMR-20000216 1.2 & $6.10 \times 10^{-5}$ & $2.63 \times 10^{-5}$ & $9.95 \times 10^{-4}$ & $1.33 \times 10^{-4}$ \\
8 & AL-SMR-20000223 1.2 & $6.44 \times 10^{-5}$ & $2.61 \times 10^{-5}$ & $6.98 \times 10^{-4}$ & $1.00 \times 10^{-4}$ \\
9 & AL-SMR-20000301 1.2 & $8.51 \times 10^{-5}$ & $3.16 \times 10^{-5}$ & $5.69 \times 10^{-4}$ & $8.92 \times 10^{-5}$ \\
10 & AL-SMR-20000308 1.2 & $3.88 \times 10^{-5}$ & $2.02 \times 10^{-5}$ & $7.94 \times 10^{-4}$ & $1.11 \times 10^{-4}$ \\
11 & AL-SMR-20000315 1.2 & $2.84 \times 10^{-5}$ & $1.92 \times 10^{-5}$ & $5.69 \times 10^{-4}$ & $9.04 \times 10^{-5}$ \\
12 & AL-SMR-20000322 1.2 & $8.82 \times 10^{-5}$ & $3.65 \times 10^{-5}$ & $7.87 \times 10^{-4}$ & $1.22 \times 10^{-4}$ \\
13 & AL-SMR-20000329 1.2 & $2.87 \times 10^{-5}$ & $1.74 \times 10^{-5}$ & $6.35 \times 10^{-4}$ & $9.28 \times 10^{-5}$ \\
14 & AL-SMR-20000405 1.1 & $1.42 \times 10^{-4}$ & $3.87 \times 10^{-5}$ & $8.11 \times 10^{-4}$ & $1.14 \times 10^{-4}$ \\
15 & AL-SMR-20000412 1.1 & $4.69 \times 10^{-5}$ & $2.34 \times 10^{-5}$ & $6.58 \times 10^{-4}$ & $9.58 \times 10^{-5}$ \\
16 & AL-SMR-20000419 1.1 & $\mathrm{~N} / \mathrm{C}$ & $\mathrm{N} / \mathrm{C}$ & $\mathrm{N} / \mathrm{C}$ & $\mathrm{N} / \mathrm{C}$ \\
17 & AL-SMR-20000426 1.1 & $1.50 \times 10^{-4}$ & $4.89 \times 10^{-5}$ & $6.35 \times 10^{-4}$ & $1.07 \times 10^{-4}$
\end{tabular}


Table D.1, cont.

\begin{tabular}{|c|c|c|c|c|c|}
\hline \multirow[b]{2}{*}{ Week } & \multirow[b]{2}{*}{ Sample ID } & \multicolumn{2}{|c|}{ Gross Alpha } & \multicolumn{2}{|c|}{ Gross Beta } \\
\hline & & Concentration & $2 \times \mathrm{TPU}$ & Concentration & $2 \times \mathrm{TPU}$ \\
\hline 18 & AL-SMR-20000503 1.1 & $8.48 \times 10^{-5}$ & $2.80 \times 10^{-5}$ & $9.59 \times 10^{-4}$ & $1.26 \times 10^{-4}$ \\
\hline 19 & AL-SMR-20000510 1.1 & $8.54 \times 10^{-5}$ & $3.10 \times 10^{-5}$ & $7.61 \times 10^{-4}$ & $1.08 \times 10^{-4}$ \\
\hline 20 & AL-SMR-20000517 1.1 & $5.83 \times 10^{-5}$ & $2.60 \times 10^{-5}$ & $8.18 \times 10^{-4}$ & $1.14 \times 10^{-4}$ \\
\hline 21 & AL-SMR-20000524 1.1 & $6.67 \times 10^{-5}$ & $2.67 \times 10^{-5}$ & $8.92 \times 10^{-4}$ & $1.20 \times 10^{-4}$ \\
\hline 22 & AL-SMR-20000531 1.1 & $4.73 \times 10^{-5}$ & $2.36 \times 10^{-5}$ & $7.87 \times 10^{-4}$ & $1.12 \times 10^{-4}$ \\
\hline 23 & AL-SMR-20000607 1.1 & $7.19 \times 10^{-5}$ & $2.81 \times 10^{-5}$ & $7.55 \times 10^{-4}$ & $1.07 \times 10^{-4}$ \\
\hline 24 & AL-SMR-20000614 1.1 & $7.79 \times 10^{-5}$ & $3.35 \times 10^{-5}$ & $4.86 \times 10^{-4}$ & $8.85 \times 10^{-5}$ \\
\hline 25 & AL-SMR-20000621 1.1 & $1.38 \times 10^{-4}$ & $4.02 \times 10^{-5}$ & $6.36 \times 10^{-4}$ & $9.60 \times 10^{-5}$ \\
\hline 26 & AL-SMR-20000628 1.1 & $1.07 \times 10^{-4}$ & $3.40 \times 10^{-5}$ & $7.96 \times 10^{-4}$ & $1.11 \times 10^{-4}$ \\
\hline 27 & AL-SMR-20000705 1.1 & $1.88 \times 10^{-4}$ & $4.79 \times 10^{-5}$ & $8.85 \times 10^{-4}$ & $1.21 \times 10^{-4}$ \\
\hline 28 & AL-SMR-20000712 1.1 & $1.37 \times 10^{-4}$ & $4.01 \times 10^{-5}$ & $9.21 \times 10^{-4}$ & $1.25 \times 10^{-4}$ \\
\hline 29 & AL-SMR-20000719 1.1 & $1.20 \times 10^{-4}$ & $3.84 \times 10^{-5}$ & $9.92 \times 10^{-4}$ & $1.34 \times 10^{-4}$ \\
\hline 30 & AL-SMR-20000726 1.1 & $1.20 \times 10^{-4}$ & $3.52 \times 10^{-5}$ & $1.18 \times 10^{-3}$ & $1.47 \times 10^{-4}$ \\
\hline 31 & AL-SMR-20000802 1.1 & $5.63 \times 10^{-5}$ & $2.83 \times 10^{-5}$ & $8.61 \times 10^{-4}$ & $1.25 \times 10^{-4}$ \\
\hline 32 & AL-SMR-20000809 1.1 & $1.08 \times 10^{-4}$ & $3.66 \times 10^{-5}$ & $8.83 \times 10^{-4}$ & $1.24 \times 10^{-4}$ \\
\hline 33 & AL-SMR-20000816 1.1 & $1.09 \times 10^{-4}$ & $3.32 \times 10^{-5}$ & $7.76 \times 10^{-4}$ & $1.07 \times 10^{-4}$ \\
\hline 34 & AL-SMR-20000823 1.1 & $8.06 \times 10^{-5}$ & $3.10 \times 10^{-5}$ & $6.64 \times 10^{-4}$ & $9.89 \times 10^{-5}$ \\
\hline 35 & AL-SMR-20000830 1.1 & $7.75 \times 10^{-5}$ & $2.94 \times 10^{-5}$ & $1.08 \times 10^{-3}$ & $1.39 \times 10^{-4}$ \\
\hline 36 & AL-SMR-20000906 1.1 & $7.46 \times 10^{-5}$ & $2.93 \times 10^{-5}$ & $1.06 \times 10^{-3}$ & $1.40 \times 10^{-4}$ \\
\hline 37 & AL-SMR-20000913 1.1 & $9.71 \times 10^{-5}$ & $3.29 \times 10^{-5}$ & $1.32 \times 10^{-3}$ & $1.64 \times 10^{-4}$ \\
\hline 38 & AL-SMR-200009201.1 & $4.37 \times 10^{-5}$ & $2.17 \times 10^{-5}$ & $8.36 \times 10^{-4}$ & $1.14 \times 10^{-4}$ \\
\hline 39 & AL-SMR-20000927 1.1 & $1.39 \times 10^{-4}$ & $4.07 \times 10^{-5}$ & $1.23 \times 10^{-3}$ & $1.58 \times 10^{-4}$ \\
\hline 40 & AL-SMR-20001004 1.1 & $1.25 \times 10^{-4}$ & $3.65 \times 10^{-5}$ & $1.27 \times 10^{-3}$ & $1.58 \times 10^{-4}$ \\
\hline 41 & AL-SMR-20001011 1.1 & $2.92 \times 10^{-5}$ & $1.76 \times 10^{-5}$ & $6.69 \times 10^{-4}$ & $9.76 \times 10^{-5}$ \\
\hline 42 & AL-SMR-20001018 1.1 & $1.02 \times 10^{-4}$ & $3.46 \times 10^{-5}$ & $7.45 \times 10^{-4}$ & $1.08 \times 10^{-4}$ \\
\hline 43 & AL-SMR-20001025 1.1 & $5.12 \times 10^{-5}$ & $2.27 \times 10^{-5}$ & $6.72 \times 10^{-4}$ & $9.69 \times 10^{-5}$ \\
\hline 44 & AL-SMR-20001101 1.1 & $3.13 \times 10^{-5}$ & $1.82 \times 10^{-5}$ & $6.02 \times 10^{-4}$ & $9.09 \times 10^{-5}$ \\
\hline 45 & AL-SMR-20001108 1.1 & $1.83 \times 10^{-4}$ & $4.70 \times 10^{-5}$ & $1.16 \times 10^{-3}$ & $1.50 \times 10^{-4}$ \\
\hline 46 & AL-SMR-20001115 1.1 & $2.03 \times 10^{-4}$ & $5.28 \times 10^{-5}$ & $1.61 \times 10^{-3}$ & $1.99 \times 10^{-4}$ \\
\hline 47 & AL-SMR-20001122 1.1 & $1.43 \times 10^{-4}$ & $3.87 \times 10^{-5}$ & $1.66 \times 10^{-3}$ & $1.96 \times 10^{-4}$ \\
\hline 48 & AL-SMR-200011291.1 & $1.71 \times 10^{-4}$ & $4.53 \times 10^{-5}$ & $1.31 \times 10^{-3}$ & $1.65 \times 10^{-4}$ \\
\hline 49 & AL-SMR-20001206 1.1 & $1.16 \times 10^{-4}$ & $3.54 \times 10^{-5}$ & $1.05 \times 10^{-3}$ & $1.37 \times 10^{-4}$ \\
\hline 50 & AL-SMR-200012131.1 & $5.36 \times 10^{-5}$ & $2.42 \times 10^{-5}$ & $6.79 \times 10^{-4}$ & $1.00 \times 10^{-4}$ \\
\hline 51 & AL-SMR-200012201.1 & $\mathrm{N} / \mathrm{C}$ & $\mathrm{N} / \mathrm{C}$ & $\mathrm{N} / \mathrm{C}$ & $\mathrm{N} / \mathrm{C}$ \\
\hline 52 & AL-SMR-20001227 1.1 & $1.01 \times 10^{-4}$ & $3.24 \times 10^{-5}$ & $1.34 \times 10^{-3}$ & $1.65 \times 10^{-4}$ \\
\hline
\end{tabular}

WIPP Air Blank

\begin{tabular}{llllll}
\hline 1 & AL-WAB-20000105 1.1 & $1.44 \times 10^{-3}$ & $4.99 \times 10^{-3}$ & $4.27 \times 10^{-2}$ & $1.96 \times 10^{-2}$ \\
2 & AL-WAB-20000112 1.1 & $4.42 \times 10^{-3}$ & $5.83 \times 10^{-3}$ & $4.37 \times 10^{-2}$ & $1.84 \times 10^{-2}$ \\
3 & AL-WAB-20000119 1.1 & $1.44 \times 10^{-3}$ & $4.05 \times 10^{-3}$ & $3.42 \times 10^{-2}$ & $1.70 \times 10^{-2}$ \\
4 & AL-WAB-20000126 1.1 & $7.30 \times 10^{-3}$ & $7.07 \times 10^{-3}$ & $4.40 \times 10^{-2}$ & $1.84 \times 10^{-2}$ \\
5 & AL-WAB-20000202 1.1 & $-1.99 \times 10^{-5}$ & $2.89 \times 10^{-3}$ & $2.77 \times 10^{-2}$ & $1.60 \times 10^{-2}$ \\
6 & AL-WAB-20000209 1.1 & $5.95 \times 10^{-3}$ & $6.55 \times 10^{-3}$ & $3.30 \times 10^{-2}$ & $1.67 \times 10^{-2}$ \\
7 & AL-WAB-20000216 1.1 & $7.44 \times 10^{-3}$ & $7.19 \times 10^{-3}$ & $3.52 \times 10^{-2}$ & $1.70 \times 10^{-2}$ \\
8 & AL-WAB-20000223 1.1 & $2.97 \times 10^{-3}$ & $5.06 \times 10^{-3}$ & $2.76 \times 10^{-2}$ & $1.59 \times 10^{-2}$ \\
9 & AL-WAB-20000301 1.1 & $1.46 \times 10^{-3}$ & $5.11 \times 10^{-3}$ & $4.52 \times 10^{-2}$ & $1.87 \times 10^{-2}$ \\
10 & AL-WAB-20000308 1.1 & $8.86 \times 10^{-3}$ & $7.73 \times 10^{-3}$ & $4.29 \times 10^{-2}$ & $1.83 \times 10^{-2}$ \\
11 & AL-WAB-20000315 1.1 & $-1.64 \times 10^{-3}$ & $5.19 \times 10^{-3}$ & $4.01 \times 10^{-3}$ & $1.12 \times 10^{-2}$
\end{tabular}


Table D.1, cont.

\begin{tabular}{|c|c|c|c|c|c|}
\hline \multirow[b]{2}{*}{ Week } & \multirow[b]{2}{*}{ Sample ID } & \multicolumn{2}{|c|}{ Gross Alpha } & \multicolumn{2}{|c|}{ Gross Beta } \\
\hline & & Concentration & $2 \times \mathrm{TPU}$ & Concentration & $2 \times \mathrm{TPU}$ \\
\hline 12 & AL-WAB-20000322 1.1 & $5.84 \times 10^{-3}$ & $7.08 \times 10^{-3}$ & $3.63 \times 10^{-2}$ & $1.88 \times 10^{-2}$ \\
\hline 13 & AL-WAB-20000329 1.1 & $2.89 \times 10^{-3}$ & $5.76 \times 10^{-3}$ & $3.43 \times 10^{-2}$ & $1.86 \times 10^{-2}$ \\
\hline 14 & AL-WAB-20000405 1.1 & $6.47 \times 10^{-3}$ & $5.72 \times 10^{-3}$ & $2.72 \times 10^{-2}$ & $1.50 \times 10^{-2}$ \\
\hline 15 & AL-WAB-20000412 1.1 & $7.29 \times 10^{-3}$ & $8.70 \times 10^{-3}$ & $5.18 \times 10^{-2}$ & $1.95 \times 10^{-2}$ \\
\hline 16 & AL-WAB-20000419 1.1 & $1.40 \times 10^{-3}$ & $6.45 \times 10^{-3}$ & $4.00 \times 10^{-2}$ & $1.79 \times 10^{-2}$ \\
\hline 17 & AL-WAB-20000426 1.1 & $7.43 \times 10^{-3}$ & $7.75 \times 10^{-3}$ & $2.52 \times 10^{-2}$ & $1.64 \times 10^{-2}$ \\
\hline 18 & AL-WAB-20000503 1.1 & $3.86 \times 10^{-3}$ & $4.41 \times 10^{-3}$ & $4.89 \times 10^{-2}$ & $1.82 \times 10^{-2}$ \\
\hline 19 & AL-WAB-20000510 1.1 & $1.88 \times 10^{-3}$ & $5.75 \times 10^{-3}$ & $3.89 \times 10^{-2}$ & $1.80 \times 10^{-2}$ \\
\hline 20 & AL-WAB-20000517 1.1 & $-6.25 \times 10^{-6}$ & $5.04 \times 10^{-3}$ & $3.83 \times 10^{-2}$ & $1.79 \times 10^{-2}$ \\
\hline 21 & AL-WAB-20000524 1.1 & $1.88 \times 10^{-3}$ & $5.75 \times 10^{-3}$ & $3.44 \times 10^{-2}$ & $1.74 \times 10^{-2}$ \\
\hline 22 & AL-WAB-20000531 1.1 & $5.94 \times 10^{-3}$ & $7.17 \times 10^{-3}$ & $3.54 \times 10^{-2}$ & $1.78 \times 10^{-2}$ \\
\hline 23 & AL-WAB-20000607 1.1 & $2.96 \times 10^{-3}$ & $5.84 \times 10^{-3}$ & $3.22 \times 10^{-2}$ & $1.74 \times 10^{-2}$ \\
\hline 24 & AL-WAB-20000614 1.1 & $7.24 \times 10^{-3}$ & $7.57 \times 10^{-3}$ & $2.83 \times 10^{-2}$ & $1.73 \times 10^{-2}$ \\
\hline 25 & AL-WAB-20000621 1.1 & $1.44 \times 10^{-3}$ & $4.92 \times 10^{-3}$ & $3.08 \times 10^{-2}$ & $1.66 \times 10^{-2}$ \\
\hline 26 & AL-WAB-20000628 1.1 & $2.89 \times 10^{-3}$ & $5.69 \times 10^{-3}$ & $4.17 \times 10^{-2}$ & $1.81 \times 10^{-2}$ \\
\hline 27 & AL-WAB-20000705 1.1 & $7.34 \times 10^{-3}$ & $6.49 \times 10^{-3}$ & $5.36 \times 10^{-2}$ & $1.86 \times 10^{-2}$ \\
\hline 28 & AL-WAB-20000712 1.1 & $4.13 \times 10^{-4}$ & $5.01 \times 10^{-3}$ & $4.85 \times 10^{-2}$ & $1.89 \times 10^{-2}$ \\
\hline 29 & AL-WAB-20000719 1.1 & $-1.06 \times 10^{-3}$ & $5.37 \times 10^{-3}$ & $3.52 \times 10^{-2}$ & $1.70 \times 10^{-2}$ \\
\hline 30 & AL-WAB-20000726 1.1 & $4.21 \times 10^{-4}$ & $5.02 \times 10^{-3}$ & $3.61 \times 10^{-2}$ & $1.71 \times 10^{-2}$ \\
\hline 31 & AL-WAB-20000802 1.1 & $4.85 \times 10^{-3}$ & $7.11 \times 10^{-3}$ & $5.61 \times 10^{-2}$ & $2.00 \times 10^{-2}$ \\
\hline 32 & AL-WAB-20000809 1.1 & $5.87 \times 10^{-3}$ & $5.79 \times 10^{-3}$ & $4.72 \times 10^{-2}$ & $1.77 \times 10^{-2}$ \\
\hline 33 & AL-WAB-20000816 1.1 & $5.77 \times 10^{-3}$ & $6.99 \times 10^{-3}$ & $4.07 \times 10^{-2}$ & $1.90 \times 10^{-2}$ \\
\hline 34 & AL-WAB-20000823 1.1 & $2.80 \times 10^{-3}$ & $6.31 \times 10^{-3}$ & $5.84 \times 10^{-2}$ & $1.96 \times 10^{-2}$ \\
\hline 35 & AL-WAB-20000830 1.1 & $5.71 \times 10^{-3}$ & $7.50 \times 10^{-3}$ & $4.82 \times 10^{-2}$ & $1.82 \times 10^{-2}$ \\
\hline 36 & AL-WAB-20000906 1.1 & $-2.94 \times 10^{-3}$ & $5.73 \times 10^{-3}$ & $2.80 \times 10^{-2}$ & $1.73 \times 10^{-2}$ \\
\hline 37 & AL-WAB-20000913 1.1 & $5.75 \times 10^{-3}$ & $7.51 \times 10^{-3}$ & $3.77 \times 10^{-2}$ & $1.78 \times 10^{-2}$ \\
\hline 38 & AL-WAB-20000920 1.1 & $-4.52 \times 10^{-6}$ & $4.04 \times 10^{-3}$ & $2.80 \times 10^{-2}$ & $1.52 \times 10^{-2}$ \\
\hline 39 & AL-WAB-20000927 1.1 & $2.84 \times 10^{-3}$ & $4.87 \times 10^{-3}$ & $4.24 \times 10^{-2}$ & $1.75 \times 10^{-2}$ \\
\hline 40 & AL-WAB-20001004 1.1 & $1.41 \times 10^{-3}$ & $3.97 \times 10^{-3}$ & $2.83 \times 10^{-2}$ & $1.54 \times 10^{-2}$ \\
\hline 41 & AL-WAB-20001011 1.1 & $1.39 \times 10^{-3}$ & $3.95 \times 10^{-3}$ & $5.67 \times 10^{-2}$ & $1.95 \times 10^{-2}$ \\
\hline 42 & AL-WAB-20001018 1.1 & $4.34 \times 10^{-3}$ & $5.75 \times 10^{-3}$ & $4.77 \times 10^{-2}$ & $1.89 \times 10^{-2}$ \\
\hline 43 & AL-WAB-20001025 1.1 & $8.77 \times 10^{-3}$ & $7.66 \times 10^{-3}$ & $3.84 \times 10^{-2}$ & $1.76 \times 10^{-2}$ \\
\hline 44 & AL-WAB-20001101 1.1 & $5.82 \times 10^{-3}$ & $6.45 \times 10^{-3}$ & $3.86 \times 10^{-2}$ & $1.76 \times 10^{-2}$ \\
\hline 45 & AL-WAB-20001108 1.1 & $7.39 \times 10^{-3}$ & $8.26 \times 10^{-3}$ & $3.87 \times 10^{-2}$ & $1.84 \times 10^{-2}$ \\
\hline 46 & AL-WAB-20001115 1.1 & $-3.00 \times 10^{-3}$ & $6.53 \times 10^{-3}$ & $2.15 \times 10^{-2}$ & $1.59 \times 10^{-2}$ \\
\hline 47 & AL-WAB-20001122 1.1 & $-4.49 \times 10^{-3}$ & $7.16 \times 10^{-3}$ & $2.84 \times 10^{-2}$ & $1.69 \times 10^{-2}$ \\
\hline 48 & AL-WAB-20001129 1.1 & $7.30 \times 10^{-3}$ & $7.06 \times 10^{-3}$ & $2.38 \times 10^{-2}$ & $1.55 \times 10^{-2}$ \\
\hline 49 & AL-WAB-20001206 1.1 & $7.28 \times 10^{-3}$ & $7.05 \times 10^{-3}$ & $4.38 \times 10^{-2}$ & $1.84 \times 10^{-2}$ \\
\hline 50 & AL-WAB-20001213 1.1 & $2.90 \times 10^{-3}$ & $4.96 \times 10^{-3}$ & $3.30 \times 10^{-2}$ & $1.68 \times 10^{-2}$ \\
\hline 51 & AL-WAB-20001220 1.1 & $4.36 \times 10^{-3}$ & $5.74 \times 10^{-3}$ & $3.18 \times 10^{-2}$ & $1.67 \times 10^{-2}$ \\
\hline 52 & AL-WAB-20001227 1.1 & $1.14 \times 10^{-3}$ & $4.07 \times 10^{-3}$ & $4.95 \times 10^{-2}$ & $1.84 \times 10^{-2}$ \\
\hline
\end{tabular}

WIPP East

\begin{tabular}{llllll}
\hline 1 & AL-WEE-20000105 1.1 & $5.40 \times 10^{-5}$ & $2.49 \times 10^{-5}$ & $9.50 \times 10^{-4}$ & $1.29 \times 10^{-4}$ \\
2 & AL-WEE-20000112 1.1 & $4.26 \times 10^{-5}$ & $2.22 \times 10^{-5}$ & $1.12 \times 10^{-3}$ & $1.47 \times 10^{-4}$ \\
3 & AL-WEE-20000119 1.1 & $1.45 \times 10^{-4}$ & $4.14 \times 10^{-5}$ & $1.42 \times 10^{-3}$ & $1.76 \times 10^{-4}$ \\
4 & AL-WEE-20000126 1.1 & $4.75 \times 10^{-5}$ & $2.15 \times 10^{-5}$ & $1.39 \times 10^{-3}$ & $1.69 \times 10^{-4}$
\end{tabular}


Table D.1, cont.

\begin{tabular}{|c|c|c|c|c|c|}
\hline \multirow[b]{2}{*}{ Week } & \multirow[b]{2}{*}{ Sample ID } & \multicolumn{2}{|c|}{ Gross Alpha } & \multicolumn{2}{|c|}{ Gross Beta } \\
\hline & & Concentration & $2 \times \mathrm{TPU}$ & Concentration & $2 \times \mathrm{TPU}$ \\
\hline 5 & AL-WEE-20000202 1.1 & $5.79 \times 10^{-5}$ & $2.50 \times 10^{-5}$ & $1.21 \times 10^{-3}$ & $1.54 \times 10^{-4}$ \\
\hline 6 & AL-WEE-20000209 1.1 & $6.58 \times 10^{-5}$ & $2.66 \times 10^{-5}$ & $8.91 \times 10^{-4}$ & $1.21 \times 10^{-4}$ \\
\hline 7 & AL-WEE-20000216 1.1 & $5.17 \times 10^{-5}$ & $2.45 \times 10^{-5}$ & $1.08 \times 10^{-3}$ & $1.42 \times 10^{-4}$ \\
\hline 8 & AL-WEE-20000223 1.1 & $3.25 \times 10^{-5}$ & $1.87 \times 10^{-5}$ & $5.96 \times 10^{-4}$ & $9.01 \times 10^{-5}$ \\
\hline 9 & AL-WEE-20000301 1.1 & $1.03 \times 10^{-4}$ & $3.66 \times 10^{-5}$ & $5.19 \times 10^{-4}$ & $8.68 \times 10^{-5}$ \\
\hline 10 & AL-WEE-20000308 1.1 & $4.14 \times 10^{-5}$ & $2.10 \times 10^{-5}$ & $8.61 \times 10^{-4}$ & $1.18 \times 10^{-4}$ \\
\hline 11 & AL-WEE-20000315 1.1 & $1.09 \times 10^{-5}$ & $1.28 \times 10^{-5}$ & $6.70 \times 10^{-4}$ & $9.94 \times 10^{-5}$ \\
\hline 12 & AL-WEE-20000322 1.1 & $5.87 \times 10^{-5}$ & $2.65 \times 10^{-5}$ & $6.99 \times 10^{-4}$ & $1.05 \times 10^{-4}$ \\
\hline 13 & AL-WEE-20000329 1.1 & $5.86 \times 10^{-5}$ & $2.43 \times 10^{-5}$ & $6.13 \times 10^{-4}$ & $9.06 \times 10^{-5}$ \\
\hline 14 & AL-WEE-20000405 1.1 & $9.36 \times 10^{-5}$ & $3.16 \times 10^{-5}$ & $7.11 \times 10^{-4}$ & $1.05 \times 10^{-4}$ \\
\hline 15 & AL-WEE-20000412 1.1 & $6.46 \times 10^{-5}$ & $2.84 \times 10^{-5}$ & $7.40 \times 10^{-4}$ & $1.07 \times 10^{-4}$ \\
\hline 16 & AL-WEE-20000419 1.1 & $4.37 \times 10^{-5}$ & $2.47 \times 10^{-5}$ & $5.78 \times 10^{-4}$ & $9.19 \times 10^{-5}$ \\
\hline 17 & AL-WEE-20000426 1.1 & $1.12 \times 10^{-4}$ & $3.89 \times 10^{-5}$ & $7.49 \times 10^{-4}$ & $1.13 \times 10^{-4}$ \\
\hline 18 & AL-WEE-20000503 1.1 & $7.78 \times 10^{-5}$ & $2.74 \times 10^{-5}$ & $1.09 \times 10^{-3}$ & $1.42 \times 10^{-4}$ \\
\hline 19 & AL-WEE-20000510 1.1 & $\mathrm{~N} / \mathrm{C}$ & $\mathrm{N} / \mathrm{C}$ & $\mathrm{N} / \mathrm{C}$ & $\mathrm{N} / \mathrm{C}$ \\
\hline 20 & AL-WEE-20000517 1.1 & $6.07 \times 10^{-5}$ & $2.77 \times 10^{-5}$ & $8.86 \times 10^{-4}$ & $1.24 \times 10^{-4}$ \\
\hline 21 & AL-WEE-20000524 1.1 & $6.57 \times 10^{-5}$ & $2.79 \times 10^{-5}$ & $9.20 \times 10^{-4}$ & $1.26 \times 10^{-4}$ \\
\hline 22 & AL-WEE-20000531 1.1 & $8.55 \times 10^{-5}$ & $3.23 \times 10^{-5}$ & $8.77 \times 10^{-4}$ & $1.23 \times 10^{-4}$ \\
\hline 23 & AL-WEE-20000607 1.1 & $7.72 \times 10^{-5}$ & $2.91 \times 10^{-5}$ & $8.79 \times 10^{-4}$ & $1.20 \times 10^{-4}$ \\
\hline 24 & AL-WEE-20000614 1.1 & $1.33 \times 10^{-4}$ & $3.96 \times 10^{-5}$ & $5.03 \times 10^{-4}$ & $8.31 \times 10^{-5}$ \\
\hline 25 & AL-WEE-20000621 1.1 & $1.42 \times 10^{-4}$ & $4.05 \times 10^{-5}$ & $7.12 \times 10^{-4}$ & $1.03 \times 10^{-4}$ \\
\hline 26 & AL-WEE-20000628 1.1 & $1.56 \times 10^{-4}$ & $4.30 \times 10^{-5}$ & $6.84 \times 10^{-4}$ & $1.01 \times 10^{-4}$ \\
\hline 27 & AL-WEE-20000705 1.1 & $1.78 \times 10^{-4}$ & $4.43 \times 10^{-5}$ & $8.51 \times 10^{-4}$ & $1.14 \times 10^{-4}$ \\
\hline 28 & AL-WEE-20000712 1.1 & $1.54 \times 10^{-4}$ & $4.32 \times 10^{-5}$ & $9.87 \times 10^{-4}$ & $1.32 \times 10^{-4}$ \\
\hline 29 & AL-WEE-20000719 1.1 & $8.99 \times 10^{-5}$ & $3.31 \times 10^{-5}$ & $9.12 \times 10^{-4}$ & $1.26 \times 10^{-4}$ \\
\hline 30 & AL-WEE-20000726 1.1 & $1.67 \times 10^{-4}$ & $4.31 \times 10^{-5}$ & $1.18 \times 10^{-3}$ & $1.48 \times 10^{-4}$ \\
\hline 31 & AL-WEE-20000802 1.1 & $7.04 \times 10^{-5}$ & $3.11 \times 10^{-5}$ & $7.73 \times 10^{-4}$ & $1.15 \times 10^{-4}$ \\
\hline 32 & AL-WEE-20000809 1.1 & $9.98 \times 10^{-5}$ & $3.60 \times 10^{-5}$ & $8.04 \times 10^{-4}$ & $1.18 \times 10^{-4}$ \\
\hline 33 & AL-WEE-20000816 1.1 & $1.19 \times 10^{-4}$ & $3.46 \times 10^{-5}$ & $7.83 \times 10^{-4}$ & $1.07 \times 10^{-4}$ \\
\hline 34 & AL-WEE-20000823 1.1 & $3.34 \times 10^{-5}$ & $2.06 \times 10^{-5}$ & $3.45 \times 10^{-4}$ & $6.44 \times 10^{-5}$ \\
\hline 35 & AL-WEE-20000830 1.1 & $8.68 \times 10^{-5}$ & $3.19 \times 10^{-5}$ & $1.12 \times 10^{-3}$ & $1.45 \times 10^{-4}$ \\
\hline 36 & AL-WEE-20000906 1.1 & $1.24 \times 10^{-4}$ & $3.80 \times 10^{-5}$ & $1.17 \times 10^{-3}$ & $1.51 \times 10^{-4}$ \\
\hline 37 & AL-WEE-20000913 1.1 & $9.54 \times 10^{-5}$ & $3.40 \times 10^{-5}$ & $1.36 \times 10^{-3}$ & $1.71 \times 10^{-4}$ \\
\hline 38 & AL-WEE-20000920 1.1 & $5.71 \times 10^{-5}$ & $2.50 \times 10^{-5}$ & $1.03 \times 10^{-3}$ & $1.34 \times 10^{-4}$ \\
\hline 39 & AL-WEE-20000927 1.1 & $1.12 \times 10^{-4}$ & $3.43 \times 10^{-5}$ & $1.17 \times 10^{-3}$ & $1.48 \times 10^{-4}$ \\
\hline 40 & AL-WEE-20001004 1.1 & $1.05 \times 10^{-4}$ & $3.33 \times 10^{-5}$ & $1.13 \times 10^{-3}$ & $1.44 \times 10^{-4}$ \\
\hline 41 & AL-WEE-20001011 1.1 & $5.56 \times 10^{-5}$ & $2.51 \times 10^{-5}$ & $6.15 \times 10^{-4}$ & $9.41 \times 10^{-5}$ \\
\hline 42 & AL-WEE-20001018 1.1 & $4.18 \times 10^{-5}$ & $2.11 \times 10^{-5}$ & $6.52 \times 10^{-4}$ & $9.65 \times 10^{-5}$ \\
\hline 43 & AL-WEE-20001025 1.1 & $7.68 \times 10^{-5}$ & $2.92 \times 10^{-5}$ & $7.49 \times 10^{-4}$ & $1.07 \times 10^{-4}$ \\
\hline 44 & AL-WEE-20001101 1.1 & $3.65 \times 10^{-5}$ & $1.90 \times 10^{-5}$ & $6.10 \times 10^{-4}$ & $9.01 \times 10^{-5}$ \\
\hline 45 & AL-WEE-20001108 1.1 & $1.51 \times 10^{-4}$ & $4.14 \times 10^{-5}$ & $1.34 \times 10^{-3}$ & $1.66 \times 10^{-4}$ \\
\hline 46 & AL-WEE-20001115 1.1 & $2.24 \times 10^{-4}$ & $5.52 \times 10^{-5}$ & $1.83 \times 10^{-3}$ & $2.20 \times 10^{-4}$ \\
\hline 47 & AL-WEE-20001122 1.1 & $1.68 \times 10^{-4}$ & $4.20 \times 10^{-5}$ & $1.73 \times 10^{-3}$ & $2.01 \times 10^{-4}$ \\
\hline 48 & AL-WEE-20001129 1.1 & $1.47 \times 10^{-4}$ & $4.16 \times 10^{-5}$ & $1.44 \times 10^{-3}$ & $1.78 \times 10^{-4}$ \\
\hline 49 & AL-WEE-20001206 1.1 & $1.09 \times 10^{-4}$ & $3.37 \times 10^{-5}$ & $1.32 \times 10^{-3}$ & $1.63 \times 10^{-4}$ \\
\hline 50 & AL-WEE-20001213 1.1 & $4.07 \times 10^{-5}$ & $2.11 \times 10^{-5}$ & $6.98 \times 10^{-4}$ & $1.02 \times 10^{-4}$ \\
\hline 51 & AL-WEE-20001220 1.1 & $4.31 \times 10^{-5}$ & $2.12 \times 10^{-5}$ & $1.15 \times 10^{-3}$ & $1.47 \times 10^{-4}$ \\
\hline 52 & AL-WEE-20001227 1.1 & $7.36 \times 10^{-5}$ & $2.87 \times 10^{-5}$ & $1.51 \times 10^{-3}$ & $1.86 \times 10^{-4}$ \\
\hline
\end{tabular}


Table D.1, cont.

\begin{tabular}{|c|c|c|c|c|c|}
\hline \multirow[b]{2}{*}{ Week } & \multirow[b]{2}{*}{ Sample ID } & \multicolumn{2}{|c|}{ Gross Alpha } & \multicolumn{2}{|c|}{ Gross Beta } \\
\hline & & Concentration & $2 \times$ TPU & Concentration & $2 \times$ TPU \\
\hline \multicolumn{6}{|c|}{ WIPP Far Field } \\
\hline 1 & AL-WFF-20000105 1.1 & $2.99 \times 10^{-5}$ & $1.80 \times 10^{-5}$ & $9.71 \times 10^{-4}$ & $1.28 \times 10^{-4}$ \\
\hline 2 & AL-WFF-20000112 1.1 & $5.72 \times 10^{-5}$ & $2.54 \times 10^{-5}$ & $1.30 \times 10^{-3}$ & $1.64 \times 10^{-4}$ \\
\hline 3 & AL-WFF-200001191.1 & $1.00 \times 10^{-4}$ & $3.36 \times 10^{-5}$ & $1.50 \times 10^{-3}$ & $1.84 \times 10^{-4}$ \\
\hline 4 & AL-WFF-20000126 1.1 & $5.29 \times 10^{-5}$ & $2.25 \times 10^{-5}$ & $1.50 \times 10^{-3}$ & $1.79 \times 10^{-4}$ \\
\hline 5 & AL-WFF-20000202 1.1 & $5.56 \times 10^{-5}$ & $2.46 \times 10^{-5}$ & $1.17 \times 10^{-3}$ & $1.50 \times 10^{-4}$ \\
\hline 6 & AL-WFF-20000209 1.1 & $8.86 \times 10^{-5}$ & $3.07 \times 10^{-5}$ & $8.75 \times 10^{-4}$ & $1.18 \times 10^{-4}$ \\
\hline 7 & AL-WFF-20000216 1.1 & $4.59 \times 10^{-5}$ & $2.23 \times 10^{-5}$ & $9.77 \times 10^{-4}$ & $1.30 \times 10^{-4}$ \\
\hline 8 & AL-WFF-20000223 1.1 & $2.20 \times 10^{-5}$ & $1.54 \times 10^{-5}$ & $6.12 \times 10^{-4}$ & $9.14 \times 10^{-5}$ \\
\hline 9 & AL-WFF-20000301 1.1 & $\mathrm{~N} / \mathrm{C}$ & $\mathrm{N} / \mathrm{C}$ & $\mathrm{N} / \mathrm{C}$ & $\mathrm{N} / \mathrm{C}$ \\
\hline 10 & AL-WFF-20000308 1.1 & $2.31 \times 10^{-5}$ & $1.64 \times 10^{-5}$ & $7.24 \times 10^{-4}$ & $1.06 \times 10^{-4}$ \\
\hline 11 & AL-WFF-20000315 1.1 & $7.75 \times 10^{-6}$ & $1.07 \times 10^{-5}$ & $5.32 \times 10^{-4}$ & $8.22 \times 10^{-5}$ \\
\hline 12 & AL-WFF-20000322 1.1 & $6.46 \times 10^{-5}$ & $2.74 \times 10^{-5}$ & $7.67 \times 10^{-4}$ & $1.10 \times 10^{-4}$ \\
\hline 13 & AL-WFF-20000329 1.1 & $3.43 \times 10^{-5}$ & $1.91 \times 10^{-5}$ & $6.09 \times 10^{-4}$ & $9.09 \times 10^{-5}$ \\
\hline 14 & AL-WFF-20000405 1.1 & $9.00 \times 10^{-5}$ & $3.08 \times 10^{-5}$ & $7.57 \times 10^{-4}$ & $1.10 \times 10^{-4}$ \\
\hline 15 & AL-WFF-20000412 1.1 & $7.05 \times 10^{-5}$ & $3.03 \times 10^{-5}$ & $6.61 \times 10^{-4}$ & $1.00 \times 10^{-4}$ \\
\hline 16 & AL-WFF-20000419 1.1 & $5.62 \times 10^{-5}$ & $2.53 \times 10^{-5}$ & $7.28 \times 10^{-4}$ & $1.03 \times 10^{-4}$ \\
\hline 17 & AL-WFF-20000426 1.1 & $1.30 \times 10^{-4}$ & $4.11 \times 10^{-5}$ & $7.48 \times 10^{-4}$ & $1.11 \times 10^{-4}$ \\
\hline 18 & AL-WFF-20000503 1.1 & $8.80 \times 10^{-5}$ & $2.91 \times 10^{-5}$ & $9.86 \times 10^{-4}$ & $1.30 \times 10^{-4}$ \\
\hline 19 & AL-WFF-20000510 1.1 & $1.17 \times 10^{-4}$ & $3.88 \times 10^{-5}$ & $7.93 \times 10^{-4}$ & $1.15 \times 10^{-4}$ \\
\hline 20 & AL-WFF-20000517 1.1 & $6.19 \times 10^{-5}$ & $2.76 \times 10^{-5}$ & $7.78 \times 10^{-4}$ & $1.12 \times 10^{-4}$ \\
\hline 21 & AL-WFF-20000524 1.1 & $7.21 \times 10^{-5}$ & $2.84 \times 10^{-5}$ & $8.77 \times 10^{-4}$ & $1.20 \times 10^{-4}$ \\
\hline 22 & AL-WFF-20000531 1.1 & $1.19 \times 10^{-4}$ & $3.80 \times 10^{-5}$ & $8.12 \times 10^{-4}$ & $1.15 \times 10^{-4}$ \\
\hline 23 & AL-WFF-20000607 1.1 & $8.11 \times 10^{-5}$ & $2.97 \times 10^{-5}$ & $7.41 \times 10^{-4}$ & $1.05 \times 10^{-4}$ \\
\hline 24 & AL-WFF-20000614 1.1 & $1.26 \times 10^{-4}$ & $3.86 \times 10^{-5}$ & $5.06 \times 10^{-4}$ & $8.36 \times 10^{-5}$ \\
\hline 25 & AL-WFF-20000621 1.1 & $1.44 \times 10^{-4}$ & $4.06 \times 10^{-5}$ & $6.73 \times 10^{-4}$ & $9.90 \times 10^{-5}$ \\
\hline 26 & AL-WFF-20000628 1.1 & $1.52 \times 10^{-4}$ & $4.25 \times 10^{-5}$ & $7.68 \times 10^{-4}$ & $1.10 \times 10^{-4}$ \\
\hline 27 & AL-WFF-20000705 1.1 & $1.24 \times 10^{-4}$ & $3.60 \times 10^{-5}$ & $8.09 \times 10^{-4}$ & $1.10 \times 10^{-4}$ \\
\hline 28 & AL-WFF-20000712 1.1 & $1.27 \times 10^{-4}$ & $3.98 \times 10^{-5}$ & $8.34 \times 10^{-4}$ & $1.18 \times 10^{-4}$ \\
\hline 29 & AL-WFF-20000719 1.1 & $1.38 \times 10^{-4}$ & $4.08 \times 10^{-5}$ & $9.69 \times 10^{-4}$ & $1.31 \times 10^{-4}$ \\
\hline 30 & AL-WFF-20000726 1.1 & $1.26 \times 10^{-4}$ & $3.63 \times 10^{-5}$ & $1.23 \times 10^{-3}$ & $1.52 \times 10^{-4}$ \\
\hline 31 & AL-WFF-20000802 1.1 & $6.74 \times 10^{-5}$ & $3.05 \times 10^{-5}$ & $8.04 \times 10^{-4}$ & $1.18 \times 10^{-4}$ \\
\hline 32 & AL-WFF-20000809 1.1 & $9.10 \times 10^{-5}$ & $3.39 \times 10^{-5}$ & $8.27 \times 10^{-4}$ & $1.19 \times 10^{-4}$ \\
\hline 33 & AL-WFF-20000816 1.1 & $1.10 \times 10^{-4}$ & $3.33 \times 10^{-5}$ & $8.07 \times 10^{-4}$ & $1.10 \times 10^{-4}$ \\
\hline 34 & AL-WFF-20000823 1.1 & $6.10 \times 10^{-5}$ & $2.68 \times 10^{-5}$ & $7.18 \times 10^{-4}$ & $1.04 \times 10^{-4}$ \\
\hline 35 & AL-WFF-20000830 1.1 & $1.15 \times 10^{-4}$ & $3.68 \times 10^{-5}$ & $1.15 \times 10^{-3}$ & $1.48 \times 10^{-4}$ \\
\hline 36 & AL-WFF-20000906 1.1 & $7.82 \times 10^{-5}$ & $2.84 \times 10^{-5}$ & $9.88 \times 10^{-4}$ & $1.29 \times 10^{-4}$ \\
\hline 37 & AL-WFF-20000913 1.1 & $5.29 \times 10^{-5}$ & $2.58 \times 10^{-5}$ & $1.28 \times 10^{-3}$ & $1.64 \times 10^{-4}$ \\
\hline 38 & AL-WFF-20000920 1.1 & $8.99 \times 10^{-5}$ & $3.15 \times 10^{-5}$ & $1.03 \times 10^{-3}$ & $1.34 \times 10^{-4}$ \\
\hline 39 & AL-WFF-20000927 1.1 & $1.12 \times 10^{-4}$ & $3.51 \times 10^{-5}$ & $1.16 \times 10^{-3}$ & $1.48 \times 10^{-4}$ \\
\hline 40 & AL-WFF-20001004 1.2 & $1.03 \times 10^{-4}$ & $3.36 \times 10^{-5}$ & $1.15 \times 10^{-3}$ & $1.47 \times 10^{-4}$ \\
\hline 41 & AL-WFF-20001011 1.2 & $3.58 \times 10^{-5}$ & $1.99 \times 10^{-5}$ & $6.31 \times 10^{-4}$ & $9.50 \times 10^{-5}$ \\
\hline 42 & AL-WFF-20001018 1.2 & $4.34 \times 10^{-5}$ & $2.13 \times 10^{-5}$ & $6.32 \times 10^{-4}$ & $9.38 \times 10^{-5}$ \\
\hline 43 & AL-WFF-20001025 1.2 & $6.93 \times 10^{-5}$ & $2.72 \times 10^{-5}$ & $6.42 \times 10^{-4}$ & $9.54 \times 10^{-5}$ \\
\hline 44 & AL-WFF-20001101 1.2 & $3.11 \times 10^{-5}$ & $1.81 \times 10^{-5}$ & $5.36 \times 10^{-4}$ & $8.37 \times 10^{-5}$ \\
\hline 45 & AL-WFF-20001108 1.2 & $1.49 \times 10^{-4}$ & $4.13 \times 10^{-5}$ & $1.23 \times 10^{-3}$ & $1.55 \times 10^{-4}$ \\
\hline 46 & AL-WFF-20001115 1.2 & $2.10 \times 10^{-4}$ & $5.40 \times 10^{-5}$ & $2.09 \times 10^{-3}$ & $2.47 \times 10^{-4}$ \\
\hline
\end{tabular}


Table D.1, cont.

\begin{tabular}{|c|c|c|c|c|c|}
\hline \multirow[b]{2}{*}{ Week } & \multirow[b]{2}{*}{ Sample ID } & \multicolumn{2}{|c|}{ Gross Alpha } & \multicolumn{2}{|c|}{ Gross Beta } \\
\hline & & Concentration & $2 \times \mathrm{TPU}$ & Concentration & $2 \times \mathrm{TPU}$ \\
\hline 47 & AL-WFF-20001122 1.2 & $1.59 \times 10^{-4}$ & $4.03 \times 10^{-5}$ & $1.02 \times 10^{-3}$ & $1.30 \times 10^{-4}$ \\
\hline 48 & AL-WFF-20001129 1.2 & $1.44 \times 10^{-4}$ & $4.00 \times 10^{-5}$ & $1.50 \times 10^{-3}$ & $1.82 \times 10^{-4}$ \\
\hline 49 & AL-WFF-20001206 1.2 & $9.65 \times 10^{-5}$ & $3.23 \times 10^{-5}$ & $1.15 \times 10^{-3}$ & $1.48 \times 10^{-4}$ \\
\hline 50 & AL-WFF-20001213 1.2 & $4.59 \times 10^{-5}$ & $2.18 \times 10^{-5}$ & $7.19 \times 10^{-4}$ & $1.03 \times 10^{-4}$ \\
\hline 51 & AL-WFF-20001220 1.2 & $7.02 \times 10^{-5}$ & $2.76 \times 10^{-5}$ & $1.19 \times 10^{-3}$ & $1.52 \times 10^{-4}$ \\
\hline 52 & AL-WFF-20001227 1.2 & $9.14 \times 10^{-5}$ & $3.08 \times 10^{-5}$ & $1.41 \times 10^{-3}$ & $1.72 \times 10^{-4}$ \\
\hline
\end{tabular}

\section{WIPP South}

\begin{tabular}{|c|c|c|c|c|c|}
\hline 1 & AL-WSS-20000105 1.1 & $\mathrm{~N} / \mathrm{C}$ & $\mathrm{N} / \mathrm{C}$ & $\mathrm{N} / \mathrm{C}$ & $\mathrm{N} / \mathrm{C}$ \\
\hline 2 & AL-WSS-20000112 1.1 & $4.67 \times 10^{-5}$ & $2.43 \times 10^{-5}$ & $9.68 \times 10^{-4}$ & $1.34 \times 10^{-4}$ \\
\hline 3 & AL-WSS-20000119 1.1 & $9.43 \times 10^{-5}$ & $3.28 \times 10^{-5}$ & $1.35 \times 10^{-3}$ & $1.69 \times 10^{-4}$ \\
\hline 4 & AL-WSS-20000126 1.1 & $7.08 \times 10^{-5}$ & $2.65 \times 10^{-5}$ & $1.43 \times 10^{-3}$ & $1.72 \times 10^{-4}$ \\
\hline 5 & AL-WSS-20000202 1.1 & $2.88 \times 10^{-5}$ & $1.74 \times 10^{-5}$ & $1.18 \times 10^{-3}$ & $1.50 \times 10^{-4}$ \\
\hline 6 & AL-WSS-20000209 1.1 & $6.92 \times 10^{-5}$ & $2.66 \times 10^{-5}$ & $8.36 \times 10^{-4}$ & $1.13 \times 10^{-4}$ \\
\hline 7 & AL-WSS-20000216 1.1 & $4.00 \times 10^{-5}$ & $2.14 \times 10^{-5}$ & $8.90 \times 10^{-4}$ & $1.22 \times 10^{-4}$ \\
\hline 8 & AL-WSS-20000223 1.1 & $4.29 \times 10^{-5}$ & $2.08 \times 10^{-5}$ & $6.61 \times 10^{-4}$ & $9.56 \times 10^{-5}$ \\
\hline 9 & AL-WSS-20000301 1.1 & $1.40 \times 10^{-4}$ & $4.07 \times 10^{-5}$ & $6.58 \times 10^{-4}$ & $9.79 \times 10^{-5}$ \\
\hline 10 & AL-WSS-20000308 1.1 & $2.69 \times 10^{-5}$ & $1.72 \times 10^{-5}$ & $8.34 \times 10^{-4}$ & $1.15 \times 10^{-4}$ \\
\hline 11 & AL-WSS-20000315 1.1 & $8.47 \times 10^{-6}$ & $1.20 \times 10^{-5}$ & $7.01 \times 10^{-4}$ & $1.03 \times 10^{-4}$ \\
\hline 12 & AL-WSS-20000322 1.1 & $4.35 \times 10^{-5}$ & $2.26 \times 10^{-5}$ & $7.64 \times 10^{-4}$ & $1.10 \times 10^{-4}$ \\
\hline 13 & AL-WSS-20000329 1.1 & $4.84 \times 10^{-5}$ & $2.24 \times 10^{-5}$ & $6.01 \times 10^{-4}$ & $9.01 \times 10^{-5}$ \\
\hline 14 & AL-WSS-20000405 1.1 & $1.08 \times 10^{-4}$ & $3.42 \times 10^{-5}$ & $6.83 \times 10^{-4}$ & $1.02 \times 10^{-4}$ \\
\hline 15 & AL-WSS-20000412 1.1 & $\mathrm{~N} / \mathrm{C}$ & $\mathrm{N} / \mathrm{C}$ & $\mathrm{N} / \mathrm{C}$ & $\mathrm{N} / \mathrm{C}$ \\
\hline 16 & AL-WSS-20000419 1.1 & $3.18 \times 10^{-5}$ & $2.42 \times 10^{-5}$ & $6.95 \times 10^{-4}$ & $1.10 \times 10^{-4}$ \\
\hline 17 & AL-WSS-20000426 1.1 & $1.38 \times 10^{-4}$ & $4.25 \times 10^{-5}$ & $6.89 \times 10^{-4}$ & $1.05 \times 10^{-4}$ \\
\hline 18 & AL-WSS-20000503 1.1 & $8.59 \times 10^{-5}$ & $2.91 \times 10^{-5}$ & $1.01 \times 10^{-3}$ & $1.33 \times 10^{-4}$ \\
\hline 19 & AL-WSS-20000510 1.1 & $1.36 \times 10^{-4}$ & $4.27 \times 10^{-5}$ & $8.06 \times 10^{-4}$ & $1.18 \times 10^{-4}$ \\
\hline 20 & AL-WSS-20000517 1.1 & $7.06 \times 10^{-5}$ & $2.90 \times 10^{-5}$ & $7.31 \times 10^{-4}$ & $1.06 \times 10^{-4}$ \\
\hline 21 & AL-WSS-20000524 1.1 & $1.01 \times 10^{-4}$ & $3.45 \times 10^{-5}$ & $8.67 \times 10^{-4}$ & $1.20 \times 10^{-4}$ \\
\hline 22 & AL-WSS-20000531 1.1 & $7.33 \times 10^{-5}$ & $2.97 \times 10^{-5}$ & $8.44 \times 10^{-4}$ & $1.19 \times 10^{-4}$ \\
\hline 23 & AL-WSS-20000607 1.1 & $8.08 \times 10^{-5}$ & $3.00 \times 10^{-5}$ & $9.14 \times 10^{-4}$ & $1.24 \times 10^{-4}$ \\
\hline 24 & AL-WSS-20000614 1.1 & $1.17 \times 10^{-4}$ & $3.69 \times 10^{-5}$ & $5.24 \times 10^{-4}$ & $8.51 \times 10^{-5}$ \\
\hline 25 & AL-WSS-20000621 1.1 & $1.42 \times 10^{-4}$ & $4.04 \times 10^{-5}$ & $6.92 \times 10^{-4}$ & $1.01 \times 10^{-4}$ \\
\hline 26 & AL-WSS-20000628 1.1 & $1.77 \times 10^{-4}$ & $4.62 \times 10^{-5}$ & $8.30 \times 10^{-4}$ & $1.16 \times 10^{-4}$ \\
\hline 27 & AL-WSS-20000705 1.1 & $2.03 \times 10^{-4}$ & $4.87 \times 10^{-5}$ & $9.42 \times 10^{-4}$ & $1.25 \times 10^{-4}$ \\
\hline 28 & AL-WSS-20000712 1.1 & $1.35 \times 10^{-4}$ & $3.94 \times 10^{-5}$ & $9.33 \times 10^{-4}$ & $1.26 \times 10^{-4}$ \\
\hline 29 & AL-WSS-20000719 1.1 & $1.13 \times 10^{-4}$ & $3.71 \times 10^{-5}$ & $9.48 \times 10^{-4}$ & $1.29 \times 10^{-4}$ \\
\hline 30 & AL-WSS-20000726 1.1 & $9.85 \times 10^{-5}$ & $3.23 \times 10^{-5}$ & $1.12 \times 10^{-3}$ & $1.42 \times 10^{-4}$ \\
\hline 31 & AL-WSS-20000802 1.1 & $6.60 \times 10^{-5}$ & $3.06 \times 10^{-5}$ & $7.70 \times 10^{-4}$ & $1.16 \times 10^{-4}$ \\
\hline 32 & AL-WSS-20000809 1.1 & $1.24 \times 10^{-4}$ & $4.05 \times 10^{-5}$ & $7.55 \times 10^{-4}$ & $1.12 \times 10^{-4}$ \\
\hline 33 & AL-WSS-20000816 1.1 & $1.28 \times 10^{-4}$ & $3.68 \times 10^{-5}$ & $8.05 \times 10^{-4}$ & $1.11 \times 10^{-4}$ \\
\hline 34 & AL-WSS-20000823 1.1 & $6.64 \times 10^{-5}$ & $2.80 \times 10^{-5}$ & $7.60 \times 10^{-4}$ & $1.09 \times 10^{-4}$ \\
\hline 35 & AL-WSS-20000830 1.1 & $8.68 \times 10^{-5}$ & $3.15 \times 10^{-5}$ & $1.06 \times 10^{-3}$ & $1.39 \times 10^{-4}$ \\
\hline 36 & AL-WSS-20000906 1.1 & $9.22 \times 10^{-5}$ & $3.25 \times 10^{-5}$ & $1.12 \times 10^{-3}$ & $1.47 \times 10^{-4}$ \\
\hline 37 & AL-WSS-20000913 1.1 & $6.40 \times 10^{-5}$ & $2.70 \times 10^{-5}$ & $1.28 \times 10^{-3}$ & $1.61 \times 10^{-4}$ \\
\hline 38 & AL-WSS-20000920 1.1 & $5.95 \times 10^{-5}$ & $2.55 \times 10^{-5}$ & $9.05 \times 10^{-4}$ & $1.21 \times 10^{-4}$ \\
\hline 39 & AL-WSS-20000927 1.1 & $1.37 \times 10^{-4}$ & $3.89 \times 10^{-5}$ & $1.12 \times 10^{-3}$ & $1.44 \times 10^{-4}$ \\
\hline 40 & AL-WSS-20001004 1.1 & $1.09 \times 10^{-4}$ & $3.50 \times 10^{-5}$ & $1.21 \times 10^{-3}$ & $1.54 \times 10^{-4}$ \\
\hline
\end{tabular}


Table D.1, cont.

\begin{tabular}{|c|c|c|c|c|c|}
\hline \multirow[b]{2}{*}{ Week } & \multirow[b]{2}{*}{ Sample ID } & \multicolumn{2}{|c|}{ Gross Alpha } & \multicolumn{2}{|c|}{ Gross Beta } \\
\hline & & Concentration & $2 \times$ TPU & Concentration & $2 \times \mathrm{TPU}$ \\
\hline 41 & AL-WSS-20001011 1.1 & $3.35 \times 10^{-5}$ & $1.94 \times 10^{-5}$ & $5.45 \times 10^{-4}$ & $8.60 \times 10^{-5}$ \\
\hline 42 & AL-WSS-20001018 1.1 & $8.13 \times 10^{-5}$ & $2.95 \times 10^{-5}$ & $6.55 \times 10^{-4}$ & $9.65 \times 10^{-5}$ \\
\hline 43 & AL-WSS-20001025 1.1 & $7.28 \times 10^{-5}$ & $2.76 \times 10^{-5}$ & $6.61 \times 10^{-4}$ & $9.68 \times 10^{-5}$ \\
\hline 44 & AL-WSS-20001101 1.1 & $4.23 \times 10^{-5}$ & $2.07 \times 10^{-5}$ & $5.47 \times 10^{-4}$ & $8.42 \times 10^{-5}$ \\
\hline 45 & AL-WSS-20001108 1.1 & $1.42 \times 10^{-4}$ & $3.96 \times 10^{-5}$ & $1.13 \times 10^{-3}$ & $1.44 \times 10^{-4}$ \\
\hline 46 & AL-WSS-20001115 1.1 & $2.05 \times 10^{-4}$ & $5.23 \times 10^{-5}$ & $1.83 \times 10^{-3}$ & $2.19 \times 10^{-4}$ \\
\hline 47 & AL-WSS-20001122 1.1 & $1.74 \times 10^{-4}$ & $4.41 \times 10^{-5}$ & $1.70 \times 10^{-3}$ & $2.01 \times 10^{-4}$ \\
\hline 48 & AL-WSS-20001129 1.1 & $1.22 \times 10^{-4}$ & $3.72 \times 10^{-5}$ & $1.44 \times 10^{-3}$ & $1.78 \times 10^{-4}$ \\
\hline 49 & AL-WSS-20001206 1.1 & $1.03 \times 10^{-4}$ & $3.28 \times 10^{-5}$ & $1.17 \times 10^{-3}$ & $1.49 \times 10^{-4}$ \\
\hline 50 & AL-WSS-20001213 1.1 & $5.90 \times 10^{-5}$ & $2.49 \times 10^{-5}$ & $7.34 \times 10^{-4}$ & $1.05 \times 10^{-4}$ \\
\hline 51 & AL-WSS-20001220 1.1 & $3.56 \times 10^{-5}$ & $1.99 \times 10^{-5}$ & $1.07 \times 10^{-3}$ & $1.40 \times 10^{-4}$ \\
\hline 52 & AL-WSS-20001227 1.1 & $1.11 \times 10^{-4}$ & $3.38 \times 10^{-5}$ & $1.45 \times 10^{-3}$ & $1.76 \times 10^{-4}$ \\
\hline
\end{tabular}

Duplicate Samples

\begin{tabular}{|c|c|c|c|c|c|}
\hline \multicolumn{6}{|c|}{ Smith Ranch (SMR) } \\
\hline 1 & AL-SMR-20000105 2.2 & $4.31 \times 10^{-5}$ & $2.38 \times 10^{-5}$ & $8.44 \times 10^{-4}$ & $1.22 \times 10^{-4}$ \\
\hline 2 & AL-SMR-20000112 2.2 & $5.53 \times 10^{-5}$ & $2.45 \times 10^{-5}$ & $1.13 \times 10^{-3}$ & $1.46 \times 10^{-4}$ \\
\hline 3 & AL-SMR-20000119 2.2 & $9.22 \times 10^{-5}$ & $3.16 \times 10^{-5}$ & $1.24 \times 10^{-3}$ & $1.56 \times 10^{-4}$ \\
\hline 4 & AL-SMR-20000126 2.2 & $7.36 \times 10^{-5}$ & $2.79 \times 10^{-5}$ & $1.25 \times 10^{-3}$ & $1.57 \times 10^{-4}$ \\
\hline 5 & AL-SMR-20000202 2.2 & $4.47 \times 10^{-5}$ & $2.19 \times 10^{-5}$ & $1.10 \times 10^{-3}$ & $1.42 \times 10^{-4}$ \\
\hline 6 & AL-SMR-20000209 2.2 & $7.01 \times 10^{-5}$ & $2.79 \times 10^{-5}$ & $8.50 \times 10^{-4}$ & $1.17 \times 10^{-4}$ \\
\hline 7 & AL-SMR-20000216 2.2 & $7.54 \times 10^{-5}$ & $2.90 \times 10^{-5}$ & $9.23 \times 10^{-4}$ & $1.25 \times 10^{-4}$ \\
\hline 8 & AL-SMR-20000223 2.2 & $5.05 \times 10^{-5}$ & $2.33 \times 10^{-5}$ & $6.13 \times 10^{-4}$ & $9.21 \times 10^{-5}$ \\
\hline 9 & AL-SMR-20000301 2.2 & $9.27 \times 10^{-5}$ & $3.30 \times 10^{-5}$ & $5.12 \times 10^{-4}$ & $8.30 \times 10^{-5}$ \\
\hline 10 & AL-SMR-20000308 2.2 & $4.19 \times 10^{-5}$ & $2.12 \times 10^{-5}$ & $7.45 \times 10^{-4}$ & $1.06 \times 10^{-4}$ \\
\hline 11 & AL-SMR-20000315 2.2 & $1.91 \times 10^{-5}$ & $1.59 \times 10^{-5}$ & $6.23 \times 10^{-4}$ & $9.49 \times 10^{-5}$ \\
\hline 12 & AL-SMR-20000322 2.2 & $5.66 \times 10^{-5}$ & $3.04 \times 10^{-5}$ & $9.20 \times 10^{-4}$ & $1.38 \times 10^{-4}$ \\
\hline 13 & AL-SMR-20000329 2.2 & $2.97 \times 10^{-5}$ & $1.80 \times 10^{-5}$ & $6.65 \times 10^{-4}$ & $9.69 \times 10^{-5}$ \\
\hline \multicolumn{6}{|c|}{ Carlsbad (CBD) } \\
\hline 14 & AL-CBD-20000405 2.2 & $1.05 \times 10^{-4}$ & $3.38 \times 10^{-5}$ & $6.79 \times 10^{-4}$ & $1.02 \times 10^{-4}$ \\
\hline 15 & AL-CBD-20000412 2.2 & $4.33 \times 10^{-5}$ & $2.37 \times 10^{-5}$ & $7.27 \times 10^{-4}$ & $1.05 \times 10^{-4}$ \\
\hline 16 & AL-CBD-20000419 2.2 & $1.90 \times 10^{-5}$ & $1.71 \times 10^{-5}$ & $6.83 \times 10^{-4}$ & $1.00 \times 10^{-4}$ \\
\hline 17 & AL-CBD-20000426 2.2 & $1.08 \times 10^{-4}$ & $3.60 \times 10^{-5}$ & $7.54 \times 10^{-4}$ & $1.09 \times 10^{-4}$ \\
\hline 18 & AL-CBD-20000503 2.2 & $9.18 \times 10^{-5}$ & $2.90 \times 10^{-5}$ & $9.67 \times 10^{-4}$ & $1.27 \times 10^{-4}$ \\
\hline 19 & AL-CBD-20000510 2.2 & $9.68 \times 10^{-5}$ & $3.37 \times 10^{-5}$ & $7.95 \times 10^{-4}$ & $1.13 \times 10^{-4}$ \\
\hline 20 & AL-CBD-20000517 2.2 & $4.66 \times 10^{-5}$ & $2.38 \times 10^{-5}$ & $7.96 \times 10^{-4}$ & $1.13 \times 10^{-4}$ \\
\hline 21 & AL-CBD-20000524 2.2 & $6.50 \times 10^{-5}$ & $2.76 \times 10^{-5}$ & $8.25 \times 10^{-4}$ & $1.15 \times 10^{-4}$ \\
\hline 22 & AL-CBD-200005312.2 & $8.44 \times 10^{-5}$ & $3.09 \times 10^{-5}$ & $7.98 \times 10^{-4}$ & $1.12 \times 10^{-4}$ \\
\hline 23 & AL-CBD-20000607 2.2 & $8.63 \times 10^{-5}$ & $3.16 \times 10^{-5}$ & $9.16 \times 10^{-4}$ & $1.25 \times 10^{-4}$ \\
\hline 24 & AL-CBD-20000614 2.2 & $1.26 \times 10^{-4}$ & $3.74 \times 10^{-5}$ & $5.26 \times 10^{-4}$ & $8.38 \times 10^{-5}$ \\
\hline 25 & AL-CBD-20000621 2.2 & $1.14 \times 10^{-4}$ & $3.59 \times 10^{-5}$ & $6.69 \times 10^{-4}$ & $9.87 \times 10^{-5}$ \\
\hline 26 & AL-CBD-20000628 2.2 & $1.42 \times 10^{-4}$ & $3.99 \times 10^{-5}$ & $7.77 \times 10^{-4}$ & $1.09 \times 10^{-4}$ \\
\hline \multicolumn{6}{|c|}{ South East Control (SEC) } \\
\hline 27 & AL-SEC-20000705 2.2 & $1.75 \times 10^{-4}$ & $4.60 \times 10^{-5}$ & $9.46 \times 10^{-4}$ & $1.27 \times 10^{-4}$ \\
\hline 28 & AL-SEC-20000712 2.2 & $1.59 \times 10^{-4}$ & $4.25 \times 10^{-5}$ & $1.02 \times 10^{-3}$ & $1.34 \times 10^{-4}$ \\
\hline 29 & AL-SEC-20000719 2.2 & $1.48 \times 10^{-4}$ & $4.22 \times 10^{-5}$ & $1.06 \times 10^{-3}$ & $1.39 \times 10^{-4}$ \\
\hline 30 & AL-SEC-20000726 2.2 & $1.46 \times 10^{-4}$ & $3.91 \times 10^{-5}$ & $1.17 \times 10^{-3}$ & $1.46 \times 10^{-4}$ \\
\hline 31 & AL-SEC-20000802 2.2 & $6.60 \times 10^{-5}$ & $3.06 \times 10^{-5}$ & $8.42 \times 10^{-4}$ & $1.23 \times 10^{-4}$ \\
\hline
\end{tabular}


Table D.1, cont.

\begin{tabular}{|c|c|c|c|c|c|}
\hline \multirow[b]{2}{*}{ Week } & \multirow[b]{2}{*}{ Sample ID } & \multicolumn{2}{|c|}{ Gross Alpha } & \multicolumn{2}{|c|}{ Gross Beta } \\
\hline & & Concentration & $2 \times \mathrm{TPU}$ & Concentration & $2 \times \mathrm{TPU}$ \\
\hline 32 & AL-SEC-20000809 2.2 & $1.02 \times 10^{-4}$ & $3.54 \times 10^{-5}$ & $9.35 \times 10^{-4}$ & $1.29 \times 10^{-4}$ \\
\hline 33 & AL-SEC-20000816 2.2 & $9.53 \times 10^{-5}$ & $3.08 \times 10^{-5}$ & $7.57 \times 10^{-4}$ & $1.05 \times 10^{-4}$ \\
\hline 34 & AL-SEC-20000823 2.2 & $4.48 \times 10^{-5}$ & $2.31 \times 10^{-5}$ & $8.03 \times 10^{-4}$ & $1.12 \times 10^{-4}$ \\
\hline 35 & AL-SEC-20000830 2.2 & $8.75 \times 10^{-5}$ & $3.18 \times 10^{-5}$ & $1.20 \times 10^{-3}$ & $1.53 \times 10^{-4}$ \\
\hline 36 & AL-SEC-20000906 2.2 & $1.17 \times 10^{-4}$ & $3.65 \times 10^{-5}$ & $1.18 \times 10^{-3}$ & $1.51 \times 10^{-4}$ \\
\hline 37 & AL-SEC-20000913 2.2 & $8.72 \times 10^{-5}$ & $3.16 \times 10^{-5}$ & $1.34 \times 10^{-3}$ & $1.68 \times 10^{-4}$ \\
\hline 38 & AL-SEC-20000920 2.2 & $8.59 \times 10^{-5}$ & $3.05 \times 10^{-5}$ & $9.77 \times 10^{-4}$ & $1.28 \times 10^{-4}$ \\
\hline 39 & AL-SEC-20000927 2.2 & $1.30 \times 10^{-4}$ & $3.96 \times 10^{-5}$ & $1.45 \times 10^{-3}$ & $1.80 \times 10^{-4}$ \\
\hline \multicolumn{6}{|c|}{ WIPP Far Field (WFF) } \\
\hline 40 & AL-WFF-20001004 2.2 & $1.12 \times 10^{-4}$ & $3.48 \times 10^{-5}$ & $1.27 \times 10^{-3}$ & $1.58 \times 10^{-4}$ \\
\hline 41 & AL-WFF-200010112.2 & $3.24 \times 10^{-5}$ & $1.88 \times 10^{-5}$ & $6.68 \times 10^{-4}$ & $9.81 \times 10^{-5}$ \\
\hline 42 & AL-WFF-20001018 2.2 & $6.13 \times 10^{-5}$ & $2.54 \times 10^{-5}$ & $6.34 \times 10^{-4}$ & $9.43 \times 10^{-5}$ \\
\hline 43 & AL-WFF-20001025 2.2 & $5.73 \times 10^{-5}$ & $2.48 \times 10^{-5}$ & $6.91 \times 10^{-4}$ & $1.01 \times 10^{-4}$ \\
\hline 44 & AL-WFF-200011012.2 & $2.43 \times 10^{-5}$ & $1.62 \times 10^{-5}$ & $4.94 \times 10^{-4}$ & $7.97 \times 10^{-5}$ \\
\hline 45 & AL-WFF-20001108 2.2 & $2.13 \times 10^{-4}$ & $4.97 \times 10^{-5}$ & $2.05 \times 10^{-3}$ & $2.36 \times 10^{-4}$ \\
\hline 46 & AL-WFF-20001115 2.2 & $2.62 \times 10^{-4}$ & $6.02 \times 10^{-5}$ & $1.95 \times 10^{-3}$ & $2.32 \times 10^{-4}$ \\
\hline 47 & AL-WFF-20001122 2.2 & $1.69 \times 10^{-4}$ & $4.18 \times 10^{-5}$ & $1.73 \times 10^{-3}$ & $2.01 \times 10^{-4}$ \\
\hline 48 & AL-WFF-20001129 2.2 & $1.31 \times 10^{-4}$ & $3.77 \times 10^{-5}$ & $1.48 \times 10^{-3}$ & $1.80 \times 10^{-4}$ \\
\hline 49 & AL-WFF-20001206 2.2 & $7.72 \times 10^{-5}$ & $2.80 \times 10^{-5}$ & $1.28 \times 10^{-3}$ & $1.58 \times 10^{-4}$ \\
\hline 50 & AL-WFF-200012132.2 & $6.30 \times 10^{-5}$ & $2.56 \times 10^{-5}$ & $8.42 \times 10^{-4}$ & $1.15 \times 10^{-4}$ \\
\hline 51 & AL-WFF-20001220 2.2 & $4.68 \times 10^{-5}$ & $2.24 \times 10^{-5}$ & $1.13 \times 10^{-3}$ & $1.45 \times 10^{-4}$ \\
\hline 52 & AL-WFF-20001227 2.2 & $7.71 \times 10^{-5}$ & $2.86 \times 10^{-5}$ & $1.61 \times 10^{-3}$ & $1.94 \times 10^{-4}$ \\
\hline
\end{tabular}

${ }^{a}$ Total propagated uncertainty

${ }^{\mathrm{b}}$ Not collected 
This page intentionally left blank. 


\section{Appendix E \\ Air Sampling Data: Mass and Volume of Composite Air Samples}

\begin{tabular}{|c|c|c|c|c|c|c|c|c|}
\hline Week & Mass & Volume & Mass & Volume & Mass & Volume & Mass & Volume \\
\hline & \multicolumn{2}{|c|}{ WIPP Far Field (WFF) } & \multicolumn{2}{|c|}{ WIPP East (WEE) } & \multicolumn{2}{|c|}{ WIPP South (WSS) } & \multicolumn{2}{|c|}{ Mills Ranch (MLR) } \\
\hline 1 & 10.1 & 625.468 & 15.4 & 566.676 & $\mathrm{~N} / \mathrm{C}^{\mathrm{a}}$ & $\mathrm{N} / \mathrm{C}$ & 12.8 & 591.196 \\
\hline 2 & 10.5 & 560.446 & 18.6 & 546.149 & 11.0 & 500.101 & 12.0 & 551.212 \\
\hline 3 & 9.4 & 563.840 & 14.8 & 551.867 & 11.4 & 554.397 & 13.8 & 534.076 \\
\hline 4 & 11.1 & 651.694 & 17.0 & 635.377 & 12.1 & 632.905 & 17.7 & 665.057 \\
\hline 5 & 5.6 & 571.669 & 15.4 & 573.827 & 10.1 & 594.422 & 8.6 & 556.783 \\
\hline 6 & 11.2 & 603.332 & 17.3 & 586.094 & 13.0 & 621.671 & 14.4 & 637.822 \\
\hline 7 & 11.8 & 580.202 & 19.8 & 543.191 & 15.7 & 554.605 & 19.5 & 567.378 \\
\hline 8 & 11.5 & 602.262 & 44.5 & 592.638 & 16.7 & 622.242 & 15.5 & 550.556 \\
\hline 9 & $\mathrm{~N} / \mathrm{C}$ & $\mathrm{N} / \mathrm{C}$ & 44.9 & 512.065 & 18.9 & 578.866 & 25.3 & 622.242 \\
\hline 10 & 6.7 & 555.386 & 12.1 & 592.954 & 9.3 & 584.014 & 10.2 & 630.458 \\
\hline 11 & 11.0 & 627.203 & 13.6 & 569.845 & 14.6 & 555.598 & 11.2 & 613.291 \\
\hline 12 & 6.9 & 559.243 & 7.3 & 542.035 & 7.1 & 559.574 & 10.7 & 621.722 \\
\hline 13 & 5.3 & 625.592 & 9.8 & 642.730 & 9.5 & 626.581 & 7.1 & 667.911 \\
\hline Total & 111.1 & 7126.337 & 250.5 & 7455.448 & 149.4 & 6984.976 & 178.8 & 7809.704 \\
\hline
\end{tabular}




\begin{tabular}{|c|c|c|c|c|c|c|c|c|}
\hline Week & Mass & Volume & Mass & Volume & Mass & Volume & Mass & Volume \\
\hline & \multicolumn{2}{|c|}{ Smith Ranch (SMR)\#1 } & \multicolumn{2}{|c|}{ Smith Ranch (SMR)\#2 } & \multicolumn{2}{|c|}{ Carlsbad (CBD) } & \multicolumn{2}{|c|}{ Southeast Control (SEC) } \\
\hline 1 & 17.2 & 560.113 & 14.8 & 506.117 & 12.0 & 558.249 & 8.8 & 605.476 \\
\hline 2 & 21.1 & 552.420 & 22.3 & 580.895 & 27.5 & 541.179 & 10.6 & 585.540 \\
\hline 3 & 22.4 & 594.052 & 20.5 & 582.974 & 21.6 & 568.348 & 12.1 & 612.279 \\
\hline 4 & 16.5 & 599.050 & 16.7 & 590.844 & 19.2 & 634.560 & 11.5 & 629.819 \\
\hline 5 & 12.6 & 585.540 & 14.1 & 580.202 & 13.8 & 571.081 & 6.4 & 598.677 \\
\hline 6 & 22.8 & 562.111 & 26.5 & 571.391 & 18.3 & 579.524 & 9.4 & 548.682 \\
\hline 7 & 33.7 & 558.448 & 27.7 & 570.184 & 26.3 & 603.989 & 13.4 & 585.136 \\
\hline 8 & 29.3 & 598.694 & 27.3 & 587.990 & 25.7 & 559.114 & 13.2 & 574.060 \\
\hline 9 & 49.2 & 564.819 & 47.8 & 567.672 & 27.8 & 556.592 & 17.9 & 632.905 \\
\hline 10 & 19.2 & 596.553 & 17.7 & 588.340 & 19.0 & 611.227 & 8.4 & 589.740 \\
\hline 11 & 56.0 & 537.387 & 55.0 & 560.981 & 21.5 & 585.832 & $\mathrm{~N} / \mathrm{C}$ & $\mathrm{N} / \mathrm{C}$ \\
\hline 12 & 18.4 & 428.479 & 18.6 & 405.364 & 10.8 & 551.212 & 8.8 & 599.416 \\
\hline 13 & 23.6 & 643.744 & 15.4 & 621.426 & 9.8 & 565.215 & 8.9 & 672.152 \\
\hline Total & 342.0 & 7381.410 & 324.4 & 7314.380 & 253.3 & 7486.122 & 129.4 & 7233.882 \\
\hline
\end{tabular}


Table E.2 Mass (mg) of air particulates and volume $\left(\mathrm{m}^{3}\right)$ of air sampled (second quarter of 2000).

\begin{tabular}{|c|c|c|c|c|c|c|c|c|}
\hline Week & Mass & Volume & Mass & Volume & Mass & Volume & Mass & Volume \\
\hline & \multicolumn{2}{|c|}{ Far Field (WFF) } & \multicolumn{2}{|c|}{ WIPP East (WEE) } & \multicolumn{2}{|c|}{ WIPP South (WSS) } & \multicolumn{2}{|c|}{ Mills Ranch (MLR) } \\
\hline 14 & 9.3 & 516.275 & 11.8 & 510.298 & 10.2 & 512.751 & 10.5 & 506.217 \\
\hline 15 & 9.4 & 535.015 & 13.0 & 559.544 & $\mathrm{~N} / \mathrm{C}^{\mathrm{a}}$ & $\mathrm{N} / \mathrm{C}$ & 14.1 & 561.966 \\
\hline 16 & 11.8 & 615.140 & 13.1 & 527.106 & 8.1 & 444.632 & 7.4 & 632.118 \\
\hline 17 & 11.1 & 512.554 & 11.1 & 488.700 & 11.8 & 507.019 & 11.2 & 493.573 \\
\hline 18 & 14.1 & 571.053 & 16.0 & 561.778 & 16.5 & 554.936 & 17.4 & 548.682 \\
\hline 19 & 17.9 & 514.797 & $\mathrm{~N} / \mathrm{C}$ & $\mathrm{N} / \mathrm{C}$ & 20.2 & 497.107 & 25.3 & 580.259 \\
\hline 20 & 8.7 & 550.228 & 14.7 & 536.293 & 12.7 & 565.828 & 14.9 & 631.931 \\
\hline 21 & 11.2 & 591.196 & 13.2 & 559.447 & 13.2 & 555.930 & 14.2 & 547.051 \\
\hline 22 & 8.3 & 547.771 & 8.9 & 536.935 & 11.1 & 545.226 & 11.2 & 586.943 \\
\hline 23 & 8.1 & 603.337 & 8.7 & 594.759 & 10.9 & 586.529 & 15.3 & 611.762 \\
\hline 24 & 7.3 & 550.921 & 8.9 & 554.054 & 11.4 & 556.852 & 13.9 & 547.239 \\
\hline 25 & 8.7 & 574.060 & 11.5 & 570.864 & 10.6 & 571.204 & 12.5 & 571.204 \\
\hline 26 & 9.3 & 554.397 & 9.1 & 558.249 & 10.6 & 556.924 & 13.3 & 549.008 \\
\hline \multirow[t]{2}{*}{ Total } & 135.2 & 7236.744 & 140.0 & 6558.027 & 147.3 & 6454.938 & 181.2 & 6861.736 \\
\hline & \multicolumn{2}{|c|}{ Smith Ranch (SMR) } & \multicolumn{2}{|c|}{ Carlsbad (CBD)\#1 } & \multicolumn{2}{|c|}{ Carlsbad (CBD)\#2 } & \multicolumn{2}{|c|}{ Southeast Control (SEC) } \\
\hline 14 & 20.3 & 545.204 & 18.2 & 534.222 & 14.6 & 505.028 & 21.7 & 522.927 \\
\hline 15 & 24.7 & 613.230 & 18.8 & 610.097 & 17.7 & 561.632 & 14.5 & 581.588 \\
\hline 16 & $\mathrm{~N} / \mathrm{C}$ & $\mathrm{N} / \mathrm{C}$ & 18.7 & 571.768 & 20.8 & 577.776 & 16.9 & 597.266 \\
\hline 17 & 18.4 & 415.338 & 17.5 & 511.698 & 20.8 & 549.069 & 16.1 & 562.301 \\
\hline 18 & 27.9 & 592.450 & 25.7 & 601.545 & 28.1 & 603.675 & $\mathrm{~N} / \mathrm{C}$ & $\mathrm{N} / \mathrm{C}$ \\
\hline 19 & 44.5 & 585.900 & 30.5 & 526.163 & 40.1 & 562.600 & 23.0 & 513.091 \\
\hline 20 & 24.0 & 583.668 & 21.2 & 585.290 & 23.4 & 570.824 & 16.2 & 585.054 \\
\hline 21 & 25.4 & 616.533 & 22.6 & 583.790 & 23.2 & 566.107 & 13.4 & 590.518 \\
\hline 22 & 17.2 & 562.301 & 15.8 & 579.865 & 20.6 & 579.865 & 9.2 & 584.600 \\
\hline 23 & 21.8 & 597.618 & 16.6 & 585.890 & 18.3 & 566.319 & 10.4 & 595.488 \\
\hline 24 & 8.3 & 444.773 & 17.5 & 559.100 & 21.2 & 586.984 & 11.2 & 605.075 \\
\hline 25 & 17.8 & 557.918 & 18.2 & 569.700 & 18.4 & 572.563 & 11.3 & 590.493 \\
\hline 26 & 14.4 & 596.553 & 14.1 & 587.640 & 15.2 & 590.493 & 8.5 & 568.961 \\
\hline Total & 264.7 & 6711.486 & 255.4 & 7406.768 & 282.4 & 7392.935 & 172.4 & 6897.362 \\
\hline
\end{tabular}

${ }^{\mathrm{a}}$ Not collected 
Table E.3. Mass (mg) of air particulates and volume $\left(\mathrm{m}^{3}\right)$ of air sampled (third quarter of 2000).

\begin{tabular}{|c|c|c|c|c|c|c|c|c|}
\hline Week & Mass & Volume & Mass & Volume & Mass & Volume & Mass & Volume \\
\hline & \multicolumn{2}{|c|}{ Far Field (WFF) } & \multicolumn{2}{|c|}{ WIPP East (WEE) } & \multicolumn{2}{|c|}{ WIPP South (WSS) } & \multicolumn{2}{|c|}{ Mills Ranch (MLR) } \\
\hline 27 & 11.2 & 615.373 & 12.4 & 611.368 & 12.0 & 586.267 & 13.1 & 599.958 \\
\hline 28 & 9.7 & 537.045 & 14.1 & 559.423 & 14.1 & 584.225 & 14.8 & 567.690 \\
\hline 29 & 11.8 & 559.114 & 15.9 & 544.851 & 14.0 & 550.228 & 13.1 & 538.824 \\
\hline 30 & 11.7 & 648.140 & 12.9 & 622.084 & 13.8 & 631.855 & 13.9 & 638.036 \\
\hline 31 & 7.0 & 486.437 & 8.7 & 486.774 & 10.0 & 474.481 & 11.9 & 489.232 \\
\hline 32 & 9.4 & 483.410 & 10.6 & 470.874 & 12.1 & 473.314 & 12.4 & 467.782 \\
\hline 33 & 10.3 & 644.689 & 11.7 & 653.288 & 11.9 & 621.543 & 15.6 & 637.370 \\
\hline 34 & 7.8 & 559.243 & 4.2 & 553.933 & 9.6 & 556.592 & 10.3 & 570.714 \\
\hline 35 & 11.5 & 558.115 & 10.3 & 555.598 & 19.4 & 572.694 & 12.6 & 555.598 \\
\hline 36 & 12.8 & 622.405 & 14.8 & 557.034 & 15.3 & 559.574 & 7.8 & 585.484 \\
\hline 37 & 9.4 & 533.418 & 10.0 & 537.708 & 12.5 & 575.543 & 13.2 & 557.918 \\
\hline 38 & 13.6 & 581.241 & 16.0 & 584.439 & 18.2 & 585.136 & 16.7 & 585.832 \\
\hline 39 & 9.3 & 573.419 & 10.6 & 599.611 & 12.9 & 583.900 & 13.2 & 556.924 \\
\hline \multirow[t]{2}{*}{ Total } & 135.5 & 7402.049 & 152.2 & 7336.985 & 175.8 & 7355.352 & 168.6 & 7351.362 \\
\hline & \multicolumn{2}{|c|}{ Smith Ranch (SMR) } & \multicolumn{2}{|c|}{ Carlsbad (CBD) } & \multicolumn{2}{|c|}{ South East (SEC)\#1 } & \multicolumn{2}{|c|}{ South East (SEC)\#2 } \\
\hline 27 & 15.3 & 546.653 & 14.6 & 532.314 & 13.4 & 574.772 & 12.8 & 546.473 \\
\hline 28 & 17.0 & 574.690 & 20.1 & 576.462 & 13.9 & 588.031 & 14.6 & 604.912 \\
\hline 29 & 21.3 & 544.526 & 26.4 & 536.932 & 15.7 & 567.333 & 15.7 & 561.632 \\
\hline 30 & 19.6 & 653.775 & 25.5 & 606.747 & 16.0 & 665.437 & 15.7 & 658.689 \\
\hline 31 & 15.2 & 477.079 & 17.6 & 482.307 & 8.7 & 486.828 & 7.7 & 474.281 \\
\hline 32 & 13.5 & 501.662 & 20.3 & 495.857 & 12.4 & 487.314 & 12.4 & 502.004 \\
\hline 33 & 16.7 & 646.055 & 23.1 & 661.168 & 9.2 & 620.461 & 11.9 & 650.037 \\
\hline 34 & 14.5 & 549.572 & 24.6 & 557.950 & 7.9 & 550.347 & 8.6 & 565.640 \\
\hline 35 & 15.7 & 584.707 & 18.4 & 553.179 & 11.3 & 547.126 & 13.2 & 566.666 \\
\hline 36 & 24.2 & 555.267 & 28.0 & 558.115 & 17.2 & 558.285 & 18.1 & 566.786 \\
\hline 37 & 19.9 & 587.290 & 26.0 & 562.301 & 15.9 & 594.947 & 15.7 & 571.170 \\
\hline 38 & 24.1 & 597.618 & 28.7 & 581.377 & 17.5 & 576.980 & 16.1 & 591.405 \\
\hline 39 & 18.2 & 534.650 & 33.3 & 562.938 & 12.1 & 550.816 & 12.0 & 526.354 \\
\hline Total & 235.2 & 7353.544 & 306.6 & 7267.647 & 171.2 & 7368.677 & 174.5 & 7386.049 \\
\hline
\end{tabular}


Table E.4. Mass (mg) of air particulates and volume $\left(\mathrm{m}^{3}\right)$ of air sampled (fourth quarter of 2000).

\begin{tabular}{|c|c|c|c|c|c|c|c|c|}
\hline & Mass & Volume & Mass & Volume & Mass & Volume & Mass & Volume \\
\hline Week & \multicolumn{2}{|c|}{ WIPP Far Field (WFF)\#1 } & \multicolumn{2}{|c|}{ WIPP Far Field (WFF)\#2 } & \multicolumn{2}{|c|}{ WIPP East (WEE) } & \multicolumn{2}{|c|}{ WIPP South (WSS) } \\
\hline 40 & 7.9 & 569.462 & 9.1 & 584.696 & 8.9 & 597.241 & 9.8 & 560.786 \\
\hline 41 & 6.2 & 554.265 & 8.3 & 566.929 & 3.1 & 539.145 & 7.3 & 530.881 \\
\hline 42 & 6.2 & 596.908 & 5.3 & 590.844 & 6.6 & 584.091 & 7.1 & 589.437 \\
\hline 43 & 6.2 & 586.180 & 5.9 & 579.427 & 5.8 & 566.165 & 5.3 & 597.618 \\
\hline 44 & 1.5 & 599.039 & 2.4 & 587.574 & 2.6 & 628.445 & 4.3 & 614.097 \\
\hline 45 & 3.3 & 601.903 & 3.8 & 621.501 & 3.5 & 605.836 & 3.7 & 622.983 \\
\hline 46 & 6.2 & 504.341 & 5.1 & 523.564 & 5.4 & 520.032 & 5.2 & 524.915 \\
\hline 47 & 6.7 & 687.582 & 6.6 & 680.354 & 5.4 & 671.988 & 7.4 & 626.646 \\
\hline 48 & 9.9 & 591.899 & 10.2 & 597.618 & 9.1 & 553.408 & 10.9 & 568.010 \\
\hline 49 & 5.1 & 584.787 & 5.9 & 615.799 & 6.9 & 612.948 & 6.9 & 607.246 \\
\hline 50 & 8.5 & 596.553 & 8.9 & 596.553 & 6.7 & 565.828 & 11.2 & 588.690 \\
\hline 51 & 6.9 & 574.401 & 8.9 & 580.117 & 9.0 & 596.198 & 9.0 & 559.447 \\
\hline 52 & 8.6 & 618.281 & 9.3 & 597.980 & 8.8 & 566.995 & 9.2 & 630.567 \\
\hline \multirow[t]{2}{*}{ Total } & 83.2 & 7665.6 & 89.7 & 7723.0 & 81.8 & 7608.3 & 97.3 & 7621.3 \\
\hline & \multicolumn{2}{|c|}{ Mills Ranch (MLR) } & \multicolumn{2}{|c|}{ Smith Ranch (SMR) } & \multicolumn{2}{|c|}{ Carlsbad (CBD) } & \multicolumn{2}{|c|}{ Southeast Control (SEC) } \\
\hline 40 & 10.3 & 577.477 & 14.3 & 596.111 & 5.8 & 584.840 & 11.4 & 572.101 \\
\hline 41 & 8.3 & 563.815 & 9.6 & 580.462 & 10.0 & 586.787 & 4.9 & 565.492 \\
\hline 42 & 6.6 & 577.702 & 6.8 & 541.352 & 7.1 & 549.783 & 4.3 & 592.992 \\
\hline 43 & 6.5 & 610.046 & 8.8 & 619.469 & 10.2 & 556.045 & 5.2 & 597.232 \\
\hline 44 & 5.9 & 609.433 & 3.9 & 592.251 & 7.3 & 585.190 & 3.8 & 605.116 \\
\hline 45 & 3.0 & 579.772 & 4.7 & 579.772 & 10.5 & 616.966 & 3.1 & 586.877 \\
\hline 46 & 6.0 & 512.350 & 4.6 & 507.824 & 10.2 & 485.914 & 4.3 & 517.230 \\
\hline 47 & 9.7 & 662.547 & 8.0 & 658.254 & 13.9 & 690.120 & 6.5 & 699.155 \\
\hline 48 & $\mathrm{~N} / \mathrm{C}^{\mathrm{a}}$ & $\mathrm{N} / \mathrm{C}$ & 10.6 & 552.948 & 15.3 & 582.628 & 10.5 & 590.440 \\
\hline 49 & 6.5 & 586.940 & 7.9 & 590.141 & 10.8 & 572.352 & 8.9 & 593.357 \\
\hline 50 & 10.7 & 577.602 & 36.3 & 566.165 & 22.8 & 576.641 & 10.2 & 592.190 \\
\hline 51 & 8.4 & 590.493 & $\mathrm{~N} / \mathrm{C}$ & $\mathrm{N} / \mathrm{C}$ & 14.3 & 602.904 & 8.8 & 579.162 \\
\hline 52 & 8.9 & 634.872 & 9.4 & 619.756 & 11.1 & 604.045 & 7.2 & 600.121 \\
\hline Total & 90.8 & 7083.0 & 124.9 & 7004.5 & 149.3 & 7594.2 & 89.1 & 7691.5 \\
\hline
\end{tabular}

${ }^{\mathrm{a}}$ Not collected 
This page intentionally left blank. 


\section{Appendix F}

\section{Time Trend Plots for Detectable Constituents in Groundwater}

The figures in this appendix show the concentrations of various groundwater constituents relative to a baseline concentration and are in a form required by NMED and the Hazardous Waste Facility Permit. Baseline concentrations were measured from 1995 through 1997. Sampling round 10 occurred in March - May 2001 and sampling round 11 occurred in September -November 2001. See Chapter 6 for more information about groundwater sampling.

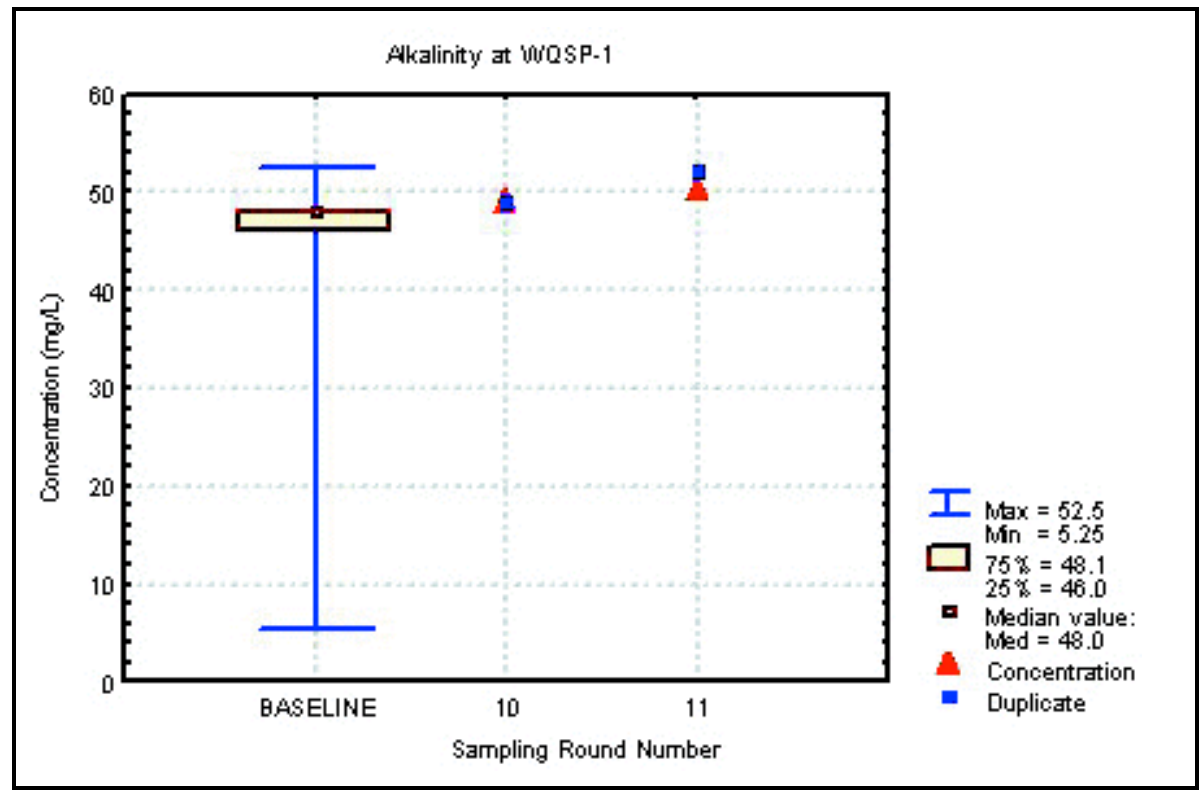

Figure F.1 Time Trend Plot for Alkalinity at WQSP-1 


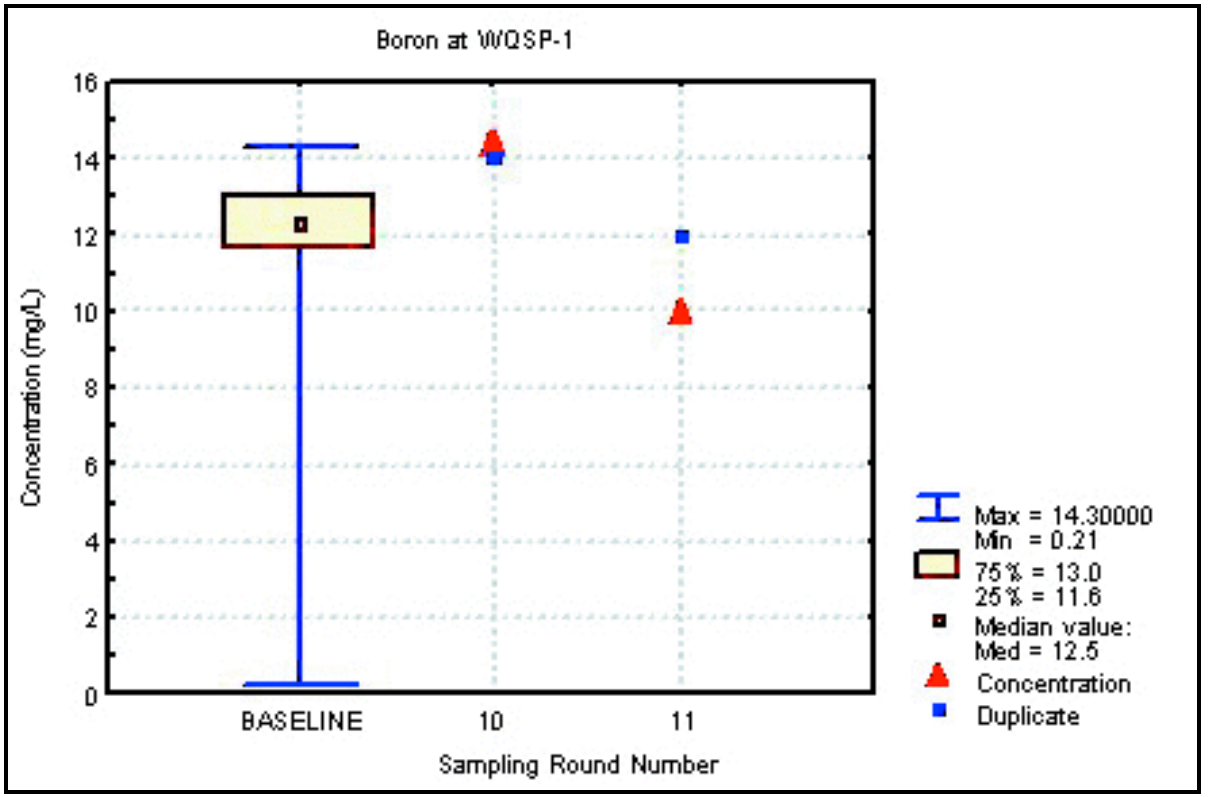

Figure F.2 Time Trend Plot for Boron at WQSP-1

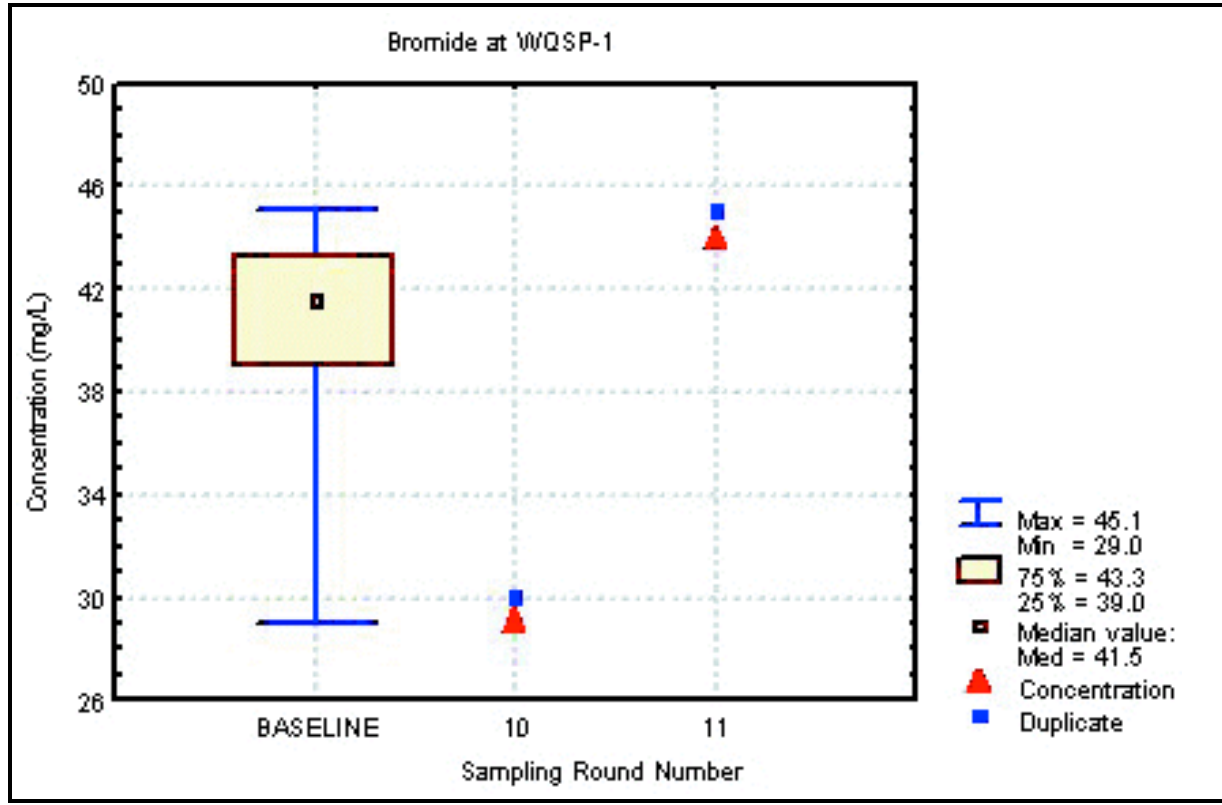

Figure F.3 Time Trent Plot for Bromide at WQSP-1 


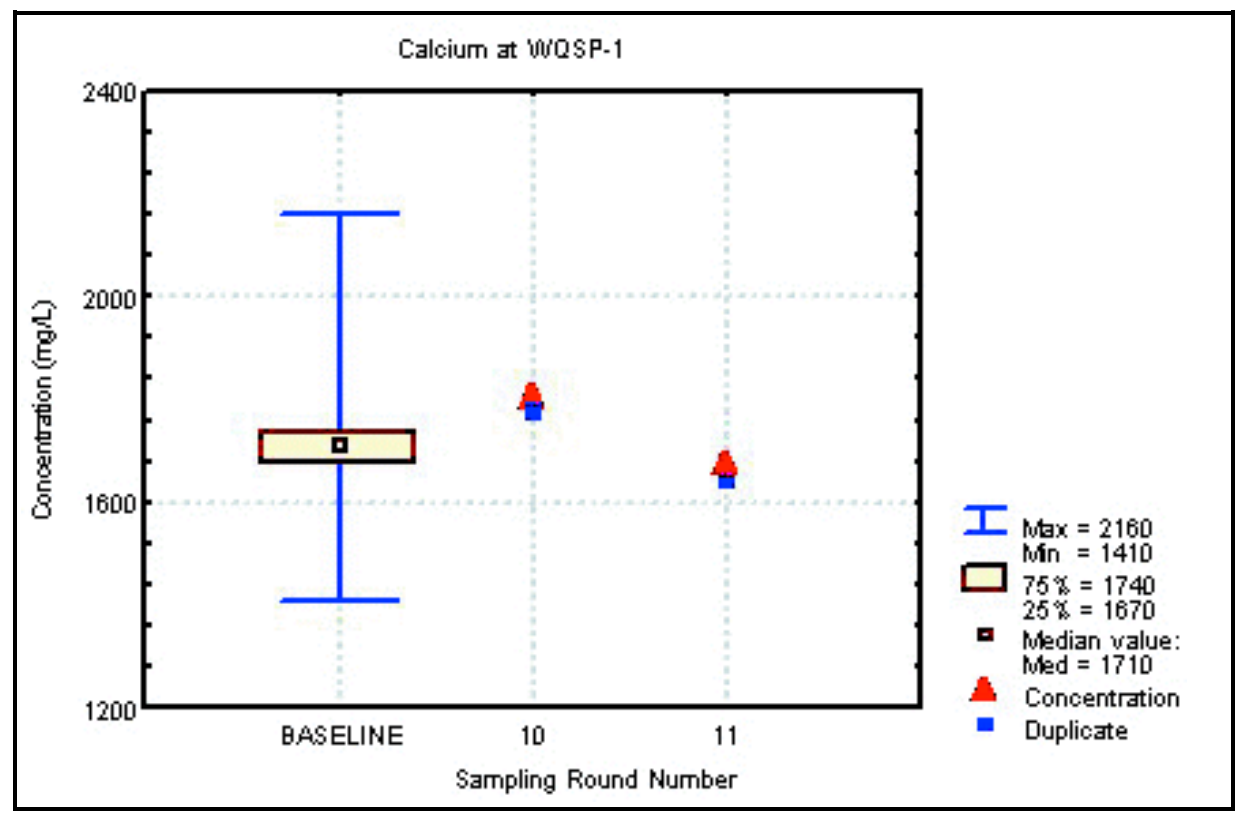

Figure F.4 Time Trend Plot for Calcium at WQSP-1

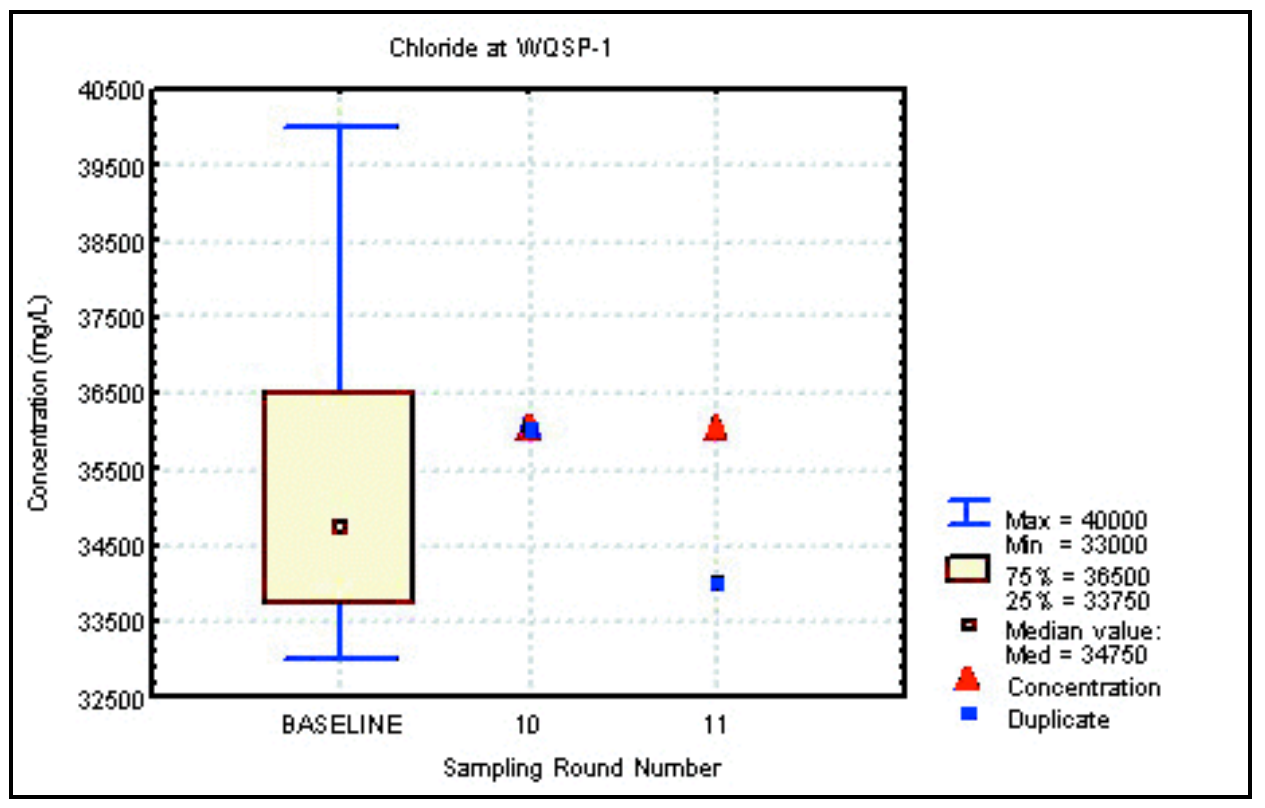

Figure F.5 Time Trent Plot for Chloride at WQSP-1 


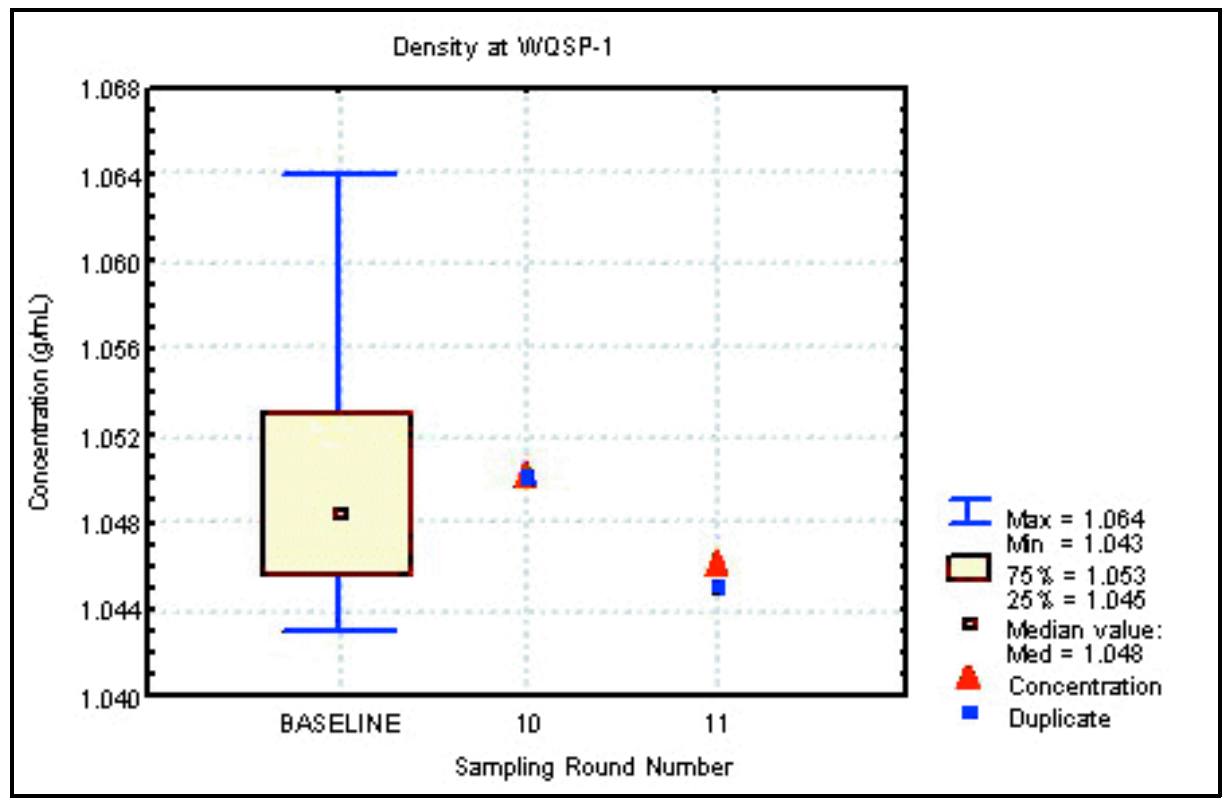

Figure F.6 Time Trend Plot for Density at WQSP-1

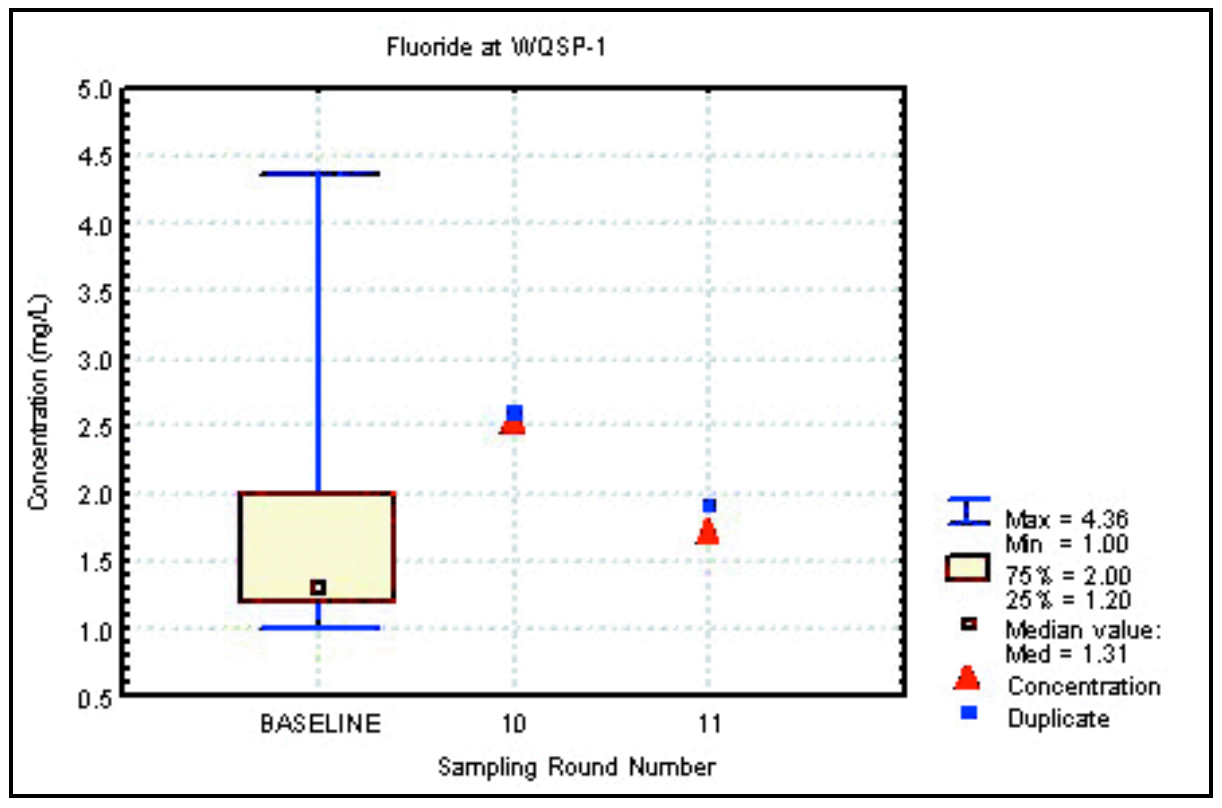

Figure F.7 Time Trent Plot for Fluoride at WQSP-1 


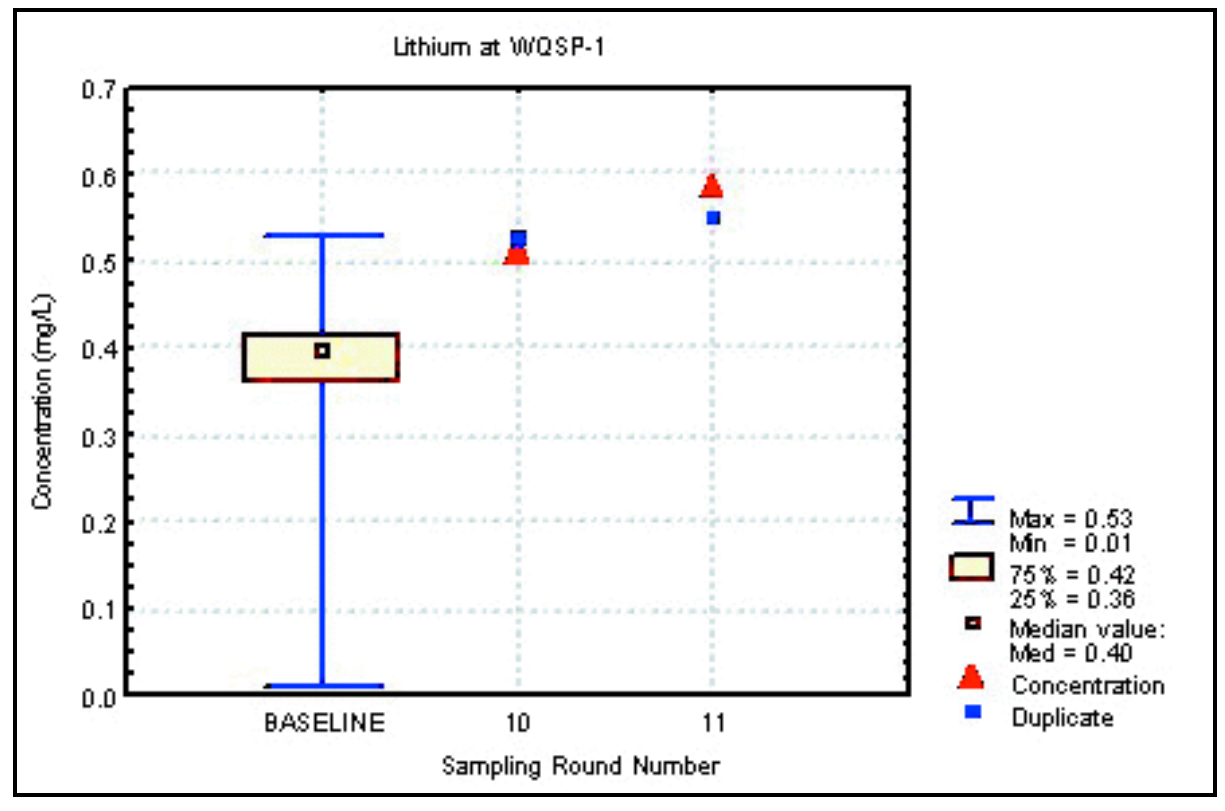

Figure F.8 Time Trend Plot for Lithium at WQSP-1

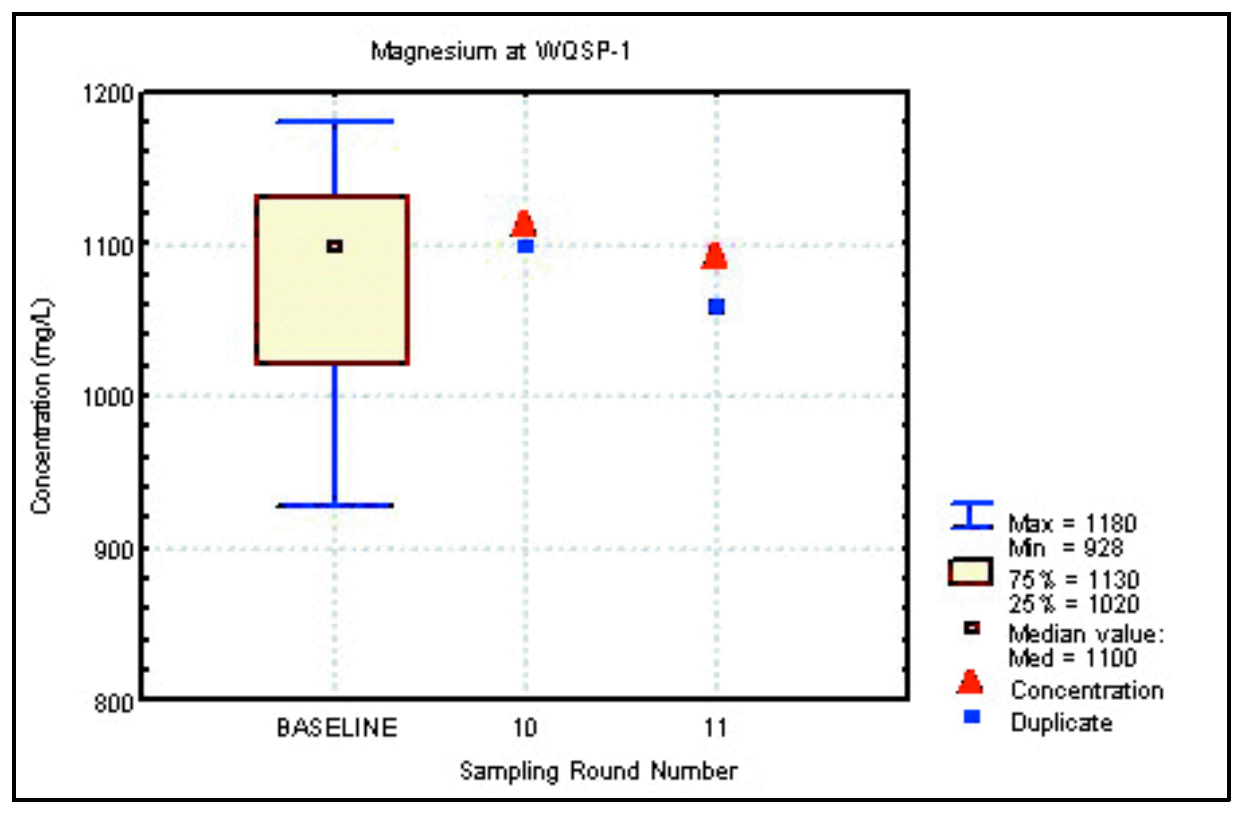

Figure F.9 Time Trent Plot for Magnesium at WQSP-1 


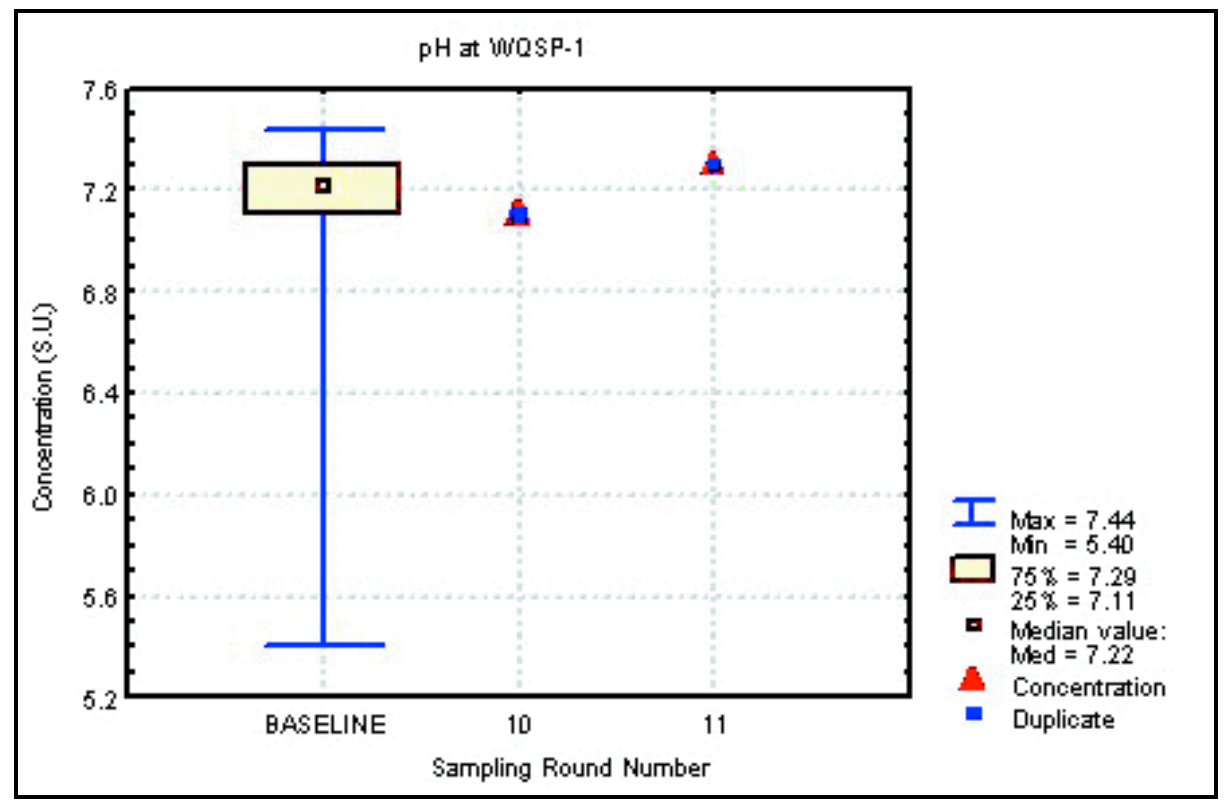

Figure F.10 Time Trend Plot for $\mathrm{pH}$ at WQSP-1

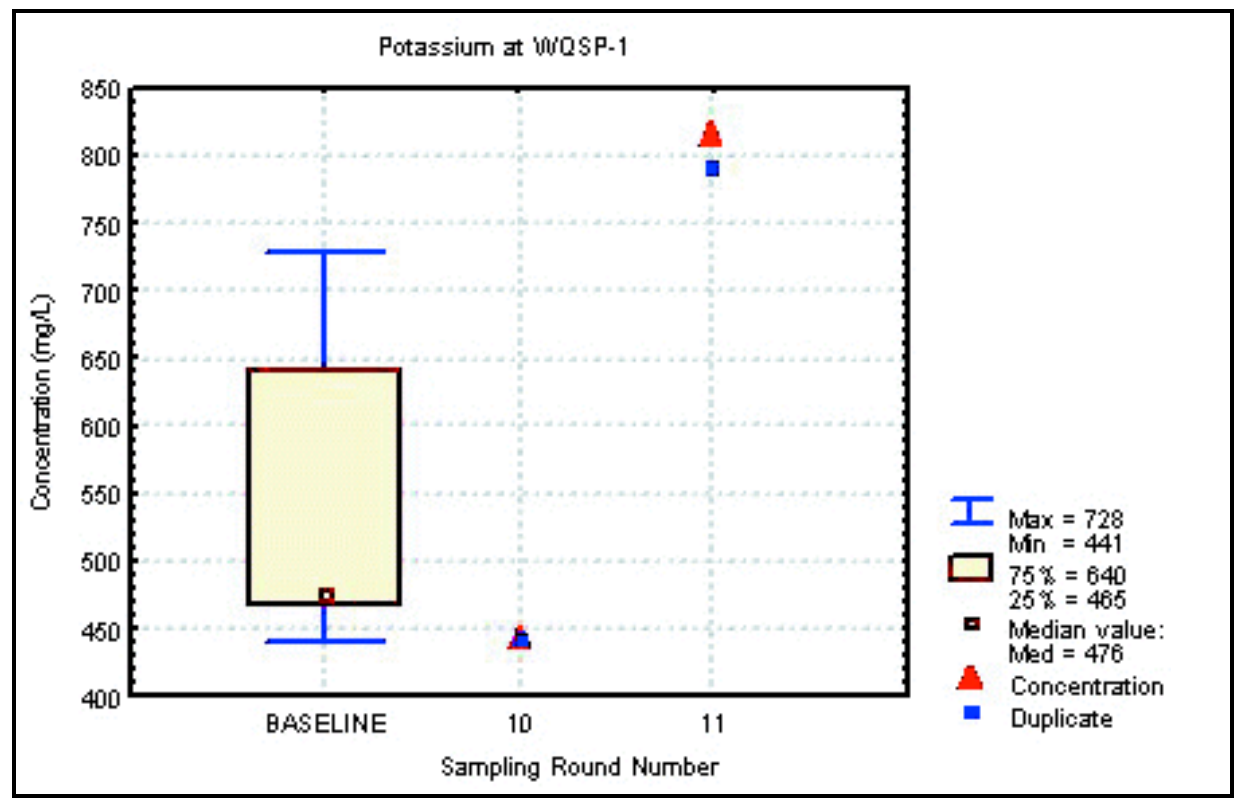

Figure F.11 Time Trent Plot for Potassium at WQSP-1 


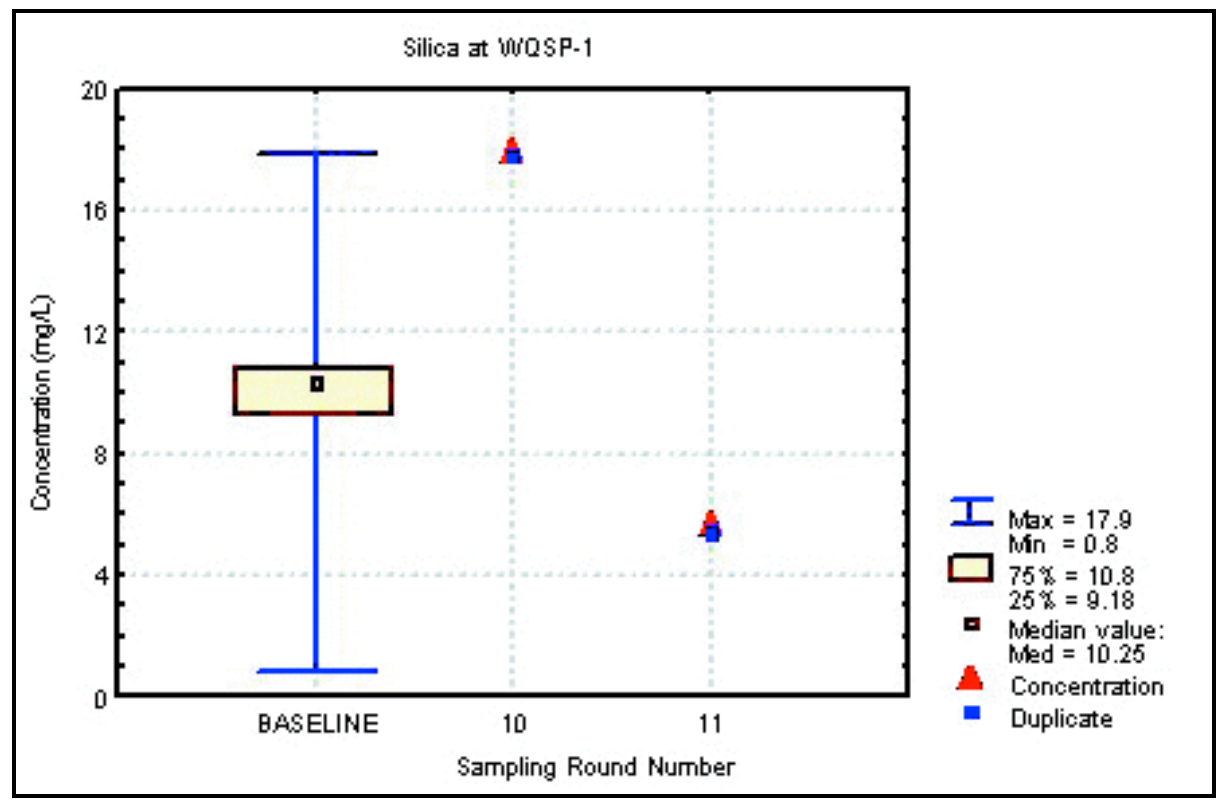

Figure F.12 Time Trend Plot for Silica at WQSP-1

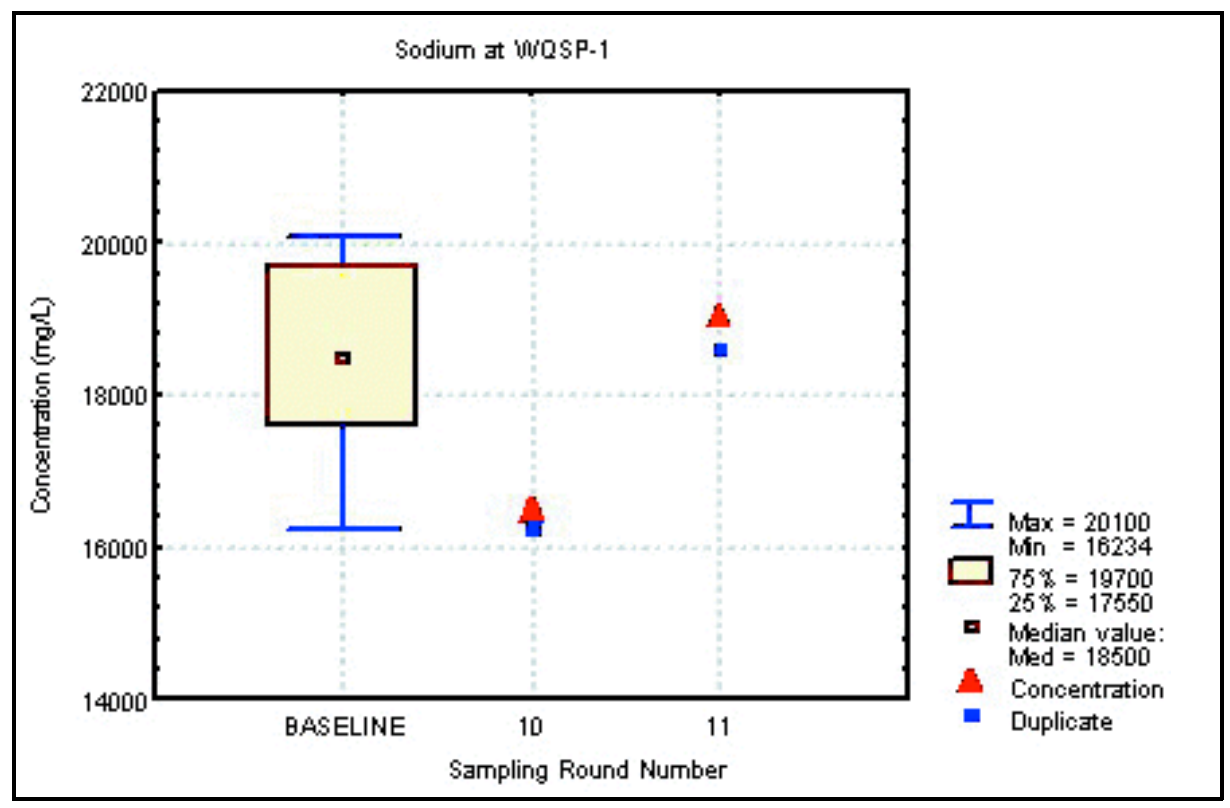

Figure F.13 Time Trent Plot for Sodium at WQSP-1 


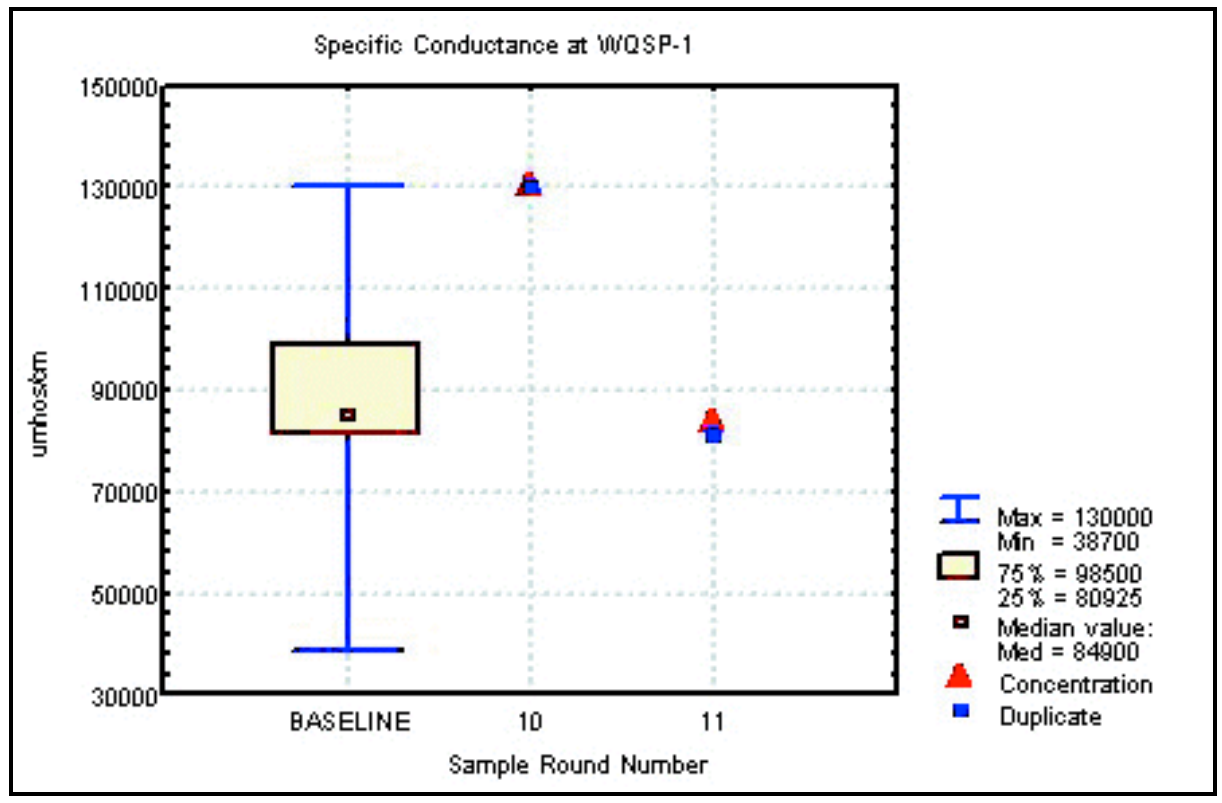

Figure F.14 Time Trend Plot for Conductance at WQSP-1

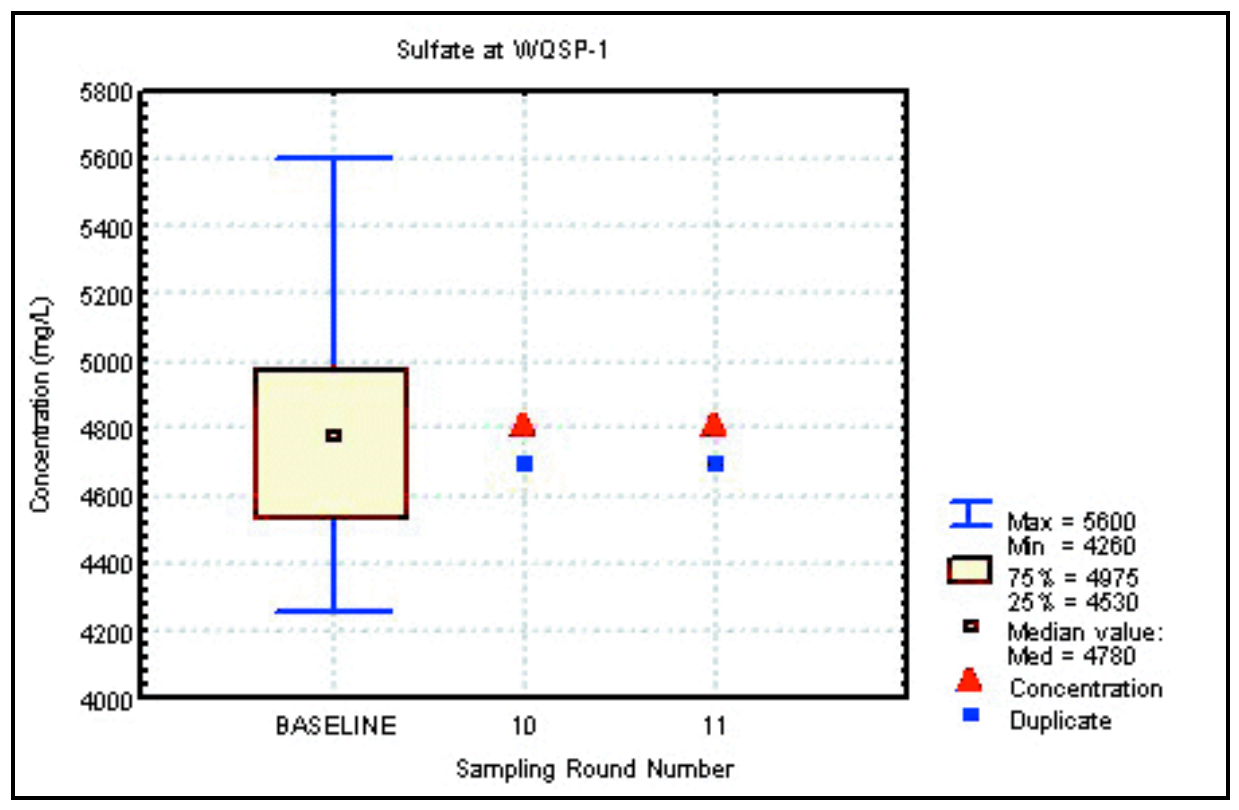

Figure F.15 Time Trent Plot for Sulfate at WQSP-1 


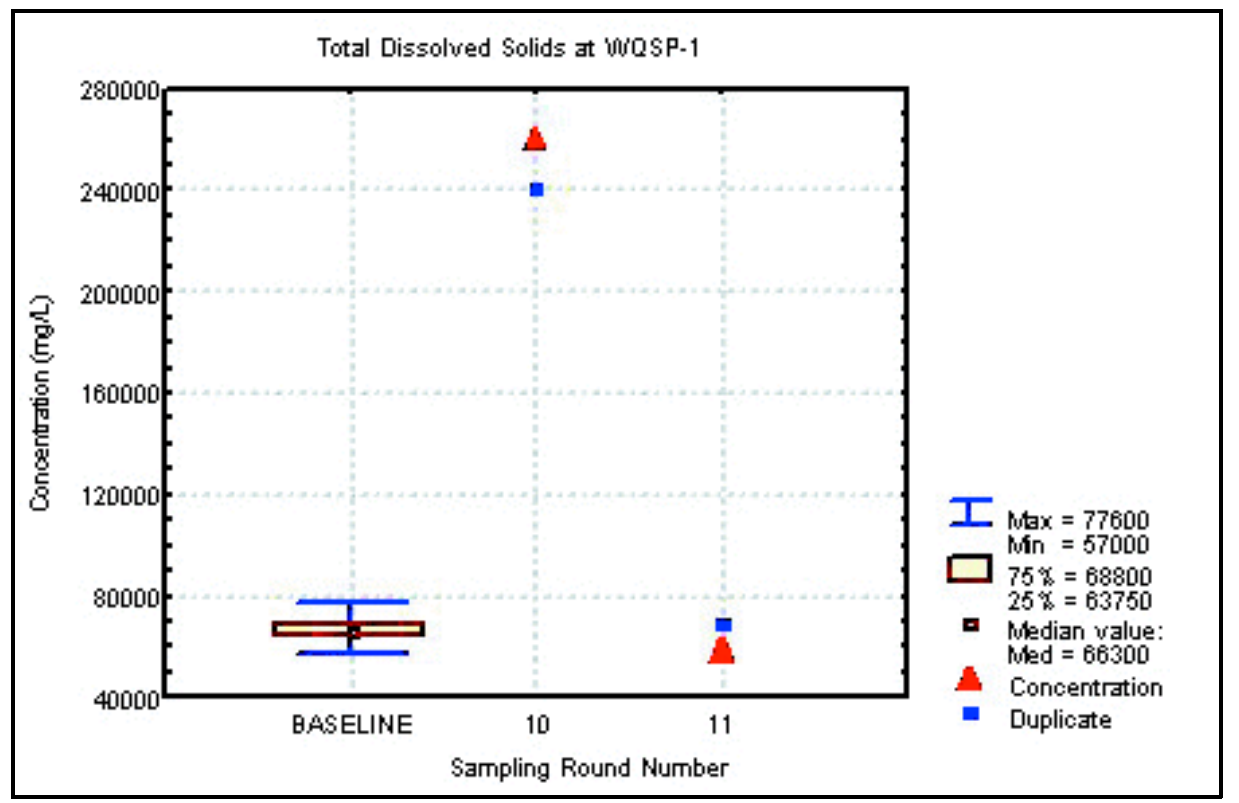

Figure F.16 Time Trend Plot for Total Dissolved Solids at WQSP-1

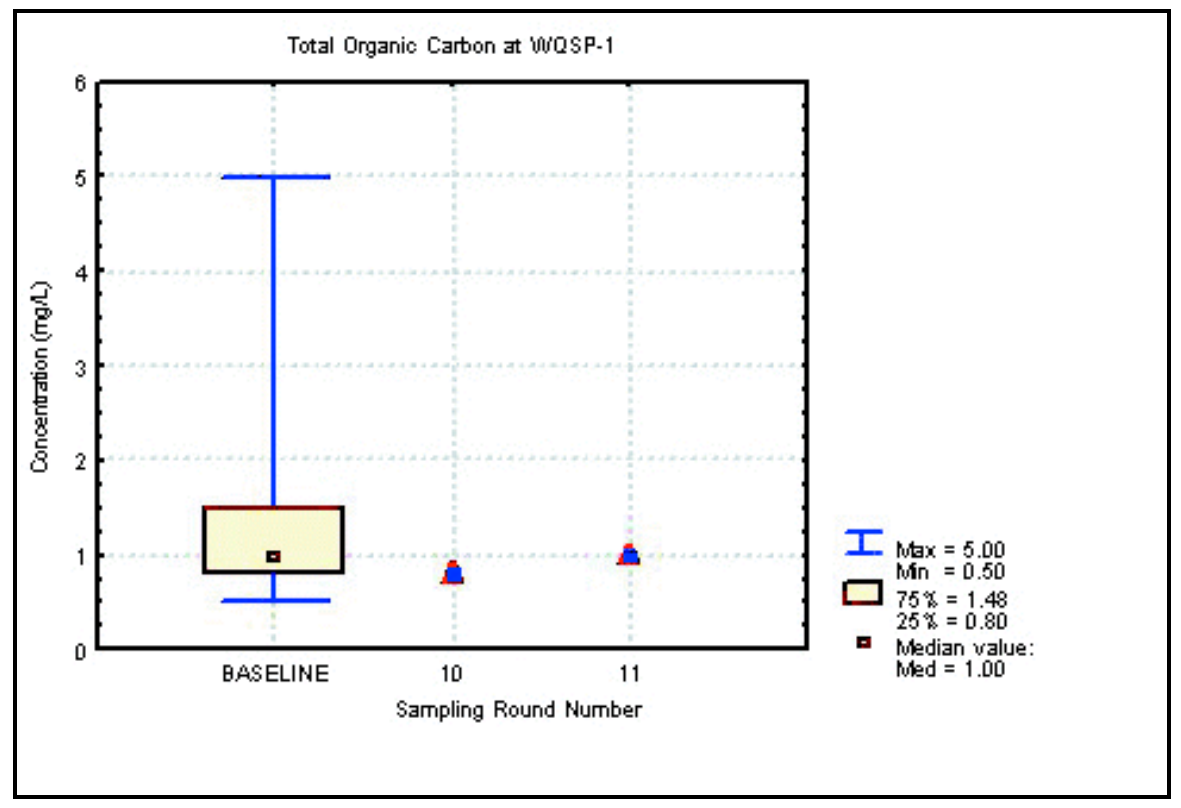

Figure F.17 Time Trent Plot for total Organic Carbon at WQSP-1 


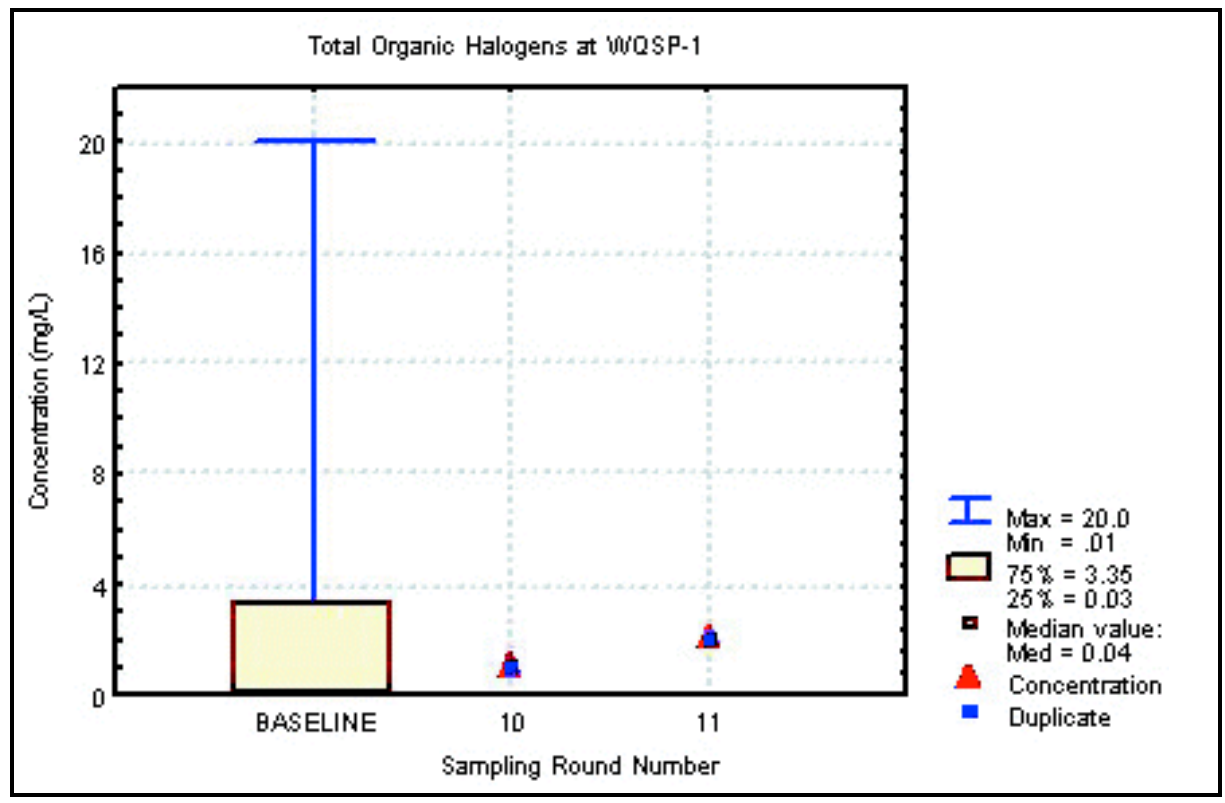

Figure F.18 Time Trend Plot for Total Organic Halogens at WQSP-1

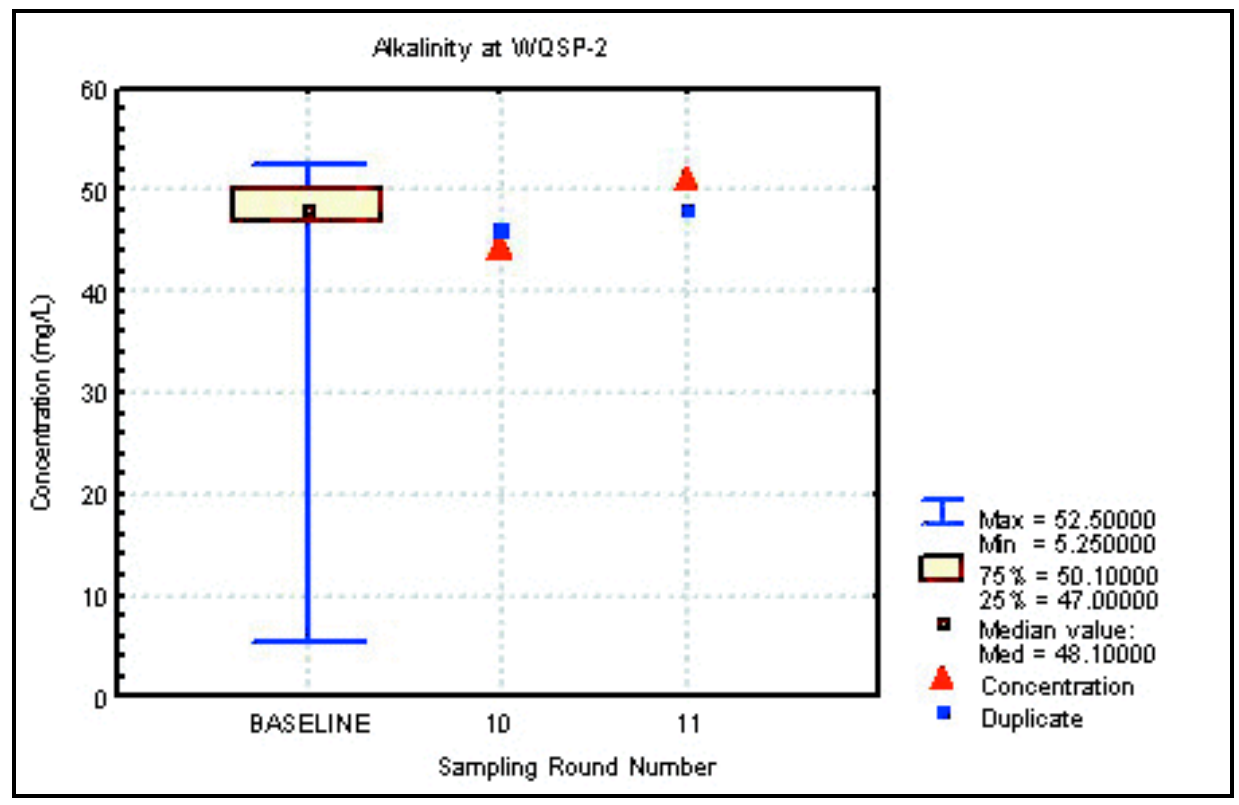

Figure F.19 Time Trent Plot for Alkalinity at WQSP-2 


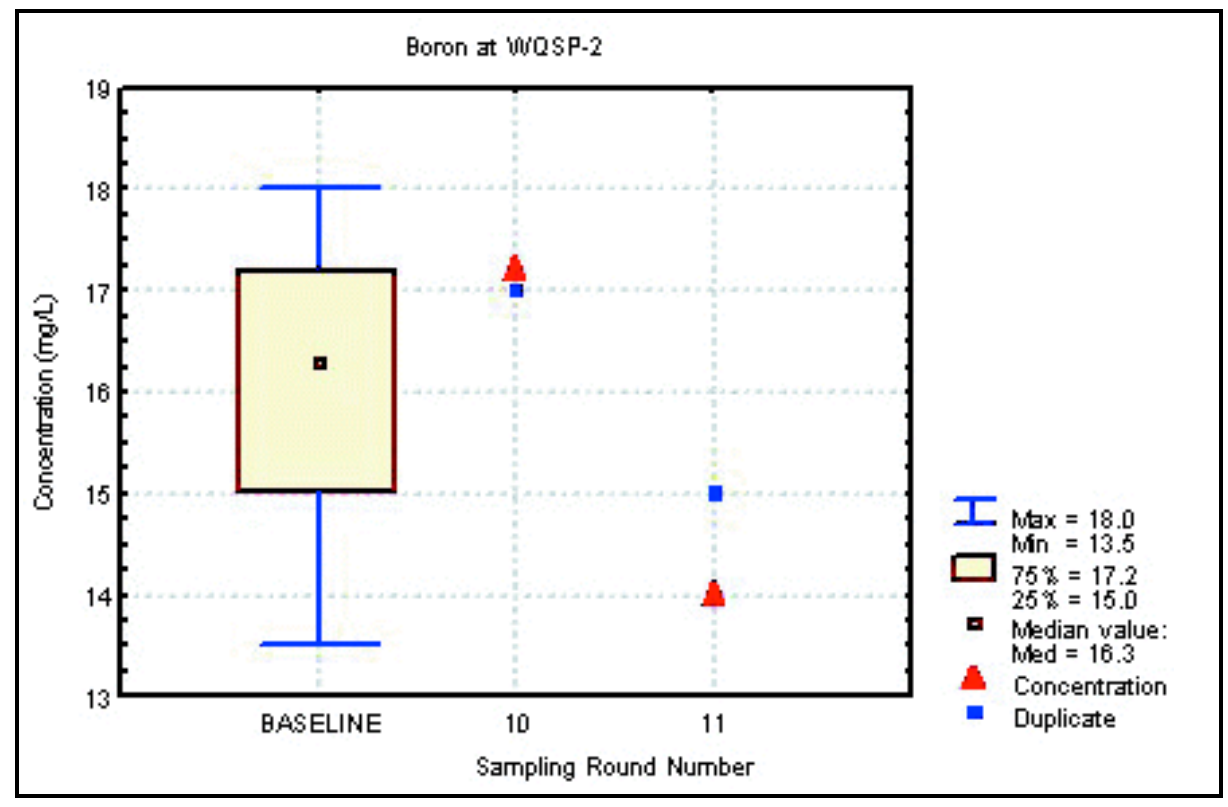

Figure F.20 Time Trend Plot for Boron at WQSP-2

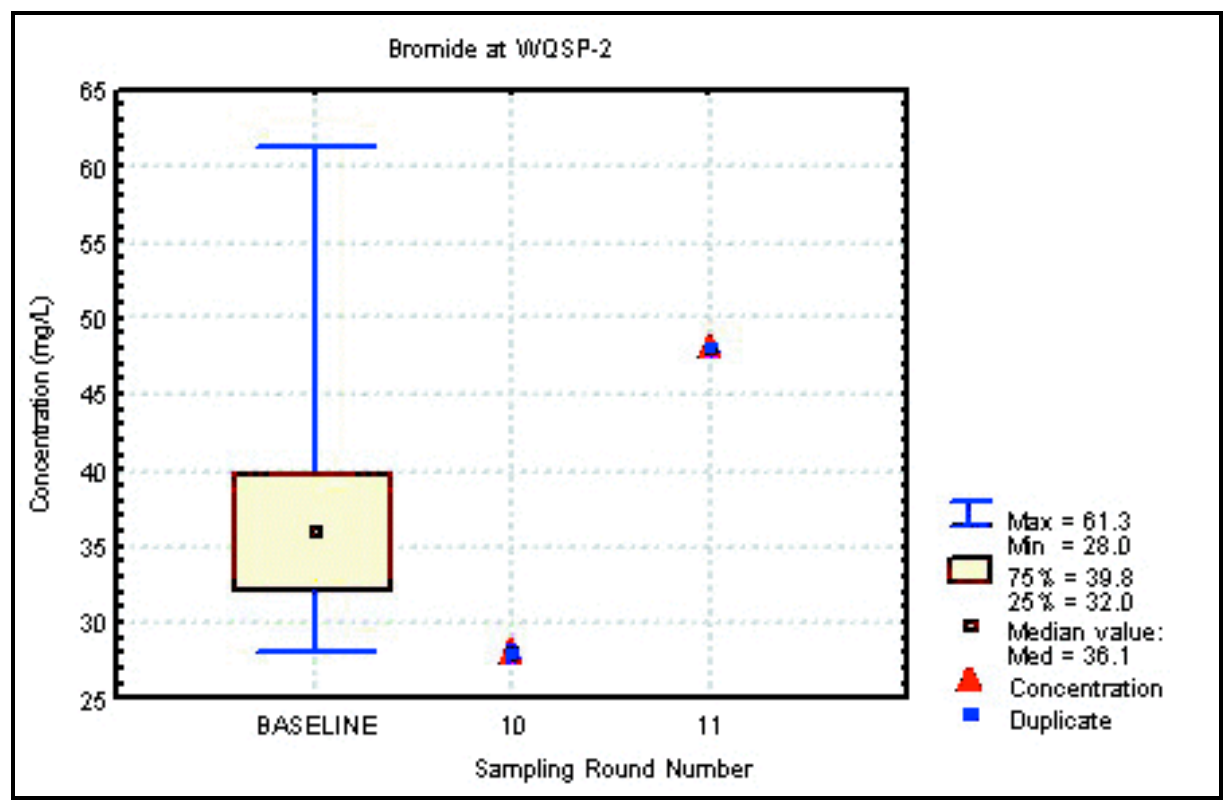

Figure F.21 Time Trent Plot for Bromide at WQSP-2 


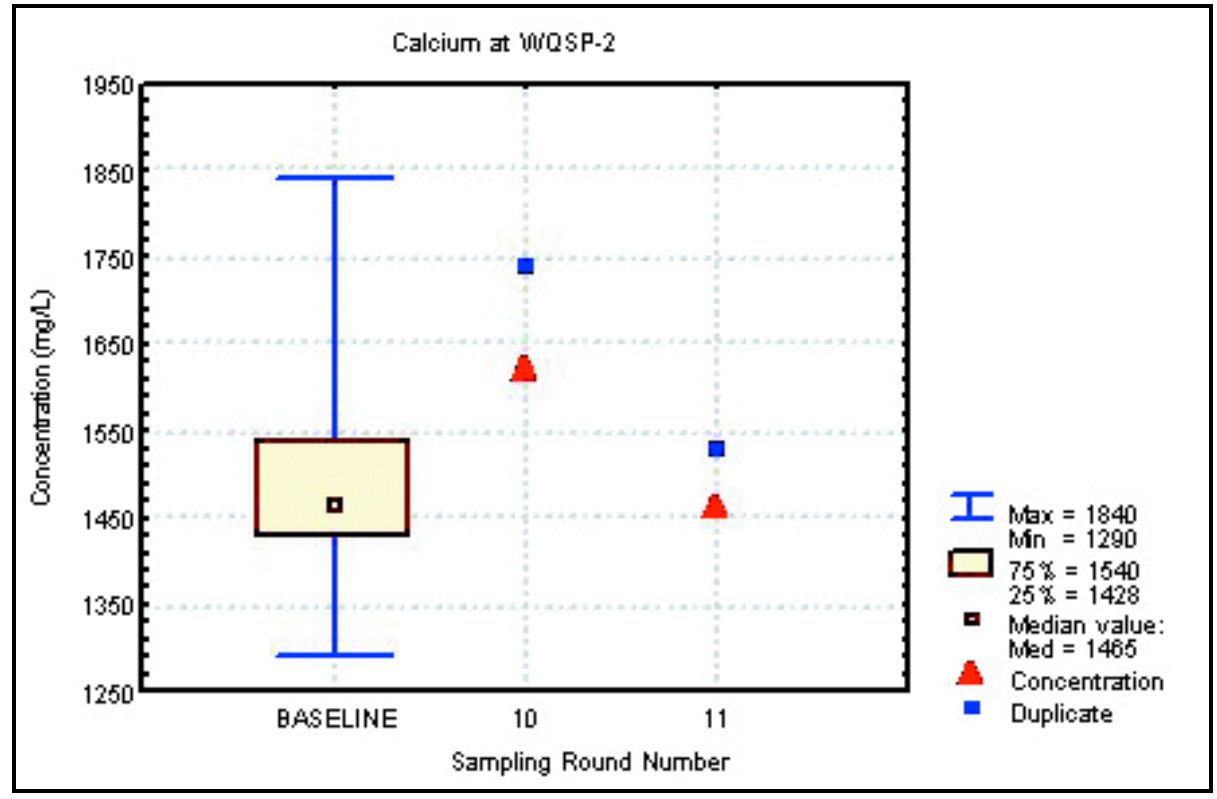

Figure F.22 Time Trend Plot for Calcium at WQSP-2

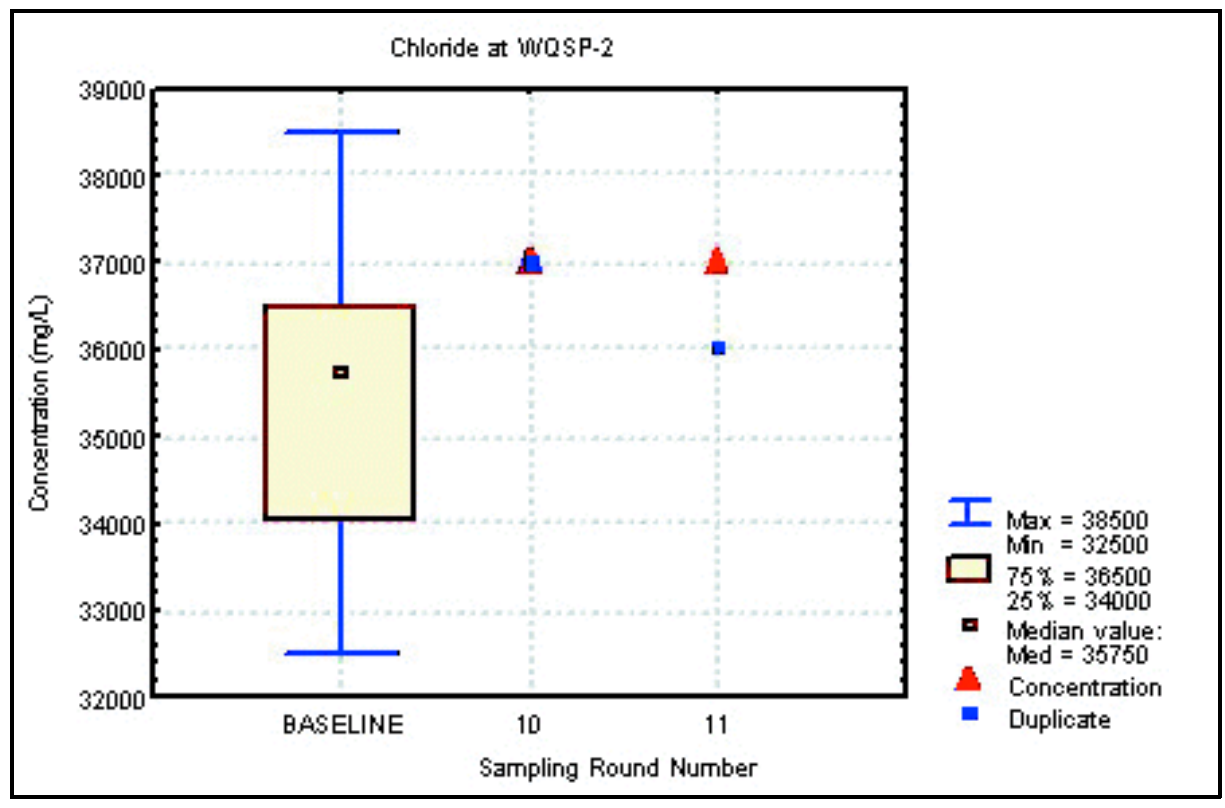

Figure F.23 Time Trent Plot for Chloride at WQSP-2 


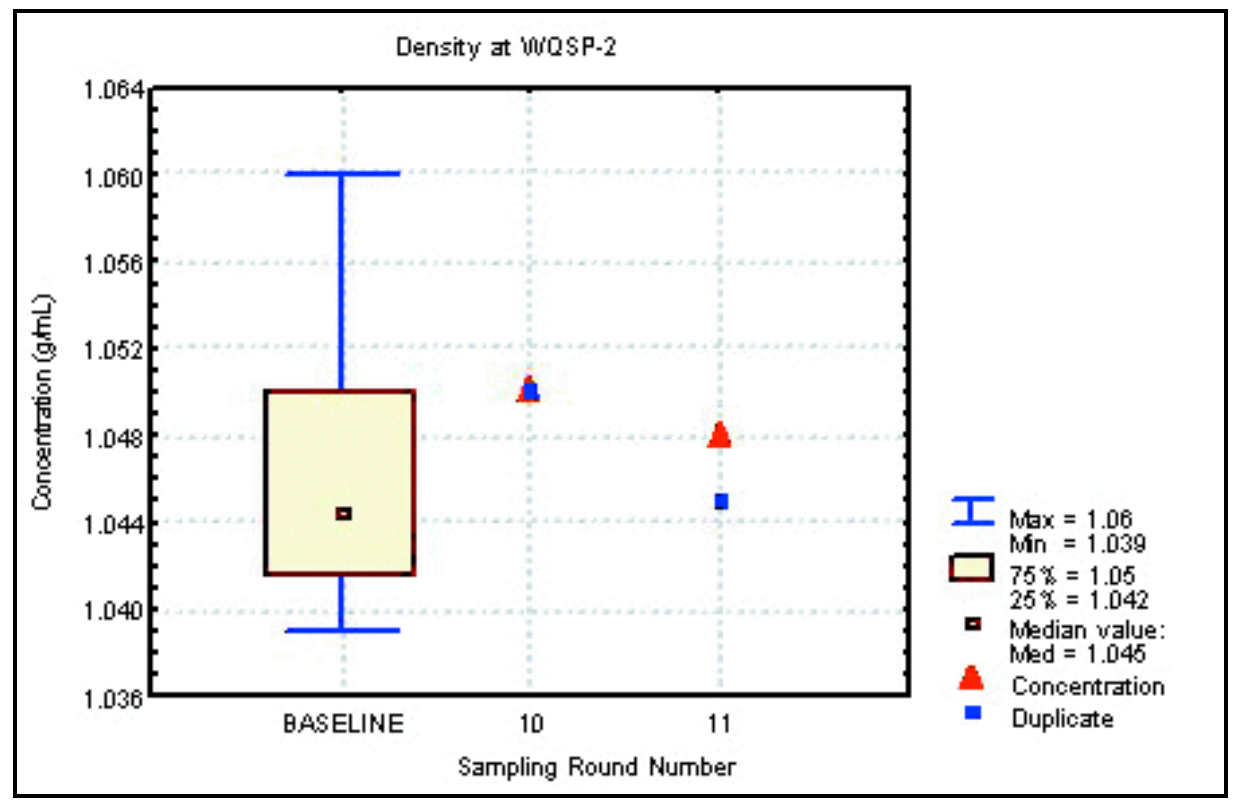

Figure F.24 Time Trend Plot for Density at WQSP-2

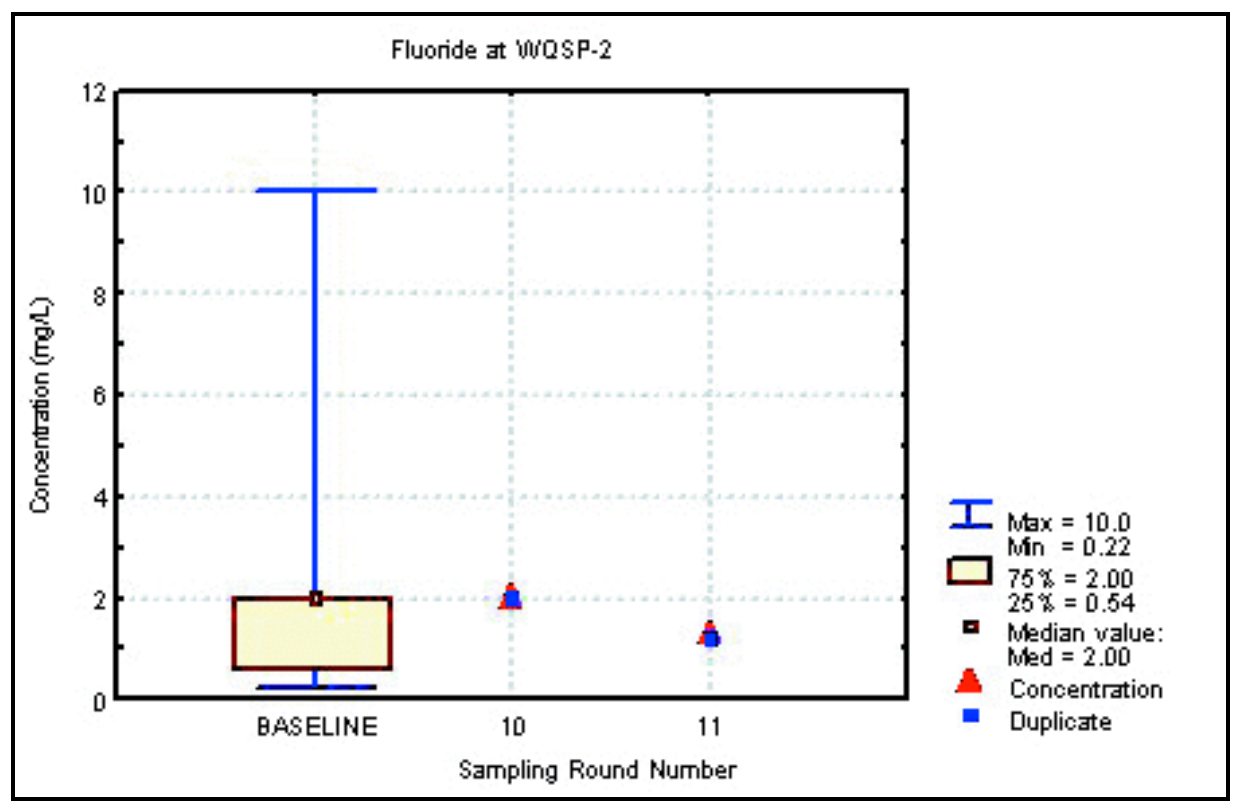

Figure F.25 Time Trent Plot for Fluoride at WQSP-2 


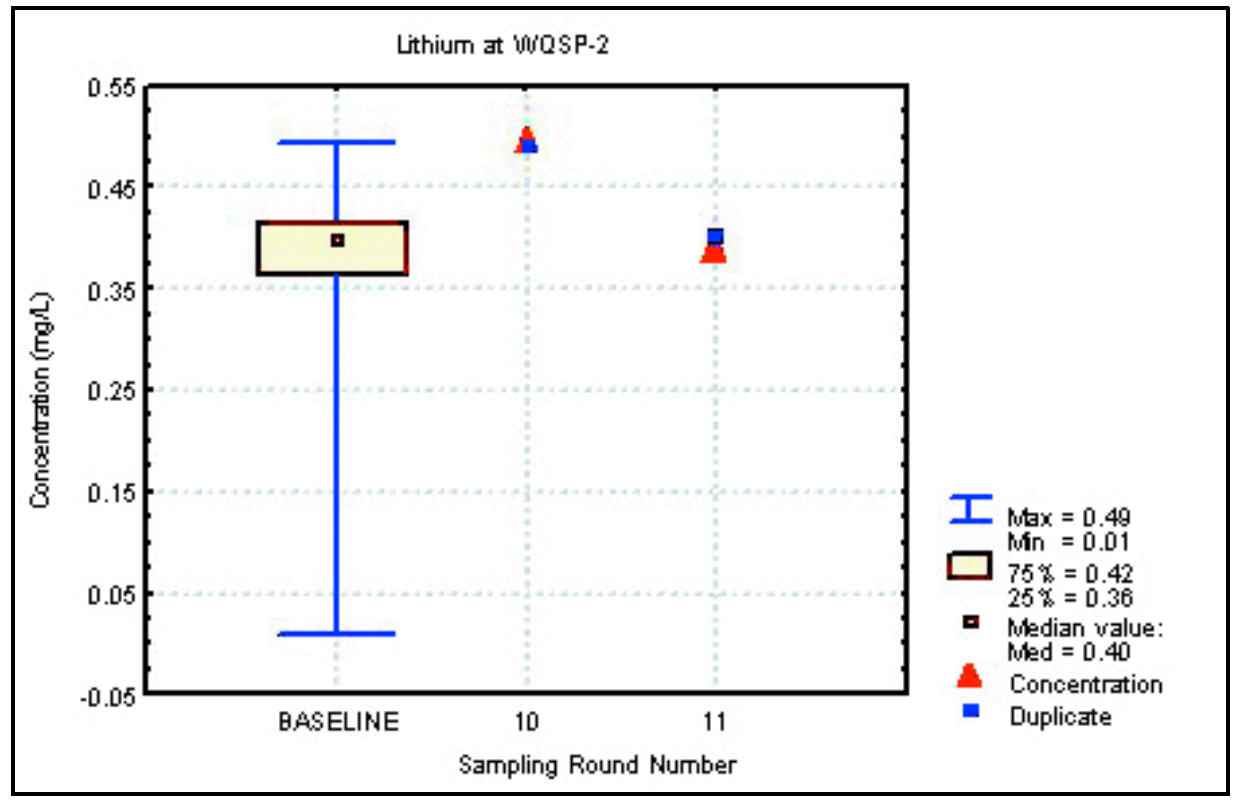

Figure F.26 Time Trend Plot for Lithium at WQSP-2

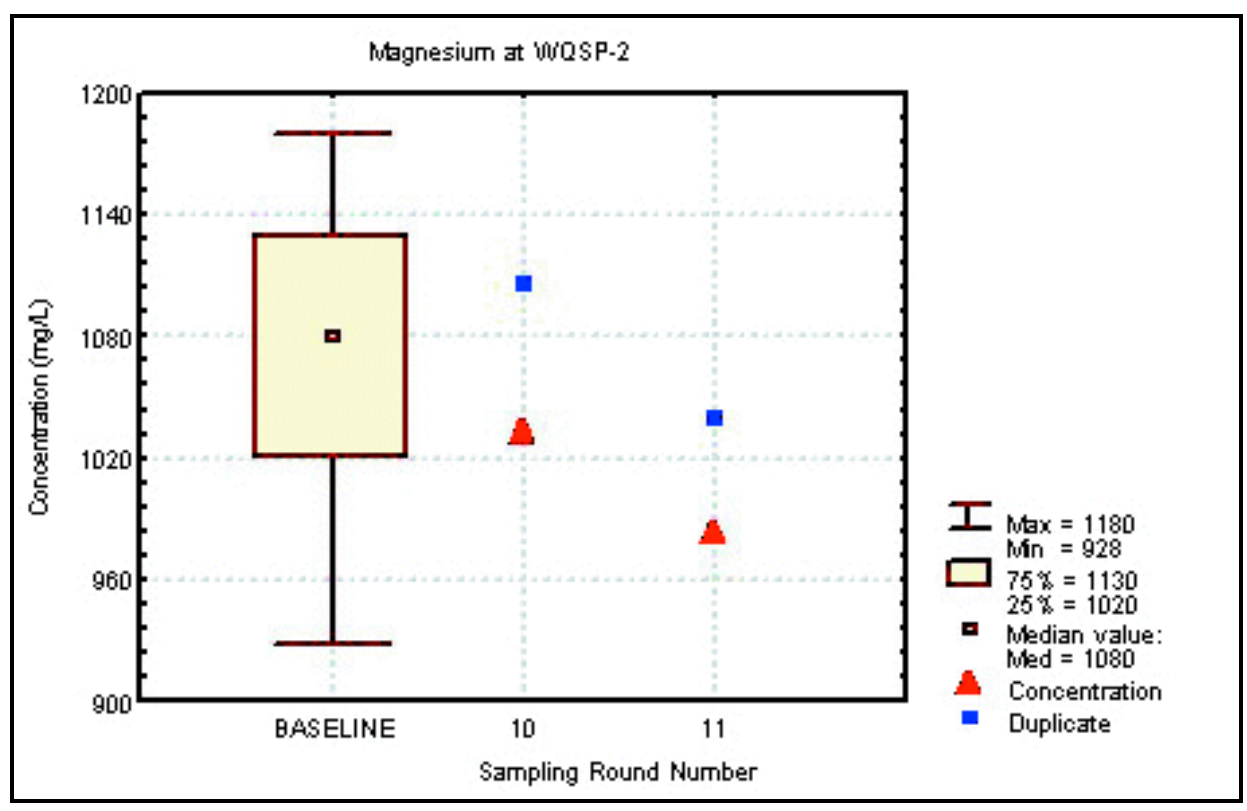

Figure F.27 Time Trent Plot for Magnesium at WQSP-2 


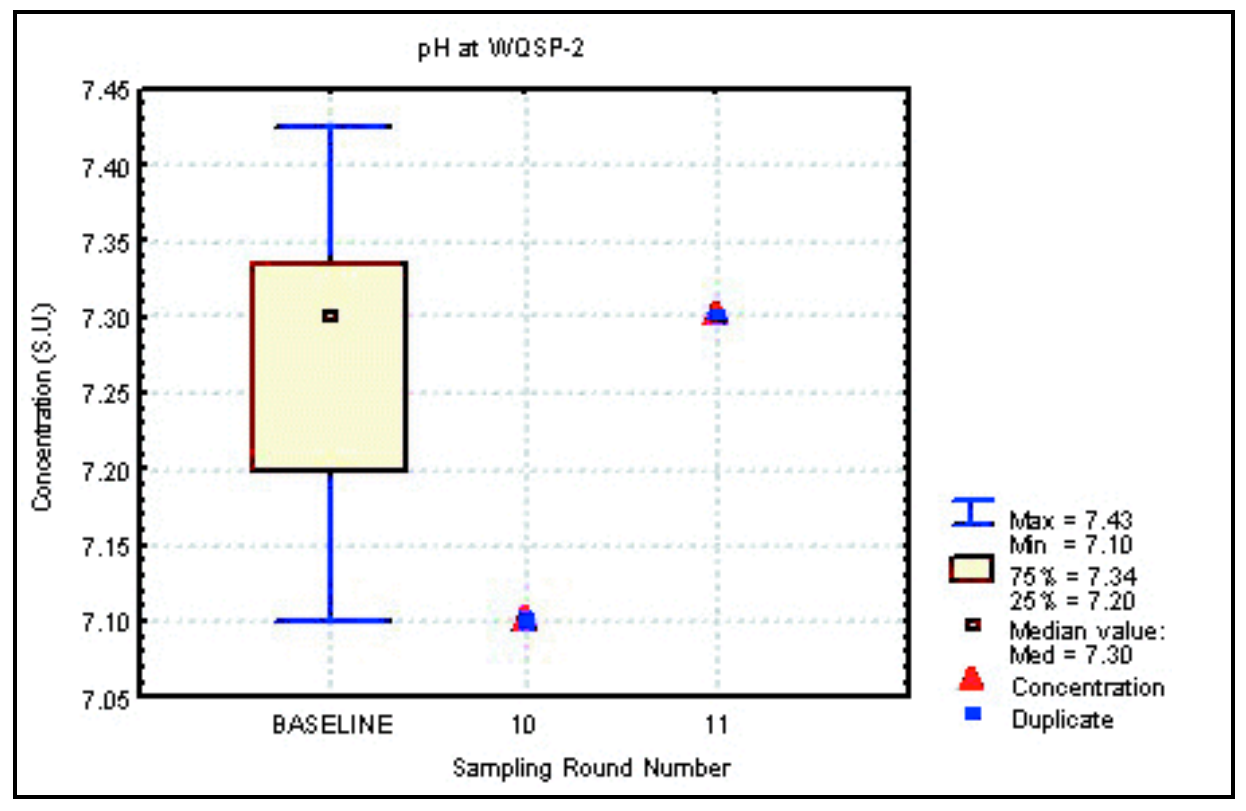

Figure F.28 Time Trend Plot for $\mathrm{pH}$ at WQSP-2

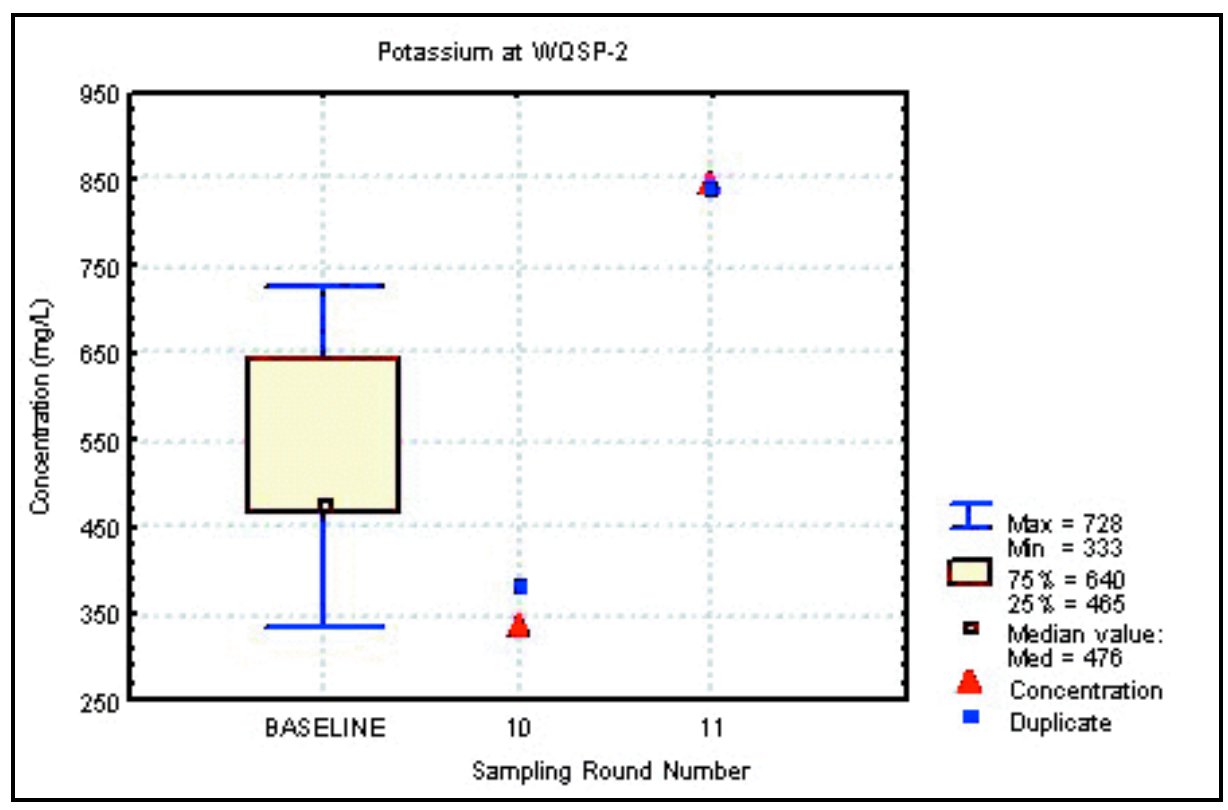

Figure F.29 Time Trent Plot for Potassium at WQSP-2 


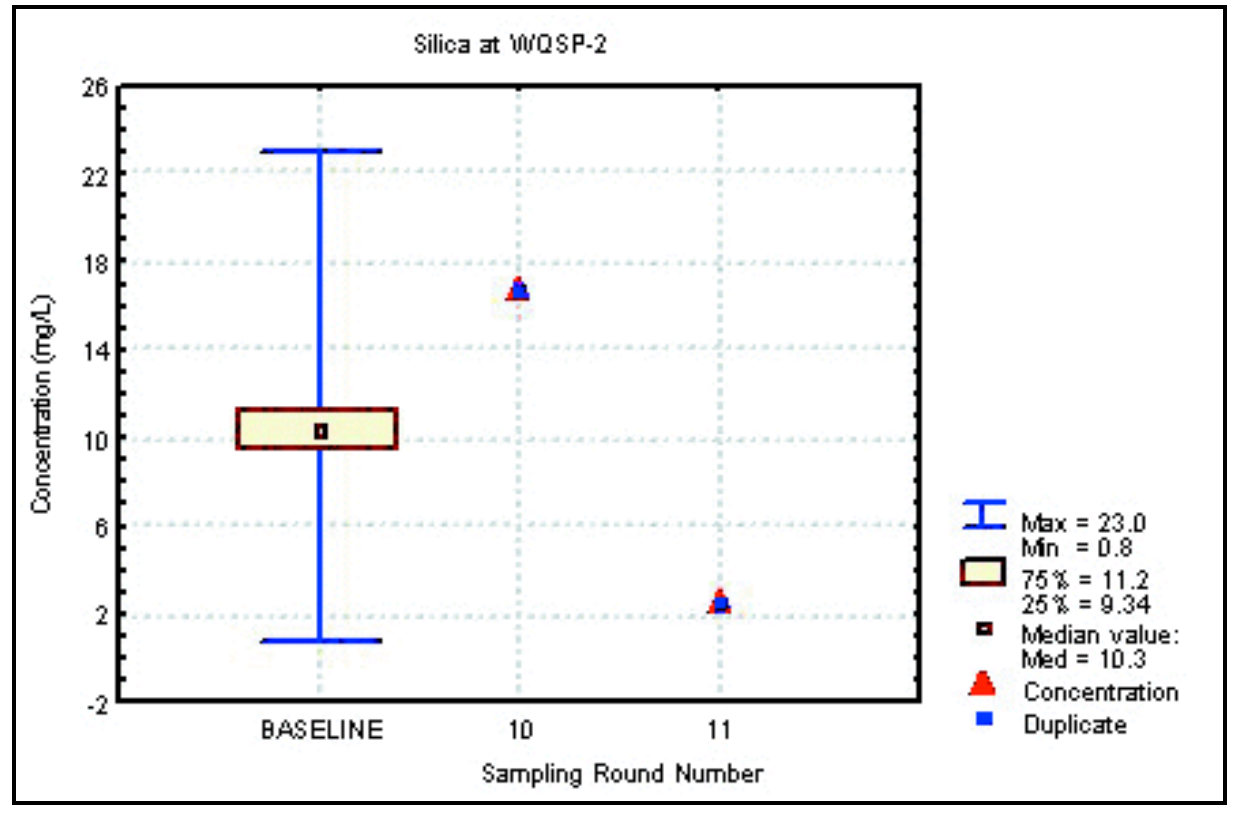

Figure F.30 Time Trend Plot for Silica at WQSP-2

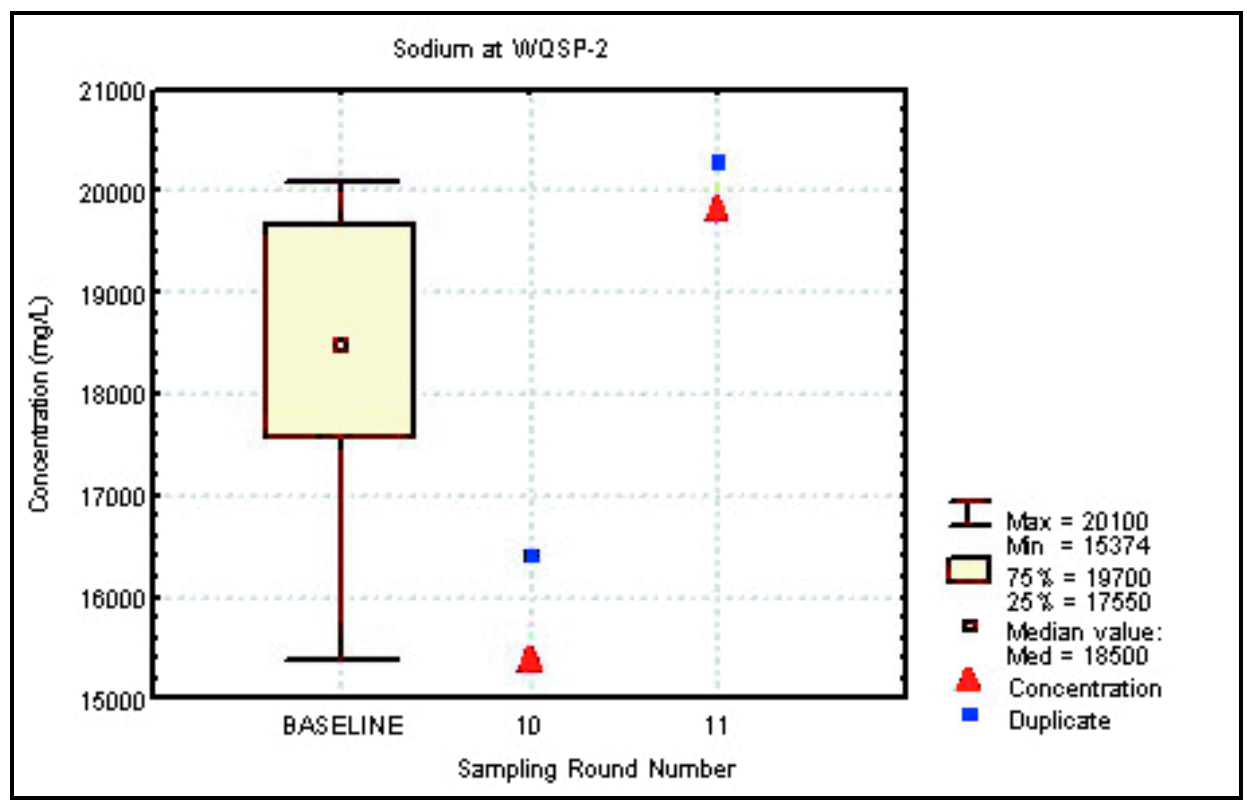

Figure F.31 Time Trent Plot for Sodium at WQSP-2 


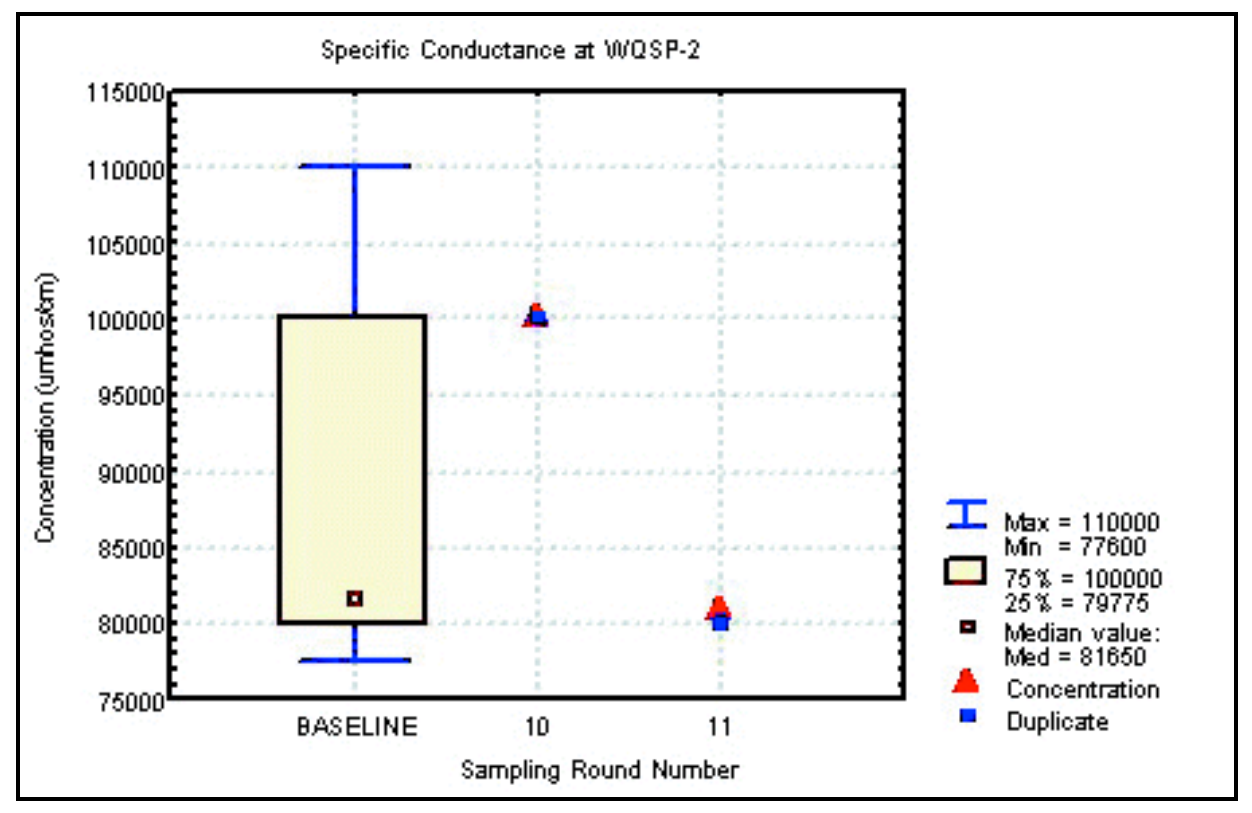

Figure F.32 Time Trend Plot for Specific Conductance at WQSP-2

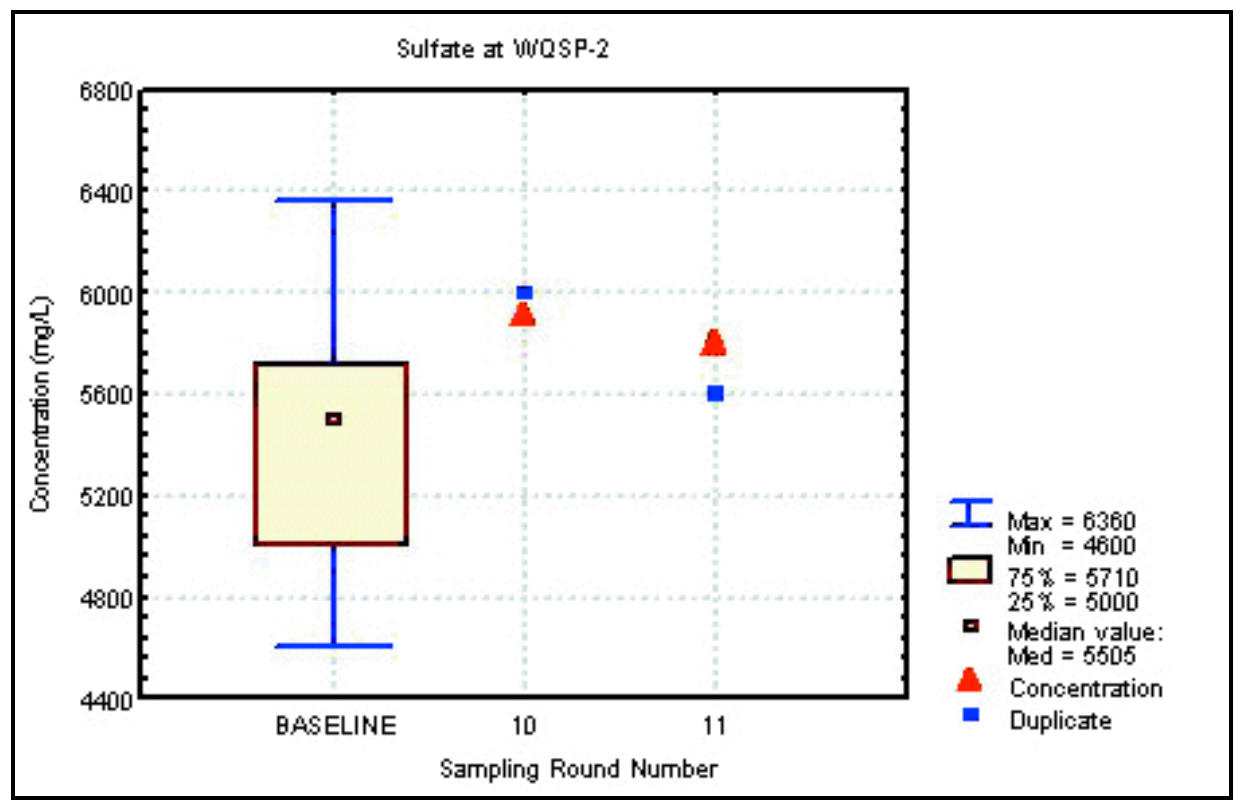

Figure F.33 Time Trent Plot for Sulfate at WQSP-2 


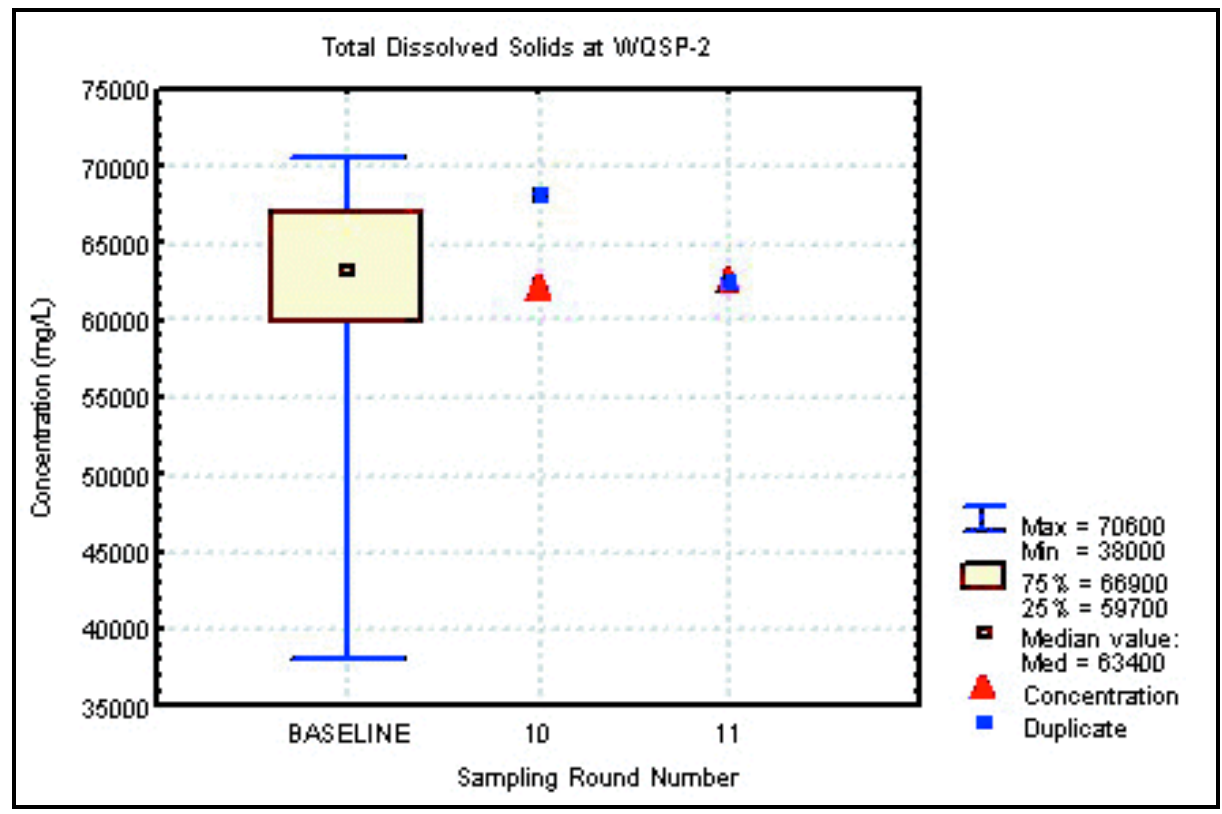

Figure F.34 Time Trend Plot for Total Dissolved Solids at WQSP-2

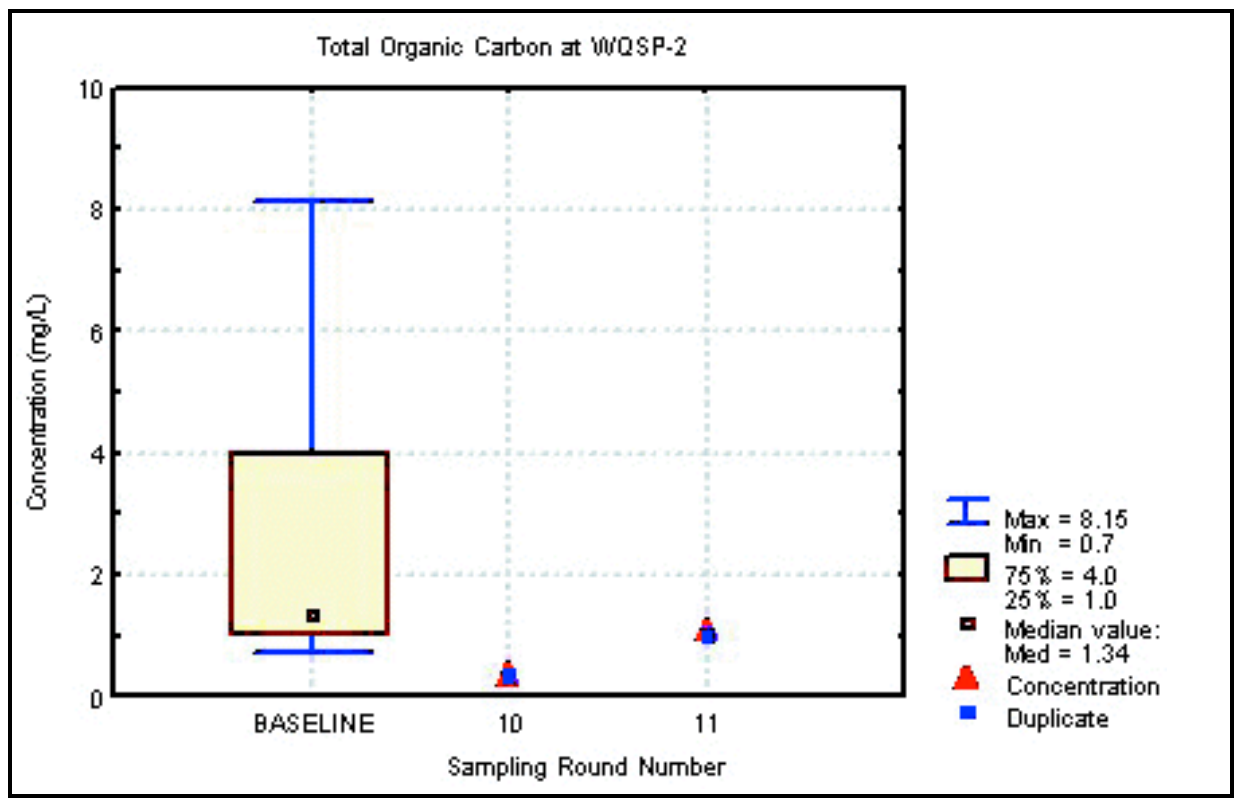

Figure F.35 Time Trent Plot for Total Organic Carbon at WQSP-2 


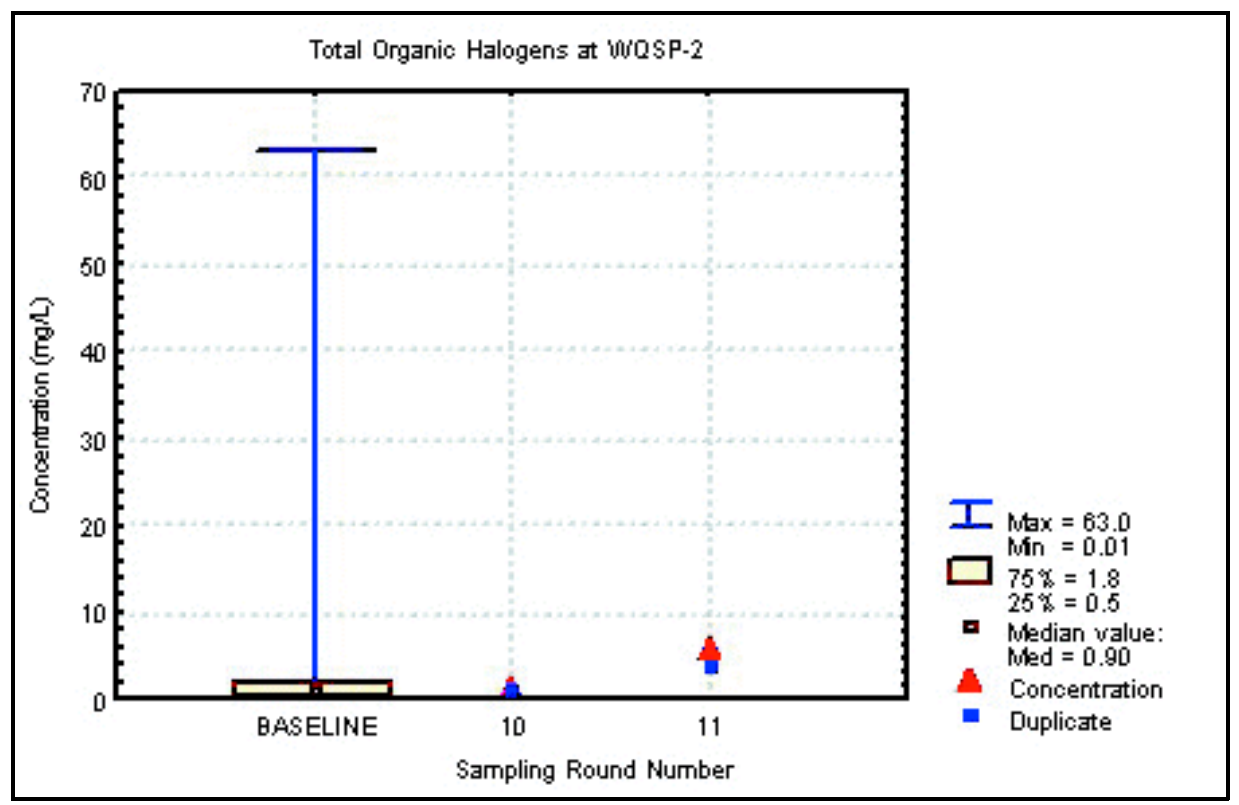

Figure F.36 Time Trend Plot for Total Organic Halogens at WQSP-2

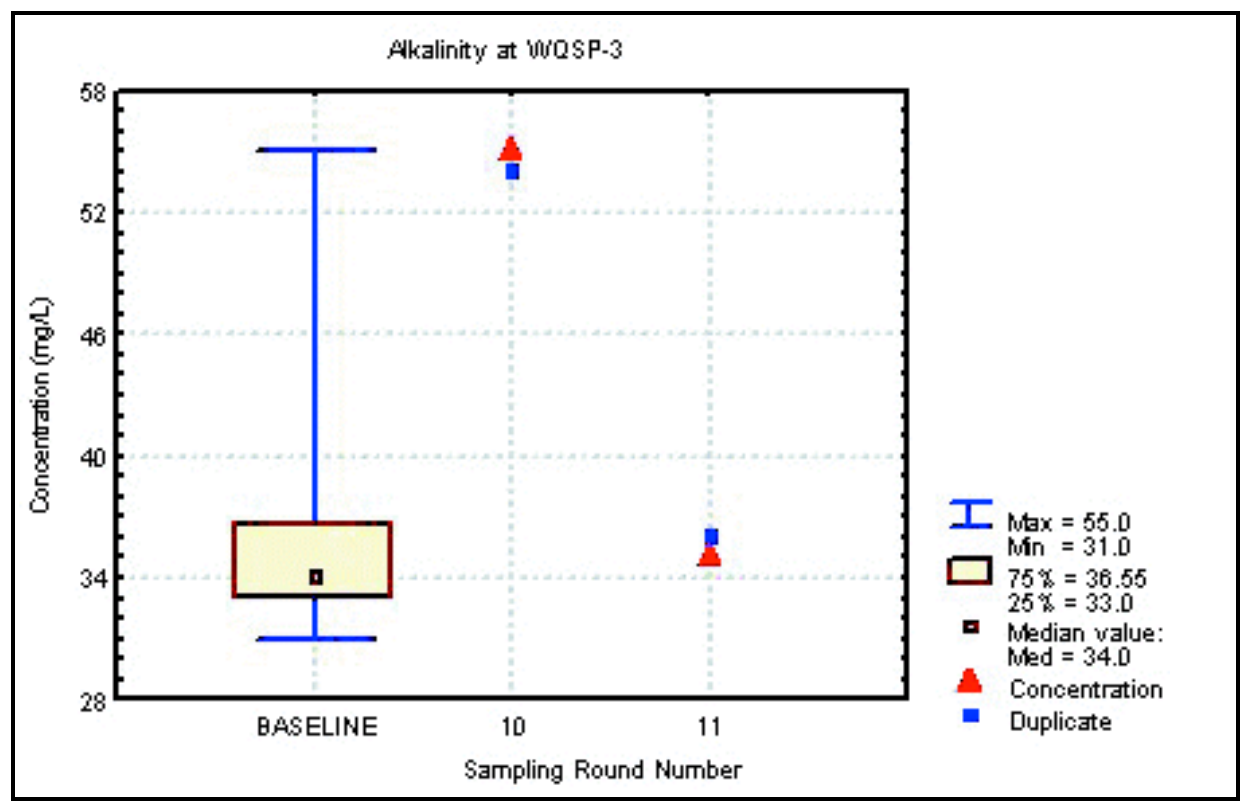

Figure F.37 Time Trent Plot for Alkalinity at WQSP-3 


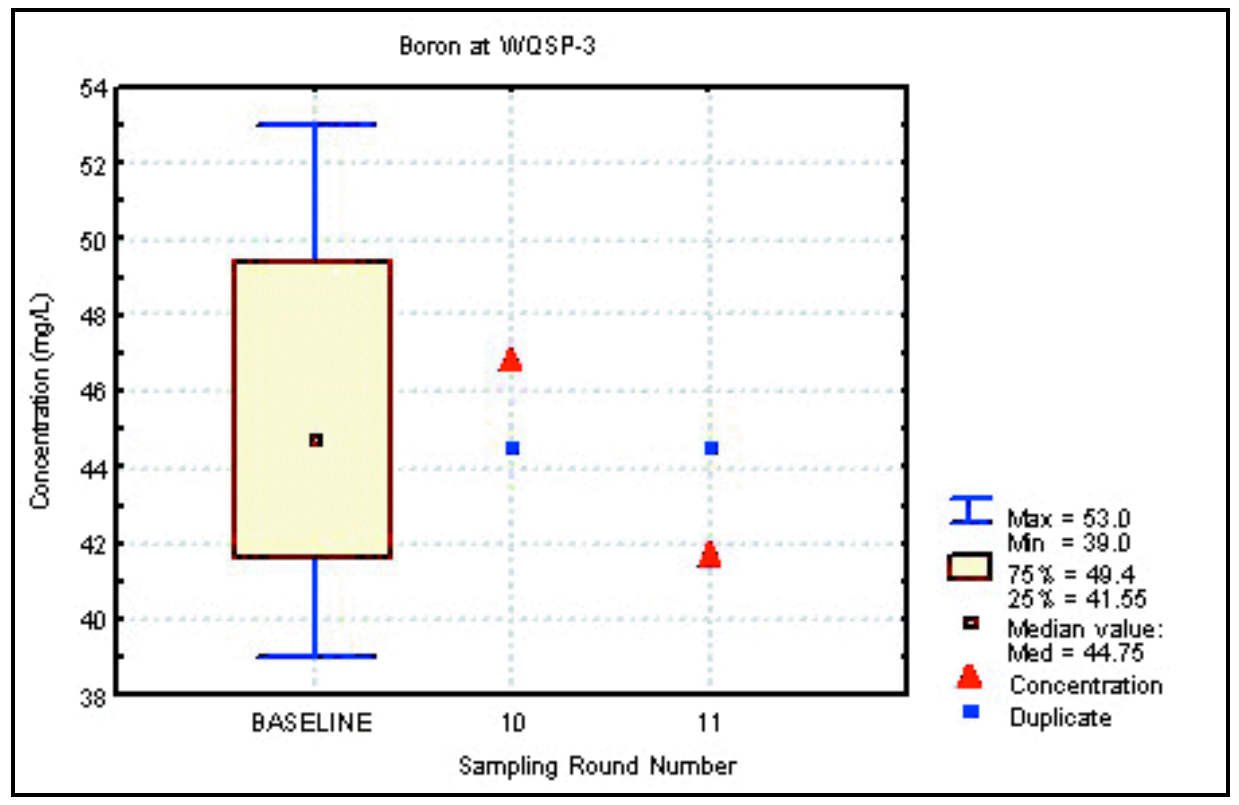

Figure F.38 Time Trend Plot for Boron at WQSP-3

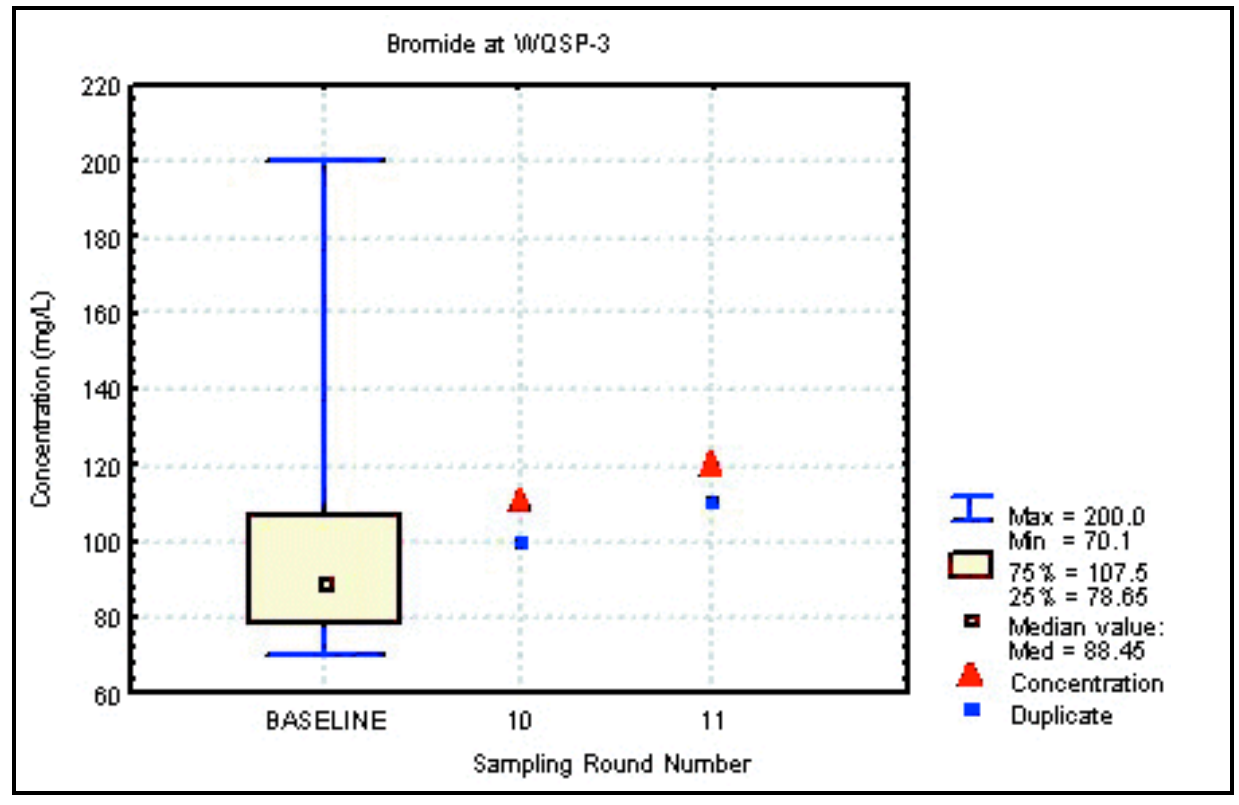

Figure F.39 Time Trent Plot for Bromide at WQSP-3 


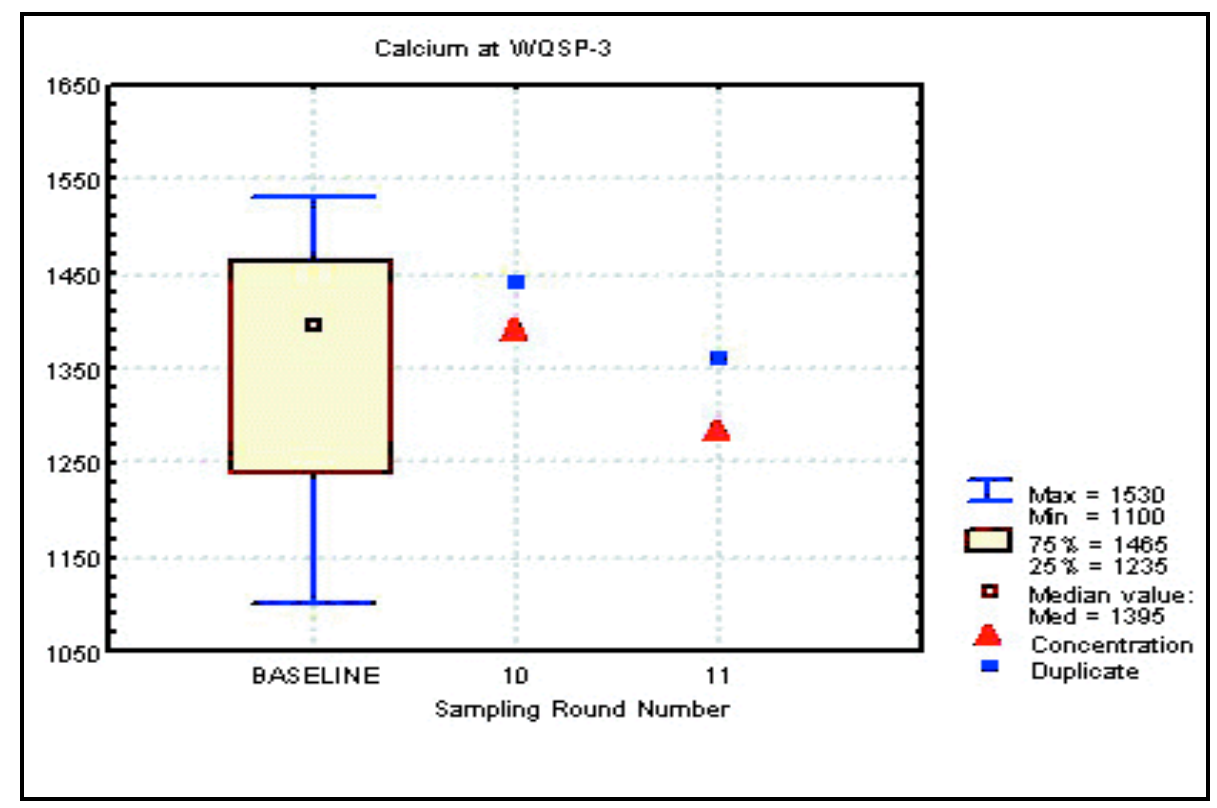

Figure F.40 Time Trend Plot for Calcium at WQSP-3

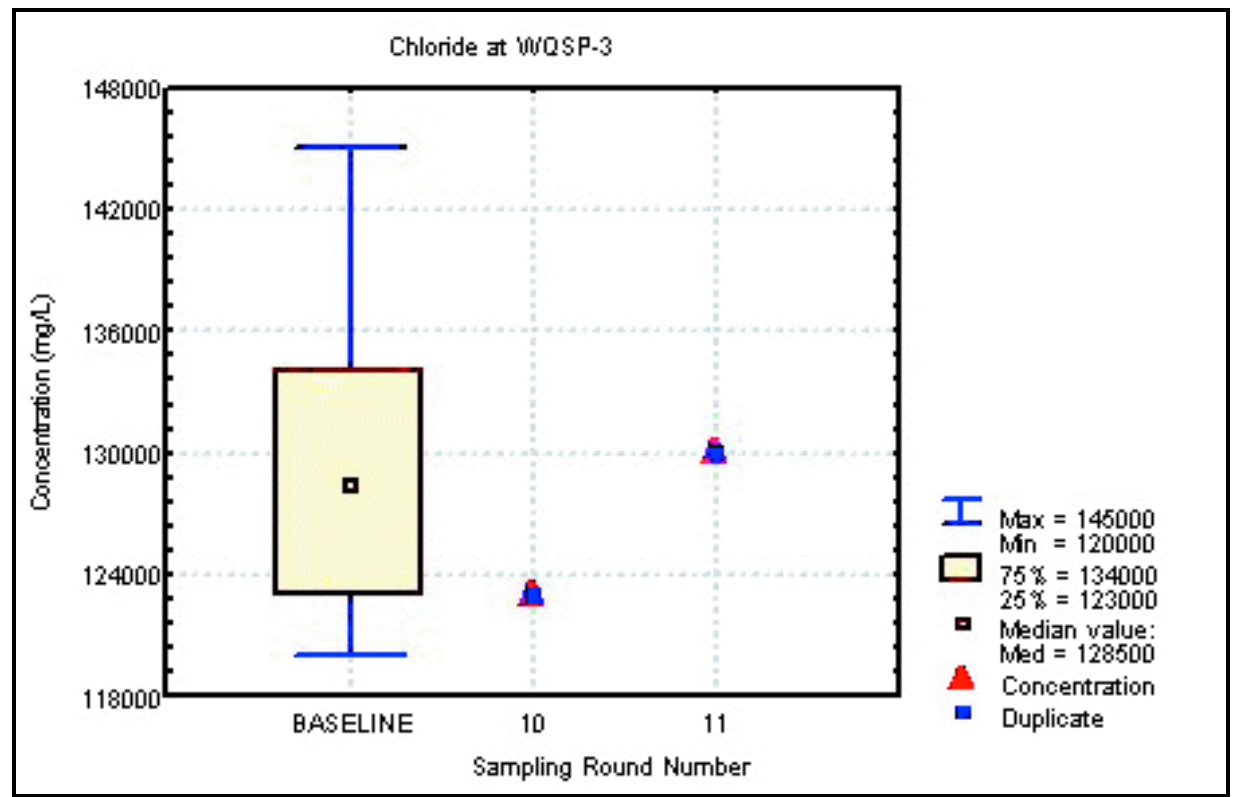

Figure F.41 Time Trent Plot for Chloride at WQSP-3 


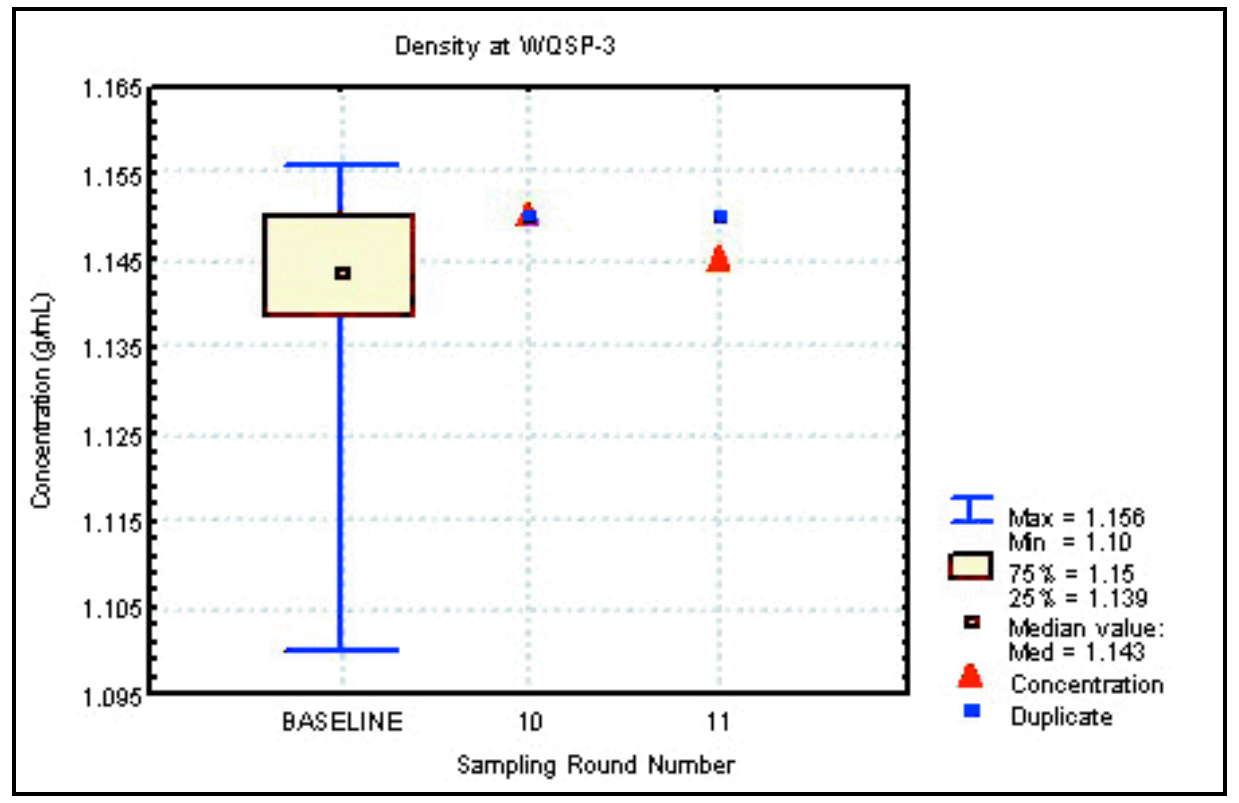

Figure F.42 Time Trend Plot for Density at WQSP-3

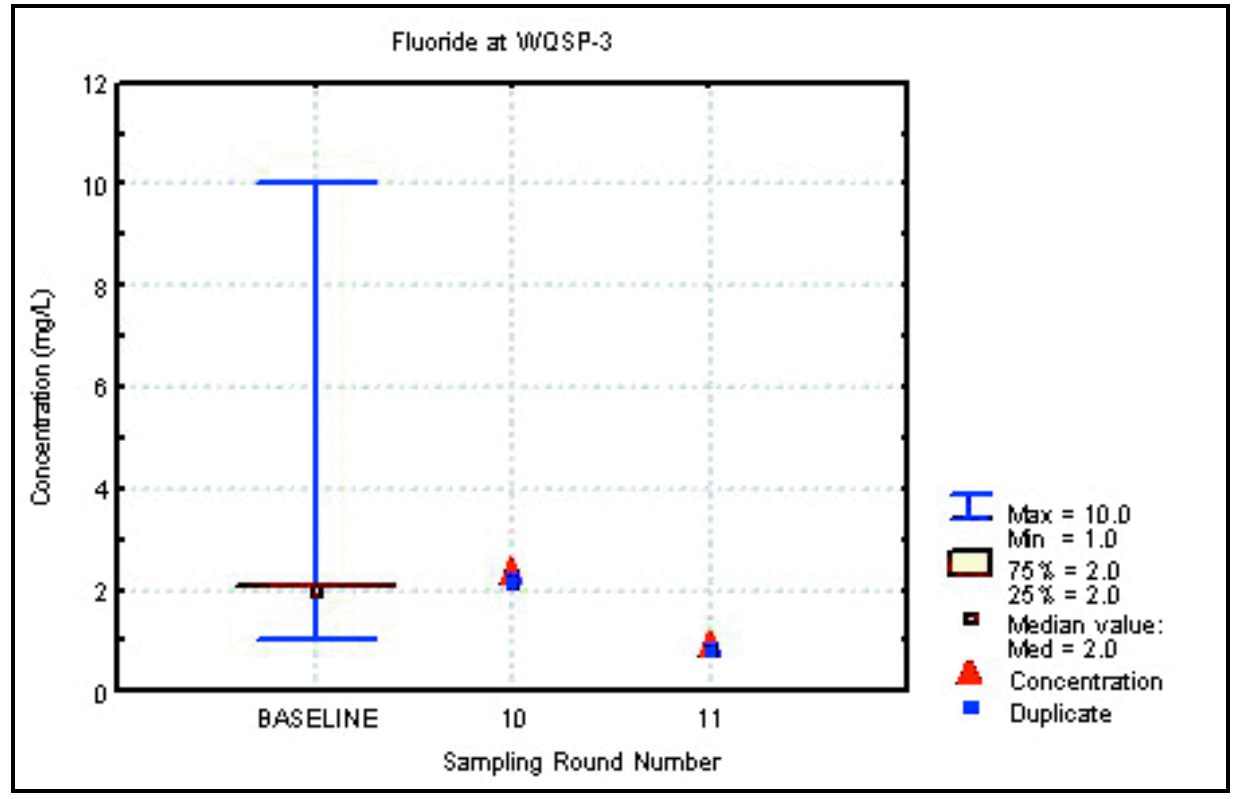

Figure F.43 Time Trent Plot for Fluoride at WQSP-3 


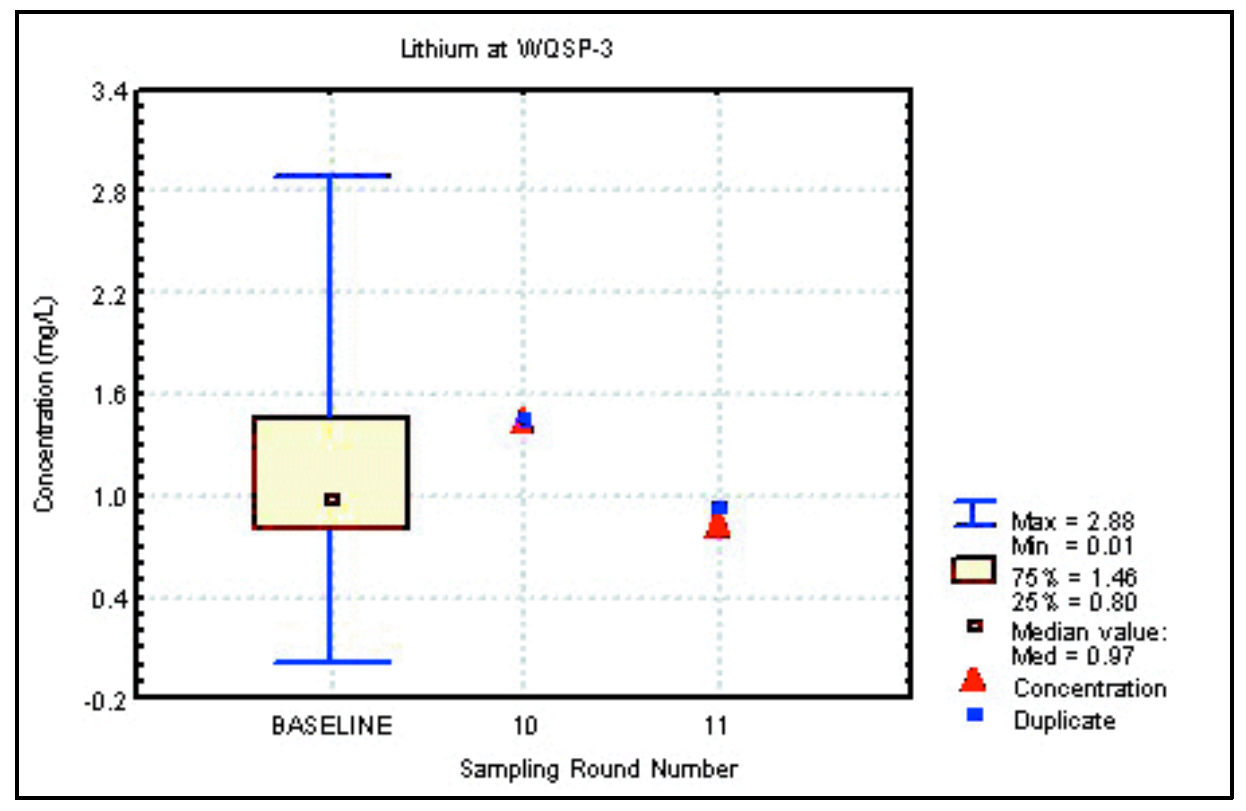

Figure F.44 Time Trend Plot for Lithium at WQSP-3

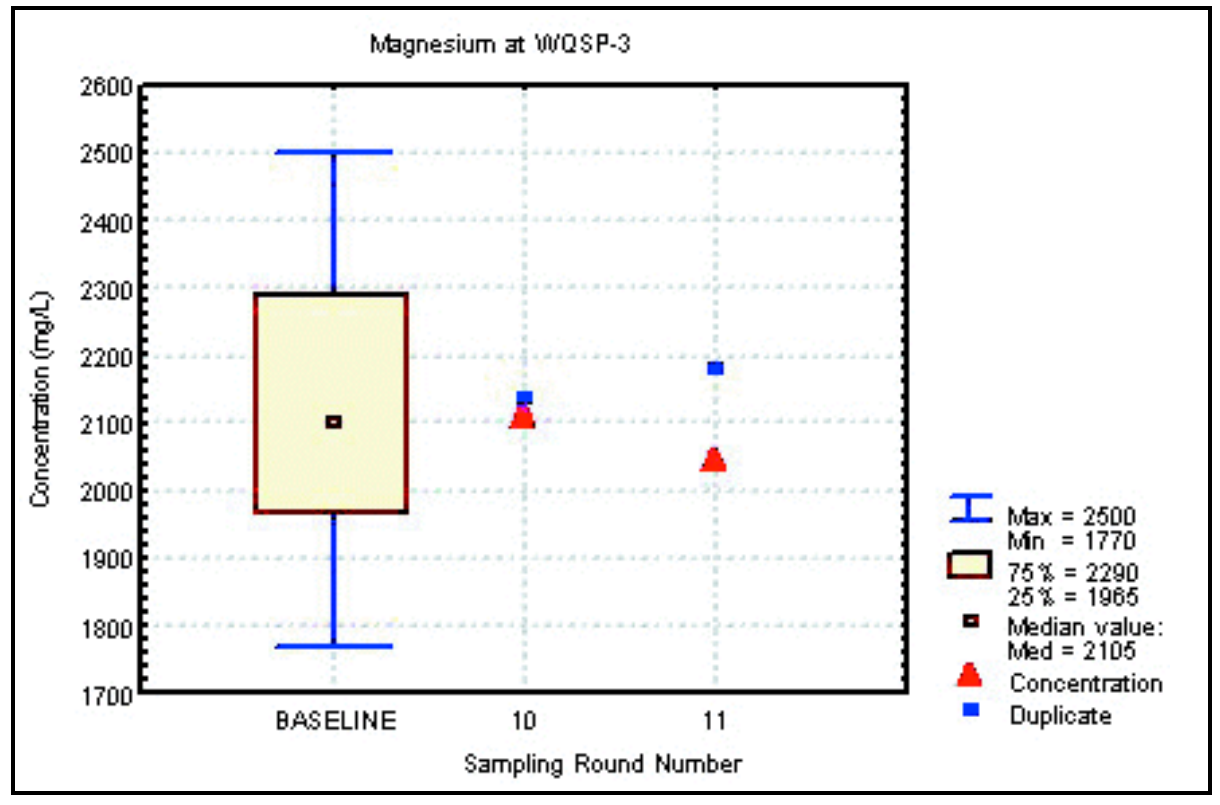

Figure F.45 Time Trent Plot for Magnesium at WQSP-3 


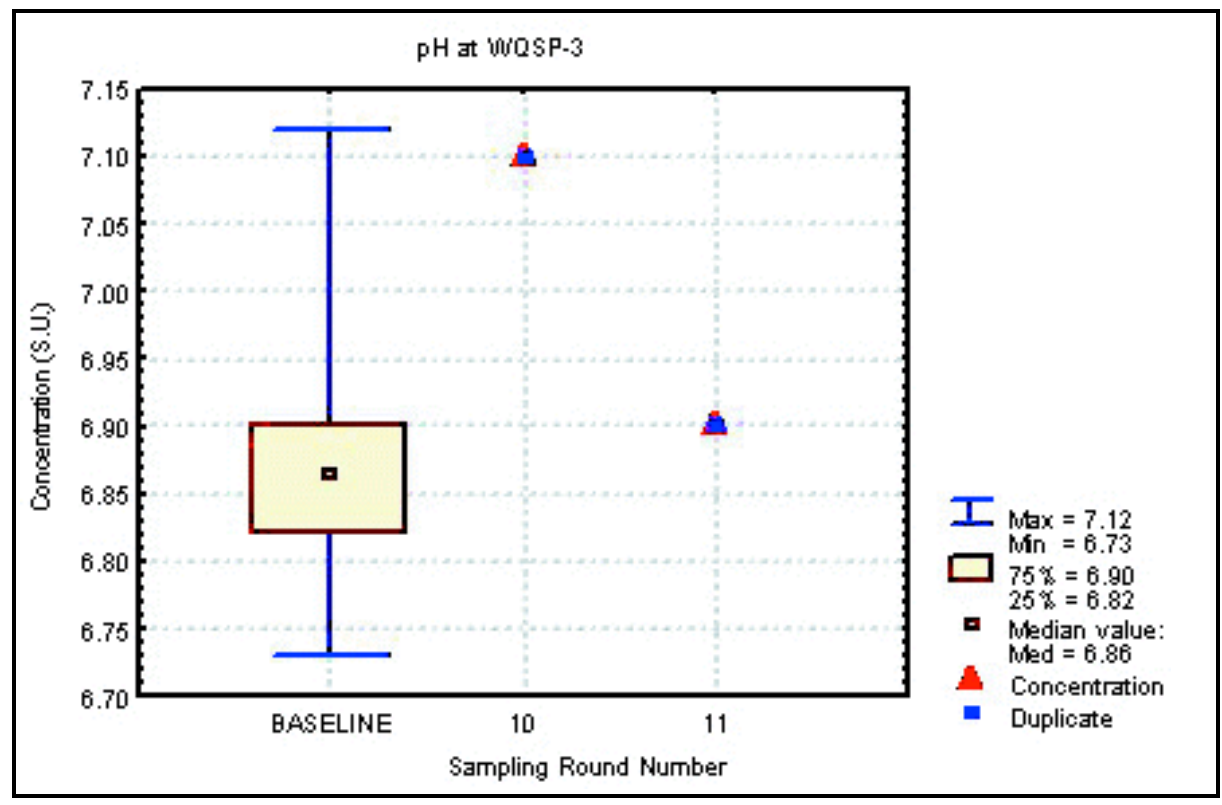

Figure F.46 Time Trend Plot for $\mathrm{pH}$ at WQSP-3

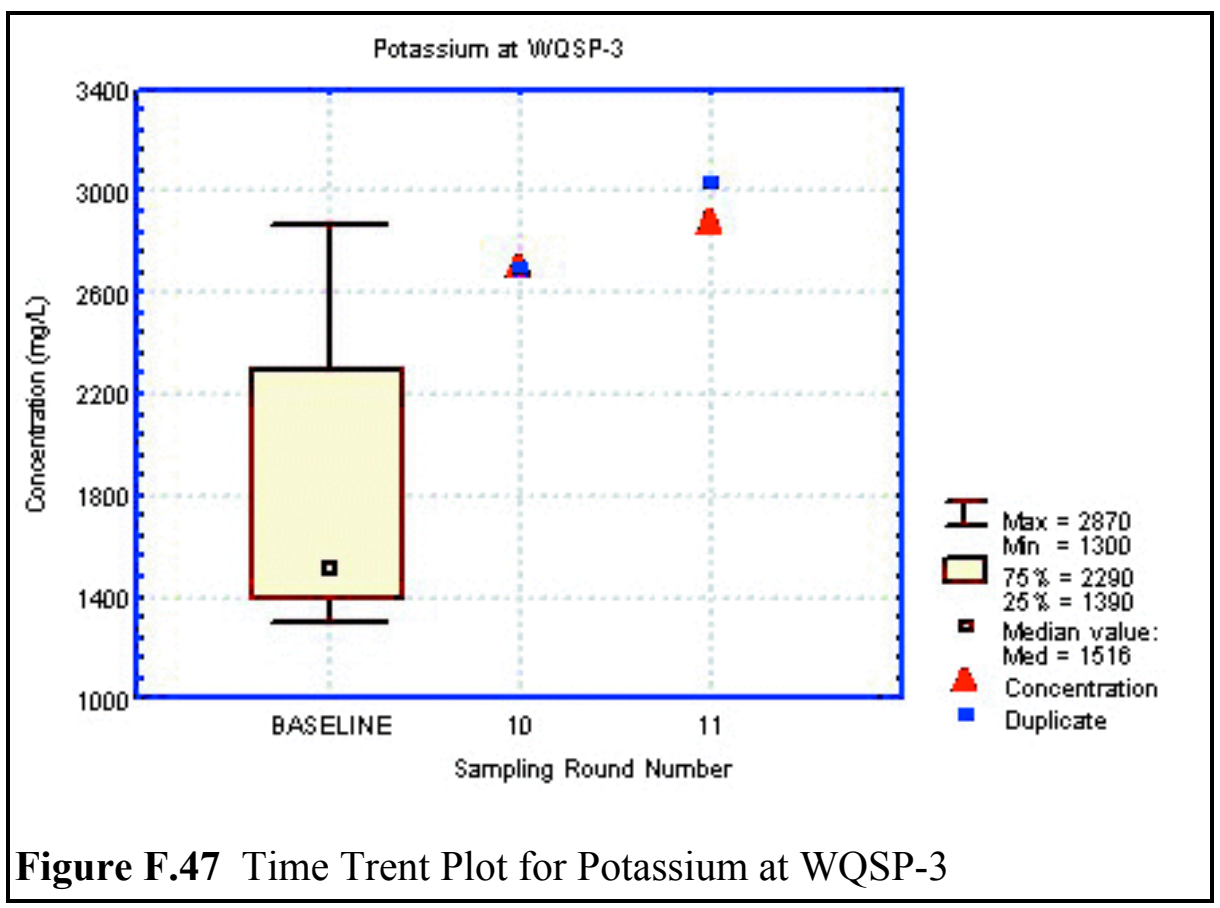




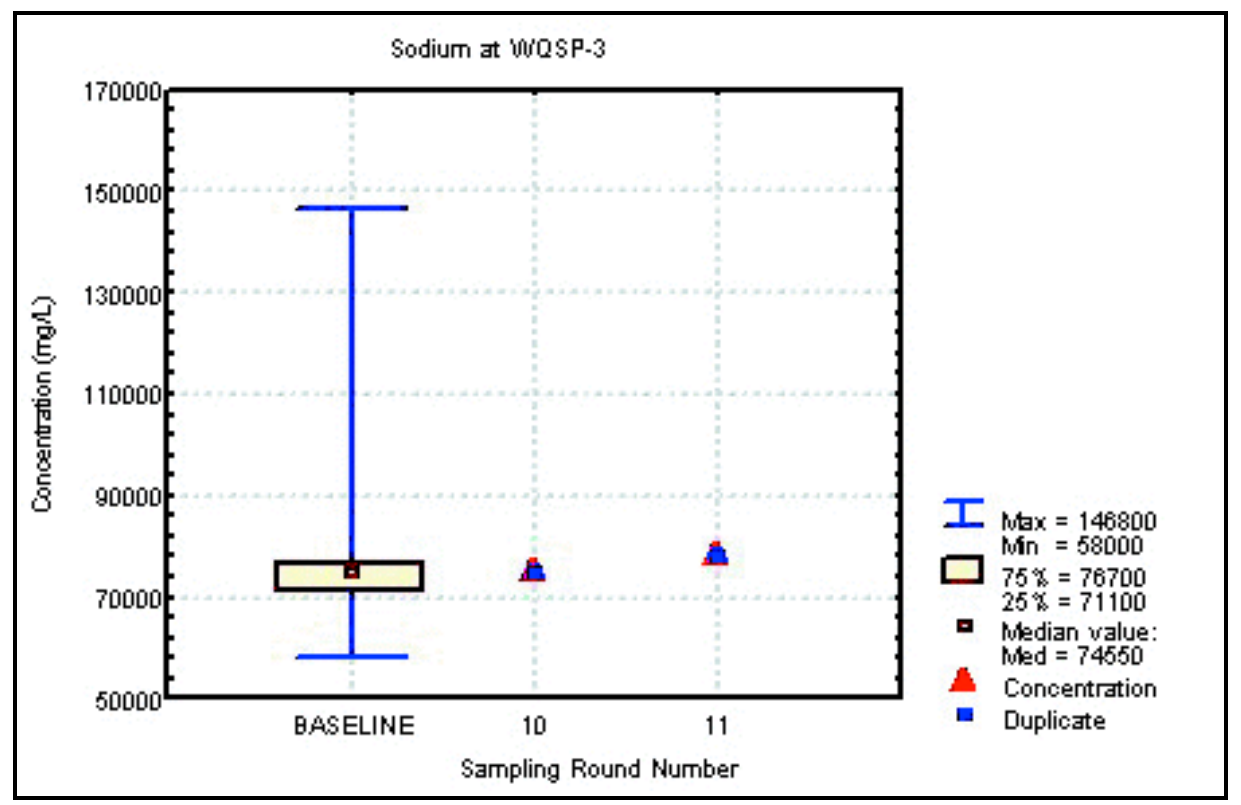

Figure F.48 Time Trend Plot for Sodium at WQSP-3

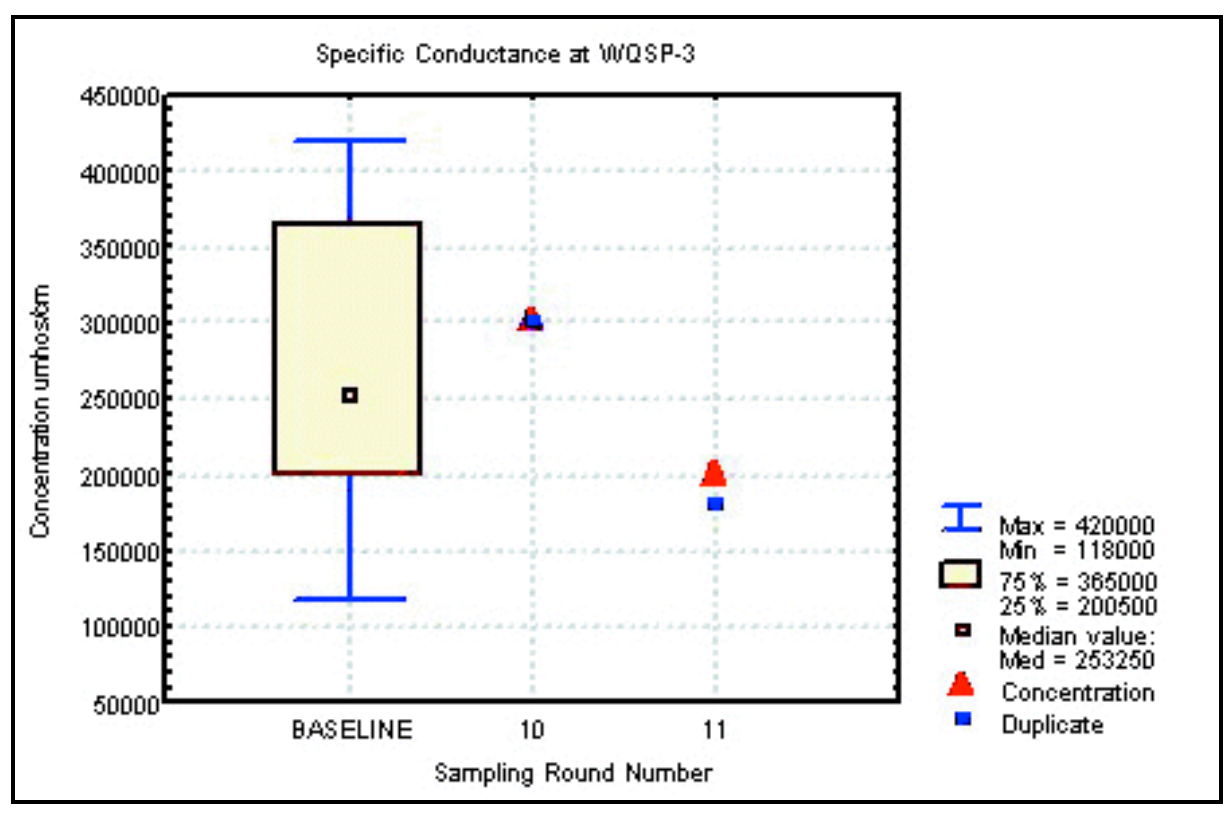

Figure F.49 Time Trent Plot for Specific Conductance at WQSP-3 


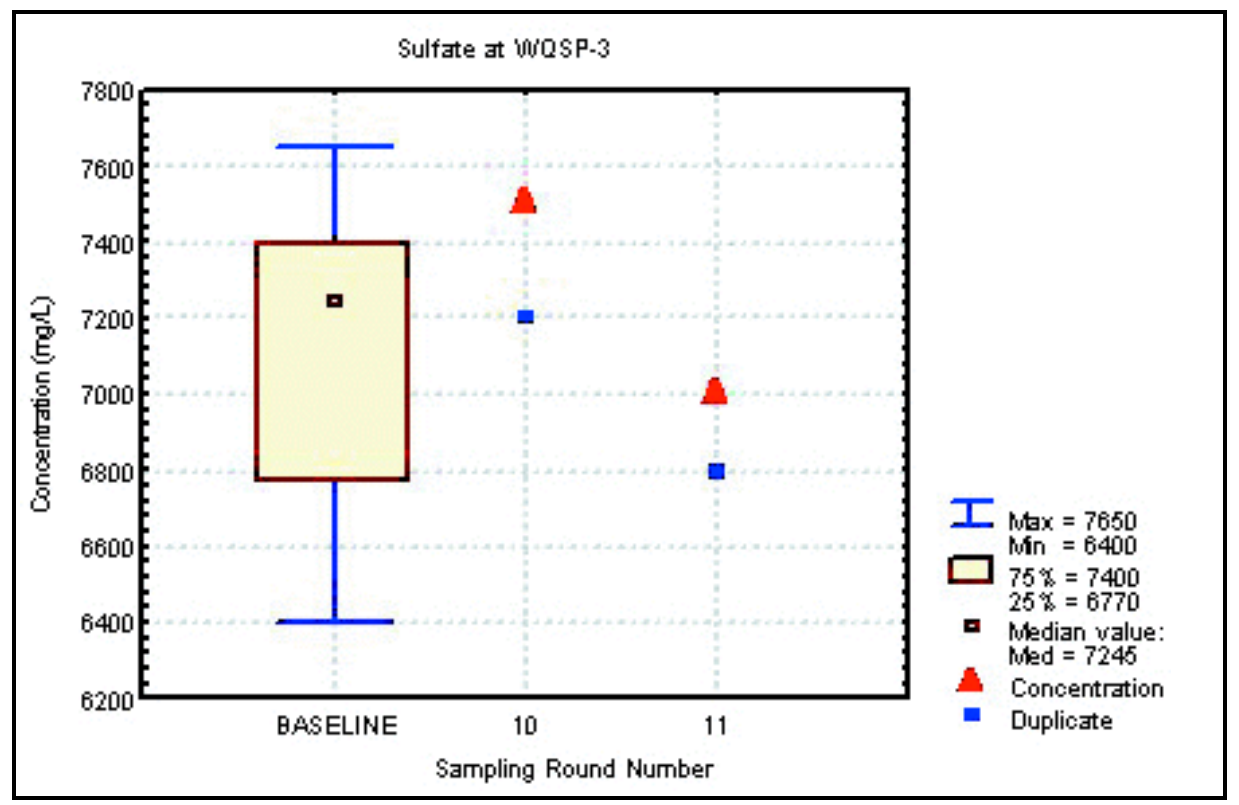

Figure F.50 Time Trend Plot for Sulfate at WQSP-3

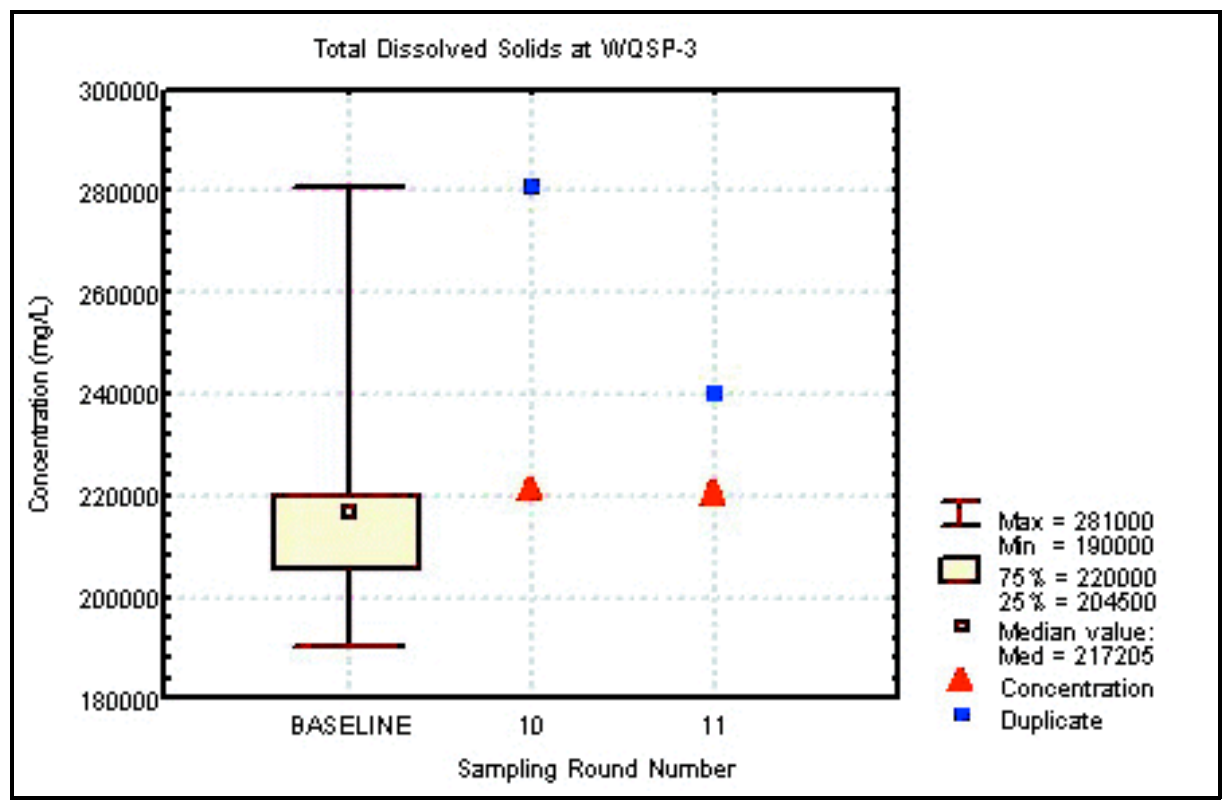

Figure F.51 Time Trent Plot for Total Dissolved Solids at WQSP-3 


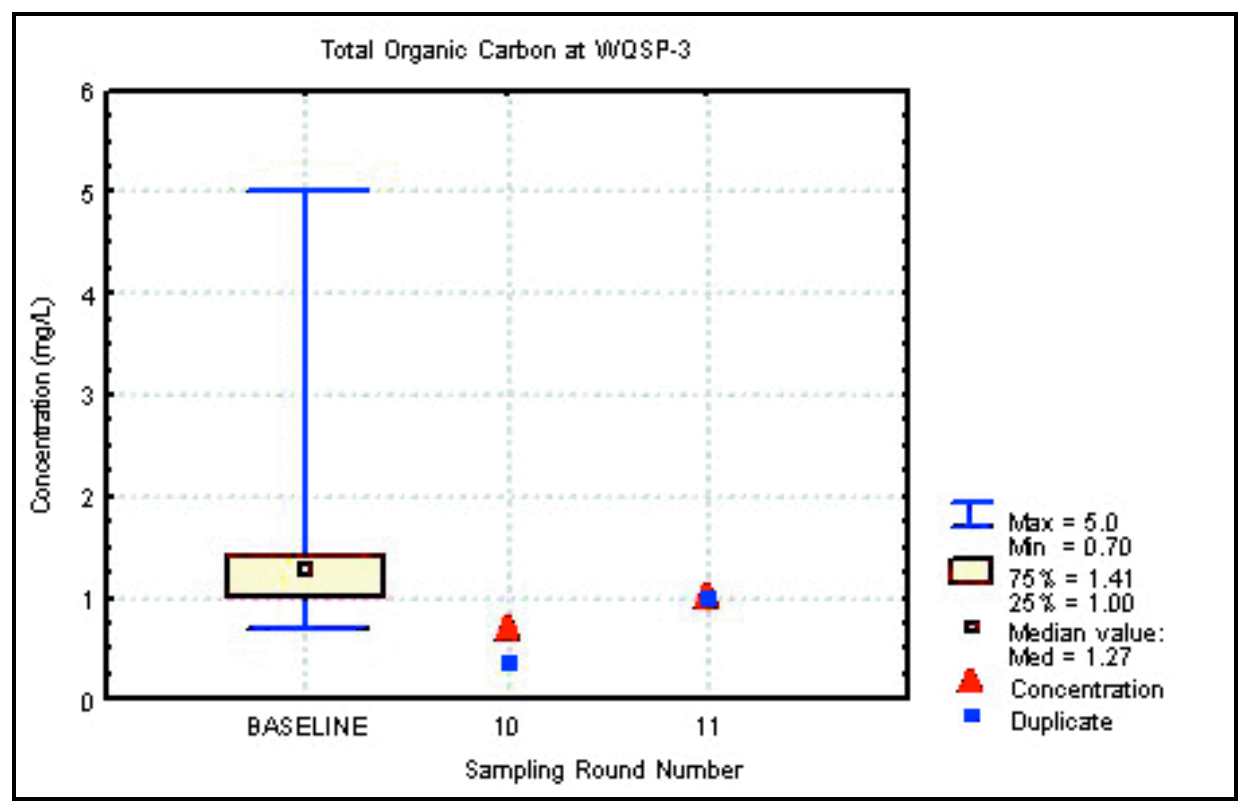

Figure F.52 Time Trend Plot for Total Organic Carbon at WQSP-3

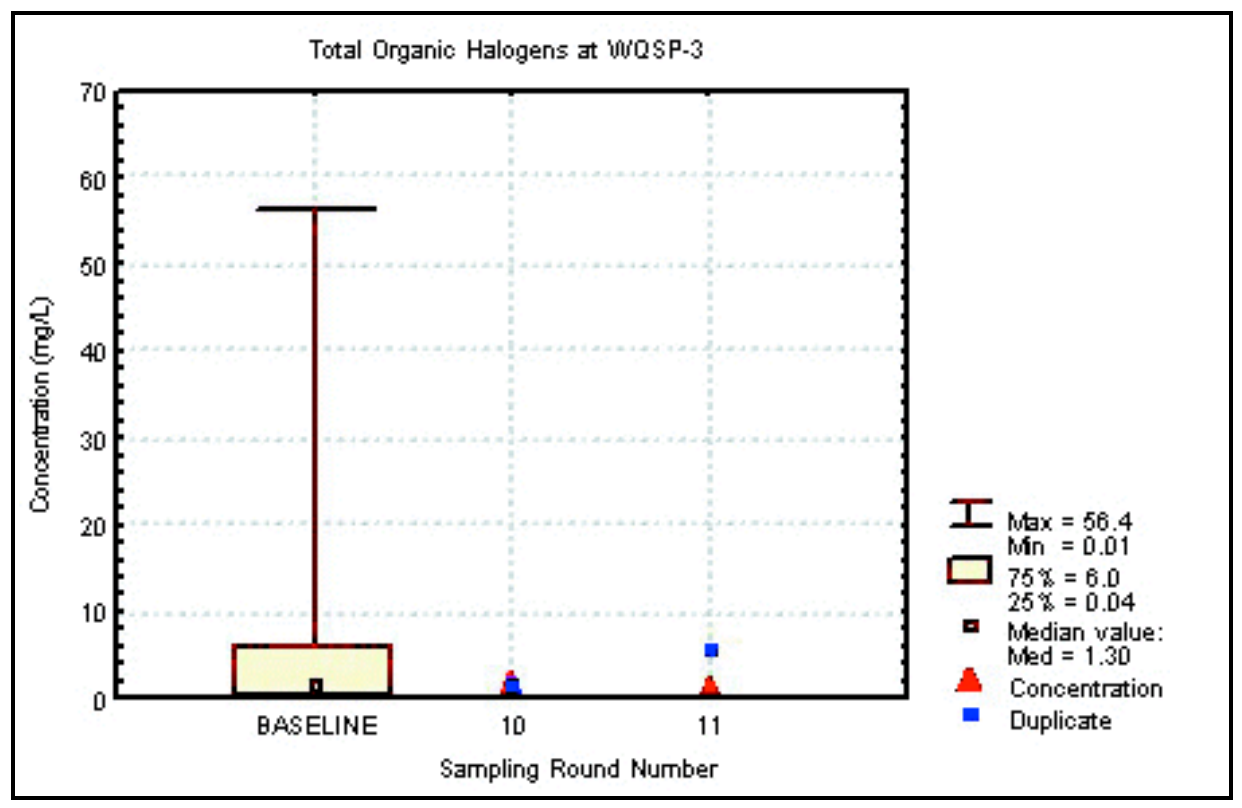

Figure F.53 Time Trent Plot for Total Organic Halogens at WQSP-3 


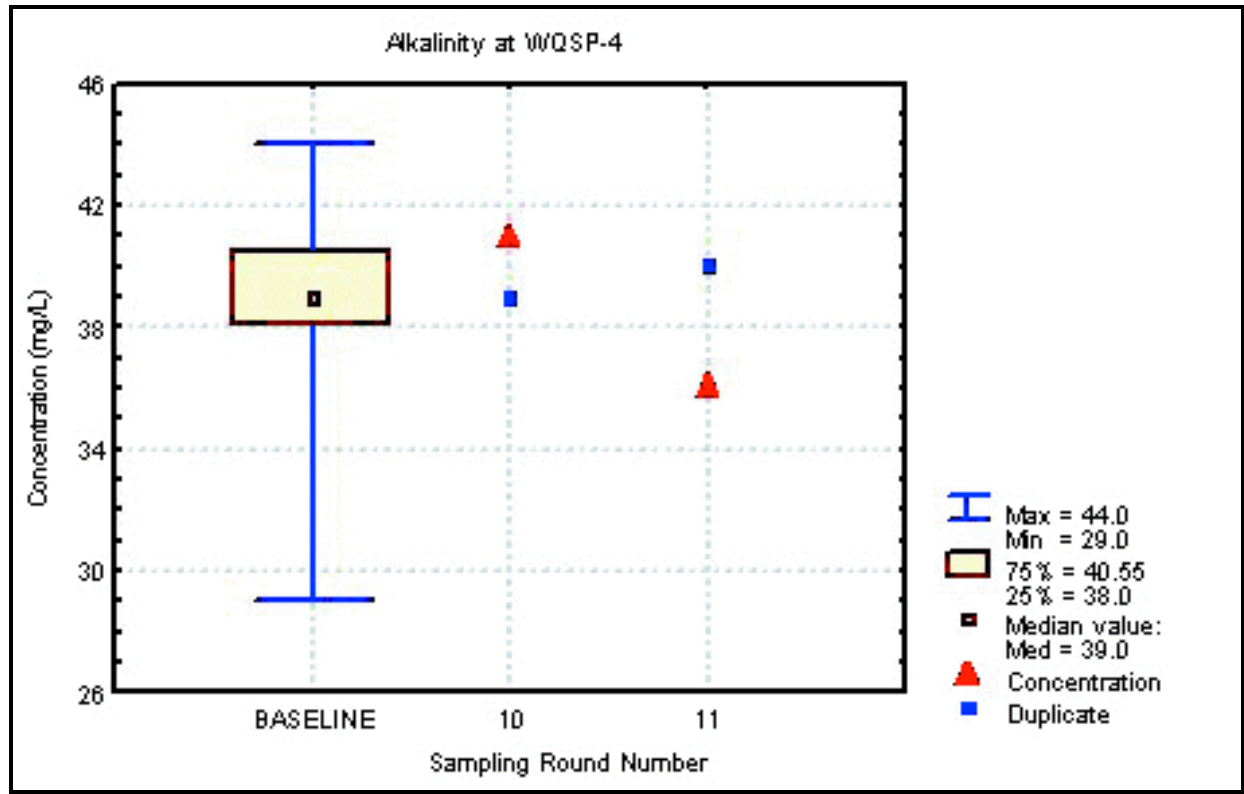

Figure F.54 Time Trend Plot for Alkalinity at WQSP-4

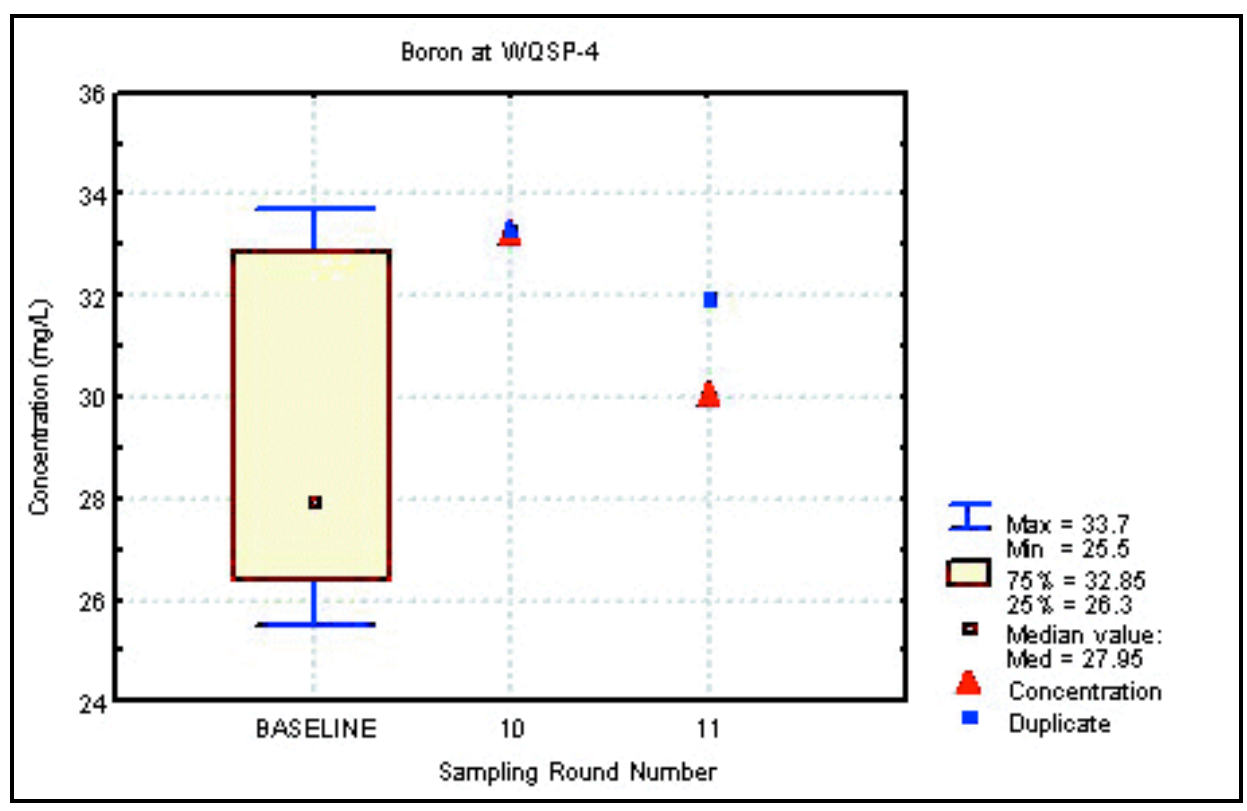

Figure F.55 Time Trent Plot for Boron at WQSP-4 


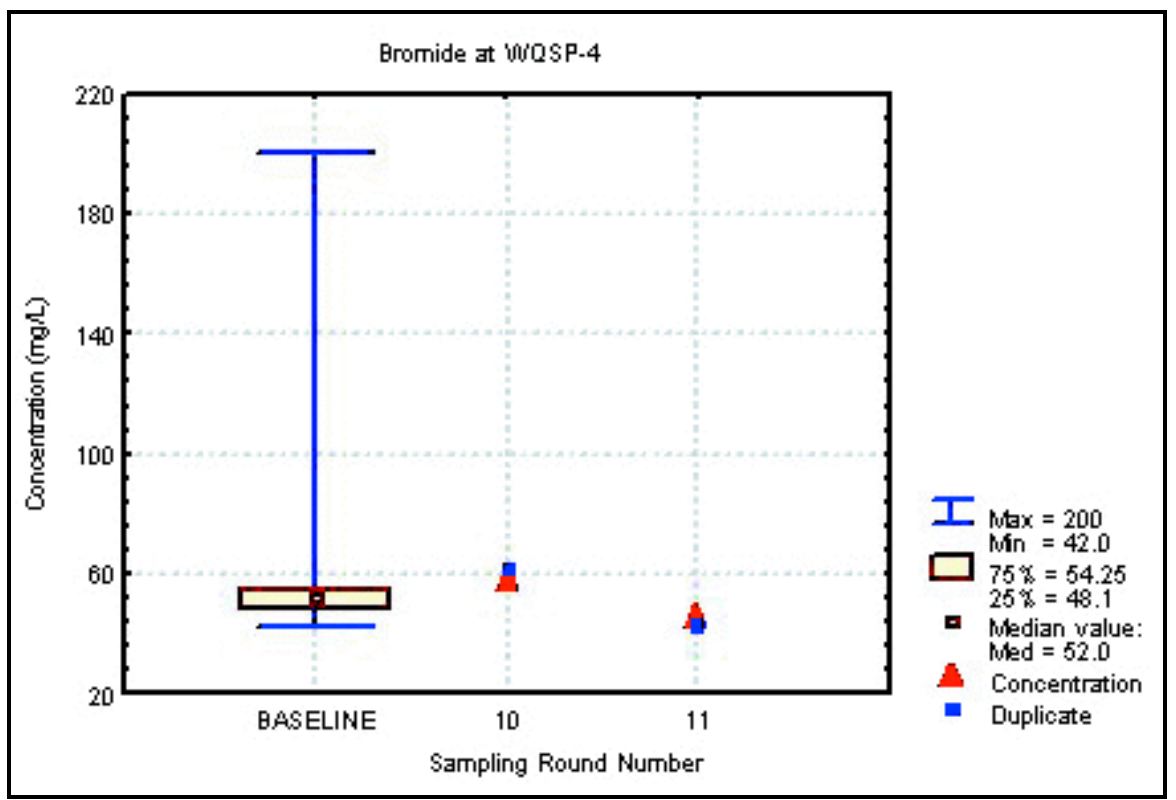

Figure F.56 Time Trend Plot for Bromide at WQSP-4

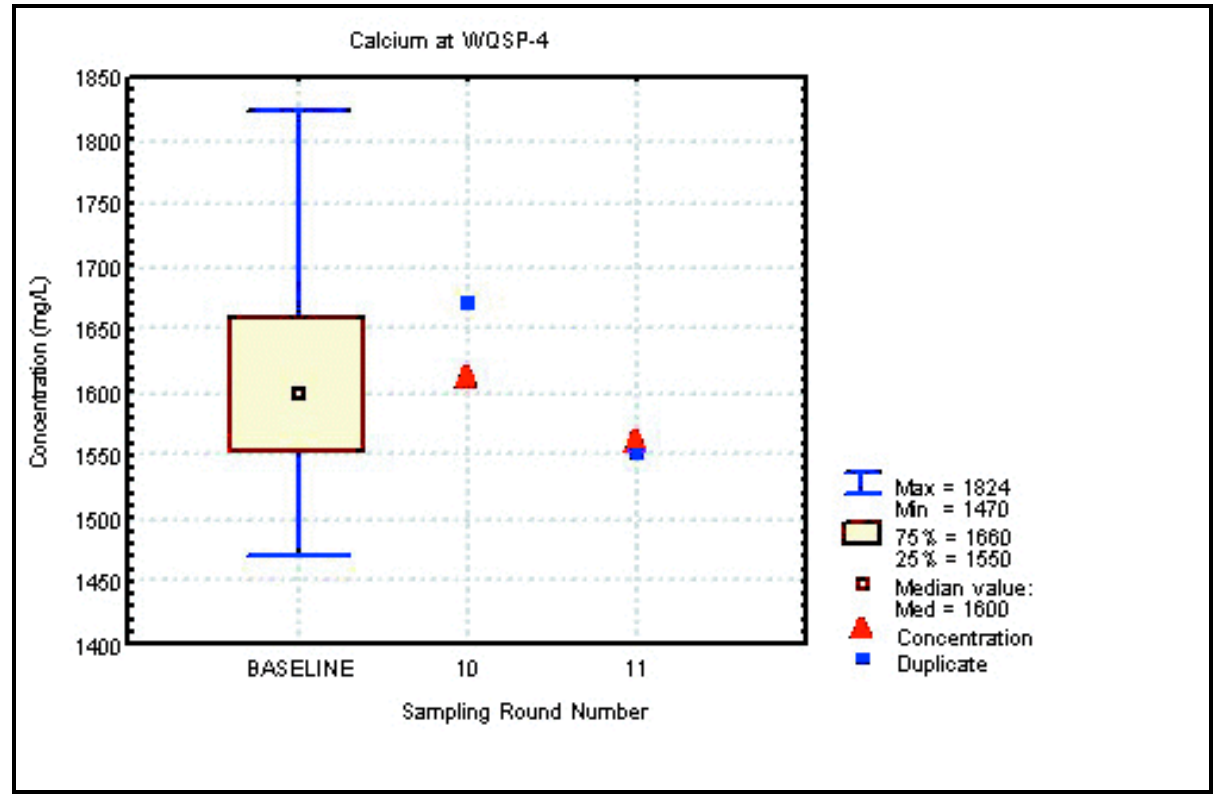

Figure F.57 Time Trent Plot for Calcium at WQSP-4 


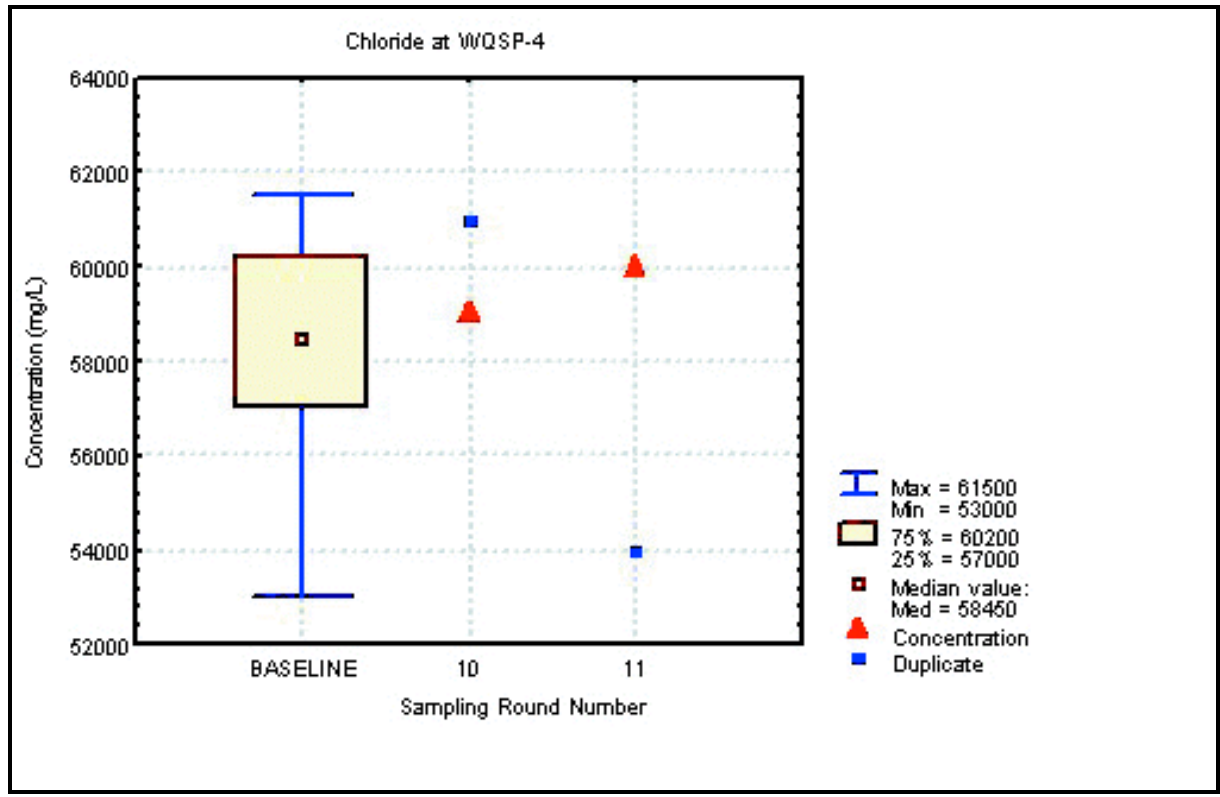

Figure F.58 Time Trend Plot for Chloride at WQSP-4

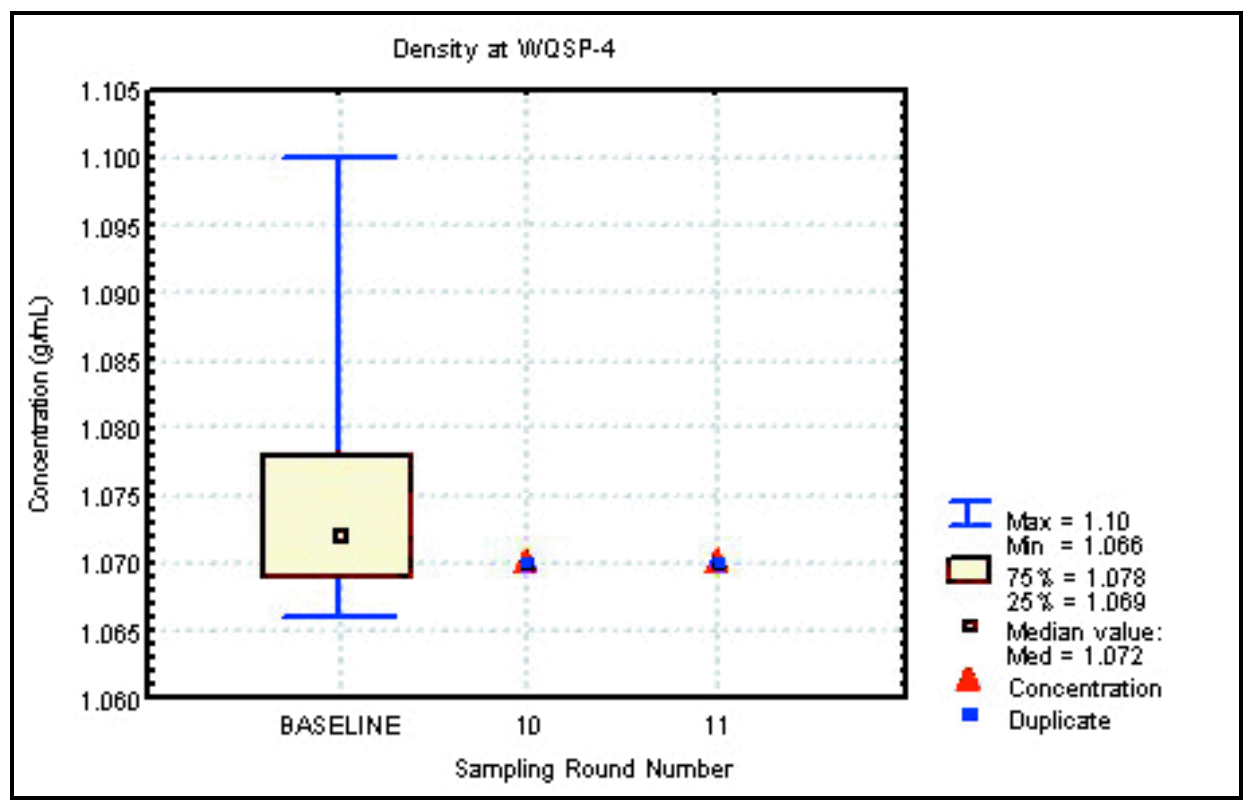

Figure F.59 Time Trent Plot for Density at WQSP-4 


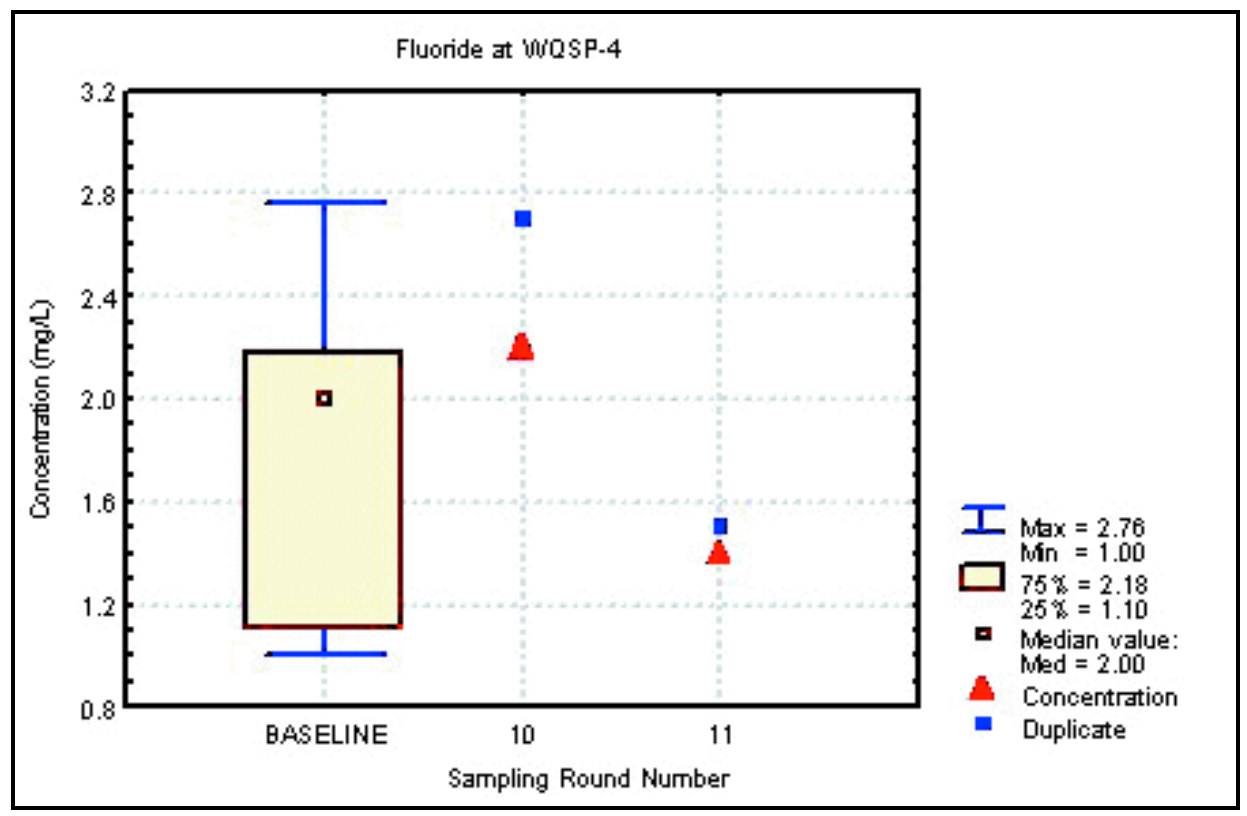

Figure F.60 Time Trend Plot for Fluoride at WQSP-4

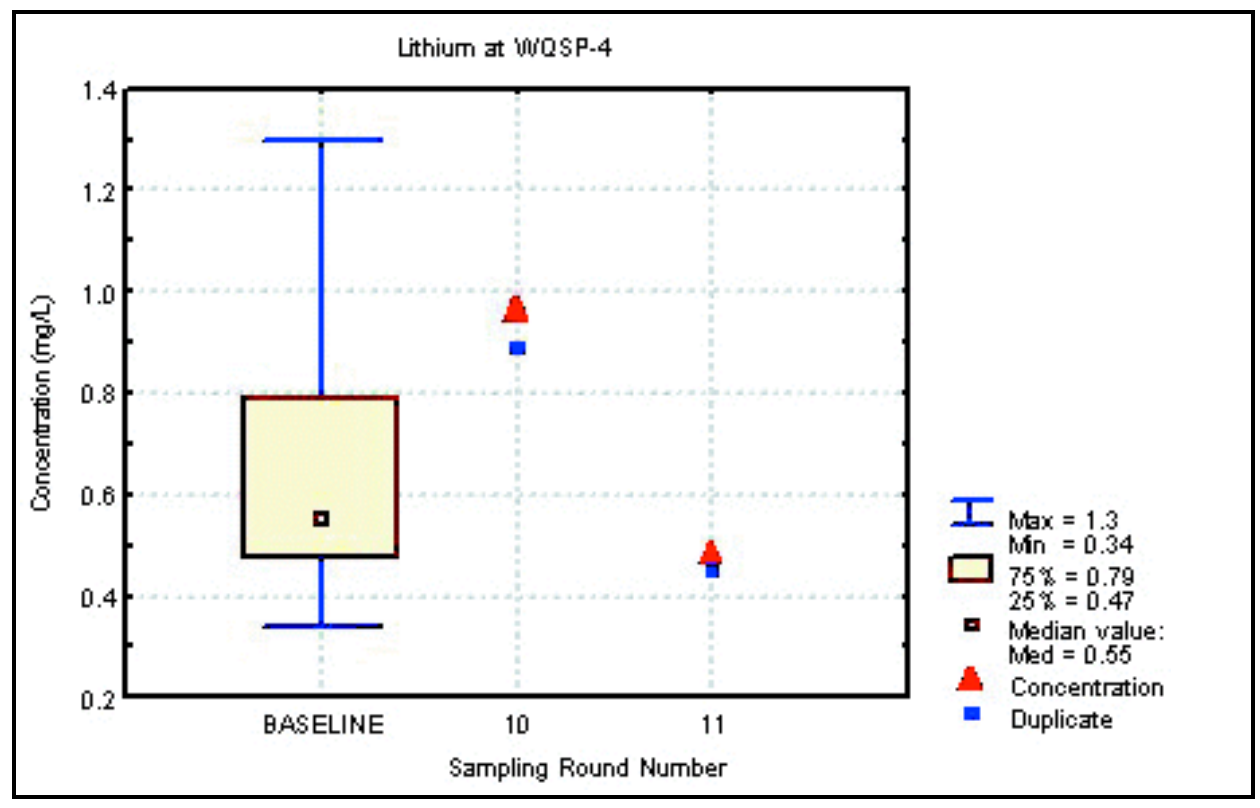

Figure F.61 Time Trent Plot for Lithium at WQSP-4 


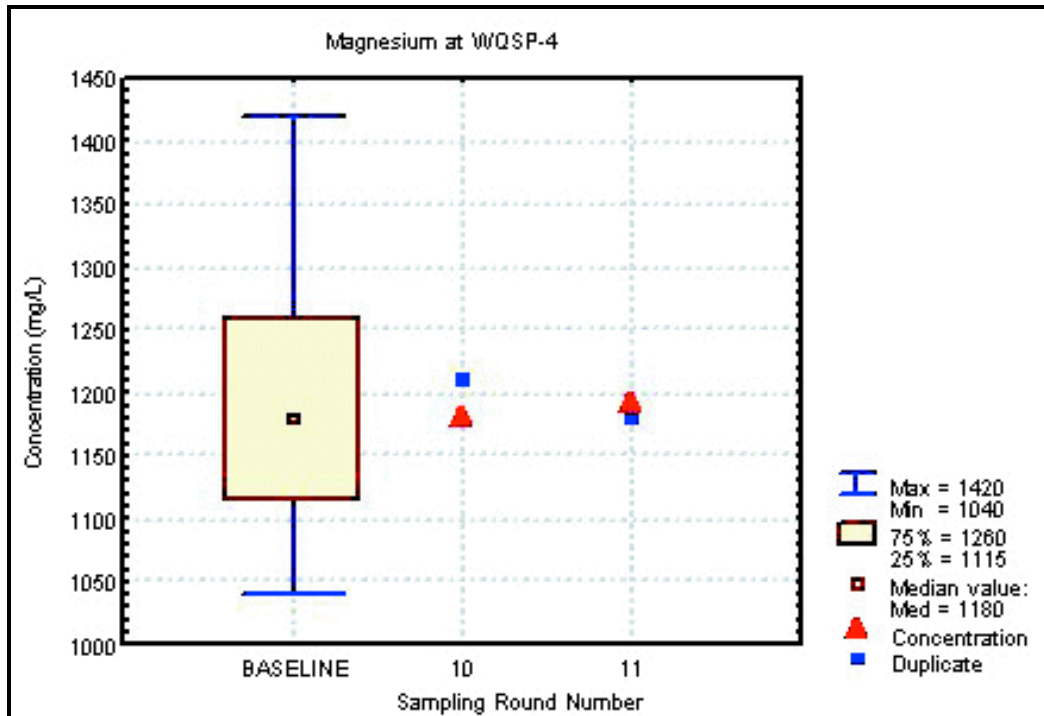

Figure F.62 Time Trend Plot for Magnesium at WQSP-4

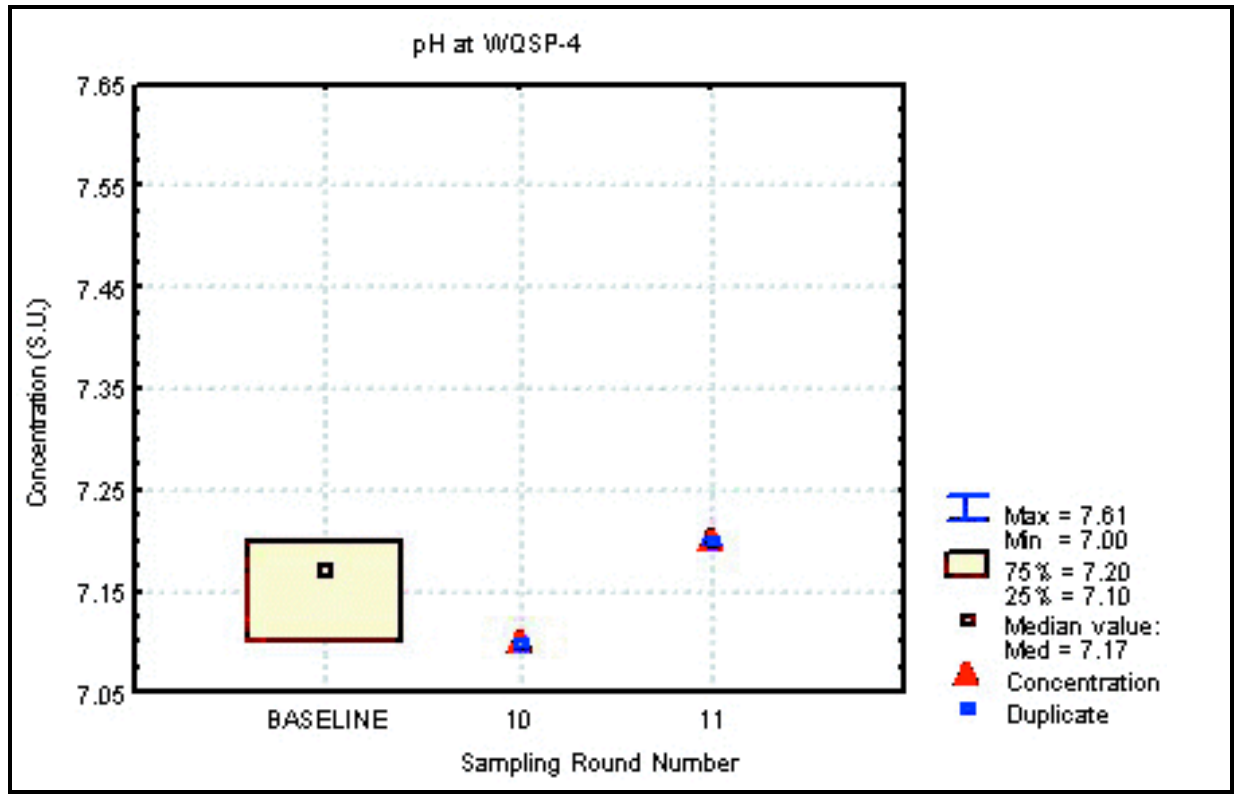

Figure F.63 Time Trent Plot for $\mathrm{pH}$ at WQSP-4 


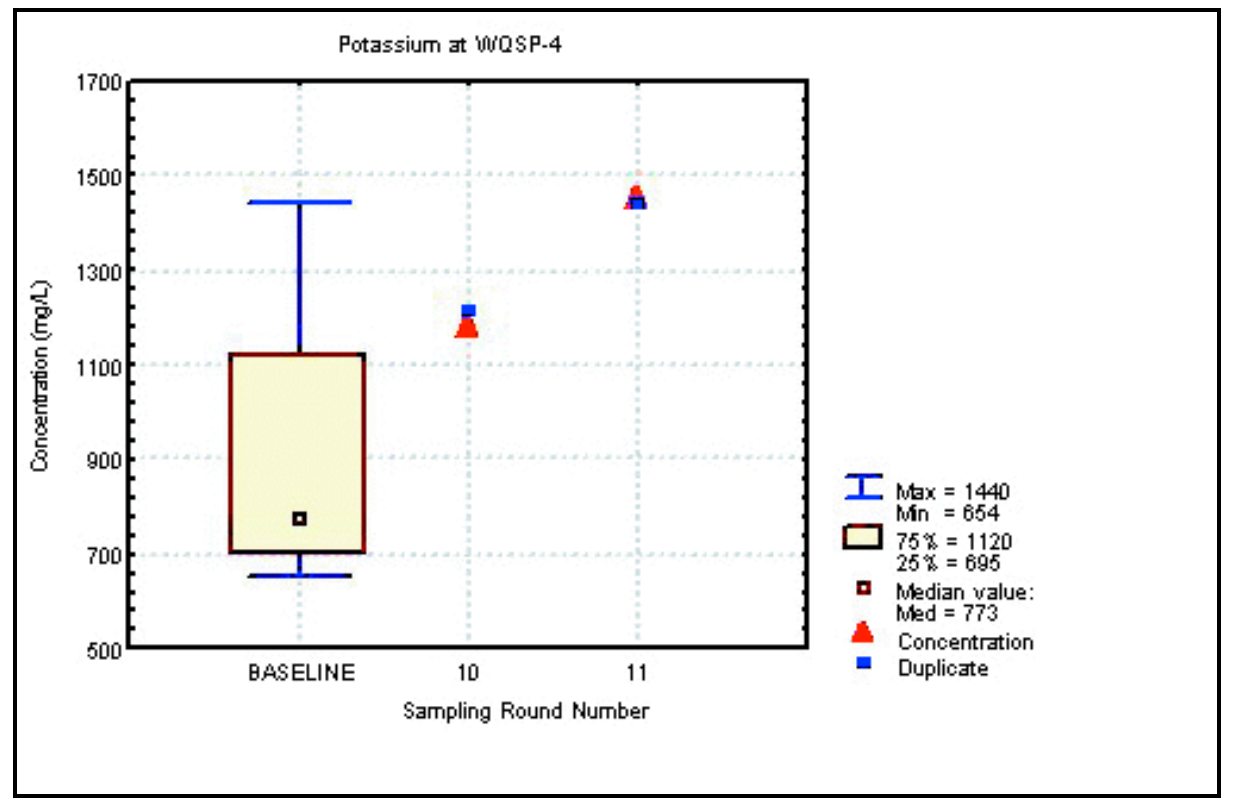

Figure F.64 Time Trend Plot for Potassium at WQSP-4

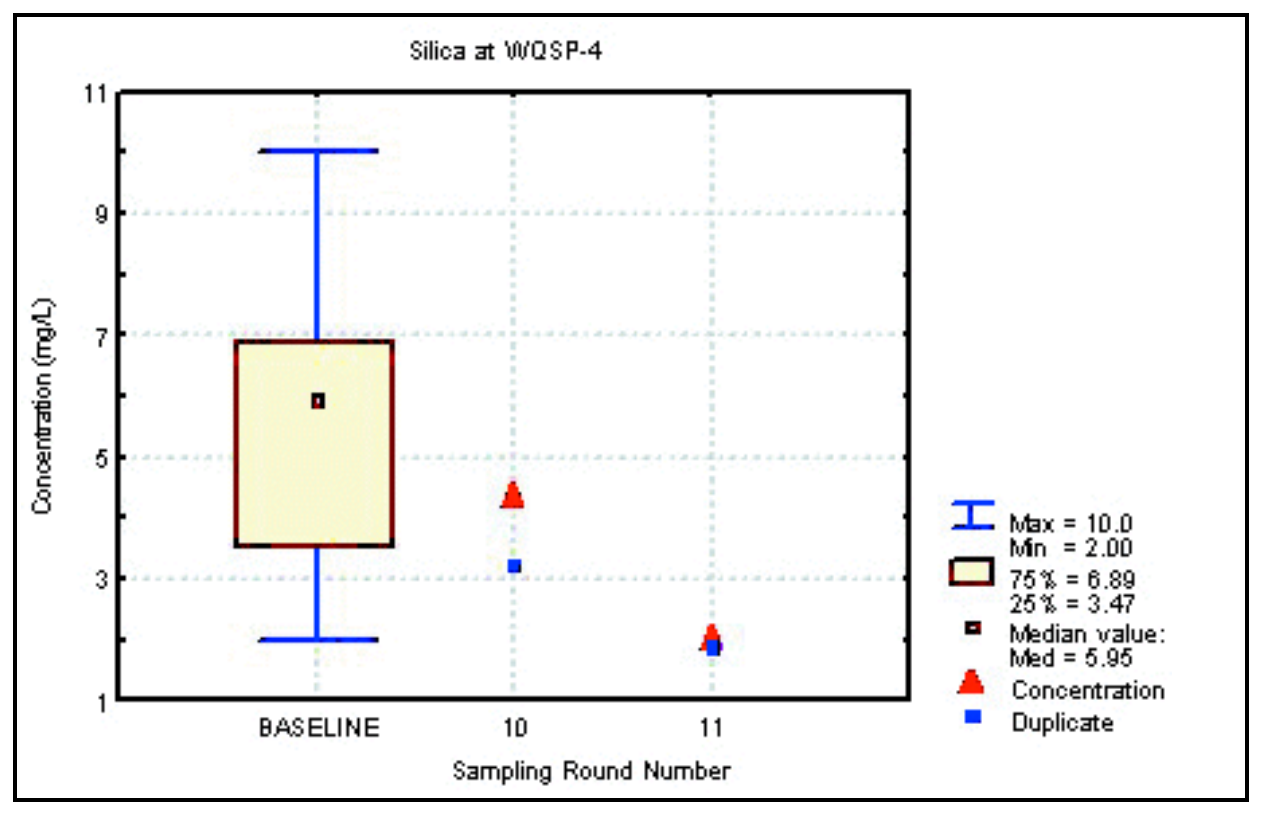

Figure F.65 Time Trent Plot for Silica at WQSP-4 


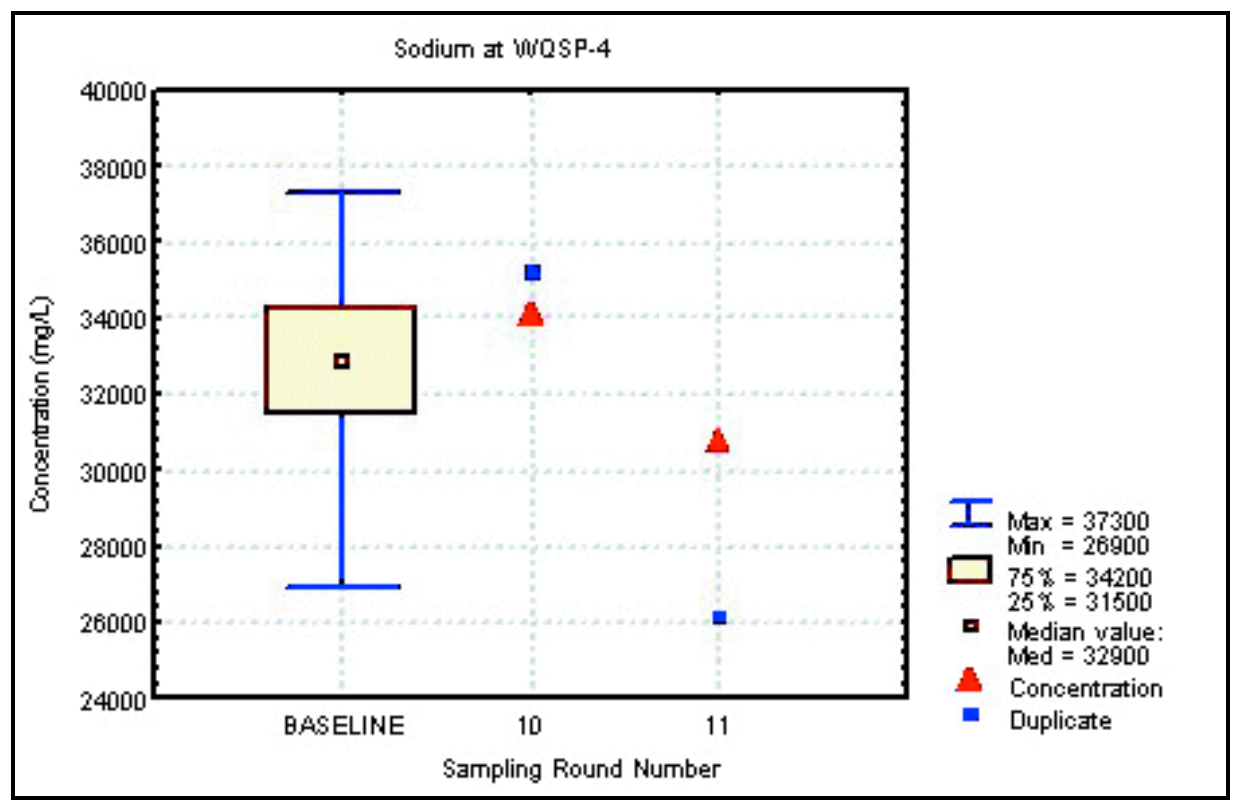

Figure F.66 Time Trend Plot for Sodium at WQSP-4

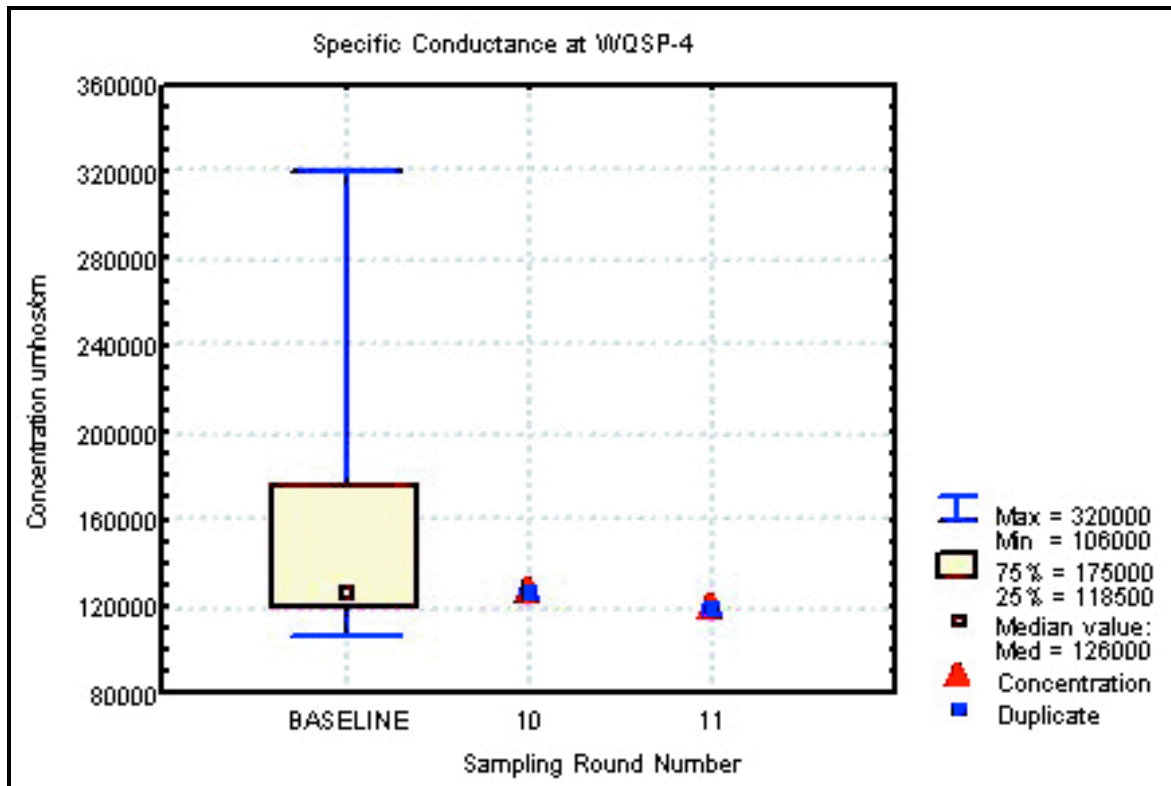

Figure F.67 Time Trent Plot for Specific Conductance at WQSP-4 


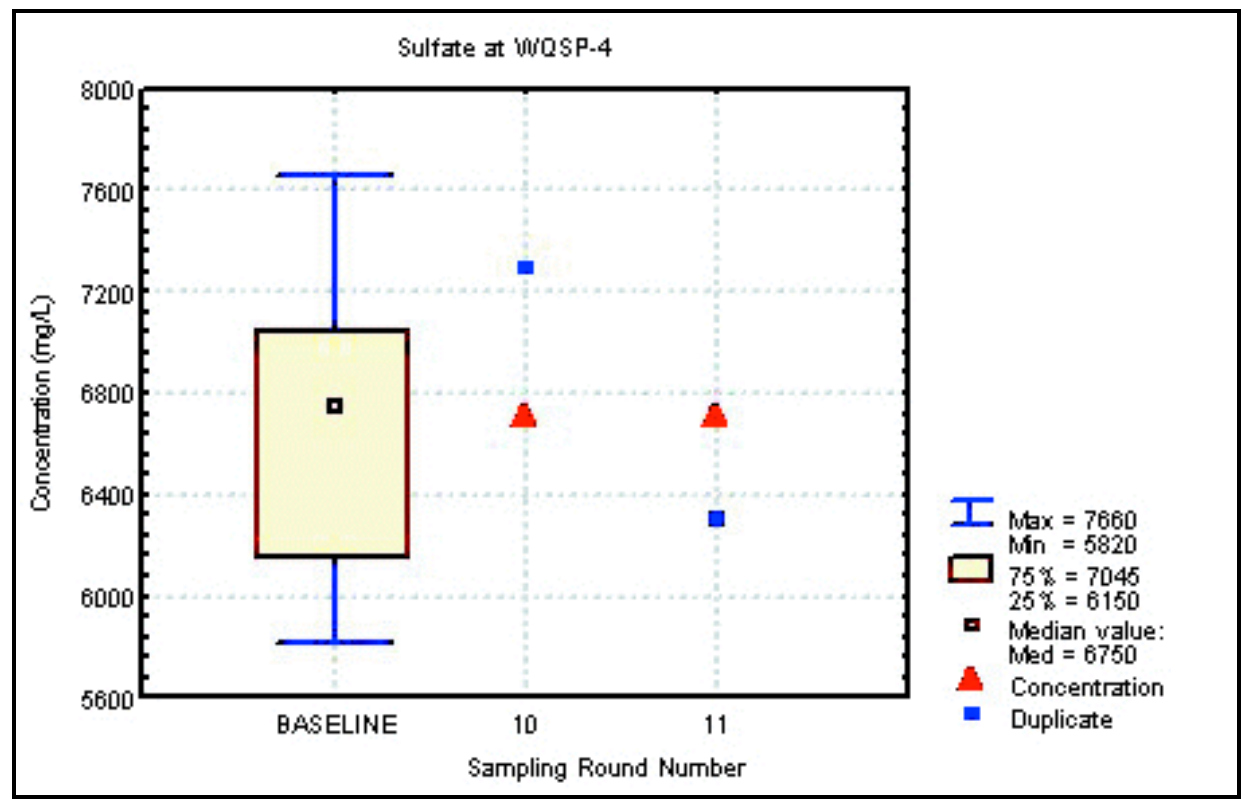

Figure F.68 Time Trend Plot for Sulfate at WQSP-4

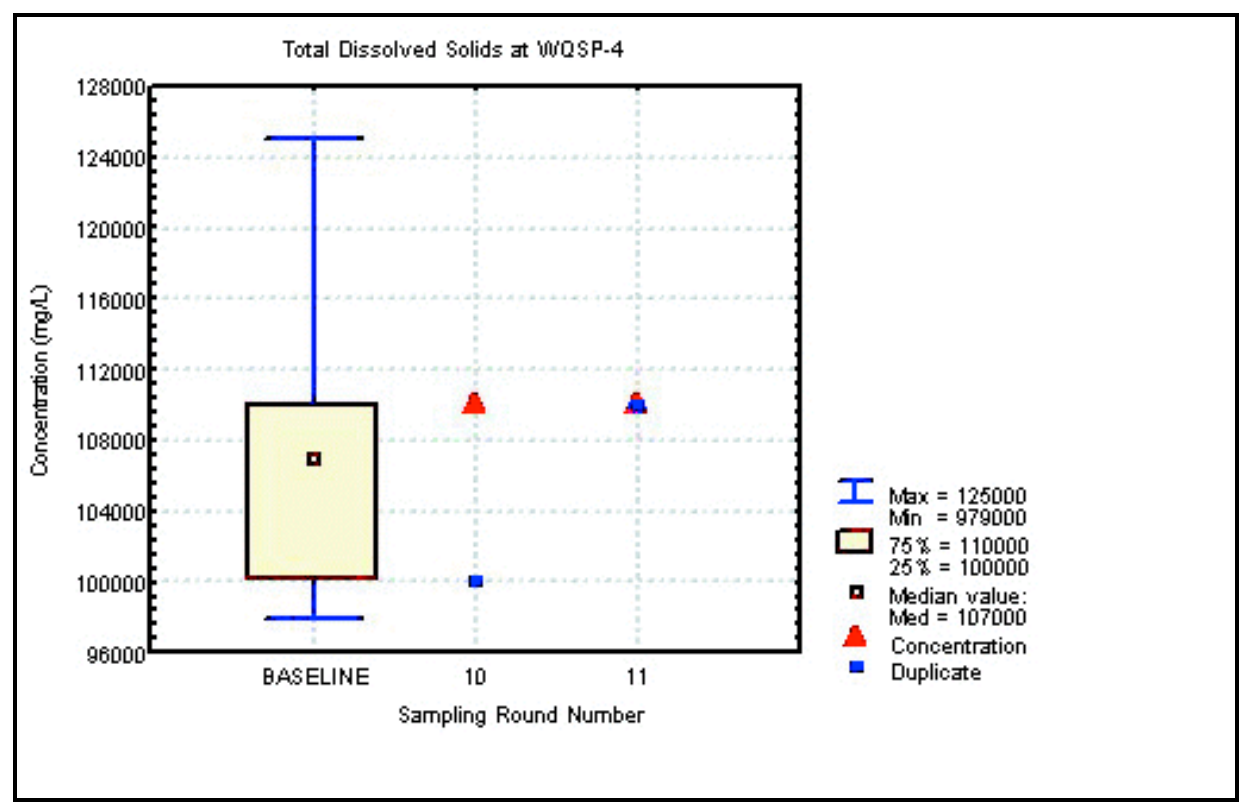

Figure F.69 Time Trent Plot for Total Dissolved Solids at WQSP-4 


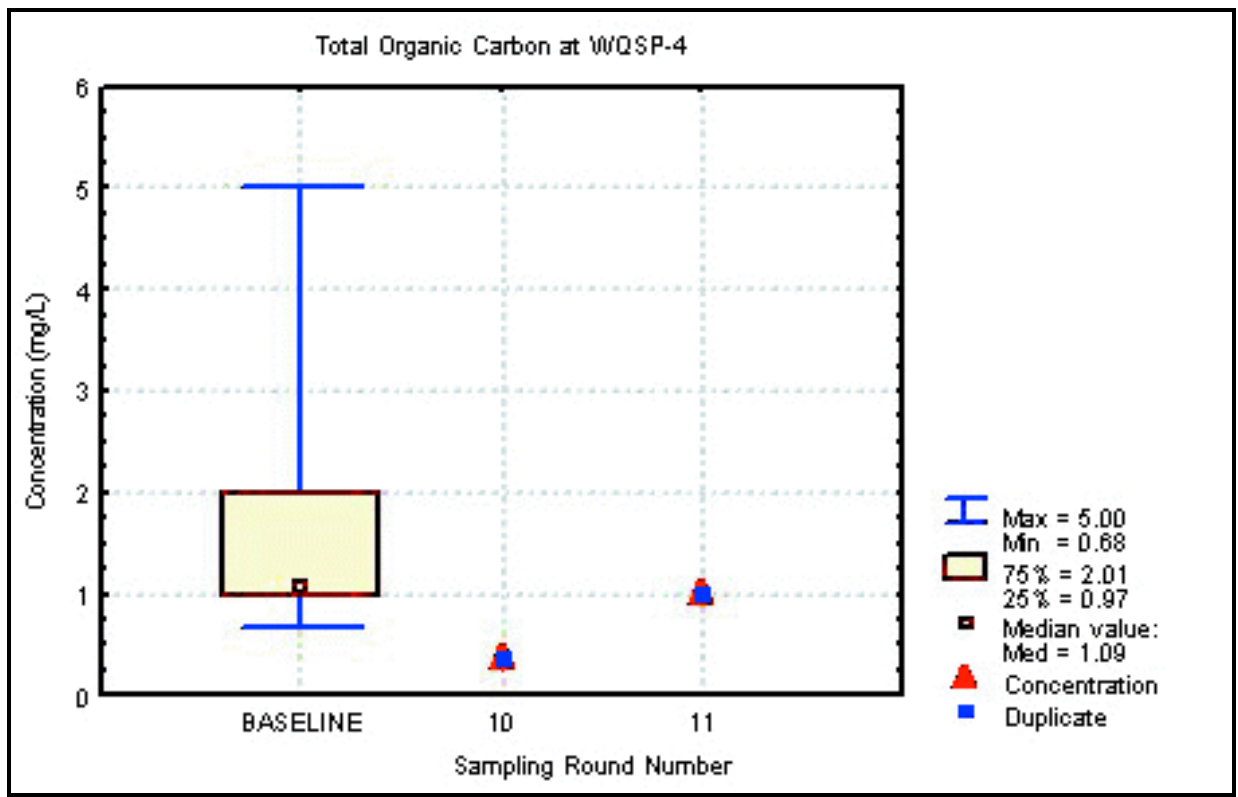

Figure F.70 Time Trend Plot for Total Organic Carbon at WQSP-4

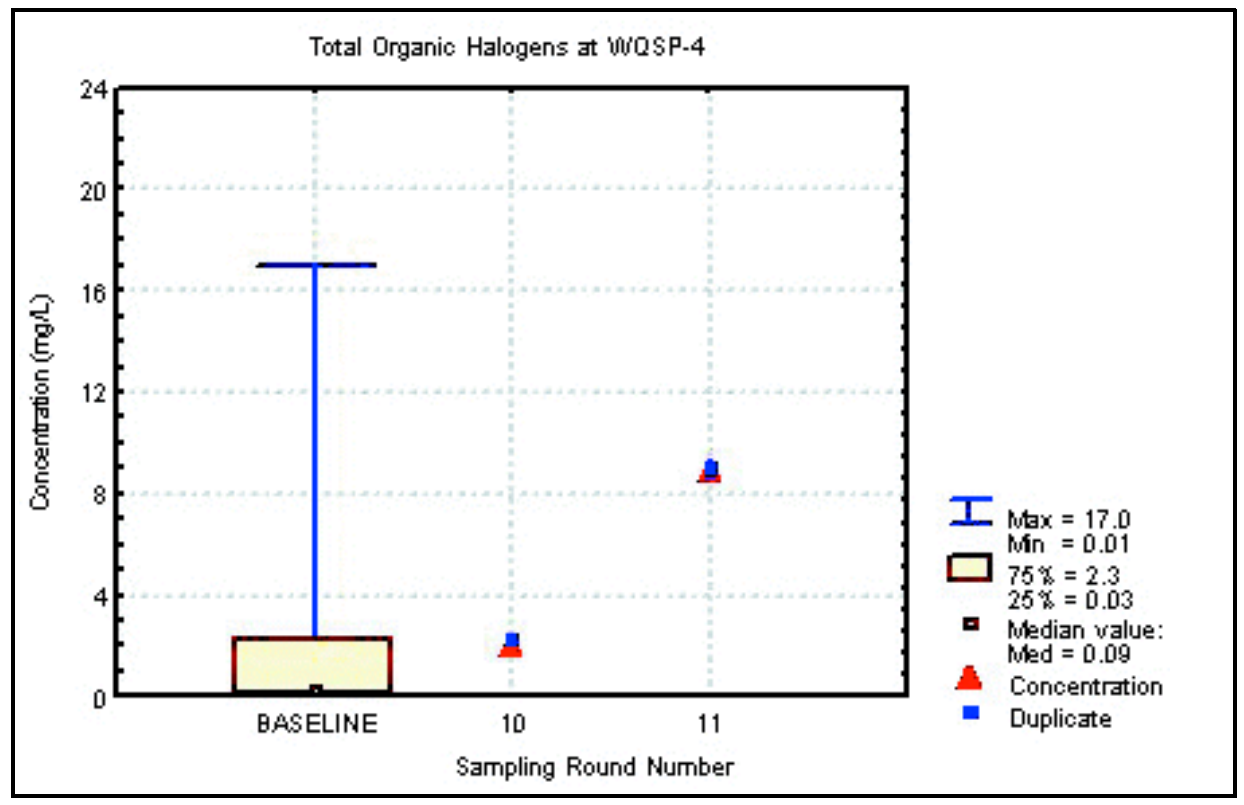

Figure F.71 Time Trent Plot for Total Organic Halogens at WQSP-4 


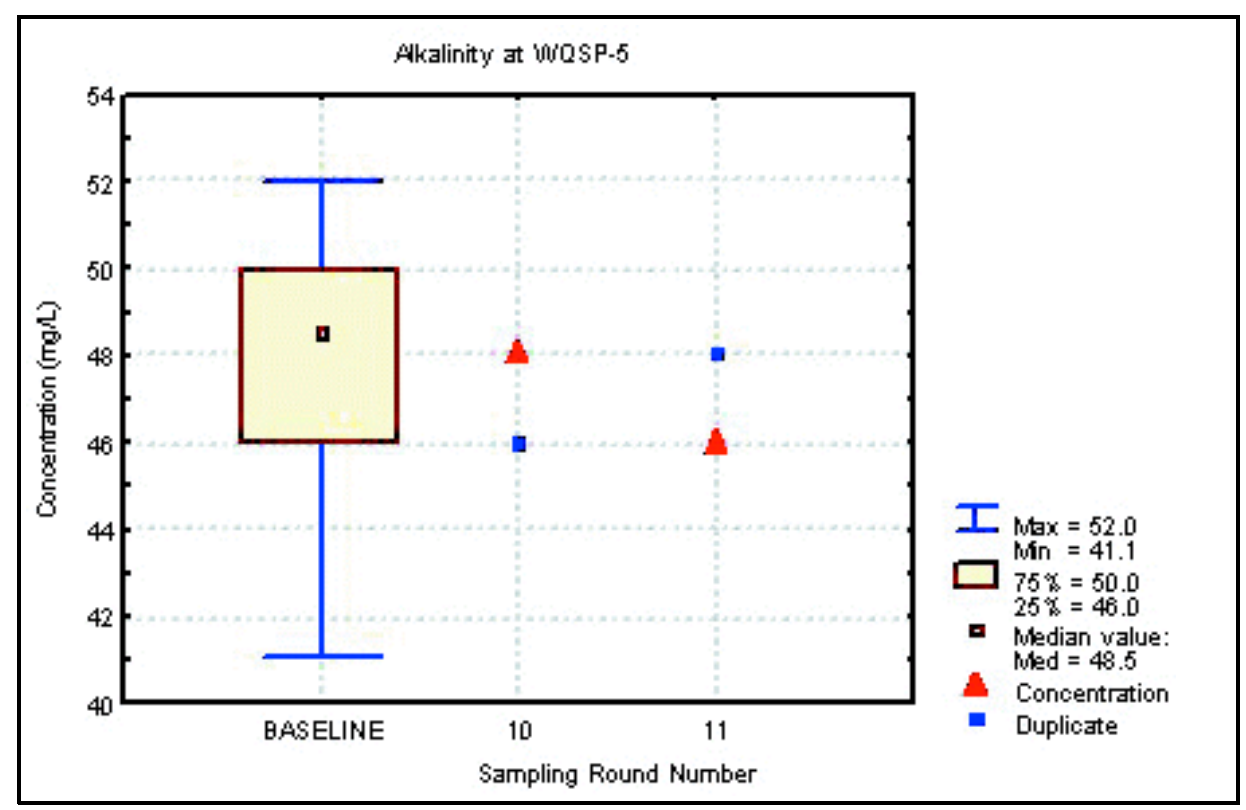

Figure F.72 Time Trend Plot for Alkalinity at WQSP-5

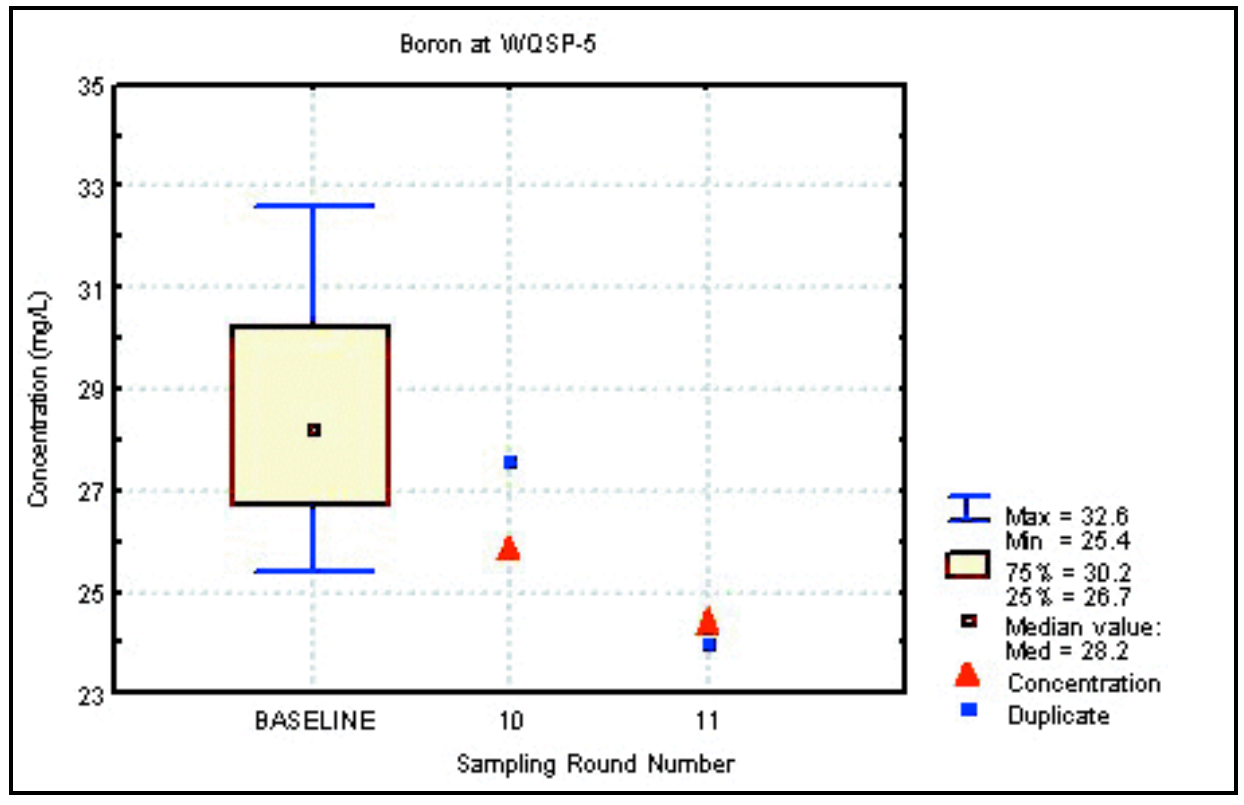

Figure F.73 Time Trent Plot for Boron at WQSP-5 


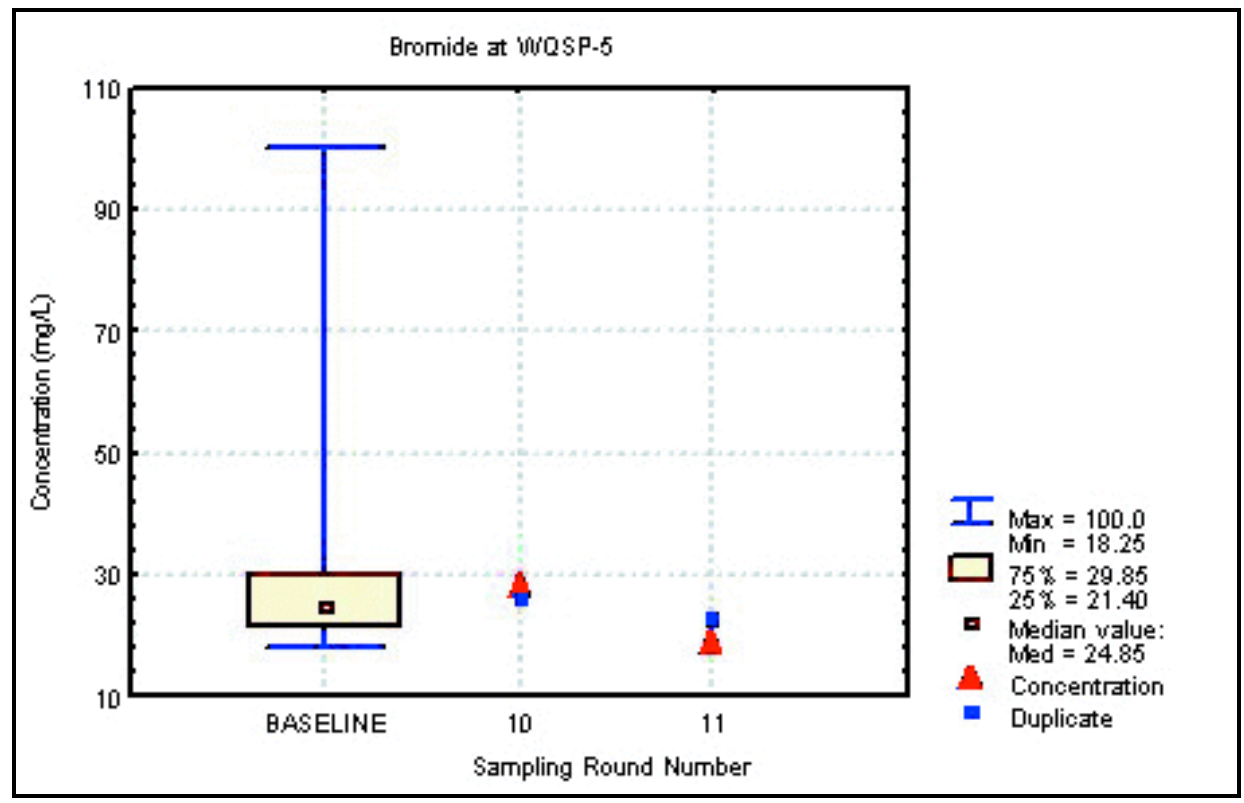

Figure F.74 Time Trend Plot for Bromide at WQSP-5

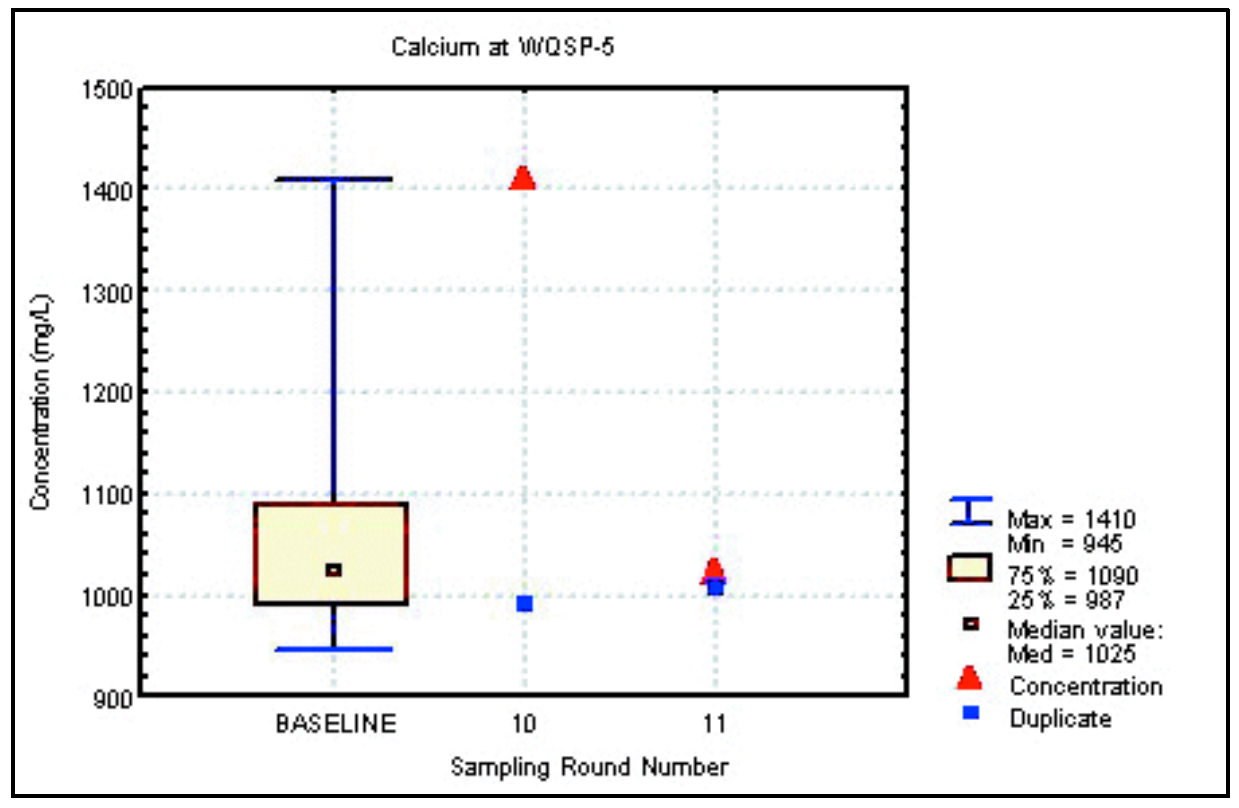

Figure F.75 Time Trent Plot for Calcium at WQSP-5 


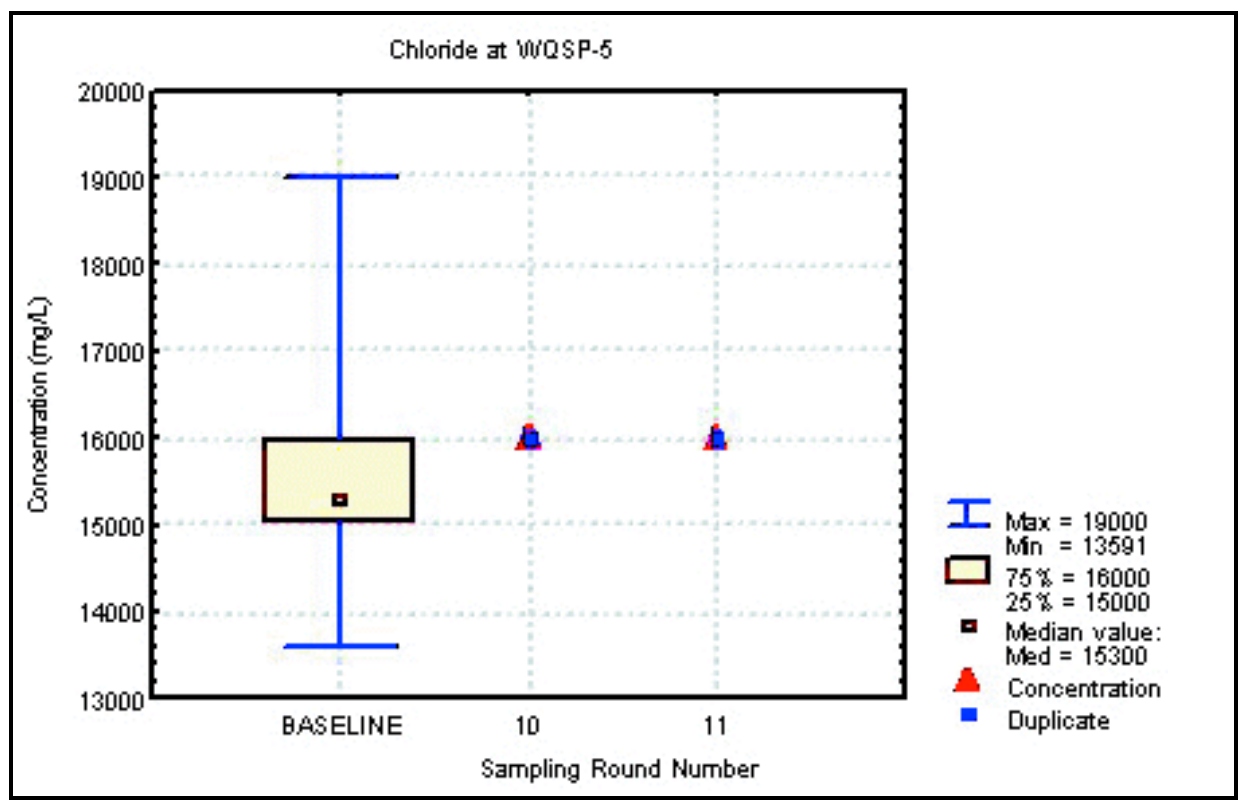

Figure F.76 Time Trend Plot for Chloride at WQSP-5

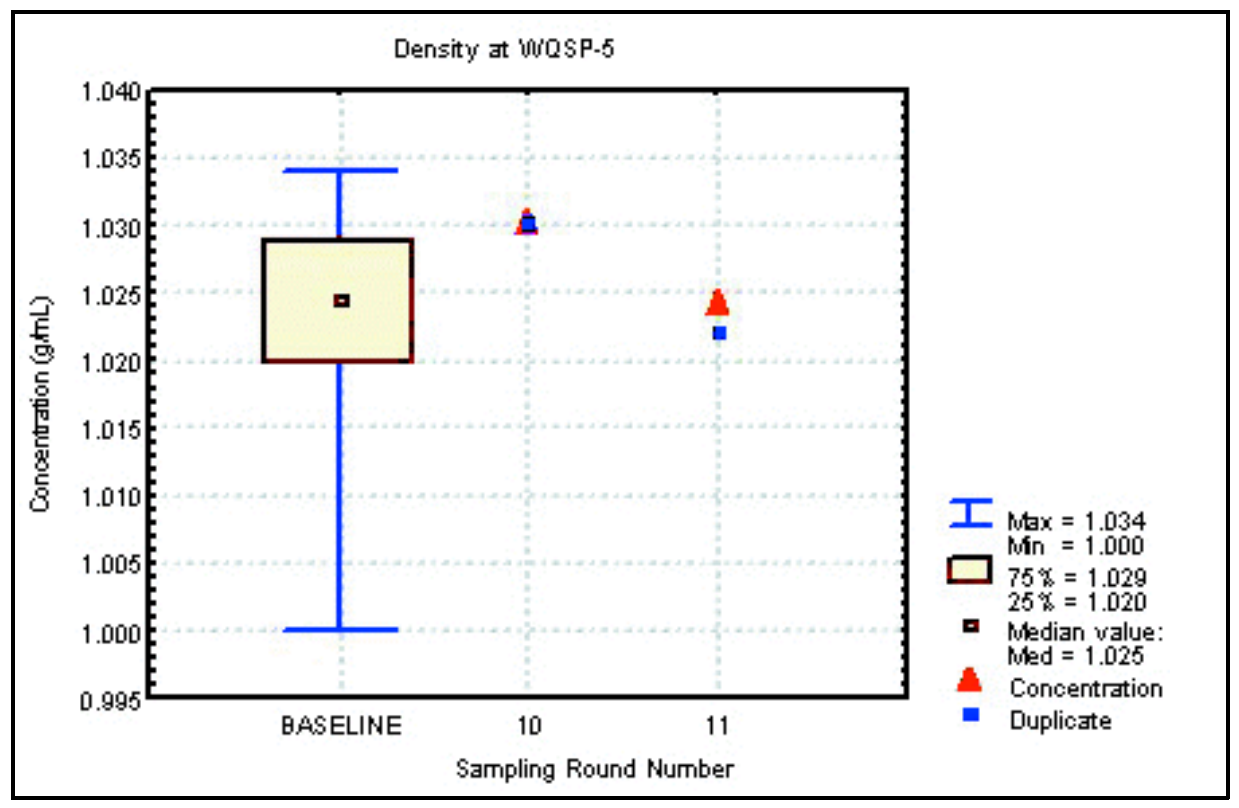

Figure F.77 Time Trent Plot for Density at WQSP-5 


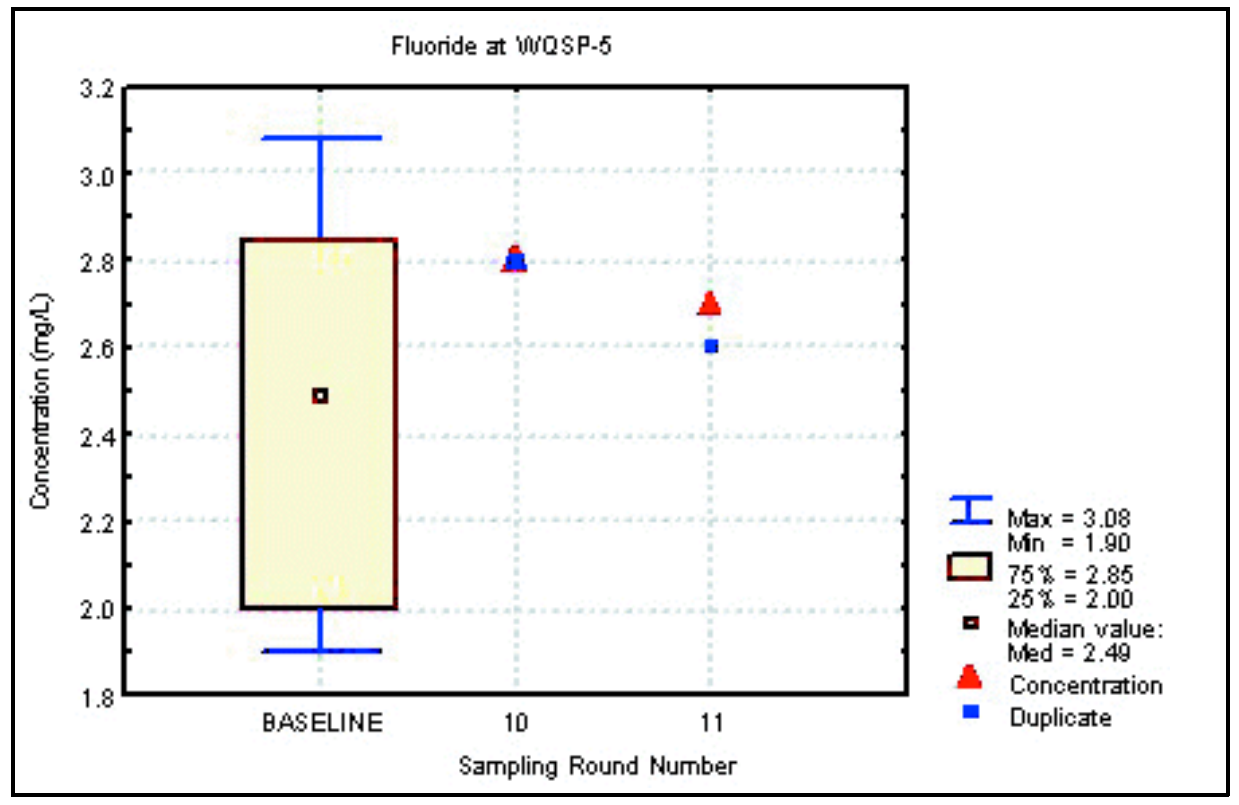

Figure F.78 Time Trend Plot for Fluoride at WQSP-5

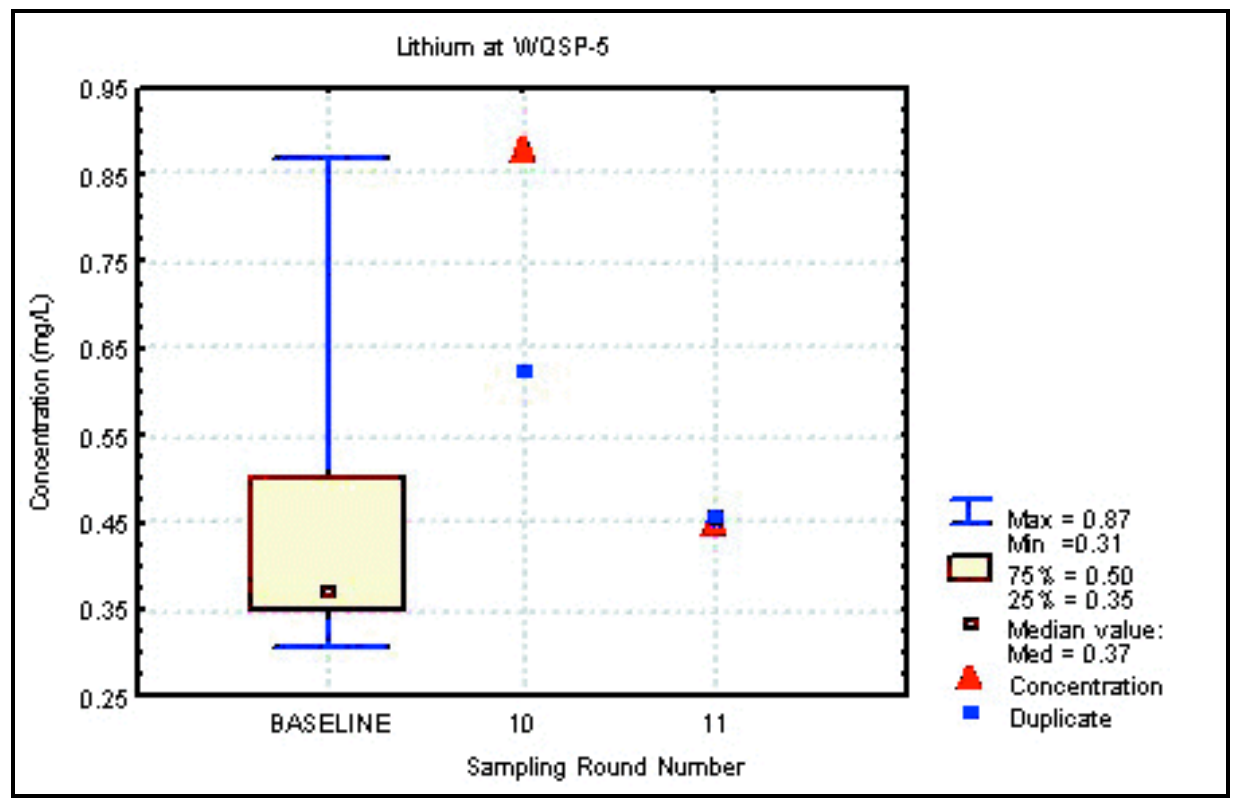

Figure F.79 Time Trent Plot for Lithium at WQSP-5 


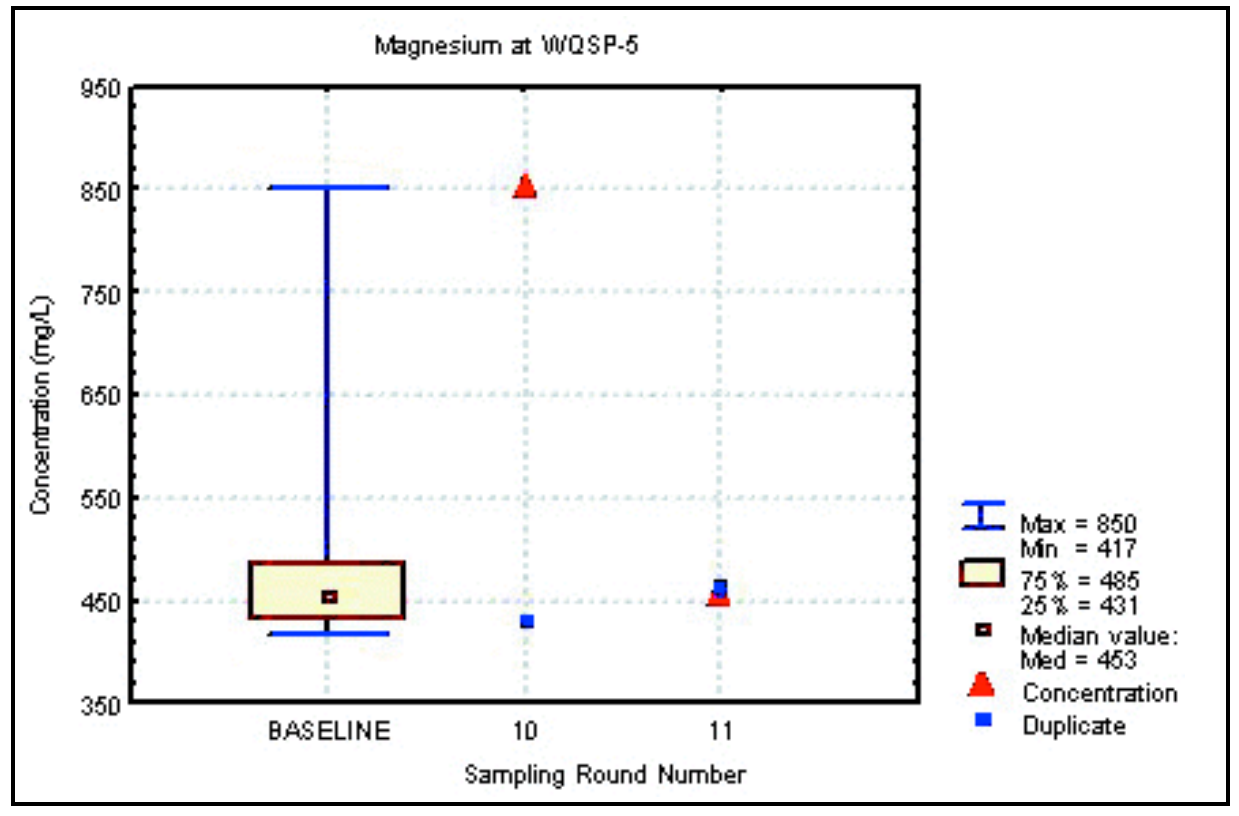

Figure F.80 Time Trend Plot for Magnesium at WQSP-5

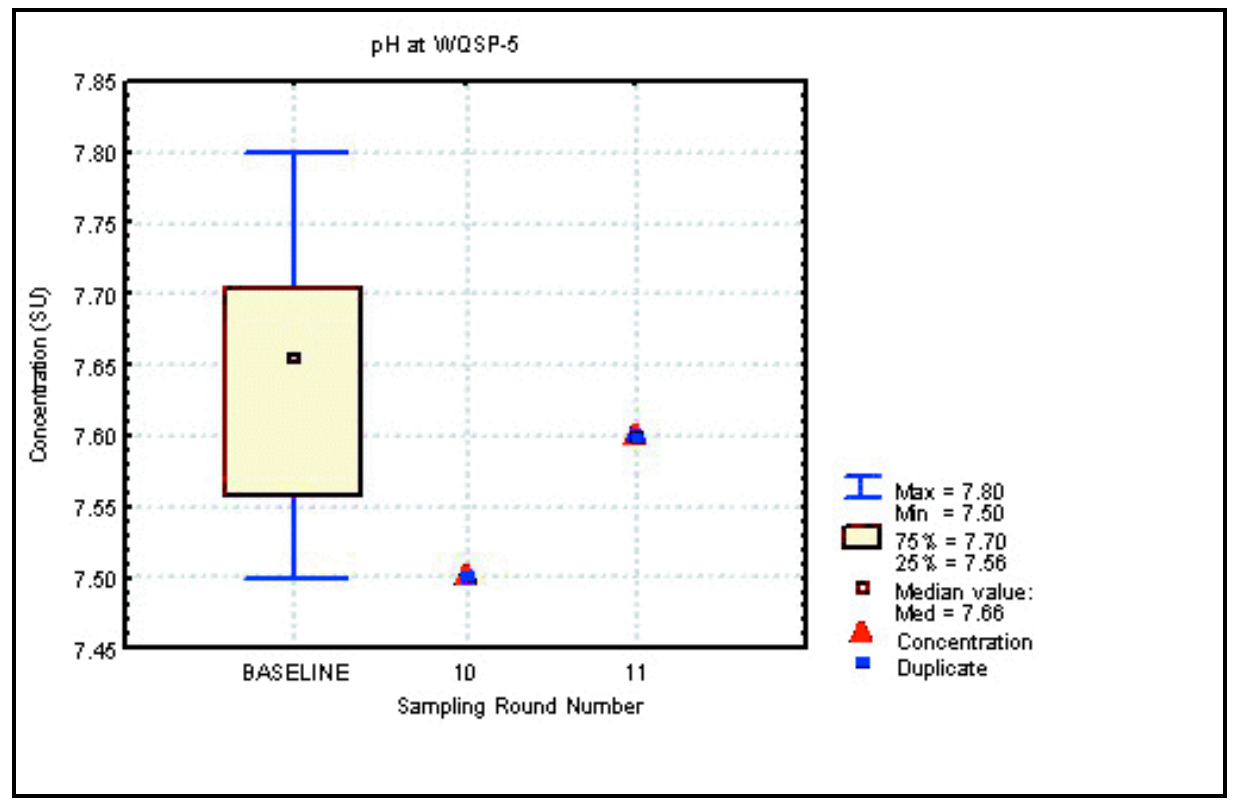

Figure F.81 Time Trent Plot for $\mathrm{pH}$ at WQSP-5 


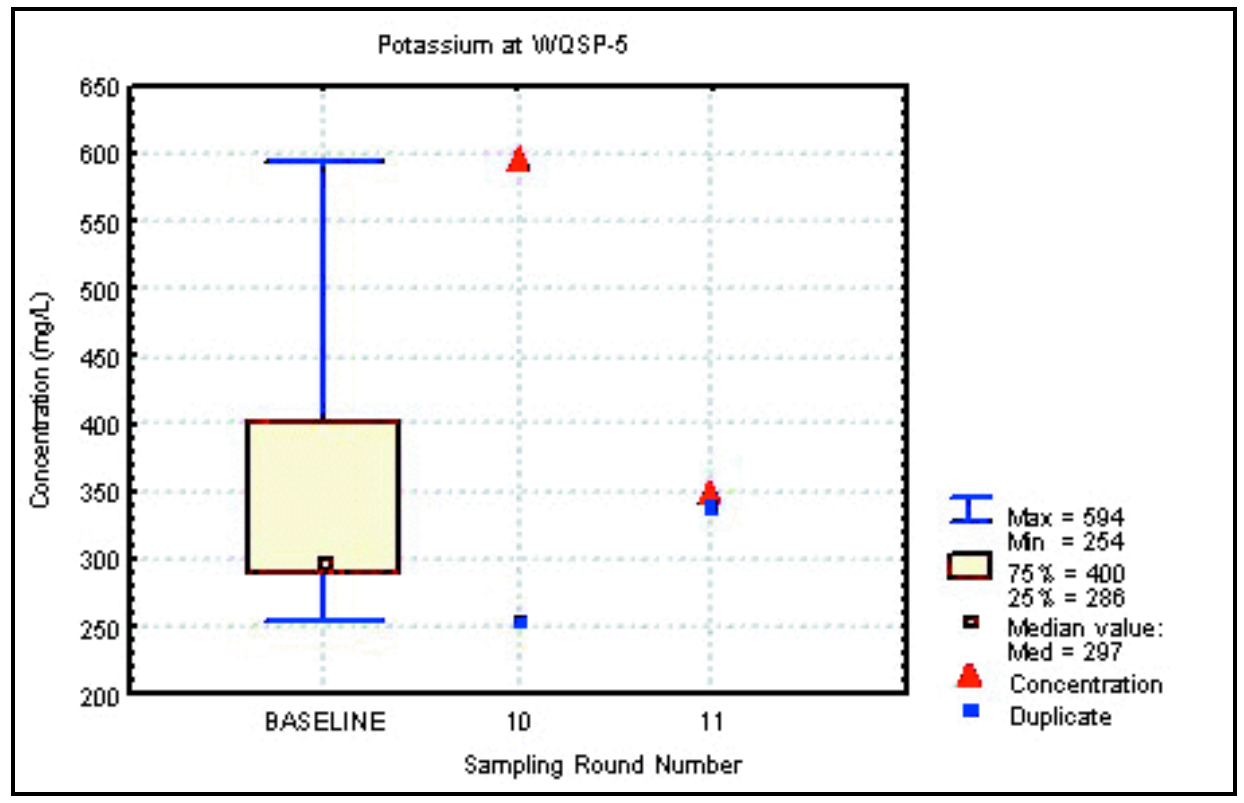

Figure F.82 Time Trend Plot for Potassium at WQSP-5

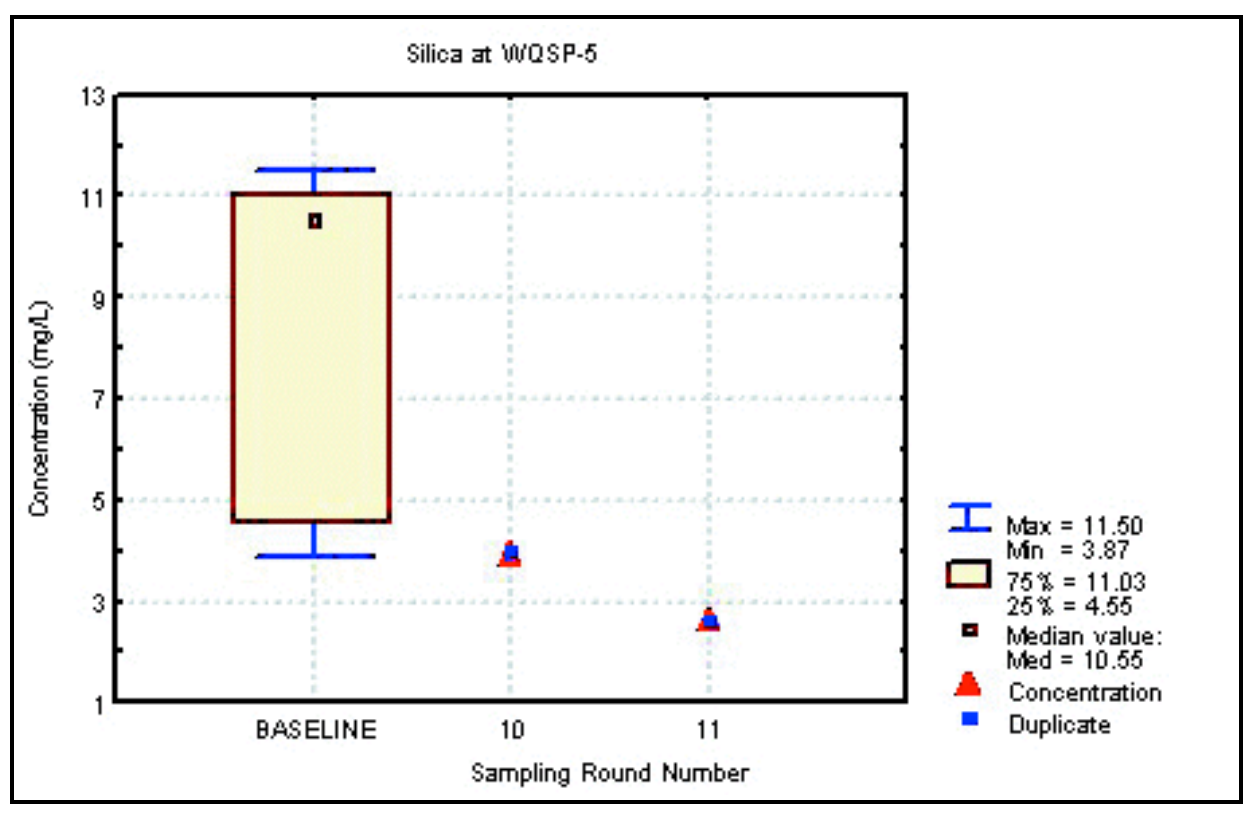

Figure F.83 Time Trent Plot for Silica at WQSP-5 


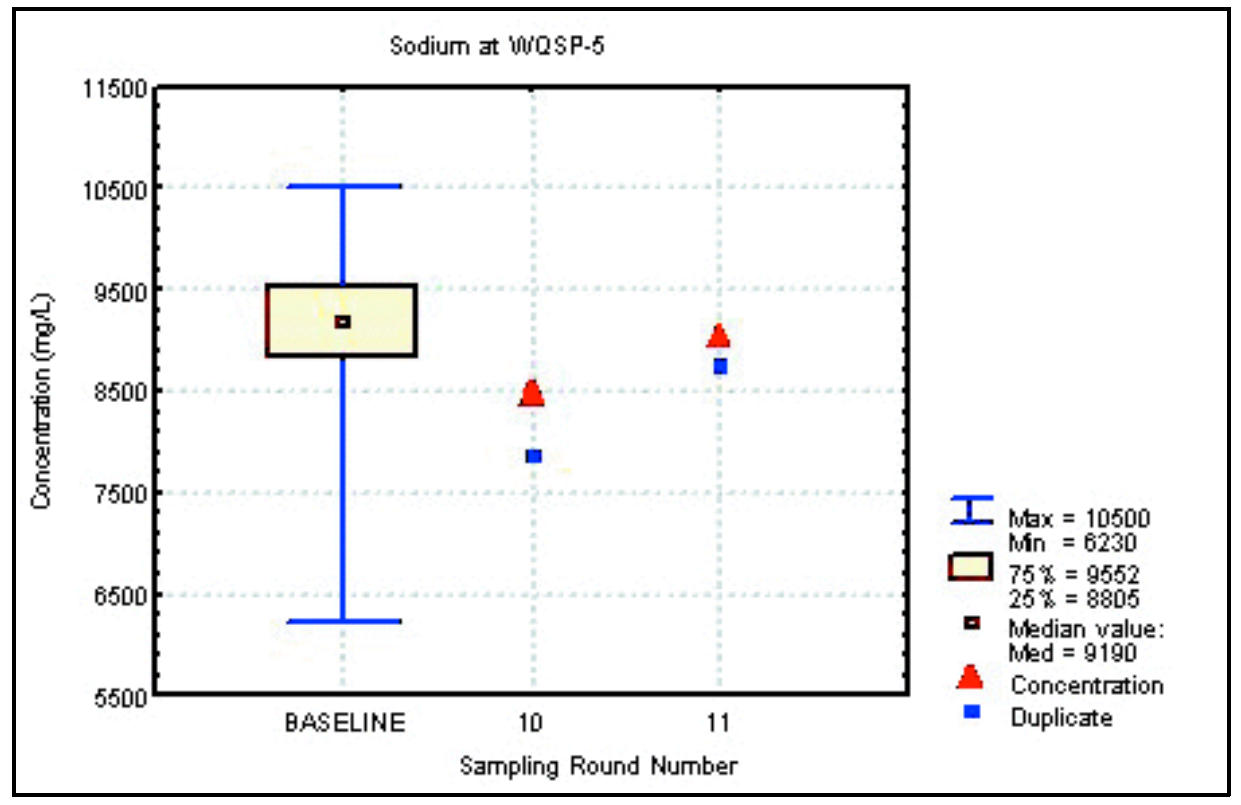

Figure F.84 Time Trend Plot for Sodium at WQSP-5

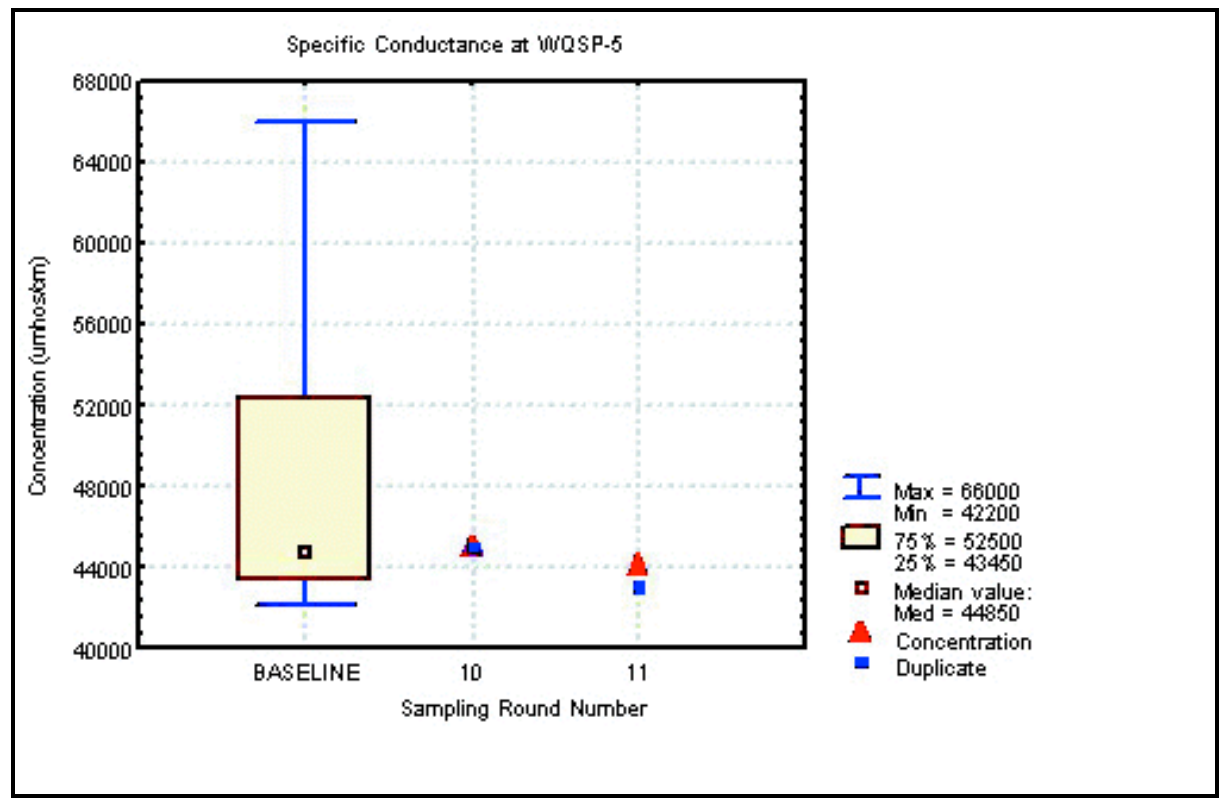

Figure F.85 Time Trent Plot for Specific Conductance at WQSP-5 


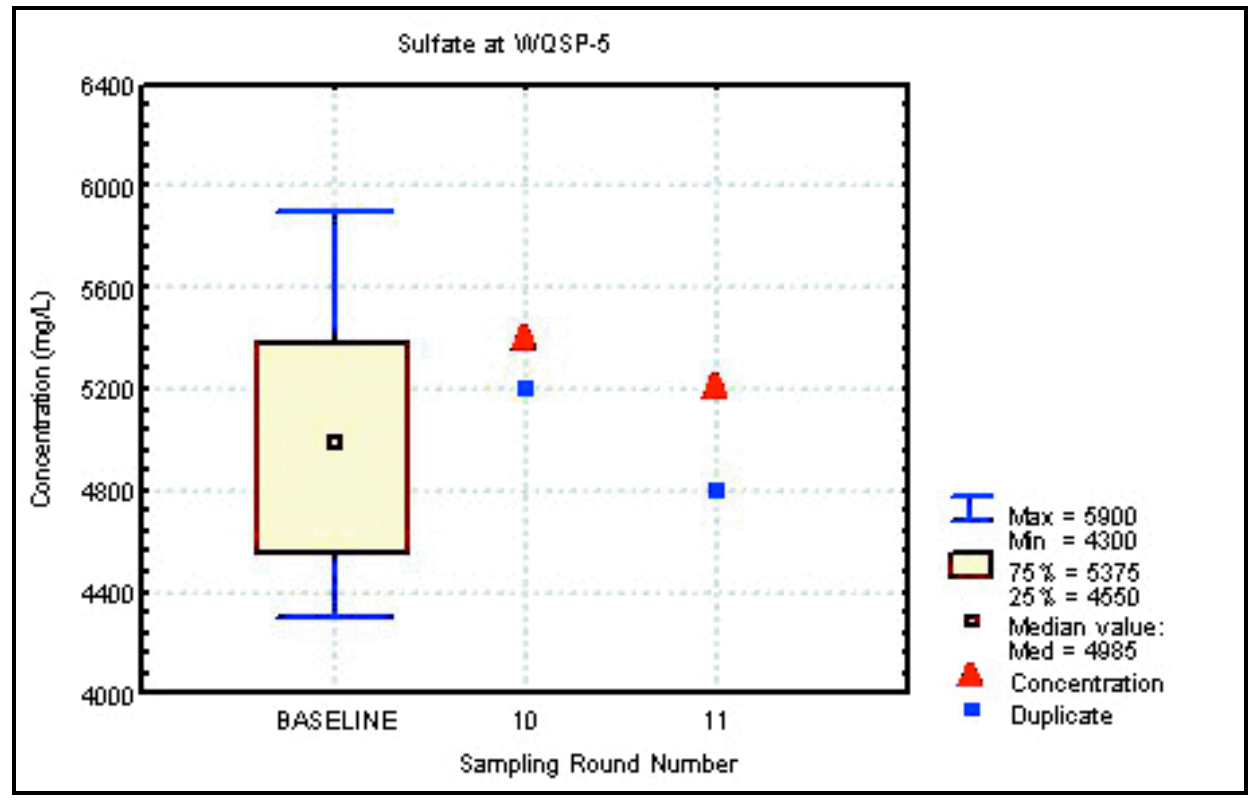

Figure F.86 Time Trend Plot for Sulfate at WQSP-5

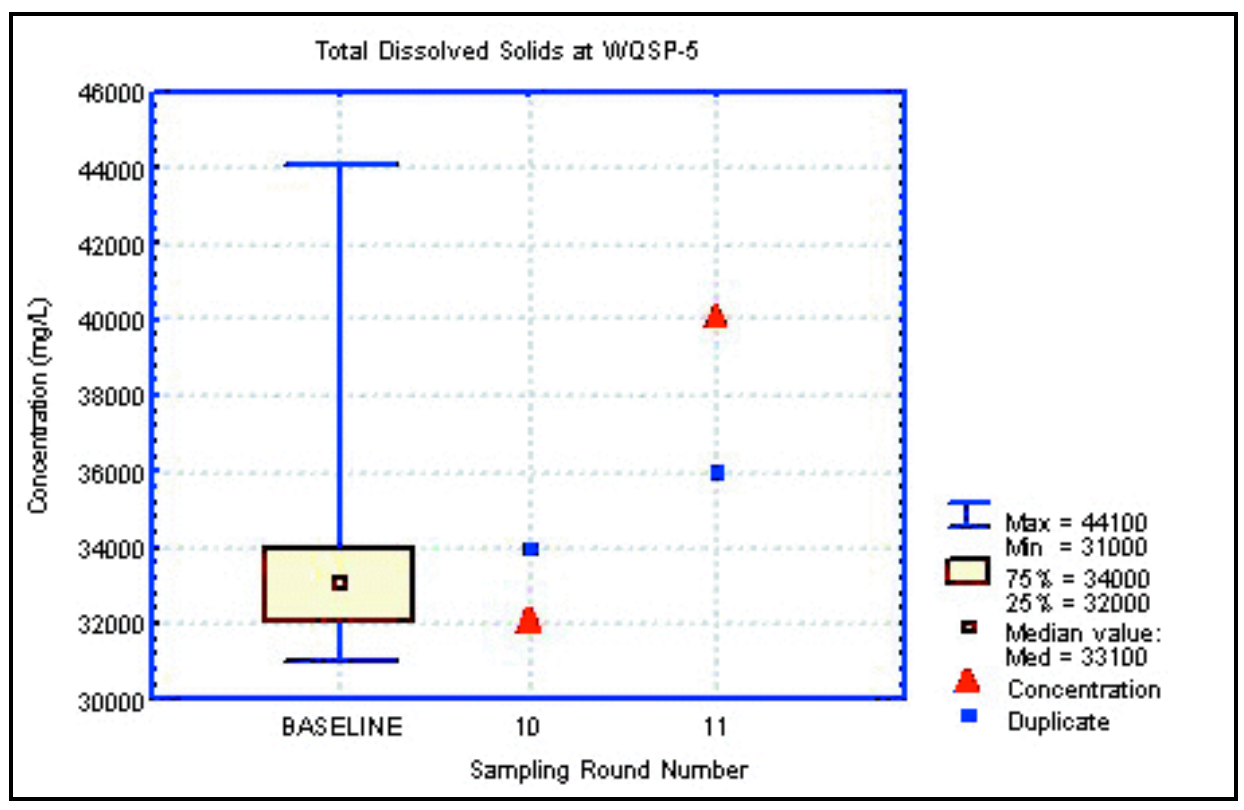

Figure F.87 Time Trent Plot for Total Dissolved Solids at WQSP-5 


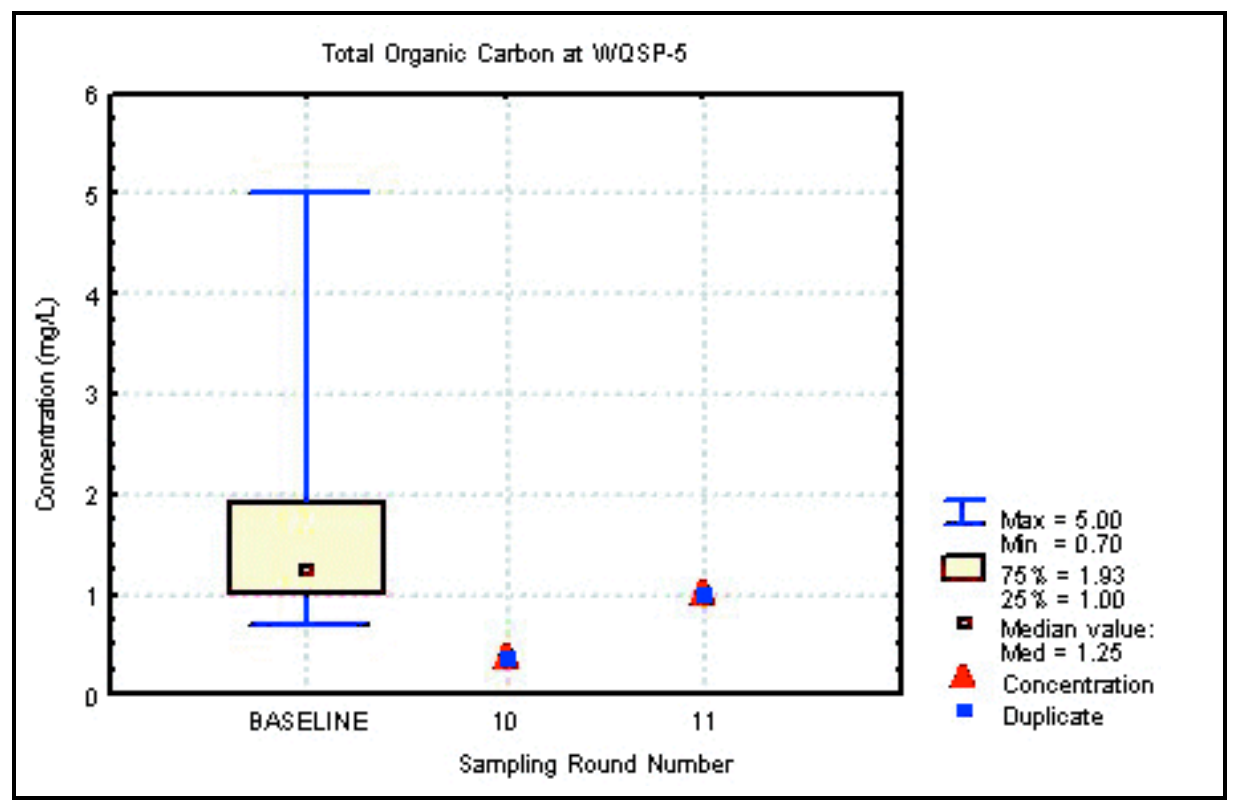

Figure F.88 Time Trend Plot for Total Organic Carbon at WQSP-5

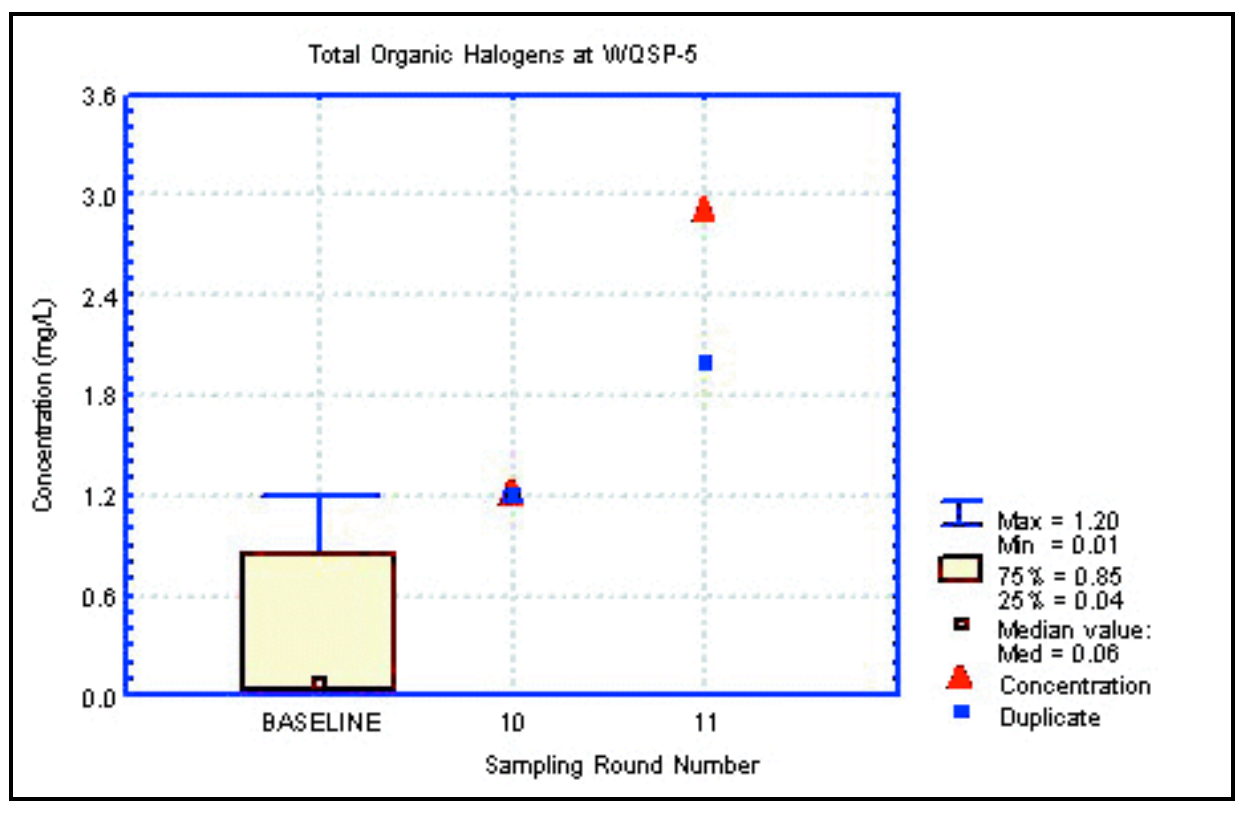

Figure F.89 Time Trent Plot for Total Organic Halogens at WQSP-5 


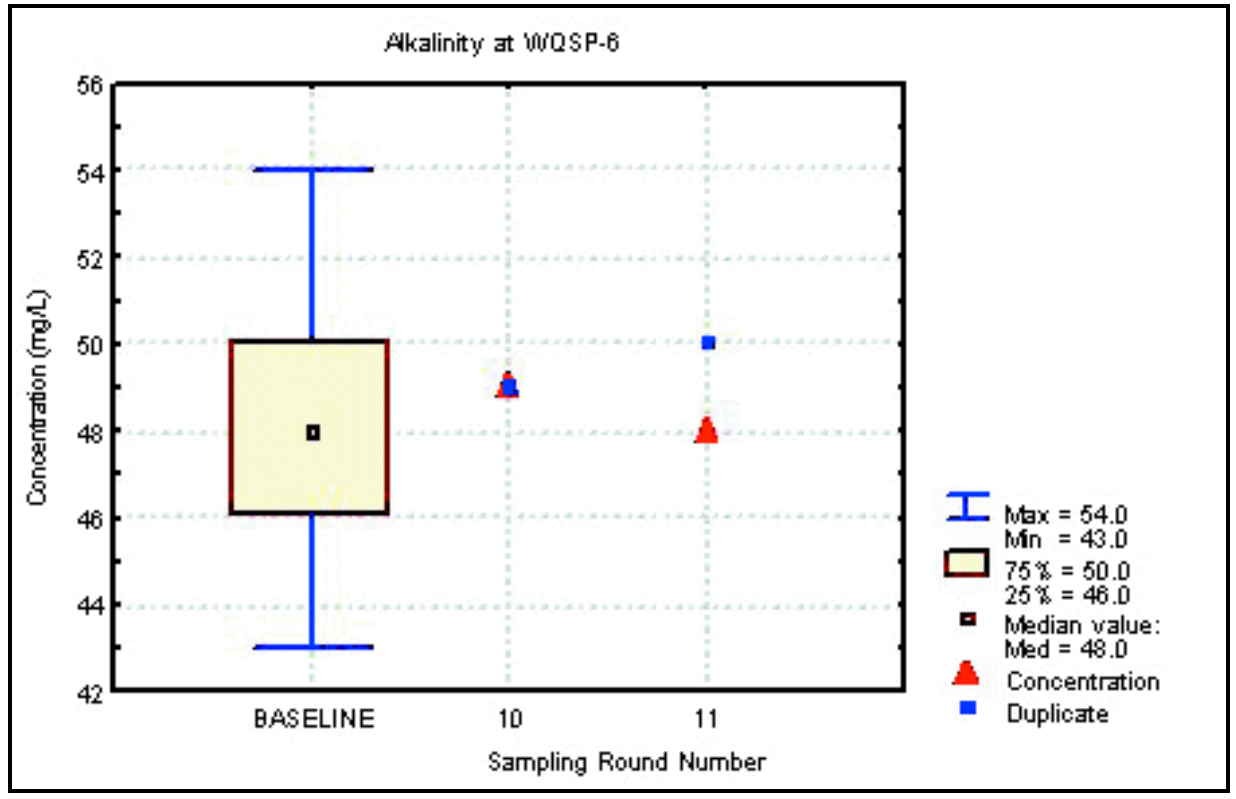

Figure F.90 Time Trend Plot for Alkalinity at WQSP-6

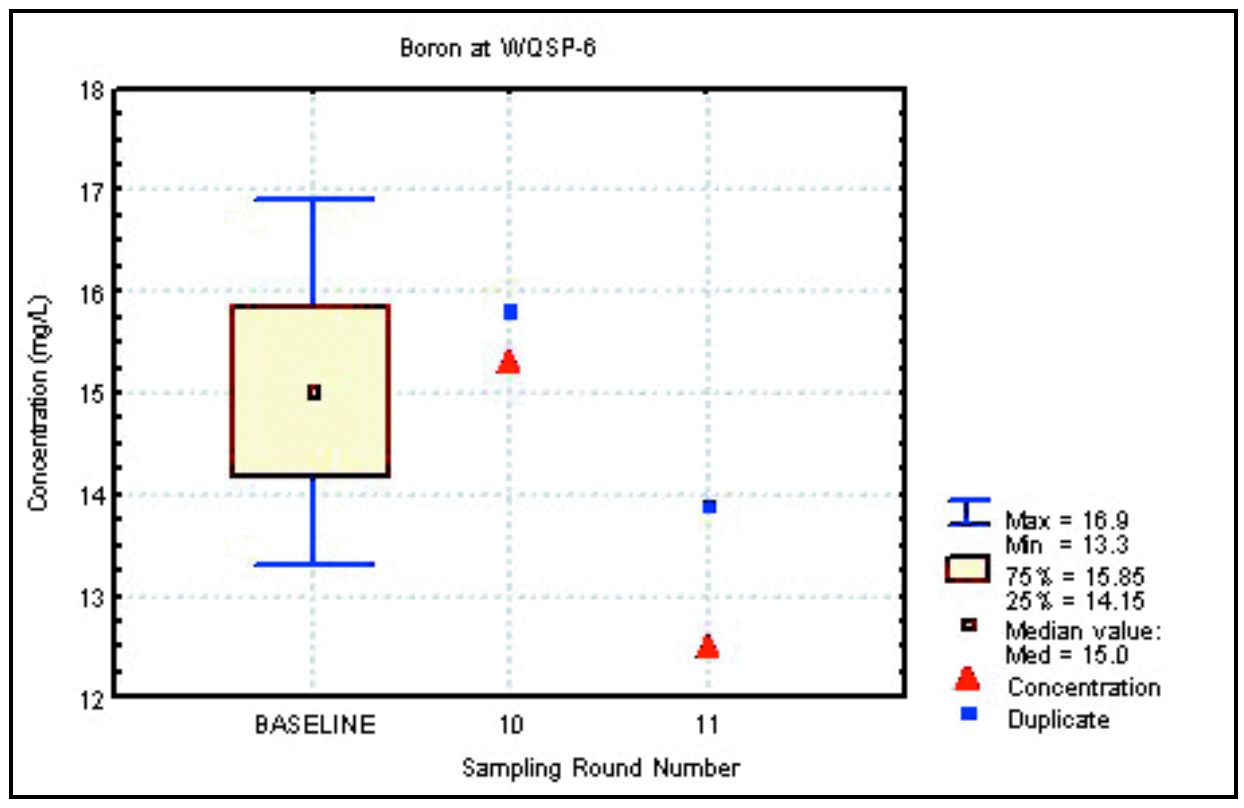

Figure F.91 Time Trent Plot for Boron at WQSP-6 


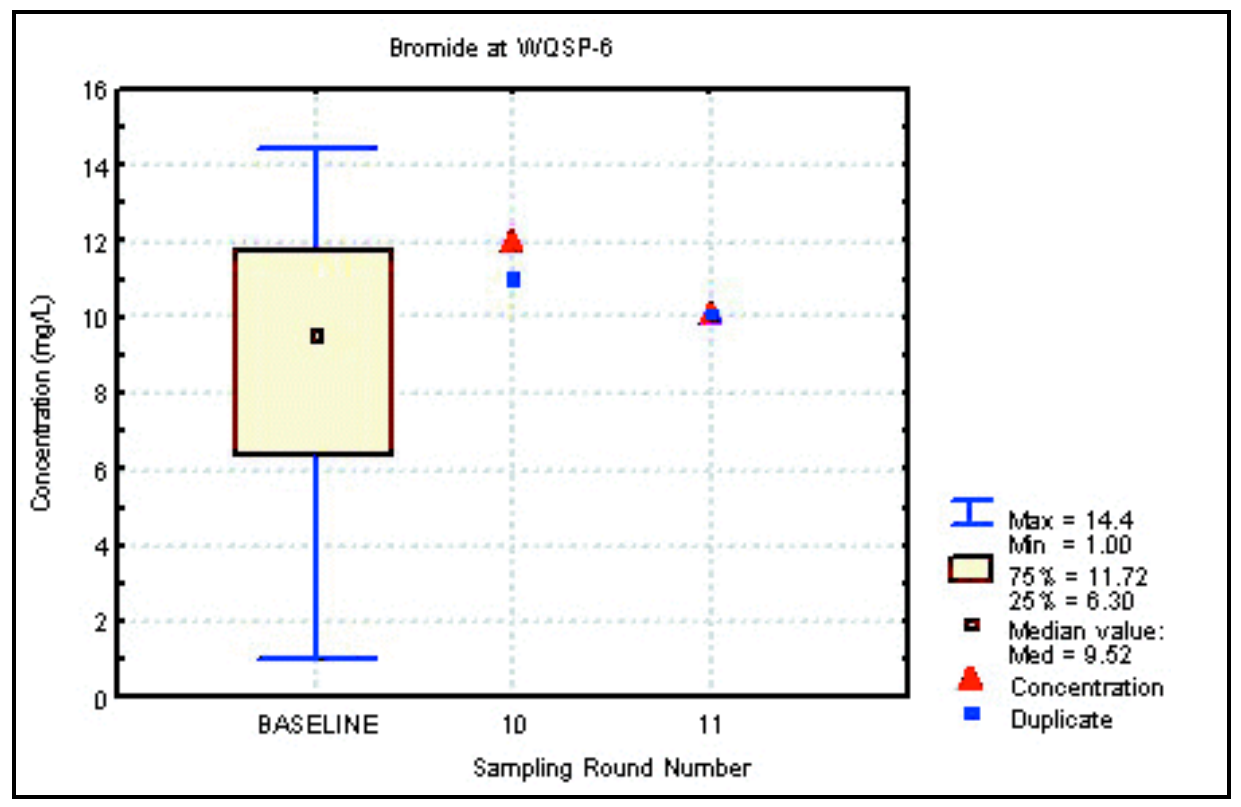

Figure F.92 Time Trend Plot for Bromide at WQSP-6

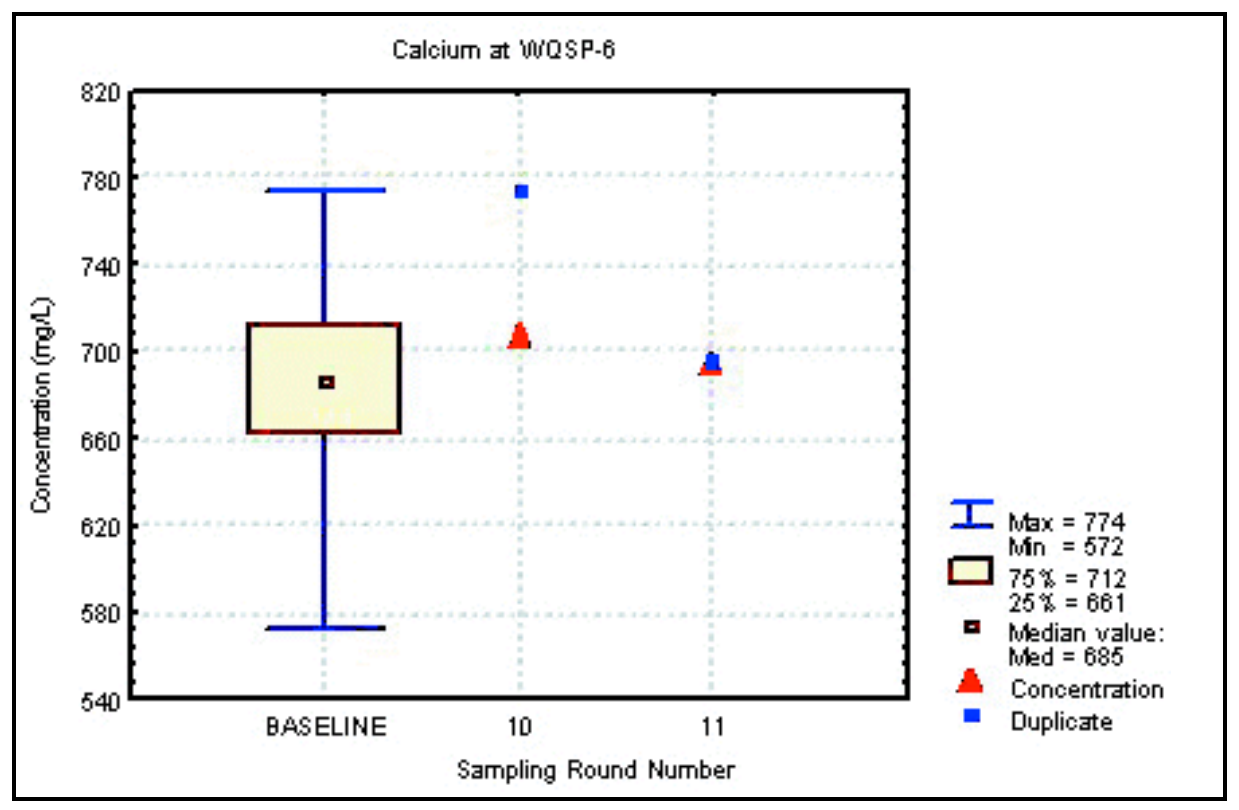

Figure F.93 Time Trent Plot for Calcium at WQSP-6 


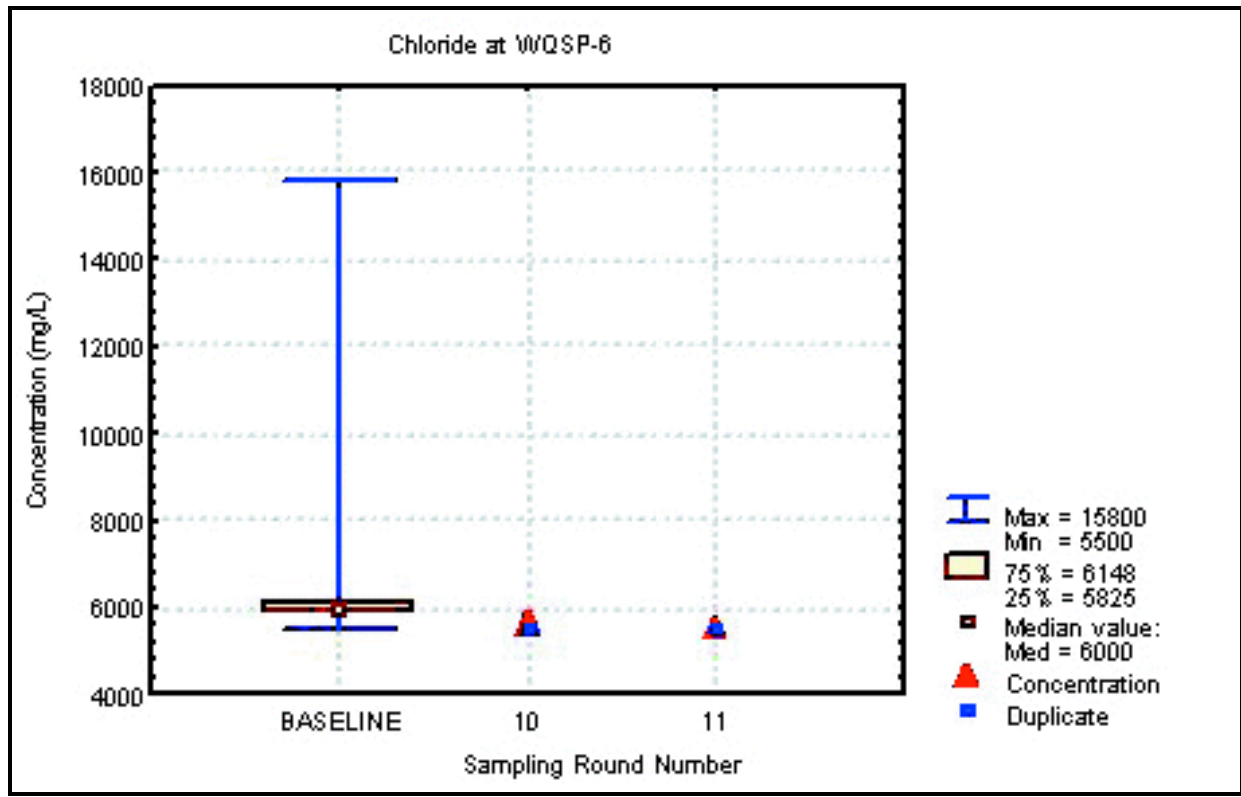

Figure F.94 Time Trend Plot for Chloride at WQSP-6

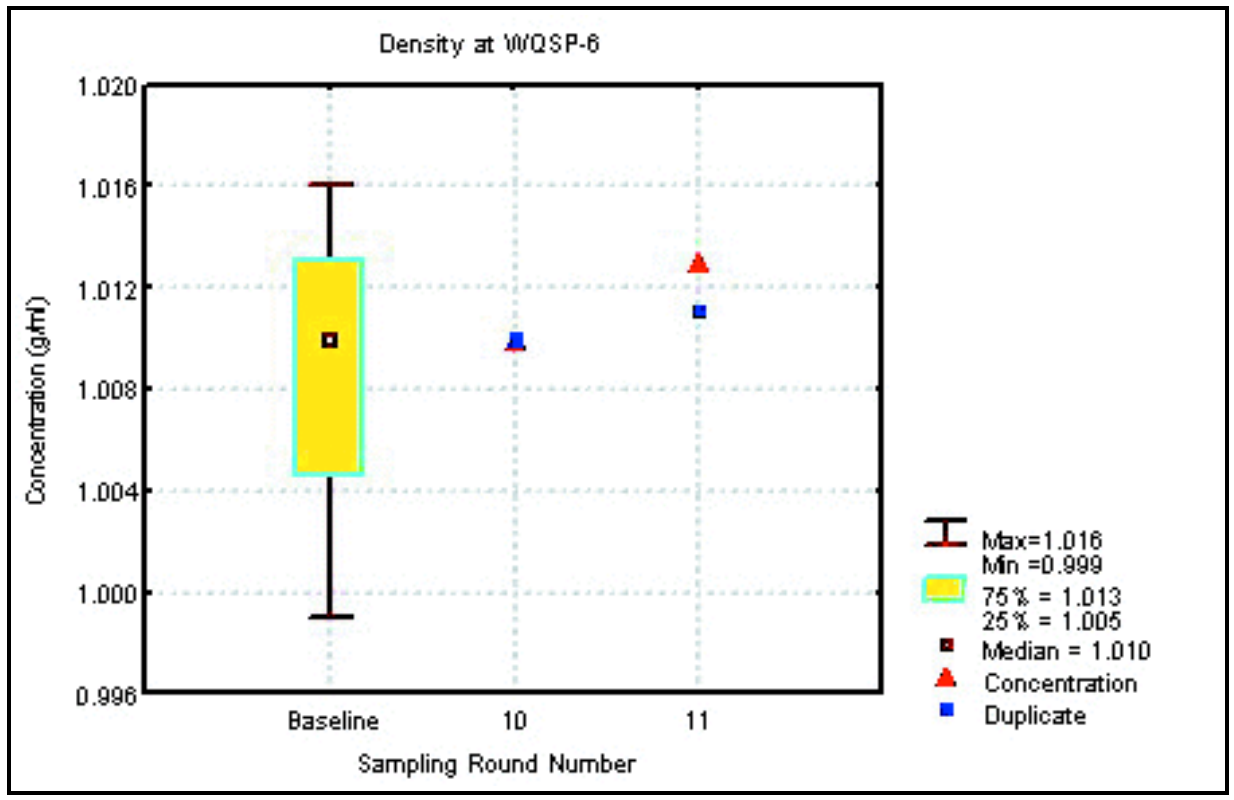

Figure F.95 Time Trent Plot for Density at WQSP-6 


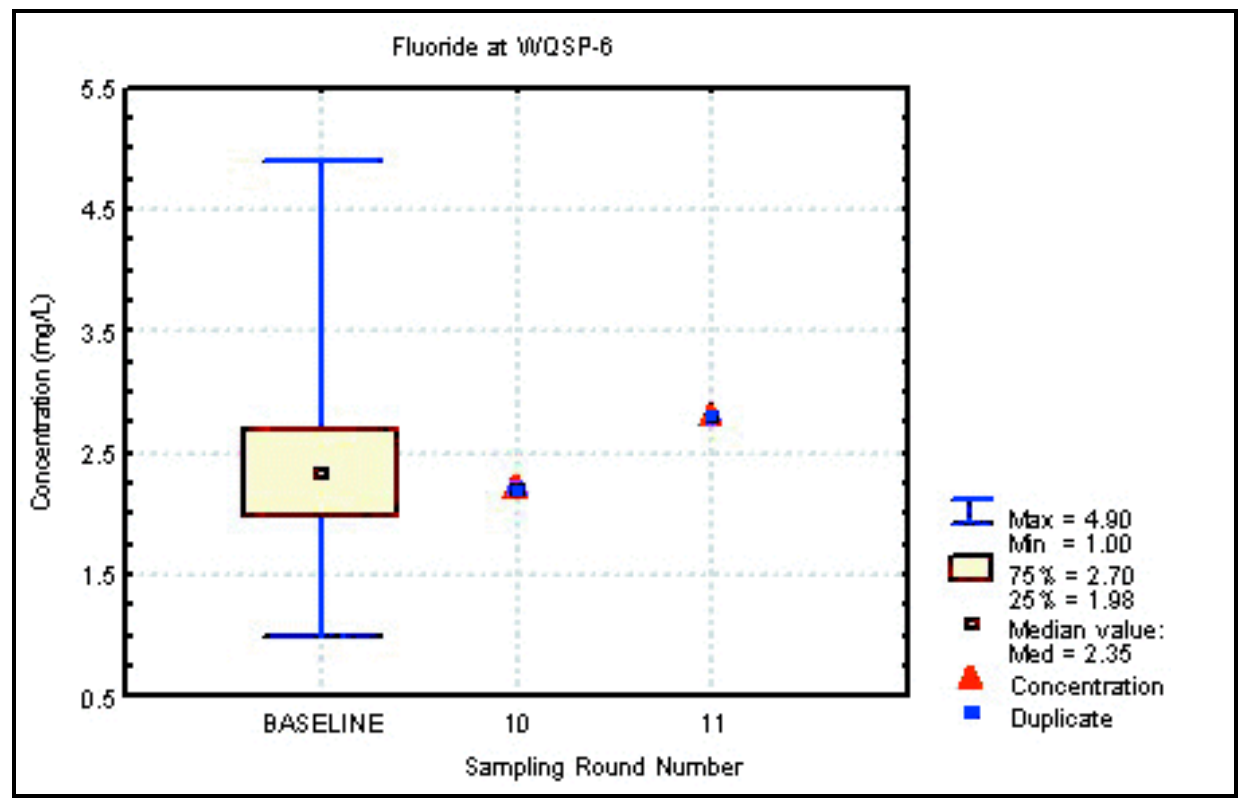

Figure F.96 Time Trend Plot for Fluoride at WQSP-6

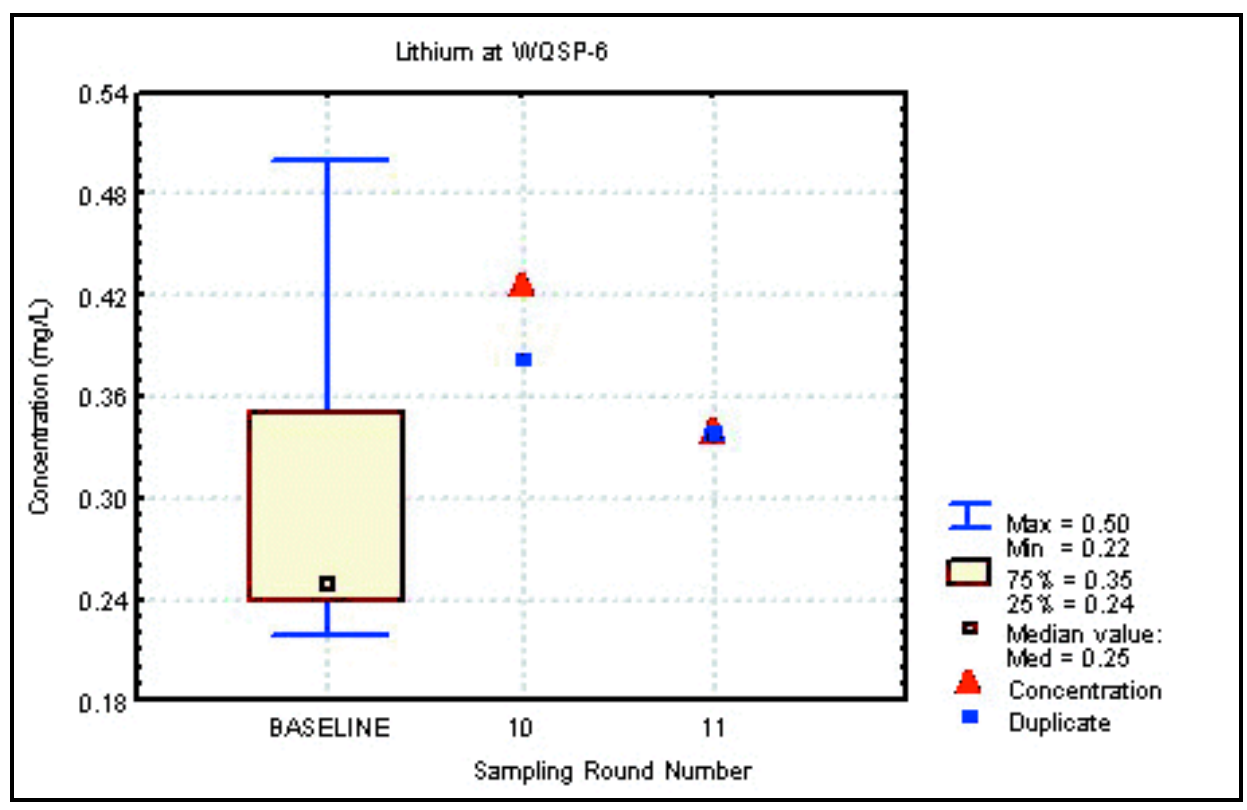

Figure F.97 Time Trent Plot for Lithium at WQSP-6 


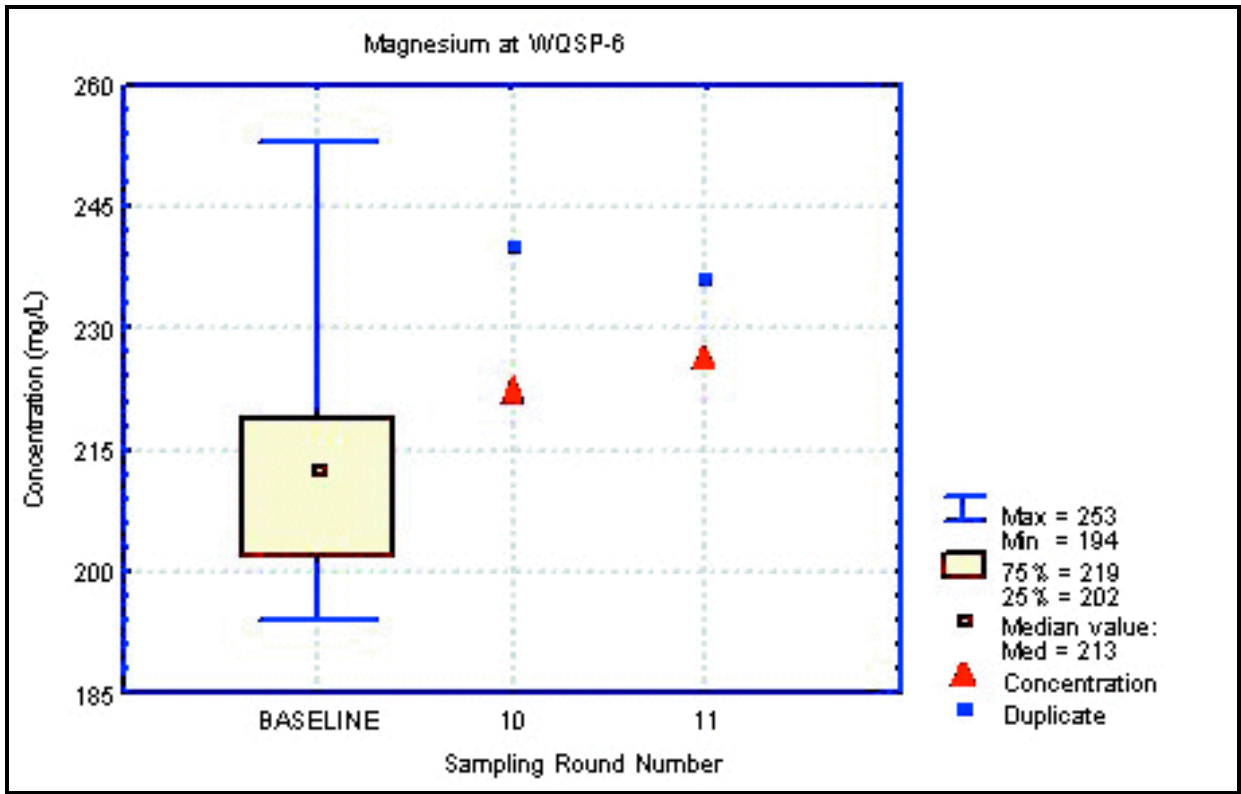

Figure F.98 Time Trend Plot for Magnesium at WQSP-6

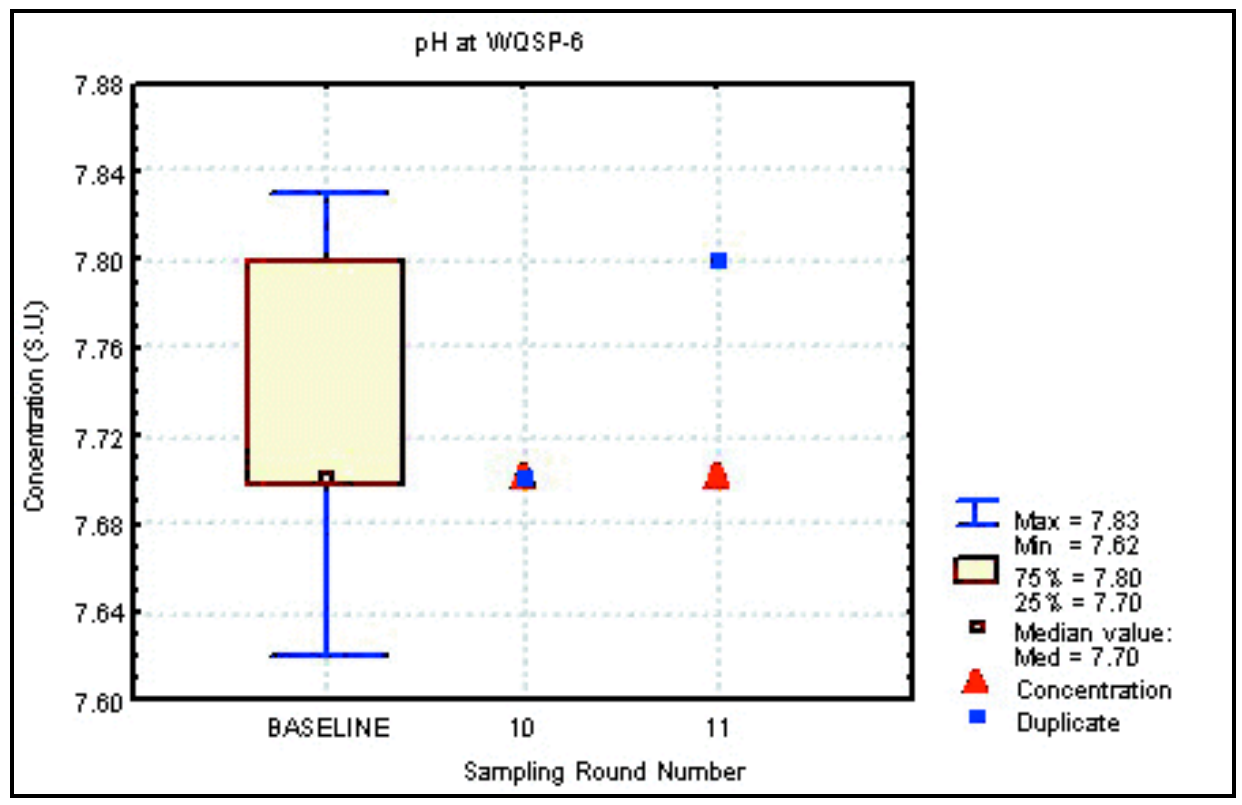

Figure F.99 Time Trent Plot for $\mathrm{pH}$ at WQSP-6 


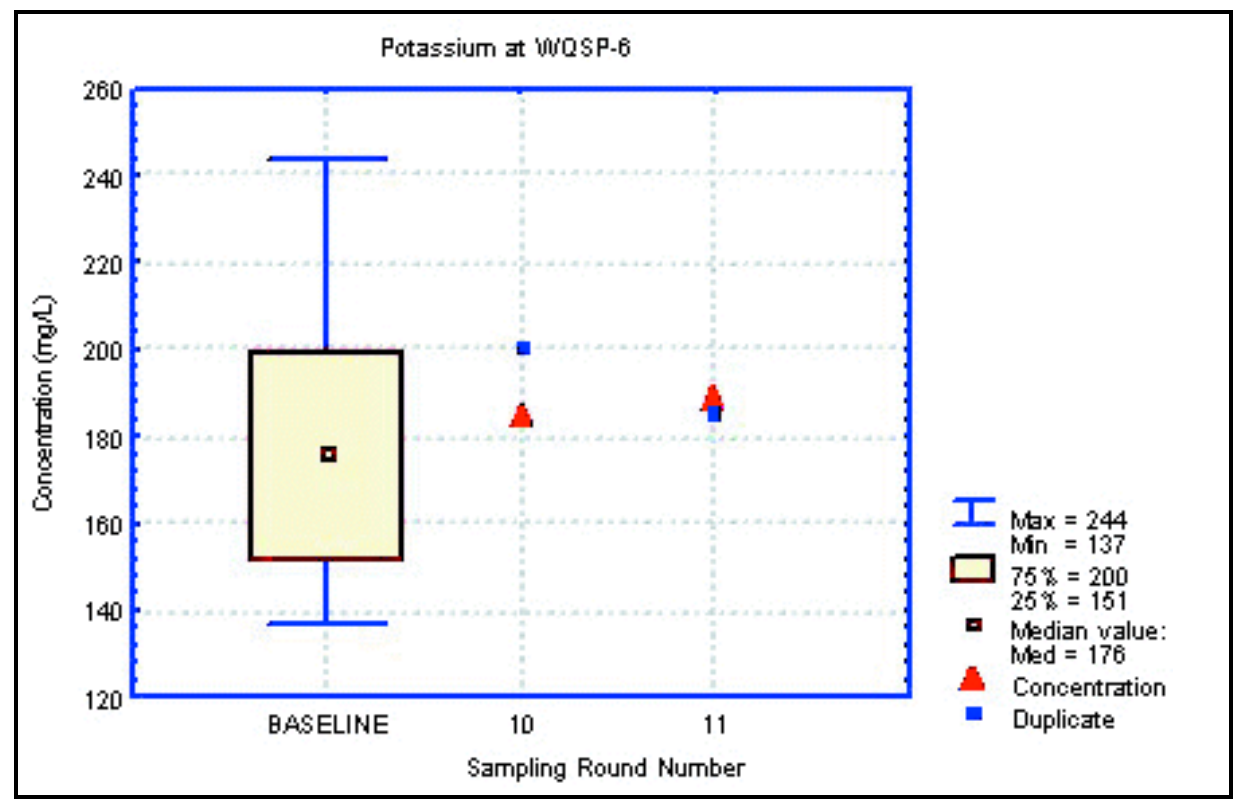

Figure F.100 Time Trend Plot for Potassium at WQSP-6

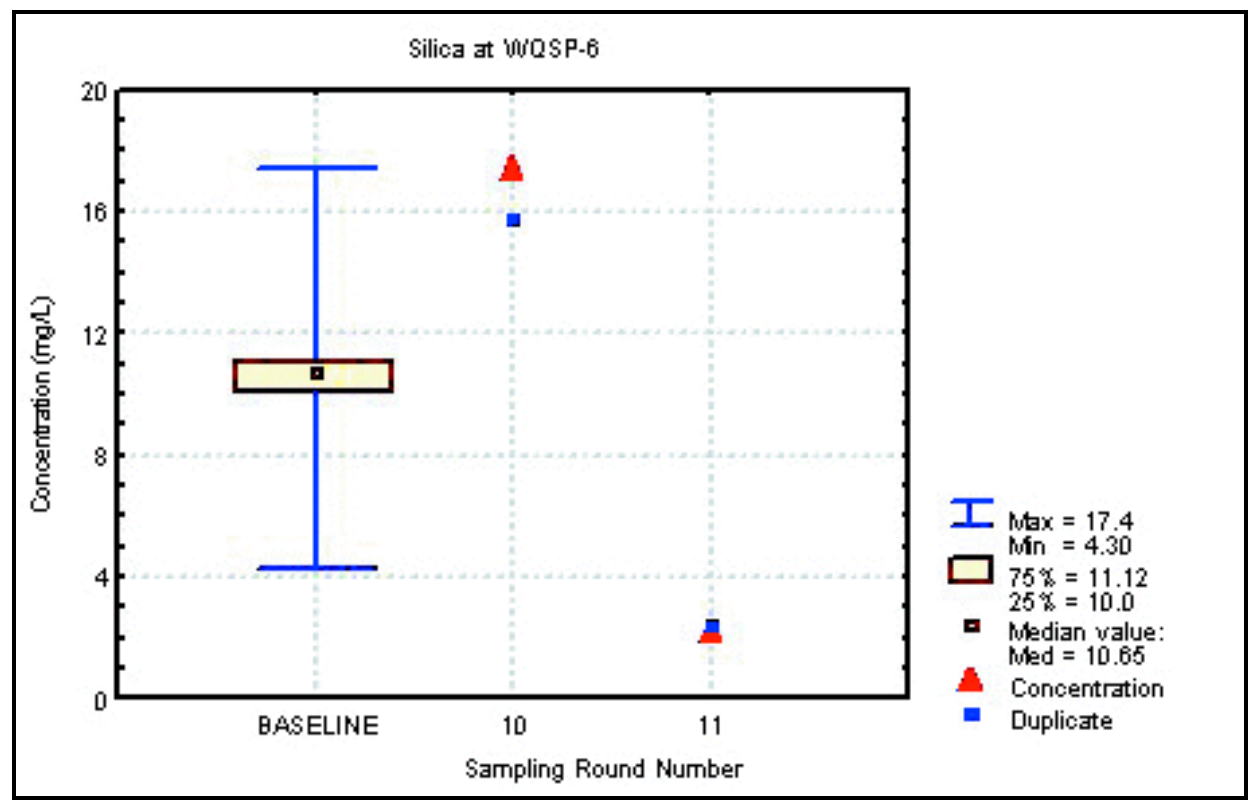

Figure F.101 Time Trent Plot for Silica at WQSP-6 


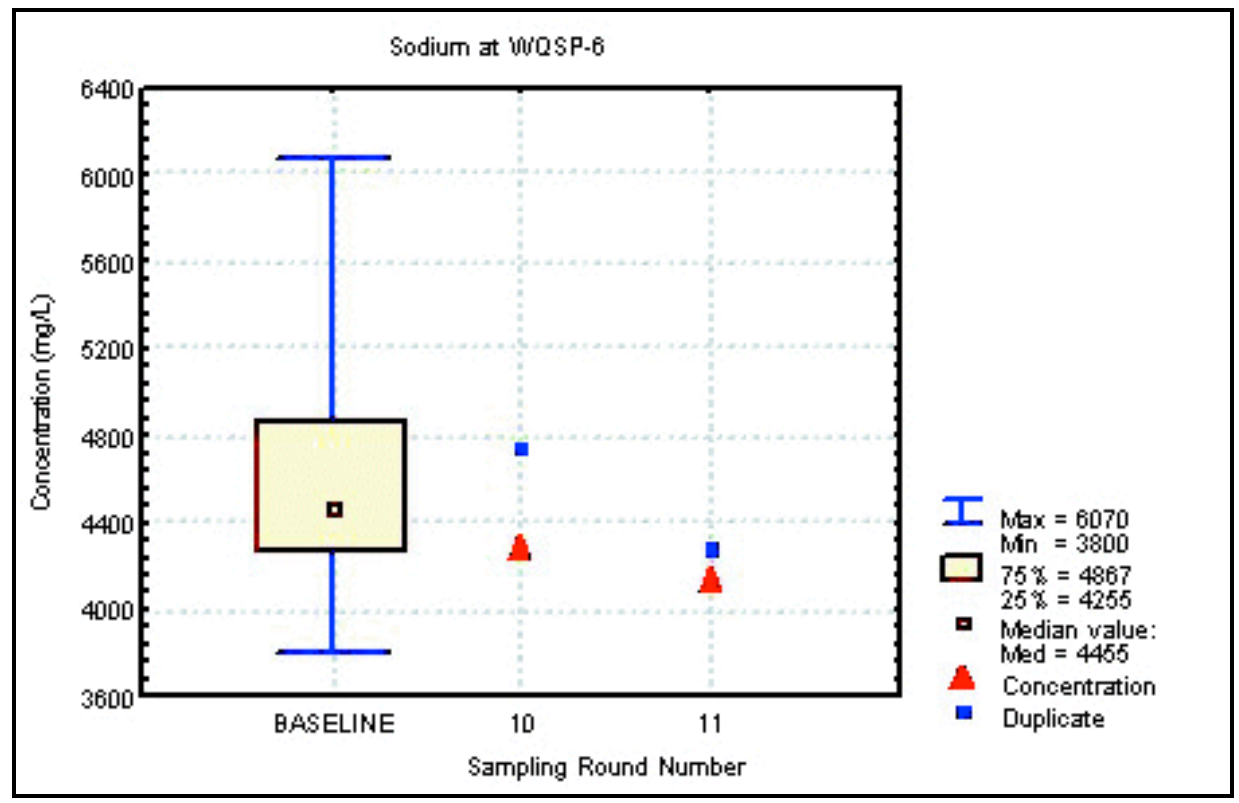

Figure F.102 Time Trend Plot for Sodium at WQSP-6

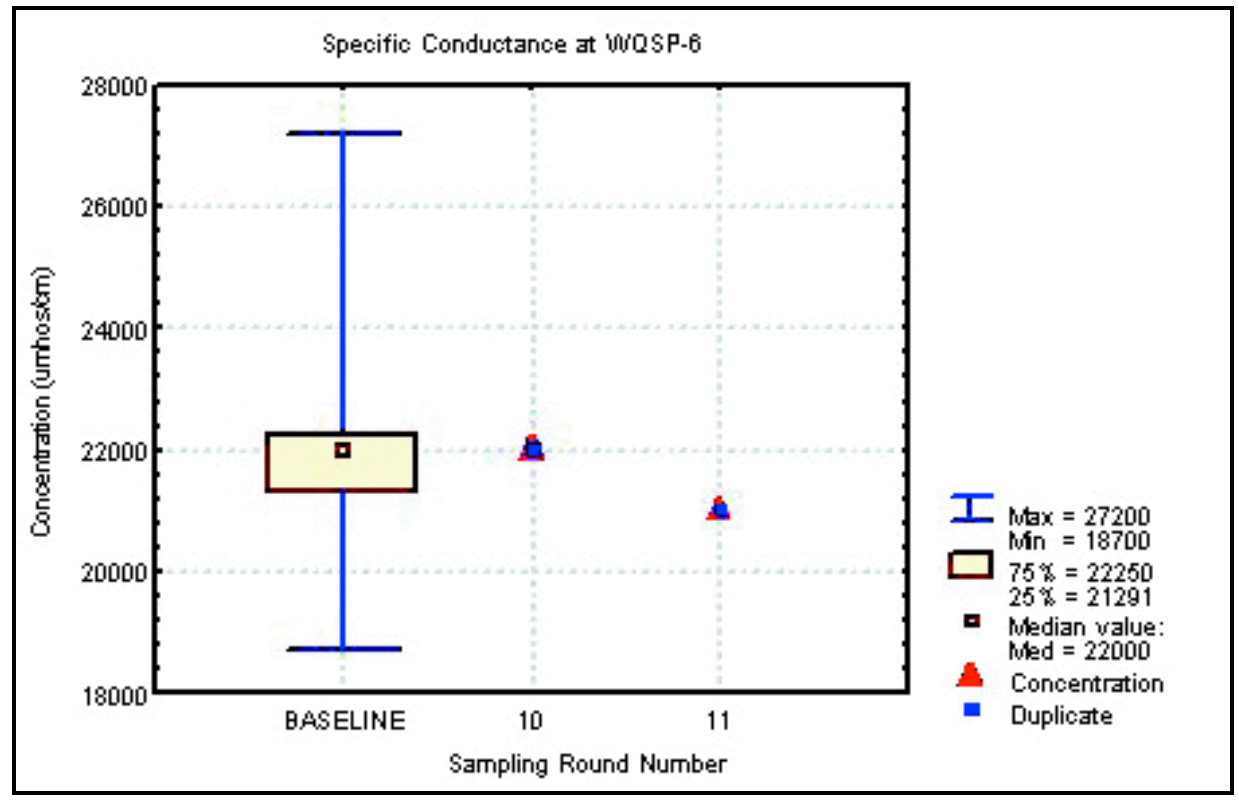

Figure F.103 Time Trent Plot for Specific Conductance at WQSP-6 


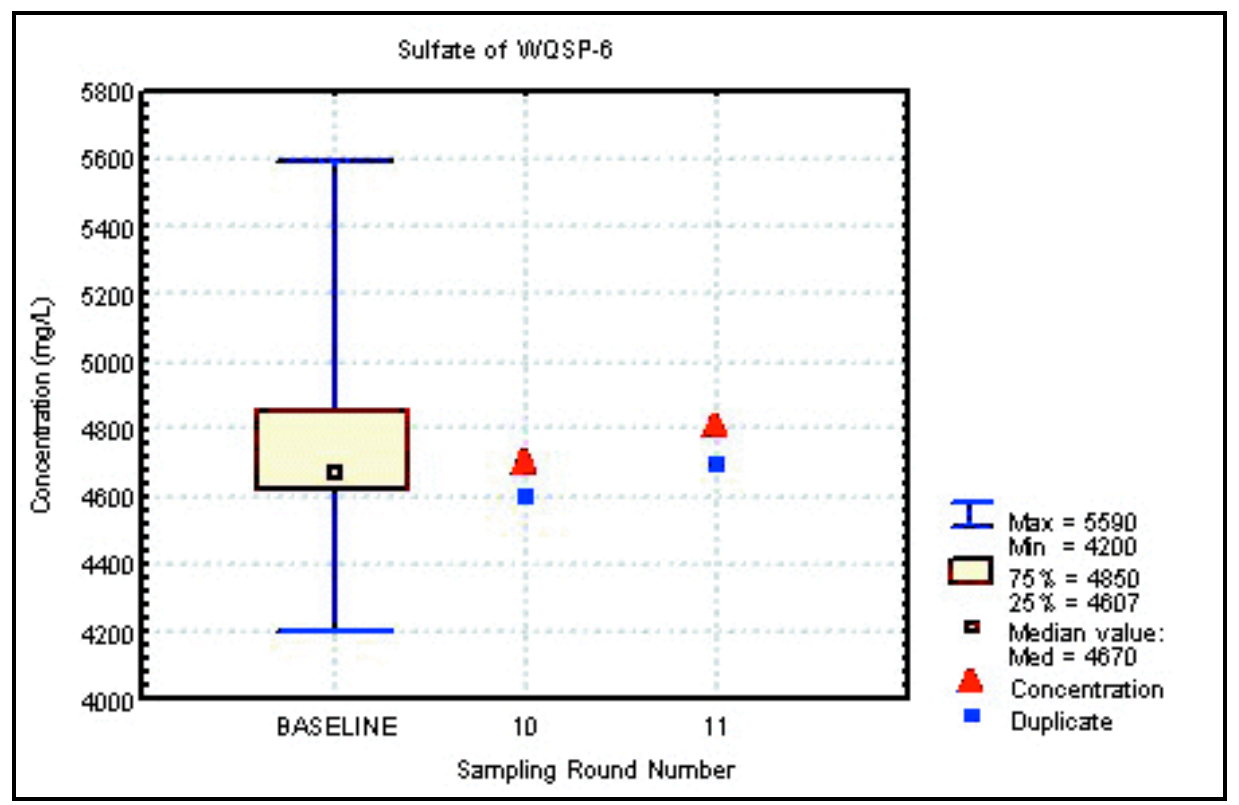

Figure F.104 Time Trend Plot for Sulfate at WQSP-6

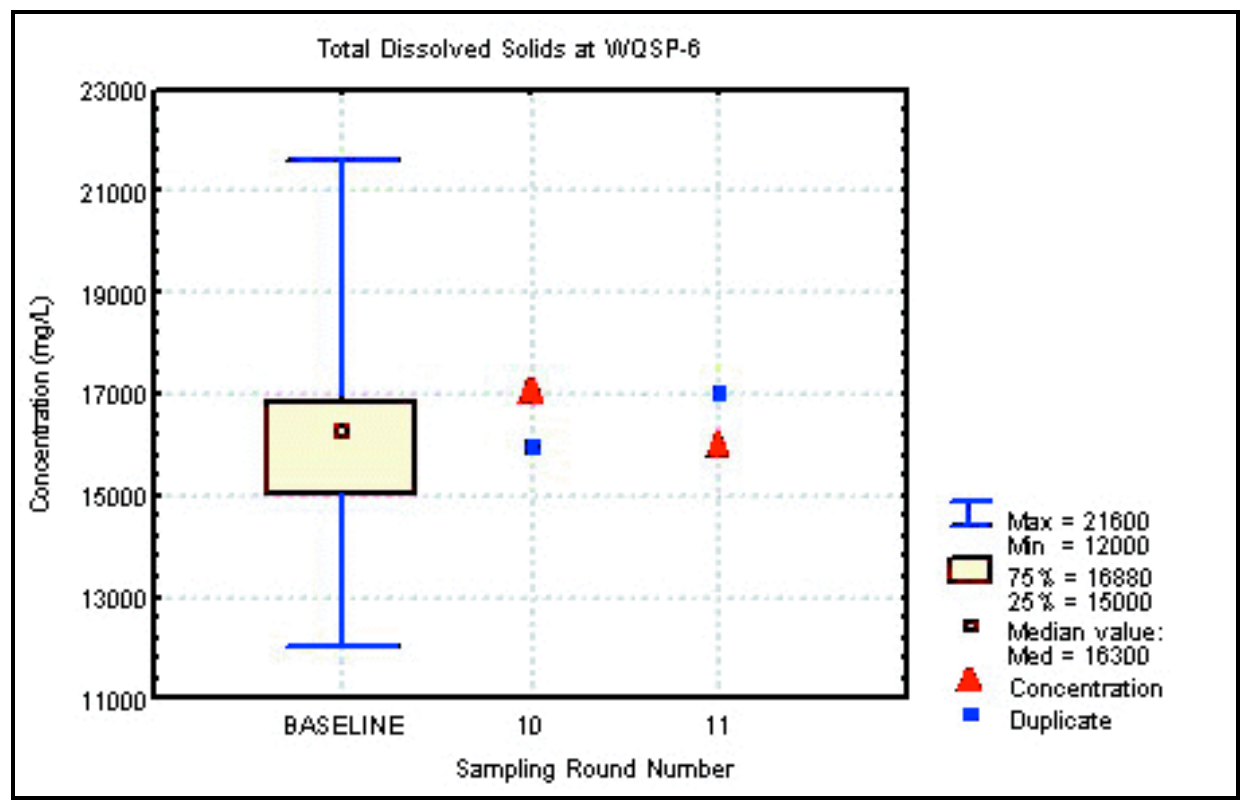

Figure F.105 Time Trent Plot for Total Dissolved Solids at WQSP-6 


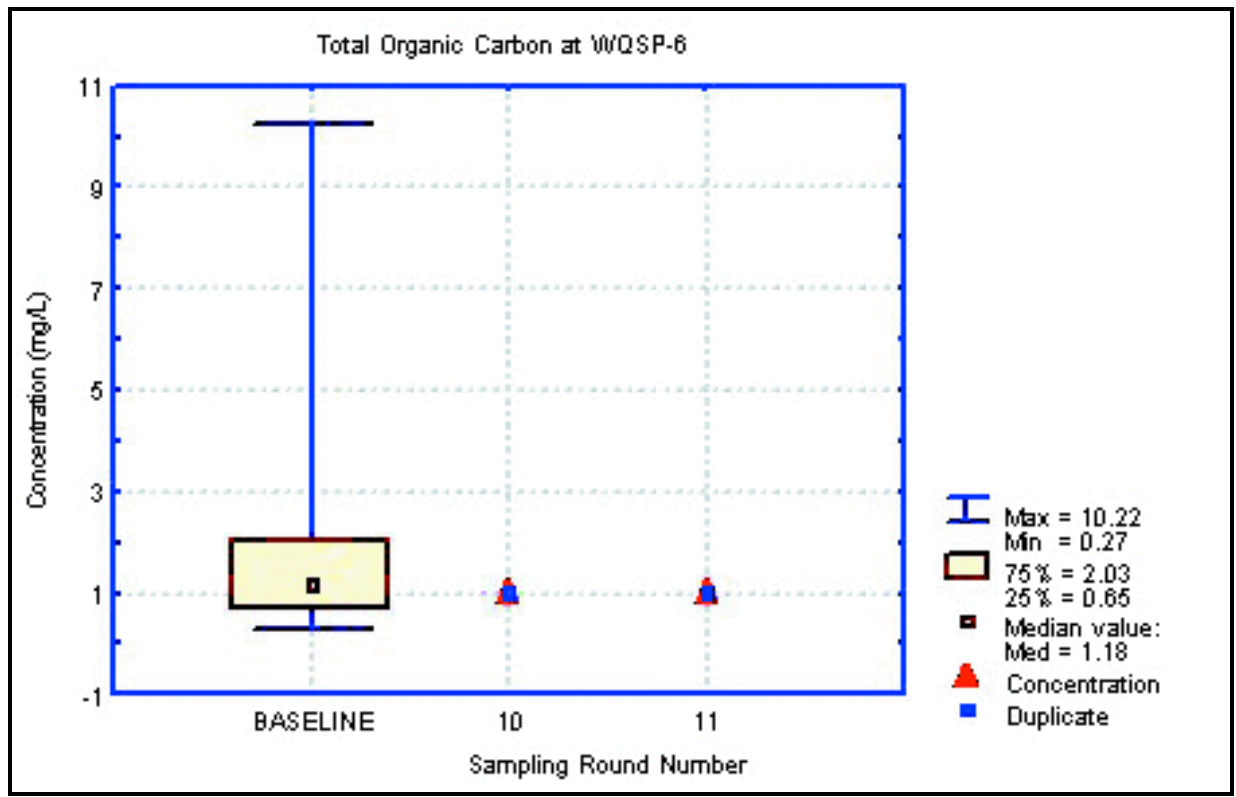

Figure F.106 Time Trend Plot for Total Organic Carbon at WQSP-6

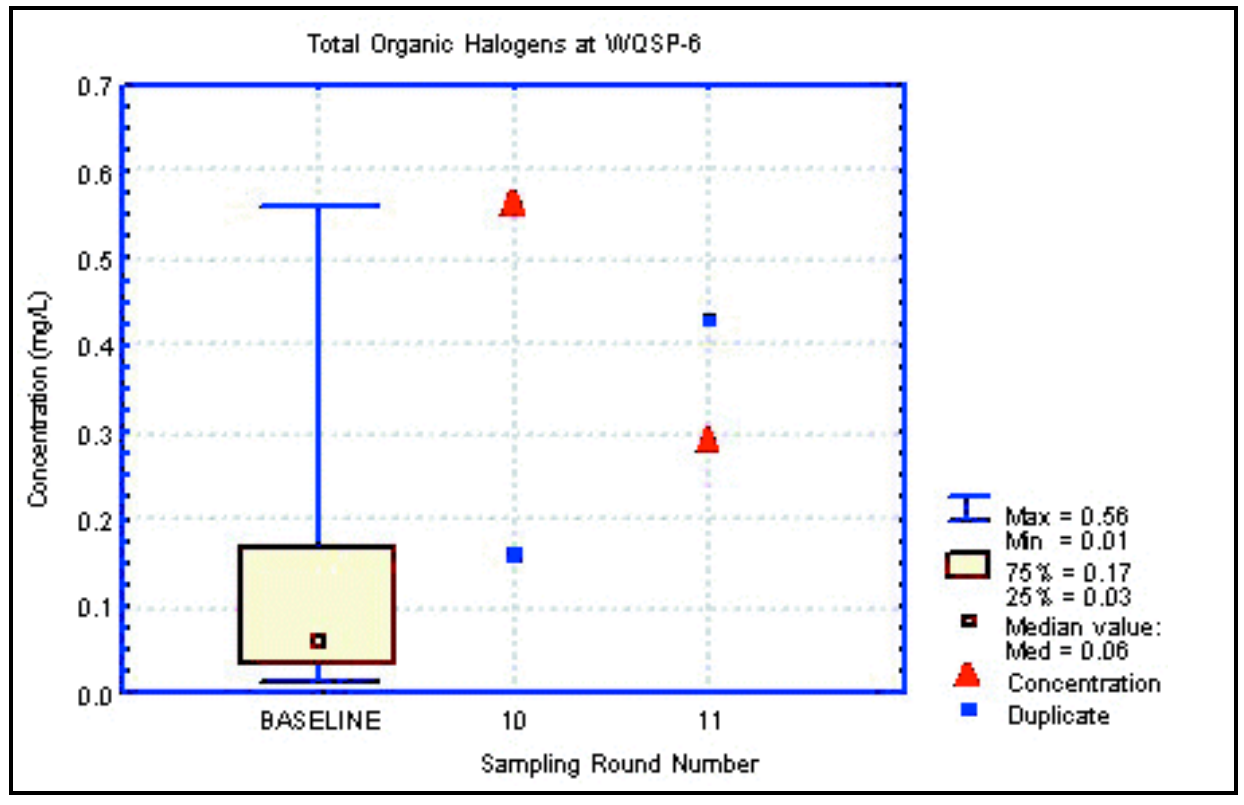

Figure F.107 Time Trent Plot for Total Organic Halogens at WQSP-6 


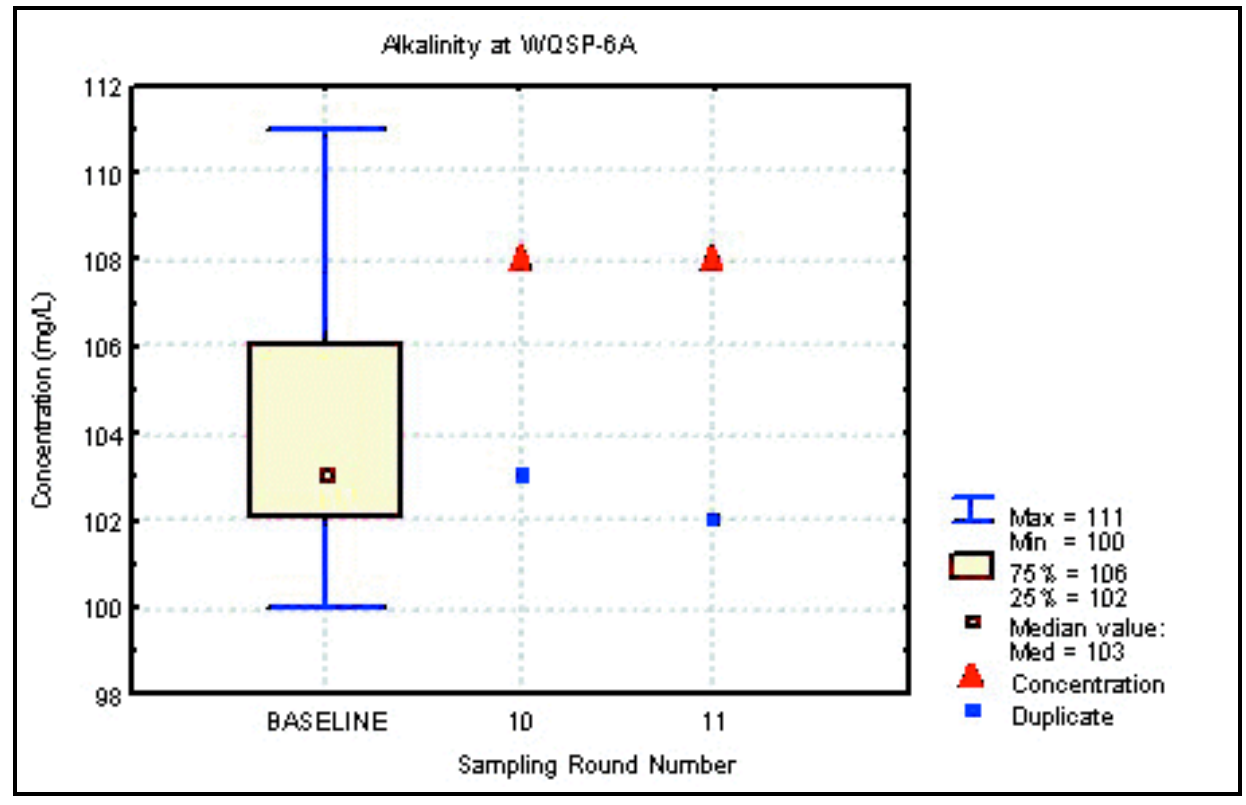

Figure F.108 Time Trend Plot for Alkalinity at WQSP-6A

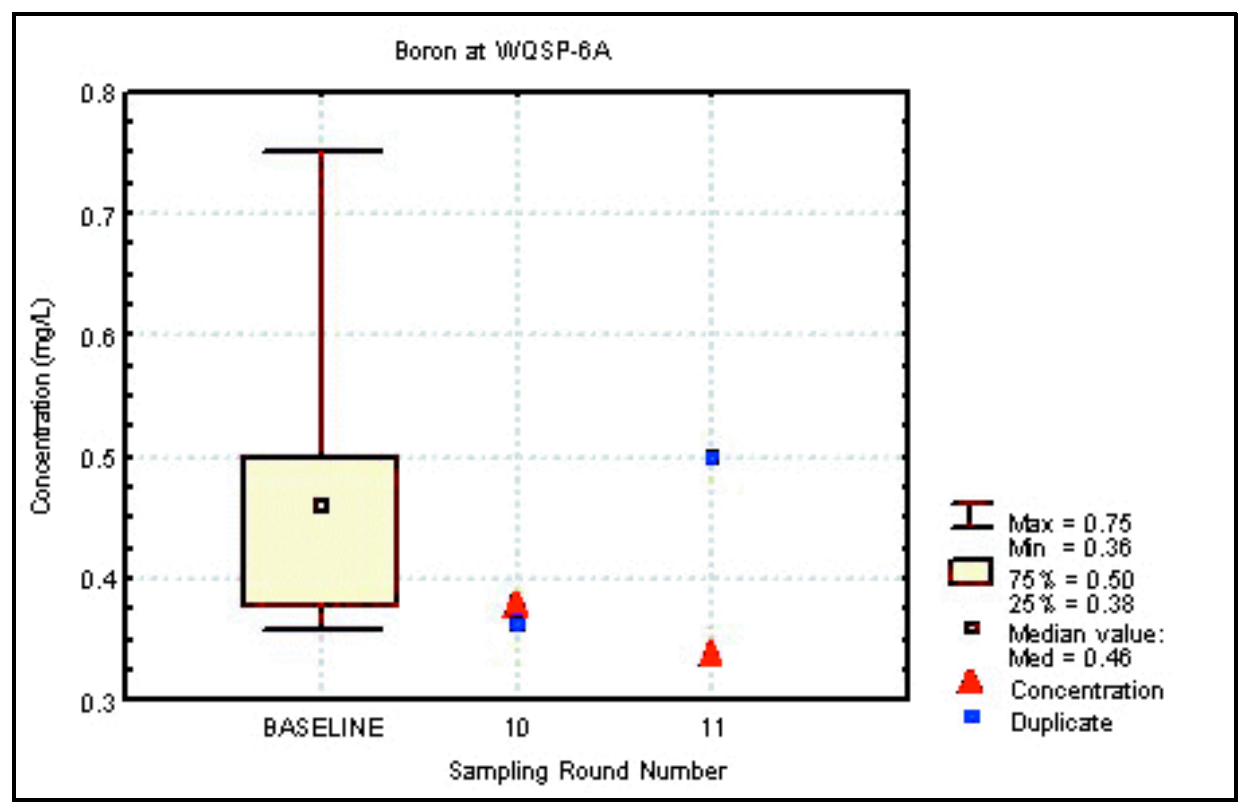

Figure F.109 Time Trent Plot for Boron at WQSP-6A 


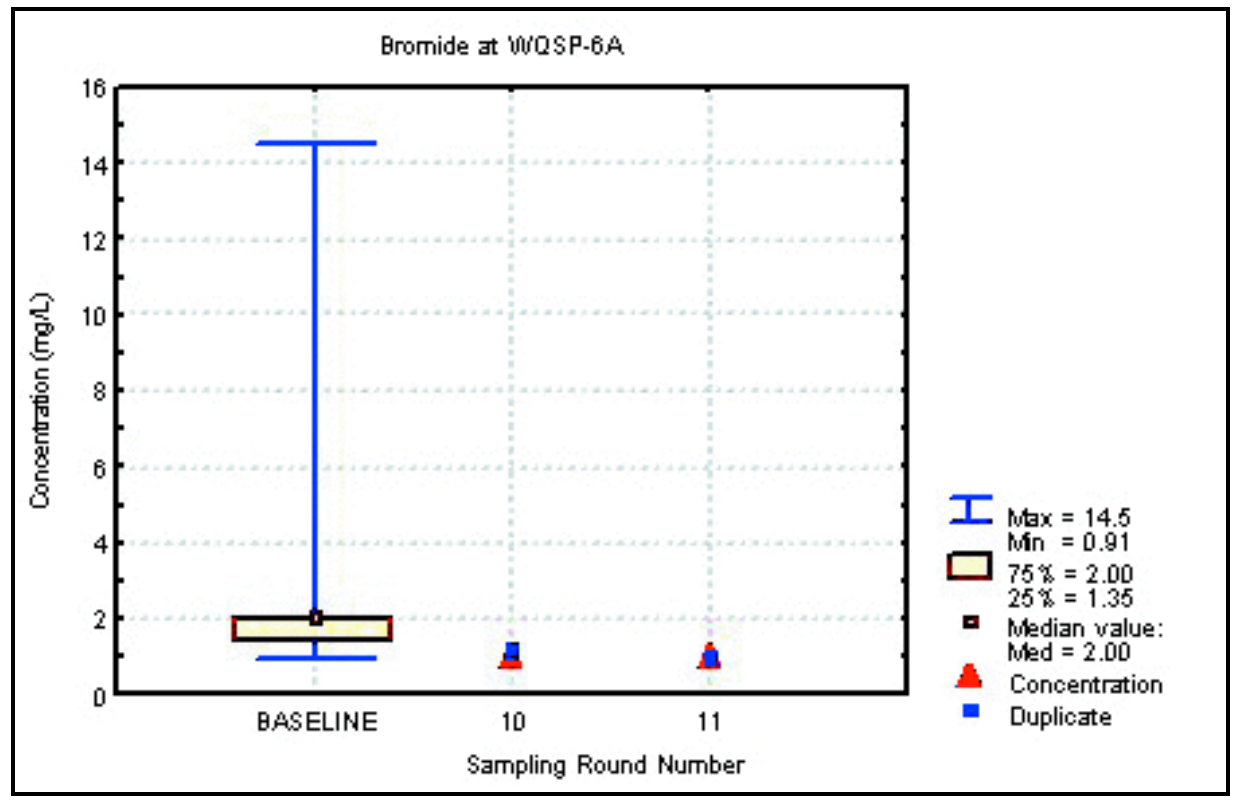

Figure F.110 Time Trend Plot for Bromide at WQSP-6A

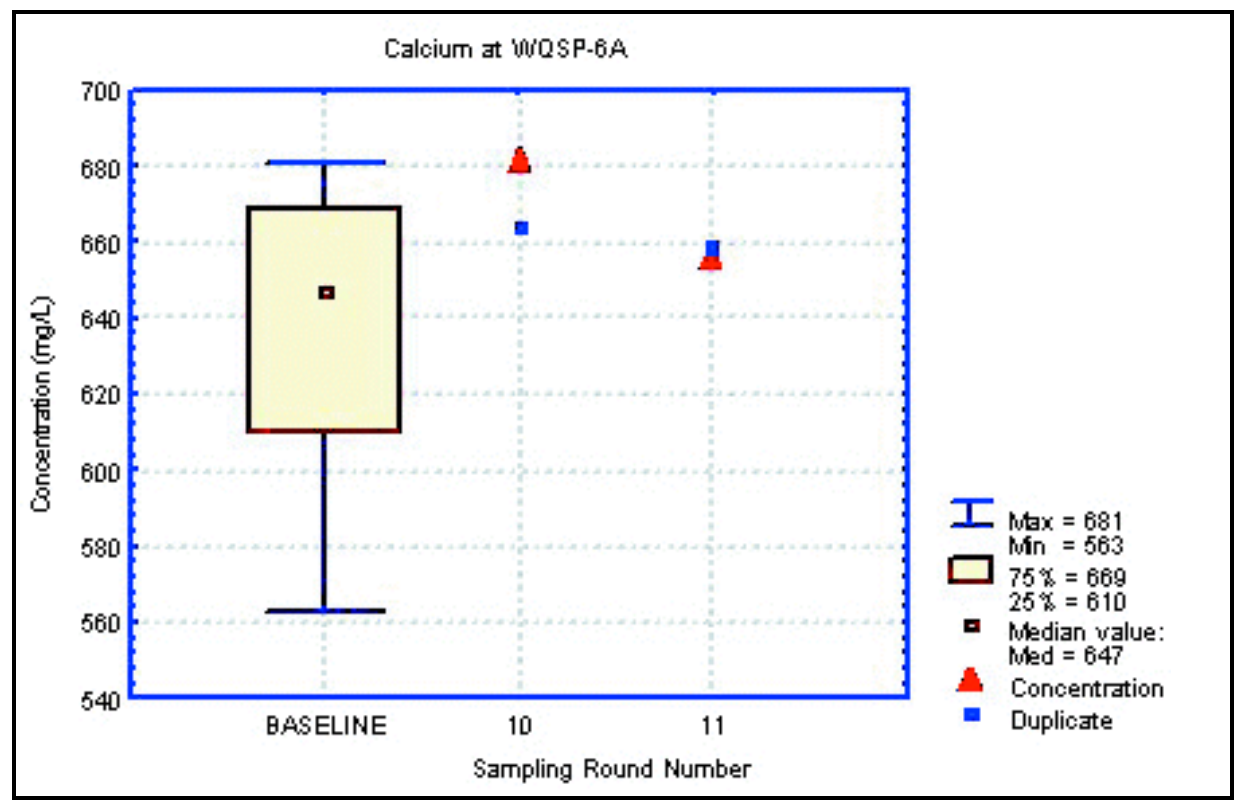

Figure F.111 Time Trent Plot for Calcium at WQSP-6A 


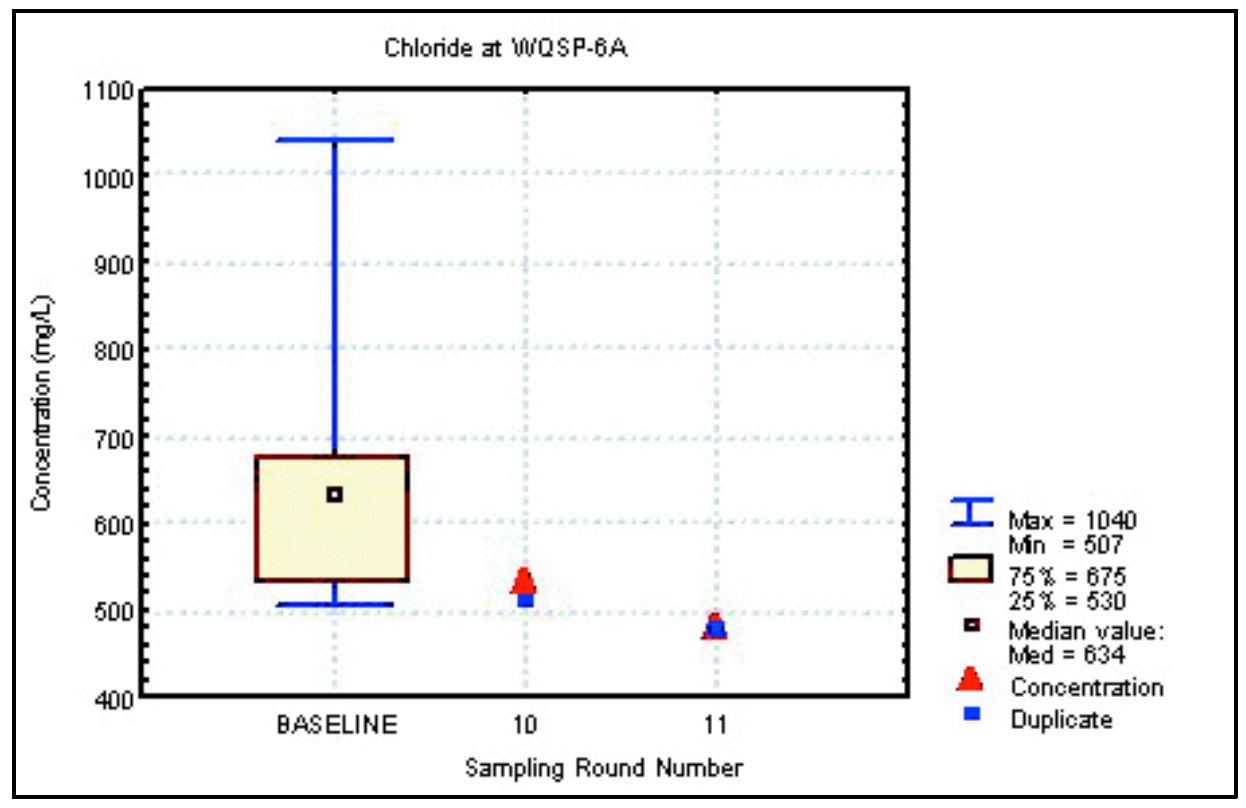

Figure F.112 Time Trend Plot for Chloride at WQSP-6A

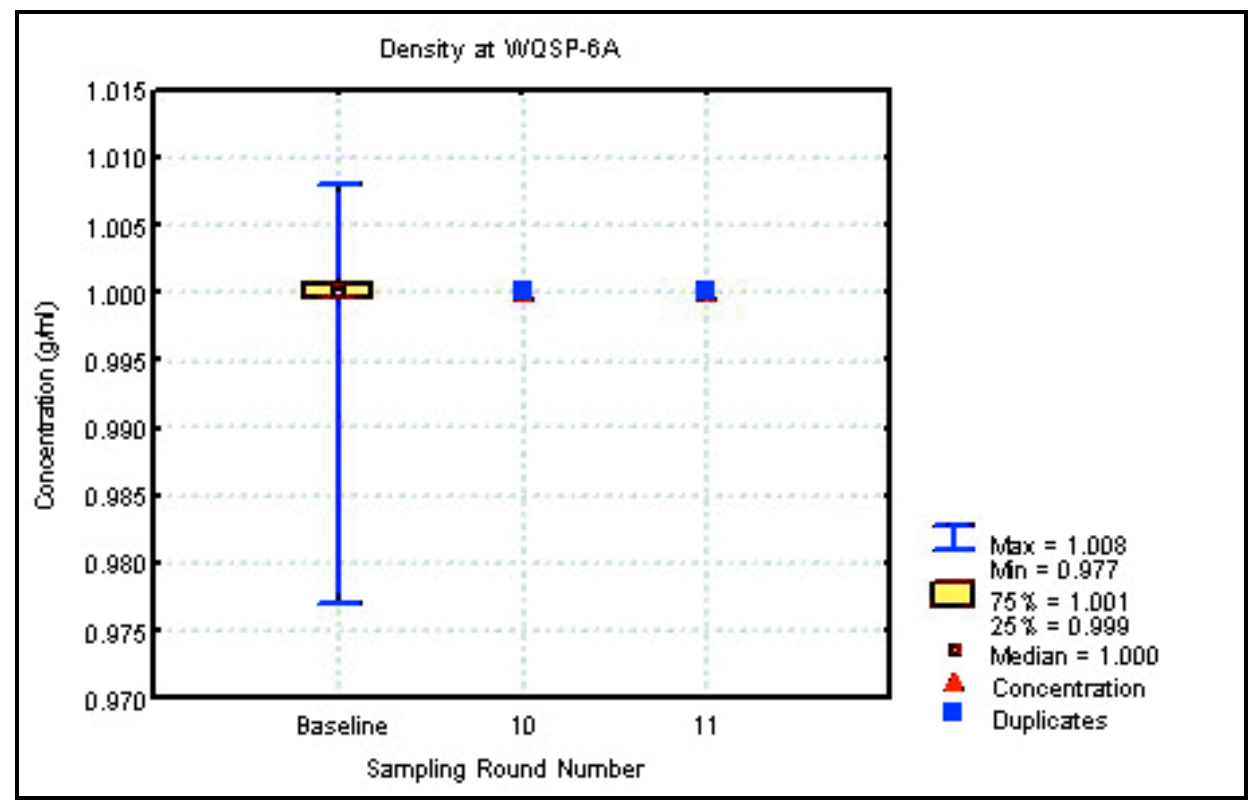

Figure F.113 Time Trent Plot for Density at WQSP-6A 


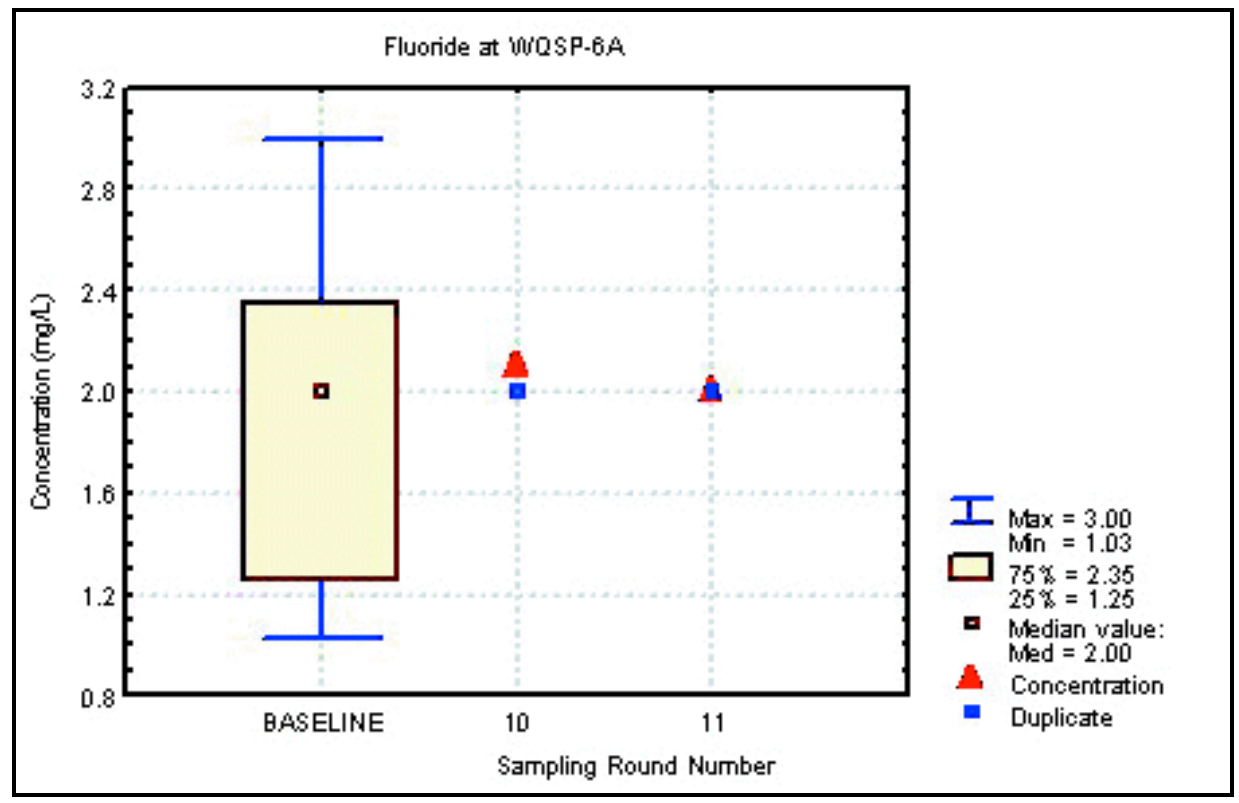

Figure F.114 Time Trend Plot for Fluoride at WQSP-6A

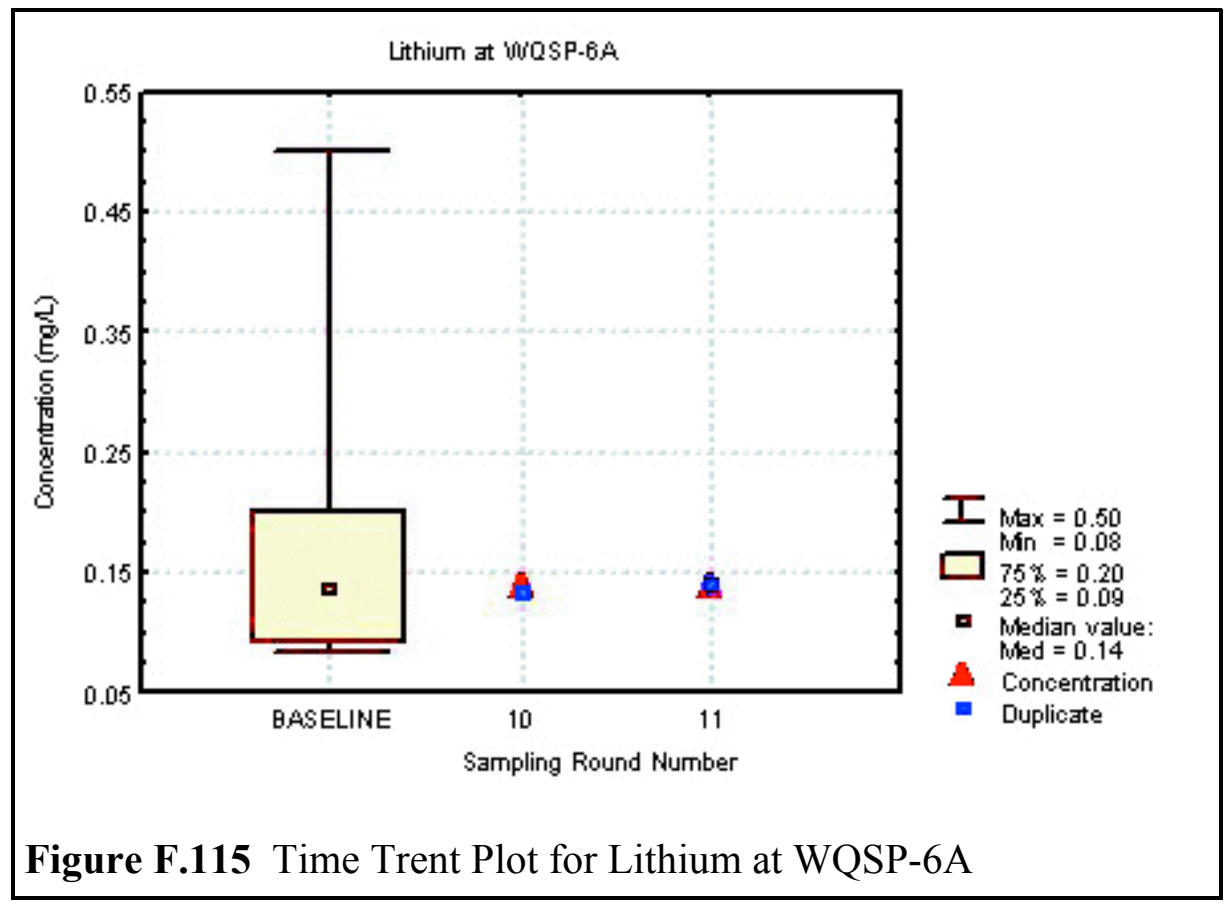




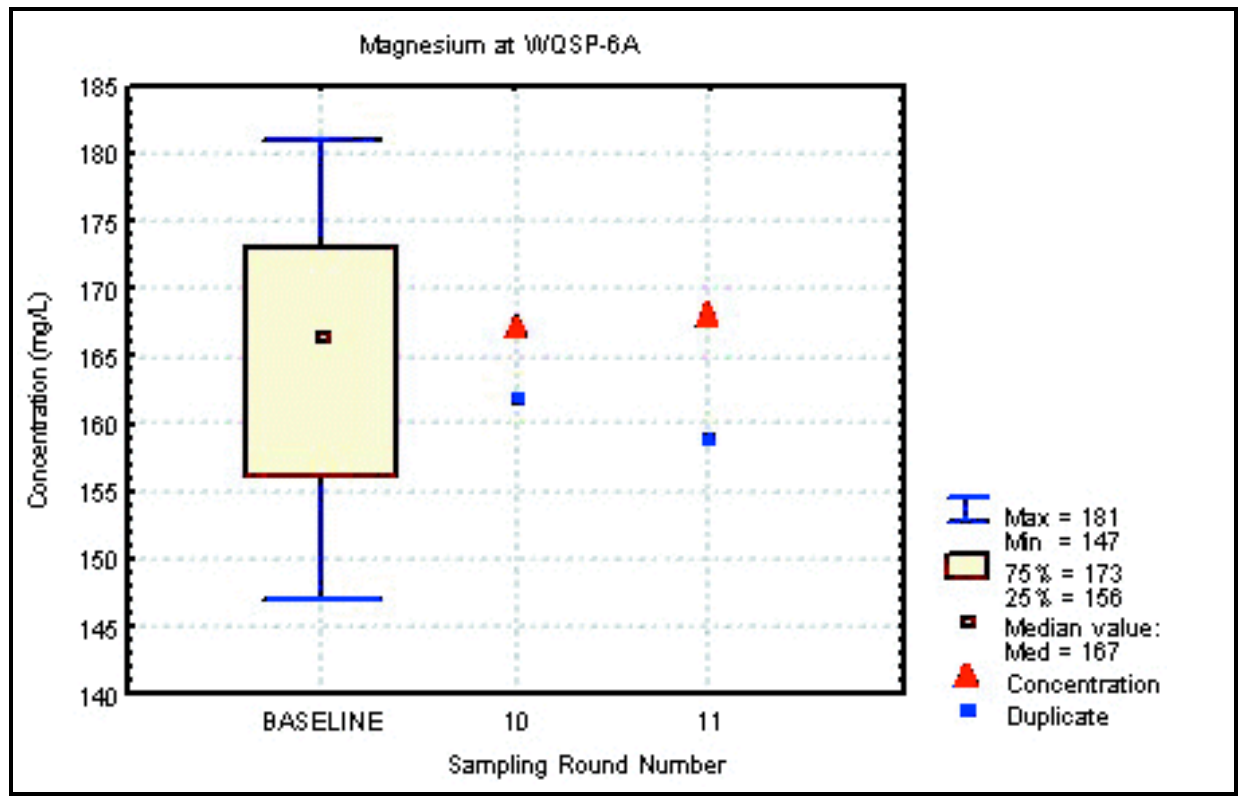

Figure F.116 Time Trend Plot for Magnesium at WQSP-6A

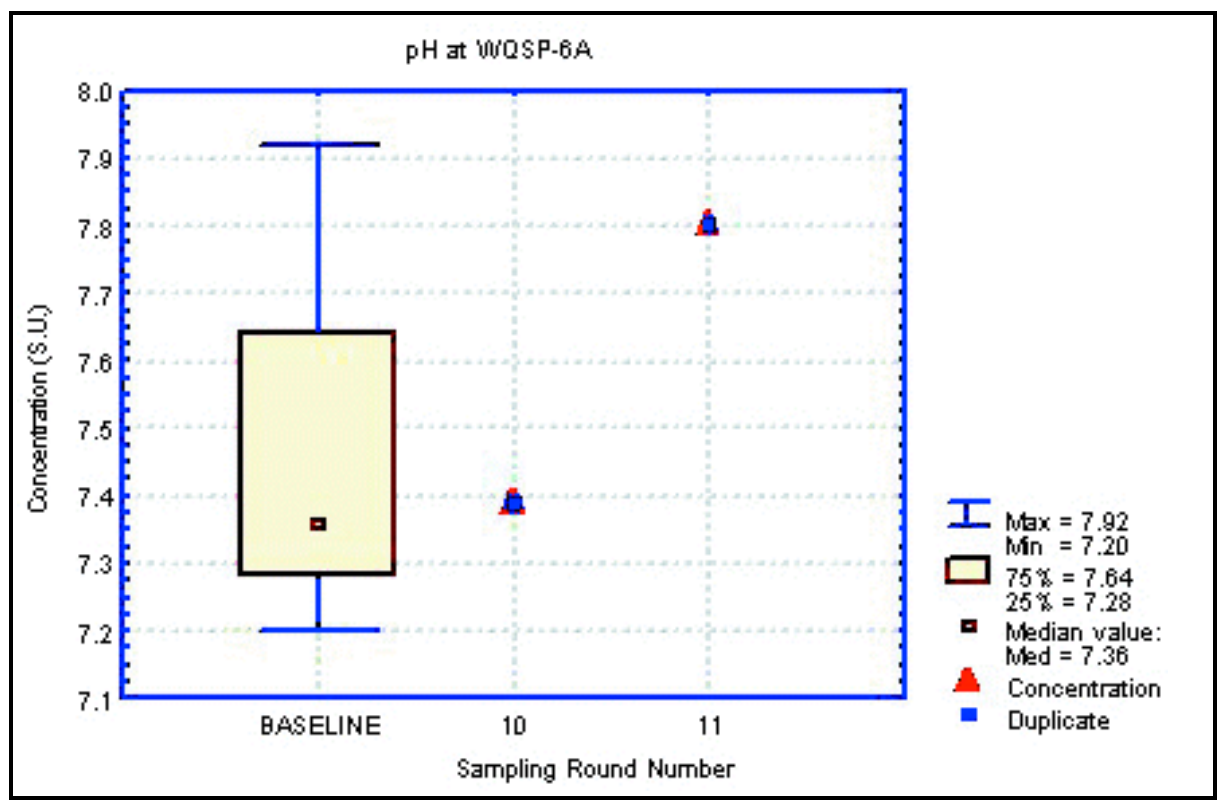

Figure F.117 Time Trent Plot for $\mathrm{pH}$ at WQSP-6A 


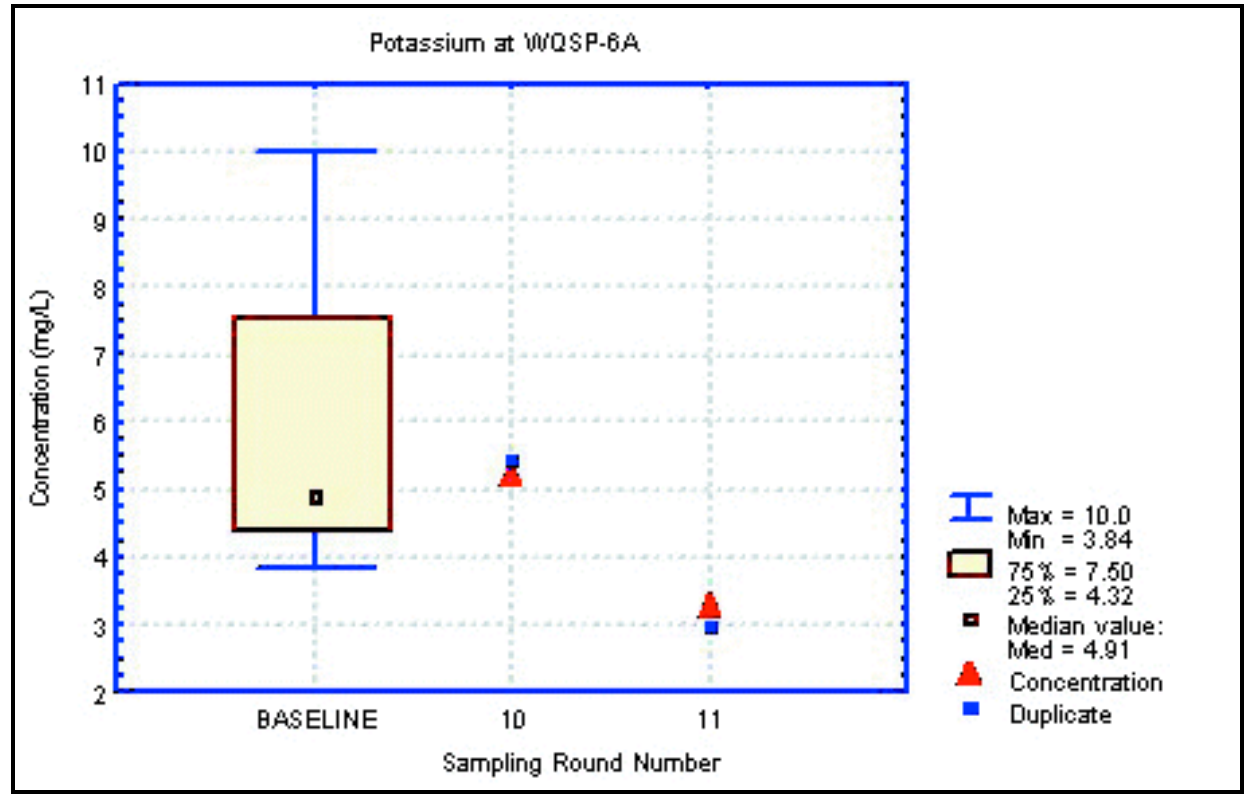

Figure F.120 Time Trend Plot for Potassium at WQSP-6A

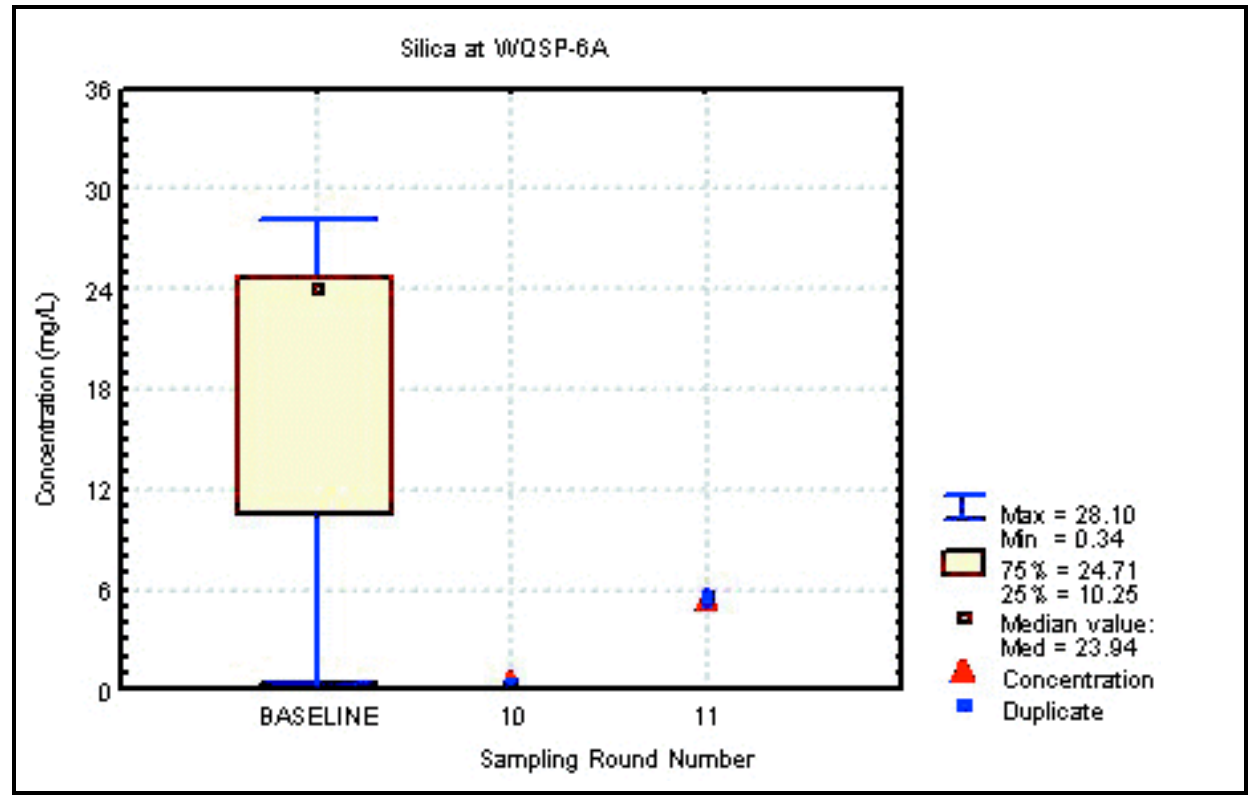

Figure F.121 Time Trent Plot for Silica at WQSP-6A 


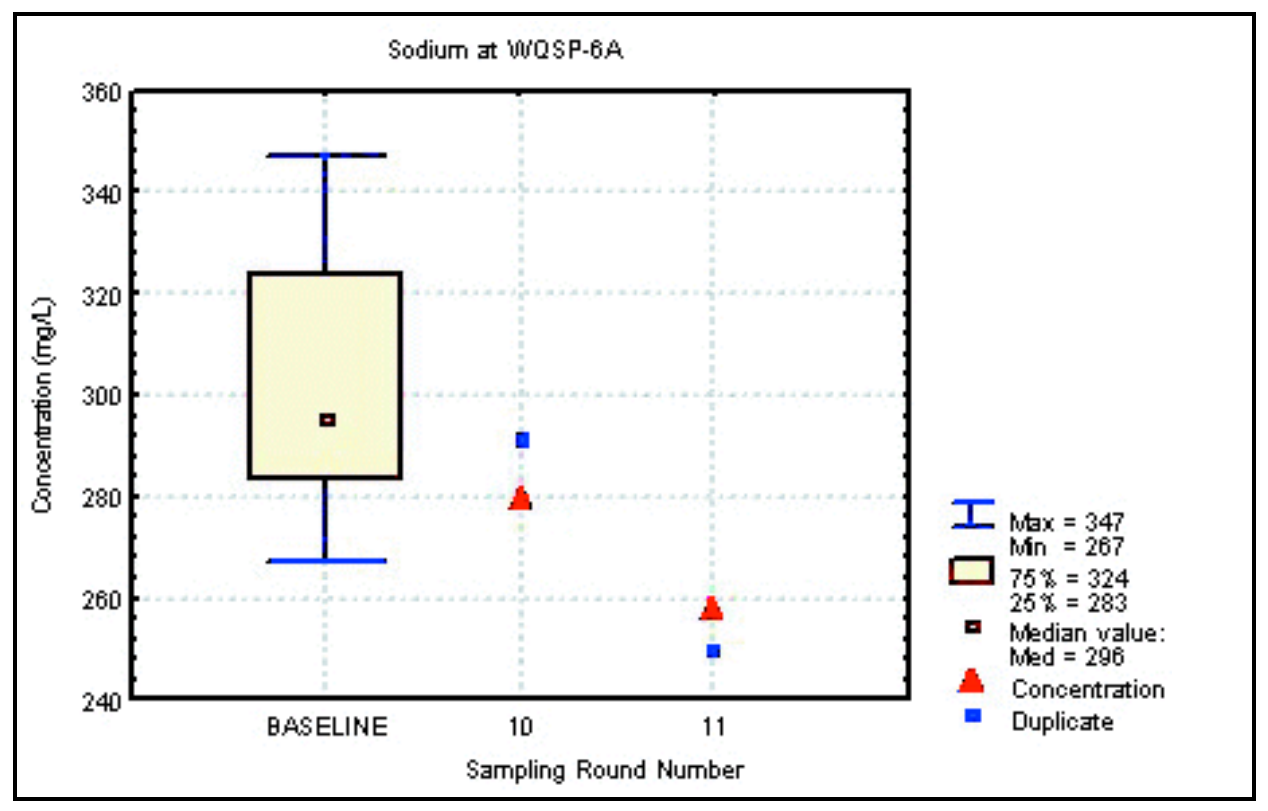

Figure F.122 Time Trend Plot for Sodium at WQSP-6A

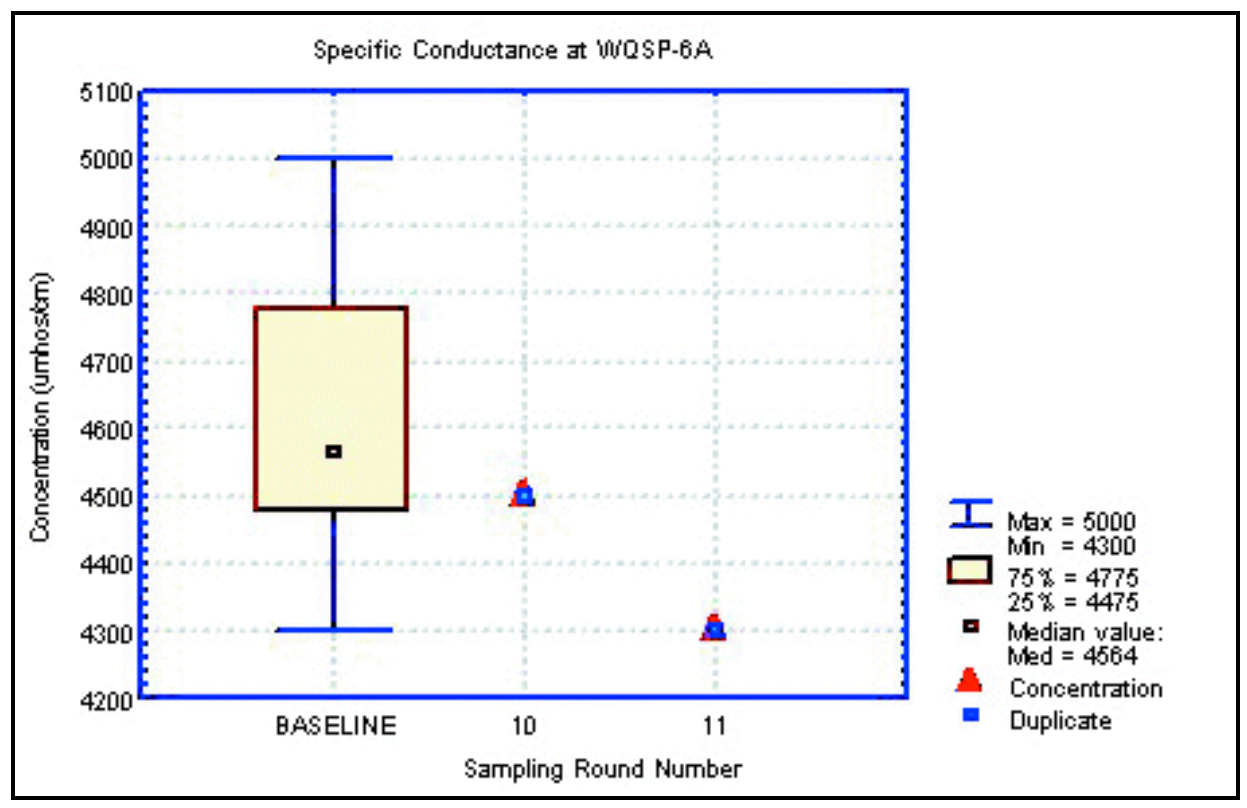

Figure F.123 Time Trent Plot for Specific Conductance at WQSP-6A 


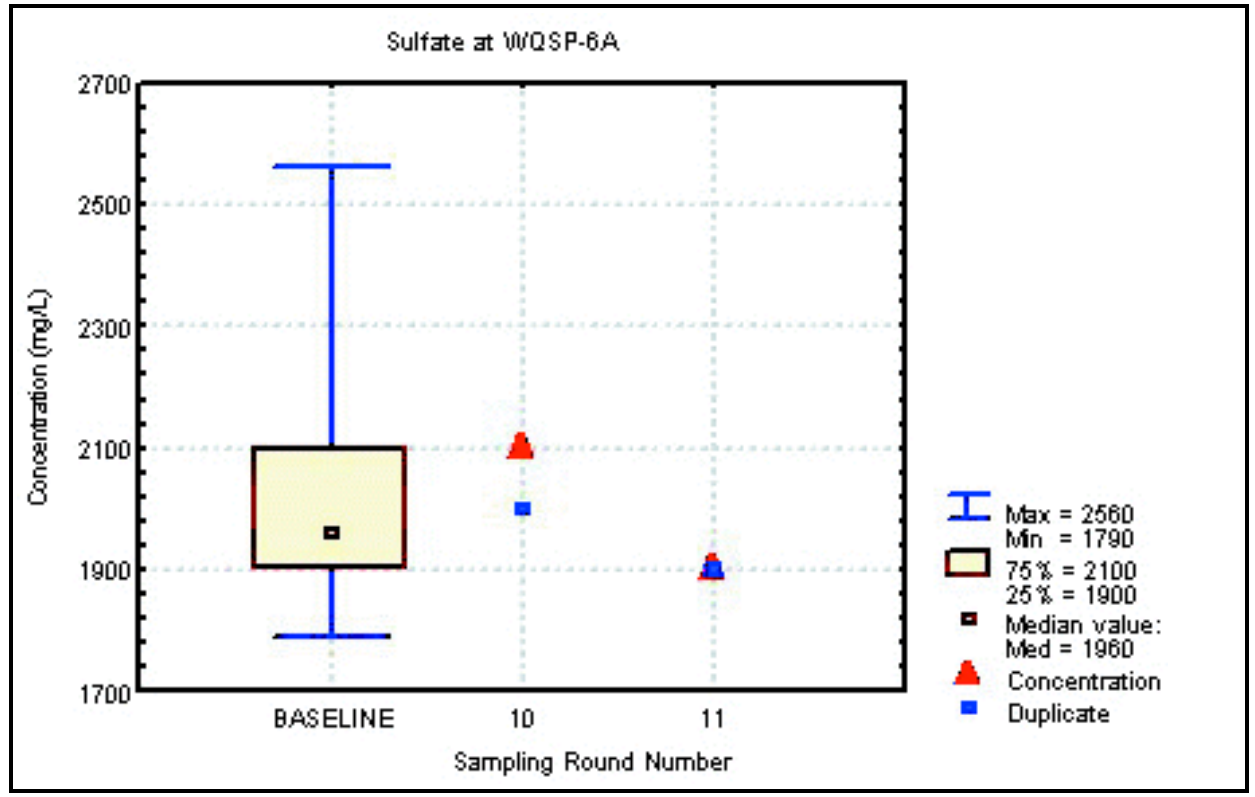

Figure F.124 Time Trend Plot for Sulfate at WQSP-6A

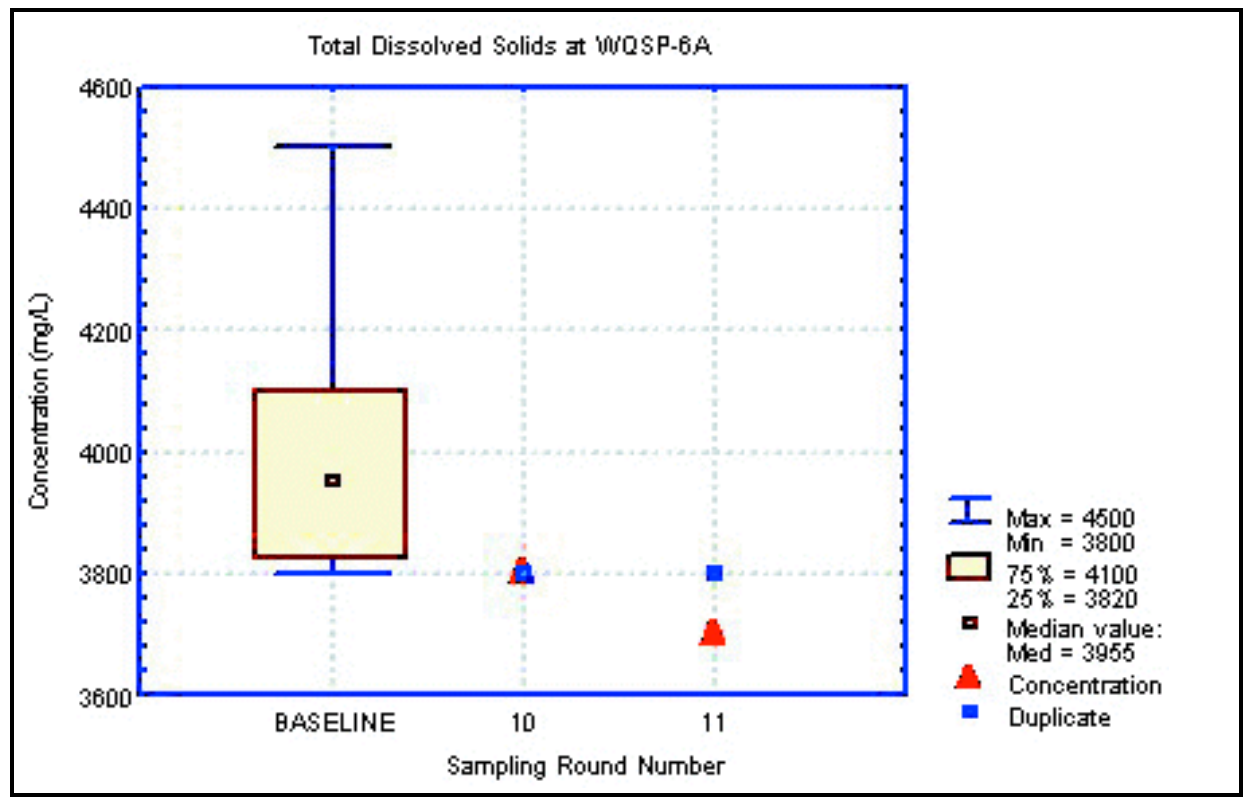

Figure F.125 Time Trent Plot for Total Dissolved Solids at WQSP-6A 


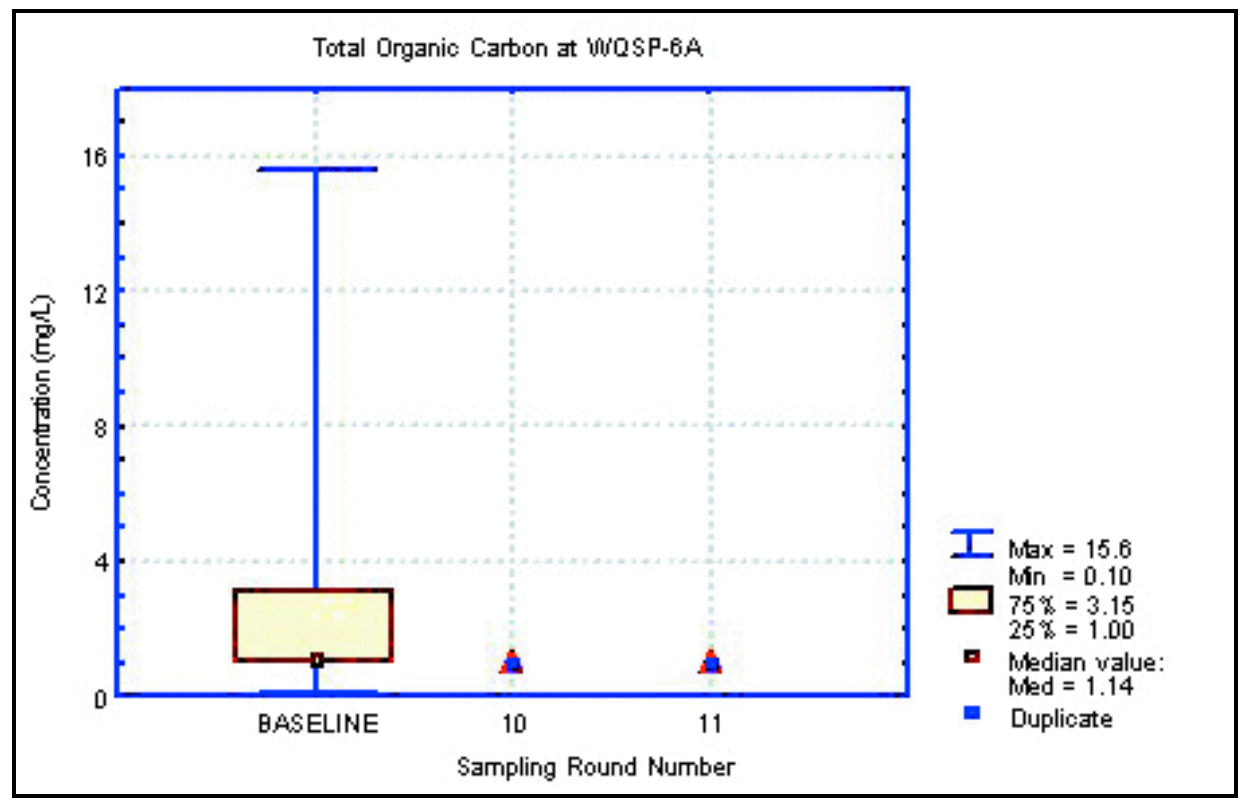

Figure F.126 Time Trend Plot for Total Organic Carbon at WQSP-6A

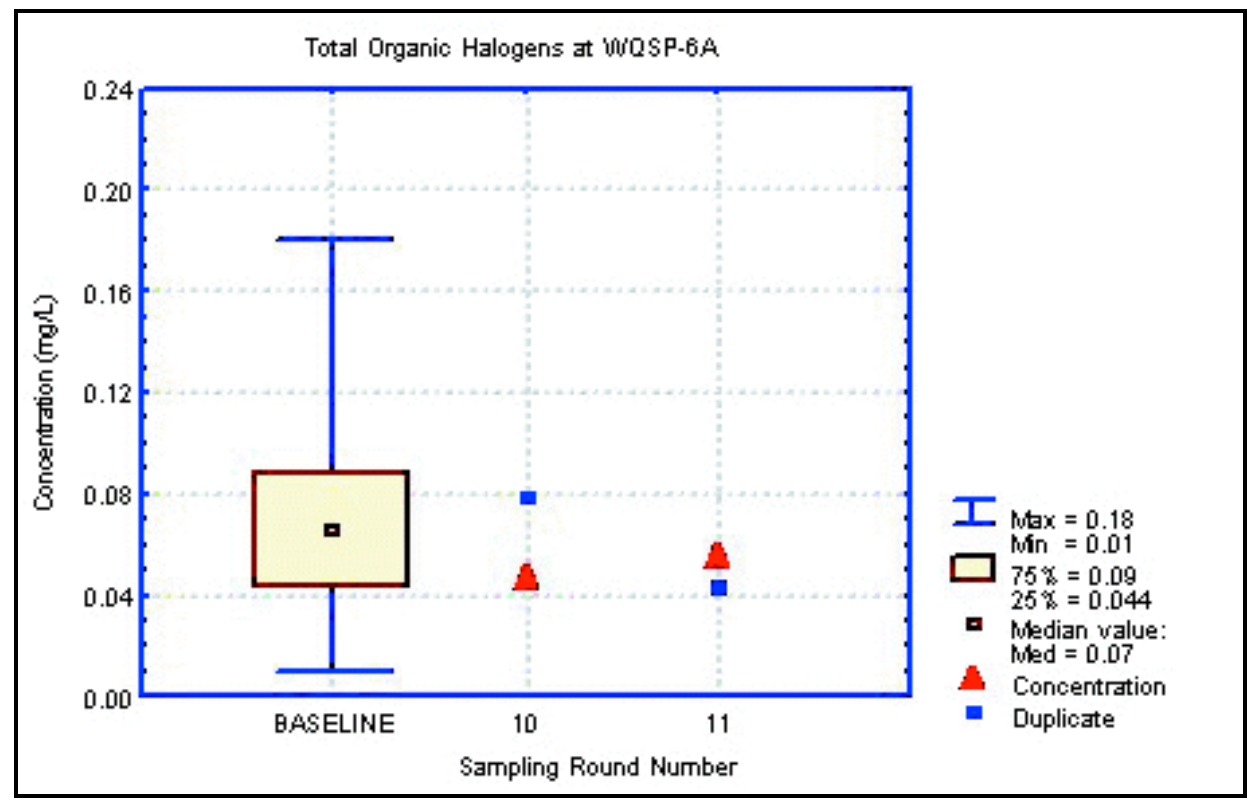

Figure F.127 Time Trent Plot for Total Organic Halogens at WQSP-6A 
This page intentionally left blank. 


\section{Appendix G \\ Air Sampling Data: Concentrations of Radionuclides}

Table G.1 Radionuclide concentrations $\left(\mathrm{Bq} / \mathrm{m}^{3}\right)$ in quarterly composite air filters collected from locations surrounding the WIPP site. See Appendix B for the sampling locations.

\begin{tabular}{|c|c|c|c|c|c|c|c|c|c|c|}
\hline \multirow[t]{2}{*}{ Location } & \multirow[t]{2}{*}{ Quarter } & {$[\mathbf{R N}]^{\mathbf{a}}$} & $2 \times T P U^{b}$ & MDC $^{\mathrm{c}}$ & [RN] & 2xTPU & MDC & [RN] & 2xTPU & MDC \\
\hline & & \multicolumn{3}{|c|}{${ }^{241} \mathrm{Am}$} & \multicolumn{3}{|c|}{${ }^{238} \mathbf{P u}$} & \multicolumn{3}{|c|}{${ }^{239+240} \mathrm{Pu}$} \\
\hline$\overline{\mathrm{CBD}}$ & 1 & $3.57 \times 10^{-8}$ & $6.01 \times 10^{-8}$ & $8.84 \times 10^{-8}$ & $1.24 \times 10^{-8}$ & $3.17 \times 10^{-8}$ & $6.67 \times 10^{-8}$ & $3.22 \times 10^{-8}$ & $6.21 \times 10^{-8}$ & $1.16 \times 10^{-7}$ \\
\hline CBD & 2 & $5.55 \times 10^{-8}$ & $8.91 \times 10^{-8}$ & $1.23 \times 10^{-7}$ & $2.29 \times 10^{-8}$ & $4.58 \times 10^{-8}$ & $6.20 \times 10^{-8}$ & $-1.83 \times 10^{-12}$ & $7.66 \times 10^{-8}$ & $2.12 \times 10^{-7}$ \\
\hline CBD & 3 & $2.61 \times 10^{-8}$ & $7.46 \times 10^{-8}$ & $1.37 \times 10^{-7}$ & $3.92 \times 10^{-9}$ & $4.50 \times 10^{-8}$ & $1.35 \times 10^{-7}$ & $1.96 \times 10^{-8}$ & $7.64 \times 10^{-8}$ & $1.82 \times 10^{-7}$ \\
\hline CBD & 4 & $1.44 \times 10^{-8}$ & $4.06 \times 10^{-8}$ & $6.05 \times 10^{-8}$ & $3.30 \times 10^{-9}$ & $2.68 \times 10^{-8}$ & $7.10 \times 10^{-8}$ & $3.97 \times 10^{-8}$ & $4.21 \times 10^{-8}$ & $6.45 \times 10^{-8}$ \\
\hline MLR & 1 & $1.98 \times 10^{-8}$ & $4.74 \times 10^{-8}$ & $3.70 \times 10^{-8}$ & $9.45 \times 10^{-9}$ & $1.89 \times 10^{-8}$ & $2.56 \times 10^{-8}$ & $5.68 \times 10^{-13}$ & $4.33 \times 10^{-8}$ & $1.02 \times 10^{-7}$ \\
\hline MLR & 2 & $9.77 \times 10^{-8}$ & $1.18 \times 10^{-7}$ & $1.61 \times 10^{-7}$ & $-8.62 \times 10^{-9}$ & $1.73 \times 10^{-8}$ & $1.22 \times 10^{-7}$ & $5.61 \times 10^{-8}$ & $7.69 \times 10^{-8}$ & $1.22 \times 10^{-7}$ \\
\hline MLR & 3 & $5.66 \times 10^{-8}$ & $7.89 \times 10^{-8}$ & $9.79 \times 10^{-8}$ & $2.31 \times 10^{-8}$ & $4.63 \times 10^{-8}$ & $6.26 \times 10^{-8}$ & $3.23 \times 10^{-8}$ & $8.82 \times 10^{-8}$ & $1.99 \times 10^{-7}$ \\
\hline MLR & 4 & $5.40 \times 10^{-8}$ & $6.58 \times 10^{-8}$ & $9.09 \times 10^{-8}$ & $5.98 \times 10^{-9}$ & $2.15 \times 10^{-8}$ & $5.64 \times 10^{-8}$ & $3.99 \times 10^{-9}$ & $3.24 \times 10^{-8}$ & $8.57 \times 10^{-8}$ \\
\hline SEC & 1 & $4.22 \times 10^{-8}$ & $6.35 \times 10^{-8}$ & $8.34 \times 10^{-8}$ & $2.52 \times 10^{-9}$ & $2.52 \times 10^{-8}$ & $6.78 \times 10^{-8}$ & $1.51 \times 10^{-8}$ & $4.09 \times 10^{-8}$ & $8.46 \times 10^{-8}$ \\
\hline SEC & 2 & $5.40 \times 10^{-8}$ & $9.64 \times 10^{-8}$ & $1.69 \times 10^{-7}$ & $-3.78 \times 10^{-9}$ & $4.60 \times 10^{-8}$ & $1.47 \times 10^{-7}$ & $1.51 \times 10^{-8}$ & $5.95 \times 10^{-8}$ & $1.47 \times 10^{-7}$ \\
\hline SEC & 3 & $3.38 \times 10^{-8}$ & $6.56 \times 10^{-8}$ & $5.12 \times 10^{-8}$ & $-1.94 \times 10^{-8}$ & $2.25 \times 10^{-8}$ & $1.26 \times 10^{-7}$ & $-3.24 \times 10^{-9}$ & $3.94 \times 10^{-8}$ & $1.26 \times 10^{-7}$ \\
\hline SEC & 4 & $3.36 \times 10^{-8}$ & $4.90 \times 10^{-8}$ & $6.20 \times 10^{-8}$ & $3.59 \times 10^{-9}$ & $2.92 \times 10^{-8}$ & $7.71 \times 10^{-8}$ & $5.38 \times 10^{-9}$ & $3.57 \times 10^{-8}$ & $8.89 \times 10^{-8}$ \\
\hline SMR & 1 & $9.92 \times 10^{-9}$ & $5.86 \times 10^{-8}$ & $1.09 \times 10^{-7}$ & $-1.69 \times 10^{-8}$ & $2.39 \times 10^{-8}$ & $9.45 \times 10^{-8}$ & $3.93 \times 10^{-8}$ & $7.59 \times 10^{-8}$ & $1.41 \times 10^{-7}$ \\
\hline SMR & 2 & $6.66 \times 10^{-8}$ & $9.19 \times 10^{-8}$ & $6.21 \times 10^{-8}$ & $-1.74 \times 10^{-8}$ & $2.47 \times 10^{-8}$ & $1.50 \times 10^{-7}$ & $5.23 \times 10^{-8}$ & $9.40 \times 10^{-8}$ & $1.87 \times 10^{-7}$ \\
\hline SMR & 3 & $4.51 \times 10^{-10}$ & $6.83 \times 10^{-8}$ & $4.62 \times 10^{-8}$ & $-1.07 \times 10^{-8}$ & $4.71 \times 10^{-8}$ & $1.40 \times 10^{-7}$ & $1.60 \times 10^{-8}$ & $7.50 \times 10^{-8}$ & $1.72 \times 10^{-7}$ \\
\hline SMR & 4 & $4.96 \times 10^{-8}$ & $6.24 \times 10^{-8}$ & $8.62 \times 10^{-8}$ & $-5.96 \times 10^{-9}$ & $2.54 \times 10^{-8}$ & $8.53 \times 10^{-8}$ & $5.96 \times 10^{-9}$ & $3.95 \times 10^{-8}$ & $9.84 \times 10^{-8}$ \\
\hline WEE & 1 & $-6.96 \times 10^{-9}$ & $7.63 \times 10^{-8}$ & $1.64 \times 10^{-7}$ & $2.25 \times 10^{-8}$ & $6.05 \times 10^{-8}$ & $1.21 \times 10^{-7}$ & $5.90 \times 10^{-8}$ & $5.77 \times 10^{-8}$ & $7.57 \times 10^{-8}$ \\
\hline WEE & 2 & $6.11 \times 10^{-8}$ & $8.70 \times 10^{-8}$ & $5.88 \times 10^{-8}$ & $-2.28 \times 10^{-8}$ & $2.65 \times 10^{-8}$ & $1.49 \times 10^{-7}$ & $1.52 \times 10^{-8}$ & $6.00 \times 10^{-8}$ & $1.49 \times 10^{-7}$ \\
\hline WEE & 3 & $4.92 \times 10^{-8}$ & $7.15 \times 10^{-8}$ & $8.87 \times 10^{-8}$ & $1.29 \times 10^{-8}$ & $4.64 \times 10^{-8}$ & $1.22 \times 10^{-7}$ & $2.58 \times 10^{-8}$ & $6.56 \times 10^{-8}$ & $1.48 \times 10^{-7}$ \\
\hline WEE & 4 & $4.26 \times 10^{-10}$ & $4.94 \times 10^{-8}$ & $2.52 \times 10^{-8}$ & $-4.55 \times 10^{-9}$ & $1.94 \times 10^{-8}$ & $6.52 \times 10^{-8}$ & $3.34 \times 10^{-8}$ & $3.92 \times 10^{-8}$ & $6.52 \times 10^{-8}$ \\
\hline WFF & 1 & $2.07 \times 10^{-8}$ & $5.78 \times 10^{-8}$ & $9.11 \times 10^{-8}$ & $1.53 \times 10^{-8}$ & $3.93 \times 10^{-8}$ & $8.25 \times 10^{-8}$ & $2.14 \times 10^{-8}$ & $8.11 \times 10^{-8}$ & $1.64 \times 10^{-7}$ \\
\hline WFF & 2 & $5.11 \times 10^{-8}$ & $8.17 \times 10^{-8}$ & $1.21 \times 10^{-7}$ & $3.68 \times 10^{-9}$ & $4.23 \times 10^{-8}$ & $1.26 \times 10^{-7}$ & $2.58 \times 10^{-8}$ & $7.03 \times 10^{-8}$ & $1.58 \times 10^{-7}$ \\
\hline WFF & 3 & $7.18 \times 10^{-8}$ & $1.01 \times 10^{-7}$ & $1.54 \times 10^{-7}$ & $-1.58 \times 10^{-8}$ & $2.24 \times 10^{-8}$ & $1.36 \times 10^{-7}$ & $3.93 \times 10^{-13}$ & $6.60 \times 10^{-8}$ & $1.83 \times 10^{-7}$ \\
\hline WFF & 4 & $1.07 \times 10^{-8}$ & $3.31 \times 10^{-8}$ & $2.24 \times 10^{-8}$ & $-1.09 \times 10^{-8}$ & $1.54 \times 10^{-8}$ & $9.34 \times 10^{-8}$ & $-1.09 \times 10^{-8}$ & $4.80 \times 10^{-8}$ & $1.43 \times 10^{-7}$ \\
\hline WSS & 1 & $7.73 \times 10^{-9}$ & $3.64 \times 10^{-8}$ & $2.84 \times 10^{-8}$ & $7.98 \times 10^{-9}$ & $1.60 \times 10^{-8}$ & $2.16 \times 10^{-8}$ & $3.59 \times 10^{-8}$ & $4.27 \times 10^{-8}$ & $6.70 \times 10^{-8}$ \\
\hline WSS & 2 & $1.63 \times 10^{-8}$ & $8.80 \times 10^{-8}$ & $1.84 \times 10^{-7}$ & $1.10 \times 10^{-8}$ & $3.96 \times 10^{-8}$ & $1.04 \times 10^{-7}$ & $8.46 \times 10^{-8}$ & $8.38 \times 10^{-8}$ & $1.04 \times 10^{-7}$ \\
\hline WSS & 3 & $1.18 \times 10^{-8}$ & $6.40 \times 10^{-8}$ & $1.23 \times 10^{-7}$ & $-7.48 \times 10^{-9}$ & $1.50 \times 10^{-8}$ & $1.06 \times 10^{-7}$ & $2.62 \times 10^{-8}$ & $7.14 \times 10^{-8}$ & $1.61 \times 10^{-7}$ \\
\hline
\end{tabular}


Table G.1 continued..

\begin{tabular}{|c|c|c|c|c|c|c|c|c|c|c|}
\hline \multirow[t]{2}{*}{ Location } & \multirow[t]{2}{*}{ Quarter } & {$[\mathbf{R N}]^{\mathrm{a}}$} & $2 \times T^{\prime b} U^{b}$ & $\mathrm{MDC}^{\mathrm{c}}$ & {$[\mathbf{R N}]$} & $2 \times T P U$ & MDC & {$[\mathbf{R N}]$} & $2 \times T P U$ & MDC \\
\hline & & \multicolumn{3}{|c|}{${ }^{241} \mathrm{Am}$} & \multicolumn{3}{|c|}{${ }^{238} \mathbf{P u}$} & \multicolumn{3}{|c|}{${ }^{239+240} \mathrm{Pu}$} \\
\hline$\overline{\mathrm{WSS}}$ & 4 & $7.96 \times 10^{-8}$ & $7.21 \times 10^{-8}$ & $9.54 \times 10^{-8}$ & $1.87 \times 10^{-8}$ & $2.57 \times 10^{-8}$ & $4.07 \times 10^{-8}$ & $1.44 \times 10^{-8}$ & $3.16 \times 10^{-8}$ & $6.69 \times 10^{-8}$ \\
\hline WAB & 1 & $1.10 \times 10^{-4}$ & $3.62 \times 10^{-4}$ & $5.71 \times 10^{-4}$ & $-5.49 \times 10^{-5}$ & $1.10 \times 10^{-4}$ & $4.93 \times 10^{-4}$ & $-1.83 \times 10^{-5}$ & $4.38 \times 10^{-4}$ & $9.78 \times 10^{-4}$ \\
\hline WAB & 2 & $1.59 \times 10^{-4}$ & $5.44 \times 10^{-4}$ & $1.02 \times 10^{-3}$ & $-9.50 \times 10^{-5}$ & $4.06 \times 10^{-4}$ & $1.36 \times 10^{-3}$ & $2.53 \times 10^{-4}$ & $4.66 \times 10^{-4}$ & $8.95 \times 10^{-4}$ \\
\hline WAB & 3 & $1.57 \times 10^{-4}$ & $5.40 \times 10^{-4}$ & $1.02 \times 10^{-3}$ & $2.35 \times 10^{-4}$ & $4.33 \times 10^{-4}$ & $8.31 \times 10^{-4}$ & $3.83 \times 10^{-4}$ & $5.24 \times 10^{-4}$ & $8.31 \times 10^{-4}$ \\
\hline WAB & 4 & $1.72 \times 10^{-4}$ & $3.52 \times 10^{-4}$ & $5.47 \times 10^{-4}$ & $-5.78 \times 10^{-5}$ & $8.18 \times 10^{-5}$ & $4.96 \times 10^{-4}$ & $8.66 \times 10^{-5}$ & $2.20 \times 10^{-4}$ & $4.96 \times 10^{-4}$ \\
\hline Minimum & & $-6.96 \times 10^{-9}$ & $7.63 \times 10^{-8}$ & $2.24 \times 10^{-8}$ & $-2.28 \times 10^{-8}$ & $2.65 \times 10^{-8}$ & $2.16 \times 10^{-8}$ & $-1.09 \times 10^{-8}$ & $4.80 \times 10^{-8}$ & $6.45 \times 10^{-8}$ \\
\hline Maximum & & $9.77 \times 10^{-8}$ & $1.18 \times 10^{-7}$ & $1.84 \times 10^{-7}$ & $2.31 \times 10^{-8}$ & $4.63 \times 10^{-8}$ & $1.50 \times 10^{-7}$ & $8.46 \times 10^{-8}$ & $8.38 \times 10^{-8}$ & $2.12 \times 10^{-7}$ \\
\hline \multirow[t]{2}{*}{ Mean $^{c}$} & & $3.65 \times 10^{-8}$ & $1.37 \times 10^{-8}$ & $9.37 \times 10^{-8}$ & $1.25 \times 10^{-9}$ & $6.28 \times 10^{-9}$ & $9.48 \times 10^{-8}$ & $2.36 \times 10^{-8}$ & $1.18 \times 10^{-8}$ & $1.29 \times 10^{-7}$ \\
\hline & & \multicolumn{3}{|c|}{${ }^{234} \mathbf{U}$} & \multicolumn{3}{|c|}{${ }^{235} \mathrm{U}$} & \multicolumn{3}{|c|}{${ }^{238} \mathbf{U}$} \\
\hline CBD & 1 & $2.58 \times 10^{-6}$ & $3.35 \times 10^{-7}$ & $1.17 \times 10^{-7}$ & $2.00 \times 10^{-7}$ & $1.12 \times 10^{-7}$ & $1.36 \times 10^{-7}$ & $2.95 \times 10^{-6}$ & $3.65 \times 10^{-7}$ & $1.50 \times 10^{-7}$ \\
\hline CBD & 2 & $2.76 \times 10^{-6}$ & $4.96 \times 10^{-7}$ & $1.96 \times 10^{-7}$ & $4.40 \times 10^{-8}$ & $9.89 \times 10^{-8}$ & $2.10 \times 10^{-7}$ & $2.55 \times 10^{-6}$ & $4.77 \times 10^{-7}$ & $2.40 \times 10^{-7}$ \\
\hline CBD & 3 & $2.88 \times 10^{-6}$ & $4.86 \times 10^{-7}$ & $1.48 \times 10^{-7}$ & $2.07 \times 10^{-7}$ & $1.30 \times 10^{-7}$ & $1.27 \times 10^{-7}$ & $2.73 \times 10^{-6}$ & $4.70 \times 10^{-7}$ & $1.59 \times 10^{-7}$ \\
\hline CBD & 4 & $1.71 \times 10^{-6}$ & $2.48 \times 10^{-7}$ & $7.70 \times 10^{-8}$ & $7.81 \times 10^{-8}$ & $6.33 \times 10^{-8}$ & $9.59 \times 10^{-8}$ & $1.80 \times 10^{-6}$ & $2.54 \times 10^{-7}$ & $6.64 \times 10^{-8}$ \\
\hline MLR & 1 & $2.43 \times 10^{-6}$ & $3.23 \times 10^{-7}$ & $1.16 \times 10^{-7}$ & $1.26 \times 10^{-7}$ & $9.85 \times 10^{-8}$ & $1.44 \times 10^{-7}$ & $2.47 \times 10^{-6}$ & $3.25 \times 10^{-7}$ & $1.16 \times 10^{-7}$ \\
\hline MLR & 2 & $2.31 \times 10^{-6}$ & $4.83 \times 10^{-7}$ & $3.99 \times 10^{-7}$ & $-3.32 \times 10^{-8}$ & $1.99 \times 10^{-7}$ & $4.61 \times 10^{-7}$ & $2.45 \times 10^{-6}$ & $4.80 \times 10^{-7}$ & $2.93 \times 10^{-7}$ \\
\hline MLR & 3 & $2.35 \times 10^{-6}$ & $4.30 \times 10^{-7}$ & $1.57 \times 10^{-7}$ & $1.70 \times 10^{-7}$ & $1.24 \times 10^{-7}$ & $1.55 \times 10^{-7}$ & $2.15 \times 10^{-6}$ & $4.08 \times 10^{-7}$ & $1.56 \times 10^{-7}$ \\
\hline MLR & 4 & $1.41 \times 10^{-6}$ & $2.54 \times 10^{-7}$ & $1.96 \times 10^{-7}$ & $2.93 \times 10^{-8}$ & $9.84 \times 10^{-8}$ & $2.08 \times 10^{-7}$ & $1.36 \times 10^{-6}$ & $2.38 \times 10^{-7}$ & $1.21 \times 10^{-7}$ \\
\hline SEC & 1 & $2.19 \times 10^{-6}$ & $3.17 \times 10^{-7}$ & $1.33 \times 10^{-7}$ & $1.34 \times 10^{-7}$ & $1.03 \times 10^{-7}$ & $1.47 \times 10^{-7}$ & $2.32 \times 10^{-6}$ & $3.25 \times 10^{-7}$ & $1.18 \times 10^{-7}$ \\
\hline SEC & 2 & $2.82 \times 10^{-6}$ & $5.06 \times 10^{-7}$ & $2.42 \times 10^{-7}$ & $1.01 \times 10^{-7}$ & $1.48 \times 10^{-7}$ & $2.84 \times 10^{-7}$ & $2.35 \times 10^{-6}$ & $4.54 \times 10^{-7}$ & $2.16 \times 10^{-7}$ \\
\hline SEC & 3 & $2.36 \times 10^{-6}$ & $4.48 \times 10^{-7}$ & $1.90 \times 10^{-7}$ & $1.78 \times 10^{-7}$ & $1.41 \times 10^{-7}$ & $2.04 \times 10^{-7}$ & $2.17 \times 10^{-6}$ & $4.32 \times 10^{-7}$ & $2.33 \times 10^{-7}$ \\
\hline SEC & 4 & $1.83 \times 10^{-6}$ & $2.52 \times 10^{-7}$ & $5.82 \times 10^{-8}$ & $1.23 \times 10^{-7}$ & $6.74 \times 10^{-8}$ & $6.87 \times 10^{-8}$ & $1.63 \times 10^{-6}$ & $2.37 \times 10^{-7}$ & $7.80 \times 10^{-8}$ \\
\hline SMR & 1 & $2.48 \times 10^{-6}$ & $3.58 \times 10^{-7}$ & $2.54 \times 10^{-7}$ & $6.99 \times 10^{-8}$ & $1.78 \times 10^{-7}$ & $3.28 \times 10^{-7}$ & $2.88 \times 10^{-6}$ & $3.73 \times 10^{-7}$ & $1.67 \times 10^{-7}$ \\
\hline SMR & 2 & $2.69 \times 10^{-6}$ & $5.01 \times 10^{-7}$ & $1.72 \times 10^{-7}$ & $1.76 \times 10^{-7}$ & $1.32 \times 10^{-7}$ & $1.47 \times 10^{-7}$ & $2.30 \times 10^{-6}$ & $4.59 \times 10^{-7}$ & $1.85 \times 10^{-7}$ \\
\hline SMR & 3 & $2.21 \times 10^{-6}$ & $4.64 \times 10^{-7}$ & $3.85 \times 10^{-7}$ & $4.81 \times 10^{-8}$ & $2.08 \times 10^{-7}$ & $4.44 \times 10^{-7}$ & $2.43 \times 10^{-6}$ & $4.70 \times 10^{-7}$ & $2.82 \times 10^{-7}$ \\
\hline SMR & 4 & $1.84 \times 10^{-6}$ & $2.68 \times 10^{-7}$ & $9.31 \times 10^{-8}$ & $8.87 \times 10^{-8}$ & $6.85 \times 10^{-8}$ & $9.98 \times 10^{-8}$ & $1.67 \times 10^{-6}$ & $2.55 \times 10^{-7}$ & $1.05 \times 10^{-7}$ \\
\hline WEE & 1 & $3.01 \times 10^{-6}$ & $3.78 \times 10^{-7}$ & $1.11 \times 10^{-7}$ & $1.20 \times 10^{-7}$ & $9.60 \times 10^{-8}$ & $1.37 \times 10^{-7}$ & $2.51 \times 10^{-6}$ & $3.39 \times 10^{-7}$ & $1.01 \times 10^{-7}$ \\
\hline WEE & 2 & $2.33 \times 10^{-6}$ & $4.59 \times 10^{-7}$ & $1.69 \times 10^{-7}$ & $1.73 \times 10^{-7}$ & $1.47 \times 10^{-7}$ & $2.21 \times 10^{-7}$ & $2.46 \times 10^{-6}$ & $4.71 \times 10^{-7}$ & $1.68 \times 10^{-7}$ \\
\hline WEE & 3 & $2.19 \times 10^{-6}$ & $4.27 \times 10^{-7}$ & $2.39 \times 10^{-7}$ & $7.10 \times 10^{-8}$ & $8.76 \times 10^{-8}$ & $1.46 \times 10^{-7}$ & $1.95 \times 10^{-6}$ & $3.91 \times 10^{-7}$ & $1.19 \times 10^{-7}$ \\
\hline WEE & 4 & $1.53 \times 10^{-6}$ & $2.35 \times 10^{-7}$ & $9.38 \times 10^{-8}$ & $9.54 \times 10^{-8}$ & $6.80 \times 10^{-8}$ & $9.65 \times 10^{-8}$ & $1.40 \times 10^{-6}$ & $2.22 \times 10^{-7}$ & $7.71 \times 10^{-8}$ \\
\hline WFF & 1 & $1.97 \times 10^{-6}$ & $2.93 \times 10^{-7}$ & $1.08 \times 10^{-7}$ & $1.33 \times 10^{-7}$ & $1.04 \times 10^{-7}$ & $1.52 \times 10^{-7}$ & $2.35 \times 10^{-6}$ & $3.22 \times 10^{-7}$ & $9.86 \times 10^{-8}$ \\
\hline WFF & 2 & $2.26 \times 10^{-6}$ & $4.34 \times 10^{-7}$ & $2.38 \times 10^{-7}$ & $1.26 \times 10^{-7}$ & $1.09 \times 10^{-7}$ & $1.45 \times 10^{-7}$ & $2.32 \times 10^{-6}$ & $4.30 \times 10^{-7}$ & $1.19 \times 10^{-7}$ \\
\hline WFF & 3 & $2.55 \times 10^{-6}$ & $4.60 \times 10^{-7}$ & $2.00 \times 10^{-7}$ & $1.19 \times 10^{-7}$ & $1.26 \times 10^{-7}$ & $2.14 \times 10^{-7}$ & $1.98 \times 10^{-6}$ & $3.97 \times 10^{-7}$ & $1.60 \times 10^{-7}$ \\
\hline WFF & 4 & $1.72 \times 10^{-6}$ & $2.50 \times 10^{-7}$ & $1.06 \times 10^{-7}$ & $4.79 \times 10^{-8}$ & $7.14 \times 10^{-8}$ & $1.39 \times 10^{-7}$ & $1.75 \times 10^{-6}$ & $2.53 \times 10^{-7}$ & $1.14 \times 10^{-7}$ \\
\hline WSS & 1 & $2.31 \times 10^{-6}$ & $3.31 \times 10^{-7}$ & $1.37 \times 10^{-7}$ & $9.32 \times 10^{-8}$ & $9.91 \times 10^{-8}$ & $1.61 \times 10^{-7}$ & $2.47 \times 10^{-6}$ & $3.41 \times 10^{-7}$ & $1.22 \times 10^{-7}$ \\
\hline
\end{tabular}


Table G. 1 continued.

\begin{tabular}{|c|c|c|c|c|c|c|c|c|c|c|}
\hline Location & Quarter & {$[\mathbf{R N}]^{\mathbf{a}}$} & $2 x T P U^{b}$ & MDC $^{c}$ & [RN] & $2 \times T P U$ & MDC & [RN] & $2 \times T P U$ & MDC \\
\hline WSS & 2 & $1.98 \times 10^{-6}$ & $4.13 \times 10^{-7}$ & $1.77 \times 10^{-7}$ & $8.14 \times 10^{-9}$ & $6.62 \times 10^{-8}$ & $1.75 \times 10^{-7}$ & $1.80 \times 10^{-6}$ & $3.92 \times 10^{-7}$ & $1.76 \times 10^{-7}$ \\
\hline$\overline{\mathrm{WSS}}$ & 3 & $2.07 \times 10^{-6}$ & $4.24 \times 10^{-7}$ & $1.64 \times 10^{-7}$ & $1.06 \times 10^{-7}$ & $1.23 \times 10^{-7}$ & $2.14 \times 10^{-7}$ & $2.36 \times 10^{-6}$ & $4.55 \times 10^{-7}$ & $1.63 \times 10^{-7}$ \\
\hline WSS & 4 & $1.81 \times 10^{-6}$ & $2.62 \times 10^{-7}$ & $8.94 \times 10^{-8}$ & $6.25 \times 10^{-8}$ & $5.80 \times 10^{-8}$ & $9.11 \times 10^{-8}$ & $1.61 \times 10^{-6}$ & $2.44 \times 10^{-7}$ & $7.50 \times 10^{-8}$ \\
\hline WAB & 1 & $1.18 \times 10^{-2}$ & $2.09 \times 10^{-3}$ & $1.66 \times 10^{-3}$ & $1.90 \times 10^{-3}$ & $1.54 \times 10^{-3}$ & $2.54 \times 10^{-3}$ & $1.42 \times 10^{-2}$ & $2.17 \times 10^{-3}$ & $1.02 \times 10^{-3}$ \\
\hline WAB & 2 & $1.26 \times 10^{-2}$ & $3.04 \times 10^{-3}$ & $2.69 \times 10^{-3}$ & $1.15 \times 10^{-3}$ & $1.59 \times 10^{-3}$ & $3.07 \times 10^{-3}$ & $1.12 \times 10^{-2}$ & $2.77 \times 10^{-3}$ & $2.13 \times 10^{-3}$ \\
\hline WAB & 3 & $1.29 \times 10^{-2}$ & $2.81 \times 10^{-3}$ & $1.68 \times 10^{-3}$ & $6.96 \times 10^{-4}$ & $1.02 \times 10^{-3}$ & $1.96 \times 10^{-3}$ & $1.38 \times 10^{-2}$ & $2.88 \times 10^{-3}$ & $1.49 \times 10^{-3}$ \\
\hline WAB & 4 & $9.83 \times 10^{-3}$ & $1.59 \times 10^{-3}$ & $7.40 \times 10^{-4}$ & $3.10 \times 10^{-4}$ & $4.11 \times 10^{-4}$ & $7.68 \times 10^{-4}$ & $1.01 \times 10^{-2}$ & $1.59 \times 10^{-3}$ & $6.11 \times 10^{-4}$ \\
\hline Minimum & & $1.41 \times 10^{-6}$ & $2.54 \times 10^{-7}$ & $5.82 \times 10^{-8}$ & $-3.32 \times 10^{-8}$ & $1.99 \times 10^{-7}$ & $6.87 \times 10^{-8}$ & $1.36 \times 10^{-6}$ & $2.38 \times 10^{-7}$ & $6.64 \times 10^{-8}$ \\
\hline Maximum & & $3.01 \times 10^{-6}$ & $3.78 \times 10^{-7}$ & $3.99 \times 10^{-7}$ & $2.07 \times 10^{-7}$ & $1.30 \times 10^{-7}$ & $4.61 \times 10^{-7}$ & $2.95 \times 10^{-6}$ & $3.65 \times 10^{-7}$ & $2.93 \times 10^{-7}$ \\
\hline \multirow[t]{2}{*}{ Mean } & & $2.24 \times 10^{-6}$ & $7.32 \times 10^{-8}$ & $1.70 \times 10^{-7}$ & $1.03 \times 10^{-7}$ & $2.23 \times 10^{-8}$ & $1.84 \times 10^{-7}$ & $2.18 \times 10^{-6}$ & $7.13 \times 10^{-8}$ & $1.49 \times 10^{-7}$ \\
\hline & & & ${ }^{40} \mathrm{~K}$ & & & ${ }^{60} \mathrm{Co}$ & & & & \\
\hline CBD & 1 & $1.08 \times 10^{-3}$ & $6.83 \times 10^{-4}$ & $1.06 \times 10^{-3}$ & $2.28 \times 10^{-5}$ & $3.61 \times 10^{-5}$ & $2.59 \times 10^{-5}$ & & & \\
\hline CBD & 2 & $1.43 \times 10^{-3}$ & $1.03 \times 10^{-4}$ & $1.57 \times 10^{-4}$ & $1.06 \times 10^{-5}$ & $1.04 \times 10^{-5}$ & $1.16 \times 10^{-5}$ & & & \\
\hline CBD & 3 & $1.51 \times 10^{-3}$ & $1.40 \times 10^{-4}$ & $1.76 \times 10^{-4}$ & $-3.44 \times 10^{-6}$ & $1.42 \times 10^{-5}$ & $1.31 \times 10^{-5}$ & & & \\
\hline CBD & 4 & $1.43 \times 10^{-3}$ & $4.27 \times 10^{-4}$ & $2.51 \times 10^{-4}$ & $-2.48 \times 10^{-5}$ & $2.00 \times 10^{-5}$ & $1.67 \times 10^{-5}$ & & & \\
\hline MLR & 1 & $1.02 \times 10^{-3}$ & $6.30 \times 10^{-4}$ & $8.80 \times 10^{-4}$ & $9.41 \times 10^{-6}$ & $3.23 \times 10^{-5}$ & $2.41 \times 10^{-5}$ & & & \\
\hline MLR & 2 & $1.85 \times 10^{-3}$ & $1.25 \times 10^{-4}$ & $1.85 \times 10^{-4}$ & $-6.98 \times 10^{-6}$ & $1.23 \times 10^{-5}$ & $1.28 \times 10^{-5}$ & & & \\
\hline MLR & 3 & $2.92 \times 10^{-4}$ & $1.04 \times 10^{-4}$ & $3.40 \times 10^{-4}$ & $6.74 \times 10^{-6}$ & $1.39 \times 10^{-5}$ & $1.33 \times 10^{-5}$ & & & \\
\hline MLR & 4 & $1.95 \times 10^{-3}$ & $5.64 \times 10^{-4}$ & $2.89 \times 10^{-4}$ & $1.27 \times 10^{-5}$ & $1.88 \times 10^{-5}$ & $1.84 \times 10^{-5}$ & & & \\
\hline SEC & 1 & $4.49 \times 10^{-3}$ & $2.53 \times 10^{-3}$ & $6.22 \times 10^{-4}$ & $-7.57 \times 10^{-6}$ & $3.64 \times 10^{-5}$ & $2.63 \times 10^{-5}$ & & & \\
\hline SEC & 2 & $1.32 \times 10^{-3}$ & $1.27 \times 10^{-4}$ & $1.76 \times 10^{-4}$ & $-2.56 \times 10^{-5}$ & $1.27 \times 10^{-5}$ & $1.24 \times 10^{-5}$ & & & \\
\hline SEC & 3 & $1.37 \times 10^{-3}$ & $1.65 \times 10^{-4}$ & $1.97 \times 10^{-4}$ & $-2.92 \times 10^{-5}$ & $1.67 \times 10^{-5}$ & $1.42 \times 10^{-5}$ & & & \\
\hline SEC & 4 & $1.62 \times 10^{-3}$ & $4.71 \times 10^{-4}$ & $2.52 \times 10^{-4}$ & $1.47 \times 10^{-5}$ & $1.72 \times 10^{-5}$ & $1.64 \times 10^{-5}$ & & & \\
\hline SMR & 1 & $5.40 \times 10^{-4}$ & $4.16 \times 10^{-4}$ & $9.49 \times 10^{-4}$ & $-4.31 \times 10^{-5}$ & $4.32 \times 10^{-5}$ & $2.61 \times 10^{-5}$ & & & \\
\hline SMR & 2 & $1.34 \times 10^{-3}$ & $1.18 \times 10^{-4}$ & $1.70 \times 10^{-4}$ & $1.31 \times 10^{-5}$ & $1.12 \times 10^{-5}$ & $1.26 \times 10^{-5}$ & & & \\
\hline SMR & 3 & $1.82 \times 10^{-4}$ & $9.82 \times 10^{-5}$ & $3.22 \times 10^{-4}$ & $2.12 \times 10^{-7}$ & $1.44 \times 10^{-5}$ & $1.34 \times 10^{-5}$ & & & \\
\hline SMR & 4 & $1.40 \times 10^{-3}$ & $4.30 \times 10^{-4}$ & $2.69 \times 10^{-4}$ & $-2.24 \times 10^{-6}$ & $1.96 \times 10^{-5}$ & $1.75 \times 10^{-5}$ & & & \\
\hline WEE & 1 & $4.95 \times 10^{-4}$ & $3.86 \times 10^{-4}$ & $8.89 \times 10^{-4}$ & $1.10 \times 10^{-5}$ & $3.39 \times 10^{-5}$ & $2.47 \times 10^{-5}$ & & & \\
\hline WEE & 2 & $1.55 \times 10^{-3}$ & $1.30 \times 10^{-4}$ & $1.85 \times 10^{-4}$ & $-1.43 \times 10^{-5}$ & $1.31 \times 10^{-5}$ & $1.33 \times 10^{-5}$ & & & \\
\hline WEE & 3 & $1.78 \times 10^{-3}$ & $1.49 \times 10^{-4}$ & $1.87 \times 10^{-4}$ & $4.41 \times 10^{-6}$ & $1.39 \times 10^{-5}$ & $1.32 \times 10^{-5}$ & & & \\
\hline WEE & 4 & $4.86 \times 10^{-4}$ & $1.73 \times 10^{-4}$ & $3.68 \times 10^{-4}$ & $-3.94 \times 10^{-6}$ & $1.85 \times 10^{-5}$ & $1.70 \times 10^{-5}$ & & & \\
\hline WFF & 1 & $5.12 \times 10^{-3}$ & $2.87 \times 10^{-3}$ & $6.03 \times 10^{-4}$ & $4.97 \times 10^{-5}$ & $4.11 \times 10^{-5}$ & $2.58 \times 10^{-5}$ & & & \\
\hline WFF & 2 & $1.42 \times 10^{-3}$ & $1.17 \times 10^{-4}$ & $1.68 \times 10^{-4}$ & $9.44 \times 10^{-6}$ & $1.06 \times 10^{-5}$ & $1.17 \times 10^{-5}$ & & & \\
\hline WFF & 3 & $1.56 \times 10^{-3}$ & $1.46 \times 10^{-4}$ & $1.81 \times 10^{-4}$ & $1.65 \times 10^{-5}$ & $1.31 \times 10^{-5}$ & $1.29 \times 10^{-5}$ & & & \\
\hline WFF & 4 & $1.70 \times 10^{-3}$ & $4.96 \times 10^{-4}$ & $2.66 \times 10^{-4}$ & $-2.15 \times 10^{-5}$ & $1.99 \times 10^{-5}$ & $1.63 \times 10^{-5}$ & & & \\
\hline
\end{tabular}


Table G. 1 continued.

\begin{tabular}{|c|c|c|c|c|c|c|c|c|c|c|}
\hline Location & Quarter & {$[\mathbf{R N}]^{\mathrm{a}}$} & $2 x T P U^{b}$ & MDC $^{\mathrm{c}}$ & {$[\mathbf{R N}]$} & 2xTPU & MDC & {$[\mathbf{R N}]$} & $2 \times T P U$ & MDC \\
\hline WSS & 1 & $5.47 \times 10^{-3}$ & $3.07 \times 10^{-3}$ & $6.42 \times 10^{-4}$ & $3.60 \times 10^{-5}$ & $3.94 \times 10^{-5}$ & $2.70 \times 10^{-5}$ & & & \\
\hline WSS & 2 & $1.63 \times 10^{-3}$ & $1.34 \times 10^{-4}$ & $1.91 \times 10^{-4}$ & $-2.74 \times 10^{-5}$ & $1.39 \times 10^{-5}$ & $1.36 \times 10^{-5}$ & & & \\
\hline WSS & 3 & $1.87 \times 10^{-3}$ & $1.50 \times 10^{-4}$ & $1.90 \times 10^{-4}$ & $9.44 \times 10^{-6}$ & $1.38 \times 10^{-5}$ & $1.33 \times 10^{-5}$ & & & \\
\hline WSS & 4 & $1.96 \times 10^{-3}$ & $5.63 \times 10^{-4}$ & $2.80 \times 10^{-4}$ & $-2.44 \times 10^{-6}$ & $1.87 \times 10^{-5}$ & $1.72 \times 10^{-5}$ & & & \\
\hline WAB & 1 & $3.26 \times 10^{1}$ & $1.84 \times 10^{1}$ & $6.51 \times 10^{0}$ & $5.82 \times 10^{-2}$ & $2.43 \times 10^{-1}$ & $1.84 \times 10^{-1}$ & & & \\
\hline WAB & 2 & $1.06 \times 10^{1}$ & $8.58 \times 10^{-3}$ & $1.23 \times 10^{0}$ & $-6.82 \times 10^{-2}$ & $8.54 \times 10^{-2}$ & $8.80 \times 10^{-2}$ & & & \\
\hline WAB & 3 & $1.13 \times 10^{1}$ & $1.40 \times 10^{0}$ & $1.78 \times 10^{0}$ & $-1.67 \times 10^{-1}$ & $1.45 \times 10^{-1}$ & $1.26 \times 10^{-1}$ & & & \\
\hline WAB & 4 & $1.15 \times 10^{1}$ & $3.42 \times 10^{0}$ & $1.94 \times 10^{0}$ & $-3.01 \times 10^{-1}$ & $1.70 \times 10^{-1}$ & $1.24 \times 10^{-1}$ & & & \\
\hline Minimum & & $1.82 \times 10^{-4}$ & $9.82 \times 10^{-5}$ & $1.57 \times 10^{-4}$ & $-4.31 \times 10^{-5}$ & $4.32 \times 10^{-5}$ & $1.16 \times 10^{-5}$ & & & \\
\hline Maximum & & $5.47 \times 10^{-3}$ & $3.07 \times 10^{-3}$ & $1.06 \times 10^{-3}$ & $4.97 \times 10^{-5}$ & $4.11 \times 10^{-5}$ & $2.70 \times 10^{-5}$ & & & \\
\hline \multirow[t]{2}{*}{ Mean } & & $1.71 \times 10^{-3}$ & $1.86 \times 10^{-4}$ & $3.73 \times 10^{-4}$ & $5.08 \times 10^{-7}$ & $4.36 \times 10^{-6}$ & $1.72 \times 10^{-5}$ & & & \\
\hline & & & ${ }^{90} \mathrm{Sr}$ & & & ${ }^{137} \mathrm{Cs}$ & & & & \\
\hline CBD & 1 & $-2.96 \times 10^{-6}$ & $2.59 \times 10^{-6}$ & $4.81 \times 10^{-6}$ & $1.11 \times 10^{-5}$ & $1.18 \times 10^{-5}$ & $1.27 \times 10^{-5}$ & & & \\
\hline CBD & 2 & $4.07 \times 10^{-6}$ & $5.00 \times 10^{-6}$ & $8.36 \times 10^{-6}$ & $4.22 \times 10^{-6}$ & $1.01 \times 10^{-5}$ & $1.15 \times 10^{-5}$ & & & \\
\hline CBD & 3 & $4.81 \times 10^{-6}$ & $5.92 \times 10^{-6}$ & $9.92 \times 10^{-6}$ & $5.71 \times 10^{-6}$ & $1.17 \times 10^{-5}$ & $1.20 \times 10^{-5}$ & & & \\
\hline CBD & 4 & $3.70 \times 10^{-7}$ & $3.33 \times 10^{-6}$ & $5.92 \times 10^{-6}$ & $1.80 \times 10^{-5}$ & $9.86 \times 10^{-6}$ & $1.17 \times 10^{-5}$ & & & \\
\hline MLR & 1 & $7.40 \times 10^{-7}$ & $1.48 \times 10^{-6}$ & $2.59 \times 10^{-6}$ & $2.23 \times 10^{-6}$ & $1.13 \times 10^{-5}$ & $1.20 \times 10^{-5}$ & & & \\
\hline MLR & 2 & $3.44 \times 10^{-6}$ & $4.88 \times 10^{-6}$ & $8.29 \times 10^{-6}$ & $-3.76 \times 10^{-6}$ & $1.15 \times 10^{-5}$ & $1.28 \times 10^{-5}$ & & & \\
\hline MLR & 3 & $2.33 \times 10^{-6}$ & $4.96 \times 10^{-6}$ & $8.58 \times 10^{-6}$ & $-8.14 \times 10^{-6}$ & $1.23 \times 10^{-5}$ & $1.23 \times 10^{-5}$ & & & \\
\hline MLR & 4 & $1.11 \times 10^{-6}$ & $3.70 \times 10^{-6}$ & $6.29 \times 10^{-6}$ & $-1.61 \times 10^{-5}$ & $1.17 \times 10^{-5}$ & $1.26 \times 10^{-5}$ & & & \\
\hline SEC & 1 & $3.70 \times 10^{-7}$ & $3.70 \times 10^{-6}$ & $6.29 \times 10^{-6}$ & $-1.13 \times 10^{-5}$ & $1.28 \times 10^{-5}$ & $1.31 \times 10^{-5}$ & & & \\
\hline SEC & 2 & $-9.25 \times 10^{-7}$ & $4.63 \times 10^{-6}$ & $8.44 \times 10^{-6}$ & $4.87 \times 10^{-6}$ & $1.12 \times 10^{-5}$ & $1.27 \times 10^{-5}$ & & & \\
\hline SEC & 3 & $5.11 \times 10^{-6}$ & $5.29 \times 10^{-6}$ & $8.77 \times 10^{-6}$ & $-3.54 \times 10^{-6}$ & $1.30 \times 10^{-5}$ & $1.32 \times 10^{-5}$ & & & \\
\hline SEC & 4 & $7.40 \times 10^{-7}$ & $3.33 \times 10^{-6}$ & $5.92 \times 10^{-6}$ & $5.08 \times 10^{-7}$ & $1.01 \times 10^{-5}$ & $1.13 \times 10^{-5}$ & & & \\
\hline SMR & 1 & $-3.70 \times 10^{-7}$ & $3.33 \times 10^{-6}$ & $5.92 \times 10^{-6}$ & $4.78 \times 10^{-7}$ & $1.22 \times 10^{-5}$ & $1.29 \times 10^{-5}$ & & & \\
\hline SMR & 2 & $2.59 \times 10^{-6}$ & $5.48 \times 10^{-6}$ & $9.47 \times 10^{-6}$ & $2.27 \times 10^{-6}$ & $1.12 \times 10^{-5}$ & $1.27 \times 10^{-5}$ & & & \\
\hline SMR & 3 & $4.14 \times 10^{-6}$ & $5.37 \times 10^{-6}$ & $8.99 \times 10^{-6}$ & $1.07 \times 10^{-5}$ & $1.19 \times 10^{-5}$ & $1.24 \times 10^{-5}$ & & & \\
\hline SMR & 4 & $-7.40 \times 10^{-7}$ & $3.70 \times 10^{-6}$ & $6.66 \times 10^{-6}$ & $1.89 \times 10^{-5}$ & $1.05 \times 10^{-5}$ & $1.25 \times 10^{-5}$ & & & \\
\hline WEE & 1 & $-3.70 \times 10^{-7}$ & $3.33 \times 10^{-6}$ & $5.55 \times 10^{-6}$ & $3.60 \times 10^{-6}$ & $1.18 \times 10^{-5}$ & $1.25 \times 10^{-5}$ & & & \\
\hline WEE & 2 & $2.59 \times 10^{-6}$ & $5.11 \times 10^{-6}$ & $8.77 \times 10^{-6}$ & $4.30 \times 10^{-6}$ & $1.18 \times 10^{-5}$ & $1.33 \times 10^{-5}$ & & & \\
\hline WEE & 3 & $4.66 \times 10^{-6}$ & $5.07 \times 10^{-6}$ & $8.40 \times 10^{-6}$ & $-3.22 \times 10^{-5}$ & $1.29 \times 10^{-5}$ & $1.21 \times 10^{-5}$ & & & \\
\hline WEE & 4 & $7.40 \times 10^{-7}$ & $2.59 \times 10^{-6}$ & $4.44 \times 10^{-6}$ & $1.01 \times 10^{-5}$ & $1.03 \times 10^{-5}$ & $1.19 \times 10^{-5}$ & & & \\
\hline WFF & 1 & $3.70 \times 10^{-7}$ & $3.33 \times 10^{-6}$ & $5.55 \times 10^{-6}$ & $-1.64 \times 10^{-5}$ & $1.27 \times 10^{-5}$ & $1.29 \times 10^{-5}$ & & & \\
\hline WFF & 2 & $1.78 \times 10^{-6}$ & $4.18 \times 10^{-6}$ & $7.25 \times 10^{-6}$ & $7.61 \times 10^{-6}$ & $1.05 \times 10^{-5}$ & $1.20 \times 10^{-5}$ & & & \\
\hline WFF & 3 & $3.37 \times 10^{-6}$ & $4.81 \times 10^{-6}$ & $8.10 \times 10^{-6}$ & $8.26 \times 10^{-6}$ & $1.15 \times 10^{-5}$ & $1.19 \times 10^{-5}$ & & & \\
\hline
\end{tabular}


Table G. 1 continued.

\begin{tabular}{|c|c|c|c|c|c|c|c|c|c|c|}
\hline Location & Quarter & {$[\mathrm{RN}]^{\mathrm{a}}$} & $2 \times T_{P U}^{b}$ & MDC $^{\mathrm{c}}$ & {$[\mathrm{RN}]$} & $2 \times T P U$ & MDC & {$[\mathrm{RN}]$} & $2 \times T P U$ & MDC \\
\hline WFF & 4 & $4.44 \times 10^{-6}$ & $4.44 \times 10^{-6}$ & $7.40 \times 10^{-6}$ & $-2.67 \times 10^{-6}$ & $1.04 \times 10^{-5}$ & $1.16 \times 10^{-5}$ & & & \\
\hline WSS & 1 & $-7.40 \times 10^{-7}$ & $3.33 \times 10^{-6}$ & $5.92 \times 10^{-6}$ & $4.27 \times 10^{-6}$ & $1.27 \times 10^{-5}$ & $1.35 \times 10^{-5}$ & & & \\
\hline WSS & 2 & $5.18 \times 10^{-7}$ & $5.11 \times 10^{-6}$ & $9.10 \times 10^{-6}$ & $3.55 \times 10^{-8}$ & $1.20 \times 10^{-5}$ & $1.34 \times 10^{-5}$ & & & \\
\hline$\overline{\mathrm{WSS}}$ & 3 & $1.11 \times 10^{-7}$ & $4.96 \times 10^{-6}$ & $8.92 \times 10^{-6}$ & $1.10 \times 10^{-5}$ & $1.17 \times 10^{-5}$ & $1.22 \times 10^{-5}$ & & & \\
\hline WSS & 4 & $7.40 \times 10^{-7}$ & $3.33 \times 10^{-6}$ & $5.92 \times 10^{-6}$ & $4.35 \times 10^{-6}$ & $1.03 \times 10^{-5}$ & $1.17 \times 10^{-5}$ & & & \\
\hline WAB & 1 & $9.62 \times 10^{-3}$ & $2.55 \times 10^{-2}$ & $4.37 \times 10^{-2}$ & $-2.28 \times 10^{-2}$ & $8.99 \times 10^{-2}$ & $9.39 \times 10^{-2}$ & & & \\
\hline WAB & 2 & $1.11 \times 10^{-2}$ & $3.18 \times 10^{-2}$ & $5.55 \times 10^{-2}$ & $5.93 \times 10^{-2}$ & $7.54 \times 10^{-2}$ & $8.59 \times 10^{-2}$ & & & \\
\hline WAB & 3 & $2.22 \times 10^{-3}$ & $3.40 \times 10^{-2}$ & $6.07 \times 10^{-2}$ & $-8.97 \times 10^{-2}$ & $1.16 \times 10^{-1}$ & $1.16 \times 10^{-1}$ & & & \\
\hline WAB & 4 & $2.22 \times 10^{-3}$ & $2.52 \times 10^{-2}$ & $4.48 \times 10^{-2}$ & $-2.02 \times 10^{-2}$ & $7.97 \times 10^{-2}$ & $8.87 \times 10^{-2}$ & & & \\
\hline Minimum & & $-2.96 \times 10^{-6}$ & $2.59 \times 10^{-6}$ & $2.59 \times 10^{-6}$ & $-3.22 \times 10^{-5}$ & $1.29 \times 10^{-5}$ & $1.13 \times 10^{-5}$ & & & \\
\hline Maximum & & $5.11 \times 10^{-6}$ & $5.29 \times 10^{-6}$ & $9.92 \times 10^{-6}$ & $1.89 \times 10^{-5}$ & $1.05 \times 10^{-5}$ & $1.35 \times 10^{-5}$ & & & \\
\hline Mean & & $1.54 \times 10^{-6}$ & $8.09 \times 10^{-7}$ & $7.16 \times 10^{-6}$ & $1.37 \times 10^{-6}$ & $2.18 \times 10^{-6}$ & $1.24 \times 10^{-5}$ & & & \\
\hline
\end{tabular}

a Radionuclide Concentration

b Total Propagated Uncertainty

${ }^{c}$ Minimum Detectable Concentration

d Arithmetic Average Concentration and MDC; TPU equals the standard deviation of the mean. 
This page intentionally left blank. 


\section{Appendix $\mathrm{H}$ \\ Authors and Contributors}

Executive Summary

Randall C. Morris, Ph.D. (ed.)

Stewart B. Jones

Irene Quintana

Wesley Nance

Chapter 1 Introduction

Randall C. Morris, Ph.D. (ed.)

Stewart B. Jones

Irene Quintana

Wesley Nance

Chapter 2 Environmental Program Information

Timothy D. Reynolds, Ph.D. (ed.)

Don L. Gilbert

Stewart B. Jones

Doug C. Lynn

Roger D. Simmons

Chapter 3 Environmental Compliance

Timothy D. Reynolds, Ph.D. (ed.)

Cindy Anderson

Rick Chavez

Koreen Guillermo

James R. Hollen

Irene Quintana

Steve Kouba

Patty Loughmiller

Doug C. Lynn

Dan Robertson

Cindy Woodin
Chapter 5 Environmental Non-Radiological

Program Information

Randall C. Morris, Ph.D. (ed.)

Wesley Boatwright

Tim W. Brown

Adela M. Cantu

Rey C. Carrasco

Mark Crawley

Oscar Garcia

Doug C. Lynn

Wesley Nance

Steve Offner

Roger Simmons

\section{Chapter 6 Ground-water Monitoring}

Timothy D. Reynolds, Ph.D. (ed.)

Melvin L. Balderrama

Mark Crawley

Butch S. Daszczyszak

William Foster

Irene Quintana

Doug C. Lynn

Ron G. Richardson

Chapter 7 Radiological Dose Assessment

Randall C. Morris, Ph.D. (ed.)

Marsha Beekman

Linda Frank-Supka

Chapter 8 Quality Assurance

Timothy D. Reynolds, Ph.D. (ed.)

Dave Weidenhoeft

\section{Appendices}

Timothy D. Reynolds, Ph.D. (ed)

\section{Administrative Support}

Janet Cook

Patricia Isaeff

Mak Walker

Data Entry

Janet Cook

Patricia Isaeff 
This page intentionally left blank. 